RODRIGO SAURI LAVIERI

\title{
MÉTODOS DE NAVEGAÇÃO INERCIAL APLICADOS A LANÇAMENTOS SUBMARINOS
}

Dissertação apresentada à Escola
Politécnica da Universidade de São
Paulo para obtenção do título de
Mestre em engenharia

São Paulo 

RODRIGO SAURI LAVIERI

\section{MÉTODOS DE NAVEGAÇÃO INERCIAL APLICADOS A LANÇAMENTOS SUBMARINOS}

Dissertação apresentada à Escola Politécnica da Universidade de São Paulo para obtenção do título de Mestre em engenharia

Área de Concentração:

Engenharia Naval e Oceânica

Orientador:

Prof. Dr. André Luís Condino

Fujarra

São Paulo 
Este exemplar foi revisado e alterado em relação à versão original, sob responsabilidade única do autor e com a anuência de seu orientador.

São Paulo, de fevereiro de 2011.

Assinatura do autor

Assinatura do orientador

\section{FICHA CATALOGRÁFICA}

Lavieri, Rodrigo Sauri

Métodos de navegação inercial aplicados a lançamentos

submarinos / R.S. Lavieri. -- ed.rev. -- São Paulo, 2011.

292 p.

Dissertação (Mestrado) - Escola Politécnica da Universidade de São Paulo. Departamento de Engenharia Naval e Oceânica.

1. Hidrostática 2. Submarinos I. Universidade de São Paulo. Escola Politécnica. Departamento de Engenharia Naval e Oceânica II. t. 
Dedico este trabalho aos meus queridos pais, Durval e Maribel. 


\section{AGRADECIMENTOS}

Ao professor André Fujarra, pela orientação e pelo apoio durante todo o desenvolvimento desta pesquisa. Certamente sua orientação estendeu-se além do caráter técnico do tema e abrangeu decisões e questionamentos inevitáveis ao indivíduo que segue o caminho da pesquisa científica.

Ao professor Eduardo Tannuri que participou ativamente da presente pesquisa e certamente contribuiu de forma decisiva na resolução dos sucessivos desafios envolvidos na mesma.

Ao professor Celso Pupo Pesce pelos valiosos conselhos durante a pesquisa e produção deste documento.

A Petrobras por apoiar a pesquisa através de recursos e informações.

Ao Centro de Engenharia Naval do IPT e seu corpo técnico pelo prestativo auxílio na execução de experimentos envolvidos na presente pesquisa.

A empresa NavCon que disponibilizou sua infra-estrutura, pessoal e tempo para que fossem realizados ensaios importantes para a presente pesquisa.

Ao futuro doutor João Dantas que pacientemente me esclareceu inúmeras questões acerca da navegação inercial ao longo do último ano.

Aos futuros engenheiros Arthur Pereira e Luigi Greco que me auxiliaram na realização da maioria dos experimentos durante a pesquisa.

Finalmente, agradeço a minha família, namorada e amigos que me apoiaram incondicionalmente na decisão de permanecer no campo da pesquisa e alcançar estes resultados. 


\section{RESUMO}

A demanda crescente por petróleo impulsiona a exploração marítima desta riqueza para águas cada vez mais profundas. O aumento da lâmina d'água exige novas soluções de engenharia principalmente no que se refere à operação de unidades flutuantes de produção.

Dentre os desafios impostos pelos novos ambientes de prospecção, destaca-se o processo de ancoragem, neste texto explorado sob a ótica da chamada estaca-torpedo. Embora já tenha sido empregada com sucesso na ancoragem de risers e FPSOs, esta solução encontra-se em constante desenvolvimento, sendo a principal fonte de informação acerca dos lançamentos da estaca-torpedo proveniente de uma unidade de medição inercial (UMI).

A presente pesquisa baseou-se no estudo desta UMI e teve como objetivos principais verificar seu desempenho e compreender a empregabilidade deste tipo de monitoração em operações submarinas de maneira mais ampla.

Além do estudo detalhado dos sensores, foi dada especial atenção aos algoritmos empregados no tratamento dos sinais provenientes da UMI. Foram estudadas técnicas de correção do sinal, quantificação de ruído, desafios inerentes aos sistemas do tipo strapdown e o processo de integração.

Como resultado final foi desenvolvido um algoritmo baseado em quatérnios, alternativo ao atualmente empregado para o processamento dos sinais provenientes da UMI que equipa a estaca-torpedo.

Palavras chave: Estaca-Torpedo, Sensores Inerciais, Acelerômetros, Girômetros, Strapdown, Quatérnios. 


\begin{abstract}
The increasing demand on crude oils constantly pushes the offshore exploitation to deeper waters. As the water depth grows, new engineering challenges arise, especially concerning to the operation of floating production units.

Among all the technical issues inherent to the new prospection environment, the mooring system is a significant topic and the development of the torpedo-pile takes place at this scenario. This mooring system has already been successfully applied in anchoring risers and FPSOs; nevertheless, it is in constant study and improvement. The major source of information about the torpedo-pile deployment comes from an inertial measurement unit (IMU).

The research presented here is based on this IMU and had as main objective verify its performance and also comprehend the applicability of such kind of unit in other subsea processes.
\end{abstract}

Along with the detailed sensors study, it was given special attention to the algorithms used to process the signals from the IMU. Signal correction techniques and noise quantification were investigated as long as challenges intrinsically related to strapdown navigation systems and the integration process.

In the end, an alternative data processing algorithm based on quaternions was produced, to be employed in torpedo-pile launching together with its IMU.

Key-Words: Torpedo Pile, Inertial Sensors, Accelerometer, Rate Gyro, Strapdown, Quaternions. 


\section{LISTA DE FIGURAS}

Figura 1 - Evolução no tempo da profundidade de produção oceânica de petróleo no Brasil (PETROBRAS)

Figura 2 - Configuração típica de linha de ancorágem em catenária ......................................... 8

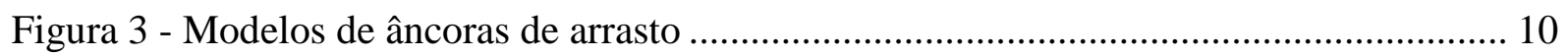

Figura 4 - Âncora tipo Stevpris no convés de uma embarcação de suporte após ter sido

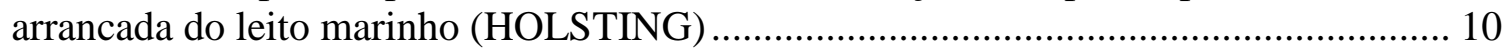

Figura 5 - Âncora de sucção sendo instalada (PENNENERGY) ............................................... 12

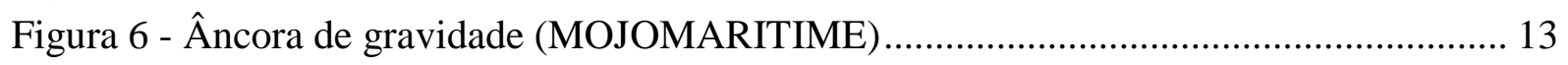

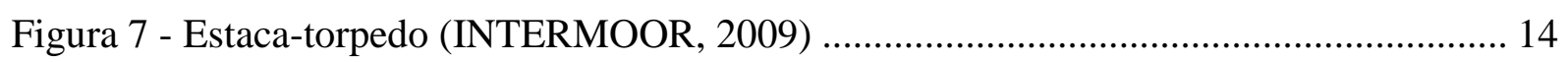

Figura 8 - Condição favorável de cravação da estaca-torpedo ............................................... 15

Figura 9 - Ilustração do funcionamento e aplicação de uma âncora do tipo VLA .................. 22

Figura 10 - Fabricação da estaca torpedo T-98 (BRANDÃO, HENRIQUES, et al., 2006).... 23

Figura 11 - Esquema ilustrando o procedimento de instalação da estaca-torpedo .................. 24

Figura 12 - Diagrama de corpo livre do trecho de amarra imediatamente atras da estaca-

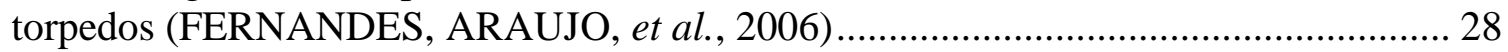

Figura 13 - Modificação da estimativa para a posição do centro hidrodinâmico para os três modelos considerados: Estaca,Estaca+Aletas e Estaca+Aletas+Linhas (FERNANDES,

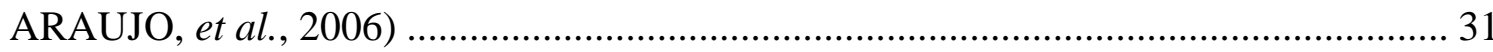

Figura 14 - Resultados analíticos e experimentais para os parâmetros cinemáticos do lançamento (FERNANDES, ARAUJO, et al., 2006) ................................................... 32

Figura 15 - Geometrias das estacas-torpedo simuladas (CARVALHO E SILVA, 2010) ....... 34

Figura 16 - Exemplo de malha gerada para as simulações de CFD (CARVALHO E SILVA,

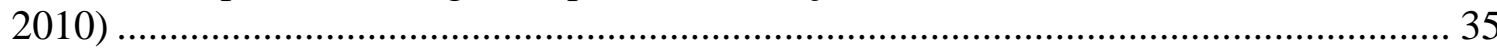

Figura 17 - Curvas de coeficiente de arrasto por ângulos de ataque para as geometrias

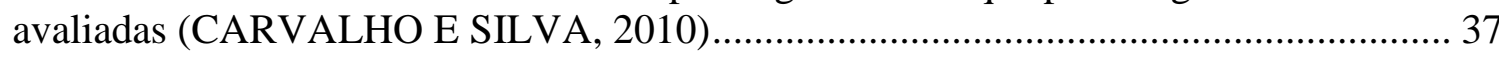

Figura 18 - Curvas do coeficiente de momento restaurador na direção tranversal a estaca para inumeros ângulos de ataque (CARVALHO E SILVA, 2010) ..................................... 38

Figura 19 - Relações fundamentais da álgebra dos quatérnios entalhada nas pedras da ponte

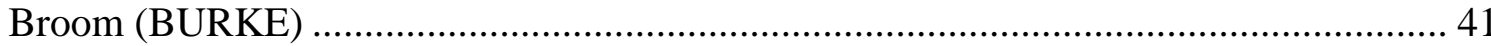

Figura 20 - Determinação do vetor em torno do qual um vetor é rotacionado no espaço ....... 55

Figura 21 - Base inercial e base solidária ao corpo inicialmente são coincidentes ................. 58

Figura 22 - Rotação em torno do eixo $\mathrm{z}$ inercial................................................................. 58

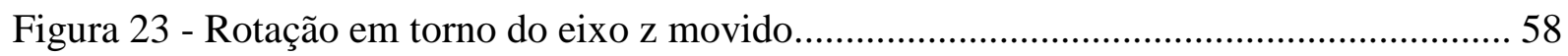

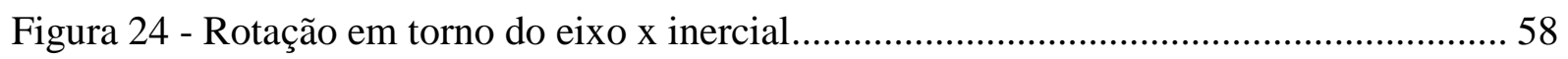

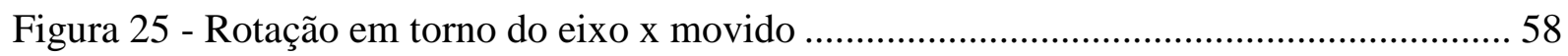

Figura 26 - Rotação em torno do eixo $\mathrm{z}$ inercial.................................................................... 59

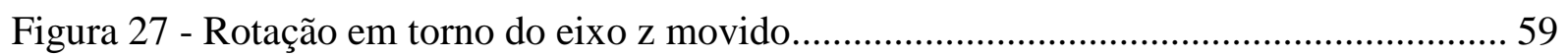

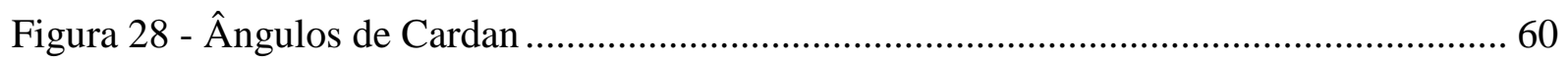

Figura 29 - Produto triplo entre quatérnios e vetores no $\mathbb{R} 3$.............................................. 70

Figura 30 - Composição de referenciais partindo de um referêncial inercial no centro do Sol80

Figura 31 - Unidade de medição inercial que emprega base estabilizadora e sensores eletro-

mecânicos (The Institute of Navigation) (CRRL) ......................................................... 86 
Figura 32 - Unidade de medição inercial que emprega tecnologia MEMS (CRRL)

Figura 33 - Distinção entre as tecnologias de acelerômetros discutidas no presente trabalho.89

Figura 34 - Princípio de funcionamento de um acelerômetro mecânico em malha aberta .......90

Figura 35 - princípio de funcionamento de um acelerômetro mecânico em malha fechada ....91

Figura 36 - Princípio de funcionamento de um acelerômetro mecânico de fibra óptica com dois graus de liberdade

Figura 37 - Acelerômetro de haste vibratória (Safran Sagem) ...............................................93

Figura 38 - Princípio de funcionamento de um acelerômetro do tipo Mach-Zehnder ............. 94

Figura 39 - Distinção entre as tecnologias de girômetros discutidas no presente trabalho ...... 95

Figura 40 - Esquema de funcionamento de um girocompasso mecânico tradicional com três suspensões Cardan (gimbals)

Figura 41 - Princípio de funcionamento de um giroscópio mecânico com um grau de liberdade

Figura 42 - Ilustração dos componentes de um giroscópio sintonizado dinamicamente (DTG)

Figura 43 - Princípio de funcionamento de um girômetro de fibra óptica

Figura 44 - Sulcos produzidos por corrosão isotrópica (ZORMAN e MEHREGANY, 2002)

Figura 45 - Grade produzida por corrosão anisotrópica, capaz de produzir geometrias precisas (ZORMAN e MEHREGANY, 2002)

Figura 46 - Princípio de funcionamento de um acelerômetro mecânico do tipo MEMS ....... 104

Figura 47 - Funcionamento de um girômetro MEMS do tipo TFG 106

Figura 48 - Fotografia do primeiro girômetro TFG de desempenho satisfatório (LAWRENCE, 1998)

Figura 49 - Princípio de funcionamento do girômetro apresentado na Figura 48.

(LAWRENCE, 1998)

Figura 50 - princípio de funcionamento do girômetro MEMS de anél ressonante

Figura 51 - Planta e fotografia do girômetro MEMS de anél ressonante (BERNSTEIN, 2003)

Figura 52 - Exemplo de curva de calibração (input x output) em que são destacados os principais parâmetros de calibração

Figura 53 - Faixas de valor para a estabilidade do bias de acordo com a tecnologia do sensor empregado (TITTERTON e WESTON, 2004)

Figura 54 - Visualização das possíveis realizações de um processo estocástico (BENDAT e PIERSOL, 2000)

Figura 55 - Tipos de ruído identificados em uma curva exemplo do desvio de Allan (IEEE

Standard Specification Format Guide and Test Procedure for Single Axis Interferometric Fiber Optic Gyros, 1997 (R2008))

Figura 56 - Gráfico do desvio de Allan do sinal proveniente dos girômetros MEMS utilizados

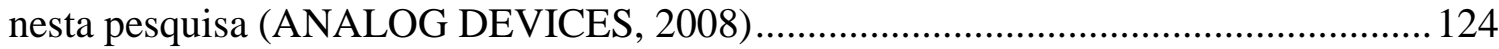

Figura 57 - Orientação dos eixos do SMET 130

Figura 58 - Pontos de ancorágem e vigas que operam como pickoff do acelerômetro MEMS (DIXON)

Figura 59 - histograma do bias na população de sensores (ANALOG DEVICES, 2008) ..... 132 
Figura 60 - Princípio de funcionamento dos giros empregados no SMET (GEEN e KRAKAUER, 2003)

Figura 61 - Fotografia do interior dos giros empregados no SMET (GEEN e KRAKAUER, 2003)

Figura 62 - Exemplo de sinal do lançamento da estaca-torpedo em que os marcos principais foram destacados

Figura 63 - Exemplo do registro de pressão(profundidade) de um lançamento da estacatorpedo

Figura 64 - Exemplo do registro de temperatura de um lançamento da estaca-torpedo........ 136

Figura 65 - Metodologia da pesquisa na forma de diagrama de blocos ................................ 140

Figura 66 - Orientação dos eixos do SMET montado ao pêndulo ......................................... 142

Figura 67 - Área de ensaio; frame de calibração ao centro e duas câmeras ao fundo ............ 143

Figura 68 - "Berço" do SMET equipado com os alvos reflexivos....................................... 143

Figura 69 - Registros do sistema de aquisição por imagem; de cima para baixo: a trajetória, a

velocidade tangencial e a atitude do SMET ................................................................ 146

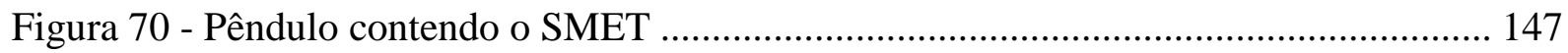

Figura 71 - Materias empregados no experimento estático dos acelerômetros; (superior esquerdo) morsa reclinável; (inferior esquerdo) montagem completa sobre o desempeno de granito; (superior direto) perspectiva explodida da peça de fixação SMET-morsa; (inferior direto) detalhe da fixação do inclinômetro ...................................................... 149

Figura 72 - Peça de fixação SMET-morsa e os furos para alinhamento do SMET ............... 149

Figura 73 - Sequência de inclinações para isolar as leituras no eixo y e z; em azul o eixo x, em verdo o eixo y e em vermelho o eixo $z$; as ilustrações da direita representam o procedimento para obtenção da leitura em y; as ilustrações da direita representam o

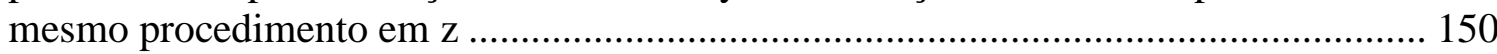

Figura 74 - Curva de calibração do acelerômetro x ............................................................ 152

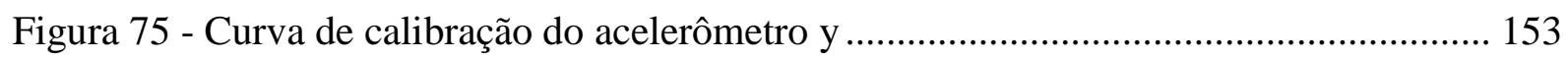

Figura 76 - Curva de calibração do acelerômetro z ............................................................... 153

Figura 77 - Esquema dos componentes de uma rate table ................................................. 155

Figura 78 - (Equerda) Alinhamento da rate table; (Direita) SMET fixado à rate table ........ 156

Figura 79 - Sinais de velocidade angular obtidos nos ensaios da rate table em que as

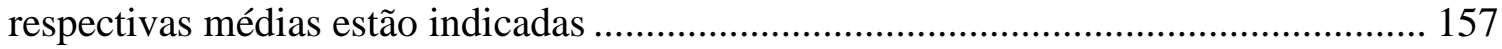

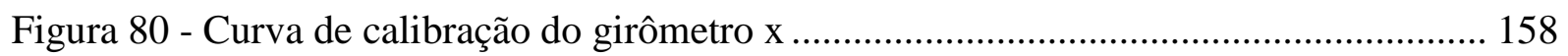

Figura 81 - Sinal de velocidade angular no eixo x de um lançamento da estaca-torpedo ..... 159

Figura 82 - Sinal apresentado na Figura 81 após a correção com o bias obtido em laboratório

Figura 83 - Registros de velocidade angular (nos ensaios estáticos correspondem ao bias do sensor) para uma faixa de temperaturas

Figura 84 - Sinal apresentado na Figura 81 após a correção com o bias modificado pela temperatura

Figura 85 - Interface da rotina de correção do sinal; neste caso é exibido um registro de velocidade angular no eixo $\mathrm{x}$

Figura 86 - Exemplo do mecanismo de seleção que permite ao usuário definir onde o movimento efetivamente cessou 
Figura 87 - Destaque da média calculada a partir do trecho estabelecido pelo usuário 165

Figura 88 - Exemplo do preenchimento dos campos bias e fator de escala 165

Figura 89 - Segunda inteface da rotina de correção do sinal; destaque para a definição manual do intervalo de integração

Figura 90 - Gráfico do desvio de Allan para um registro de aceleração X do SMET de cerca de 90 minutos.

Figura 91 - Gráfico do desvio de Allan para um registro de aceleração Y do SMET de cerca de 90 minutos.

Figura 92 - Gráfico do desvio de Allan para um registro de aceleração Z do SMET de cerca de 90 minutos.

Figura 93 - Gráfico do desvio de Allan para um registro de velocidade angular no eixo Z do SMET de cerca de 90 minutos.

Figura 94 - Gráfico do desvio de Allan para um registro de velocidade angular no eixo X do SMET de cerca de 90 minutos.

Figura 95 - Gráfico do desvio de Allan para um registro de velocidade angular no eixo Y do SMET de cerca de 90 minutos.

Figura 96 - Estaca-torpedo e nacela que contem o SMET durante o lançamento (PETROBRAS, 2007)

Figura 97 - Vaso de pressão que contem o SMET durante o lançamento (PETROBRAS, 2007)

Figura 98 - Registro de acelerações de um lançamento da estaca-torpedo destacando a região de interesse e empregada no algoritmo

Figura 99 - Curva de velocidade vertical (integral da aceleração no eixo x) sem nenhuma correção

Figura 100 - Curva de velocidade vertical (integral da aceleração no eixo x) após o método iterativo de correção do bias

Figura 101 - Esquema de obtenção da orientação inicial da estaca empregando o ROV ......177

Figura 102 - Caracterização da inclinação da estaca-torpedo .............................................. 179

Figura 103 - Comparação entre inclinações medidas e calculadas, em graus........................ 182

Figura 104 - Fixação do SMET rotacionado ..................................................................... 183

Figura 105 - Desvio na predição da rotação própria decorrente do ângulo de inclinaçaõ; neste caso a rotação própria imposta foi zero

Figura 106 - Visualização computacional do modelo analítico de pêndulo esférico indicando a orientação da base correspondente ao SMET (azul - eixo x; verde - eixo y; vermelho eixo z)

Figura 107 - Sinais artificiais produzidos; (de cima para baixo) trajetória, acelerações e velocidades angulares; (da esquerda para direita) o pendulo plano e o pêndulo esférico

Figura 108 - Trajetórias pendulares geradas artificialmente (vermelha) reproduzidas empregando o algoritmo desenvolvido (preto); (esquerda) pendulo plano; (direita) pendulo esférico; (de cima para baixo) verifica-se o acúmulo do desvio proveniente do maior tempo de integração

Figura 109 - Efeito da aceleração da gravidade na reconstrução da trajetória

Figura 110 - Efeito de desvios da condição inicial na reconstrução da trajetória; (esquerda) desvio angular; (direita) desvio na velocidade inicial 
Figura 111 - Efeito do erro na condição inicial associado a presença da aceleração da gravidade no sinal

Figura 112 - Efeito do tempo de integração no erro dos sinais ruidosos

Figura 113 - Efeitos das correções do sinal sobre a reconstrução da trajetória. No primeiro gráfico a linha azul corresconde a aceleração registrada no eixo x, verde em y e vermelho em $\mathrm{z}$.

Figura 114 - (Esquerda) Atitude da estaca sobreposta a trajetória para o caso em não foi aplicada nenhuma correção ao sinal; (Direita) Mesma representação para o caso em que bias e fator de escala foram corrigidos

Figura 115 - (Esquerda)Trajetória da estaca sobreposta ao cenário do lançamento; (Direita)Ponto em que ocorre a velocidade máxima e estimativa da profundidade de penetração.

Figura 116 - (Esquerda) Identificação da deriva na estimativa da velocidade vertical; (Direita) Estimativa de velocidades após a correção do bias na aceleração x .

Figura 117 - Tentativa de correção do bias de aceleração por meio dos dados fornecidos pelo fabricante.

Figura 118 - Base solidária ao SMET após reconstrução empregando quatérnios (perspectiva)

Figura 119 - Base solidária ao SMET após reconstrução empregando quatérnios (vista lateral)

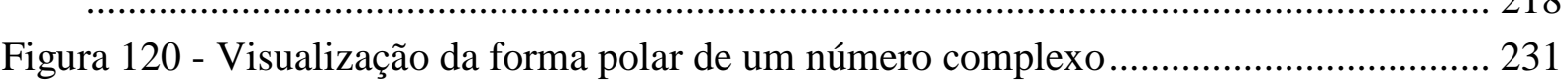

Figura 121 - Visualização da soma de números complexos ................................................ 232

Figura 122 - Ilustração proveniente do manual do aparelho demonstrando o procedimento de verificação da calibração.

Figura 123 - Vista de topo do conjunto morsa, suporte e SMET identificando pontos para medição e verificação do alinhamento.

Figura 124 - Orientação do SMET montado sobre o suporte. Os eixos y e z na figura referemse aos eixos sensíveis do SMET; A linha tracejada representa o eixo em torno do qual a inclinação da morsa foi variada

Figura 125 - Montagem reproduzindo $\zeta=0^{\circ}$ (experimentos 201 a 300) 239

Figura 126 - Montagem reproduzindo $\zeta=90^{\circ}$ (experimentos 101 a 200) 240 


\section{LISTA DE TABELAS}

Tabela 1 - Principais sistemas de amarração e suas aplicações............................................... 9

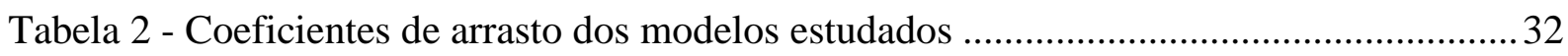

Tabela 3 - Situações em que ocorre o gimbal lock ................................................................ 65

Tabela 4 - Relação de preços e técnologias de sensores inerciais ..........................................116

Tabela 5 - Densidade espectral de potência de cada tipo de ruído ........................................ 121

Tabela 6 - Quantificação dos ruídos a partir da AVAR ........................................................ 122

Tabela 7 - Resumo das tecnologias de sensores e erros típicos........................................... 125

Tabela 8 - Dados dos acelerômetros empregados no SMET (ANALOG DEVICES, 2008) .131

Tabela 9 - Dados dos girômetros empregados no SMET (ANALOG DEVICES, 2008) ...... 134

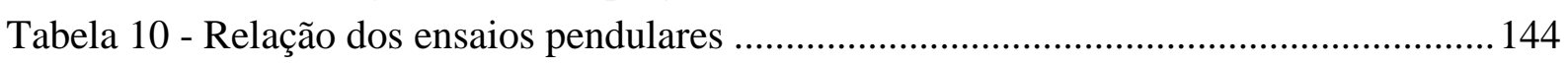

Tabela 11 - Parâmetros de calibração obtidos para os acelerômetros do SMET .................... 154

Tabela 12 - Parâmetros de calibração obtidos para os girômetros do SMET ..........................158

Tabela 13 - Inclinações finais calculadas ......................................................................... 180

Tabela 14 - Exemplos de dados esperados e obtidos a partir dos ensaios em rate table ....... 184

Tabela 15 - Erros de posição e inclinação das reconstruções realizadas a partir de sinais

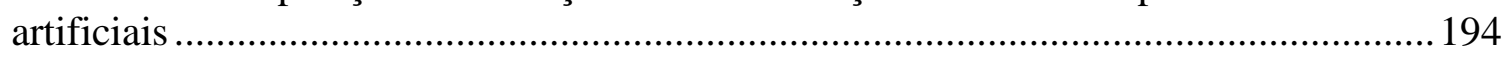

Tabela 16 - Erros de posição e inclinação das reconstruções realizadas a partir de sinais artificiais acrescidos da leitura (artificial) da gravidade............................................... 195

Tabela 17 - Resumo dos erros de posição dos testes com ruído............................................ 198

Tabela 18 - Resumo dos erros de inclinação dos testes com ruído ........................................ 198

Tabela 19 - Comparação das estimativas de velocidade vertical máxima (m/s) ....................207

Tabela 20 - Comparação das estimativas de profundidade de cravamento (m) .....................208

Tabela 21 - Comparação entre estimativas da inclinação final $\left({ }^{\circ}\right)$.......................................213

Tabela 22 - Comparação entre estimativas do Azimute $\left({ }^{\circ}\right)$...................................................2215

Tabela 24 - Verificação do nível do desempeno .................................................................237

Tabela 25 - Verificação do alinhamento do SMET ...............................................................237

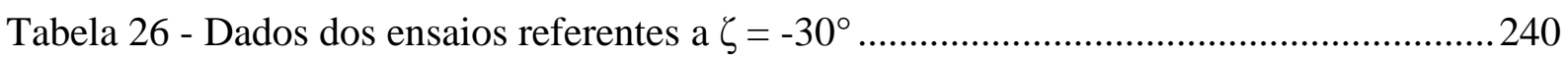

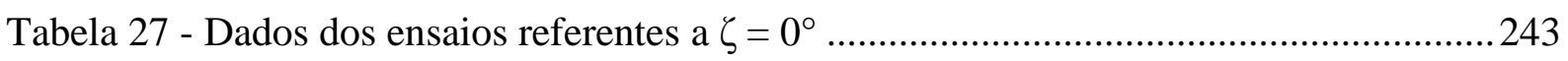

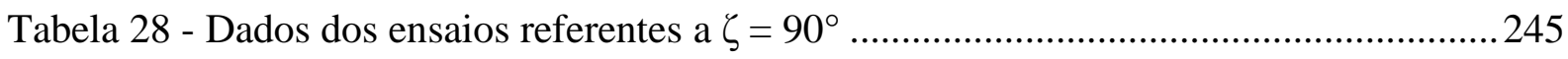

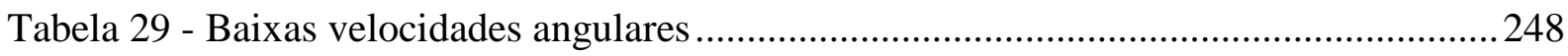

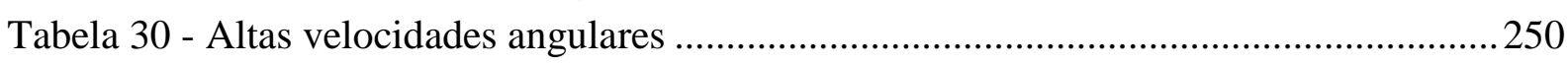

Tabela 31 - Velocidade variando segundo uma senoide ..................................................250

Tabela 32 - Repetições da mesma velocidade angular .................................................... 251 


\section{LISTA DE SÍMBOLOS}

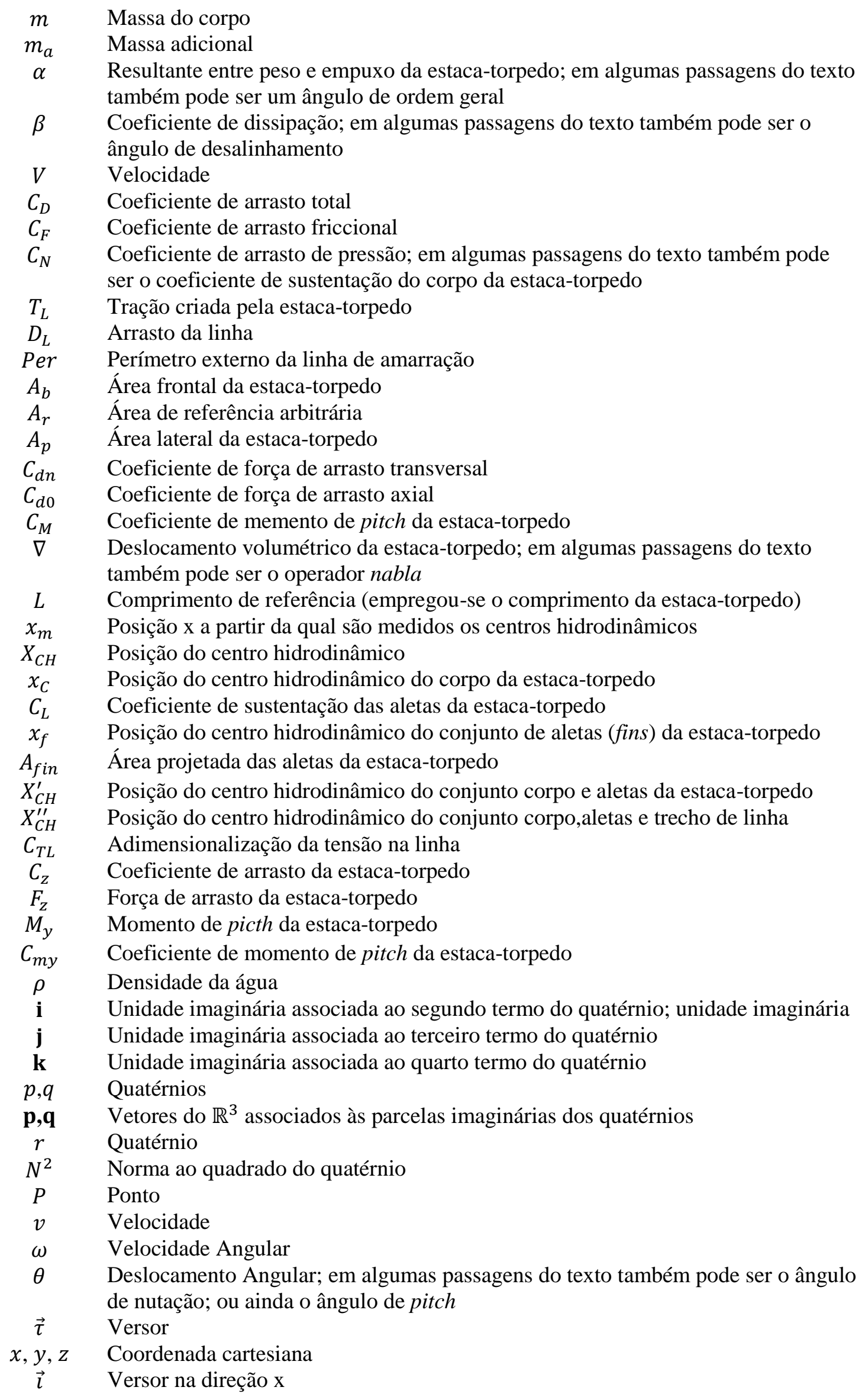




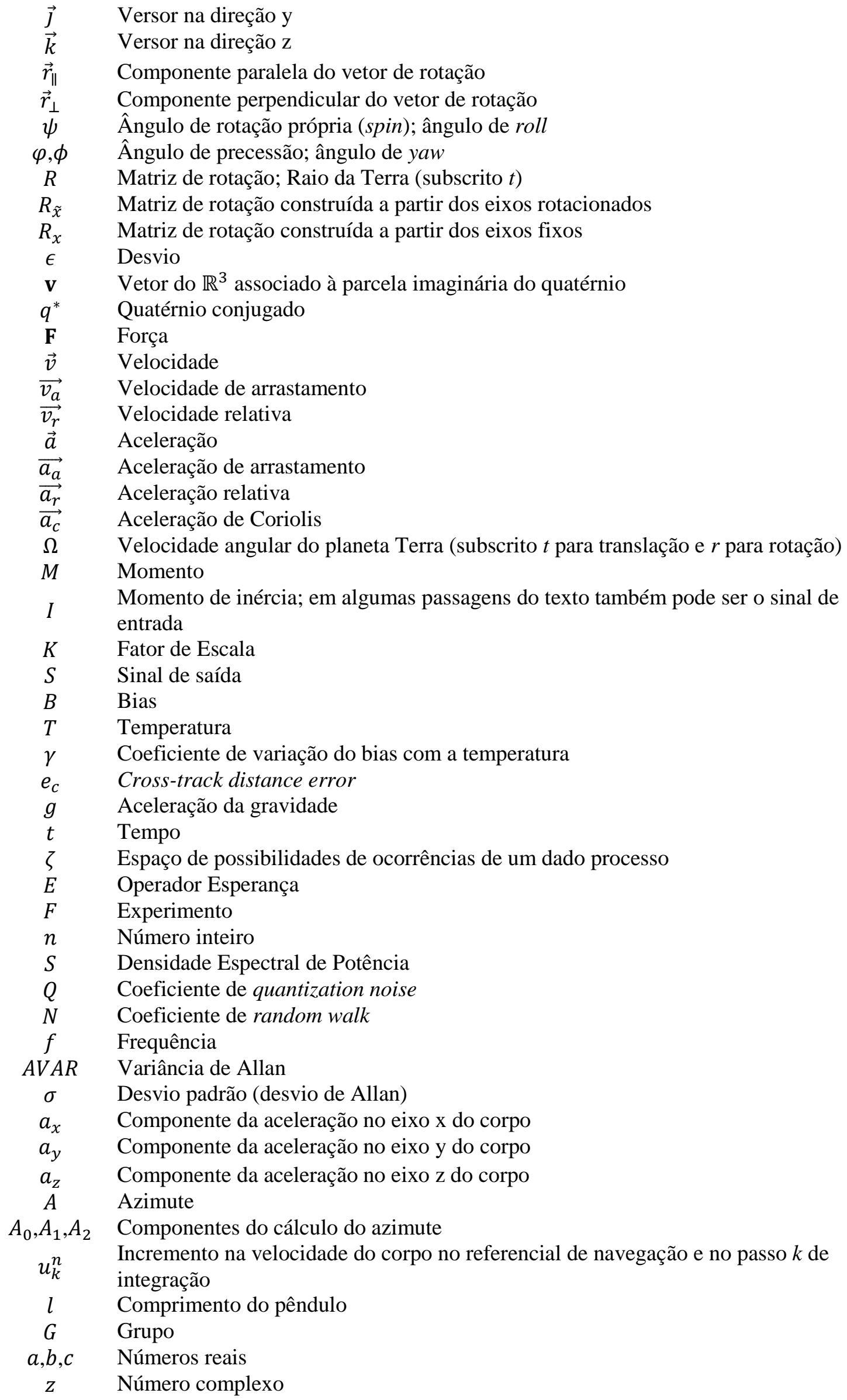




\section{SIGLAS}

API - American Petroleum Institute

AVAR - Allan's Variance

CFD - Computional Fluid Dynamics

DEP - Densidade espectral de potência

DTG - Dinamically tuned Gyroscope

FPSO - Floating Production Storage and Offloading

GPS - Global Positioning System

MEMS - Micro-Electro-Mechanical Systems

MOEMS - Micro-Opto Eletromechanical Systems

ROV - Remotely Operated underwater Vehicle

SMET - Sistema de Monitoração da Estaca Torpedo

SMS - Spread Mooring System

SS - Semi-Submersível

TLP - Tension-leg platform

UMI - Unidade de Medição Inercial 



\section{SUMÁRIO}

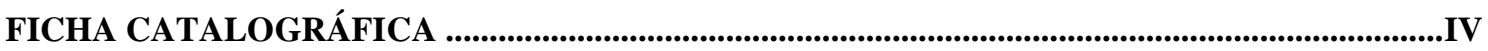

LISTA DE FIGURAS ..........................................................................................................................

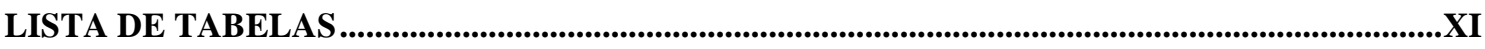

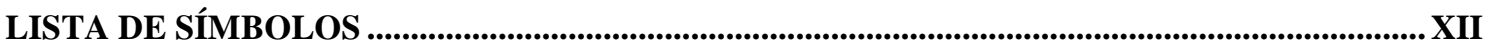

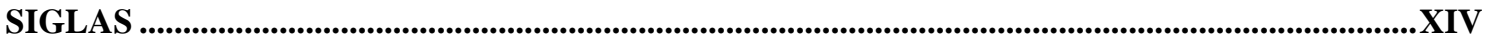

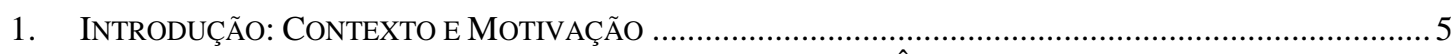

1.1. MANUTENÇÃO DA POSIÇÃo EMPREGANDO AMARRAÇÕES E ÂNCORAS ...............................................

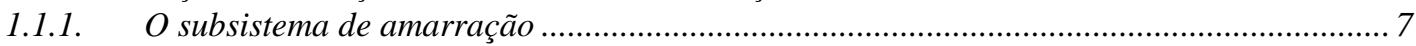

1.1.2. O subsistema de ancoragem ………………......................................................... 9

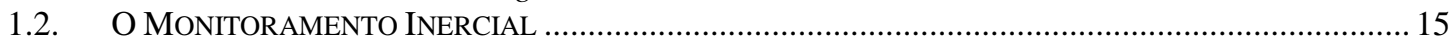

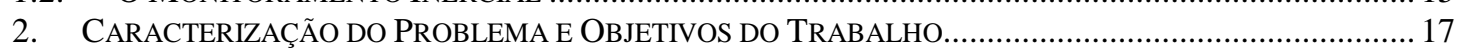

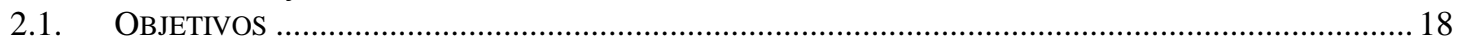

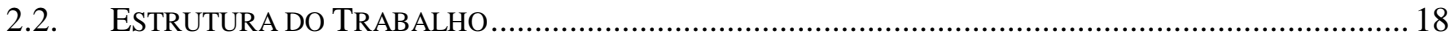

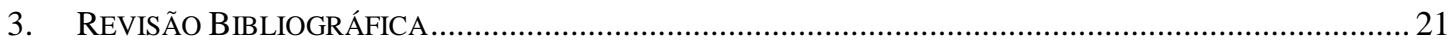

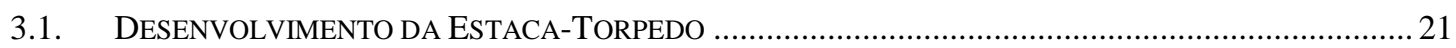

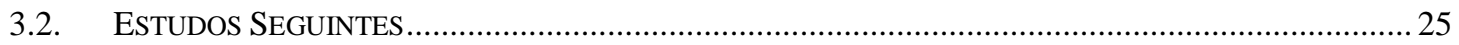

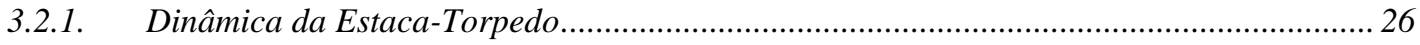

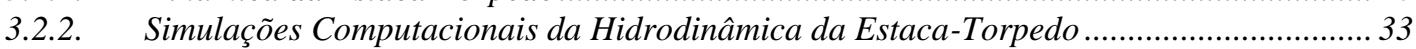

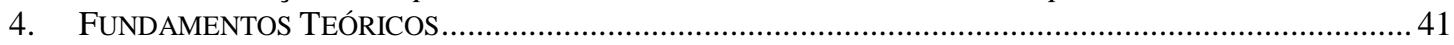

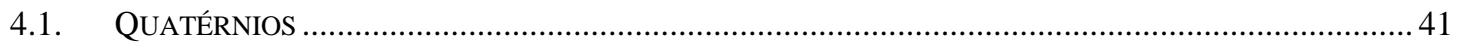

4.1.1. Quatérnio Conjugado, Norma e Inversos....................................................................... 45

4.2. CINEMÁtICA DO CORPO RíGIDO E ORIENTAÇão ESPACIAL........................................................... 47

4.2.1. Rotação de um Vetor em torno de um Eixo que o Intercepta ................................................ 53

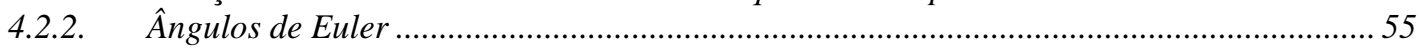

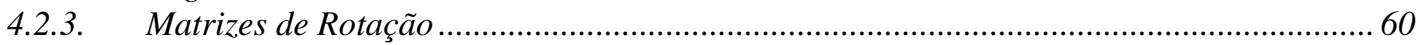

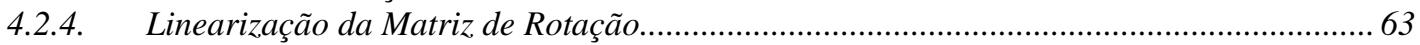

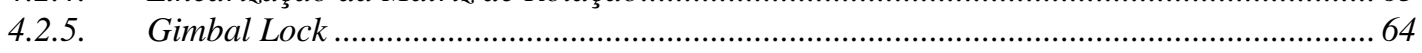

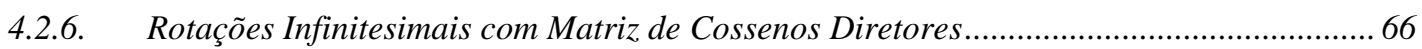

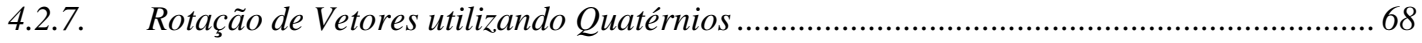

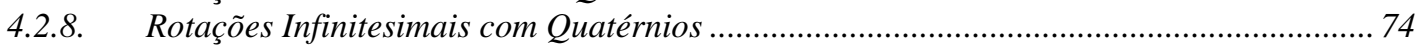

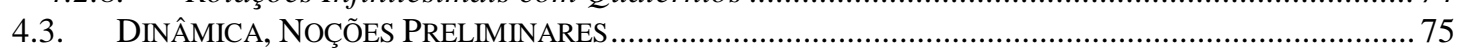

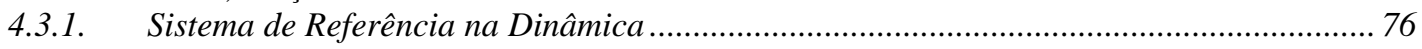

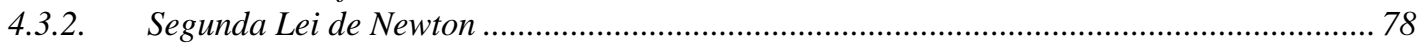

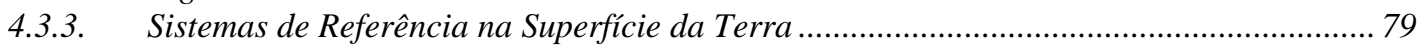

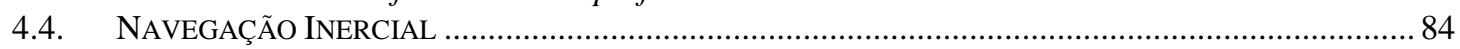

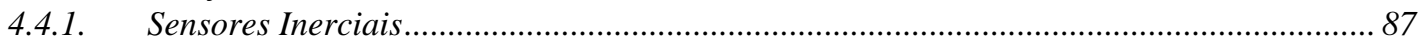

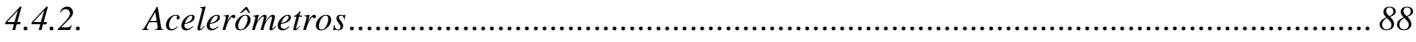

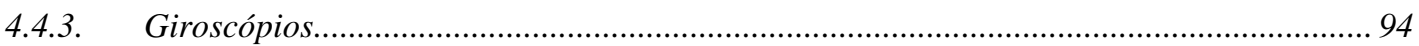

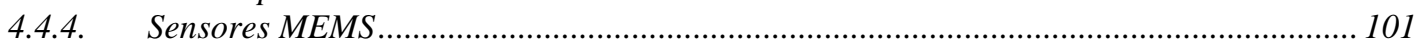

4.4.5. Erros associados a Acelerômetros e Giroscópios ……………………………............... 110

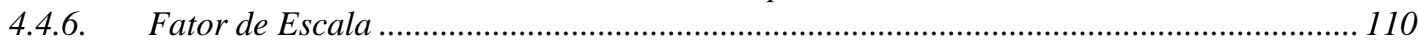

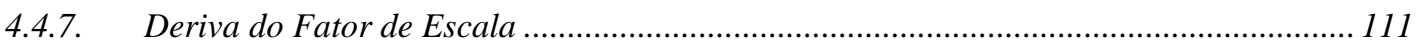

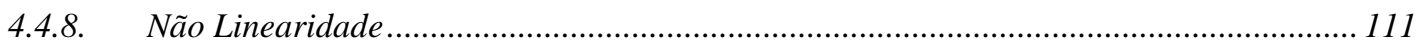

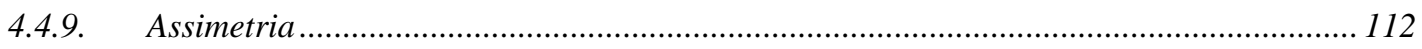

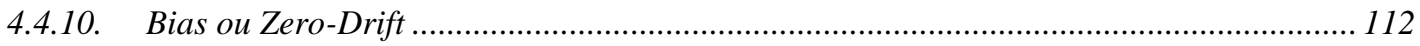

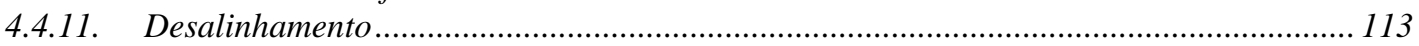

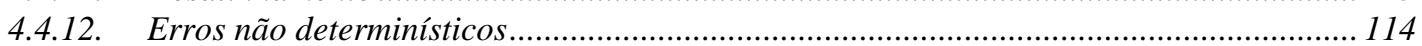

4.4.13. Definições matemáticas associadas ao processo estocástico ……………………............ 117

4.4.14. Análise espectral das componentes do ruído ................................................................ 120

4.4.15. Cálculo da Variância de Allan a partir do sinal original............................................... 124

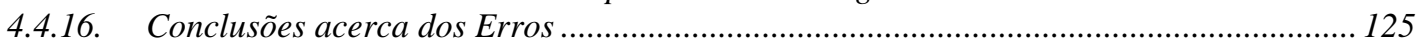

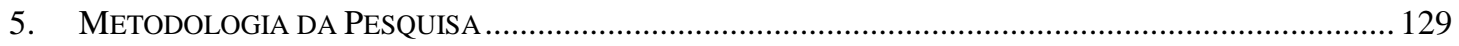

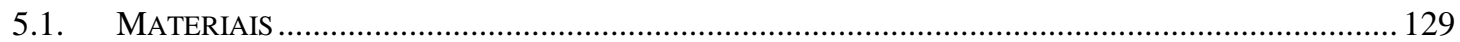

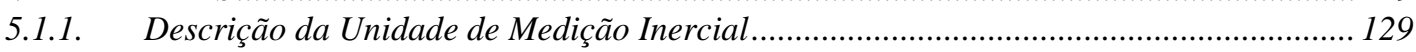

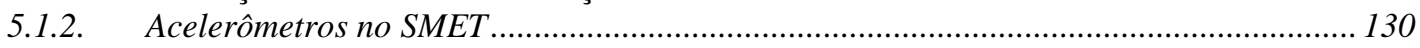

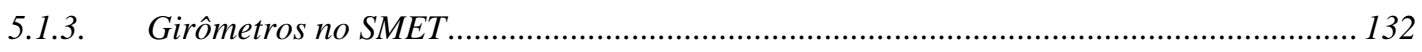




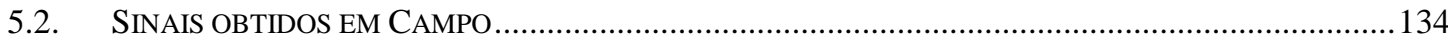

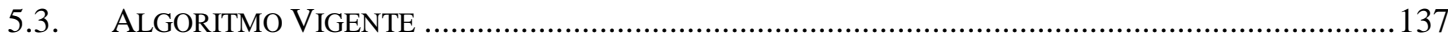

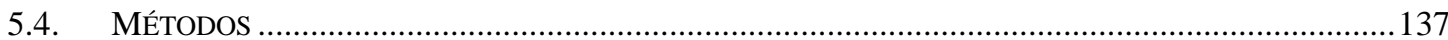

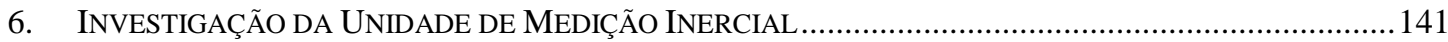

6.1. EXPERIMENTO PENDULAR (AVALIAÇÃO DO SMET COMO UM TODO) .......................................141

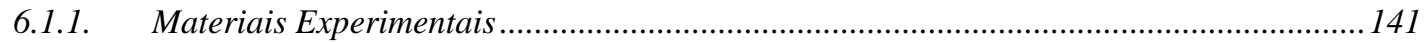

6.1.2. Métodos Experimentais............................................................................................ 144

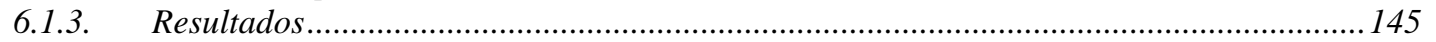

6.2. EXPERIMENTOS COM OS ACELERÔMETROS ...................................................................... 148

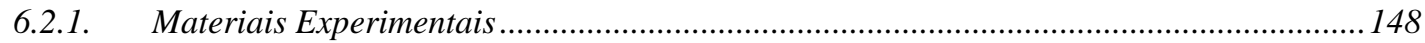

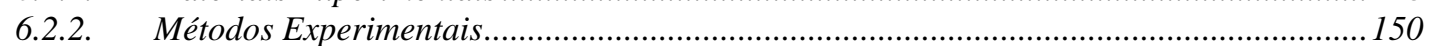

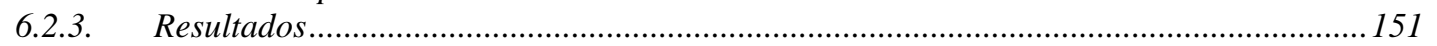

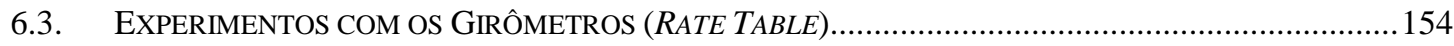

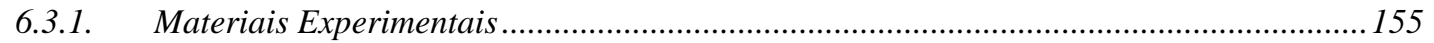

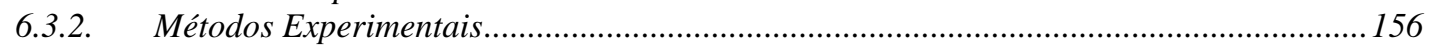

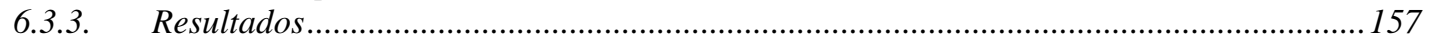

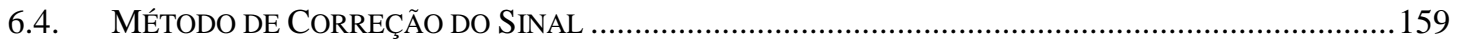

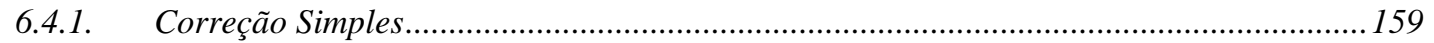

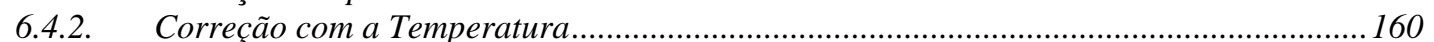

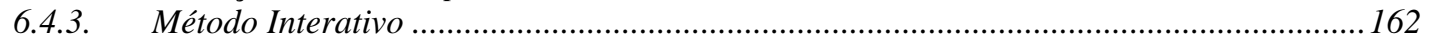

6.4.4. Análise dos Sinais por meio da Variância de Allan...................................................... 167

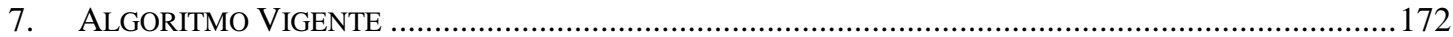

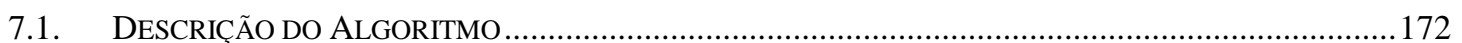

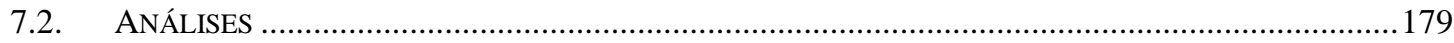

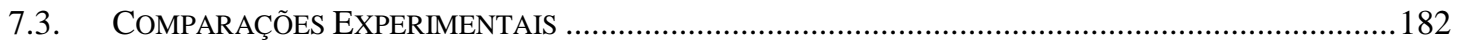

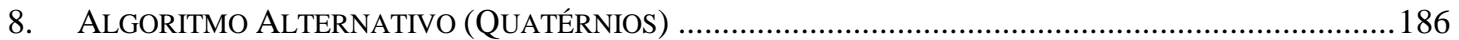

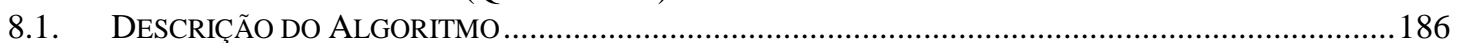

8.2. TESTES DO ALGORITMO COM SINAL ARTIFICIAL .................................................................. 190

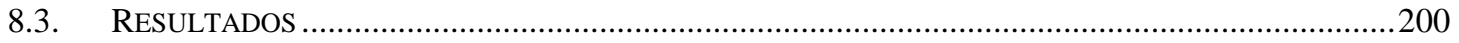

9. CONCLUSÕES E CONSIDERAÇÕES FINAIS À LUZ DAS COMPARAÇÕES ........................................206

9.1. PARÂMETROS DE INTERESSE NA TRAJETÓRIA DA ESTACA-TORPEDO.........................................206

9.1.1. Velocidade Máxima e Profundidade de Penetração .......................................................206

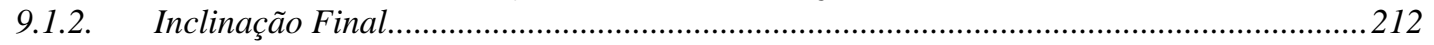

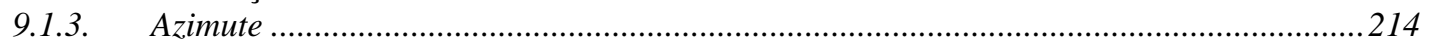

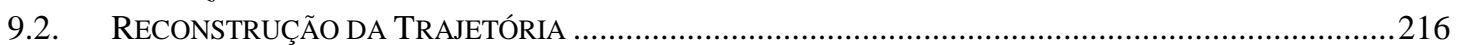

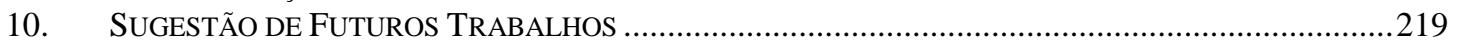

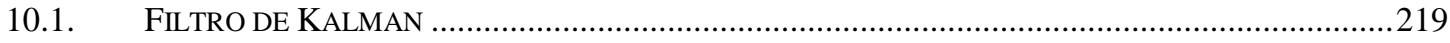

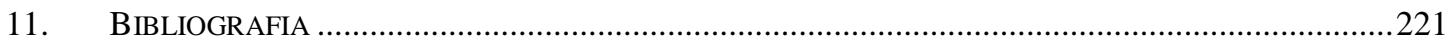

APENDICE A - REVISÃo DE CONCEITOS MATEMÁTICOS ...............................................................222

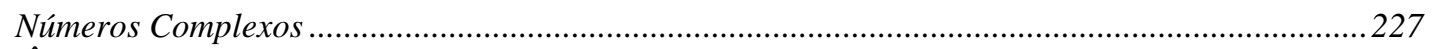

APÊNDICE B - PROCEDIMENTOS EXPERIMENTAIS DETALHADOS …...........................................2235

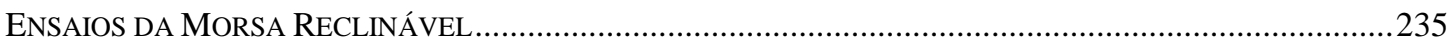

Verificação da Calibração do Inclinômetro ...........................................................................................2 235

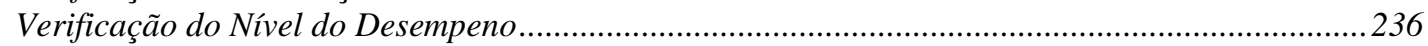

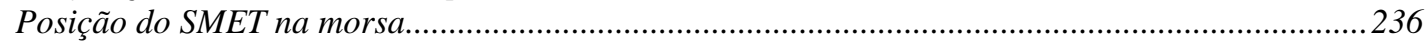

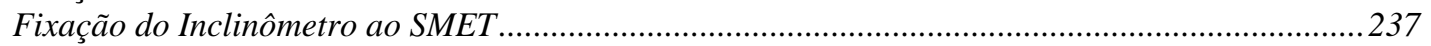

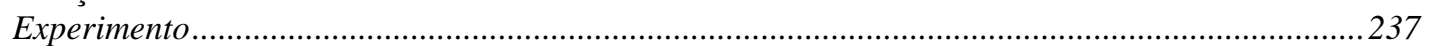

Leitura do Ângulo ............................................................................................................................ 237

Tabela de Ensaios na Morsa Reclinável (Dados Obtidos) .......................................................... 238

Ensaios na Rate Table .......................................................................................................................248

APÊNDICE C - RESULTADOS DE TODOS OS SINAIS DE LANÇAMENTO DISPONÍVEIS..............................2252

APÊNDICE D - ROTINAS COMPUTACIONAIS DESENVOLVIDAS ........................................................268

ANEXO A - ESPECIFICAÇÕES TÉCNICAS DA RATE TABLE .........................................................22 


\section{INTROduÇão: CONTEXTO E MOTIVAÇÃO}

No Brasil, a exploração de petróleo no mar iniciou-se em meados da década de 1970 com a descoberta e as primeiras perfurações no campo de Garoupa, bacia de Campos, estado do Rio de Janeiro.

Graças às lâminas d'água relativamente pequenas naquela localidade, de 120 a 160 metros, as primeiras unidades de produção empregadas caracterizavam-se como fixas, valendo-se de estruturas metálicas para se manterem presas ao leito marinho.

Com o aumento das lâminas d'água, a partir de 1977, passou-se a empregar unidades flutuantes de produção, representando um salto tecnológico que coincidiu com a estratégia do governo brasileiro de reduzir a dependência nacional do petróleo estrangeiro, na época em torno de $70 \%$ a $80 \%$ da demanda interna total. Daquele momento em diante foram, então, descobertos inúmeros campos de prospecção na costa sudeste do Brasil, cada vez mais profundos, conforme ilustrado na Figura 1.

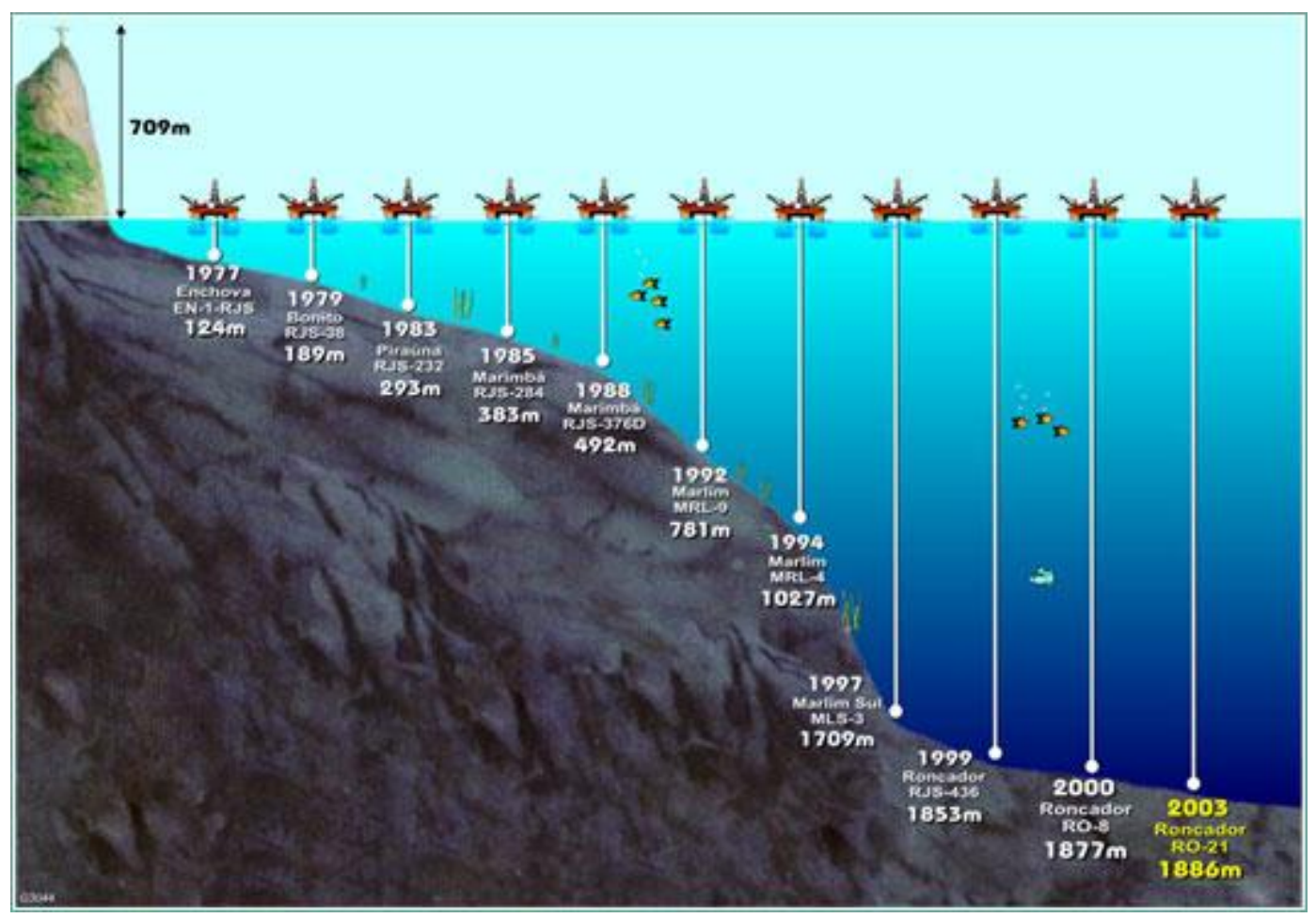

Figura 1 - Evolução no tempo da profundidade de produção oceânica de petróleo no Brasil (PETROBRAS) 
Importante destacar que, embora mais versáteis, as unidades flutuantes de produção passaram a exigir sistemas mais eficientes de manutenção da posição e, em certos casos, capazes de também minimizar as oscilações impostas pelos agentes ambientais.

Sendo assim, um forte aprimoramento na tecnologia dos sistemas de ancoragem se mostrou vital à expansão da capacidade de produção oceânica de petróleo e gás natural. Juntamente com a necessidade de explorar campos mais profundos, fazendo-o de forma ágil e eficiente, vieram as tecnologias diferentes de sistemas para a manutenção da posição, ou na nomenclatura inglesa: stationkeeping systems.

Um sistema de manutenção da posição, como o próprio nome indica, deve manter a posição do sistema flutuante durante sua operação, mediante a ação dos diferentes agentes ambientais, particularmente as ondas, os ventos e as correntezas. Há dois tipos básicos de sistemas de manutenção da posição:

- Os que de alguma forma conectam o sistema flutuante ao leito marinho;

- E os que dispensam tal conexão, pois empregam propulsores e um sistema de controle para contraporem-se às excitações externas e, com isso, manter a unidade flutuante na mesma posição com relação a um referencial fixo em terra.

Esta segunda forma de manutenção da posição é conhecida como sistema de posicionamento dinâmico, comumente identificada pela sigla inglesa DP - Dynamic Positioning, não abordada no âmbito deste texto.

Serão discutidos, portanto, apenas elementos relacionados ao primeiro tipo de sistema de manutenção da posição, em particular aqueles relacionados à ancoragem, ou seja, os dispositivos que fixam as linhas de amarração ao leito marinho. Alguns destes sistemas de ancoragem requerem o conhecimento da posição final em que a estrutura de fixação se encontra após o lançamento e, para tanto, acabam utilizando unidades de monitoração e medição inercial de movimentos durante sua instalação.

Tendo em vista que qualquer equipamento eletrônico corre risco de se danificar ou de ser perdido durante o lançamento de um sistema de ancoragem ou estrutura análoga ${ }^{1}$, soluções de baixo custo para a monitoração inercial mostram-se interessantes, desde que sejam capazes de

\footnotetext{
${ }^{1} \mathrm{O}$ conhecimento da posição final sobre o leito, ou mesmo sob este, não é demanda apenas dos sistemas de ancoragem. Tal necessidade pode ser estendida para inúmeros outros lançamentos submarinos como, por exemplo, o caso do posicionamento de manifolds.
} 
fornecer dados confiáveis de posição, quando comparados com sistemas mais robustos e $\operatorname{precisos}^{2}$.

É neste contexto que se enquadra a presente pesquisa, focada no estudo e aprimoramento de unidades inerciais de baixo custo para o emprego em lançamentos submarinos. No entanto, ainda no âmbito deste capítulo introdutório, cabe definir de forma mais detalhada os principais sistemas descritos anteriormente, detendo atenção particular sobre aqueles referentes ao sistema de manutenção da posição por intermédio de amarrações e âncoras.

\subsection{Manutenção da Posição Empregando Amarrações e Âncoras}

Sistemas de manutenção da posição que empregam amarrações, amplamente empregados em unidades flutuantes de produção, podem ser subdivididos em: subsistema de amarração e subsistema de ancoragem. A seguir cada um destes subsistemas será detalhado.

\subsubsection{O subsistema de amarração}

Amarração é o conjunto de linhas que conectam a estrutura flutuante ao sistema de ancoragem, este, fixo ao leito marinho. Os elementos em questão ou, comumente chamados de linhas de amarração, são estruturas compostas de segmentos de amarras, cabos de aço e/ou cabos poliméricos. A Figura 2 apresenta uma configuração típica de linha empregada em um sistema de amarração do tipo catenária.

${ }^{2}$ Atualmente, alguns lançamentos podem empregar a triangulação de sinais de um conjunto de sonares dispostos no entorno da localidade em que o sistema será instalado. Trata-se, no entanto, de uma forma de monitoração bastante cara. 


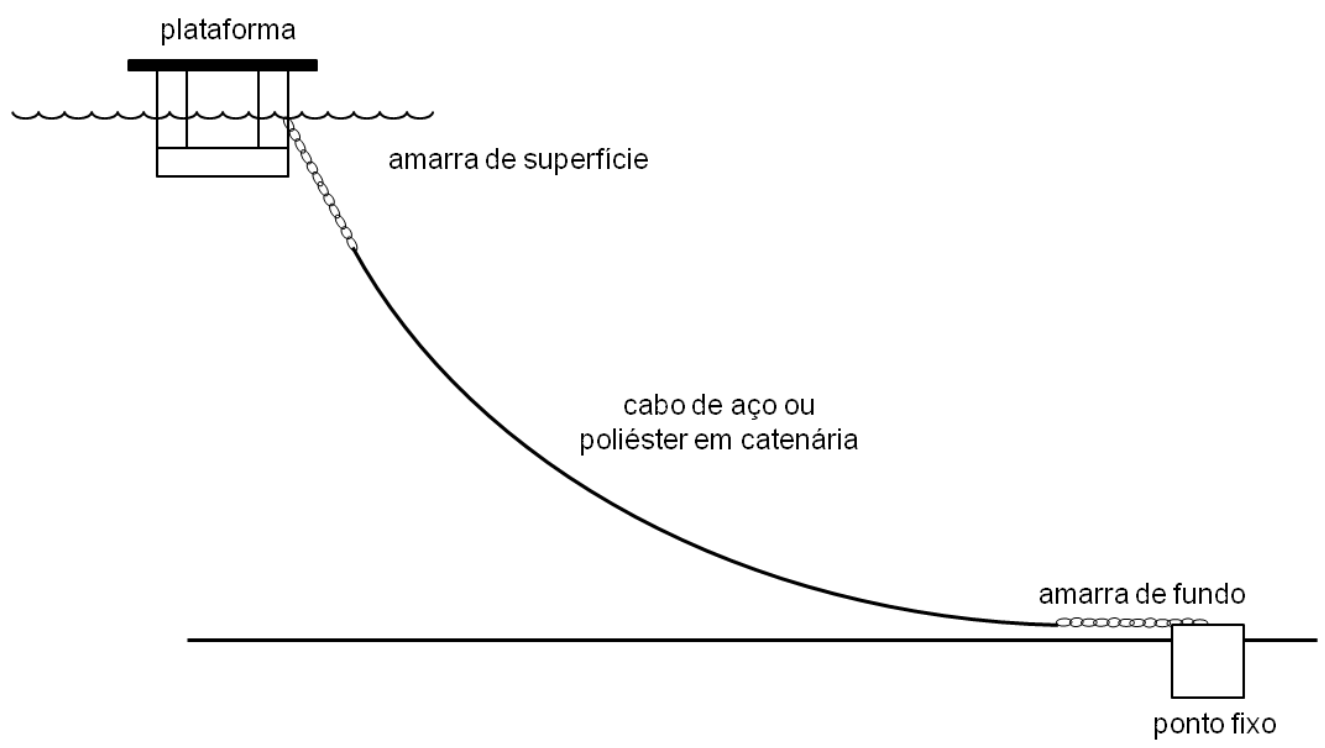

Figura 2 - Configuração típica de linha de ancorágem em catenária

De acordo com a Figura 2, percebe-se um trecho de corrente próximo à plataforma, assim como outro próximo ao leito marinho. O restante da linha é composta por um cabo de aço ou de poliéster.

O sistema de amarração pode, ainda, ser composto por inumeras linhas concentradas em um mesmo ponto no solo espalhadas. O primeiro caso é tipicamente empregado na manutenção da posição de estruturas flutuantes como navios e embarcações em geral. Por outro lado, nos casos em que há inúmeras linhas espalhadas - em inglês spread mooring - a aplicação é mais extensa, incorporando, inclusive, plataformas do tipo semi-submersível, Floating Production Storage and Offloading Units (FPSOs), etc.

Há um terceiro tipo de amarração em que um conjunto de tendões - normalmente tubos metálicos - é fixo às fundações no leito marinho e ascendem verticalmente até a plataforma, mantendo-a com um volume imerso maior que o do corpo livre. Essa imersão forçada faz com que os tendões permaneçam intensamente tracionados, garantindo a posição do sistema flutuante.

Foge ao escopo deste trabalho descrever em detalhes todos os tipos de sistemas de amarração. No entanto, a Tabela 1 apresenta de forma sintética as informações que mais interessam ao contexto traçado. 
Tabela 1 - Principais sistemas de amarração e suas aplicações

\begin{tabular}{|l|l|l|l|} 
Sistema & \multicolumn{2}{c|}{ de } & \multicolumn{2}{c|}{ Número de Linhas } & Pré-tensão \\
Amarração & FPSO (auto alinhado) & de 6 a 12 & Vinculado ao projeto \\
\hline Turret & TLP & de 6 a 10 & $\begin{array}{l}\text { 25 30\% do deslocamento } \\
\text { da plataforma }\end{array}$ \\
\hline Tendões & FPSO, SS, Spar & de 16 a 24 & $\begin{array}{l}\text { Trata-se de um valor } \\
\text { ajustável de acordo com a } \\
\text { condição ambiental, } \\
\text { justamente a } \\
\text { característica deste tipo } \\
\text { de sistema de amarração }\end{array}$ \\
\hline
\end{tabular}

Com base na Tabela 1, é possível constatar que cada um dos sistemas de amarração envolve certo tipo de pré-tração. A pré-tração, assim como a direção em que a linha assume com relação ao plano vertical de referência, são características do sistema de amarração que determinam a escolha do subsistema de ancoragem empregado.

\subsubsection{O subsistema de ancoragem}

Os principais tipos de ancoragem são descritos a seguir.

\section{Âncora de fixação por arrasto}

A tecnologia de âncoras fixas por arrasto avançou consideravelmente nos últimos anos. São inúmeras as formas (Figura 3) e arranjos destes equipamentos, incorporando ou não partes móveis. Em testes, mesmo âncoras sem partes móveis operando em solo macio vêm apresentado grande capacidade de fixação.

Atualmente, graças ao desenvolvimento desses dispositivos, âncoras de fixação por arrasto são alternativas atraentes para sistemas de ancoragem, principalmente por conta da facilidade de instalação e desempenho comprovado. De fato, a maioria dos sistemas móveis ou fixos de ancoragem usa âncoras de arrasto, pois podem ser instaladas e testadas antes mesmo da 
plataforma ser trazida para o local. Âncoras desse tipo podem, ainda, ser reutilizadas como mostra a Figura 4.

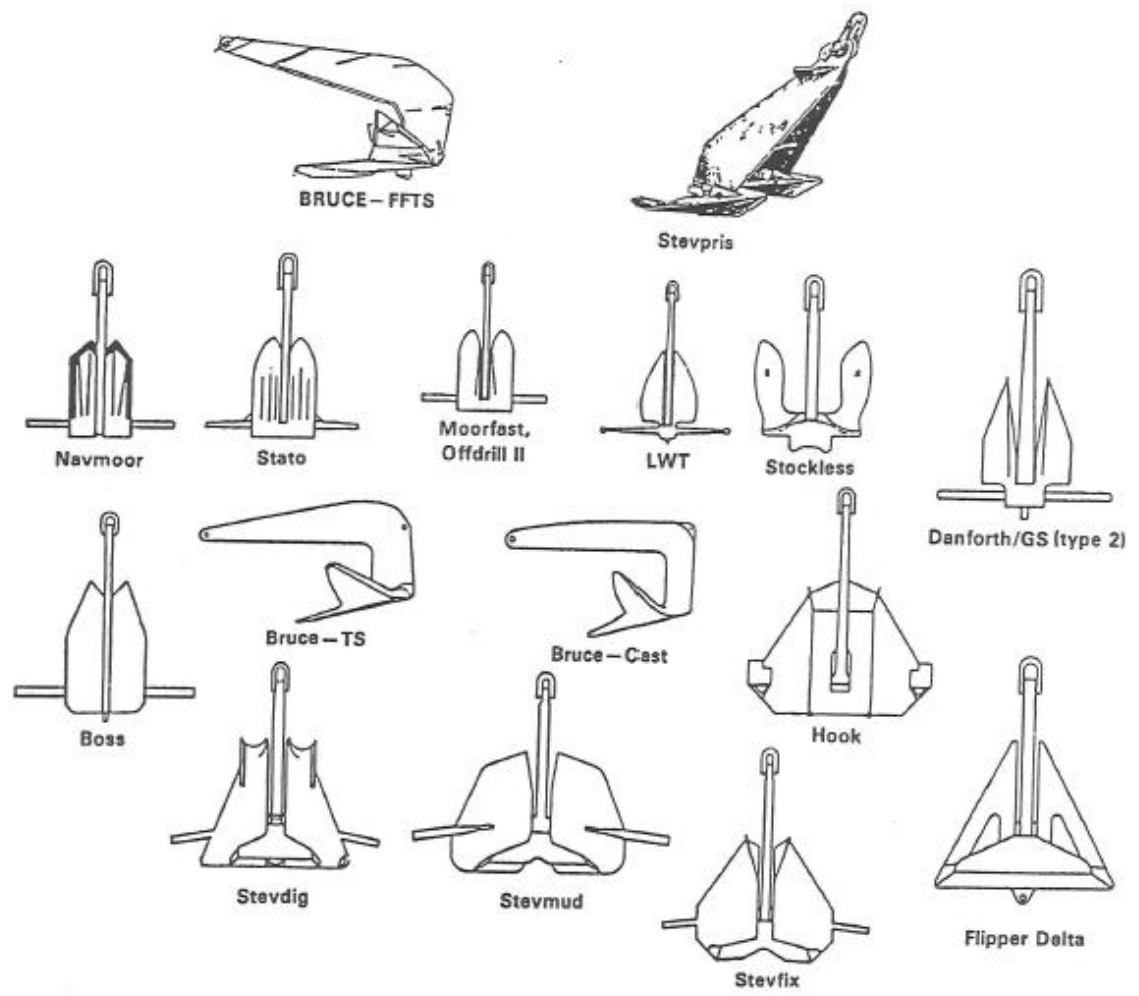

Figura 3 - Modelos de âncoras de arrasto

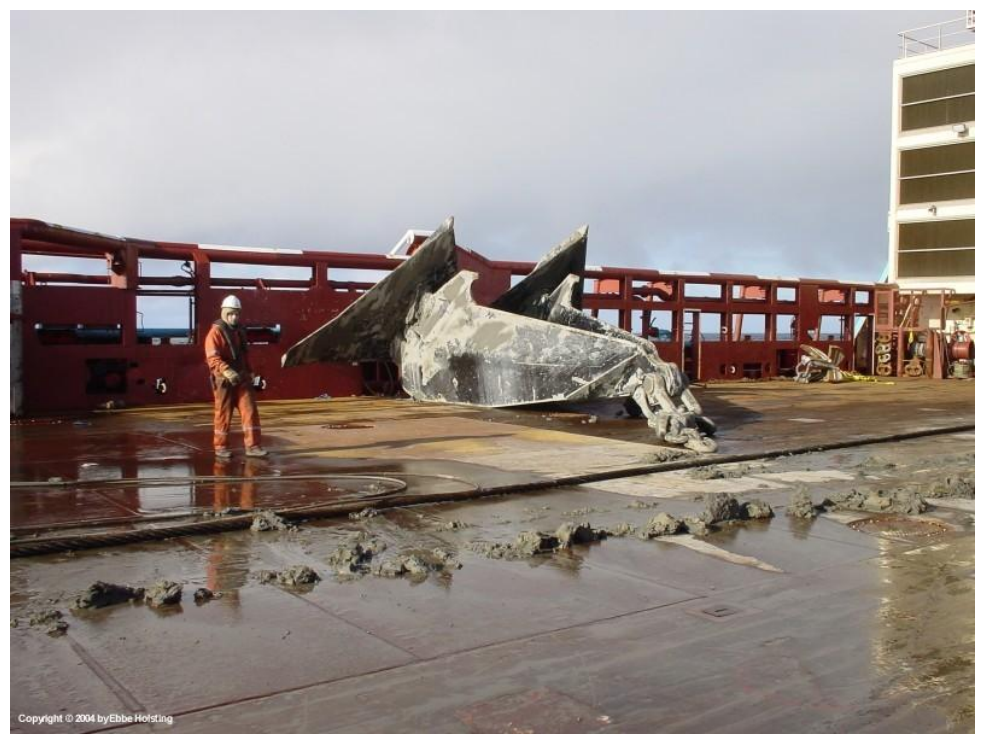

Figura 4 - Âncora tipo Stevpris no convés de uma embarcação de suporte após ter sido arrancada do leito marinho (HOLSTING)

\section{Âncoras em estaca}


Neste tipo de âncora, em estaca, a resistência às forças de "arrancamento" vertical e horizontal é função principalmente das dimensões da própria estaca, da maneira como é instalada, bem como do tipo, rigidez e resistência do solo adjacente à mesma.

A capacidade de fixação horizontal da estaca pode ser aumentada substancialmente com a adição de certos elementos ao topo da mesma, como asas ou saias.

As estacas são geralmente instaladas por meio de martelos guiados, embora métodos como injeção, ou perfuração e posterior enterramento, também possam ser empregados sem grandes problemas a partir de unidades de perfuração. Em especial, os processos de perfuração e injeção podem provocar modificações significativas no solo que circunda a estada afetando assim sua capacidade de fixação. Tais efeitos devem ser levados em consideração.

A esse respeito, práticas recomendadas pela American Petroleum Istitude (API) fornecem informações detalhadas sobre o desenho e instalação de estacas guiadas.

A principal diferença entre estas âncoras e as do tipo estaca-torpedo, que serão apresentadas mais a diante no texto, esta na forma de fixação. Estas estacas são inseridas no solo por meios artificiais, descritos anteriormente enquanto a estaca-torpedo é lançada de certa altura do leito marinho e cravada por gravidade.

\section{Âncoras de Sucção}

Uma âncora de sucção emprega tal efeito - a sucção de água e areia - para penetrar lentamente no leito marinho.

A âncora de sucção pode assumir muitas formas, sendo a mais comum caracterizada por um grande cilindro (Figura 5), podendo chegar a mais de $5 \mathrm{~m}$ de diâmetro por quase $25 \mathrm{~m}$ de comprimento. De modo geral, a estaca de sucção (âncora de sucção) é uma solução viável em solos macios ou moderadamente duros.

Quando baixada até o leito marinho, a estaca de sucção penetra até certa profundidade graças a seu peso próprio e cria, com isso, uma área selada entre o solo e seu interior, que, por sua vez, permite o início da sucção. Desta forma, a água é bombeada para fora dessa área confinada no interior do cilindro, fazendo com que a estaca ancore-se ao leito marinho. Tendo penetrado o leito marinho, a operação de sucção é interrompida e por vezes é adicionado lastro às câmaras superiores da estaca para aumentar sua capacidade de resistir a cargas verticais. 
Para alguns solos muito macios, a âncora de sucção deve penetrar o suficiente para alcançar uma área cujo substrato apresente boa resistência às cargas de "arrancamento", em certos casos, requerendo estruturas muito longas e, consequentemente, de difícil manipulação.

Por outro lado, para solos muito duros pode não ser possível penetrar o suficiente e, portanto, proporcionar a força de fixação adequada.

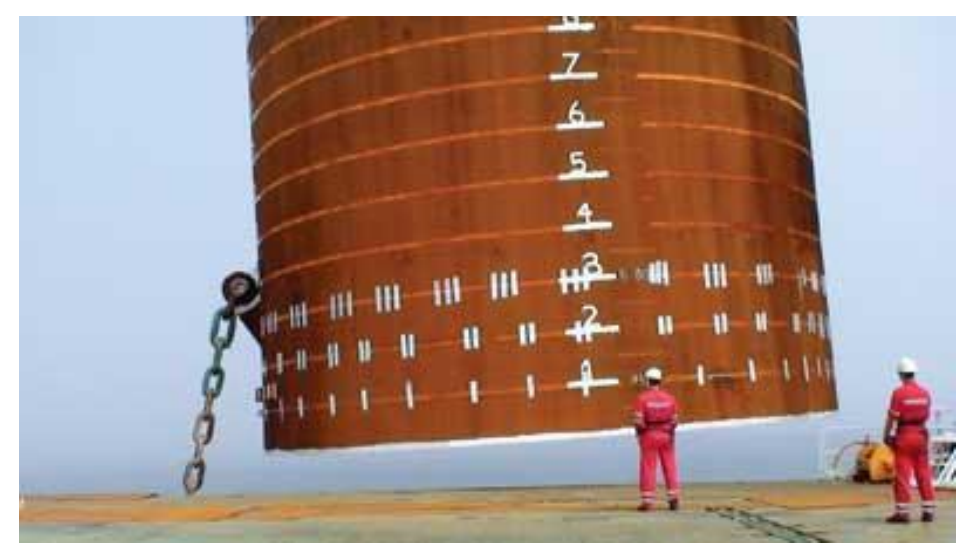

Figura 5 - Âncora de sucção sendo instalada (PENNENERGY)

\section{Âncora propelida}

$\mathrm{O}$ conceito de âncora propelida foi inicialmente desenvolvido pela Marinha Americana e utilizado para ancoragem de embarcações leves em águas rasas.

Em linhas gerais, o sistema utiliza uma âncora similar às de arrasto, porém menor, que é baixada até o leito marinho com a linha de ancoragem. Então, uma carga explosiva é acionada, impulsionando a âncora na direção do leito marinho enterrando a mesma. Até onde se sabe, este tipo de sistema de ancoragem nunca foi adaptado para âncoras de grande porte como as empregadas nos sistemas de manutenção da posição de unidade flutuantes produtoras de petróleo.

\section{Âncoras de gravidade}

Âncoras de gravidade são lastros pesados, geralmente grandes blocos de concreto ou aço (Figura 6), material de sucata ou mesmo outros materiais de elevada densidade, lançados ao leito marinho. A capacidade de resistir a forças verticais depende fundamentalmente do peso do material submerso. A capacidade de resistir a cargas horizontais depende do atrito entre a âncora e o solo, bem como da resistência ao cisalhamento do solo sob a âncora. 
Por serem lançadas, há um menor controle da posição em que se encontram no leito marinho, assim como a velocidade com que tais estruturas atingem o solo. Estas informações associadas ao conhecimento geológico da região em que tais lastros são lançados certamente aprimorariam as previsões quanto à capacidade de fixação destas estruturas.

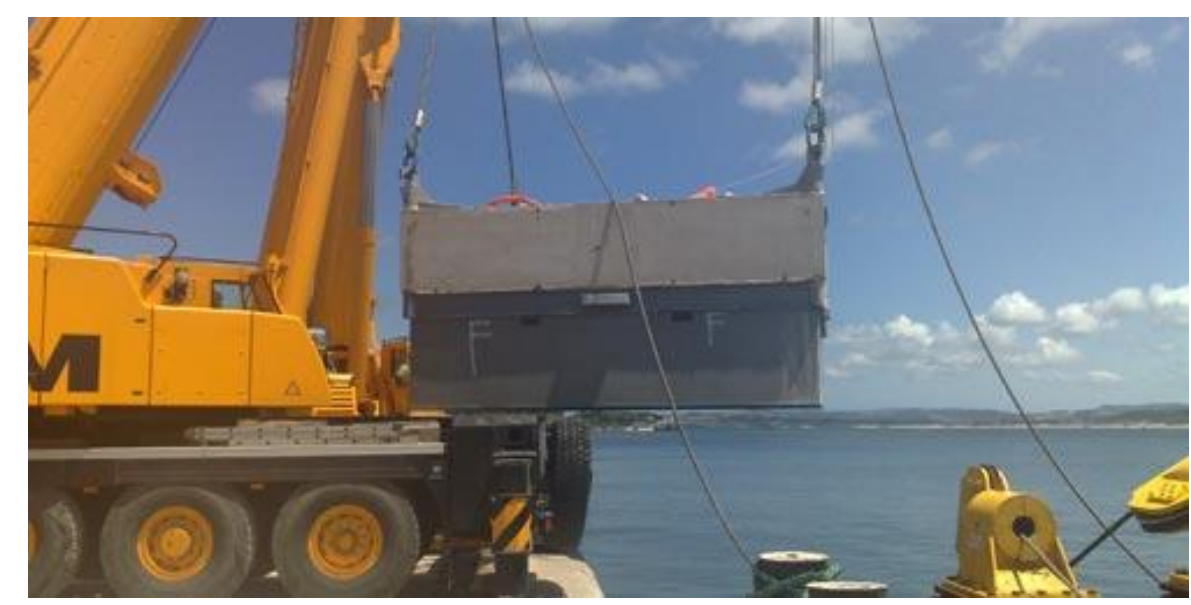

Figura 6 - Âncora de gravidade (MOJOMARITIME)

\section{As estacas-torpedo3}

A estaca-torpedo combina as características dos sistemas de ancoragem por estaca com as do sistema por gravidade.

Trata-se de uma grande estaca de aço, com certa de $17 \mathrm{~m}$ de comprimento e quase $1,5 \mathrm{~m}$ de diâmetro (Figura 7), presa à linha de ancoragem. Este conjunto é, então, abandonado de certa altura a partir do leito marinho e penetra o mesmo graças à quantidade de movimento que adquire durante a queda.

Até o ano de 2004, este tipo de âncora já havia sido empregado na instalação de nove unidades flutuantes no campo de Marlin, Bacia de Campos.

Trata-se de um sistema com relativa facilidade de instalação, independente da lâmina d'água em que se pretende fazer a ancoragem. Entretanto, as principais questões relacionadas ao emprego da estaca-torpedo dizem respeito aos seus apêndices e, principalmente, a posição que assume após sua cravação e acomodação no leito marinho.

3 O sistema de ancoragem denominado estaca-torpedo foi desenvolvido pela Petrobras durante o programa PROCAP2000 ( programa plurianual de desafios visando colocar em operação sistemas de produção de petróleo e gás em lâminas d'água de 2000 metros. Entre 1993 e 1999, o programa envolveu o desenvolvimento de 20 projetos, dentre eles a estaca Torpedo, cuja patente, entretanto, data de 2003, fazendo deste, um sistema bastante recente. 


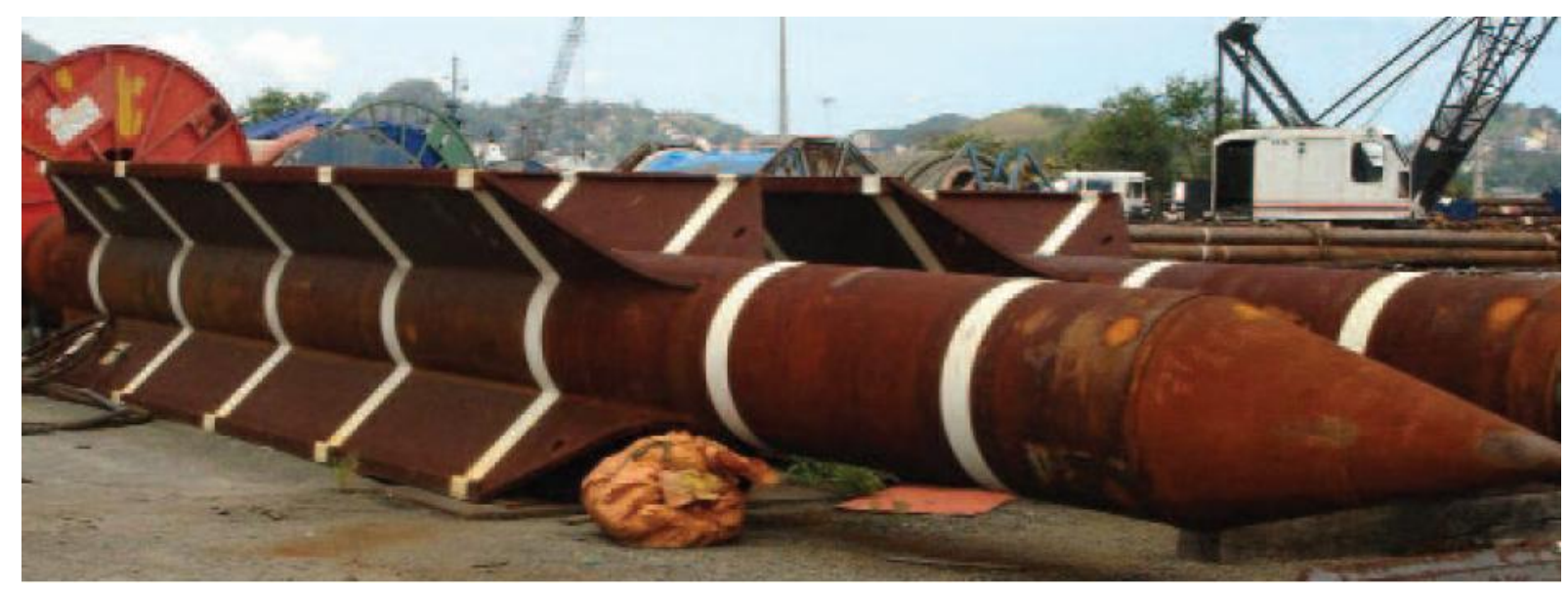

Figura 7 - Estaca-torpedo (INTERMOOR, 2009)

O primeiro parâmetro decisivo na capacidade de fixação da estaca-torpedo diz respeito à profundidade de penetração no leito marinho. Essa profundidade depende das características do solo e da velocidade com que a estaca-torpedo atinge o mesmo.

A altura mínima da estaca com relação ao leito determina se esta será capaz de atingir sua velocidade terminal ao tocar o leito. Obviamente, a velocidade terminal, ou velocidade máxima, depende não só do peso próprio como também das forças hidrodinâmicas.

O segundo parâmetro importante envolvido no processo de cravação é a atitude da estacatorpedo após sua acomodação enterrada no solo. Para tanto, a atitude do corpo no espaço pode ser descrita por meio de sua inclinação, precessão e rotação própria - estes parâmetros correspondem à descrição de Euler para a atitude do corpo e serão detalhados em profundidade no decorrer do texto. 

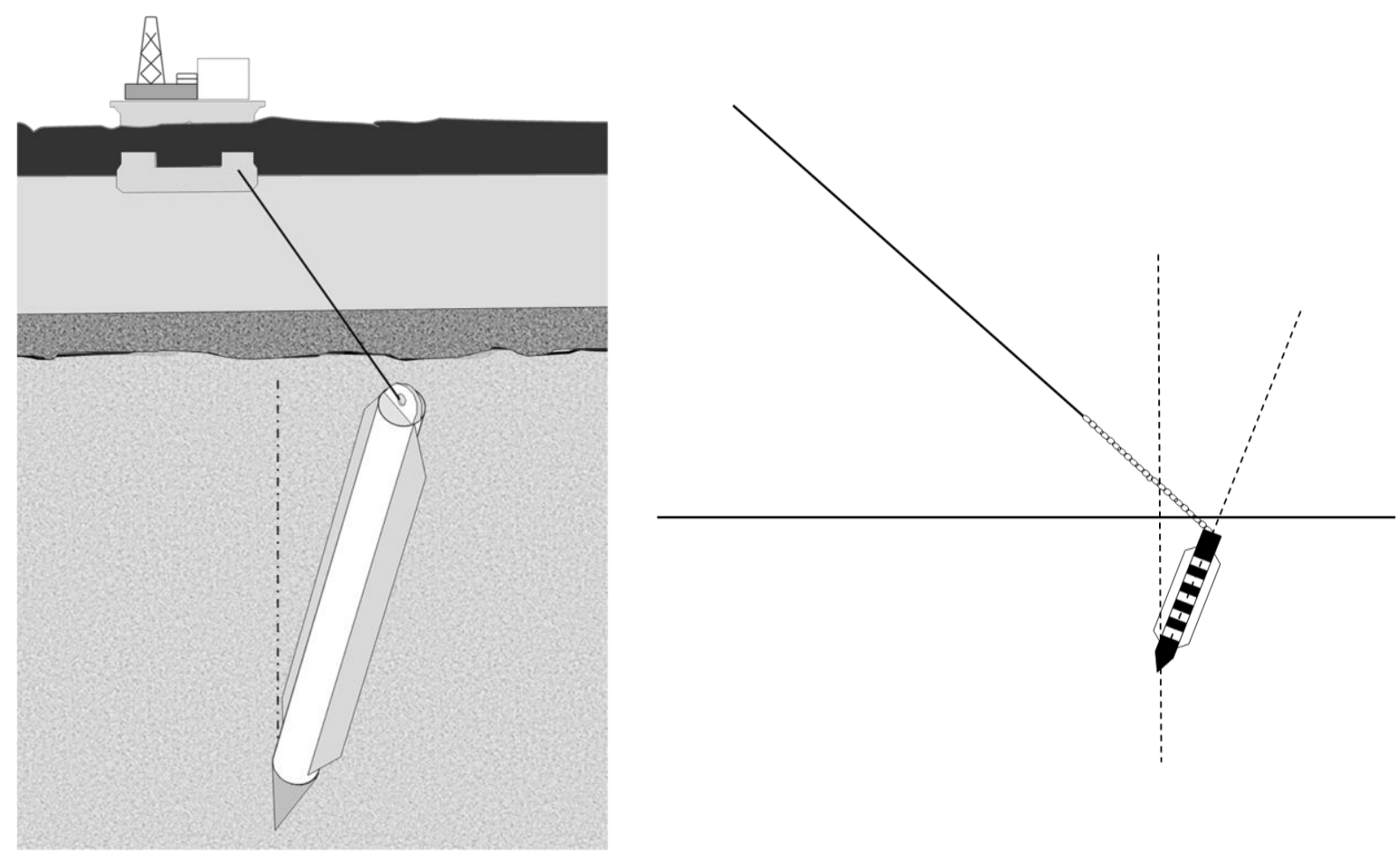

Figura 8 - Condição favorável de cravação da estaca-torpedo

É intuitivo concluir que a maior capacidade de fixação da estaca-torpedo ocorrerá quando esta assumir um ângulo de precessão com uma diferença de $180^{\circ}$ com relação ao azimute da linha de amarração, conforme ilustra a Figura 8. Por sua vez, a inclinação do corpo com relação ao plano vertical de referência, não nula, é o que permite definir um ângulo de precessão para a estaca. Finalmente, a rotação própria do corpo deve ser conhecida para que se possa estimar a eficiência das aletas da estaca no que tange à capacidade de fixação da mesma.

Portanto, assim como outros anteriores, trata-se de um sistema de ancoragem que necessita de um monitoramento que permita a determinação de sua atitude final, por exemplo, um sistema de monitoração inercial como descrito na seção seguinte.

\subsection{O MONITORAMENTO INERCIAL}

Nas descrições anteriores foi apontada a necessidade de se conhecer parâmetros da cinemática de algumas estruturas lançadas ao leito marinho.

No entanto, em condições ambientais como as encontradas no mar, sabe-se que é impossível empregar sistemas convencionais como os Global Position System (GPS). Sabe-se também que o posicionamento por triangulação de sinais de sonar é bastante caro e requer a montagem 
prévia de emissores e receptores de ondas sonoras (transponders). Desta forma, o emprego de Unidades de Medição Inerciais (UMI) se mostra a melhor alternativa para tal monitoração.

Contudo, para que sejam conseguidos registros com qualidade suficiente para a navegação, a UMI deve ser equipada com sensores bastante precisos e, consequentemente, de custo elevado. Tais limitações trazem dificuldades para que a medição inercial se difunda nos lançamentos submarinos, principalmente de estruturas que se alojarão sob o solo, nos quais correm o risco de serem perdidas durante o processo de instalação ou recuperação.

A solução reside, portanto, no estudo e aprimoramento do uso de unidades de medição inerciais de baixo custo. Entende-se por baixo custo, UMIs cujos sensores sejam do tipo MEMS (Micro-Electro-Mechanical Systems) e custem no máximo algumas dezenas de dólares. Cabe lembrar que sensores inerciais de alto desempenho, eletro-mecânicos ou de fibra óptica chegam a custar milhares de dólares, cada um.

Quanto à tecnologia inercial sugerida, não era possível empregá-la em navegação quando os MEMS começaram a ser desenvolvidos, pois os sinais provenientes eram ruidosos e imprecisos. No início, tais sensores eram empregados apenas para registrar grandes acelerações ou mudanças na velocidade angular, como por exemplo, as envolvidas em uma colisão ou capotagem automobilística.

Atualmente, bastante melhorada, a navegação inercial empregando sensores MEMS é ainda um desafio tecnológico e, assim sendo, tema para inúmeros trabalhos científicos, alguns deles citados ao longo deste texto. Neste contexto, a navegação atual a partir de MEMS prescinde de detalhes com relação aos erros associados à leitura dos sensores, assim como o emprego de técnica conhecida como fusão sensorial.

Buscando focar justamente esta aplicação, o presente trabalho seleciona e estuda uma UMI nacional empregada na monitoração de lançamentos de sistemas de ancoragem do tipo estacatorpedo, de agora em diante denominada apenas por SMET (Sistema de Monitoração da Estaca-Torpedo).

Nos tópicos seguintes esse problema será mais bem caracterizado e a estrutura deste texto apresentada. 


\section{Caracterização do Problema e Objetivos do Trabalho}

Após sua criação e testes bem sucedidos, a estaca-torpedo passou a ser largamente empregada na ancoragem de unidades de produção, principalmente do tipo FPSO em uma configuração conhecida como taut-leg - as linhas de amarração permanecem esticadas formando uma reta entre o ponto de fixação no solo e a plataforma.

Além da redução nos custos de instalação - no que se refere ao processo -, o uso dessa tecnologia nacional reduziu os custos de aquisição das âncoras, pois a principal empresa de prospecção nacional detém sua patente.

No entanto, novas tecnologias estão sujeitas a verificação e aprovação por parte das sociedades classificadoras e, neste caso, a preocupação concentra-se principalmente na capacidade de fixação deste novo sistema de ancoragem.

Na tentativa de aprimorar os modelos matemáticos empregados na estimação das cargas de "arrancamento", o conhecimento da cinemática da estaca-torpedo durante seu lançamento fazse necessário, particularmente com relação a alguns parâmetros específicos deste movimento, dentre os quais: a velocidade vertical máxima e a atitude final da estaca, segundo um referencial conhecido.

A solução para se obter tais parâmetros foi equipar a estaca-torpedo com uma unidade de medição inercial, o SMET.

O SMET é um dispositivo alimentado por baterias que contém acelerômetros, girômetros, um transdutor de pressão, um termômetro e uma unidade de armazenamento de dados ${ }^{4}$.

Antes de cada lançamento da estaca-torpedo, o SMET é pré-programado e acondicionado em um pequeno vaso de pressão fixado à lateral do corpo da estaca. O conjunto é, então, baixado até certa distância do leito marinho; nesta condição um ROV é empregado para verificar a orientação da estaca-torpedo; é dado início à aquisição de dados do SMET e, em seguida, fazse a liberação. A estaca-torpedo atinge o solo cerca de dez segundos depois, penetrando-o até a estabilização, quando todas as velocidades são nulas.

Segundo as definições feitas durante a pré-programação do aparelho, passado certo tempo do início, o SMET interrompe a aquisição e, em seguida, um ROV vai até o local em que ocorreu a cravação da estaca-torpedo, buscando o cabo utilizado para a recuperação da UMI.

\footnotetext{
${ }^{4}$ O SMET investigado durante esta pesquisa possuía número de identificação " 5 " e acredita-se ter sido fabricado entre o ano de 2006 e 2007.
} 
Uma vez recuperada, os dados do SMET são transferidos para um computador, onde são submetidos a um procedimento de cálculo, a partir do qual é feita a determinação dos parâmetros de interesse citados anteriormente.

O presente trabalho foi motivado pela necessidade de se verificar a capacidade de uma unidade SMET, bem como dos algoritmos empregados no processamento dos dados colhidos em prever os parâmetros de interesse do lançamento de uma estaca-torpedo.

Para desenvolver tal tarefa, o autor teve acesso a uma das unidades de medição inercial (SMET), assim como teve a oportunidade de interagir com projetistas e usuários da mesma. Foram também disponibilizados registros de dezesseis lançamentos reais realizados no ano de 2007 amplamente empregados neste trabalho.

\subsection{OBJETIVOS}

Neste contexto, são dois os objetivos deste trabalho:

Verificar o desempenho do SMET e dos algoritmos de processamento de dados na determinação dos parâmetros de interesse, e propondo eventuais melhorias no equipamento, softwares e procedimentos;

Servir como texto introdutório ao desenvolvimento de sistemas de navegação inercial de baixo custo, passíveis de aplicação em experimentos no campo da engenharia naval, oceânica e submarina.

\subsection{Estrutura do Trabalho}

Deste ponto em diante, o trabalho foi dividido em três grandes tópicos: Revisão Bibliográfica e Fundamentos Teóricos; Estudo de Caso e Conclusões.

A revisão bibliográfica, juntamente com o tópico de fundamentos teóricos, traz uma compilação de estudos recentes sobre o tema e os principais recortes da matemática, física e engenharia; na percepção do autor, importantes à compreensão do problema proposto. Essa parte do texto e a forma como ela foi construída, tem forte conexão com um dos objetivos estabelecidos anteriormente.

O capítulo "Estudo de Caso" apresenta os trabalhos desenvolvidos ao longo de aproximadamente um ano e meio de testes com o SMET, bem como a descrição e aplicação 
dos métodos de cálculo empregados atualmente para o procedimento atual de instalação de unidades flutuantes utilizando a estaca-torpedo.

Finalmente, no capítulo de Conclusões, são apresentados e discutidos criticamente os resultados auferidos, particularmente aqueles com impacto direto sobre a qualidade dos parâmetros de interesse e que, de certa forma, determinam a aplicabilidade, ou não, de uma UMI de baixo custo (como o SMET) em problemas de monitoração inercial. Além disso, neste capítulo também são apresentadas limitações, correções e sugestões de trabalhos a serem desenvolvidos em complemento aos mais adiante apresentados. 


\section{REVISÃo BIBLIOGRÁFICA}

Nos itens seguintes será apresentada uma breve revisão dos trabalhos mais recentes publicados acerca do desenvolvimento da estaca-torpedo. Embora não versem propriamente sobre o sistema de monitoração inercial, contextualizarão os estudos apresentados nesta dissertação, já que todos os artigos estudados apresentam resultados experimentais obtidos via medições inerciais.

\subsection{Desenvolvimento da Estaca-Torpedo}

Neste item serão resumidas as informações contidas em (BRANDÃO et al., 2006) que versam sobre o desenvolvimento e os primeiros testes da estaca-torpedo como sistema de ancoragem de grandes unidades de produção.

Estacas como sistema de ancoragem são quase tão antigas quanto a própria exploração de petróleo offshore. Duas patentes reivindicadas pela Petrobras do final da década de 1980 e início da década de 1990 constituem, provavelmente, as origens da estaca-torpedo em sua forma mais conhecida. A patente PI-704412 introduz o conceito de ponta fechada e cônica enquanto a patente PI-9002463 caracteriza um corpo de aço preenchido com material de elevado peso específico. A estaca-torpedo, com geometria bastante similar as atuais, esta caracterizada na patente americana US006106199 datada de 1996, assim como seu processo de instalação.

Inicialmente, estes dispositivos foram empregados na ancoragem de risers flexíveis. Apenas em 2001 foi certificado o projeto de uma estaca-torpedo para ancoragem de uma plataforma de perfuração em grande profundidade que, por sua vez, começou a operar em 2002. A partir deste ponto, e pelos 3 anos que se seguiram, cerca de 50 estacas-torpedo similares foram instaladas na bacia de Campos, Rio de Janeiro. Tratava-se de estacas relativamente pequenas, com 43 toneladas.

Em 2004, foi certificado o uso da estaca descrita anteriormente como sistema de ancoragem de uma unidade de armazenamento flutuante (FSO) chamada Avaré, situada na bacia de Santos, estado de São Paulo. Esta unidade de armazenamento consistia em um navio tanque de 30000 DWT (Deadweight Tonnage) de capacidade convertido. 
Concomitantemente, a partir do ano 2000 foi iniciado o projeto de uma versão maior da estaca-torpedo, chamada T-98, com 98 toneladas, 17 metros de comprimento e 1,07 metros de diâmetro. Este desenvolvimento visava atender a nova plataforma FPSO chamada P-50. Tratava-se de um casco de VLCC (Very Large Crude Carrier) convertido em unidade de produção e armazenamento de petróleo, com capacidade de 270000 DWT.

Os estudos inicialmente envolveram a determinação das cargas nas linhas de ancoragem, por meio da simulação dos movimentos da plataforma, frente às condições ambientais. A plataforma em questão empregaria 18 linhas espalhadas (spread mooring) na proa e popa da embarcação em uma configuração chamada DICAS (differentiated compliance anchoring system). Determinou-se, ainda, que tais linhas demandariam âncoras com grande capacidade de resistir a esforços verticais.

Até então, eram dois os principais sistemas de ancoragem indicados para esforços de “arrancamento" verticais: as ancoras de sucção e as chamadas VLA (Vertical Load Anchors). Estas últimas são, na realidade, estruturas similares as âncoras de arrasto, com placas móveis que se alojam profundamente no leito marinho, como mostra a Figura 9.

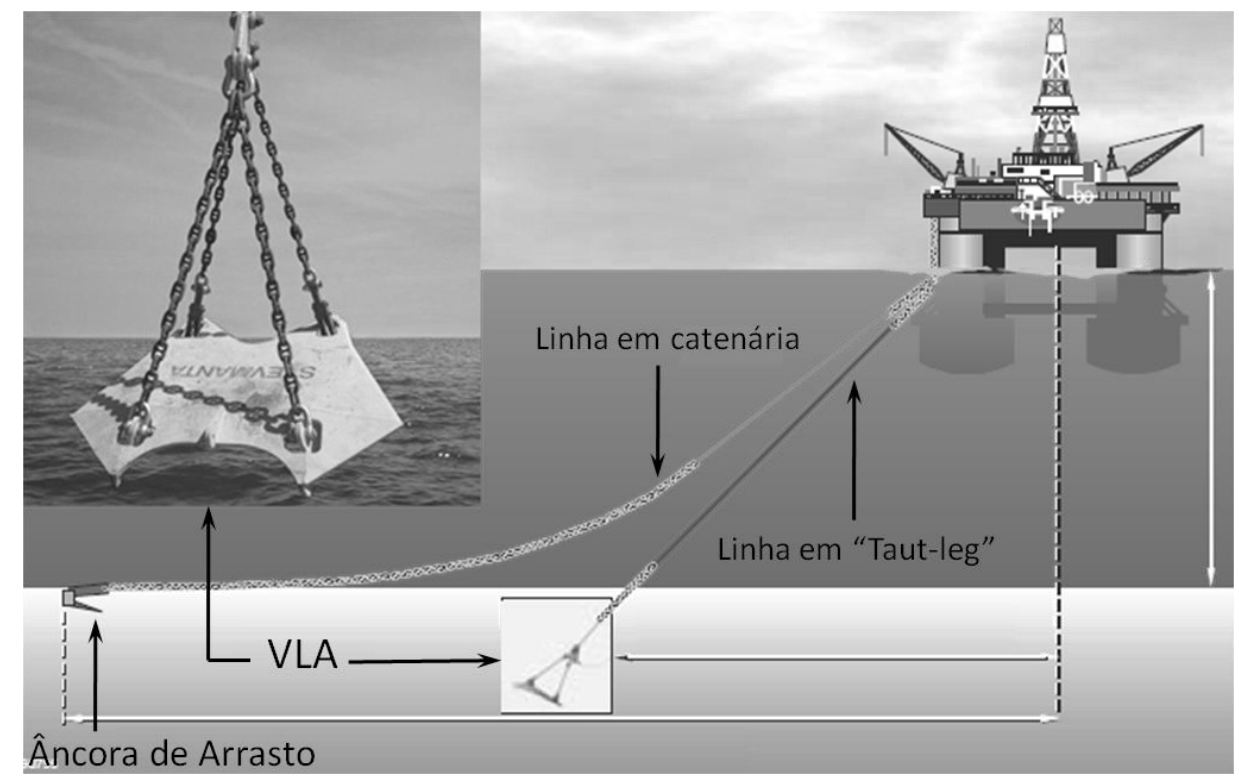

Figura 9 - Ilustração do funcionamento e aplicação de uma âncora do tipo VLA

A estaca-torpedo foi desenvolvida visando substituir as VLAs.

A capacidade de fixação da estaca foi estimada inicialmente por meio de simulações computacionais realizadas empregando-se um software de elementos finitos, de 
desenvolvimento próprio da companhia de exploração, capaz de resolver modelos elastoplásticos estáticos não lineares. (BRANDÃO et al., 2006)

Esta bateria de simulações varreu inúmeras profundidades de penetração da estaca, assim como ângulos de inclinação com a vertical. Da mesma forma, foram avaliadas diferentes inclinações do solo e características do mesmo. Nestas simulações, foi assumido que a força de "arrancamento" opera na direção mais favorável à remoção da estaca, ou seja, na direção em que a capacidade de fixação é minimizada. Esta hipótese foi feita por não ser possível, naquele momento, conhecer a direção em que ocorria a inclinação - ângulo e precessão da estaca. Sob essa hipótese, qualquer inclinação da estaca com relação à vertical implica na redução da capacidade de fixação do sistema.

Depois de verificada a viabilidade do emprego da estaca como sistema de ancoragem no âmbito das simulações computacionais, foi iniciada, em 2001, a fabricação de dois protótipos da estaca T-98, Figura 10.

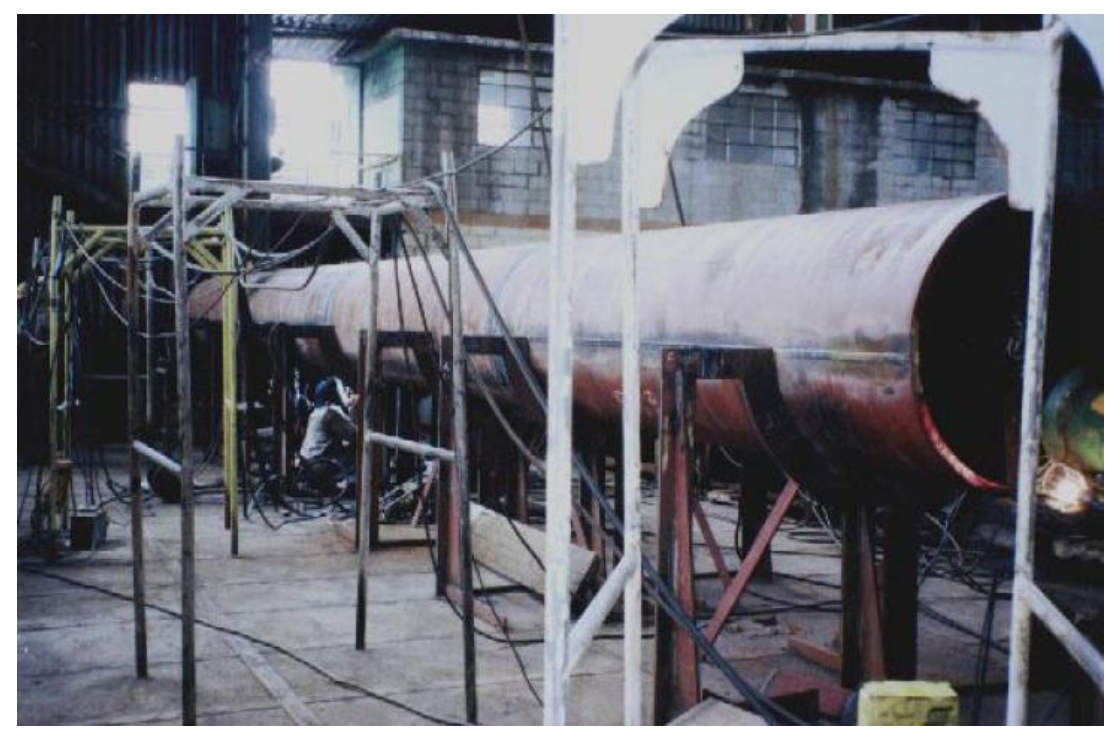

Figura 10 - Fabricação da estaca torpedo T-98 (BRANDÃO et al., 2006)

Em abril de 2002, as duas estacas-torpedo T-98 foram testadas nos arredores do campo de Albacora Leste onde, futuramente, seria instalada a P-50. Os testes visavam verificar o manuseio das estacas a bordo, assim como se as mesmas atingiriam a velocidade máxima estimada e, consequentemente, a profundidade de penetração adequada. 
Verificou-se que as estacas não atingiram a profundidade de penetração requerida e esse fato foi associado ao elevado arrasto proveniente do cabo, até então de poliéster, que conectava a estaca-torpedo à embarcação de apoio.

No ano seguinte, 2003, os testes foram repetidos empregando cabos de aço no lugar do poliéster. Nestes testes, embora a velocidade final esperada tenha sido alcançada, os cabos de aço sofreram um tipo de falha chamada bird-cage na qual os filamentos torcidos do cabo flambam graças à intensa força de compressão. Embora essa falha não provoque a ruptura do cabo, ela promove deformações plásticas.

O problema de bird-cage foi solucionado em agosto do 2004, durante uma terceira bateria de testes que incorporou um dispositivo de desconexão rápida conhecido como gancho Pelikelo. Estes testes aprimoraram o processo de lançamento da estaca que passou a envolver duas embarcações AHV (navios de ancoragem) na configuração ilustrada pela Figura 11.

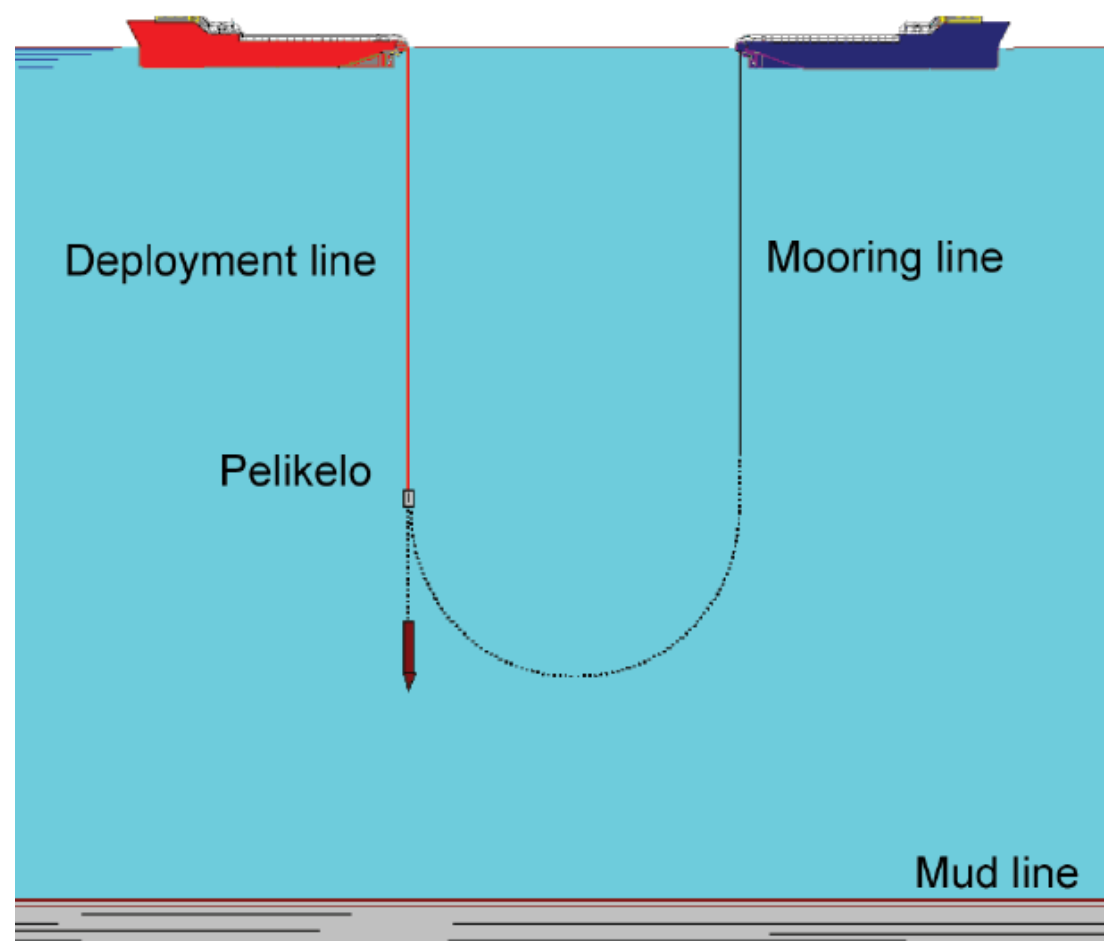

Figura 11 - Esquema ilustrando o procedimento de instalação da estaca-torpedo (BRANDÃO et al., 2006)

Estes foram os primeiros testes que empregaram unidades de monitoração inercial (SMETs) para verificar os parâmetros da penetração do torpedo. Deste ponto em diante, todos os 
lançamentos da estaca-torpedo passaram a empregar o SMET, principalmente por ser este o único equipamento que informa se a estaca alojou-se no leito com alguma inclinação.

As estacas foram instaladas em caráter definitivo no campo de Albacora durante a segunda metade do ano de 2005. A máxima penetração nos solos mais macios chegou a $20 \mathrm{~m}$ enquanto nas áreas de solo mais compacto alcançou $16 \mathrm{~m}$, ambos os resultados coerentes com as previsões. As leituras do sistema de monitoração indicaram que nenhuma das estacas-torpedo lançadas assumiu inclinação final superior a $10^{\circ}$ com relação à vertical.

Durante este processo de instalação, o tempo médio para o lançamento de uma estaca-torpedo foi de aproximadamente 10 horas, enquanto a recuperação dos dados de monitoração e a instalação das bóias que sustentarão as linhas de ancoragem antes da chegada da plataforma levaram em média 4 horas. Esta média de 14 horas para todo o processo de instalação foi significativamente inferior ao tempo médio requerido para a instalação de uma âncora do tipo VLA, com cerca de dois dias.

\subsection{Estudos SEguintes}

O processo de lançamento da estaca-torpedo possui uma clara divisão entre o período de aceleração no qual a estaca se desloca na água e o período de cravação, onde ocorre a desaceleração e onde a estaca desloca-se no interior do leito marinho.

Ambos os processos resultam nas características de fixação da estaca-torpedo: a profundidade de penetração e a atitude final da mesma.

No item anterior foi apresentado um breve histórico do desenvolvimento da estaca-torpedo, da sua origem até sua utilização mais recente. Neste processo foram empregadas simulações computacionais para a determinação dos carregamentos aos quais a estaca estaria submetida, bem como para a estimação da capacidade de fixação da estaca. Estas simulações guiaram o projeto da estaca-torpedo. Entretanto, estes estudos persistem, tanto graças à necessidade crescente de prever precisamente o comportamento das estacas empregadas atualmente, quanto pelo interesse de se desenvolverem novos modelos, maiores e mais pesados.

Neste tópico serão revisados alguns estudos recentes sobre ambas as etapas do lançamento: a queda e a cravação. A primeira etapa envolve, claramente, questões associadas à dinâmica e a hidrodinâmicas da estaca-torpedo e das linhas presas a ela. A segunda etapa engloba estudos acerca da interação entre a estaca e o leito marinho. 


\subsubsection{Dinâmica da Estaca-Torpedo}

Conhecer o modelo físico e matemático que reproduz o comportamento da estaca, além de auxiliar as etapas de projeto, direciona as possíveis medições do lançamento desta âncora em laboratório ou em campo.

O trabalho de (FERNANDES et al., 2006) constituiu a primeira publicação de um estudo acerca da dinâmica da estaca-torpedo. Não é possível, no entanto, afirmar se estudos similares foram realizados anteriormente, em âmbito interno à empresa que desenvolveu a tecnologia da estaca-torpedo.

O documento citado acima apresentou, basicamente, dois modelos para a dinâmica da estaca, um deles sem considerar a influência das amarras e outro considerando tais efeitos. Os modelos matemáticos foram suportados por experimentos realizados no tanque de provas da Universidade Federal do Rio de Janeiro, nos quais uma réplica em escala reduzida da estacatorpedo foi submetida a alguns lançamentos verticais.

Os modelos apresentados a seguir, reproduzidos de (FERNANDES et al., 2006), referem-se ao procedimento de instalação apresentado na Figura 11 e detalhado no item anterior.

Após a liberação do gancho Pelikelo, a estaca-torpedo acelera impelida apenas pela gravidade, em direção ao leito marinho. Este trecho de sua trajetória, quando assumido completamente vertical, pode ser descrito pela equação (1)

$$
\left(m+m_{a}\right) \frac{d V}{d t}=\alpha-\beta V^{2}
$$

Da forma como foi apresentada, é imediato identificar na equação um termo inercial proporcional a massa e massa adicional da estaca, um termo dissipativo proporcional à velocidade ao quadrado e uma força externa, neste caso a resultante entre a gravidade e o empuxo do corpo submerso - chamado também de peso aparente.

$\mathrm{O}$ artigo em questão concentra-se principalmente em determinar o parâmetro $\beta$, ou seja, o coeficiente de arrasto da estaca-torpedo em sua trajetória vertical, incluindo, segundo certas hipóteses, a parcela referente ao trecho de amarra que está preso à estaca. 
Para a estimativa do coeficiente de arrasto da estaca foi empregada a chamada hipótese de Froude que separa o arrasto em componentes. São estas: a parcela de pressão, proveniente do descolamento da camada limite; a parcela friccional; a parcela de onda e o arrasto gerado pelos apêndices. Com exceção do arrasto de onda, as demais parcelas envolvem fenômenos viscosos e, dessa forma, dependem do número de Reynolds do escoamento. A parcela de onda por sua vez esta associada ao adimensional de Froude e relaciona-se com a gravidade. No caso em estudo, esta última parcela não existe, pois o corpo encontra-se totalmente submerso.

O principal benefício no método de Froude para a predição da resistência ao avanço do sistema é a correspondência entre os coeficientes de resistência residual ${ }^{5}$ do modelo e da embarcação real, quando ambas deslocam-se com o mesmo número de Froude. Entretanto, em (FERNANDES et al., 2006), a parcela residual do arrasto não possui relação com o adimensional de Froude, tornando a correspondência citada acima impossível. Sendo o número de Reynolds o principal adimensional envolvido nas forças de arrasto da estacatorpedo, e sabendo-se que na maioria das vezes, é impraticável compatibilizar este adimensional entre o modelo e a situação real, os autores foram forçados a assumir certas hipóteses simplificadoras.

O coeficiente de arrasto da estaca-torpedo sozinha foi modelado como mostra a equação (2).

$$
C_{D}=C_{F}(R e)+C_{N}
$$

É sugerida a divisão do arrasto em uma parcela friccional, cuja formulação foi proposta pela ITTC (International Towing Tank Conference) de 1957, e outra que incorpore os efeitos de descolamento da camada limite e geração de esteira. Dada a natureza das forças envolvidas na segunda parcela do arrasto e a geometria esbelta da estaca-torpedo foi assumido em (FERNANDES et al., 2006) que esta parcela independe do número de Reynolds. Esta hipótese permitiu que fosse feita a correspondência entre os coeficientes $C_{N}$ do modelo e do caso real.

\footnotetext{
${ }^{5}$ No método de Froude tradicional para a predição da resistência ao avanço de embarcações, resistência residual corresponde à resistência total subtraída da parcela friccional. O termo residual incorpora arrastos provenientes da formação de ondas e das diferenças de pressão entre a proa e a popa decorrente do descolamento da camada limite.
} 
Embora o número de Reynolds do modelo testado no tanque de provas não tenha sido o mesmo do caso real, a escala do modelo foi definida de forma a garantir que o regime de escoamento do modelo fosse totalmente turbulento - buscou-se um $R e$ superior a $10^{6}$.

O estudo busca também incorporar os efeitos associados à presença das amarras durante o lançamento da estaca. Trata-se, entretanto, de um grande aumento na complexidade da análise, pois a amarra em questão é composta por um trecho de amarra cujas características hidrodinâmicas são de difícil previsão, assim como a interação entre seus elos durante a queda.

Para lidar com este problema assume-se no artigo que o trecho de corrente é um corpo rígido e que sobre ele atuam apenas forças na direção vertical, como mostra o diagrama de corpo livre da Figura 12.

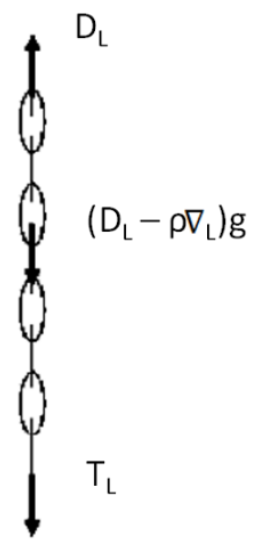

Figura 12 - Diagrama de corpo livre do trecho de amarra imediatamente atras da estaca-torpedos (FERNANDES et al., 2006)

As forças atuantes sobre o trecho de amarra são: a tração proveniente da estaca $T_{L}$, seu peso aparente e seu arrasto $D_{L}$. Segundo o artigo, das variáveis listadas a de mais difícil predição é o arrasto da linha. Este parâmetro foi estabelecido por meio de inúmeros testes nos quais foram variados tanto o diâmetro da seção da linha quanto o comprimento da mesma.

Coeficientes de forças hidrodinâmicas são habitualmente adimensionalizados por meio da pressão dinâmica e de uma área de referência. No caso estudado, observou-se que empregar como área de referência um produto entre o comprimento do trecho de amarra e o diâmetro médio desta resultaria em um coeficiente que se relaciona linearmente com o comprimento. Assim, chamando-se de $C_{D L / P e r}$ o coeficiente de arrasto calculado com base na área de 
referência descrita anteriormente, experimentos comprovaram a relação apresentada na equação (3).

$$
\frac{\partial C_{D L / P e r}}{\partial l} \cong 0,044
$$

A dimensionalização desta equação resulta na expressão para o arrasto da linha, mostrado na equação (4).

$$
D_{L}=\left(\frac{\partial C_{D L / P e r}}{\partial l} l \frac{1}{2} \rho P e r\right) V_{T}^{2} l
$$

Ainda neste trabalho, é discutida a influência do arrasto do trecho de linha fixo à estaca na sua estabilidade direcional. Esta questão é igualmente tratada de modo simplificado e, segundo os autores, reduz-se a estabelecer a nova posição longitudinal do centro hidrodinâmico da estacatorpedo, agora acrescida da linha de amarração.

Para o estudo da estabilidade direcional, passa a ser necessário considerar a presença de forças - perturbações - transversais. Da mesma forma, deve-se considerar o chamado momento de Munk, efeito direto da hipótese de que as forças hidrodinâmicas são sempre aplicadas em um mesmo ponto do corpo.

(FERNANDES et al., 2006) emprega uma forma das equações de Jorgensen apresentadas em (TRIANTALYLLOU e HOUVER, 2004) adaptada para corpos esbeltos e cilíndricos. Tais equações são apresentadas a seguir.

$$
\begin{gathered}
C_{N}=\frac{A_{b}}{A_{r}} \sin 2 \alpha \cos \frac{\alpha}{2}+\frac{A_{p}}{A_{r}} C_{d n} \sin ^{2} \alpha \\
C_{D}=C_{d 0} \cos ^{2} \alpha \\
C_{M}=-\frac{\nabla-A_{b}\left(L-x_{m}\right)}{A_{r} L} \sin 2 \alpha \cos \frac{\alpha}{2}-C_{d n} \frac{A_{p}}{A_{r}}\left(\frac{x_{m}-x_{c}}{L}\right) \sin ^{2} \alpha
\end{gathered}
$$


Nas equações acima, os parâmetros $A_{b}, A_{p}$ e $A_{r}$ corresponde respectivamente às áreas da base - área frontal -, lateral - em planta - e uma área de referência arbitrariamente selecionada. $\mathrm{O}$ parâmetro $\alpha$, por sua vez, corresponde ao ângulo de ataque da estaca-torpedo.

Na equação (7), o coeficiente $C_{d n}$ é o adimensional associado à força de arrasto transversal. Em se tratando de uma força de arrasto que possui relação com a viscosidade, esta grandeza depende do número de Reynolds. Este, por sua vez, é calculado com base na projeção do diâmetro da estaca, evidenciando a natureza da força em questão.

Cabe, ainda, esclarecer que a distância $x_{m}$ é inicialmente arbitrária, porém, após definido o momento de Munk com relação a este pólo, deve-se manter sua coerência.

Entretanto, o cálculo destes coeficientes é fundamentalmente empregado na determinação do centro hidrodinâmico da estaca, segundo a equação (8).

$$
X_{C H}=x_{m}+x_{C}-\frac{C_{M}}{C_{N}} L
$$

Lembrando apenas que o centro hidrodinâmico do corpo da estaca é o ponto a partir do qual o momento de Munk não varia com a mudança da sustentação.

As equações anteriores referem-se apenas as características hidrodinâmicas do corpo da estaca, porém o artigo propõe incorporar os efeitos das aletas assim como o da linha de amarração. Tais efeitos modificam a posição do centro hidrodinâmico do conjunto. São apresentadas as equações (9) e (10).

$$
\begin{gathered}
X_{C H}^{\prime}=\frac{C_{N}\left(x_{c}-\frac{C_{M} L}{C_{N}}\right)+C_{L} x_{f} \frac{A_{\text {fin }}}{A_{r}}}{C_{N}+C_{L} \frac{A_{\text {fin }}}{A_{r}}} \\
X_{C H}^{\prime \prime}=\frac{C_{N}^{\prime} x_{C H}^{\prime}+C_{T L} \sin \alpha}{C_{N}^{\prime}+C_{T L} \sin \alpha}
\end{gathered}
$$

As equações apresentadas acima são médias ponderadas entre centros hidrodinâmicos, em os pesos empregados são os coeficientes das forças. 
A variável $C_{N}^{\prime}$ é identificada desta forma para indicar que se trata do coeficiente de forças transversais provenientes do conjunto corpo-aletas.

Os resultados $X_{C H}, X_{C H}^{\prime}$ e $X_{C H}^{\prime \prime}$ são apresentados simultaneamente na figura (13), evidenciando o papel estabilizador das aletas e da linha de ancoragem presa à estaca.

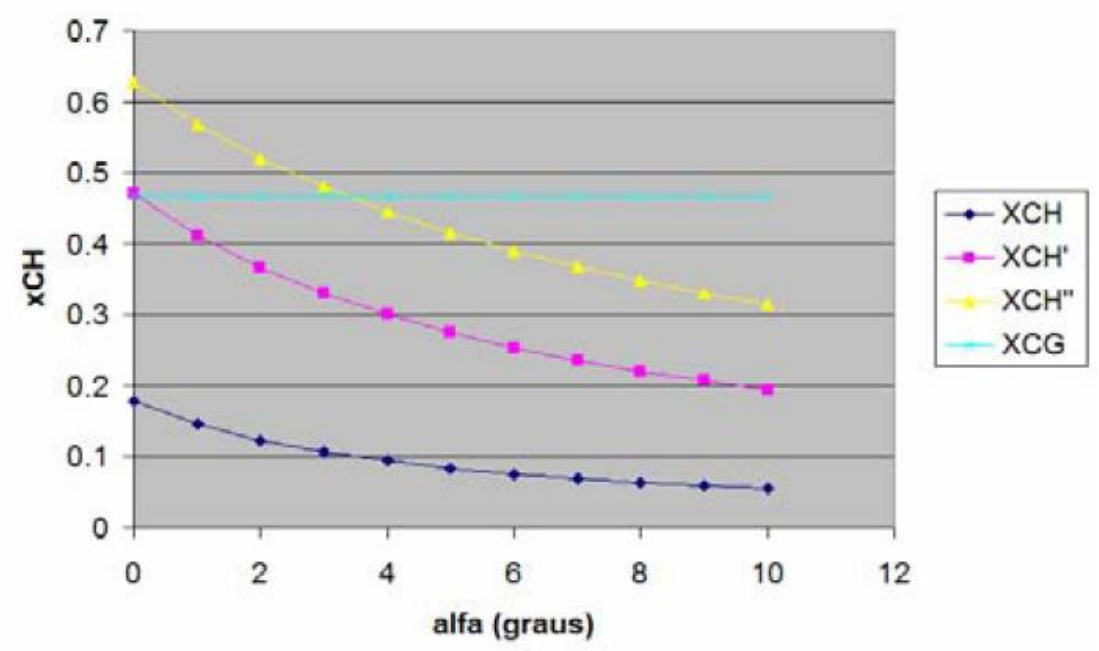

Figura 13 - Modificação da estimativa para a posição do centro hidrodinâmico para os três modelos considerados: Estaca,Estaca+Aletas e Estaca+Aletas+Linhas (FERNANDES et al., 2006)

Embora não fique claro no trabalho em questão, aparentemente os coeficientes hidrodinâmicos foram obtidos por meio de ajustes, visando igualar os resultados provenientes da equação (1), bem como, aos obtidos experimentalmente.

Este ajuste fica evidente na figura (14). As curvas interrompidas correspondem aos testes com os modelos nos quais a queda teve de ser limitada à profundidade do tanque.

As curvas contínuas, por sua vez, representam o modelo matemático desenvolvido e adequadamente ajustado. No artigo, estas curvas são identificadas pela sigla EMM (Extrapolated Mathematical Model). 


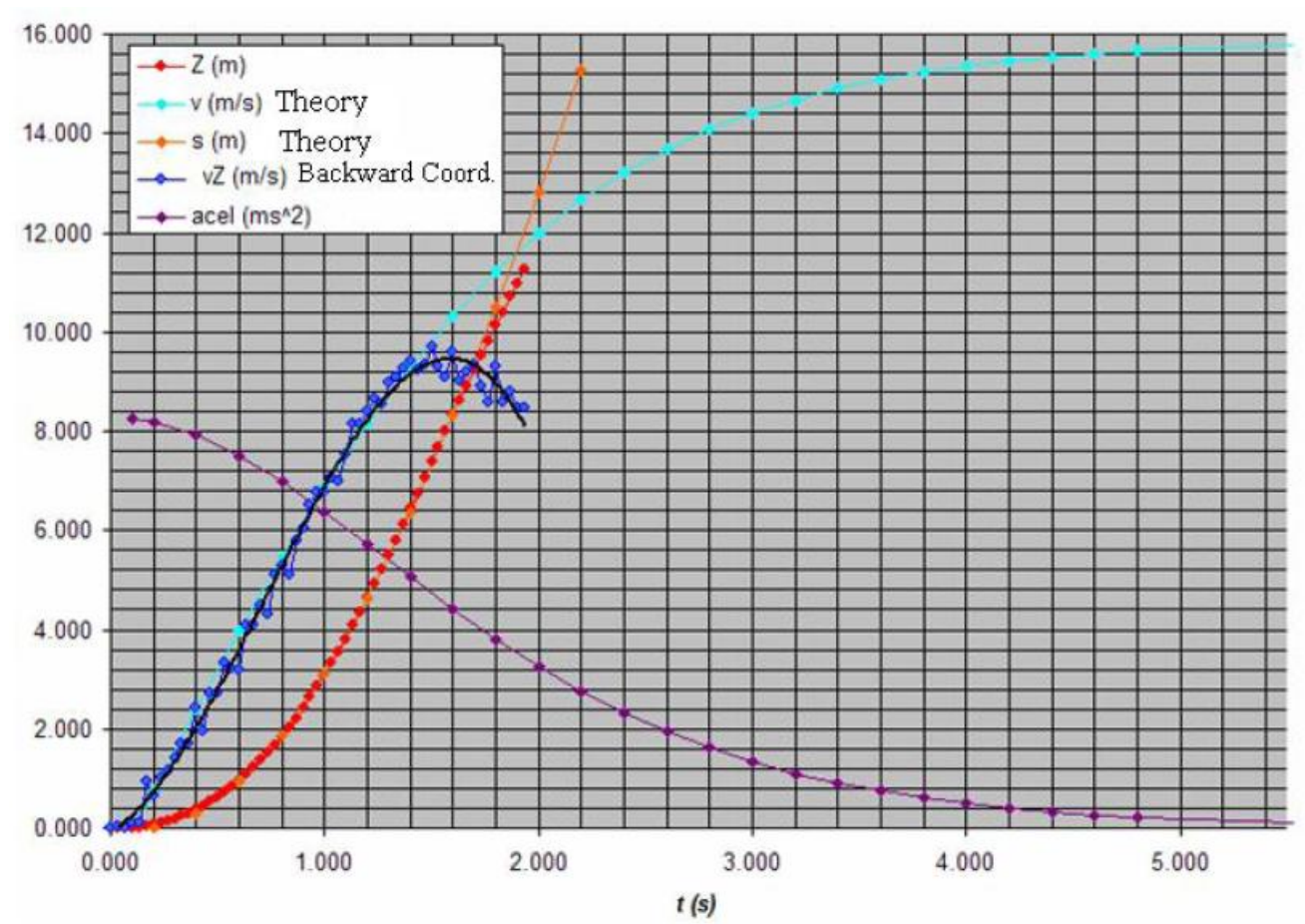

Figura 14 - Resultados analíticos e experimentais para os parâmetros cinemáticos do lançamento (FERNANDES et al., 2006)

A Tabela 2, extraída do artigo, condensa alguns coeficientes de arrasto obtidos experimentalmente.

Tabela 2 - Coeficientes de arrasto dos modelos estudados

\begin{tabular}{|c|c|}
\hline Configuração do Experimento & Coeficiente de Arrasto Obtido \\
\hline Estaca com aletas sem nenhuma linha & 1,45 \\
\hline Estaca com linha de 4,5m & 2,65 \\
\hline Estaca com linha de 4,5m e polias & 3,05 \\
\hline Estaca com linha de 6,7m e polias & 5,00 \\
\hline Estaca com linha de 13m e polias & 7,00 \\
\hline
\end{tabular}

Os resultados de (FERNANDES et al., 2006) constituem estimativas iniciais para parâmetros decisivos no lançamento das estacas, a velocidade máxima - fortemente atrelada ao coeficiente de arrasto do conjunto - e a atitude final do corpo que, no que se refere ao período de queda livre da estaca, depende fundamentalmente da estabilidade direcional deste sistema. 
No item seguinte será discutido um trabalho em que estas mesmas características são investigadas com ajuda de CFD (Copitional Fluid Dynamics).

\subsubsection{Simulações Computacionais da Hidrodinâmica da Estaca- Torpedo}

O trabalho discutido neste tópico situa-se em uma etapa posterior do desenvolvimento da estaca-torpedo. Em princípio, (CARVALHO E SILVA, 2010) desenvolveu este trabalho motivado pelo comportamento inesperado de certo protótipo de estaca. A versão que se testava na ocasião possuía massa e comprimento maiores que as versões utilizadas na ancoragem da plataforma P-50, as estacas T-98.

Durante a etapa de testes, em um dos lançamentos, a estaca divergiu de sua trajetória original atingindo grandes ângulos de inclinação, fato este indesejável para o sistema de ancoragem. Após a recuperação da estaca observou-se que uma de suas aletas apresentava um empenamento, provavelmente fruto de algum tipo de colisão durante seu manuseio.

A forma escolhida para analisar a possível correlação entre o defeito na aleta e o comportamento durante o lançamento foi simular a hidrodinâmica da estaca em um software de CFD. Entretanto, a investigação não esteve restrita a estaca danificada e englobou dois modelos já consolidados, assim como guiou o projeto de um terceiro modelo.

(CARVALHO E SILVA, 2010) inicia seu artigo apontando a necessidade de direcionar o projeto da estaca-torpedo para aspectos hidrodinâmicos e não apenas geotécnicos. O meio destacado pelo autor para desempenhar tal tarefa é, entre outras coisas, o emprego do CFD como importante ferramenta de projeto da estaca.

Como já citado, as geometrias analisadas correspondem à estaca T-98, amplamente utilizada, uma versão maior com $21 \mathrm{~m}$ de comprimento e um terceiro modelo com $22 \mathrm{~m}$, porém com ligeiras modificações na extensão das aletas. Estas configurações são exibidas na Figura 15. 


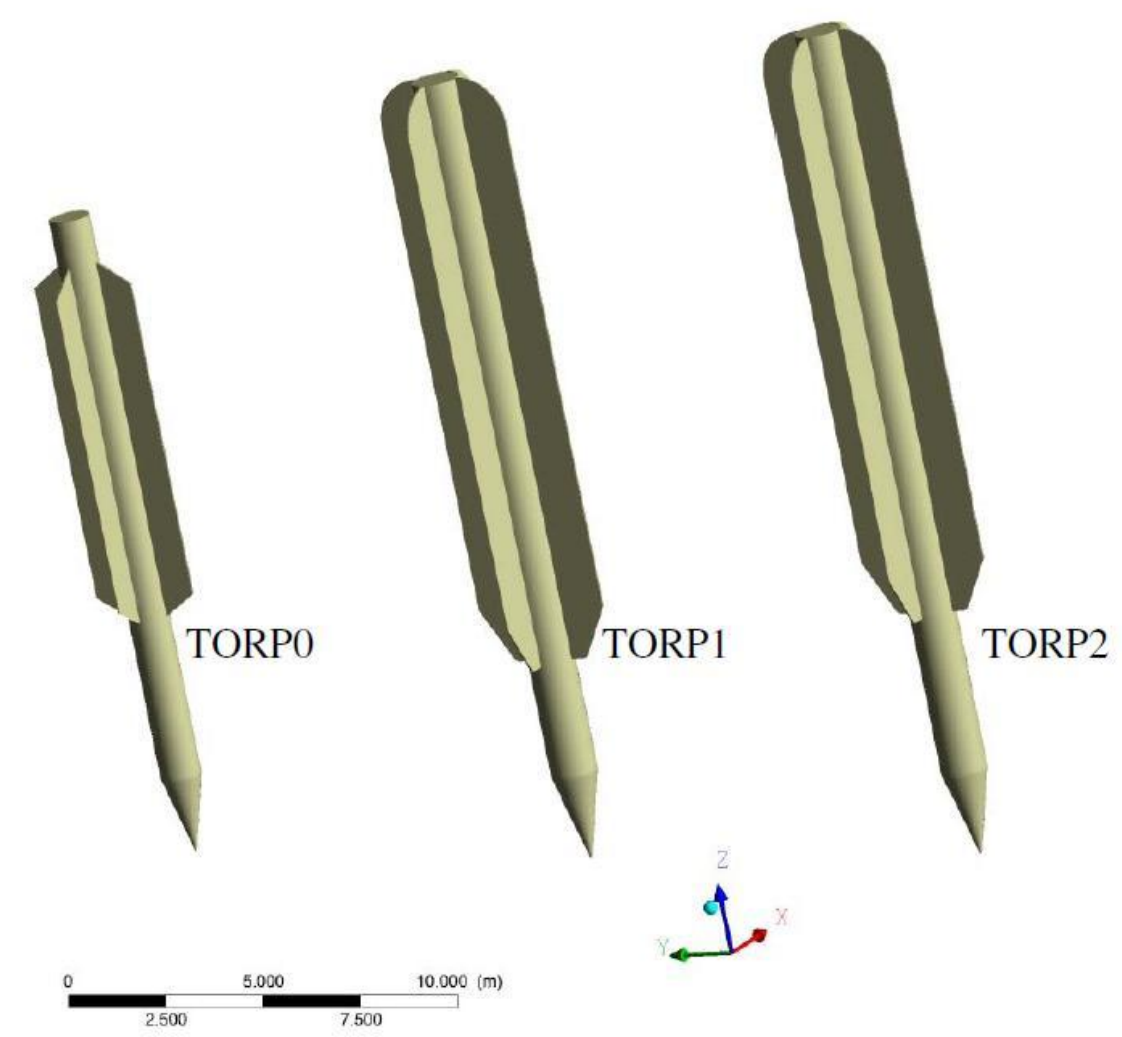

Figura 15 - Geometrias das estacas-torpedo simuladas (CARVALHO E SILVA, 2010)

Foram feitas pequenas simplificações geométricas, tais como: a retirada de pequenas estruturas no final das aletas e do olhal que prende a estaca à linha de amarração. Por outro lado, há uma importante simplificação no modelo como um todo, já que em nenhum caso foi incorporado um trecho de amarra. Esta simplificação baseia-se, provavelmente, na conclusão do artigo (FERNANDES et al., 2006), discutido anteriormente, de que a linha de amarração desempenha um papel positivo para a estabilidade direcional. Tal fato permite afirmar que, quaisquer que sejam os resultados referentes à estabilidade da estaca nas simulações sem o trecho de linha, estes serão menos favoráveis que o caso real.

Em se tratando de simulações numéricas nas quais foram considerados efeitos viscosos ou seja, foi resolvida a equação completa de Navier-Stokes, mostrou-se necessário definir um volume de controle discretizado ao redor da geometria de interesse. Esta etapa do trabalho envolveu a utilização de softwares geradores de malhas volumétricas. (CARVALHO E SILVA, 2010) emprega um software comercial chamado ICEM.

Inicialmente, as dimensões do volume de controle foram suficientemente grandes para garantir que as condições impostas ao contorno do volume não interferissem no escoamento 
próximo ao corpo analisado. Encontrar as dimensões que atendam tal critério é, geralmente, um processo de tentativa e erro, no qual se deve ter em mente que volumes demasiadamente extensos demandem grande capacidade computacional. No artigo em questão, foi empregado um volume de controle cilíndrico no qual a estaca foi posicionada em seu eixo central, alinhada com o mesmo e deslocada no sentido de uma das extremidades do cilindro. Essa medida é comum neste tipo de simulação, pois a perturbação no escoamento habitualmente é mais extensa atrás do corpo analisado.

As dimensões escolhidas para o volume de controle foram cerca de 15 comprimentos de estaca na direção longitudinal do cilindro e o diâmetro de aproximadamente 7,5 comprimentos de estaca.

O volume de controle foi, então, subdividido em aproximadamente quatro milhões de elementos tetraédricos e prismáticos, de forma a garantir que, próximo a estaca e na região da sua esteira, o tamanho dos elementos fosse suficientemente pequeno para captar precisamente os gradientes de pressão e velocidade. A Figura 16 demonstra um corte da malha gerada para uma das geometrias.

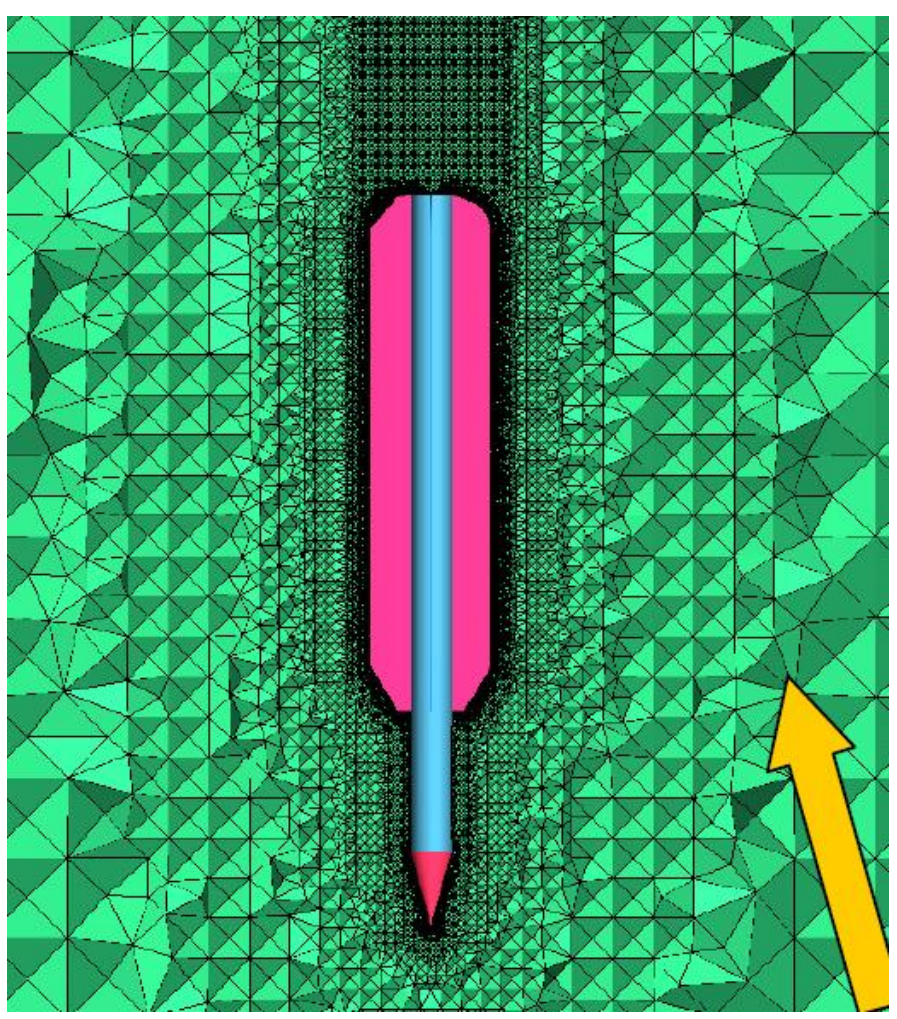

Figura 16 - Exemplo de malha gerada para as simulações de CFD (CARVALHO E SILVA, 2010) 
Assim como para a geração de malha, (CARVALHO E SILVA, 2010) empregou um programa comercial de simulação, o Ansys CFX. Este software é composto por três partes principais: o pré-processador, onde são impostas as condições de controle; o solver, onde as equações diferenciais são resolvidas numericamente; e o pós-processador, que permite a visualização dos resultados.

Todas as simulações foram feitas em regime permanente, ou seja, assumindo-se que a estaca desloca-se com velocidade constante, neste caso $20 \mathrm{~m} / \mathrm{s}$. Esta velocidade já havia sido prevista em (BRANDÃO et al., 2006) e por meio das medições em campo empregando-se o SMET.

Neste tipo de simulação mantém-se o corpo que se deseja analisar fixo enquanto na fronteira do volume de controle é imposta uma velocidade para o escoamento. A direção da velocidade imposta define o ângulo de ataque do corpo, uma vez que o mesmo permanece sempre alinhado ao volume de controle.

Esta técnica foi empregada por (CARVALHO E SILVA, 2010) para obter as forças de arrasto - forças alinhadas ao escoamento - e os momentos de arfagem (pitch) - momentos em torno de um eixo perpendicular ao eixo longitudinal da estaca - para diversos ângulos de ataque.

O momento de pitch foi calculado com relação ao centro de gravidade da estaca, sendo seu vetor paralelo ao eixo de referência y. O autor denomina esta grandeza de momento de restauração na direção y.

As equações (11) e (12) apresentam as fórmulas típicas para a adimensionalização de forças e momentos hidrodinâmicos.

$$
\begin{gathered}
C_{z}=\frac{F_{z}}{\frac{1}{2} \rho V_{0}^{2} A_{f}} \\
C_{m y}=\frac{M_{y}}{\frac{1}{2} \rho V_{0}^{2} A_{f} L}
\end{gathered}
$$


Sendo $F_{z}$ e $M_{y}$ a força e momento obtidos e as variáveis precedidas de "C" os coeficientes associados aos mesmos. A adimensionalização empregou como área de referência a área frontal da estaca-torpedo, $A_{f}$.

Foram realizadas simulações para os seguintes ângulos de ataque: $-15^{\circ},-10^{\circ},-5^{\circ},-2,5^{\circ}, 0^{\circ}$, $2,5^{\circ}, 5^{\circ}, 10^{\circ}$ e $15^{\circ}$. Os resultados obtidos por (CARVALHO E SILVA, 2010) estão compilados na Figura 17 e na Figura 18.

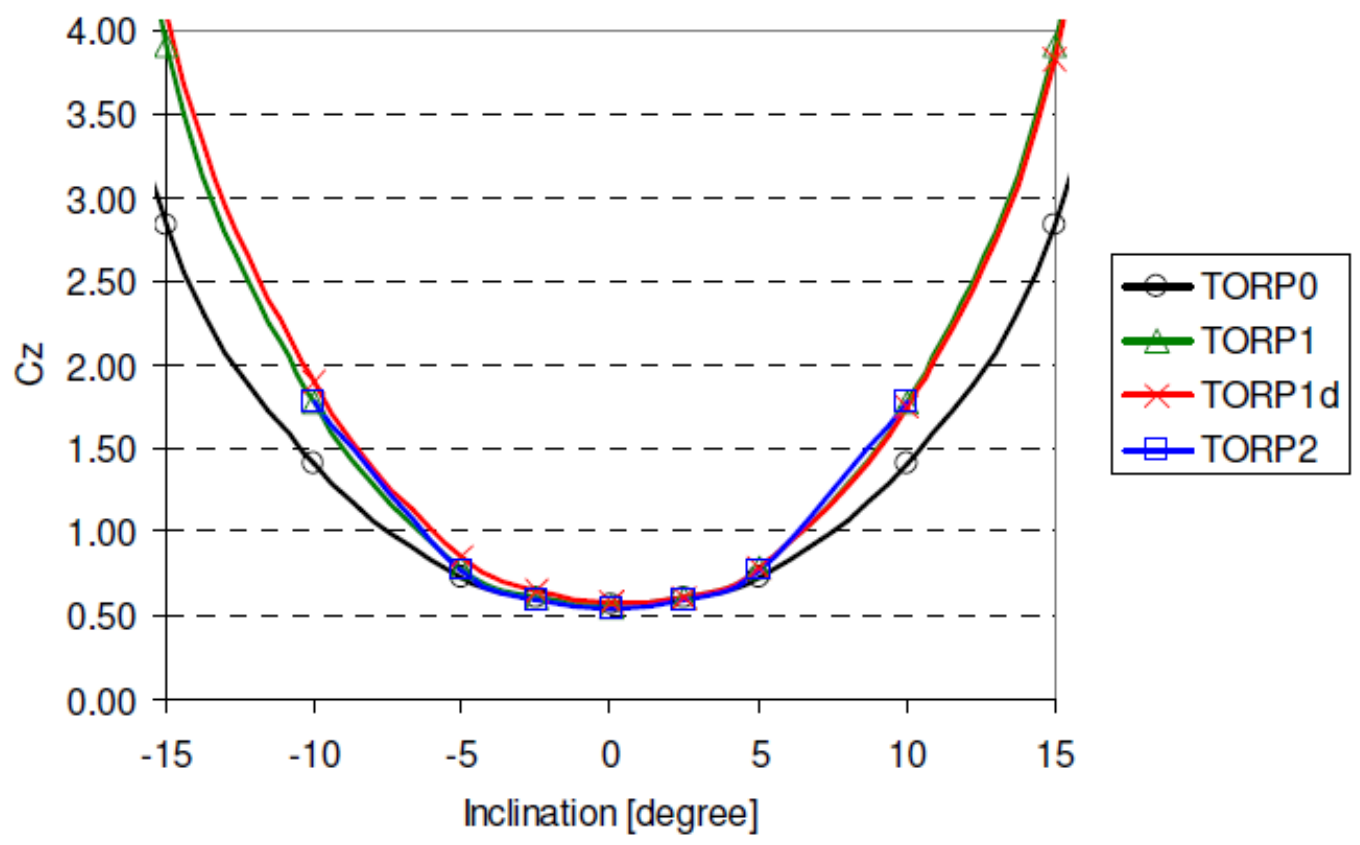

Figura 17 - Curvas de coeficiente de arrasto por ângulos de ataque para as geometrias avaliadas (CARVALHO E SILVA, 2010)

Os resultados obtidos não foram coerentes com aqueles mostrados por (FERNANDES et al., 2006), mesmo para o caso em que não foram considerados os efeitos das correntes atrás da estaca. Neste último trabalho, o coeficiente de arrasto obtido analiticamente foi de 0,37 , enquanto os experimentos fornecerem os resultados listados na Tabela 2.

Inúmeras razões podem levar a estas discrepâncias. Sabe-se que a predição de arrasto por meio de CFD é um procedimento trabalhoso e impreciso. Desta forma, a diferença existente entre o modelo analítico e a simulação numérica é absolutamente aceitável. Outra questão importante é a semelhança entre as geometrias empregadas. Sabe-se que (CARVALHO E SILVA, 2010) estudou, além da estaca T-98, dois outros modelos distintos daquele.

No que se refere à diferença entre os resultados experimentais e os numéricos, é provável que tenha surgido, pois, durante os experimentos, o ângulo de ataque dos modelos da estaca não 
foi controlado. As curvas do coeficiente de arrasto apresentam acentuada elevação quando se afastam do valor zero, (Figura 17).

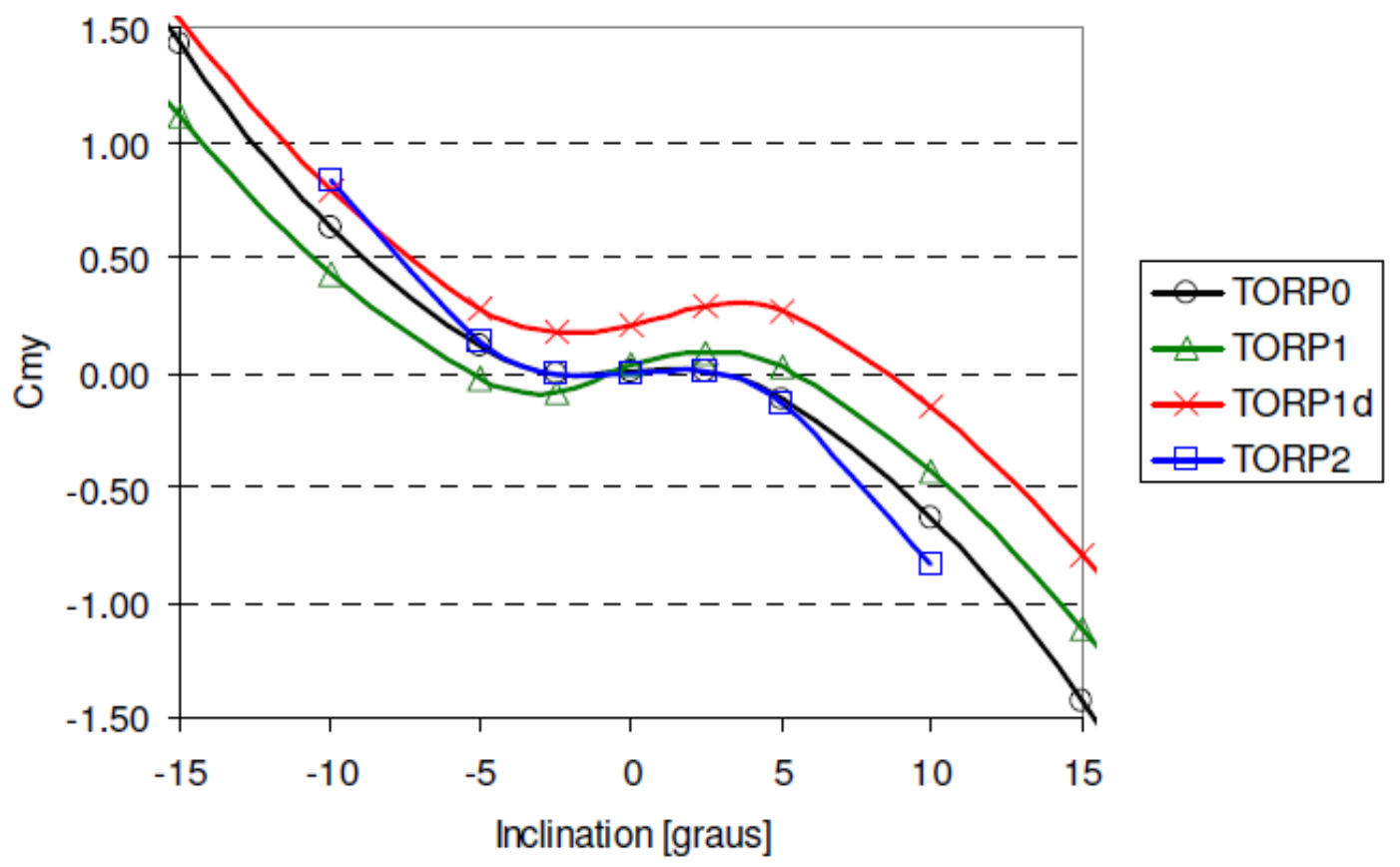

Figura 18 - Curvas do coeficiente de momento restaurador na direção tranversal a estaca para inumeros ângulos de ataque (CARVALHO E SILVA, 2010)

A Figura 18 apresenta os valores obtidos para os coeficientes de momento restaurador. É desejável que a derivada do momento restaurador, neste caso de pitch com relação ao ângulo de ataque, seja negativa. Garantir esta característica significa garantir a estabilidade estática neste grau de liberdade, pois caso ocorra aumento do ângulo de ataque, o momento diminui, consequentemente, reduzindo o ângulo de ataque.

A natureza da geometria levou a curvas não lineares e, em certas geometrias e faixas de ângulos, a estabilidade estática não esteve garantida.

Assim, conhecer precisamente as forças hidrodinâmicas atuantes sobre a estaca permite que se construa o modelo dinâmico do lançamento. Entretanto, tais forças são de difícil predição, pois são fruto de combinações de movimentos, efeitos potenciais e viscosos. Há referências que apresentam formas simplificadas para determinação destas forças. Habitualmente, tais grandezas são representadas pelas chamadas derivadas hidrodinâmicas e compõem matrizes cujas linhas e colunas correspondem aos estados de movimento do corpo. As derivadas hidrodinâmicas, por sua vez, são calculadas pelos mais variados métodos, como por exemplo, o método das faixas utilizado em (NIELSEN, 1960). 
Os trabalhos de (FERNANDES et al., 2006) e (CARVALHO E SILVA, 2010) buscaram descrever a dinâmica da estaca e, para isso, calcularam algumas das forças hidrodinâmicas atuantes na estaca durante seu lançamento.

No capítulo seguinte será feita uma breve revisão de tópicos das ciências básicas que foram empregados nas análises realizadas durante a presente pesquisa e cujos resultados são apresentados nos capítulos finais. 


\section{Fundamentos Teóricos}

A seguir serão apresentados os principais conceitos das ciências básicas e dos princípios tecnológicos utilizados nas análises do Estudo de Caso.

Inicialmente será feita uma breve revisão da matemática que suporta a cinemática do corpo rígido que, por sua vez, fundamenta os algoritmos empregados na análise dos sinais provenientes da estaca. Na segunda parte deste capítulo será dado enfoque as tecnologias de sensores inerciais existentes, seu emprego e, finalmente, os erros e ruídos inerentes a tais dispositivos.

Tópicos de matemática básica foram deslocados para a seção de apêndices deste texto e podem ser consultados pelo leitor a qualquer momento.

\subsection{QuATÉRNIOS}

A quádrupla desenvolvida por Hamilton em 1843 foi chamada Quaternion, ou Quatérnio em português (palavra em latim para quádrupla). Aparentemente, a relação fundamental entre os termos imaginários do quatérnio lhe surgiu enquanto caminhava ao largo do Royal Canal, em Dublin, e a idéia lhe pareceu tão brilhante que Hamilton a registrou nas rochas da ponte Broom (Figura 19).

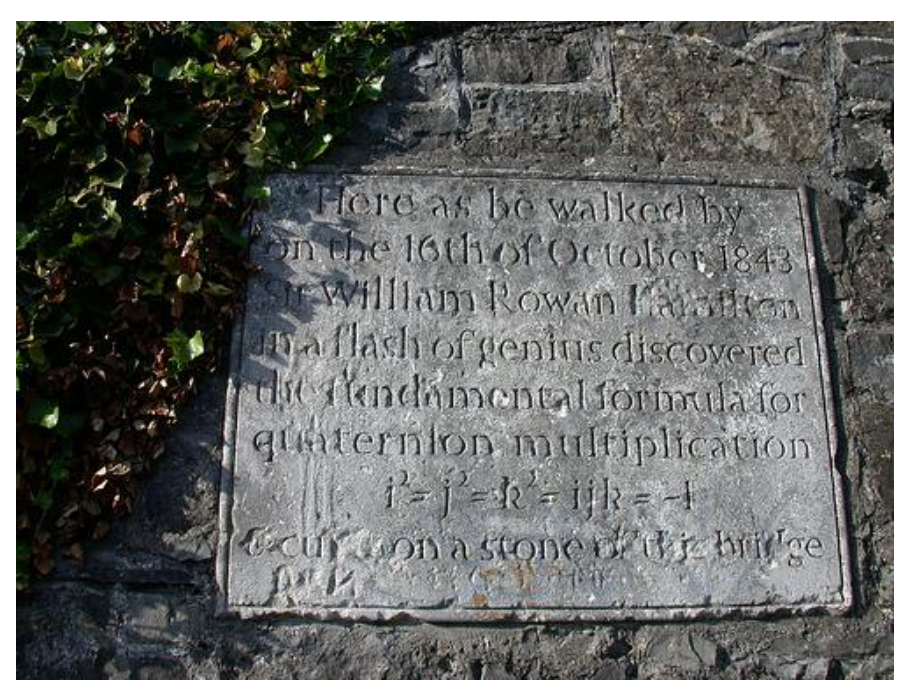

Figura 19 - Relações fundamentais da álgebra dos quatérnios entalhada nas pedras da ponte Broom (BURKE) 
As consequências da relação proposta por Hamilton, assim como a álgebra dos quatérnios, são discutidas adiante.

Os quatérnios são considerados hipercomplexos. É possível enquadrar os reais como hipercomplexos de ordem 1, os números complexos como hipercomplexos de ordem 2 e, seguindo esse raciocínio, os quatérnios são hipercomplexos de ordem 4. Porém, os quatérnios, ou, de maneira geral, os hipercomplexos de ordem superior a 2, não possuem todas as propriedades de corpo, como possuem os reais e os complexos. Os hipercomplexos de ordem superior são anéis não comutativos - consultar APENDICE A para mais informações - e, sendo assim, a multiplicação de dois quatérnios não é comutativa.

Um quatérnio é um número da forma $q=a+b i+c j+d k$, em que " $a, b, c$ " e " $d$ " são reais e " $i, j, k$ " são as unidades imaginárias. As unidades imaginárias respeitam a relação mostrada na Figura 19 e na equação (13),

$$
\begin{gathered}
\mathbf{i}^{2}=\mathbf{j}^{2}=\mathbf{k}^{2}=\mathbf{i j k}=-1 \\
\mathbf{i j}=\mathbf{k}=-\mathbf{j i} \\
\mathbf{j k}=\mathbf{i}=-\mathbf{k} \mathbf{j} \\
\mathbf{k i}=\mathbf{j}=-\mathbf{i k}
\end{gathered}
$$

Tais relações garantem à multiplicação dos quatérnios grande semelhança com o produto de vetores.

Antes de apresentar a multiplicação de quatérnios são definidas a igualdade e a adição, assim como é feito para os números complexos no APÊNDICE A.

Dois quatérnios são iguais, se e somente se, cada um de seus termos for igual. Assim, se:

$$
\begin{aligned}
& p=p_{0}+\mathbf{i} p_{1}+\mathbf{j} p_{2}+\mathbf{k} p_{3} \\
& q=q_{0}+\mathbf{i} q_{1}+\mathbf{j} q_{2}+\mathbf{k} q_{3}
\end{aligned}
$$

Então, $p=q$ se:

$$
\begin{aligned}
& p_{0}=q_{0} \\
& p_{1}=q_{1} \\
& p_{2}=q_{2} \\
& p_{3}=q_{3}
\end{aligned}
$$


A adição de quatérnios é absolutamente análoga à adição de complexos. São somados os componentes correspondentes como mostrado em (23), ou seja:

$$
p+q=\left(p_{0}+q_{0}\right)+\mathbf{i}\left(p_{1}+q_{1}\right)+\mathbf{j}\left(p_{2}+q_{2}\right)+\mathbf{k}\left(p_{3}+q_{3}\right)
$$

Como anel não comutativo para a multiplicação, os quatérnios apresentam associatividade e comutatividade na adição, assim como um termo nulo e termos simétricos. O elemento neutro da adição é simplesmente “0” ou:

$$
q=0+\mathbf{i} 0+\mathbf{j} 0+\mathbf{k} 0=0
$$

E o simétrico da adição ou negativo é:

$$
-q=-q_{0}+\mathbf{i}\left(-q_{1}\right)+\mathbf{j}\left(-q_{2}\right)+\mathbf{k}\left(-q_{3}\right)
$$

A multiplicação dos quatérnios é a operação que desperta maior interesse. Entendendo o quatérnio como a extrapolação tri-dimensional do número complexo, do ponto de vista geométrico, a multiplicação de dois quatérnios deve promover a rotação de um vetor no espaço. Tal interpretação geométrica será mostrada e tratada em mais detalhes no item 4.2.7. Antes disso, porém, são mostrados os processos algébricos associados à multiplicação de quatérnios.

Inicialmente, o produto de um quatérnio por um escalar é bastante simples e análogo ao produto de um escalar por um vetor. Sendo $c$ o escalar e $q$ um quatérnio:

$$
c q=c q_{0}+\mathbf{i} c q_{1}+\mathbf{j} c q_{2}+\mathbf{k} c q_{3}
$$

O produto entre dois quatérnios é mostrado a seguir. Sejam $p$ e $q$ dois quatérnios: 


$$
\begin{gathered}
p q=\left(p_{0}+\mathbf{i} p_{1}+\mathbf{j} p_{2}+\mathbf{k} p_{3}\right)\left(q_{0}+\mathbf{i} q_{1}+\mathbf{j} q_{2}+\mathbf{k} q_{3}\right)= \\
=p_{0} q_{0}+\mathbf{i} p_{1} q_{0}+\mathbf{j} p_{2} q_{0}+\mathbf{k} p_{3} q_{0}+\mathbf{i} p_{0} q_{1}+\mathbf{i}^{2} p_{1} q_{1}+\mathbf{i} \mathbf{j} p_{2} q_{1}+\mathbf{i} \mathbf{k} p_{3} q_{1}+\mathbf{j} p_{0} q_{2} \\
+\mathbf{j i} p_{1} q_{2}+\mathbf{j}^{2} p_{2} q_{2}+\mathbf{j} \mathbf{k} p_{3} q_{2}+\mathbf{k} p_{0} q_{3}+\mathbf{k i} p_{1} q_{3}+\mathbf{k} \mathbf{j} p_{2} q_{3} \\
+\mathbf{k}^{2} p_{3} q_{3}
\end{gathered}
$$

Aplicando-se agora as relações fundamentais (14), (15) e (16) obtém-se a equação (28):

$$
\begin{gathered}
=p_{0} q_{0}+\mathbf{i} p_{0} q_{1}+\mathbf{j} p_{0} q_{2}+\mathbf{k} p_{0} q_{3}+\mathbf{i} p_{1} q_{0}-p_{1} q_{1}+\mathbf{k} p_{1} q_{2}-\mathbf{j} p_{1} q_{3}+\mathbf{j} p_{2} q_{0} \\
-\mathbf{k} p_{2} q_{1}-p_{2} q_{2}+\mathbf{i} p_{2} q_{3}+\mathbf{k} p_{3} q_{0}+\mathbf{j} p_{3} q_{1}-\mathbf{i} p_{3} q_{2}-p_{3} q_{3}
\end{gathered}
$$

A manipulação algébrica seguinte é feita para identificar, na expressão, termos análogos ao produto escalar e vetorial no espaço $\mathbb{R}^{3}$.

$$
\begin{aligned}
p q & =p_{0} q_{0}-\left(p_{1} q_{1}+p_{2} q_{2}+p_{3} q_{3}\right)+p_{0}\left(\mathbf{i} q_{1}+\mathbf{j} q_{2}+\mathbf{k} q_{3}\right) \\
& +q_{0}\left(\mathbf{i} p_{1}+\mathbf{j} p_{2}+\mathbf{k} p_{3}\right)+\mathbf{i}\left(p_{2} q_{3}-p_{3} q_{2}\right)+\mathbf{j}\left(p_{3} q_{1}-p_{1} q_{3}\right) \\
& +\mathbf{k}\left(p_{1} q_{2}-p_{2} q_{1}\right)
\end{aligned}
$$

Dessa forma, é possível identificar as estruturas algébricas: do produto entre escalares; entre vetor e escalar; um produto escalar entre vetores e um produto vetorial, todos no espaço $\mathbb{R}^{3}$. Tais operações vetoriais são mais facilmente identificáveis se o quatérnio for escrito como um escalar somado a um vetor, ou seja, $p=p_{0}+\mathbf{p}$ e $q=q_{0}+\mathbf{q}$

Sendo $\mathbf{p}$ e $\mathbf{q}$ vetores do $\mathbb{R}^{3}$, correspondentes aos coeficientes reais das unidades imaginárias do quatérnio, a expressão (29) pode ser reescrita da seguinte forma,

$$
p q=p_{0} q_{0}-\mathbf{p} \cdot \mathbf{q}+p_{0} \mathbf{q}+q_{0} \mathbf{p}+\mathbf{p} \times \mathbf{q}
$$

Lembrando apenas que $\mathbf{p} \cdot \mathbf{q}$ corresponde ao produto escalar de $\mathbf{p}$ e $\mathbf{q}$ e $\mathbf{p} \times \mathbf{q}$ ao respectivo produto vetorial.

A fórmula (30) é a definição habitual do produto de quatérnios, porém é interessante, conhecer a forma matricial dessa definição, principalmente para implementações computacionais.

Chamando de $r$ o produto dos quatérnios $p$ e $q$, os componentes de $r$ podem ser escritos como, 


$$
\begin{aligned}
& r_{0}=p_{0} q_{0}-p_{1} q_{1}-p_{2} q_{2}-p_{3} q_{3} \\
& r_{1}=p_{0} q_{1}+p_{1} q_{0}+p_{2} q_{3}-p_{3} q_{2} \\
& r_{2}=p_{0} q_{2}-p_{1} q_{3}+p_{2} q_{0}+p_{3} q_{1} \\
& r_{3}=p_{0} q_{3}+p_{1} q_{2}-p_{2} q_{1}+p_{3} q_{0}
\end{aligned}
$$

E, na forma matricial,

$$
\left[\begin{array}{l}
r_{0} \\
r_{1} \\
r_{2} \\
r_{3}
\end{array}\right]=\left[\begin{array}{cccc}
p_{0} & -p_{1} & -p_{2} & -p_{3} \\
p_{1} & p_{0} & -p_{3} & p_{2} \\
p_{2} & p_{3} & p_{0} & -p_{1} \\
p_{3} & -p_{2} & p_{1} & p_{0}
\end{array}\right]\left[\begin{array}{c}
q_{0} \\
q_{1} \\
q_{2} \\
q_{3}
\end{array}\right]
$$

O anel deve conter o elemento neutro ou identidade da multiplicação. Para os quatérnios, assim como para os complexos, a identidade é a identidade real, o número real 1 . A equação (36) apresenta o quatérnio identidade no qual há apenas a parte real e unitária.

$$
q=1+0
$$

\subsubsection{Quatérnio Conjugado, Norma e Inversos}

Assim como os números complexos, os quatérnios possuem conjugados. Trata-se de um conceito importante na determinação da norma do quatérnio e no cálculo do seu inverso.

A construção do quatérnio conjugado é análoga a do complexo conjugado, em que a parte imaginária do número tem o sinal trocado. Fazendo o mesmo no caso do quatérnio:

$$
q=q_{0}+\mathbf{i} q_{1}+\mathbf{j} q_{2}+\mathbf{k} q_{3}
$$

Seu conjugado é dado por:

$$
q^{*}=q_{0}-\mathbf{i} q_{1}-\mathbf{j} q_{2}-\mathbf{k} q_{3}
$$

Ou, ainda:

$$
q^{*}=q_{0}-\mathbf{q}
$$


A notação (39) torna fácil mostrar que, como no caso dos complexos, o quadrado de um quatérnio é um número real.

$$
\begin{gathered}
N^{2}(q)=\left(q_{0}-\mathbf{q}\right)\left(q_{0}+\mathbf{q}\right) \\
N^{2}(q)=q_{0} q_{0}+(-\mathbf{q}) \cdot \mathbf{q}+q_{0} \mathbf{q}+(-\mathbf{q}) q_{0}+(-\mathbf{q}) \times \mathbf{q} \\
N^{2}(q)=q_{0}^{2}-\mathbf{q} \cdot \mathbf{q}
\end{gathered}
$$

E o produto escalar $\mathbf{q} \cdot \mathbf{q}$ corresponde a:

$$
\begin{gathered}
\mathbf{q} \cdot \mathbf{q}=\mathbf{i}^{2} q_{1}^{2}+\mathbf{j}^{2} q_{2}^{2}+\mathbf{k}^{2} q_{3}^{2} \\
\mathbf{q} \cdot \mathbf{q}=-q_{1}^{2}-q_{2}^{2}-q_{3}^{2}=-\left(q_{1}^{2}+q_{2}^{2}+q_{3}^{2}\right)
\end{gathered}
$$

Desta forma, substituindo (44) em (40) chega-se a equação (45).

$$
N^{2}(q)=q_{0}^{2}-\left[-\left(q_{1}^{2}+q_{2}^{2}+q_{3}^{2}\right)\right]=q_{0}^{2}+q_{1}^{2}+q_{2}^{2}+q_{3}^{2}
$$

É simples demonstrar que, embora a multiplicação de quatérnios não seja comutativa, o resultado do produto entre um quatérnio e seu conjugado independe da ordem com que a operação é realizada.

A norma do quatérnio é calculada analogamente a norma do número complexo, ou seja, extraindo-se a raiz quadrada do produto do quatérnio pelo seu conjugado.

$$
|q|^{2}=q_{0}^{2}+q_{1}^{2}+q_{2}^{2}+q_{3}^{2}=N^{2}(q)
$$

O cálculo da norma é idêntico ao cálculo de um vetor no espaço $\mathbb{R}^{4}$ e isso permite que se faça uma associação entre os significados dessas grandezas. A norma do quatérnio pode ser interpretada como seu comprimento.

O último tópico dessa breve revisão da álgebra dos quatérnios é o cálculo do seu inverso. $\mathrm{O}$ anel dos quatérnios possui um inverso para todo o elemento não nulo como visto anteriormente.

O cálculo do inverso é, novamente, análogo ao que se faz com números complexos. 


$$
\frac{1}{q_{0}+\mathbf{q}}=\frac{1}{q_{0}+\mathbf{q}} \cdot \frac{q_{0}-\mathbf{q}}{q_{0}-\mathbf{q}}=\frac{q_{0}-\mathbf{q}}{N^{2}(q)}=\frac{q^{*}}{N^{2}(q)}
$$

\subsection{CinemÁtica do CORPO RíGIDO E ORIENTAÇão EsPaCIAL}

Diz-se que um corpo é rígido quando a distância entre seus diferentes pontos não varia ao longo do tempo. Essa definição pode ser traduzida matematicamente na forma de equações de vínculo entre pontos pertencentes ao corpo, que impõem que as diferenças de posição relativas sejam constantes. As demonstrações seguintes são baseadas em (GIACAGLIA, 1982) e (FRANÇA e MATSUMURA, 2001).

Sejam $P i$ e $P j$ vetores de posição de dois pontos pertencentes ao corpo, medidos em relação a um referencial arbitrário, o vínculo citado anteriormente pode ser escrito como:

$$
\left|\left(P_{i}-P_{j}\right)\right|^{2}=\text { constante }
$$

A idéia de corpo rígido é uma aproximação da realidade, pois, na natureza, não há corpo que não apresente deformação frente à aplicação de uma força. Deste modo pode-se empregar a idéia de corpo rígido sempre que as deformações possuírem magnitude muito inferior aos deslocamentos do corpo.

As deformações serão pequenas caso a rigidez do material seja elevada e/ou se as forças envolvidas forem proporcionalmente baixas. Problemas envolvendo choques, que habitualmente envolvem forças elevadas, podem requerer o emprego do modelo geral, ou seja, do modelo de corpo deformável.

Supondo que se deseje estudar o movimento do corpo rígido, é possível estabelecer um importante vínculo cinemático proveniente da derivação dos vínculos expressos na equação (49).

$$
\frac{d}{d t}\left|\left(P_{i}-P_{j}\right)\right|^{2}=\frac{d}{d t}\left[\left(P_{i}-P_{j}\right) \cdot\left(P_{i}-P_{j}\right)\right]=2\left(v_{i}-v_{j}\right) \cdot\left(P_{i}-P_{j}\right)=0
$$

Onde, de forma geral, a derivada do vetor $P_{i}$ no tempo é o vetor velocidade $v_{i}$.

O vínculo estabelecido pela equação (49) permite determinar o campo de velocidades de um corpo rígido conhecendo-se a velocidade e posição de um ponto qualquer pertencente a ele. A equação (49) mostra, também, que o vetor velocidade relativa entre dois pontos quaisquer é 
perpendicular a reta que une tais pontos ou, ainda, a projeção das velocidades dos pontos sobre a reta que os une é sempre a mesma, quaisquer que sejam os pontos pertencentes ao corpo rígido.

$\mathrm{O}$ caso mais simples de movimento rígido é aquele em que o vetor $\left(P_{i}-P_{j}\right)$ se mantém constante ao longo do tempo. Nesse casso,

$$
\frac{d}{d t}\left(P_{i}-P_{j}\right)=\left(v_{i}-v_{j}\right)=0
$$

Ou seja:

$$
v_{i}=v_{j}
$$

para qualquer $P_{i}$ e $P_{j}$ pertencentes ao corpo. Esse tipo de movimento é chamado translação e a velocidade comum a todos os pontos do sólido é chamada velocidade de translação.

O segundo tipo de movimento possível para o corpo rígido é aquele em que pelo menos um vetor $\left(P_{i}-P_{j}\right)$ se mantém fixo ao longo do tempo. A reta que contém o vetor $\left(P_{i}-P_{j}\right)$ é chamada eixo de rotação e o movimento em questão é chamado movimento de rotação. Todos os pontos do corpo pertencentes à reta descrita anteriormente permaneceram fixos durante o movimento de rotação decorrente do vínculo estabelecido pela equação (49).

Supondo $P_{i}$ e $P_{i}^{*}$ pertencentes ao eixo de rotação e $P_{j}$ não, aplicando-se a equação (49) ao caso do movimento de rotação,

$$
\begin{aligned}
& \left(v_{j}\right) \cdot\left(P_{i}-P_{j}\right)=0 \\
& \left(v_{j}\right) \cdot\left(P_{i}^{*}-P_{j}\right)=0
\end{aligned}
$$

É possível observar que, para que (52) e (53) sejam satisfeitas simultaneamente, $v_{j}$ deve ser perpendicular ao plano que contém os três pontos em questão. Essa relação determina que o vetor velocidade de qualquer partícula que não pertença ao eixo de rotação seja tangente a uma circunferência perpendicular a ele e com centro neste. Graças à rigidez do corpo é possível afirmar, também, que pontos com a mesma distância ao eixo de rotação possuem a mesma velocidade e aceleração.

Pontos que pertençam a um plano passando pelo eixo instantâneo de rotação em um instante de tempo pertencerão a este plano durante todo o movimento. Essa propriedade permite 
definir a chamada velocidade angular do corpo rígido. Essa velocidade corresponde à taxa de variação do ângulo formado entre dois planos que contêm e se intersectam no eixo de rotação do corpo, sendo um deles fixo do ponto de vista de um referencial externo e outro solidário ao corpo.

A velocidade angular é expressa na forma de um vetor cuja direção coincide com o eixo de rotação do corpo e o modulo é dado por:

$$
\omega=\frac{d \theta}{d t}
$$

Sendo $\theta$ o ângulo entre os dois planos descritos no parágrafo anterior e evolua no tempo de forma contínua.

Tendo definido o vetor velocidade angular, é possível estabelecer a relação deste com o vetor velocidade de um ponto qualquer pertencente ao corpo no movimento de rotação. Imaginando novamente $\overrightarrow{v_{J}}$ (agora designado de maneira vetorial),

$$
\overrightarrow{v_{J}}=\omega r \vec{\tau}
$$

Seu módulo corresponde ao produto da velocidade angular do corpo pela distância entre o ponto analisado e o eixo de rotação, $r$, e possui direção dada pelo versor $\vec{\tau}$, cuja direção é perpendicular ao plano que contém o eixo de rotação e é tangente a trajetória circular descrita anteriormente. Segundo essa consideração, a equação (55) pode ser reescrita da seguinte forma,

$$
\overrightarrow{v_{J}}=\vec{\omega} \times \vec{r}
$$

Definindo-se o vetor $\vec{r}$ como sendo aquele que une a projeção do ponto $P_{j}$ ao próprio. Esse produto vetorial produz a direção do versor $\vec{\tau}$. A equação (56) pode, ainda, ser escrita da seguinte forma:

$$
\overrightarrow{v_{J}}=\vec{\omega} \times\left(\vec{P}_{l}-\vec{P}_{J}\right)
$$

Sendo $P_{i}$ pertencente ao eixo de rotação do corpo. 
"O ato de movimento corresponde ao conjunto de todas as velocidades de todos os pontos em um instante de tempo. O ato de movimento é instantâneo." (GIACAGLIA, 1982)

O caso geral do movimento de um corpo rígido é a composição do movimento de translação com o de rotação. Nesse caso, diferentemente da translação, os pontos possuem velocidades distintas. E essas diferenças provêm da existência de rotação.

Em um dado instante de tempo é possível imaginar um eixo de rotação em torno do qual as velocidades pontuais podem ser determinadas pela equação (57), acrescida da velocidade com a qual o corpo translada, que coincide com a velocidade dos pontos pertencentes ao eixo de rotação e, por isso:

$$
\overrightarrow{v_{J}}=\overrightarrow{v_{l}}+\vec{\omega} \times\left(\overrightarrow{P_{l}}-\overrightarrow{P_{J}}\right)
$$

A equação (58) é conhecida como fórmula fundamental da cinemática. Essa fórmula descreve o ato de movimento de um corpo rígido, sendo conhecidos: um ponto pertencente ao eixo instantâneo de rotação, a velocidade instantânea de rotação e a velocidade instantânea de translação do corpo.

Há uma consequência importante da fórmula fundamental que é o fato de, em cada instante de tempo, a projeção das velocidades de quaisquer pontos do corpo rígido sobre o eixo de rotação, e por isso sobre $\vec{\omega}$, serem iguais. Isso significa também que, em cada instante de tempo, o vetor velocidade de cada ponto do corpo rígido possui uma parcela paralela a $\vec{\omega}$. Há pontos nos quais a velocidade total é paralela ao eixo de rotação e é possível demonstrar que o lugar geométrico que contém tais pontos é uma reta. Essa reta varia com o tempo e recebe o nome de eixo helicoidal instantâneo. Desta forma, os pontos pertencentes ao eixo helicoidal instantâneo são, em cada instante, aqueles que possuem a menor velocidade total.

Voltando a atenção para o vetor $\vec{\omega}$, novamente podem-se dar interpretações matemáticas e geométricas.

Chamando $\left(P_{i}-P_{j}\right)$ de $\vec{r}$, a equação (58) pode ser reescrita da seguinte forma:

$$
\dot{\vec{r}} \cdot \vec{r}=0
$$

Supondo $P_{j}$ coincidente com a origem de um sistema de coordenadas $x, y, z$ solidário ao corpo: 


$$
\begin{gathered}
\vec{r}=\left(P_{i}-0\right)=x \vec{\imath}+y \vec{\jmath}+z \vec{k} \\
\dot{\vec{r}}=x \dot{\vec{\imath}}+y \dot{\vec{\jmath}}+z \dot{\vec{k}}
\end{gathered}
$$

Onde $\vec{\imath}, \vec{\jmath}, \vec{k}$ são versores que orientam os eixos do sistema de coordenadas e $x, y, z$ são escalares constantes, pois o referencial é solidário ao corpo.

Imaginando que o corpo realize um movimento de rotação pura, as derivadas dos versores da base podem ser reescritas segundo as equações (62), (63) e (64).

$$
\begin{aligned}
\dot{\vec{\imath}} & =\vec{\omega} \times \vec{\imath} \\
\dot{\vec{\jmath}} & =\vec{\omega} \times \vec{\jmath} \\
\dot{\vec{k}} & =\vec{\omega} \times \vec{k}
\end{aligned}
$$

Analogamente, o vetor velocidade angular pode ser escrito em termos do sistema de coordenadas estabelecido,

$$
\vec{\omega}=\omega_{x} \vec{\imath}+\omega_{y} \vec{\jmath}+\omega_{z} \vec{k}
$$

Onde $\omega_{x}, \omega_{y}, \omega_{z}$ são escalares que variam com o tempo. Substituindo (65) em (62), (63) e (64) os termos paralelos aos versores do lado direito das equações são cancelados restando apenas:

$$
\begin{aligned}
& \dot{\vec{\imath}}=\omega_{y} \vec{\jmath}+\omega_{z} \vec{k} \\
& \dot{\vec{\jmath}}=\omega_{x} \vec{\imath}+\omega_{z} \vec{k} \\
& \dot{\vec{k}}=\omega_{x} \vec{\imath}+\omega_{y} \vec{\jmath}
\end{aligned}
$$

Realizando o produto escalar conveniente nas equações (66), (67) e (68) é possível determinar as componentes do vetor velocidade angular, na base $x y z$ :

$$
\begin{aligned}
\omega_{x} & =\dot{\vec{\jmath}} \cdot \vec{k} \\
\omega_{y} & =\dot{\vec{k}} \cdot \vec{\imath} \\
\omega_{z} & =\dot{\vec{\imath}} \cdot \vec{\jmath}
\end{aligned}
$$




$$
\vec{\omega}=(\dot{\vec{\jmath}} \cdot \vec{k}) \vec{\imath}+(\dot{\vec{k}} \cdot \vec{\imath}) \vec{\jmath}+(\dot{\vec{\imath}} \cdot \vec{\jmath}) \vec{k}
$$

Outra interpretação para $\vec{\omega}$ pode ser obtida por meio da formula fundamental, segundo a qual:

$$
\dot{\vec{r}}=\overrightarrow{v_{0}}+\vec{\omega} \times \vec{r}
$$

Em que $\vec{r}$ é o vetor posição de um ponto $P$ pertencente ao corpo, medido a partir da origem de um sistema de coordenadas solidário ao corpo rígido.

Reescrevendo os vetores em termos das suas componentes no sistema de coordenadas $x, y, z$ :

$$
(\dot{x}(P), \dot{y}(P), \dot{z}(P))=(\dot{x}(0), \dot{y}(0), \dot{z}(0))+\left(\omega_{x}, \omega_{y}, \omega_{z}\right) \times(x, y, z)
$$

E realizando o produto vetorial $\left(\omega_{x}, \omega_{y}, \omega_{z}\right) \times(x, y, z)$, tem-se:

$(\dot{x}(P), \dot{y}(P), \dot{z}(P))=(\dot{x}(0), \dot{y}(0), \dot{z}(0))+\left[\left(\omega_{y} z-\omega_{z} y\right),\left(\omega_{z} x-\omega_{x} z\right),\left(\omega_{x} y-\omega_{y} x\right)\right]$

Reescrevendo a equação em cada uma de suas componentes, obtêm-se então:

$$
\begin{aligned}
& \dot{x}(P)=\dot{x}(0)+\left(\omega_{y} z-\omega_{z} y\right) \\
& \dot{y}(P)=\dot{y}(0)+\left(\omega_{z} x-\omega_{x} z\right) \\
& \dot{z}(P)=\dot{z}(0)+\left(\omega_{x} y-\omega_{y} x\right)
\end{aligned}
$$

Calculando-se as derivadas parciais de $\dot{x}, \dot{y}, \dot{z}$ em $P$ :

$$
\begin{array}{ccc}
\frac{\partial \dot{x}}{\partial x}=0 & \frac{\partial \dot{x}}{\partial y}=-\omega_{z} & \frac{\partial \dot{x}}{\partial z}=\omega_{y} \\
\frac{\partial \dot{y}}{\partial x}=\omega_{z} & \frac{\partial \dot{y}}{\partial y}=0 & \frac{\partial \dot{y}}{\partial z}=-\omega_{x} \\
\frac{\partial \dot{z}}{\partial x}=-\omega_{y} & \frac{\partial \dot{z}}{\partial y}=\omega_{x} & \frac{\partial \dot{z}}{\partial z}=0
\end{array}
$$

Obtêm-se as derivadas parciais (79) que correspondem ao gradiente do vetor velocidade do ponto $P$. É possível observar que o traço da matriz gradiente de velocidades é nulo, ou seja, o 
divergente do vetor velocidade é nulo. Essa é uma conclusão importante e característica do movimento do corpo rígido.

$$
\operatorname{div} \dot{\vec{r}}=0
$$

$\mathrm{O}$ produto vetorial do operador $\nabla$ pelo vetor velocidade calculado no ponto $\mathrm{P}$ resulta no chamado rotacional do campo de velocidades (no ponto em questão).

$$
\nabla \times \dot{\vec{r}}=\left|\begin{array}{ccc}
i & j & k \\
\frac{\partial}{\partial x} & \frac{\partial}{\partial y} & \frac{\partial}{\partial z} \\
\dot{x} & \dot{y} & \dot{z}
\end{array}\right|=\left(\frac{\partial \dot{z}}{\partial y}-\frac{\partial \dot{y}}{\partial z}\right) \vec{\imath}+\left(\frac{\partial \dot{x}}{\partial z}-\frac{\partial \dot{z}}{\partial x}\right) \vec{\jmath}+\left(\frac{\partial \dot{y}}{\partial x}-\frac{\partial \dot{x}}{\partial y}\right) \vec{k}=\operatorname{rot} \dot{\vec{r}}
$$

Substituindo as relações (79) na equação (81):

$$
\left(\omega_{x}+\omega_{x}\right) \vec{\imath}+\left(\omega_{y}+\omega_{y}\right) \vec{\jmath}+\left(\omega_{z}+\omega_{z}\right) \vec{k}=\operatorname{rot} \dot{\vec{r}}
$$

E, portanto:

$$
\vec{\omega}=\frac{1}{2} \operatorname{rot} \dot{\vec{r}}
$$

"Esta última relação é, na realidade, a origem da definição do rotacional de um vetor." (GIACAGLIA, 1982)

\subsubsection{Rotação de um Vetor em torno de um Eixo que o Intercepta}

Trata-se de uma aplicação prática dos conceitos mostrados no item anterior.

O vetor que sofrerá a rotação pode representar a reta ligando um ponto de interesse de um corpo rígido ao seu baricentro e, neste caso, o giro será realizado em torno do eixo de rotação. Seja $\vec{n}$ um versor representando o eixo de rotação e $\vec{r}$ o vetor que será girado. Para tal determinação, deseja-se conhecer o vetor rotacionado $\rho(\vec{r})$, ou, mais precisamente, suas componentes. A estratégia sugerida em (BIASI e GATTASS, 2002) é representar o vetor $\vec{r}$ em suas componentes paralela e perpendicular ao eixo de rotação representado por $\vec{n}$, ou seja: 


$$
\vec{r}=\vec{r}_{\|}+\vec{r}_{\perp}
$$

As componentes paralela e perpendicular podem, então, ser determinadas da seguinte forma,

$$
\begin{gathered}
\vec{r}_{\|}=(\vec{n} \cdot \vec{r}) \vec{n} \\
\vec{r}_{\perp}=\vec{r}-\vec{r}_{\|}=\vec{r}-(\vec{n} \cdot \vec{r}) \vec{n}
\end{gathered}
$$

O vetor $\vec{r}_{\|}$é a projeção de $\vec{r}$ em $\vec{n}$ e, por isso, permanece constante ao longo da rotação (neste caso, imagina-se que o eixo de rotação permaneça inalterado durante a rotação).

$$
\rho\left(\vec{r}_{\|}\right)=\vec{r}_{\|}
$$

Por sua vez, a componente perpendicular está contida em um plano normal ao vetor $\vec{n}$, que conterá, ainda, o vetor $\rho\left(\vec{r}_{\perp}\right)$ e o vetor proveniente do produto vetorial $\vec{n} \times \vec{r}_{\perp}$. Valendo-se da mesma nomenclatura usada em (BIASI e GATTASS, 2002), $\vec{v}$ será a designação do produto vetorial $\vec{n} \times \vec{r}_{\perp}$, ou seja:

$$
\vec{v}=\vec{n} \times \vec{r}_{\perp}=\vec{n} \times\left(\vec{r}-\vec{r}_{\|}\right)=\vec{n} \times \vec{r}-\vec{n} \times \vec{r}_{\|}=\vec{n} \times \vec{r}
$$

O vetor $\rho\left(\vec{r}_{\perp}\right)$ pode, agora, ser determinado por meio da combinação linear de $\vec{v}$ e $\vec{r}-$ $(\vec{n} \cdot \vec{r}) \vec{n}$.

A Figura 20 baseada na referência (BIASI e GATTASS, 2002) ilustra as passagens anteriores. 

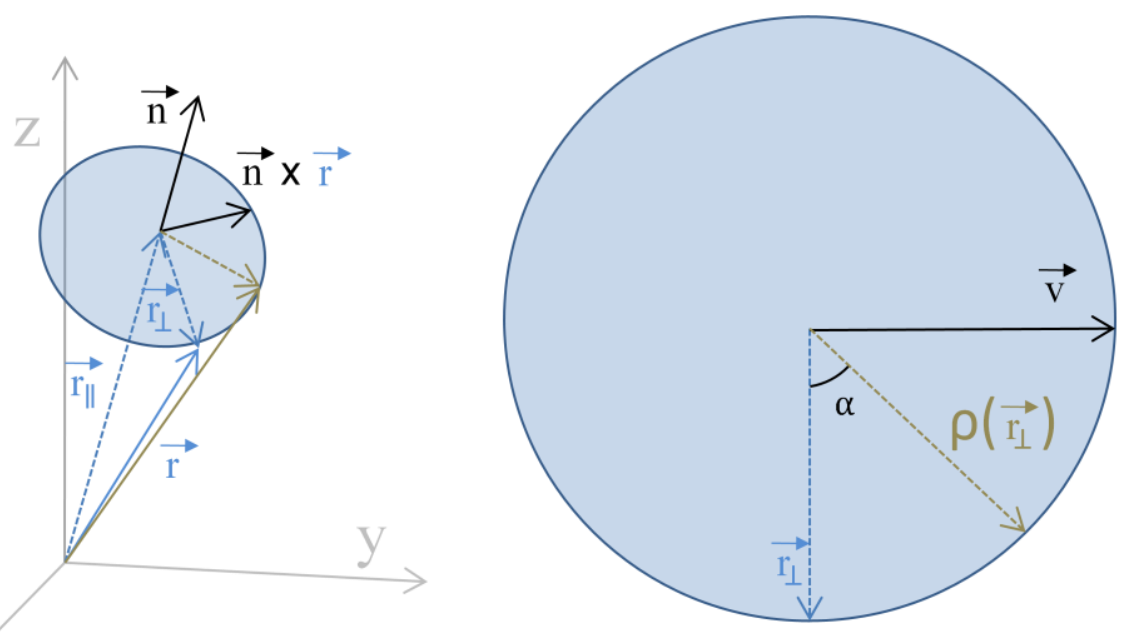

Figura 20 - Determinação do vetor em torno do qual um vetor é rotacionado no espaço

Chamando de $\alpha$ o ângulo formado entre $\vec{r}_{\perp}$ e $\rho\left(\vec{r}_{\perp}\right)$, como mostra a Figura 20, esta última pode ser escrita como:

$$
\rho\left(\vec{r}_{\perp}\right)=(\cos \alpha) \vec{r}_{\perp}+(\sin \alpha) \vec{v}
$$

Somando as componentes do vetor rotacionado, e fazendo as substituições,

$$
\begin{aligned}
\rho(\vec{r}) & =\rho\left(\vec{r}_{\|}+\vec{r}_{\perp}\right)=\rho\left(\vec{r}_{\|}\right)+\rho\left(\vec{r}_{\perp}\right)=\vec{r}_{\|}+(\cos \alpha) \vec{r}_{\perp}+(\sin \alpha) \vec{v} \\
& =(\vec{n} \cdot \vec{r}) \vec{n}+(\cos \alpha)(\vec{r}-(\vec{n} \cdot \vec{r}) \vec{n})+(\sin \alpha)(\vec{n} \times \vec{r}) \\
& =(\vec{n} \cdot \vec{r}) \vec{n}+(\cos \alpha) \vec{r}-(\cos \alpha)(\vec{n} \cdot \vec{r}) \vec{n}+(\sin \alpha)(\vec{n} \times \vec{r}) \\
& +(\sin \alpha)(\vec{n} \times \vec{r})
\end{aligned}
$$

O vetor rotacionado pode ser escrito como,

$$
\rho(\vec{r})=(\cos \alpha) \vec{r}+(1-\cos \alpha)(\vec{n} \cdot \vec{r}) \vec{n}+(\sin \alpha)(\vec{n} \times \vec{r})
$$

\subsection{2. Ângulos de Euler}

Para a definição dos Ângulos de Euler, inicialmente, é preciso conhecer o conceito de rotações principais. 
Em um espaço Euclideano tri-dimensional os três vetores da equação (92) formam uma base ortonormal para o espaço vetorial.

$$
x=(1,0,0), y=(0,1,0), z=(0,0,1)
$$

Se tais vetores funcionarem como eixos de rotação podem ser chamados de eixos principais (não confundir com eixos principais de inércia). As rotações em torno de tais eixos são chamadas rotações principais.

Os ângulos de Euler são uma forma de descrever a posição angular de um corpo por meio da aplicação consecutiva de três rotações principais.

Para um sistema orientado pela regra da mão direita, há doze sequências para aplicação das três rotações principais, e cada uma delas pode ser considerada uma convenção de ângulos de Euler. A mais comum é aquela proposta por Leonhard Euler no século XVII, sequência $Z, x, Z$ ou 3,1,3. Além das diferentes ordens com as quais pode-se aplicar as rotações principais, é possível fazê-las em termos da base fixa no espaço ou da base rotacionada.

Independentemente da base escolhida, fixa ou rotacionada, as sequências de rotações possíveis são:

$$
\begin{aligned}
& (x, y, x),(x, y, z),(x, z, x),(x, z, y),(y, x, y),(y, x, z), \\
& (y, z, x),(y, z, y),(z, x, y),(z, x, z),(z, y, x),(z, y, z)
\end{aligned}
$$

Aquelas em destaque são as mais utilizadas.

No conjunto de sequências, ou parametrizações apresentadas, é possível identificar dois tipos principais: as que empregam os três eixos e aquelas que empregam apenas dois deles. $\mathrm{O}$ primeiro caso será explicado mais adiante e o segundo caso será utilizado no exemplo a seguir.

É importante ressaltar que cada sequência resulta numa atitude final diferente.

A grande contribuição de Euler nesse estudo específico foi demonstrar que qualquer orientação no espaço pode ser alcançada através de uma rotação em torno de um eixo nesse espaço. Tal eixo não é necessariamente um eixo pertencente ao sistema de coordenadas e as parametrizações de orientação empregando ângulos de Euler não levam, de forma imediata, a conhecimento o eixo de rotação.

O eixo de rotação foi detalhado no item 4.2, mas cabe ressaltar que tal eixo no espaço tridimensional possui três componentes em uma base ortogonal arbitrária e, por isso, 
conhecendo-se a magnitude da rotação, é possível descrever quaisquer rotações realizar empregando três variáveis. Essa conclusão é coerente com a noção intuitiva de que um corpo que possua um ponto fixo no espaço tri-dimensional possui três graus de liberdade de rotação. Antes de detalhar as sequências e seus empregos, é importante observar as implicações da utilização das medidas angulares em relação às bases fixas ou rotacionadas.

Nas explicações a seguir serão utilizadas as letras $x, y, z$ para designar a base fixa no espaço e as letras $(\tilde{x}, \tilde{y}, \tilde{z})$ para a base rotacionada.

Empregando-se a sequência $z, x, z$, no caso da rotação fixa no espaço (ou estática), todas as rotações principais são em torno dos eixos fixos $z, x$. A primeira rotação de um ângulo $\psi$ é feita em torno do eixo z (Figura 22), seguida por uma rotação de um ângulo $\theta$ em torno do eixo $x$ (Figura 24) e, por fim, uma rotação de um ângulo $\varphi$ em torno do eixo z fixo (Figura 26).

Quando o plano $\tilde{x} \tilde{y}$ é girado de $\theta$, ele passa a intersectar o plano xy em uma reta que pode ser chamada de linha de nós. Este termo provém da mecânica celeste e designa a linha formada entre o plano da órbita de certo corpo com um plano de referência, por exemplo, a linha formada pela intersecção do plano em que um satélite orbita e o plano criado pela eclíptica ${ }^{6}$ da terra ou mesmo o plano equatorial.

No caso em que o referencial permanece fixo ao corpo (ou rotativo), todas as rotações são em torno dos eixos principais $\tilde{z}$ e $\tilde{x}$. Inicialmente os dois referenciais, $x, y, z$ e $\tilde{x}, \tilde{y}, \tilde{z}$, são coincidentes. A primeira rotação de um ângulo $\varphi$ é em torno do eixo z̃. Esta rotação leva os eixos $\tilde{y}$ e $\tilde{x}$ para uma nova orientação. A segunda rotação de um ângulo $\theta$ é em torno do novo eixo $\tilde{x}$, que funcionará como linha de nós. A terceira rotação de um ângulo $\psi$ é feita em torno do eixo $\tilde{z}$, rotacionado, e move os eixos $\tilde{x}$ e $\tilde{y}$ para a posição final.

Habitualmente, nas parametrizações envolvendo dois eixos, por exemplo: $z, x, z$ embora as letras gregas possam variar, normalmente $\psi, \theta$ e $\varphi$, recebem o nome de: rotação própria ou spin, nutação e precessão,.

\footnotetext{
${ }^{6}$ Eclíptica é o plano que contém a órbita da terra ao redor do Sol.
} 


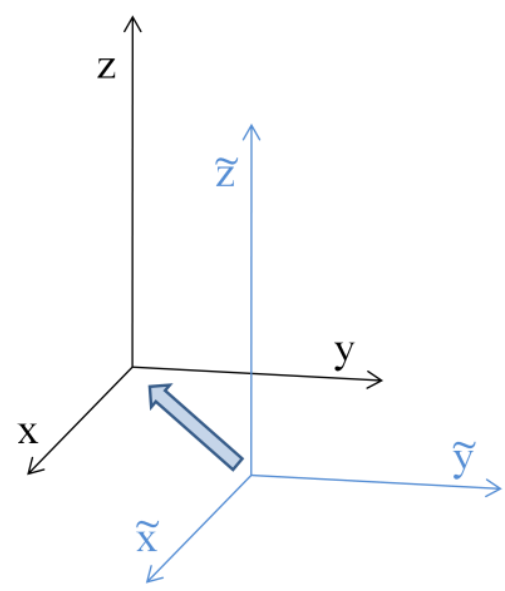

Figura 21 - Base inercial e base solidária ao corpo inicialmente são coincidentes

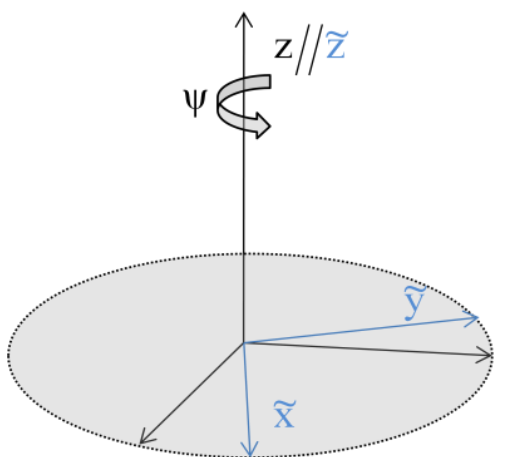

Figura 22 - Rotação em torno do eixo z inercial

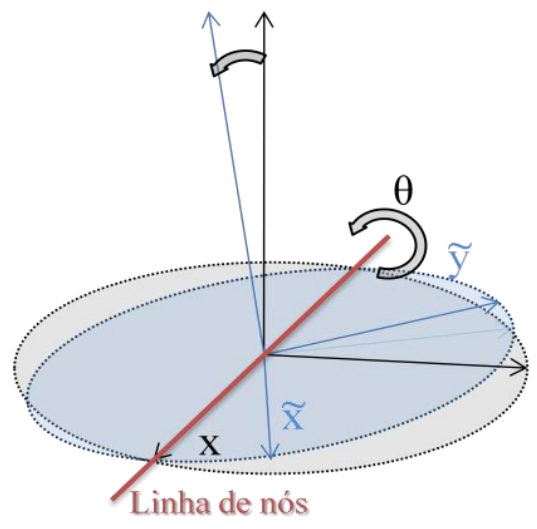

Figura 24 - Rotação em torno do eixo x inercial

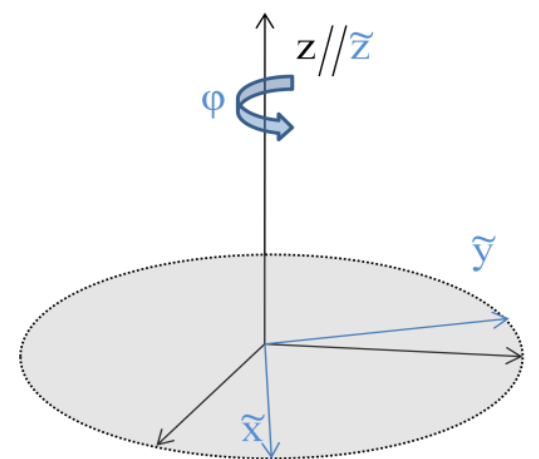

Figura 23 - Rotação em torno do eixo z movido

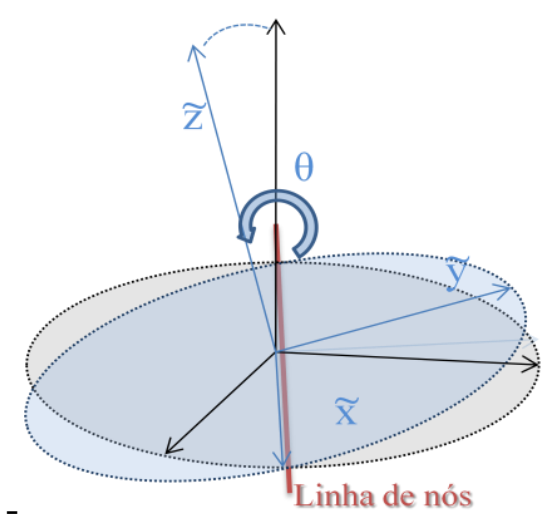

Figura 25 - Rotação em torno do eixo x movido 


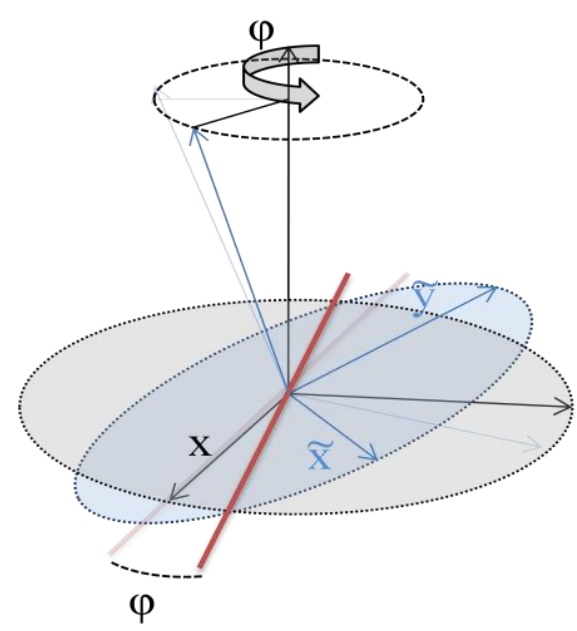

Figura 26 - Rotação em torno do eixo z inercial

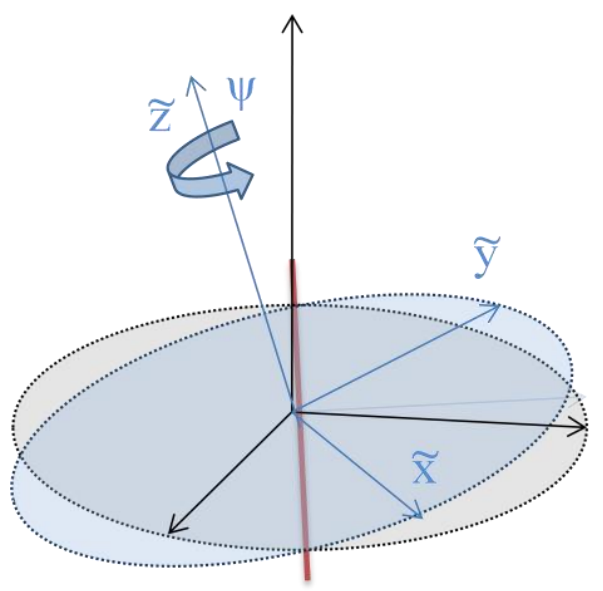

Figura 27 - Rotação em torno do eixo z movido

É possível demonstrar que tanto as rotações em torno do eixo fixo, como as realizadas em torno dos eixos rotacionados, resultaram na mesma atitude final do referencial $\tilde{x} \tilde{y} \tilde{z}$, porém, para tanto, o spin e a precessão tiveram suas ordens invertidas:

$R_{z}(\phi) R_{x}(\theta) R_{z}(\psi)=R_{\tilde{Z}}(\psi) R_{\tilde{x}}(\theta) R_{\tilde{Z}}(\phi)$

Sendo $\mathrm{R}$ o operador que gira os vetores em torno de um eixo principal designado pelo seu índice.

Se considerada a ordem baseada no tipo de movimento, a conclusão é que uma sequência de rotações na base rotacionada é a sequência inversa da aplicada na base fixa.

Esta igualdade permite que se caracterize spin, nutação e precessão, independentemente do sistema de coordenadas, fixo ou rotacionado. Neste caso, continuar-se-á usando a sequência $Z, X, Z$ como exemplo, mas as conclusões podem ser aplicáveis de forma imediata em quaisquer sequências dos tipos: $(x, y, x),(x, z, x),(y, x, y),(y, z, y),(z, y, z)$.

O spin deve girar os eixos $\tilde{x}$ e $\tilde{y}$ sem alterar o plano ao qual estes pertencem. A nutação faz com que os planos xy e $\tilde{x} \tilde{y}$ deixem de ser paralelos e, por isso, cria a linha de nós. A precessão gira a linha de nós no plano xy (fixo).

A precessão, na definição apresentada, depende da existência de uma linha de nós, ou seja, da intersecção entre os planos fixo e rotacionado e, para tanto, deve ter havido nutação.

Na Figura 23, rotação própria e precessão se confundem, já que não há linha de nós. No caso em que a base é solidária ao corpo, pode-se imaginar que a linha de nós é posicionada antes mesmo de ser gerada, enquanto no caso em que a base é fixa, a linha de nós é criada e posteriormente movida. 
O outro tipo de sequência de rotações importante é aquele que emprega rotações nos três eixos. A convenção deste tipo mais comum é a $(x, y, z)$ e, embora possa ser considerada uma convenção de Euler, é habitualmente chamada de ângulos de Cardan, ângulos de Tait-Bryan, ou ainda, convenção náutica. Nesse tipo de parametrização $\psi, \theta, \phi$ recebem, respectivamente, os nomes de roll, pitch e yaw.

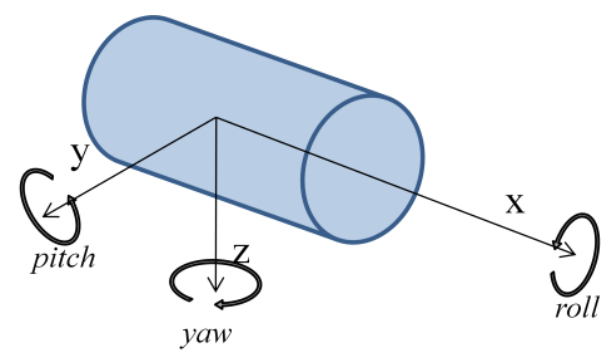

Figura 28 - Ângulos de Cardan

O tipo e a ordem da sequência empregada resultam em atitudes finais distintas e isto é traduzido nas matrizes de rotação resultantes de cada parametrização.

\subsubsection{Matrizes de Rotação}

Uma matriz de rotação é um operador que, ao ser aplicado a um vetor, rotaciona o mesmo, preservando seu módulo. Para preservar o módulo do vetor a matriz deve possuir determinante unitário.

As matrizes de rotação empregadas na dinâmica dos corpos rígidos pertencem ao espaço tridimensional e são normalmente ortogonais. Sendo assim, considerando R uma matriz de rotação,

$$
R^{T}=R^{-1}
$$

A rotação promovida pela matriz pode respeitar a chamada "regra da mão direita" e, para tanto, $\operatorname{det} R=1$, ou a "regra da mão esquerda" e, neste caso, $\operatorname{det} R=-1$.

A matriz de rotação pode, alternativamente, ser escrita em termos da base fixa no espaço, ou da base rotacionada.

Matriz de cossenos diretores é outro nome habitual dado à matriz de rotação. 
As matrizes de rotação são a operacionalização matemática das rotações definidas pelos ângulos de Euler e, por isso, ângulos utilizados nas matrizes de rotação são conhecidos como ângulos de Euler.

Do ponto de vista das matrizes de rotação, a escolha da base de coordenadas - fixas no espaço ou no corpo - corresponde a construí-las nas formas diretas ou inversas que, graças às propriedades destacadas anteriormente, equivale as suas traspostas (equação (94)). O seu emprego levará uma matriz de posição original para uma condição rotacionada, ou da condição rotacionada para a respectiva posição original.

A multiplicação de duas matrizes de rotação leva a uma terceira matriz, também de rotação, que corresponde à aplicação consecutiva das duas matrizes originais. É importante notar que a ordem com que as rotações são aplicadas é inversa àquela com que a expressão é montada. Como se sabe, o produto de matrizes não é uma operação comutativa, ou seja, deve-se atentar para a ordem com que se realizam as operações matriciais de rotação.

A matriz de rotação pode ser construída a partir do produto, na sequência correta, de três matrizes de rotação, cada uma dessas em torno de um eixo principal.

$$
\begin{array}{rlrl}
R_{\tilde{z}}(\psi) & =\left[\begin{array}{ccc}
\cos \psi & \sin \psi & 0 \\
-\sin \psi & \cos \psi & 0 \\
0 & 0 & 1
\end{array}\right] & R_{z}(\psi)=\left[\begin{array}{ccc}
\cos \psi & -\sin \psi & 0 \\
\sin \psi & \cos \psi & 0 \\
0 & 0 & 1
\end{array}\right] \\
R_{\tilde{x}}(\theta)=\left[\begin{array}{cccc}
1 & 0 & 0 \\
0 & \cos \theta & \sin \theta \\
0 & -\sin \theta & \cos \theta
\end{array}\right] & R_{x}(\theta)=\left[\begin{array}{ccc}
1 & 0 & 0 \\
0 & \cos \theta & -\sin \theta \\
0 & \sin \theta & \cos \theta
\end{array}\right] \\
R_{\tilde{z}}(\phi)=\left[\begin{array}{ccc}
\cos \phi & \sin \phi & 0 \\
-\sin \phi & \cos \phi & 0 \\
0 & 0 & 1
\end{array}\right] & R_{z}(\phi)=\left[\begin{array}{ccc}
\cos \phi & -\sin \phi & 0 \\
\sin \phi & \cos \phi & 0 \\
0 & 0 & 1
\end{array}\right]
\end{array}
$$

E, desta forma:

$$
\begin{aligned}
& R_{\tilde{z}}(\psi) R_{\tilde{x}}(\theta) R_{\tilde{z}}(\phi)= \\
& =\left[\begin{array}{ccc}
\cos \psi \cos \phi-\cos \theta \sin \phi \sin \psi & \cos \psi \sin \phi+\cos \theta \cos \phi \sin \psi & \sin \psi \sin \theta \\
-\cos \phi \sin \psi-\cos \theta \cos \psi \sin \phi & -\sin \psi \sin \phi+\cos \theta \cos \phi \cos \psi & \cos \psi \sin \theta \\
\sin \theta \sin \phi & -\sin \theta \cos \phi & \cos \theta
\end{array}\right]
\end{aligned}
$$




$$
\begin{aligned}
& R_{z}(\psi) R_{x}(\theta) R_{z}(\phi)= \\
& =\left[\begin{array}{ccc}
\cos \psi \cos \phi-\cos \theta \sin \phi \sin \psi & -\cos \psi \sin \phi-\cos \theta \cos \phi \sin \psi & \sin \phi \sin \theta \\
\cos \phi \sin \psi+\cos \theta \cos \psi \sin \phi & -\sin \psi \sin \phi+\cos \theta \cos \phi \cos \psi & -\sin \theta \cos \psi \\
\sin \theta \sin \phi & \cos \phi \sin \theta & \cos \theta
\end{array}\right]
\end{aligned}
$$

Como foi dito, a matriz resultante da rotação na sequência $(3,1,3)$,escrita em termos dos giros em torno dos eixos fixos no espaço, é exatamente a transposição daquela obtida por meio das rotações em torno dos eixos solidários ao corpo.

Importante destacar que todas as matrizes mostradas acima são matrizes ortogonais e com determinante unitário - matrizes ortonormais .

No caso das convenções que empregam rotações nos três eixos, mais usadas na navegação de aeronaves e embarcações, as matrizes de rotação serão outras. Conforme mencionado, neste tipo de parametrização as rotações não correspondem às precessões, nutações e spins. No entanto, neste texto empregar-se-á o mesmo conjunto de símbolos para designá-las: $\psi, \theta, \phi$ recebendo os nomes de roll, pitch e yaw, respectivamente.

Neste caso, as matrizes de rotação são escritas da seguinte forma,

$$
\begin{aligned}
& R_{\tilde{z}}(\psi)=\left[\begin{array}{ccc}
1 & 0 & 0 \\
0 & \cos \psi & \sin \psi \\
0 & -\sin \psi & \cos \psi
\end{array}\right] \\
& R_{\tilde{y}}(\theta)=\left[\begin{array}{ccc}
\cos \theta & 0 & -\sin \theta \\
0 & 1 & 0 \\
\sin \theta & 0 & \cos \theta
\end{array}\right] \\
& R_{\tilde{x}}(\phi)=\left[\begin{array}{ccc}
\cos \phi & \sin \phi & 0 \\
-\sin \phi & \cos \phi & 0 \\
0 & 0 & 1
\end{array}\right]
\end{aligned}
$$

Obviamente, o produto das três matrizes corresponde à convenção escolhida. Americanos e Ingleses, por exemplo, usam habitualmente a ordem $(3,2,1)-y a w$, pitch e roll. No entanto, a seguir são apresentadas as matrizes correspondentes às convenções e $(3,2,1)$ e $(1,2,3)$.

$$
\begin{aligned}
& R_{\tilde{x}}(\phi) R_{\tilde{y}}(\theta) R_{\tilde{z}}(\psi) \\
& =\left[\begin{array}{ccr}
\cos \theta \cos \phi & \cos \theta \sin \phi & -\sin \theta \\
\sin \psi \sin \theta \cos \phi-\cos \psi \sin \phi & \sin \psi \sin \theta \sin \phi+\cos \psi \cos \phi & \cos \theta \sin \\
\cos \psi \sin \theta \cos \phi+\sin \psi \sin \phi & \cos \psi \sin \theta \sin \phi-\sin \psi \cos \psi & \cos \theta \cos
\end{array}\right.
\end{aligned}
$$




$$
\begin{aligned}
& R_{\tilde{z}}(\psi) R_{\tilde{y}}(\theta) R_{\tilde{x}}(\phi) \\
& =\left[\begin{array}{ccc}
\cos \theta \cos \psi & -\cos \phi \sin \psi+\sin \phi \sin \theta \cos \psi & \sin \phi \sin \psi+\cos \phi \sin \theta \mathrm{c} \\
\cos \theta \sin \psi & \cos \phi \cos \psi+\sin \phi \sin \theta \sin \psi & -\sin \phi \cos \psi+\cos \phi \sin \theta \\
-\sin \theta & \sin \phi \cos \theta & \cos \phi \cos \theta
\end{array}\right.
\end{aligned}
$$

Considerando-se a matriz (99) construída a partir de rotações executadas em torno do conjunto de eixos fixos, pode-se dizer que a matriz (100) corresponde ao mesmo conjunto de rotações aplicadas aos eixos rotacionados - comparação ilustrada entre a Figura 21 e a Figura 27.

\subsubsection{Linearização da Matriz de Rotação}

Para algumas aplicações é interessante que as equações sejam lineares. As funções que empregam ângulos de Euler possuem, basicamente, formas trigonométricas.

Para um dado sistema, se for possível, busca-se aplicar a hipótese de pequenas inclinações, ou seja, ângulos de Euler próximos de zero. Neste caso, a linearização empregada é:

$$
\begin{gathered}
\cos \alpha \rightarrow 1 \\
\operatorname{sen} \alpha \rightarrow \alpha \rightarrow 0
\end{gathered}
$$

Por meio das expansões de Taylor do seno e do cosseno, pode-se verificar a ordem do erro associado a tal linearização. Assim:

$$
\begin{gathered}
\operatorname{sen} \alpha=\operatorname{sen}(0)+\frac{\cos (0)}{1 !} \alpha-\frac{\operatorname{sen}(0)}{2 !} \alpha^{2}-\frac{\cos (0)}{3 !} \alpha^{3}+\frac{\operatorname{sen}(0)}{4 !} \alpha^{4}+\cdots \\
\operatorname{sen} \alpha=\alpha-\frac{\alpha^{3}}{3 !}+\frac{\alpha^{5}}{5 !}+\cdots \\
\cos \alpha=\cos (0)-\frac{\operatorname{sen}(0)}{1 !} \alpha-\frac{\cos (0)}{2 !} \alpha^{2}+\frac{\operatorname{sen}(0)}{3 !} \alpha^{3}+\frac{\cos (0)}{4 !} \alpha^{4}+\cdots \\
\cos \alpha=1-\frac{\alpha^{2}}{2 !}+\frac{\alpha^{4}}{4 !}+\cdots
\end{gathered}
$$

As equações (104) e (106) demonstram que o erro em adotar a linearização proposta é de segunda ordem no caso do cosseno, e de terceira ordem no caso do seno. 
A seguir são apresentadas respectivamente as matrizes linearizadas correspondentes às equações (96) e (97), referentes à sequência $(3,1,3)$, e às equações $(99)$ e $(100)$, referentes às sequência $(3,2,1)$ e $(1,2,3)$.

$$
\begin{gathered}
R_{\tilde{z}}(\psi) R_{\tilde{x}}(\theta) R_{\tilde{z}}(\phi)=\left[\begin{array}{ccc}
1 & \phi+\psi & 0 \\
-\phi-\psi & 1 & \theta \\
0 & -\theta & 1
\end{array}\right] \\
R_{z}(\psi) R_{x}(\theta) R_{z}(\phi)=\left[\begin{array}{ccc}
1 & -\phi-\psi & 0 \\
\phi+\psi & 1 & -\theta \\
0 & \theta & 1
\end{array}\right] \\
R_{\tilde{x}}(\phi) R_{\tilde{y}}(\theta) R_{\tilde{z}}(\psi)=\left[\begin{array}{ccc}
1 & \phi & -\theta \\
-\phi & 1 & \psi \\
\theta & -\psi & 1
\end{array}\right] \\
R_{\tilde{z}}(\psi) R_{\tilde{y}}(\theta) R_{\tilde{x}}(\phi)=\left[\begin{array}{ccc}
1 & -\phi & \theta \\
\phi & 1 & -\psi \\
-\theta & \psi & 1
\end{array}\right]
\end{gathered}
$$

\subsubsection{Gimbal Lock}

O temor gimbal pode ser atribuído a qualquer suporte que possa girar em torno de um eixo fixo.

Habitualmente os gimbal systems são uma série de anéis concêntricos, interligados por eixos que permitem rotações de uns em relação aos outros. Se imaginarmos uma sequência de três anéis concêntricos, dispostos perpendicularmente em relação aos outros, e fixando ao anel mais interno um corpo, essa montagem permitirá que o mesmo assuma qualquer atitude no espaço. Em realidade, os movimentos de cada um dos anéis correspondem exatamente a cada uma das rotações de Euler.

Para se descrever tais movimentos é necessário optar por uma certa sequência de rotações. Além disso, todo giro deve, necessariamente, respeitar a ordem definida.

Ao se executarem giros arbitrários poderá surgir uma situação particular de alinhamento de dois dos eixos entorno dos quais se está realizando as rotações. Neste momento, nem todo o espaço das rotações possíveis poderá ser atingido em uma próxima sequência de rotações. Essa situação é conhecida como gimbal lock. 
No gimbal lock, perde-se um grau de liberdade de rotação e, a partir do instante em que este fenômeno ocorre, não se pode alcançar posições no plano perpendicular ao plano de gimbal lock sem que se executem rotações intermediárias.

Importante destacar que todas as sequências possíveis de ângulos de Euler apresentam o fenômeno de gimbal lock, evidentemente em planos distintos.

A Tabela 3 mostra as diferentes convenções de ângulos de Euler e os respectivos planos e ângulos nos quais ocorre o fenômeno de gimbal lock.

Tabela 3 - Situações em que ocorre o gimbal lock

\begin{tabular}{|l|l|l|}
\hline $\mathrm{x}, \mathrm{y}, \mathrm{z} / 1,2,3$ & Eixos x e $\mathrm{z}$ alinham-se & Eixo y rotacionado de 0 ou $\mathrm{n} \pi+\pi / 2, \mathrm{n} \in \mathbb{Z}$ \\
\hline $\mathrm{x}, \mathrm{z}, \mathrm{y} / 1,3,2$ & Eixos x e y alinham-se & Eixo z rotacionado de 0 ou $\mathrm{n} \pi+\pi / 2, \mathrm{n} \in \mathbb{Z}$ \\
\hline $\mathrm{z}, \mathrm{x}, \mathrm{y} / 3,1,2$ & Eixos z e y alinham-se & Eixo x rotacionado de 0 ou $\mathrm{n} \pi+\pi / 2, \mathrm{n} \in \mathbb{Z}$ \\
\hline $\mathrm{z}, \mathrm{y}, \mathrm{x} / 3,2,1$ & Eixos z e x alinham-se & Eixo y rotacionado de 0 ou $\mathrm{n} \pi+\pi / 2, \mathrm{n} \in \mathbb{Z}$ \\
\hline $\mathrm{y}, \mathrm{x}, \mathrm{z} / 2,1,3$ & Eixos y e z alinham-se & Eixo x rotacionado de 0 ou $\mathrm{n} \pi+\pi / 2, \mathrm{n} \in \mathbb{Z}$ \\
\hline $\mathrm{y}, \mathrm{z}, \mathrm{x} / 2,3,1$ & Eixos y e x alinham-se & Eixo z rotacionado de 0 ou $\mathrm{n} \pi+\pi / 2, \mathrm{n} \in \mathbb{Z}$ \\
\hline $\mathrm{x}, \mathrm{y}, \mathrm{x} / 1,2,1$ & Eixos x e $\tilde{x}$ alinham-se & Eixo y rotacionado de 0 ou $\mathrm{n} \pi+\pi / 2, \mathrm{n} \in \mathbb{Z}$ \\
\hline $\mathrm{x}, \mathrm{z}, \mathrm{x} / 1,3,1$ & Eixos x e $\tilde{x}$ alinham-se & Eixo $\mathrm{z}$ rotacionado de 0 ou $\mathrm{n} \pi+\pi / 2, \mathrm{n} \in \mathbb{Z}$ \\
\hline $\mathrm{y}, \mathrm{x}, \mathrm{y} / 2,1,2$ & Eixos y e $\tilde{y}$ alinham-se & Eixo x rotacionado de 0 ou $\mathrm{n} \pi+\pi / 2, \mathrm{n} \in \mathbb{Z}$ \\
\hline $\mathrm{y}, \mathrm{z}, \mathrm{y} / 2,3,2$ & Eixos y e $\tilde{y}$ alinham-se & Eixo z rotacionado de 0 ou $\mathrm{n} \pi+\pi / 2, \mathrm{n} \in \mathbb{Z}$ \\
\hline $\mathrm{z}, \mathrm{x}, \mathrm{z} / 3,1,3$ & Eixos z e $\tilde{z}$ alinham-se & Eixo x rotacionado de 0 ou $\mathrm{n} \pi+\pi / 2, \mathrm{n} \in \mathbb{Z}$ \\
\hline $\mathrm{z}, \mathrm{y}, \mathrm{z} / 3,2,3$ & Eixos z e $\tilde{z}$ alinham-se & Eixo y rotacionado de 0 ou $\mathrm{n} \pi+\pi / 2, \mathrm{n} \in \mathbb{Z}$ \\
\hline
\end{tabular}

Uma forma de observar matematicamente o efeito do gimbal lock ocorre quanto se tenta obter os ângulos de Euler a partir da matriz de rotação na situação em que os eixos de rotação estão muito próximos de se alinharem.

Tomando como exemplo a matriz de rotação associada à sequência $(3,2,1)$, equação $(100)$, os ângulos de Euler associados aquele operador são dados por:

$$
\begin{aligned}
& \psi=\tan ^{-1}\left(\frac{c_{21}}{c_{11}}\right) \\
& \theta=\sin ^{-1}\left(-c_{31}\right) \\
& \phi=\tan ^{-1}\left(\frac{c_{32}}{c_{33}}\right)
\end{aligned}
$$


Sendo $c_{\mathrm{ij}}$ os termos da matriz de rotação.

Como mostrado na Tabela 3 o problema de gimbal lock ocorre quando o eixo 2 é rotacionado de $\pi / 2$. Neste caso, a matriz de rotação assume a seguinte forma:

$$
\begin{aligned}
& R_{\tilde{z}}(\psi) R_{\tilde{y}}(\theta) R_{\tilde{x}}(\phi) \\
& =\left[\begin{array}{ccc}
0 & -\cos \phi \sin \psi+\sin \phi \cos \psi & \sin \phi \sin \psi+\cos \phi \cos \psi \\
0 & \cos \phi \cos \psi+\sin \phi \sin \psi & -\sin \phi \cos \psi+\cos \phi \sin \psi \\
-1 & 0 & 0
\end{array}\right]
\end{aligned}
$$

Desta forma, é possível observar que surgem indeterminações nas expressões (111), (112) e (113), pois numerador e denominador tendem a zero. Indeterminação semelhante pode ser observada na própria matriz de rotação, reescrita a partir da equação (113), empregando-se relações trigonométricas.

$$
R_{\tilde{z}}(\psi) R_{\tilde{y}}(\theta) R_{\tilde{x}}(\phi)=\left[\begin{array}{ccc}
0 & -\sin (\psi-\phi) & \cos (\psi-\phi) \\
0 & \cos (\psi-\phi) & \sin (\psi-\phi) \\
-1 & 0 & 0
\end{array}\right]
$$

Na expressão (115), $\psi$ e $\phi$ se confundem, pois promovem o mesmo giro no espaço.

Tipicamente, sempre que uma singularidade se aproxima, o problema de gimbal lock é contornado modificando-se a descrição das rotações, ou seja, a convenção de ângulos de Euler. Alternativa comum também é representar as rotações por meio de Quatérnios.

\subsubsection{Rotações Infinitesimais com Matriz de Cossenos Diretores}

É uma transformação ortogonal que modifica muito pouco os eixos coordenados iniciais.

Trata-se de uma transformação linear no espaço e, por isso, possui representação matricial. A matriz de transformação infinitesimal, que recebe esta designação por aplicar rotações desta ordem de grandeza, é muito próxima da matriz identidade e, habitualmente, é representada da seguinte forma:

$$
\tilde{x}=(\mathrm{I}+\epsilon) x
$$

Sendo $I$ a matriz identidade e $\epsilon$ uma matriz de diagonal nula, composta por termos infinitesimais nas demais posições. 
É possível verificar que a sequência das operações não importa no caso das matrizes de rotações infinitesimais ou, em outras palavras, as transformações infinitesimais comutam. Tal demonstração encontra-se em (GOLDSTEIN, 1980).

Agora, supondo duas transformações infinitesimais, $\left(1+\epsilon_{1}\right)$ e $\left(1+\epsilon_{2}\right)$, um dos produtos possíveis é:

$$
\left(1+\epsilon_{1}\right)\left(1+\epsilon_{2}\right)=1+\epsilon_{2}+\epsilon_{1}+\epsilon_{1} \epsilon_{2}
$$

E outro:

$$
\left(1+\epsilon_{2}\right)\left(1+\epsilon_{1}\right)=1+\epsilon_{1}+\epsilon_{2}+\epsilon_{2} \epsilon_{1}
$$

Neste caso, descartando os infinitesimais de ordem superior, tem-se que:

$$
\begin{aligned}
& \left(1+\epsilon_{1}\right)\left(1+\epsilon_{2}\right)=1+\epsilon_{2}+\epsilon_{1} \\
& \left(1+\epsilon_{2}\right)\left(1+\epsilon_{1}\right)=1+\epsilon_{1}+\epsilon_{2}
\end{aligned}
$$

E, assim, como a soma de matrizes é sempre comutativa:

$$
\left(1+\epsilon_{1}\right)\left(1+\epsilon_{2}\right)=\left(1+\epsilon_{2}\right)\left(1+\epsilon_{1}\right)
$$

Após verificar que as transformações infinitesimais comutam, ou seja, a ordem com que são executadas não modifica o resultado final, é importante observar o comportamento das matrizes infinitesimais no caso da escolha do sistema de coordenadas, fixo ou solidário ao corpo.

Foi mostrado anteriormente que, para uma determinada sequência de ângulos de Euler, do ponto de vista matemático, a mudança no sistema de coordenadas corresponde a empregar a matriz de transformação inversa ou, ainda, sua transposta (ver equação (264)).

Desta forma, se $A=1+\epsilon$ é a matriz de transformação infinitesimal, então, sua inversa será dada por:

$$
A^{-1}=1-\epsilon
$$

Assim, é possível se obter de forma simples a equação (122), pois: 


$$
A A^{-1}=(1+\epsilon)(1-\epsilon)=1-\epsilon+\epsilon-\epsilon^{2}=1-\epsilon^{2}
$$

E, negligenciando o termo de ordem superior:

$$
A A^{-1}=1
$$

O que concorda com a definição de matriz inversa.

\subsubsection{Rotação de Vetores utilizando Quatérnios}

Nesse item buscar-se-á a interpretação geométrica dos quatérnios e a descrição de como eles funcionam como operadores de rotação no espaço. Importante destacar que o texto a seguir não é uma mera transcrição das referências, mas uma leitura crítica e adaptada das mesmas, face ao tema em estudo.

$\mathrm{O}$ primeiro aspecto importante a ser discutido diz respeito à origem distinta de vetores e quatérnios.

Os vetores, comuns à cinemática espacial, pertencem ao espaço $\mathbb{R}^{3}$, enquanto os quatérnios, como conjunto de seus coeficientes, pertencem ao espaço $\mathbb{R}^{4}$. Para que um quatérnio funcione como operador linear no $\mathbb{R}^{3}$ é preciso entender o vetor como um quatérnio sem parte real.

Como visto no item 4.1 é comum dividir o quatérnio em parte real e uma parte vetorial associada a suas unidades imaginárias. Da mesma forma, sendo $\mathbf{v}$ um vetor do espaço tridimensional,

$$
v=0+\mathbf{v}
$$

Onde $v$ será o quatérnio correspondente ao vetor $\mathbf{v}$.

Quatérnios com partes reais nulas são, portanto, chamados de quatérnios puros.

Sendo assim, desejando-se multiplicar um quatérnio por um vetor do espaço tridimensional, este deve ser escrito na forma de um quatérnio puro, ou seja:

$$
\mathbf{v}=(a, b, c) \rightarrow v=(0, a, b, c)
$$


Como dito anteriormente, para a cinemática, o grande interesse nos quatérnios se deve a sua multiplicação permitir rotações de vetores no espaço por meio de operações algébricas relativamente simples. Desta forma, a habitual matriz de rotação pode ser substituída por um operador que possui apenas 4 termos. Neste caso, além da redução no número de termos, as rotações empregando quatérnios não apresentam o problema de gimbal lock.

Para que um quatérnio promova apenas uma rotação quando multiplicado por um vetor é necessário que possua norma unitária. Lembrar que o cálculo da norma de um quatérnio foi detalhado no item 4.1.1.

Esta característica pode ser comparada ao determinante unitário da matriz de rotação.

A seguir será apresentado o procedimento para rotação de um vetor por meio de um quatérnio, descrição baseada em (BIASI e GATTASS, 2002).

Seja $\mathbf{r}$ um vetor com componentes $r_{x}, r_{y}, r_{z}$. Para que se efetue sua rotação, primeiramente, é preciso escrevê-lo na forma de um quatérnio puro $p=(0, r)$, ou seja, com parte real nula.

A rotação aplicada será representada pelo quatérnio de norma unitária $q=(s, \mathbf{v})$.

Então, para que se realize a rotação, deve-se multiplicar o quatérnio pelo vetor e posteriormente multiplicar o produto obtido pelo quatérnio de rotação inverso. Antes da demonstração de que essa operação corresponde efetivamente à rotação do vetor em torno de um eixo especificado pelo quatérnio, cabe recordar a equação (47) para se observar que a relação (127) é válida se a norma do quatérnio é unitária.

$$
q^{-1}=q^{*}
$$

A rotação, assim, pode ser escrita como:

$$
R_{q}(p)=q p q^{*}
$$

Lembrando que o produto empregado é o de quatérnios.

Desta forma, expandindo a expressão (128):

$$
\begin{gathered}
q p q^{*}=(s, \mathbf{v})(0, \mathbf{r})(s,-\mathbf{v})= \\
(s, \boldsymbol{v})(0 s-\mathbf{r} \cdot-\mathbf{v},-0 \mathbf{v}+s \mathbf{r}+\mathbf{r} \times-\mathbf{v})= \\
(s, \mathbf{v})(\mathbf{r} \cdot \mathbf{v}, s \mathbf{r}-\mathbf{r} \times \mathbf{v})= \\
(s(\mathbf{r} \cdot \mathbf{v})-\mathbf{v} \cdot(s \mathbf{r}-\mathbf{r} \times \mathbf{v}), s(s \mathbf{r}-\mathbf{r} \times \mathbf{v})+(\mathbf{r} \cdot \mathbf{v}) \mathbf{v}+\mathbf{v} \times(s \mathbf{r}-\mathbf{r} \times \mathbf{v}))=
\end{gathered}
$$




$$
\begin{gathered}
\left(s(\mathbf{r} \cdot \mathbf{v})-\mathbf{v} \cdot s \mathbf{r}-\mathbf{v} \cdot(-\mathbf{r} \times \mathbf{v}), s^{2} \mathbf{r}-s \mathbf{r} \times \mathbf{v}+(\mathbf{r} \cdot \mathbf{v}) \mathbf{v}+\mathbf{v} \times s \mathbf{r}+\mathbf{v} \times(-\mathbf{r} \times \mathbf{v})\right) \\
= \\
\left(s(\mathbf{r} \cdot \mathbf{v})-s(\mathbf{r} \cdot \mathbf{v})+\mathbf{v} \cdot(\mathbf{r} \times \mathbf{v}), s^{2} r+s \mathbf{v} \times \mathbf{r}+(\mathbf{r} \cdot \mathbf{v}) \mathbf{v}+s \mathbf{v} \times \mathbf{r}+\mathbf{v} \times(\mathbf{v} \times \mathbf{r})\right) \\
=\quad \\
\left(\mathbf{v} \cdot(\mathbf{r} \times \mathbf{v}), s^{2} \mathbf{r}+(\mathbf{r} \cdot \mathbf{v}) \mathbf{v}+2 s \mathbf{v} \times \mathbf{r}+(\mathbf{v} \cdot \mathbf{r}) \mathbf{v}-(\mathbf{v} \cdot \mathbf{v}) \mathbf{r}\right)= \\
\left(0, s^{2} \mathbf{r}-(\mathbf{v} \cdot \mathbf{v}) \mathbf{r}+2(\mathbf{v} \cdot \mathbf{r}) \mathbf{v}+2 s \mathbf{v} \times \mathbf{r}\right)
\end{gathered}
$$

O desenvolvimento que resultou na expressão (129) frisa, ainda, que estejam implícitas as relações vetoriais:

$$
\begin{gathered}
\mathbf{a} \cdot(\mathbf{b} \times \mathbf{a})=0 \\
\mathbf{a} \times \mathbf{b}=-\mathbf{b} \times \mathbf{a} \\
\mathbf{a} \times(\mathbf{b} \times \mathbf{c})=(\mathbf{a} \cdot \mathbf{c}) \mathbf{b}-(\mathbf{a} \cdot \mathbf{b}) \mathbf{c}
\end{gathered}
$$

Sendo $\mathbf{a}, \mathbf{b}$ e $\mathbf{c}$ vetores do $\mathbb{R}^{3}$.

É importante notar que o resultado (129) é sempre um quatérnio puro e pode ser imediatamente interpretado como um vetor no $\mathbb{R}^{3}$, como desejado. Este resultado é garantido pela equação (128) graças ao segundo produto com o quatérnio conjugado.

A Figura 29, adaptada de (KUIPERS, 1999), ajuda a visualizar como o desenvolvimento (129) gera um quatérnio puro e que possui correspondência direta com os vetores no $\mathbb{R}^{3}$.

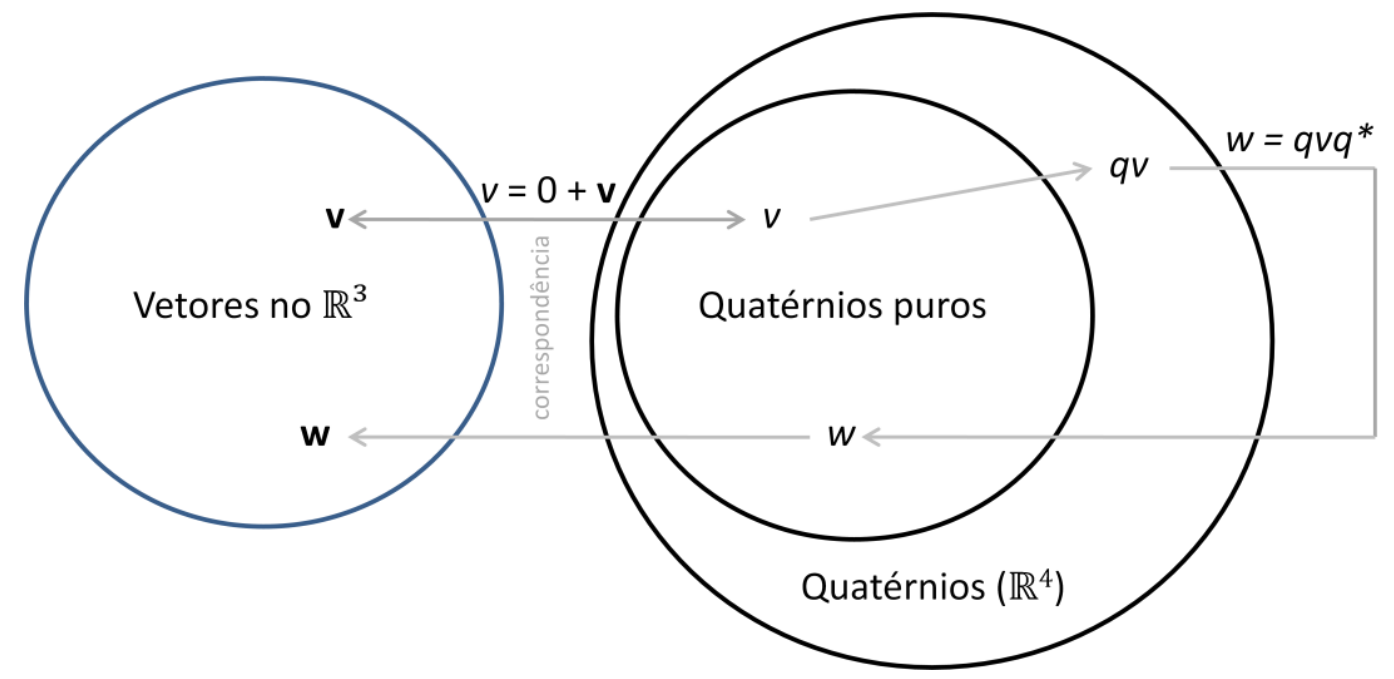

Figura 29 - Produto triplo entre quatérnios e vetores no $\mathbb{R}^{3}$

Como dito anteriormente, o quatérnio de rotação possui norma unitária, ou seja: 


$$
|q|^{2}=s^{2}+|\mathbf{v}|^{2}=1
$$

Conhecendo-se, ainda, a relação:

$$
\cos ^{2} \theta+\sin ^{2} \theta=1
$$

É possível fazer as seguintes associações:

$$
\begin{gathered}
\cos ^{2} \theta=s^{2} \\
\sin ^{2} \theta=|\mathbf{v}|^{2}
\end{gathered}
$$

Garantindo-se que:

$$
|\mathbf{v}| \neq 0
$$

Para que as igualdades (133) e (134) sejam únicas, deve-se estabelecer um intervalo para o ângulo $\theta$, de 0 a $2 \pi$, ou habitualmente de $-\pi$ a $\pi$.

O quatérnio de rotação $q$ pode ser escrito em termos de $\theta$ da seguinte forma:

$$
q=(s, \mathbf{v})=\left(\cos \theta, \frac{\mathbf{v}}{|\mathbf{v}|} \sin \theta\right)
$$

Esta forma de se escrever um quatérnio de rotação permite visualizar mais facilmente o funcionamento deste operador e, mais precisamente, visualizar o produto triplo sobre os vetores do $\mathbb{R}^{3}$.

Reescrevendo-se a equação resultante de (129) com as correspondências mostradas em (133) e (134) é possível obter a equação (137):

$$
\begin{aligned}
(0, & \left.s^{2} \mathbf{r}-(\mathbf{v} \cdot \mathbf{v}) \mathbf{r}+2(\mathbf{v} \cdot \mathbf{r}) \mathbf{v}+2 s \mathbf{v} \times \mathbf{r}\right)= \\
\left(0,\left(\cos ^{2} \theta\right) \mathbf{r}\right. & -\left(\sin \theta \frac{\mathbf{v}}{|\mathbf{v}|} \cdot \sin \theta \frac{\mathbf{v}}{|\mathbf{v}|}\right) \mathbf{r}+2\left(\sin \theta \frac{\mathbf{v}}{|\mathbf{v}|} \cdot \mathbf{r}\right) \sin \theta \frac{\mathbf{v}}{|\mathbf{v}|} \\
& \left.+2 \cos \theta\left(\sin \theta \frac{\mathbf{v}}{|\mathbf{v}|}\right) \times \mathbf{r}\right)
\end{aligned}
$$


Fazendo-se a mudança de variável (138), chega-se a equação (139):

$$
\begin{gathered}
\frac{\mathbf{v}}{|\mathbf{v}|}=\mathbf{u} \\
\left(0,\left(\cos ^{2} \theta\right) \mathbf{r}-\left(\sin ^{2} \theta \mathbf{u} \cdot \mathbf{u}\right) \mathbf{r}+\left(2 \sin ^{2} \theta\right)(\mathbf{u} \cdot \mathbf{r}) \mathbf{u}+(2 \cos \theta \sin \theta) \mathbf{u} \times \mathbf{r}\right)
\end{gathered}
$$

Finalmente, empregando-se relações trigonométricas simples, obtém-se:

$$
\begin{gathered}
\left(0,\left(\cos ^{2} \theta\right) \mathbf{r}-\left(\sin ^{2} \theta\right) \mathbf{r}+(1-\cos 2 \theta)(\mathbf{u} \cdot \mathbf{r}) \mathbf{u}+(\sin 2 \theta) \mathbf{u} \times \mathbf{r}\right)= \\
\left(0,\left(\cos ^{2} \theta-\sin ^{2} \theta\right) \mathbf{r}+(1-\cos 2 \theta)(\mathbf{u} \cdot \mathbf{r}) \mathbf{u}+(\sin 2 \theta) \mathbf{u} \times \mathbf{r}\right)= \\
(0,(\cos 2 \theta) \mathbf{r}+(1-\cos 2 \theta)(\mathbf{u} \cdot \mathbf{r}) \mathbf{u}+(\sin 2 \theta) \mathbf{u} \times \mathbf{r})=
\end{gathered}
$$

É possível perceber que a expressão resultante possui a parcela vetorial muito semelhante à equação da rotação de um vetor em torno de um eixo, rever equação (91) mostrada na seção 4.2.1. Igualando as duas expressões é possível encontrar a seguinte relação:

$$
2 \theta=\alpha
$$

Realizando-se a substituição (141), conclui-se que o resultado do produto triplo (128) corresponde à rotação do vetor $\mathbf{r}$ em torno do eixo $\mathbf{v}$ de um ângulo $\alpha$.

Conhecendo-se a relação entre $\theta$ e a magnitude da rotação de um vetor em torno de outro, pode-se escrever o quatérnio de rotação como:

$$
q=\left(\cos \frac{\alpha}{2}, \frac{\mathbf{v}}{|\mathbf{v}|} \sin \frac{\alpha}{2}\right)
$$

Onde $\alpha$ é a magnitude do ângulo de rotação.

A expressão (142) é a forma mais prática de construir o quatérnio de rotação e será amplamente utilizada neste trabalho.

O maior benefício de se empregar quatérnios para executar rotações no espaço é a facilidade com que se consegue compor rotações sem nunca recair em situações de gimbal lock. A composição de rotações é feita simplesmente multiplicando-se sucessivamente os quatérnios de rotação e aplicando-se o resultado ao produto triplo (128). Ou seja, sendo $q_{1}$ e $q_{2}$ dois quatérnios de rotação e $\mathbf{r}$ um vetor representado por um quatérnio puro: 


$$
\begin{aligned}
& R_{q_{1}}(r)=q_{1} r q_{1}^{*} \\
& R_{q_{2}}(r)=q_{2} r q_{2}^{*}
\end{aligned}
$$

Desta forma, a composição das rotações corresponde a:

$$
R_{q_{2}}\left(R_{q_{1}}(r)\right)=R_{q_{2}}\left(q_{1} r q_{1}^{*}\right)=q_{2} q_{1} r q_{1}^{*} q_{2}^{*}
$$

Chamando-se:

$$
q_{3}=q_{2} q_{1}
$$

Resta, então, apenas mostrar que $q_{1}^{*} q_{2}^{*}$ corresponde ao conjugado de $q_{3}$.

Para tanto, é empregada uma propriedade facilmente demonstrável, segundo a qual, o conjugado do produto de dois quatérnios corresponde ao produto de cada um dos quatérnios conjugados na ordem inversa, ou seja:

$$
q_{3}^{*}=\left(q_{2} q_{1}\right)^{*}=q_{1}^{*} q_{2}^{*}
$$

Este resultado mostra que:

$$
R_{q_{2}}\left(R_{q_{1}}(r)\right)=q_{3} r q_{3}^{*}
$$

E, portanto, confirma a regra de composição de rotações por meio da multiplicação de quatérnios.

No caso de se empregar os quatérnios para descrever a rotação de um corpo no espaço, a principal dificuldade reside em conhecer instantaneamente o eixo de rotação do corpo.

Tendo em vista essa dificuldade, é conveniente descrever a mudança de atitude como uma sucessão de giros em torno de eixos conhecidos. Essa idéia é a mesma descrita anteriormente, quando se discutiu a construção da matriz de rotação. 
Além disso, lembrando-se da discussão anteriormente conduzida acerca das inúmeras sequências de rotações possíveis no espaço, deste ponto em diante será empregada a sequência $(1,2,3)$ ou $(x, y, z)$.

Em lugar de empregar as matrizes de rotação, o que se faz a seguir é a "operacionalização" dos ângulos de Euler por meio dos quatérnios.

\subsubsection{Rotações Infinitesimais com Quatérnios}

Assim como realizado para as matrizes de rotação, é conveniente verificar o comportamento do quatérnio como operador no caso em que as rotações são diminutas.

Um quatérnio de rotação promove a rotação em torno de um determinado eixo. Sendo assim, verificar a correspondência entre sequências de rotação demanda que sejam realizadas ao menos duas rotações consecutivas. O encadeamento de rotações por meio de quatérnios é feito pelas simples multiplicações dos quatérnios de rotação individuais. Verificando-se a comutatividade dessa operação de multiplicação, para o caso de pequenas rotações, é possível afirmar que a ordem com a qual as rotações são executadas não é importante.

Recorrendo à nomenclatura utilizada no item 4.1, sejam $p$ e q quatérnios de rotação cujas representações são dadas a seguir:

$$
\begin{aligned}
& p=\left(p_{0}, p_{1}, p_{2}, p_{3}\right) \\
& q=\left(q_{0}, q_{1}, q_{2}, q_{3}\right)
\end{aligned}
$$

Aplicando em (149) e (150) a correspondência apresentada na equação (136), obtêm-se (151) e (152).

$$
\begin{aligned}
& p=\left(\cos \left(\theta_{p}\right), \mathrm{p}_{1} \sin \left(\theta_{p}\right), \mathrm{p}_{2} \sin \left(\theta_{p}\right), \mathrm{p}_{3} \sin \left(\theta_{p}\right)\right) \\
& q=\left(\cos \left(\theta_{q}\right), \mathrm{q}_{1} \sin \left(\theta_{q}\right), \mathrm{q}_{2} \sin \left(\theta_{q}\right), \mathrm{q}_{3} \sin \left(\theta_{q}\right)\right)
\end{aligned}
$$

Sendo $\mathrm{p}_{1}, \mathrm{p}_{2}, \mathrm{p}_{3}$ e $\mathrm{q}_{1}, \mathrm{q}_{2}, \mathrm{q}_{3}$ as componentes dos vetores em torno dos quais a rotação é realizada e $\theta_{p}$ e $\theta_{q}$ os dobros das magnitudes destas rotações.

Substituindo as componentes dos quatérnios p e q na equação (34) é possível construir o quatérnio correspondente ao produto $p q$ e $q p$. 
$p q$

$=\left[\begin{array}{l}\cos \left(\theta_{p}\right) \cos \left(\theta_{q}\right)-\mathrm{p}_{1} \sin \left(\theta_{p}\right) \mathrm{q}_{1} \sin \left(\theta_{q}\right)-\mathrm{p}_{2} \sin \left(\theta_{p}\right) \mathrm{q}_{2} \sin \left(\theta_{q}\right)-\mathrm{p}_{3} \sin \left(\theta_{p}\right) \mathrm{q}_{3} \operatorname{si} \\ \mathrm{p}_{1} \sin \left(\theta_{p}\right) \cos \left(\theta_{q}\right)+\cos \left(\theta_{p}\right) \mathrm{q}_{1} \sin \left(\theta_{q}\right)-\mathrm{p}_{3} \sin \left(\theta_{p}\right) \mathrm{q}_{2} \sin \left(\theta_{q}\right)+\mathrm{p}_{2} \sin \left(\theta_{p}\right) \mathrm{q}_{3} \operatorname{si} \\ \mathrm{p}_{1} \sin \left(\theta_{p}\right) \cos \left(\theta_{q}\right)+\mathrm{p}_{3} \sin \left(\theta_{p}\right) \mathrm{q}_{1} \sin \left(\theta_{q}\right)+\cos \left(\theta_{p}\right) \mathrm{q}_{2} \sin \left(\theta_{q}\right)-\mathrm{p}_{1} \sin \left(\theta_{p}\right) \mathrm{q}_{3} \operatorname{si} \\ \mathrm{p}_{3} \sin \left(\theta_{p}\right) \cos \left(\theta_{q}\right)-\mathrm{p}_{2} \sin \left(\theta_{p}\right) \mathrm{q}_{1} \sin \left(\theta_{q}\right)+\mathrm{p}_{1} \sin \left(\theta_{p}\right) \mathrm{q}_{2} \sin \left(\theta_{q}\right)+\cos \left(\theta_{p}\right) \mathrm{q}_{3} \operatorname{si}\end{array}\right.$

$q p$

$$
=\left[\begin{array}{l}
\cos \left(\theta_{p}\right) \cos \left(\theta_{q}\right)-\mathrm{p}_{1} \sin \left(\theta_{p}\right) \mathrm{q}_{1} \sin \left(\theta_{q}\right)-\mathrm{p}_{2} \sin \left(\theta_{p}\right) \mathrm{q}_{2} \sin \left(\theta_{q}\right)-\mathrm{p}_{3} \sin \left(\theta_{p}\right) \mathrm{q}_{3} \mathrm{si} \\
\cos \left(\theta_{p}\right) \mathrm{q}_{1} \sin \left(\theta_{q}\right)+\mathrm{p}_{1} \sin \left(\theta_{p}\right) \cos \left(\theta_{q}\right)-\mathrm{p}_{2} \sin \left(\theta_{p}\right) \mathrm{q}_{3} \sin \left(\theta_{q}\right)+\mathrm{p}_{3} \sin \left(\theta_{p}\right) \mathrm{q}_{2} \mathrm{~s} \\
\cos \left(\theta_{p}\right) \mathrm{q}_{2} \sin \left(\theta_{q}\right)+\mathrm{p}_{1} \sin \left(\theta_{p}\right) \mathrm{q}_{3} \sin \left(\theta_{q}\right)+\mathrm{p}_{2} \sin \left(\theta_{p}\right) \cos \left(\theta_{q}\right)-\mathrm{p}_{3} \sin \left(\theta_{p}\right) \mathrm{q}_{1} \mathrm{~s} \\
\cos \left(\theta_{p}\right) \mathrm{q}_{3} \sin \left(\theta_{q}\right)-\mathrm{p}_{1} \sin \left(\theta_{p}\right) \mathrm{q}_{2} \sin \left(\theta_{q}\right)+\mathrm{p}_{2} \sin \left(\theta_{p}\right) \mathrm{q}_{1} \sin \left(\theta_{q}\right)+\mathrm{p}_{3} \sin \left(\theta_{p}\right) \mathrm{c}
\end{array}\right.
$$

Para que valha a comutatividade, a expressão (155) deve ser verdadeira.

$$
p q-q p=0
$$

Ou seja,

$$
\left[\begin{array}{c}
0 \\
-2 \mathrm{p}_{3} \sin \left(\theta_{p}\right) \mathrm{q}_{2} \sin \left(\theta_{q}\right)+2 \mathrm{p}_{2} \sin \left(\theta_{p}\right) \mathrm{q}_{3} \sin \left(\theta_{q}\right) \\
2 \mathrm{p}_{3} \sin \left(\theta_{p}\right) \mathrm{q}_{1} \sin \left(\theta_{q}\right)-2 \mathrm{p}_{1} \sin \left(\theta_{p}\right) \mathrm{q}_{3} \sin \left(\theta_{q}\right) \\
-2 \mathrm{p}_{2} \sin \left(\theta_{p}\right) \mathrm{q}_{1} \sin \left(\theta_{q}\right)+2 \mathrm{p}_{1} \sin \left(\theta_{p}\right) \mathrm{q}_{2} \sin \left(\theta_{q}\right)
\end{array}\right]=\left[\begin{array}{l}
0 \\
0 \\
0 \\
0
\end{array}\right]
$$

Linearizando o lado esquerdo da expressão (156) em torno de zero - supondo $\theta_{p} \rightarrow 0$ e $\theta_{q} \rightarrow 0$ - percebe-se que seus três últimos termos tendem rapidamente a zero, pois são de ordem superior. Isso torna a expressão verdadeira e confirma a hipótese de comutatividade na multiplicação de quatérnios de pequenas rotações.

\subsection{Dinâmica, Noções Preliminares}

Neste tópico serão apresentados conceitos e definições ligadas à dinâmica dos corpos. Este conteúdo subsidiará os estudos acerca dos sensores inerciais e as grandezas por eles medidas. No âmbito da cinemática, os sistemas de referência dividem-se em fixos e móveis. Os do segundo tipo são empregados no tratamento de problemas envolvendo composição de 
movimento. Um referencial móvel é, simplesmente, aquele que apresenta movimento com relação a um referencial fixo.

Sendo puramente matemática, a cinemática permite que se estabeleçam arbitrariamente os referenciais fixos.

Por outro lado, no estudo da dinâmica, a escolha do referencial é fundamental para a eficiência dos modelos matemáticos em descrever precisamente as forças causadoras do movimento. A seguir será apresentada uma breve discussão sobre os cuidados na escolha dos referenciais, segundo descrições pertinentes à Dinâmica.

O presente tópico foi desenvolvido tendo como referência os autores (GIACAGLIA, 1982) e (SOMMERFELD, 1970). Como complemento a esse último autor foram utilizados trechos provenientes da primeira tradução para o inglês do primeiro volume Princípios Matemáticos da Filosofia Natural de Newton, realizada por Andrew Motta e publicada em 1729.

\subsubsection{Sistema de Referência na Dinâmica}

The same is true for the concept of force as for all other physical concepts and names: word definition have very little meaning; physically significant definition are obtained as soon as we prescribe a way of measuring the quantity in question. (SOMMERFELD, 1970)

Tal afirmação ressalta a necessidade, no campo da Física, de se quantificar as grandezas naturais. Entretanto, qualquer quantificação requer uma escala como base de comparação. $\mathrm{O}$ movimento de uma partícula no espaço pode ser descrito por três coordenadas espaciais ${ }^{7}$ $x, y, z$, e uma medida de tempo $t$. Tais medidas são, necessariamente, tomadas a partir de um referencial. Sob a ótica da primeira lei de Newton, "Todo corpo persevera em seu estado de repouso, ou de movimento uniforme em uma linha reta, a menos que seja compelido a mudar este estado por forças impressas nele."

Uma base é adequada como referencial quando se encontra fixa a um ponto material que, por sua vez, está em seu estado natural de movimento ${ }^{8}$. No entanto, verificar tais características requer um referencial absoluto.

\footnotetext{
${ }^{7}$ Cada uma delas tomada segundo direções não paralelas.

${ }^{8}$ Nota-se que os estados de repouso ou de movimento uniforme (retilíneo) são tratados indistintamente e são considerados estados naturais do corpo.
} 
Tempo Absoluto, Verdadeiro e Matemático, de si mesmo e de sua natureza, flui igualmente sem influência de nada externo e é chamado, por outro nome, de Duração9. [...] Espaço Absoluto, em sua própria natureza, permanece sempre similar e imóvel ininfluenciável por nada externo. (op.cit, tradução livre deste autor)

O referencial ideal seria aquele solidário ao espaço absoluto, em que se mede o tempo com relação ao tempo absoluto, segundo a definição proposta por Newton para tal, e do qual poderia se definir o estado de movimento de qualquer outro sistema de referência.

Sommerfeld aponta, ainda, a incapacidade de Newton em distinguir tal espaço absoluto de um que se mova retilineamente e de forma uniforme com relação ao primeiro. Esta incapacidade é intrínseca às transformações de Galileu que, por sua vez, sustentam o chamado princípio da relatividade da mecânica clássica.

Embora hoje sejam conhecidos o princípio da relatividade especial e geral, no contexto da presente pesquisa, as transformações de Galileu são válidas e aplicáveis.

Uma vez aceita e compreendida a equivalência entre dois referenciais, se diferirem apenas por um movimento uniforme de translação, resta identificar um referencial inercial adequado.

Na prática, "[...] uma base de referência é ideal quando sustenta suficientemente bem a lei da inércia de Galileu ${ }^{10}$ para um corpo suficientemente livre de forças." (SOMMERFELD, 1970), tradução livre deste autor.

Estrelas e constelações distantes fornecem indicações suficientemente constantes para eixos coordenados empregados na descrição de fenômenos mecânicos na Terra e próximos dela. Da mesma forma, o dia sideral ${ }^{11}$ é suficientemente regular para ser utilizado como referência de tempo.

Sendo assim, um sistema de referência cuja origem coincide com o centro do Sol, e cujas direções principais apontam para estrelas distantes, é adequado para a compreensão da dinâmica na Terra. Esta, por outro lado, não constitui um referencial inercial, pois se move sobre uma trajetória elíptica em torno do Sol.

Antes de prosseguir com o raciocínio, e tendo verificado as características de um referencial fixo sobre a superfície da Terra, cabe apresentar a base da dinâmica proposta por Newton.

\footnotetext{
${ }^{9}$ Imediatamente antes deste trecho, em seu trabalho, Newton explica que distinguirá Absoluto de Relativo, Verdadeiro de Aparente e Matemático de Comum.

${ }^{10}$ Costuma-se também chamá-la de Lei da Inércia de Galileu no lugar de primeira lei de Newton.

${ }^{11}$ É o tempo que a Terra leva para dar uma volta exata em torno do seu eixo.
} 


\subsubsection{Segunda Lei de Newton}

Também chamada Lei Fundamental da Dinâmica, a lei que intitula este item permitiu agregar a origem dos movimentos ao estudo da cinemática. Na tradução feita por Andrew Motte do Principia de Newton, tal lei é apresentada da seguinte forma:

“A alteração do movimento é sempre proporcional à força motriz impressa; e se dá na direção da linha reta na qual esta força é impressa."

Por "alteração do movimento", Newton referiu-se à modificação temporal da grandeza quantidade de movimento ou momentum, previamente definida em seu documento. Denominando esta última grandeza de q, a segunda lei é escrita segundo a equação (157).

$$
\dot{\mathbf{q}}=\mathbf{F}
$$

No caso particular em que a massa do corpo mantém-se constante, a lei assume sua forma amplamente conhecida:

$$
m \dot{\mathbf{v}}=\mathbf{F}
$$

Nesta forma, a lei costuma ser chamada de "Lei da Aceleração de Newton". Tal lei estende-se ao caso análogo para o movimento de rotação, relacionando, então, quantidade de movimento angular com a resultante dos torques aplicados.

Atendo-se apenas ao primeiro membro da equação (158), nota-se a necessidade de se definir previamente um referencial no qual a aceleração é medida. A relação observada por Newton corresponde à realidade natural no caso em que o referencial escolhido seja um referencial inercial, discutido no item anterior.

Somerfeld (1970), no que se refere ao lado direito da equação (158), preocupa-se em descrever a grandeza força.

[...] temos , ao menos, uma ideia qualitativa de "força" que adquirimos de forma bem direta por meio da experiência quando usamos nossos músculos. Adicionalmente, a Terra nos proveu com o padrão de comparação gravidade, com a qual podemos medir todas as outras forças quantitativamente. (SOMMERFELD, 1970) tradução livre deste autor 
Seguindo em seu texto, o autor apresenta formas de quantificar a força por meio de massas conhecidas e uma "balança de tentativa". Ainda que conceitual, este método de medição de forças permite atribuir significado físico a esta grandeza como indica a citação de Sommerfeld apresentada no item anterior.

Sendo assim, força, enquanto grandeza física perceptível e mensurável, afeta o estado de movimento do corpo segundo a equação (158), caso a observação seja realizada a partir de um referencial inercial.

\subsubsection{Sistemas de Referência na Superfície da Terra}

Mostrou-se, a partir das definições de Newton, que a Terra não é um referencial inercial, pois se move segundo uma trajetória elíptica em torno do Sol. Um referencial fixo à superfície da Terra apresenta, ainda, movimento de rotação com relação ao eixo norte-sul do planeta, sendo, por isso, não inercial. No entanto, sobre a superfície da Terra se encontra grande parte dos sistemas dinâmicos cuja descrição interessa ao homem, dentre eles, o problema de queda livre descrito nesta pesquisa.

Assim, faz-se necessário compreender os efeitos de se considerar como sistema de referência uma base fixa à superfície do nosso planeta. Para tanto, deve-se retornar à cinemática, onde há apenas referenciais fixos e móveis. As fórmulas cinemáticas da composição de movimentos são apresentadas a seguir:

$$
\begin{gathered}
\vec{v}=\overrightarrow{v_{a}}+\overrightarrow{v_{r}} \\
\vec{a}=\overrightarrow{a_{a}}+\overrightarrow{a_{r}}+\overrightarrow{a_{c}}
\end{gathered}
$$

Na expressão (159), a velocidade absoluta de um ponto corresponde à soma vetorial da velocidade de arrastamento $\overrightarrow{v_{a}}$ - velocidade com a qual o referencial móvel se desloca com relação ao referencial fixo - e a velocidade relativa $\overrightarrow{v_{r}}$ - velocidade do ponto com relação ao referencial móvel.

As letras subscritas presentes na expressão (160) são análogas às empregadas na expressão (159) sendo, assim, necessário apenas definir $\overrightarrow{a_{c}}$. Esta parcela é chamada aceleração complementar ou aceleração de Coriolis. Tal aceleração surge do processo de derivação da expressão de composição de velocidades ${ }^{12}$.

\footnotetext{
${ }^{12}$ Demonstração presente em (FRANÇA e MATSUMURA, 2001) p.102 e 103.
} 
Foi mostrado anteriormente que, para a descrição de qualquer fenômeno na Terra e em seus arredores, é adequado considerar um sistema de referência cuja origem se encontra no centro do Sol e cujos versores apontem para estrelas distantes, como mostra a Figura 30. Por "adequado" compreende-se que, do ponto de vista deste referencial, a segunda lei de Newton se aplica da forma como é mostrada na equação (158). Este, então, será o referencial fixo a partir do qual será desenvolvida a composição de movimentos.

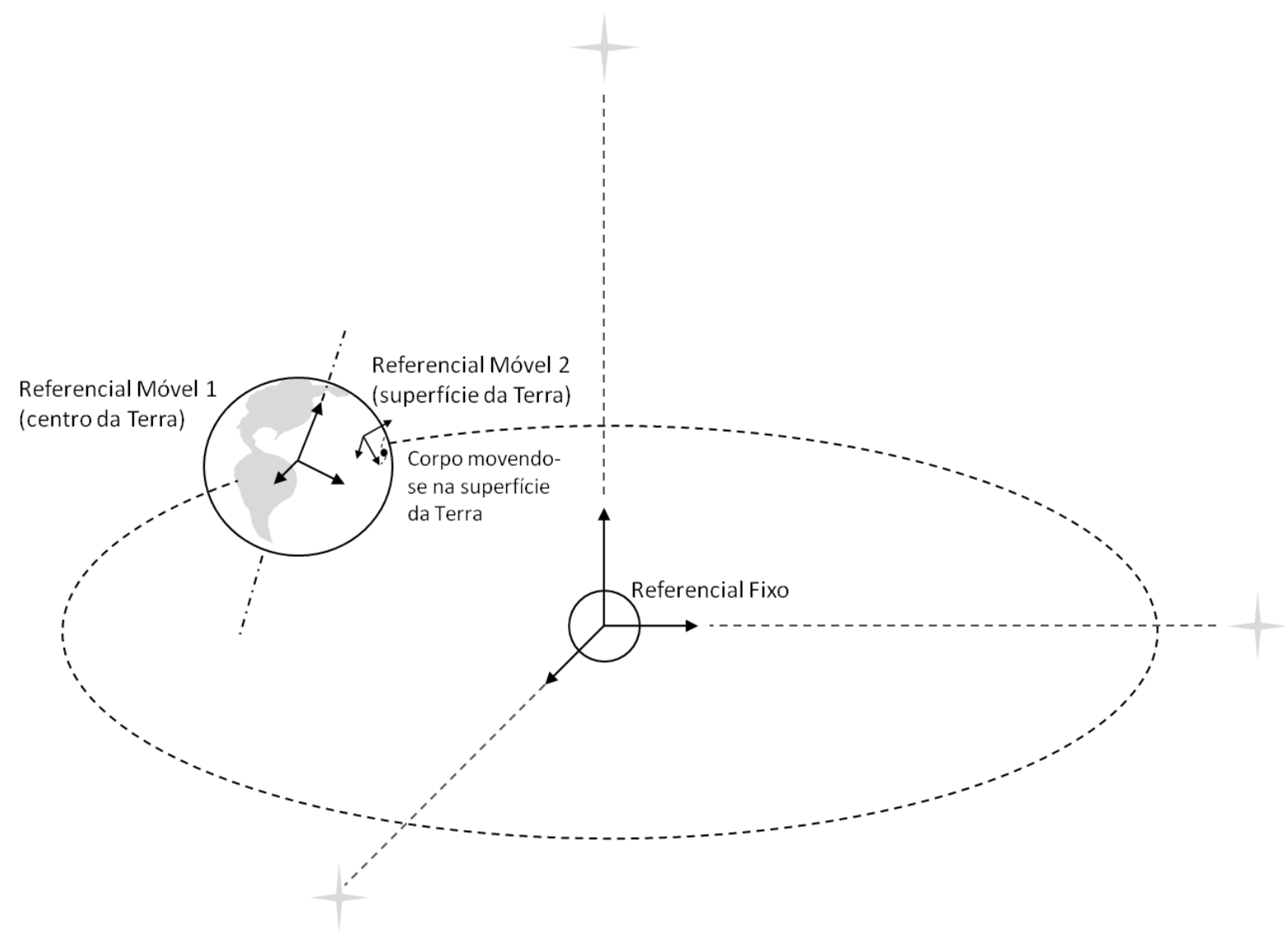

Figura 30 - Composição de referenciais partindo de um referêncial inercial no centro do Sol

É necessário, ainda, conhecer as características de um referencial na superfície da Terra. Trata-se, então, de um referencial que se move com relação ao centro do planeta e que, por sua vez, move-se com relação ao referencial fixos no centro do sistema solar. A Figura 30 ilustra a sequência de referenciais móveis. Segundo essa configuração, a equação de composição de acelerações (160) assume a seguinte forma:

$$
\vec{a}=\overrightarrow{a_{r}}+\left(\overrightarrow{a_{a t}}+\overrightarrow{a_{a r}}\right)+\left(\overrightarrow{a_{c t}}+\overrightarrow{a_{c r}}\right)
$$


A partir da equação (161) é possível verificar que a aceleração relativa - medida por um sensor na superfície da Terra - corresponderá à aceleração absoluta subtraída de alguns termos. O desenvolvimento subseqüente visa verificar a magnitude destes termos.

Embora a órbita da Terra possua formato elíptico, os focos desta figura encontram-se relativamente próximos, fazendo com que a trajetória possa ser aproximada por um círculo. Partindo desta hipótese, é possível calcular uma velocidade angular aproximada de:

$$
\Omega_{t} \cong \frac{2 \pi}{365 \text { dias }} \cong 2 \cdot 10^{-7} \mathrm{rad} / \mathrm{s}
$$

Sabendo ainda que a distância aproximada entre o Sol e o planeta Terra é de $1,49 \times 10^{11} \mathrm{~m}$, é possível estimar a aceleração centrípeta associada a esse movimento de translação por meio da equação abaixo.

$$
\overrightarrow{a_{a t}}=\Omega_{t}^{2} R_{o} \overrightarrow{n_{o}} \cong \overrightarrow{n_{o}}\left(5,9 \cdot 10^{-3}\right) \mathrm{m} / \mathrm{s}^{2}
$$

A aceleração estimada na equação (163) é um vetor que aponta para o centro da órbita terrestre, ou seja, para o Sol, seguindo a hipótese de órbita circular feita anteriormente.

O próximo passo na composição de movimentos é considerar a aceleração de um referencial fixo na superfície da Terra com relação ao seu centro. Novamente, é possível calcular de forma aproximada a velocidade angular da Terra em torno de seu eixo norte-sul por meio da expressão:

$$
\Omega_{r} \cong \frac{2 \pi}{1 \mathrm{dia}} \cong 7,3 \cdot 10^{-5} \mathrm{rad} / \mathrm{s}
$$

Sendo o raio da Terra aproximadamente $6378 \mathrm{~km}$, pode-se calcular a parcela de arrastamento em qualquer latitude. No caso particular em que o referencial encontra-se sobre a linha do equador, o valor da aceleração é dado por:

$$
\overrightarrow{a_{r}}=\Omega_{r}{ }^{2} R_{t} \overrightarrow{n_{t}} \cong \overrightarrow{n_{t}}\left(3,4 \cdot 10^{-2}\right) \mathrm{m} / \mathrm{s}^{2}
$$

O resultado da equação (165) apresenta o valor máximo assumido pela componente $\overrightarrow{a_{r}}$. Esta aceleração de arrastamento tende a diminuir conforme o referencial em questão é assumido mais próximo dos pólos do planeta. 
As componentes de aceleração complementar dizem respeito a movimentos com relação a referenciais que apresentam rotação. Neste caso, o movimento do referencial na superfície do planeta, com relação ao referencial fixo - absoluto - e o movimento de um ponto material na superfície com relação ao referencial móvel, também sobre a superfície do planeta.

$$
\begin{aligned}
& \overrightarrow{a_{c t}}=2 \overrightarrow{\Omega_{t}} \times\left(\Omega_{r} R_{t} \overrightarrow{n_{t}}\right) \\
& \left|\overrightarrow{a_{c t}}\right|=2 \Omega_{t} \Omega_{r} R_{t} \sin \alpha
\end{aligned}
$$

O valor máximo para o módulo da aceleração complementar $\overrightarrow{a_{c t}}$ ocorre quando $\sin \alpha=1 \rightarrow$ $\alpha=\frac{\pi}{2}$.

O ângulo $\alpha$ não é determinável de maneira simples, pois a direção do vetor da velocidade tangencial de um corpo na superfície da Terra varia ao longo da rotação, precessão e translação do planeta. Entretanto, para os fins deste tópico, basta conhecer aproximadamente sua ordem de grandeza e compreender se este ângulo atinge a situação em que a aceleração complementar estudada é máxima.

Caso a Terra transladasse com seu eixo de rotação perpendicular à eclíptica, os vetores velocidade tangencial estariam contidos em planos paralelos a esta e, por isso, sempre perpendiculares ao vetor velocidade de rotação de translação do planeta. Sabe-se, entretanto, que o eixo de rotação da Terra precessiona e, fazendo-o, possui certo ângulo de nutação. Este ângulo vale aproximadamente $23^{\circ}$ com relação ao eixo vertical - perpendicular ao plano da eclíptica.

De posse destas informações, pode-se, ao menos aproximadamente, determinar o valor de $\alpha$.

$$
90^{\circ}-23^{\circ} \leq \alpha \leq 90^{\circ}+23^{\circ}
$$

Então, retomando o cálculo do valor de $\left|\overrightarrow{a_{c t}}\right|$, na situação limite:

$$
\begin{gathered}
\left|\overrightarrow{a_{c t}}\right|=2 \Omega_{t} \Omega_{r} R_{t} 1 \\
\left|\overrightarrow{a_{c t}}\right|=2 \cdot 2 \cdot 10^{-7} \cdot 7,3 \cdot 10^{-5} \cdot 6,4 \cdot 10^{6} \cong 1,9 \cdot 10^{-4} \mathrm{~m} / \mathrm{s}^{2}
\end{gathered}
$$

A segunda aceleração complementar, apresentada na equação (161), corresponde à aceleração de Coriolis associada a um ponto material que se desloca sobre a superfície da Terra, com relação a um referencial fixo na superfície e que, por sua vez, rotaciona juntamente com o 
planeta. A expressão (170) quantifica esta aceleração e evidencia sua dependência com a velocidade do ponto material.

$$
\overrightarrow{a_{c r}}=2 \overrightarrow{\Omega_{r}} \times \overrightarrow{v_{r}}
$$

Assumindo, novamente, a situação limite para o produto vetorial, na qual os vetores são perpendiculares, a expressão que corresponde ao módulo desta aceleração se reduz a:

$$
\left|\overrightarrow{a_{c r}}\right| \cong 1,5 \cdot 10^{-4} \cdot\left|\overrightarrow{v_{r}}\right|
$$

Finalmente, agrupando todos os termos calculados para a aceleração do ponto material, nas situações em que seus valores são máximos, obtém-se a expressão (172):

$$
\vec{a}=\overrightarrow{a_{r}}+\left(5,9 \cdot 10^{-3}\right) \overrightarrow{n_{o}}+\left(3,4 \cdot 10^{-2}\right) \overrightarrow{n_{t}}+\left(1,9 \cdot 10^{-4}\right) \overrightarrow{n_{c t}}+\left(1,5 \cdot 10^{-4} \cdot\left|\overrightarrow{v_{r}}\right|\right) \overrightarrow{n_{c r}}
$$

Desta expressão, é possível constatar que a aceleração relativa, medida por um referencial fixo na superfície do planeta, corresponde à aceleração absoluta, a qual se relaciona diretamente com a segunda lei de Newton, a menos de certos termos, cujas ordens de grandeza são inferiores a $10^{-1} \mathrm{~m} / \mathrm{s}^{2}$. Essa afirmação depende, ainda, de que as velocidades de deslocamento do ponto material mantenham-se em níveis moderados.

Conclui-se, com isso, que um referencial fixo a superfície da Terra é adequado à descrição de movimentos e mantém a lei fundamental da Dinâmica até níveis de aceleração como os apresentados a cima. 


\subsection{NAVEGAÇÃo INERCIAL}

Navegação pode ser definida como o processo de dirigir o movimento de um veículo de um ponto a outro.

Embora essa definição envolva dirigir, o termo é comumente utilizado para designar o simples conhecimento da posição em relação a um referencial, bem como a direção e a magnitude da velocidade com que se caminha no espaço.

(AUSMAN, 1962) refere-se à navegação acrescida do controle como Guidance, reservando o termo Navigation para o ato de situar-se no espaço.

Assim, neste trabalho a palavra navegação não englobará o controle do veículo.

Ainda de acordo com (AUSMAN, 1962), existem quatro formas básicas para se realizar navegação:

- Métodos que dependem basicamente da observação e reconhecimento de pontos fixos, way points;

- Extensão do método 1, porém aplicando mapa. Os pontos fixos são identificados no mapa e associados a um sistema de referência (reference frame). Desta forma, buscase determinar a própria posição nesse sistema de referência;

- Observação de fenômenos naturais para definir a localização própria - observação de astros fixos, também conhecida como position fixing;

- Aquela onde a posição é calculada com base no conhecimento da posição inicial e velocidade (módulo e direção) ao longo do tempo, dead reckoning (cômputo exato, cálculo preciso).

De acordo com esta classificação, a denominada Navegação Inercial provêm, portanto, da quarta forma listada acima.

As operações de um sistema de navegação inercial dependem das leis da mecânica clássica formuladas por Newton. A segunda lei de Newton associa a resultante de forças atuantes em um corpo e a aceleração do mesmo, sendo tal relação proporcional a massa, assumida invariante no tempo.

Desta forma, conhecendo-se a aceleração, é possível calcular a mudança na velocidade e na posição do corpo por intermédio de sucessivas integrações com relação ao tempo. Neste caso, as acelerações são medidas por intermédio de sensores chamados acelerômetros. 
Normalmente, um sistema de navegação inercial conta com três desses aparelhos, cada um deles capaz de detectar acelerações ${ }^{13}$, preferencialmente em uma única direção. Desta maneira, os acelerômetros são montados habitualmente de forma que seus eixos sensíveis fiquem ortogonais entre si.

Para que seja possível a navegação com relação ao referencial, é necessário conhecer a direção para a qual os acelerômetros estão apontando.

Por outro lado, o movimento de rotação do corpo com relação ao referencial inercial pode ser detectado por sensores giroscópicos e essa informação utilizada para determinar a orientação dos acelerômetros a cada instante. Assim, é possível resolver as acelerações no sistema de referência, antes do processo de integração ser realizado.

Baseando-se em (AUSMAN, 1962), pode-se decompor uma UMI (Unidade de Medição Inercial) em três elementos operacionais básicos:

- Um vetor aceleração;

- Um referencial de atitude;

- E um computador.

O vetor aceleração é a leitura instantânea proveniente dos três acelerômetros montados ortogonalmente entre si.

A referência de atitude estabelece, ou mede, a orientação dos acelerômetros com relação ao sistema de referência externo, segundo o qual a navegação ocorre. Isso é necessário para que o vetor de aceleração instantânea possa ser integrado apropriadamente em velocidade e posição. Giroscópios são invariavelmente empregados como base dos dispositivos, nos mais variados arranjos possíveis.

O computador, por sua vez, é um elemento operacional que resolve as equações da aceleração, calculando a aceleração da gravidade, efetuando as integrações e fazendo transformações de coordenada, quando necessário.

Diferentemente de muitos outros tipos de sistemas de navegação, sistemas inerciais são completamente auto-suficientes, no sentido de que não dependem da transmissão de sinais do veículo ou recepção de fontes externas.

\footnotetext{
${ }^{13}$ A rigor, os acelerômetros são sensíveis a forças às quais são submetidos. As acelerações são obtidas indiretamente por meio da segunda lei de Newton e são dependentes do referencial - ver item 4.3.
} 
Contudo, sistemas de navegação inercial dependem da disponibilidade do conhecimento preciso da posição inicial. As medições inerciais são, então, usadas para obter estimativas das mudanças de posição que ocorrem em seguida.

Os sistemas de navegação inercial se dividem em dois grupos distintos: os sistemas montados sobre plataformas estabilizadoras e sistemas do tipo strapdown.

As plataformas estabilizadoras, como o próprio nome indica, são dispositivos que empregam giroscópios e suspensões para manter o conjunto de sensores alinhado à uma direção conhecida durante toda a navegação. Esse tipo de sistema, ilustrado na Figura 31, embora permita a integração direta do sinal dos sensores para que se conheça a posição do veículo, requerem complexos dispositivos elétricos e mecânicos para garantir sua orientação.

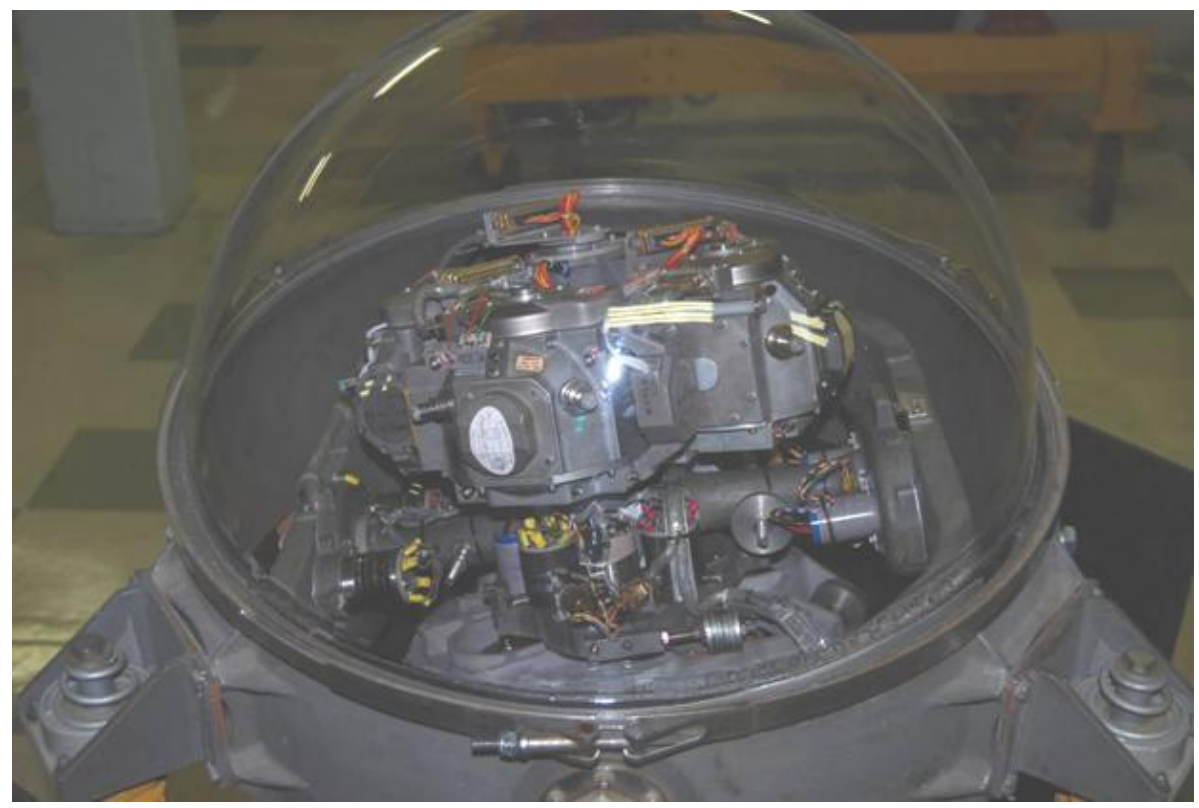

Figura 31 - Unidade de medição inercial que emprega base estabilizadora e sensores eletromecânicos (The Institute of Navigation) (CRRL)

São dispositivos proporcionalmente grandes, pesados e de custo elevado, atualmente empregados na navegação de grandes embarcações, aeronaves e veículos espaciais. Esse tipo de sistema é amplamente discutido em (AUSMAN, 1962).

O segundo tipo de sistema inercial citado é chamado strapdown, por ser fixo ao veículo durante a navegação. Neste caso, a atitude dos sensores muda juntamente com a direção do corpo que se está monitorando. Além disso, o tratamento computacional é mais complexo, tendo em vista a necessidade de se conhecer instantaneamente a direção dos eixos sensíveis dos sensores com relação a um referencial "fixo" de navegação e efetuar a transformação pertinente antes de cada passo da integração. Graças a esse fato, a tecnologia strapdown se 
desenvolveu juntamente com a tecnologia de processamento dos computadores. Embora mais recente, esta tecnologia tem se difundido rapidamente nas diversas áreas que aplicam sistemas inerciais como, por exemplo, as industrias bélica e de satélites.

Os sistemas strapdown tendem a ser mais compactos, leves e, somados à tecnologia de sensores MEMS (Micro-Electro-Mechanical Systems), podem ser extremamente baratos. A Figura 32 mostra uma unidade de medição inercial strapdown MEMS, destacando seu tamanho reduzido.

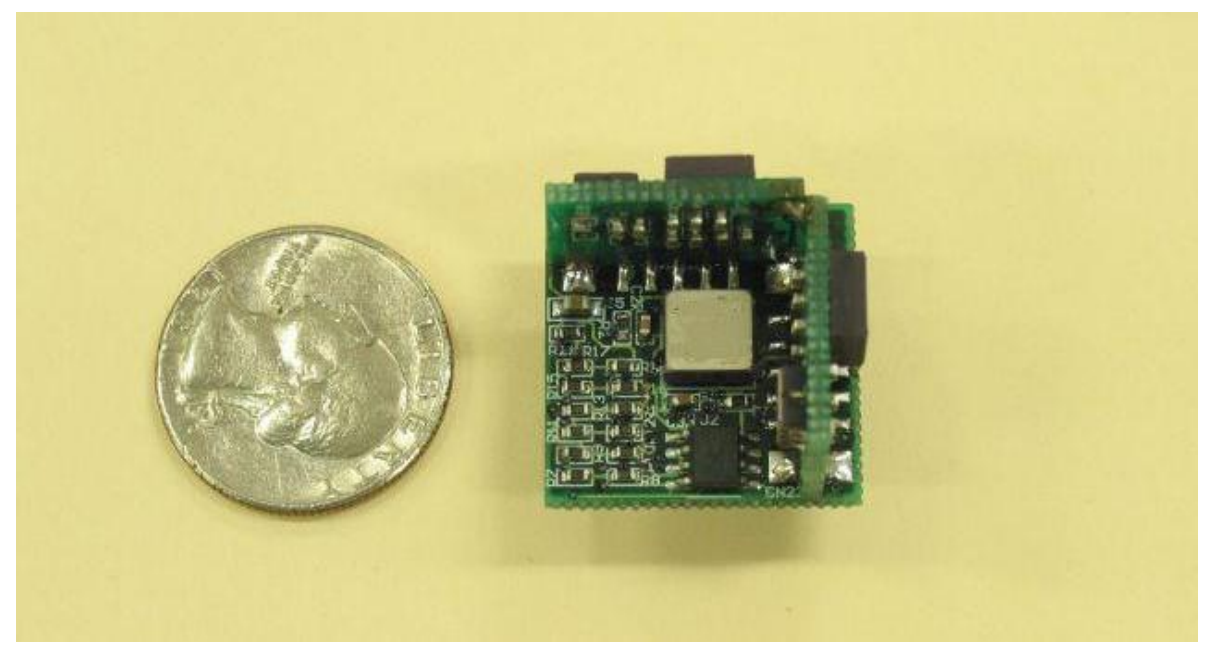

Figura 32 - Unidade de medição inercial que emprega tecnologia MEMS (CRRL)

\subsubsection{Sensores Inerciais}

Sensores são instrumentos capazes de traduzir a variação de uma determinada grandeza, medindo sua variação em uma escala definida. Um termômetro de mercúrio, por exemplo, detecta a variação da temperatura do ambiente por meio da expansão do líquido no seu interior. A expansão é quantificada por meio de uma escala impressa no corpo do termômetro e sobreposta à coluna de mercúrio.

Existem inúmeros tipos de sensores que se valem dos mais diversos fenômenos físicos para registrarem a variação da grandeza estudada, os quais empregam diferentes escalas para registrarem tais grandezas.

Neste trabalho os dois tipos de sensores estudados são o acelerômetro e o giroscópio. Ambos são chamados sensores inerciais, pois são sensíveis a mudanças nos seus estados de movimento. Acelerômetros medem a força a qual estão submetidos que, por sua vez, em um referencial adequado, relaciona-se diretamente com a aceleração. Os girômetros registram a 
velocidade angular em que o dispositivo se encontra. Ambos são dispositivos eletrônicos e, por isso, empregam uma faixa de tensões elétricas como escala de medida.

\subsubsection{Acelerômetros}

Nos sistemas de navegação, a medida da aceleração tem como finalidade determinar a velocidade e a posição do corpo.

A aceleração pode ser detectada pelo próprio corpo, enquanto a determinação direta da velocidade, ou posição, requer algum tipo de referencial externo. Na realidade, o corpo percebe as forças atuantes sobre ele e os acelerômetros, presos a este corpo, as sentem da mesma forma. Sendo assim, o acelerômetro é o dispositivo capaz de detectar a resultante das forças atuantes sobre uma pequena massa em seu interior.

Estando o corpo e os acelerômetros presos a ele em movimento com relação a um referencial inercial, é valida a segunda lei de Newton e a resultante medida pelos instrumentos tem correspondência direta com a aceleração do corpo. Em termos práticos, os referenciais para movimentos próximos à superfície da Terra encontram-se fixos ao planeta. Movimentos sobre a superfície da Terra estão sujeitos a forças artificiais decorrentes da característica não inercial dos referenciais fixos ao solo. Estas forças, entretanto, possuem magnitudes proporcionais a direção e velocidade dos movimentos e, como visto no item 4.3.3, são relativamente pequenas para veículos terrestre, marinhos ou objetos em queda livre. Desta forma, as medidas de força dos acelerômetros presos a corpos como estes correspondem à aceleração translacional e à aceleração da gravidade segundo a lei fundamental da dinâmica.

Neste texto os acelerômetros foram divididos em dois grupos principais, como fizeram (TITTERTON e WESTON, 2004): os mecânicos e os de estado sólido. Foi dada, ainda, especial ênfase aos acelerômetros do tipo MEMS sendo essa designação refere-se à tecnologia de fabricação, e não ao princípio de funcionamento (conforme já comentado). Desta forma, podem haver sensores mecânicos ou de estado sólido com tecnologia MEMS. A Figura 33 apresenta na forma de diagrama a divisão entre as tecnologias de acelerômetros discutidas. 


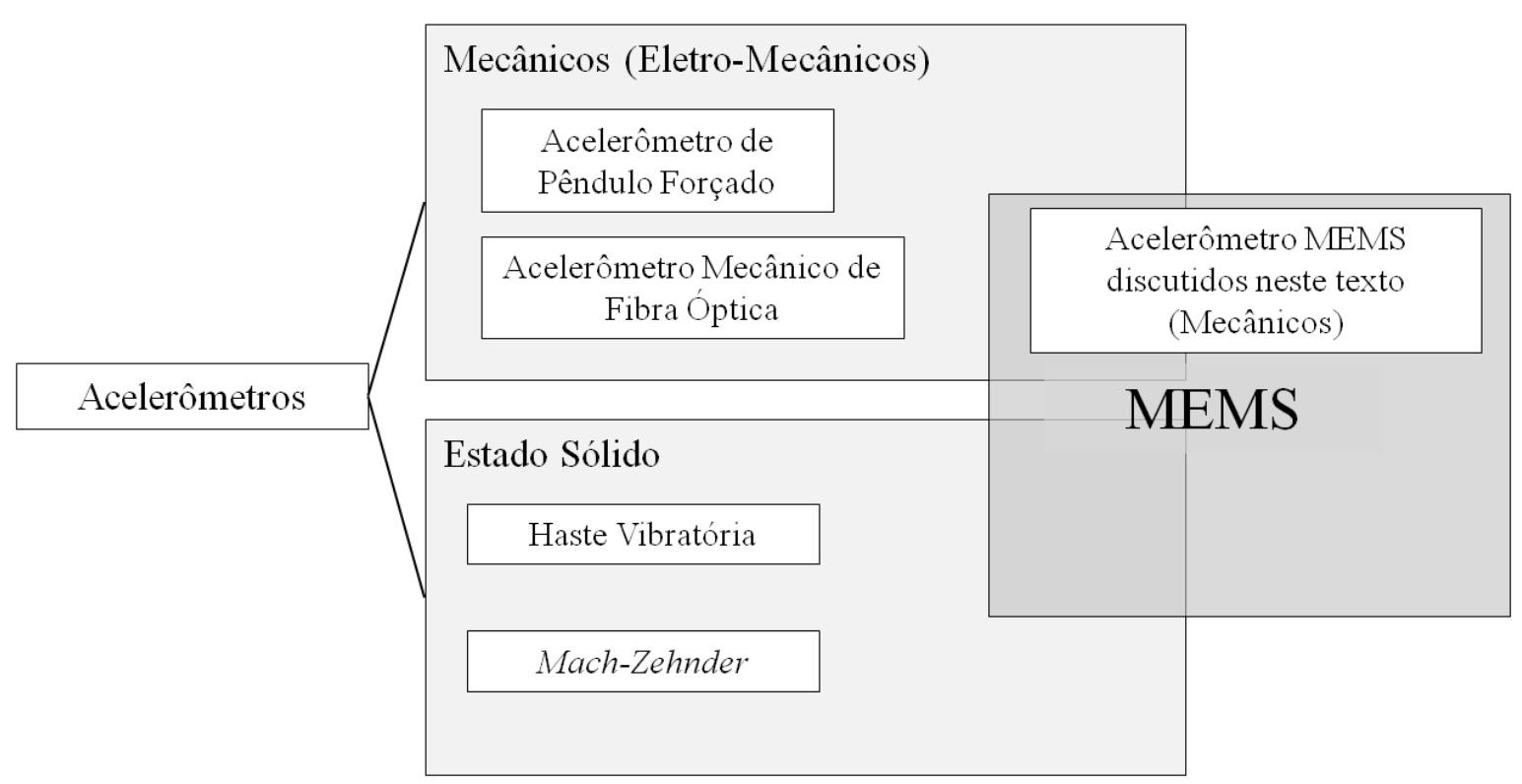

Figura 33 - Distinção entre as tecnologias de acelerômetros discutidas no presente trabalho

O diagrama apresenta apenas uma fração das tecnologias existentes, selecionadas dentre as mais comumente encontradas. Não faz parte do escopo desta pesquisa esgotar os tipos de sensores inerciais, nem tão pouco detalhar em profundidade seus funcionamentos.

\section{Acelerômetros Mecânicos}

Um acelerômetro mecânico é composto por três elementos básicos:

- Uma massa, normalmente chamada de "massa de prova";

- Uma suspensão, que posiciona a massa;

- E um transdutor (pickoff), que recebe o deslocamento ou análogo e converte em um sinal elétrico de saída.

Não é sempre obvio onde estão cada um dos elementos citados acima. Tomando como exemplo um bloco piezoelétrico, com duas faces sensíveis à diferença de potencial entre elas, a massa é o próprio bloco, a suspensão é a constante piezoelétrica do material e o pickoff é o próprio efeito piezoelétrico. Blocos piezoelétricos são usados para medir vibrações; em geral, eles não são sensíveis o suficiente para a maioria dos sistemas de navegação, (LAWRENCE, 1998).

Para os acelerômetros nos quais o deslocamento indica a aceleração, atribui-se a designação de acelerômetros em malha aberta, em inglês, open loop.

Um acelerômetro mecânico em malha aberta é fundamentalmente uma massa de prova, suspensa por molas presas a uma carcaça hermética, ver Figura 34. Ao conjunto é, então, 
adicionado um amortecedor para impedir que a massa oscile por longos períodos após a interrupção da aceleração do conjunto. De acordo com esta construção, quando esse tipo de sensor é acelerado, a mola se deflete e, juntamente com o amortecedor, produz a força necessária para transmitir aceleração à massa de prova.

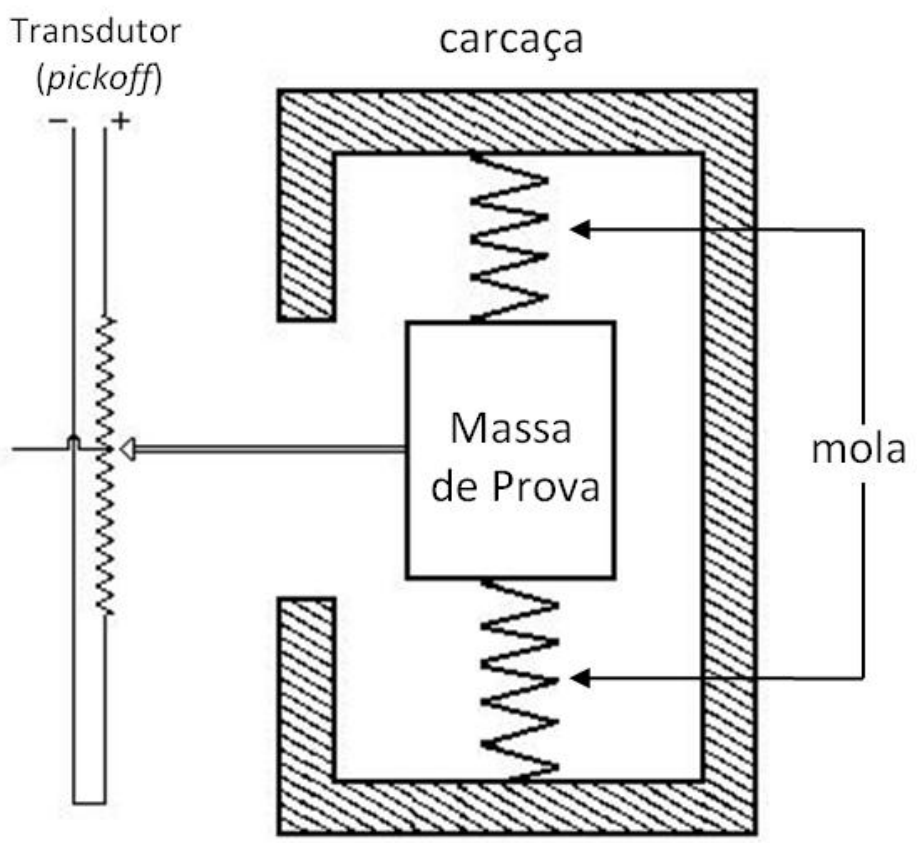

Figura 34 - Princípio de funcionamento de um acelerômetro mecânico em malha aberta

Por outro lado, no caso de sensores em malha fechada, evita-se o deslocamento da massa de prova, pois detectar pequenos desvios da posição nula é um processo muito mais preciso do que registrar a magnitude da deflexão da mola.

Sensores em malha fechada dependem do sistema de feedback para conterem o elemento sensível. Sendo assim, além dos itens constituintes básicos, descritos anteriormente, este tipo de sensor requer ainda:

- Uma forçante

- Um gerador de força elétrica ou magnética, projetados para se oporem à força inercial; No caso de sensores em malha fechada, a leitura de aceleração provém do próprio sistema de feedback, atuando na tentativa de manter a massa de referência próxima da posição nula posição em que o deslocamento da massa ou deflexão da haste também é nulo.

São inúmeras as configurações e os tipos de acelerômetros mecânicos, porém, todos seguem o mesmo princípio de funcionamento. A título de exemplo, a seguir serão detalhados dois tipos de acelerômetros mecânicos. 


\section{Acelerômetro de pêndulo forçado}

Esse tipo de acelerômetro em malha fechada é composto por um pêndulo fixo à carcaça por meio de uma articulação; uma massa de prova fixa a extremidade oposta do pêndulo; um transdutor capaz de detectar qualquer desvio da posição nula - estes últimos podendo ser elementos ópticos, indutivos ou capacitivos; elementos que exerçam força sobre a massa para mantê-la na mesma posição com relação a carcaça e a própria carcaça, normalmente preenchida com óleo de baixa viscosidade ou gás seco (Figura 35).

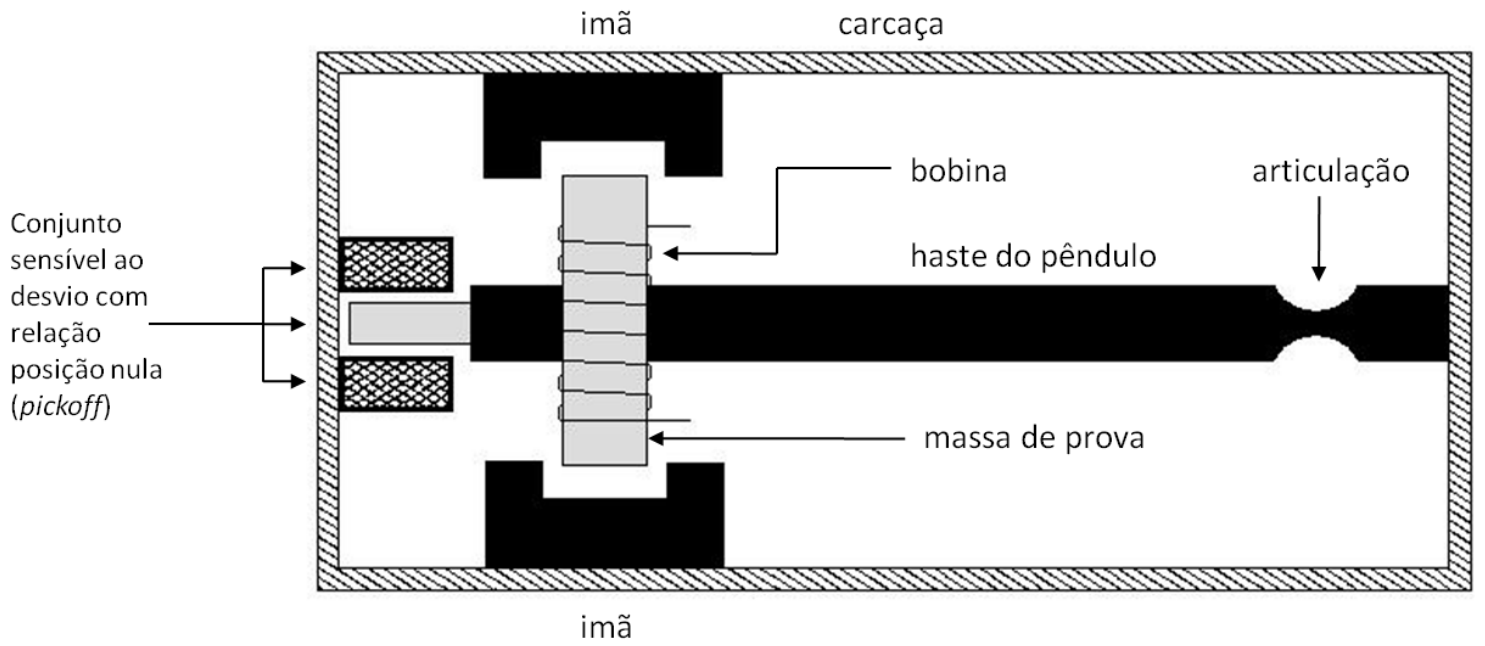

Figura 35 - princípio de funcionamento de um acelerômetro mecânico em malha fechada

Na configuração mostrada na Figura 35, o dispositivo na extremidade livre do pêndulo é um sensor capaz de medir a variação na capacitância entre as faces fixas à carcaça e as faces do pêndulo, indicando, por exemplo, que a haste se desviou da posição nula e a corrente passando pela bobina de restauração deve ser modificada. A leitura de aceleração, neste caso, é proporcional a corrente que passa pela bobina.

\section{Acelerômetro mecânico de fibra óptica}

Assim como o sensor descrito anteriormente, o acelerômetro de fibra óptica também emprega um pêndulo com uma massa de prova presa em uma de suas extremidades. No entanto, neste caso, a haste do pêndulo é um filamento de fibra óptica que transporta um feixe de laser de 
um emissor fixo à carcaça até uma pequena lente na extremidade oposta, onde se encontra a massa. A lente colima o feixe que é projetado sobre uma malha de sensores foto sensíveis.

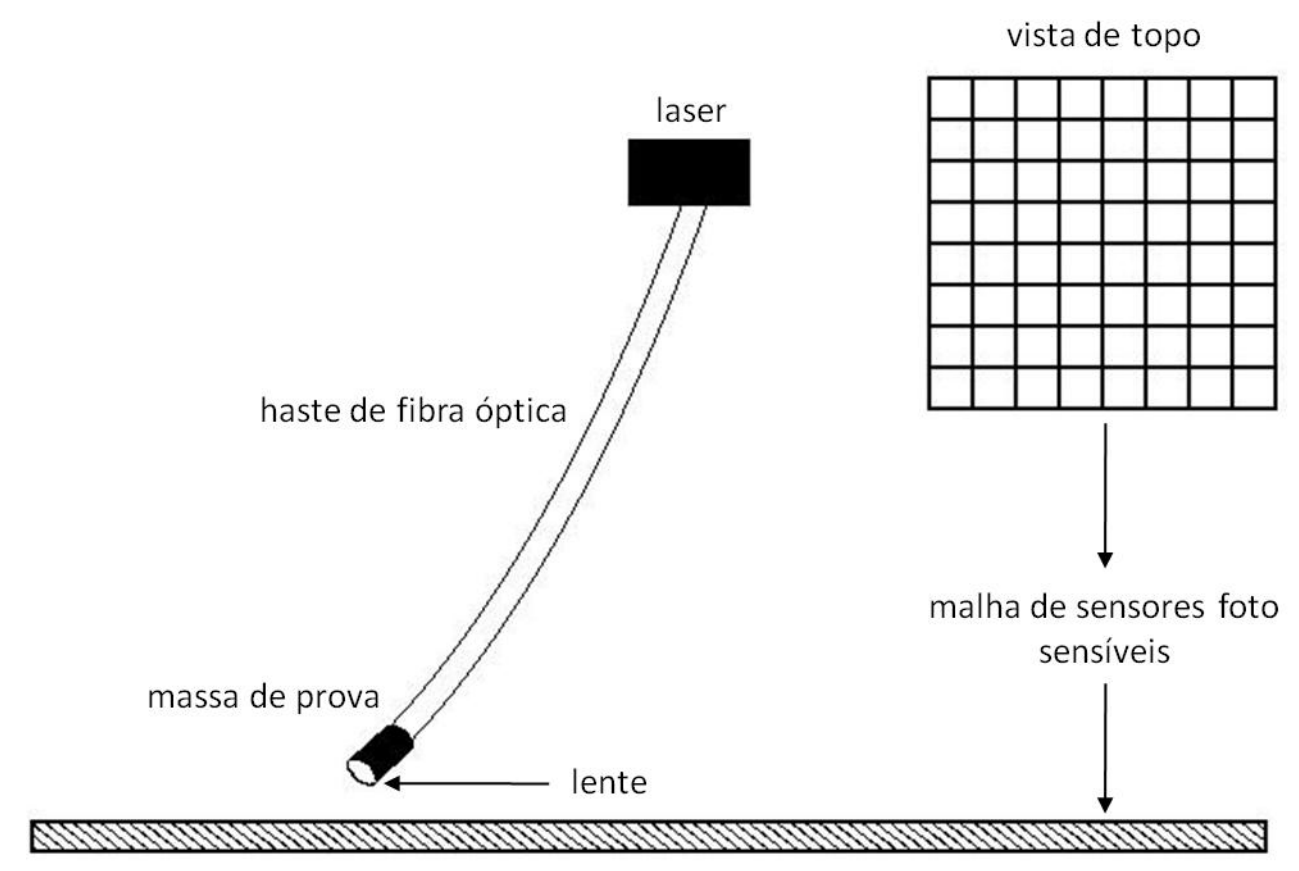

Figura 36 - Princípio de funcionamento de um acelerômetro mecânico de fibra óptica com dois graus de liberdade

Empregar a fibra óptica como haste tem produzido excelentes resultados, pois este material possui boa resistência estrutural e elevado módulo de elasticidade, além de ser pouco sensível a mudanças de temperatura (TITTERTON e WESTON, 2004).

A configuração apresentada esquematicamente na Figura 36 permite medição de acelerações em qualquer direção do plano que contém a malha de sensores.

\section{Acelerômetros de estado sólido}

São acelerômetros que empregam tecnologias recentes, principalmente no campo da engenharia de materiais.

Neste campo são amplamente empregados materiais piezoelétricos.

Sensores de estado sólido tendem a ser compactos, robustos e apresentam boa confiabilidade. São inúmeras as configurações possíveis como será mostrado a seguir. 


\section{$\underline{\text { Haste vibratória }}$}

A configuração típica de um acelerômetro desta natureza emprega duas hastes de material piezoelétrico - habitualmente fabricadas em quartzo - acopladas a massas de prova.

As hastes, quando estimuladas por uma corrente elétrica, vibram na freqüência natural do material com o qual foram fabricadas. Ao sofrer aceleração, o conjunto transmite essa aceleração às massas de prova, que comprimem ou tracionam as hastes vibratórias. Estas, por sua vez, sob tração, passam a vibrar em uma frequiência distinta. A diferença na frequência de vibração é registrada e é proporcional a aceleração do sensor.

Os acelerômetros de haste vibratória, como o mostrado na Figura 37, são sensores em malha aberta.

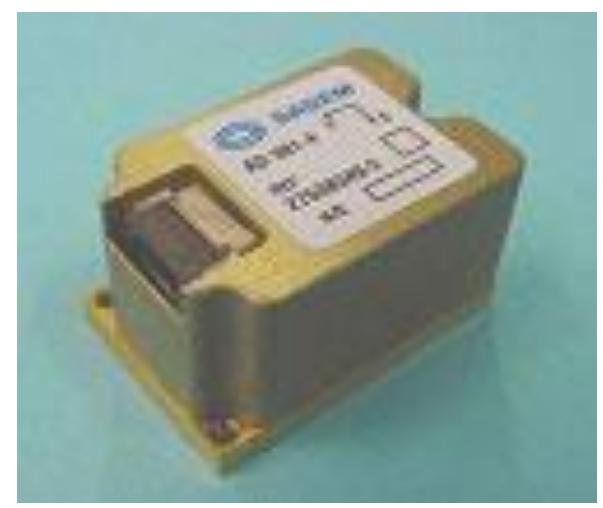

Figura 37 - Acelerômetro de haste vibratória (Safran Sagem)

A presença de duas hastes torna o sistema simétrico e favorece a anulação de inúmeras resultantes indesejáveis. Esse fato será mais bem discutido adiante neste capítulo.

\section{Acelerômetros de fibra óptica}

Assim como o acelerômetro de fibra óptica descrito anteriormente, este, também enquadrado como acelerômetro de estado sólido, emprega tal material como meio de leitura do sinal de saída. A diferença esta no uso mais amplo das propriedades do material e do emprego de métodos interferométricos para o registro das grandezas.

Interferômetros são dispositivos capazes de medir deslocamentos de magnitude muito pequena e com grande precisão. O fazem medindo as diminutas diferenças de fase entre feixes de luz - ondas eletromagnéticas - que percorrem caminhos distintos, ampliados graças ao fenômeno de batimento. Mais detalhes sobre montagens possíveis para um interferômetro, 
assim como inúmeras outras técnicas ópticas aplicadas à metrologia podem ser encontradas em (GASVIK, 2002).

Um exemplo de acelerômetro que emprega esta tecnologia é o chamado acelerômetro interferométrico de Mach-Zehnder. Nesse tipo de dispositivo, uma massa de prova presa a um ou dois filamentos de fibra ótica traciona ou comprime tais filamentos, consequentemente, modificando as distâncias percorridas pela luz. Essa mudança no caminho óptico provoca a diferença de fase passível de leitura por um interferômetro. A Figura 38 apresenta de forma esquemática a montagem de um acelerômetro de Mach-Zehnder que emprega duas fibras ópticas.

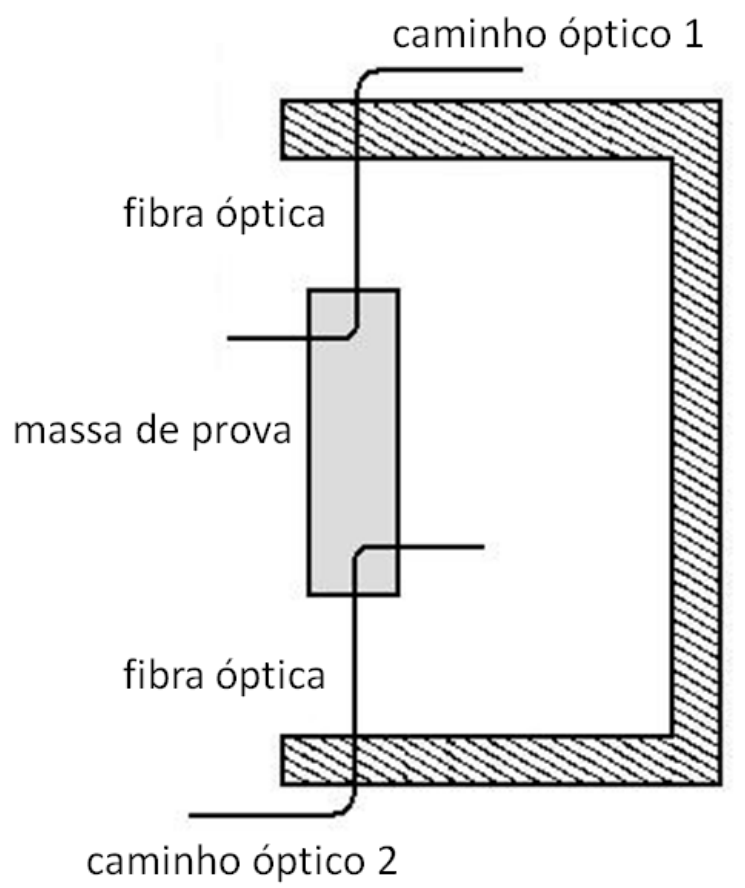

Figura 38 - Princípio de funcionamento de um acelerômetro do tipo Mach-Zehnder

\subsubsection{Giroscópios}

Giroscópios são sensores projetados para medir a variação da atitude de um corpo com relação a um referencial fixo ou registrar a velocidade angular deste corpo. Giroscópios tradicionalmente utilizam as propriedades inerciais de um rotor girando em alta velocidade. Tal rotor possui momento angular proporcional à velocidade angular em que se encontra e a sua distribuição polar de massa - momento de inércia polar.

O momento angular é uma grandeza vetorial e, por isso, é caracterizada por uma magnitude, uma direção e um sentido. Qualquer modificação do momento angular de um corpo requer a 
ação de um torque externo. Sendo assim, na ausência de torque, o rotor tende a permanecer alinhado ao eixo de rotação original.

O giroscópio é, em linhas gerais, um rotor girando em grande velocidade, suportado por um conjunto de suspensões Cardan, também chamadas de gimbals, livres para girar umas com relação às outras. A mais externa dessas suspensões é fixa à carcaça do sensor, configuração com a qual se busca não transmitir torque ao rotor interno, embora esse objetivo seja, em parte, uma idealização.

O conjunto de gimbals externos ao rotor move-se solidário ao corpo no qual o giroscópio esta instalado, enquanto o rotor mantém sua direção original servindo, assim, como referencial para o registro dos deslocamentos angulares.

Atualmente, uma série de outras tecnologias tem sido empregada para medir velocidades angulares, como por exemplo: girômetros de fibra óptica, que se valem dos princípios interferométricos descritos anteriormente. Tais sensores são também chamados de giroscópios, mesmo não se valendo das propriedades dinâmicas de um corpo em rotação.

Assim como no item 4.4.2, a seguir é apresentado um diagrama ilustrando a distinção de tecnologias de girômetros e giroscópios, discutidas nos próximos itens.

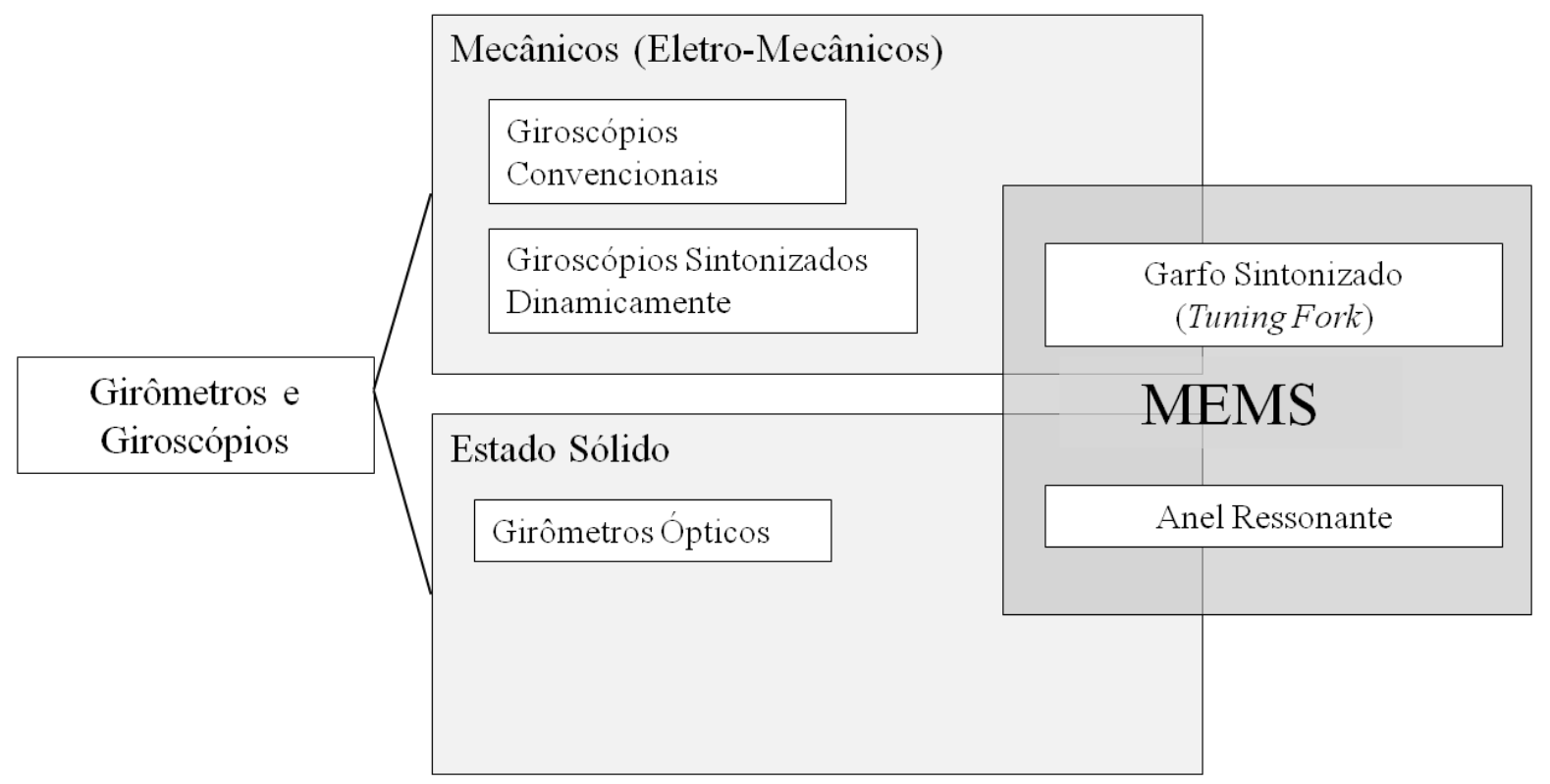

Figura 39 - Distinção entre as tecnologias de girômetros discutidas no presente trabalho

Novamente, cabe advertir o leitor de que se trata apenas de um pequeno recorte das tecnologias existentes e as discussões subsequentes restringem-se aos princípios de funcionamento dos sensores. 


\section{Configurações tradicionais}

O princípio de funcionamento de um giroscópio tradicional foi descrito na introdução deste tópico.

Como mencionado, a conservação do momento angular do rotor é a propriedade garantidora da direção de referência do sensor. Desta forma, é desejável que o momento angular seja elevado e, para tanto, os projetistas procuram garantir que a maior parte da massa do sensor encontre-se no rotor, distantes do centro de rotação, estratégia com a qual se eleva o momento de inércia deste elemento. Segundo esta construção, tais dispositivos tendem a ser grandes e pesados.

Giroscópios de configuração tradicional, embora empreguem tecnologias amplamente conhecidas - os primeiros giroscópios foram desenvolvidos por Léon Foucault em meados do século XIX - ainda são equipamentos caros por possuírem mecanismos complexos, com inúmeras partes móveis que exigem elevada precisão de fabricação.

Sensores que se valem da inércia do rotor para garantir a direção de referência são chamados giroscópios livres. Tais sensores, também chamados giros-compassos, são em malha aberta, pois registram diretamente os deslocamentos angulares por meio de pickoffs angulares, posicionadas nas uniões entre os gimbals (Figura 40).

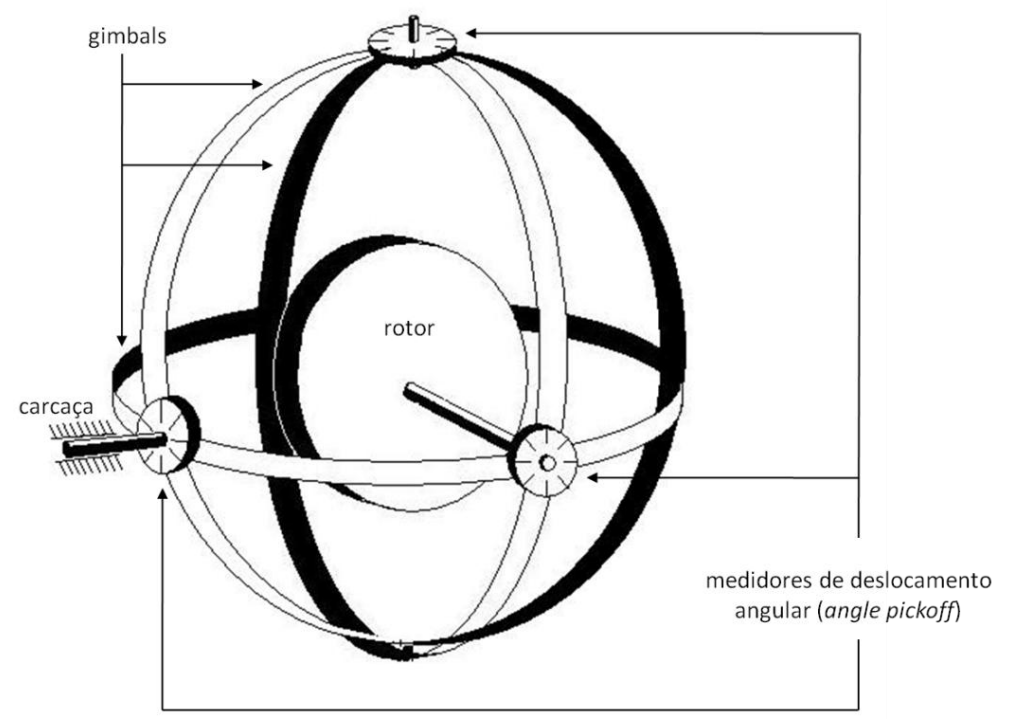

Figura 40 - Esquema de funcionamento de um girocompasso mecânico tradicional com três suspensões Cardan (gimbals) 
Assim como as suspensões Cardan visam isolar o rotor de qualquer torque proveniente da carcaça, e consequentemente do corpo na qual as mesmas se encontram fixadas, pode-se seguir o caminho inverso e garantir que o rotor acompanhe os movimentos da carcaça por meio da aplicação de torques controlados.

Um corpo rígido e axi-simétrico, que possui velocidade angular em torno do seu eixo de simetria, quando submetido a um torque externo não paralelo ao eixo de rotação, reage com um torque conhecido como binário giroscópico, cuja direção é perpendicular ao vetor de rotação própria do corpo e à direção de aplicação do torque externo. Sabe-se que a magnitude do binário giroscópico é proporcional ao momento angular do rotor e à velocidade de precessão que, para o caso do giroscópio de um grau de liberdade (Figura 41), corresponde à velocidade angular aplicada no eixo sensível do sensor.

(MERIAN, 1967) obtém a equação que relaciona a velocidade angular à qual o giroscópio é submetido com o momento giroscópico resultante, partindo das equações dinâmicas de um corpo axi-simétrico girando em torno de um ponto e assumindo que o mesmo possua velocidade de rotação própria (o spin) e precessão constantes, assim como mantém um ângulo de inclinação (a nutação) igualmente constante a $\frac{\pi}{2}$. Nesta situação, a equação do momento é dada por:

$$
M=I \dot{\phi} \dot{\psi}
$$

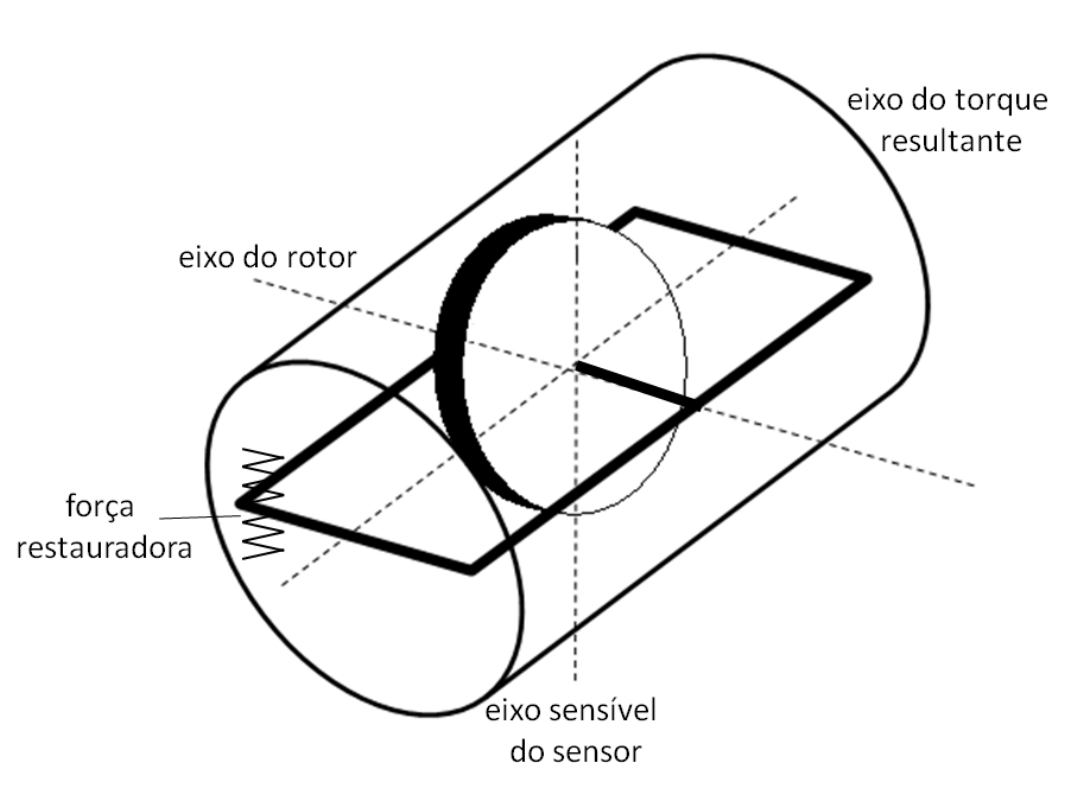

Figura 41 - Princípio de funcionamento de um giroscópio mecânico com um grau de liberdade 
Observa-se na Figura 41 que a mola produz o torque que mantém o único gimbal em posição fixa com relação à carcaça. Para esta montagem, conhecendo-se a velocidade de rotação $\dot{\phi}$ do rotor, seu momento de inércia I e supondo-se a mola linear, pode-se determinar a velocidade angular no eixo sensível, apenas observando-se a deflexão deste último componente.

Vale observar que a equação (173) pressupõe pequenas deflexões da mola ilustrada na Figura 41.

\section{Giroscópio sintonizado dinamicamente (Dinamically Tuned Gyroscope)}

Inicialmente concebidos na década de 1940, os giroscópios sintonizados dinamicamente (DTGs) somente tornaram-se funcionais cerca de vinte anos depois, com a introdução de elementos flexíveis nas uniões entre o rotor e o gimbal interno e deste com o eixo de rotação. Esse aparelho, ilustrado de forma simplificada na Figura 42, foi chamado de "Gyroflex".

Os DTGs representam uma alternativa de menor custo em relação aos tradicionais giroscópios eletro-mecânicos. De acordo com (BARROS e JUNQUEIRA, 2005), pode-se chegar a reduções de até $75 \%$ no custo.

Essa configuração tende a ser mais compacta e robusta, visto que emprega apenas um gimbal posicionado internamente. Seu principio de funcionamento baseia-se na idéia de manter o rotor livre dos torques impostos ao sensor e, com isso, utilizá-lo como referência para medição de direção ou, no caso mais comum em que o sistema é em malha fechada, movê-lo juntamente com a carcaça por meio da aplicação de torques controlados. Assim, para uma velocidade angular específica, chamada velocidade de sintonia, o rotor gira equilibrado em um plano cuja direção normal depende da rigidez dos conectores elásticos.

Tais sensores permitem ajustar a rigidez destes conectores, permitindo o alinhamento preciso do rotor com uma direção conhecida.

(BARROS e JUNQUEIRA, 2005) também apresentam detalhes do equacionamento dinâmico deste tipo de dispositivo. 


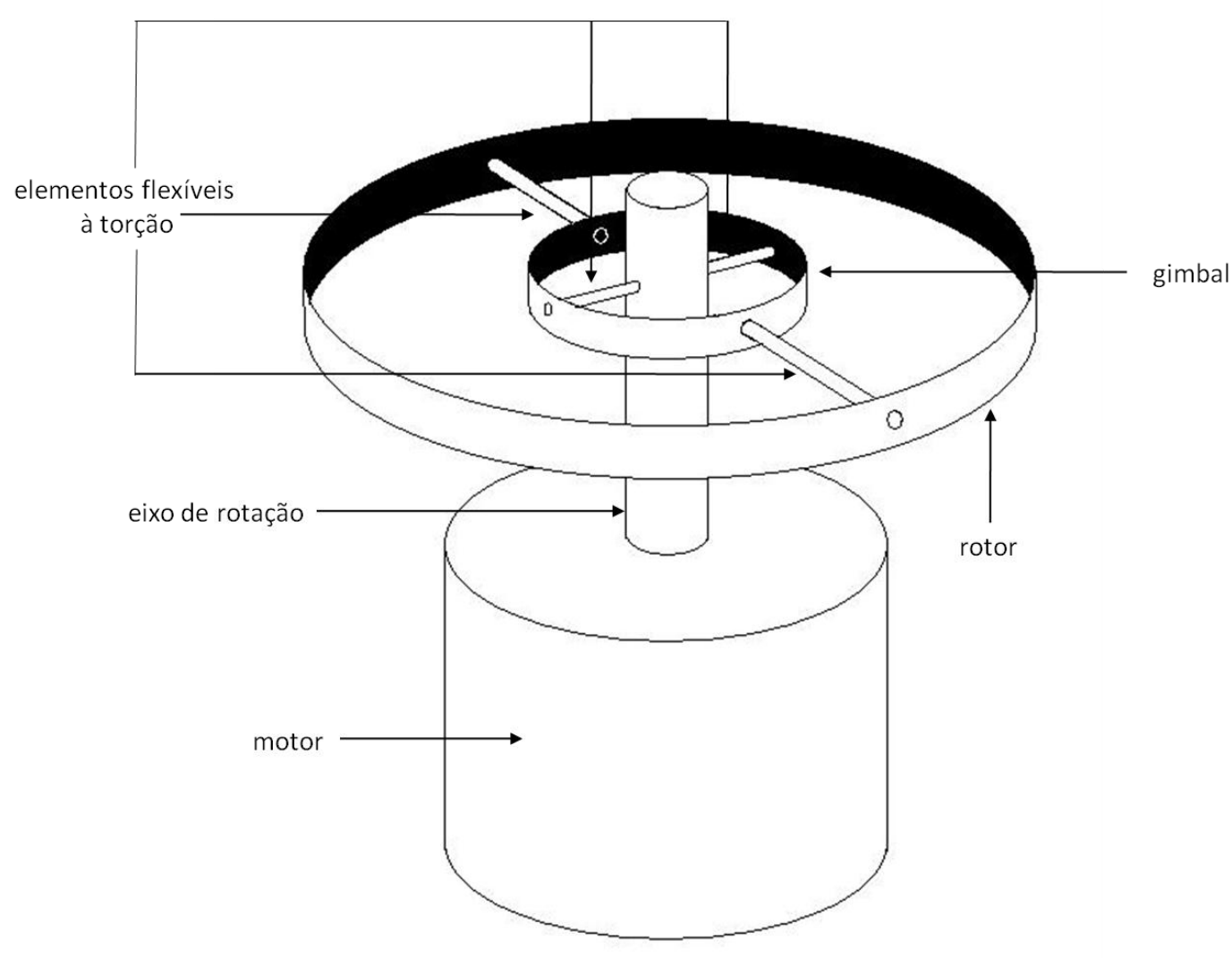

Figura 42 - Ilustração dos componentes de um giroscópio sintonizado dinamicamente (DTG)

\section{Giroscópios Ópticos}

O termo aplica-se a toda a classe de sensores que emprega ondas eletromagnéticas para registrar rotação. Podem ser empregadas ondas pertencentes ao espectro visível ou próximas ao infravermelho.

Os giroscópios ópticos registram a rotação por meio de efeitos interferométricos, como os descritos anteriormente para o caso dos acelerômetros.

Embora a tecnologia do interferômetro tenha sido inicialmente desenvolvida por Michelson no século XIX, sua aplicação na medição de rotações data de 1913, com a constatação do chamado efeito Sagnac.

De acordo com este efeito, dois feixes de luz que percorrem trajetórias fechadas em sentidos opostos apresentam diferença de fase quando projetados sobre um alvo comum, caso o sistema contendo tais caminhos seja rotacionado com velocidade angular perpendicular ao plano das trajetórias. A Figura 43 auxilia a visualização deste efeito. 


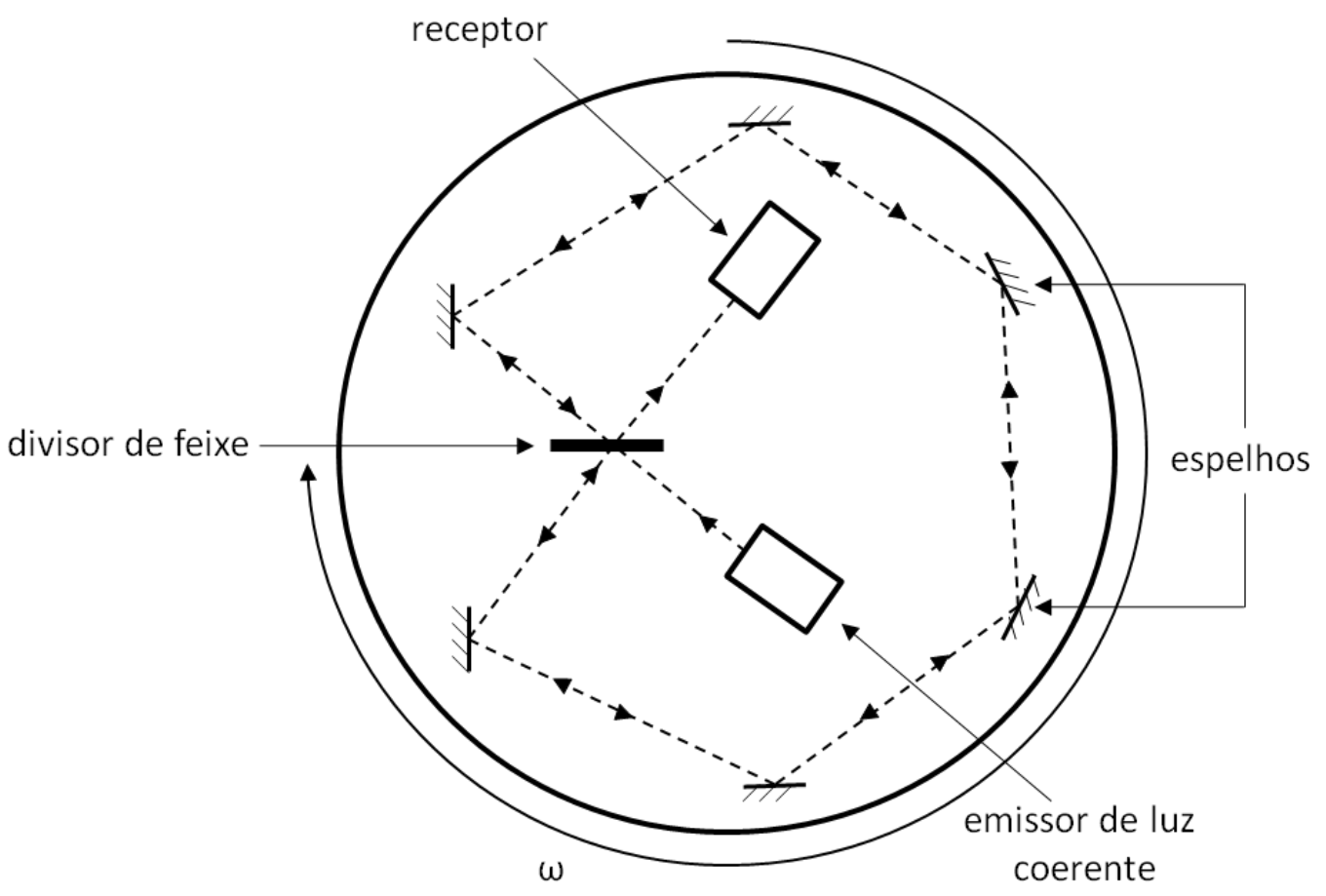

Figura 43 - Princípio de funcionamento de um girômetro de fibra óptica

É possível observar na Figura 33 que um feixe de luz coerente ${ }^{14}$ partindo de um emissor atinge um divisor de feixe, de onde partem dois feixes de mesma fase. Os feixes percorrem um polígono fechado e voltam a incidir sobre o divisor de feixe, que os sobrepõem e encaminham para o receptor. Quando o conjunto é rotacionado com velocidade $\omega$, ocorre uma aparente modificação nos caminhos ópticos dos feixes, o que provoca modificação na fase entre eles. Por não estarem em fase, ao serem projetados sobre um anteparo, os feixes criam as chamadas franjas de interferência.

Graças à interferência destrutiva entre os feixes projetados, uma franja identificada por uma faixa clara e outra escura é criada a cada meio comprimento de onda da luz. Sabendo que a luz visível possui ondas com comprimento que variam entre 400 e $700 \mathrm{~nm}$, uma franja de interferência é criada caso ocorra uma mudança aparente do caminho ótico de cerca de $300 \mathrm{~nm}$. Sendo assim, um sensor simples, montado no receptor, capaz de detectar a presença ou ausência de luz, permite o registro da velocidade angular, visto que esta causa a aparente diferença no caminho ótico entre os feixes. Caso esta diferença entre os caminhos ópticos seja superior a meio comprimento de onde, ou seja $300 \mathrm{~nm}$, o sensor passa a produzir leitura.

O emprego da fibra óptica permitiu a fabricação de sensores relativamente compactos, porém capazes de gerar grandes diferenças de fase entre os feixes e, com isso, produzir leituras

\footnotetext{
${ }^{14}$ Ondas de luz de mesma freqüência, direção e fase
} 
precisas mesmo para pequenas velocidades angulares. Isso se deve ao fato de que os filamentos de fibra óptica podem ser enrolados em forma de bobinas, produzindo um efeito análogo ao aumento do raio do sensor. Empregando malhas de sensores foto sensíveis nos receptores e bobinas contendo cerca de $7 \mathrm{~km}$ de fibra óptica é possível registrar velocidades angulares da ordem de $10^{-30} / \mathrm{h}$.

Atualmente os sensores que empregam os princípios de funcionamento descritos acima são os chamados giroscópios de anel de laser e giroscópios de fibra óptica.

\subsubsection{Sensores MEMS}

MEMS (Micro-Electro-Mechanical Systems) é a integração de elementos mecânicos, atuadores, sensores e componentes eletrônicos; dispostos em um substrato de proporções microscópicas, tipicamente uma placa de silício.

Enquanto a maior parte das produções materiais humanas, até então, possuem dimensões cuja ordem variava entre $10^{2}$ e $10^{-2}$ metros, a tecnologia MEMS permitiu a fabricação de dispositivos medindo entre $10^{-4}$ e $10^{-6}$ metros.

O processo de fabricação de dispositivos MEMS remete, pelo menos, a idade média quando artesãos decoravam armaduras com intrincados desenhos, produzidos pela corrosão controlada das placas de metal. Em uma época mais recente - primeira metade do século XXa corrosão controlada foi estabelecida como principal método de fabricação de placas de circuito impresso. Esta é a tecnologia que, desde a década de 1950, vem sendo empregada na fabricação de dispositivos eletro-mecânicos de pequenas dimensões

Embora hoje existam inúmeros métodos de fabricação, o mais comum e amplamente empregado é o método da corrosão úmida (Wet etching).

Basicamente, o processo consiste em aplicar uma máscara protetora sobre um substrato que mantém exposto o material que se deseja remover. O conjunto máscara substrato é, então, mergulhado em uma solução contendo algum componente químico capaz de corroer o material do substrato. Uma vez realizada a corrosão, o conjunto é removido da solução, a reação de corrosão é interrompida e a máscara removida, revelando a geometria final do componente.

Longas pesquisas levaram ao aperfeiçoamento desta técnica de modo a garantir características dimensionais precisas. Como exemplo de controle sobre o processo, pode-se destacar o uso de corrosivos isotrópicos e anisotrópicos. 
Corrosivos isotrópicos, habitualmente representados por compostos ácidos, promovem o desgaste do material igualmente em todas as direções, dando origem a sulcos como os mostrados na Figura 44.

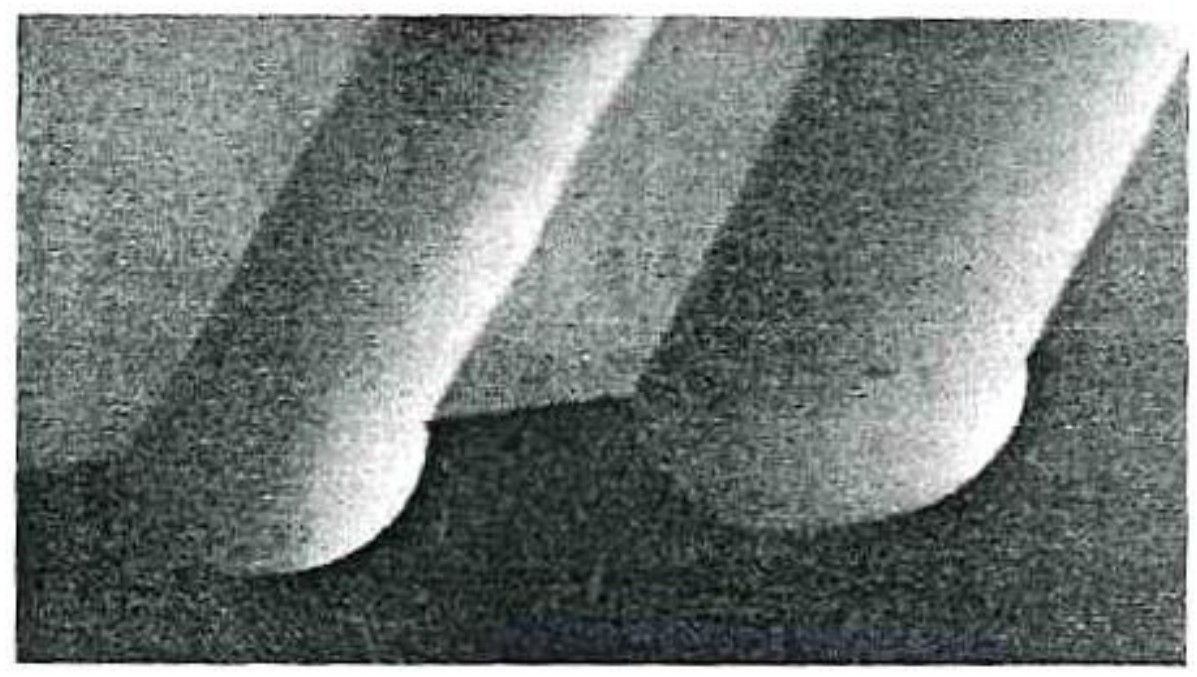

Figura 44 - Sulcos produzidos por corrosão isotrópica (ZORMAN e MEHREGANY, 2002)

A corrosão controlada isotrópica foi a primeira a ser desenvolvida e, embora exija menos controle e seja mais rápida, não permite a produção de “cortes" profundos e precisos no substrato.

Na década de 1960 os laboratórios Bell aperfeiçoaram o processo de corrosão úmida anisotrópica. Este segundo processo promove a corrosão em velocidades distintas, de acordo com a orientação das faces expostas dos cristais.

Embora seja um processo cerca de cinco vezes mais lento que o anterior, a corrosão anisotrópica (Figura 45) permitiu a produção de entalhes profundos e preciso. 


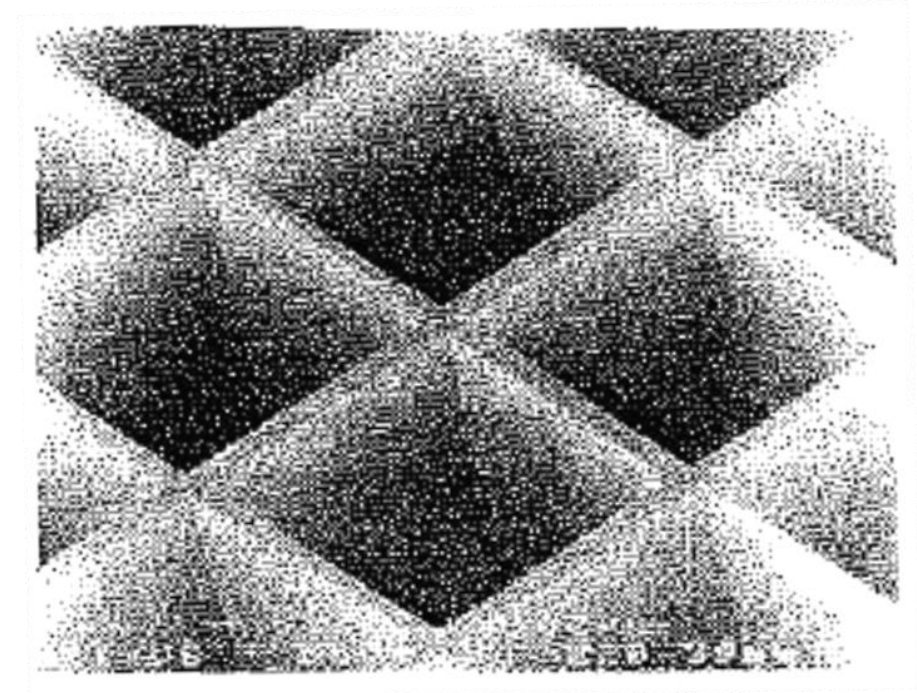

Figura 45 - Grade produzida por corrosão anisotrópica, capaz de produzir geometrias precisas (ZORMAN e MEHREGANY, 2002)

A referência (ZORMAN e MEHREGANY, 2002) discute amplamente os materiais empregados, os processos de fabricação, os empregos e a modelagem dos sistemas MEMS.

No que se refere aos sensores inerciais, a tecnologia MEMS foi inicialmente aplicada na fabricação de acelerômetros miniaturizados voltados para o emprego na indústria automobilística. Tais dispositivos foram, e ainda são, amplamente empregados nos sistemas de disparo de air bags, por exemplo.

Como resultado, os acelerômetros MEMS progrediram tecnologicamente mais quando comparados com os sensores de velocidade angular e hoje possuem desempenho superior. Mesmo assim, de acordo com (TITTERTON e WESTON, 2004) o emprego de sensores MEMS em navegação inercial tem motivado milhares de cientistas ao redor do mundo, graças aos inúmeros benefícios que a tecnologia permite, quais sejam:

- Miniaturização;

- Baixo peso;

- Baixo consumo de energia;

- Robustez a impactos;

- Baixo custo de produção;

- Baixa necessidade de manutenção. 
Atualmente, tem se desenvolvido a aplicação de sistemas de pickoff ópticos aos sensores do tipo MEMS, levando-os à tecnologia conhecida como MOEMS (micro-opto eletromechanical systems).

Sensores que se valem do desvio de um feixe luminoso ou métodos interferométricos para registrar o deslocamento da(s) massa(s) de prova permitem aumento na resolução e diminuição nos níveis de ruído característicos das tecnologias MEMS tradicionais.

\section{Acelerômetros MEMS}

Os acelerômetros MEMS são compostos por um mecanismo feito de silício, disposto no interior de uma carcaça metálica ou plástica. São dispositivos com um número reduzido de partes móveis (inferior a 5 partes, quando comparados com as demais tecnologias de acelerômetros).

Assim como os sensores descritos anteriormente, os acelerômetros que empregam tecnologia MEMS dividem-se, basicamente, em eletro mecânicos e vibratórios, podendo ainda ser em malha aberta ou fechada.

Acelerômetros MEMS eletro mecânicos, de maneira análoga àquela tecnologia empregada na fabricação convencional, possuem uma massa de prova sustentada por uma ou mais hastes que se defletem, proporcionalmente a aceleração à qual o sensor é submetido.

A Figura 46 apresenta esquematicamente um acelerômetro MEMS mecânico, cuja massa de prova é suportada acima de uma base de vidro por duas hastes que sofrem torção quando o conjunto é acelerado.

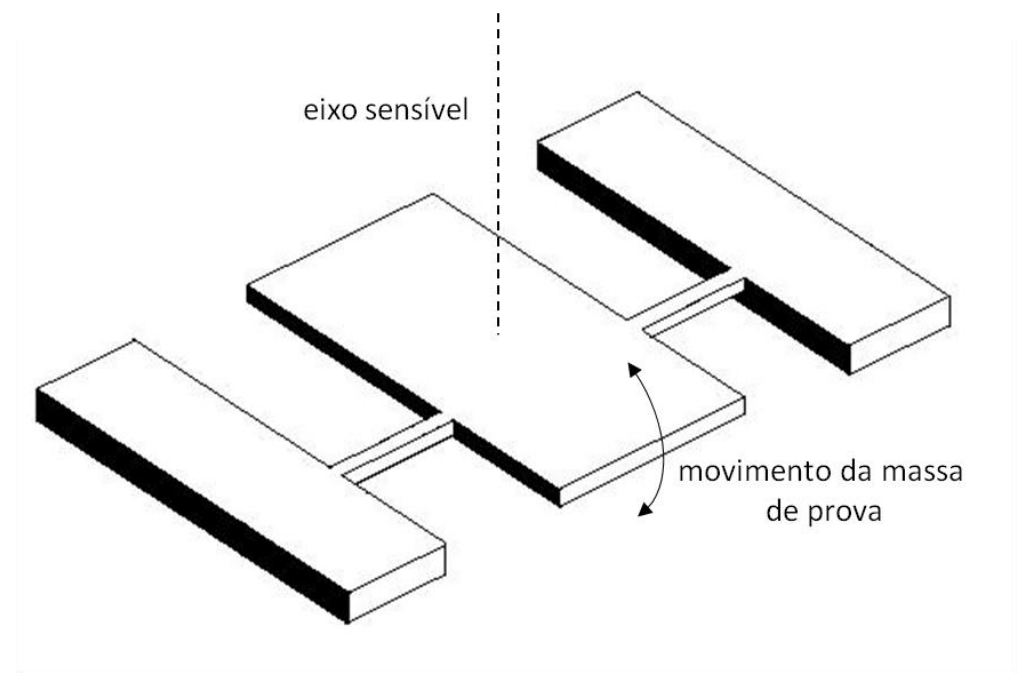

Figura 46 - Princípio de funcionamento de um acelerômetro mecânico do tipo MEMS 
Neste caso, a medida de aceleração é feita registrando-se a diferença na capacitância entre a massa de prova e um eletrodo no substrato de vidro.

A tecnologia MEMS permite, ainda, a fabricação de micro atuadores, tornando possível produzir acelerômetros em malha fechada, análogos ao exemplificado na Figura 46.

Assim como os acelerômetros eletro-mecânicos em malha fechada, os sensores MEMS desse tipo apresentam precisão aprimorada. (TITTERTON e WESTON, 2004) comentam em seu texto sobre certo acelerômetro MEMS em malha fechada, cujo intervalo dinâmico ${ }^{15}$ parte de $100 \mu g$ até $2 g$.

Outra família de acelerômetros MEMS compreende os acelerômetros cujo princípio de funcionamento é a viga vibratória.

Assim como os acelerômetros deste tipo descritos anteriormente, seus análogos fabricados com tecnologia MEMS usam como método de medição a variação da frequência natural de vibração de uma ou mais vigas, quando as mesmas sofrem tração proveniente da inércia das massas de prova fixadas as suas extremidades.

Vale notar que a tecnologia MEMS favorece a fabricação de mecanismos planos montados sobre algum tipo de substrato e, sendo assim, vigas vibratórias e massas de prova são dispostas horizontalmente, assim como o eixo sensível do sensor.

Para esta finalidade, o silício apresenta excelente linearidade elástica, permitindo um controle preciso sobre a freqüência de vibração, sendo que o conjunto todo é contido em uma cápsula selada a vácuo, tornando o amortecimento muito baixo. Tais características têm permitido o desenvolvimento de acelerômetros vibratórios MEMS de grande precisão.

\section{Giroscópios MEMS}

Giroscópios MEMS são dispositivos que não possuem elementos rotativos - conhecidos como rotores - e empregam a aceleração de Coriolis aplicada a uma massa de prova vibratória para medir a velocidade angular a qual o conjunto está submetido. A aceleração de Coriolis surge em uma direção ortogonal ao eixo de rotação e à direção do movimento oscilante da massa, possuindo magnitude dada por (174):

$$
a_{c}=2 \mathrm{v} \Omega
$$

\footnotetext{
${ }^{15}$ Intervalo em que ocorre leitura antes que o sensor atinja seus limites físicos
} 
Na equação (174) v corresponde à velocidade instantânea dos pontos da massa de prova e $\Omega$ à componente da velocidade angular aplicada ao sensor no seu eixo sensível.

Segundo (TITTERTON e WESTON, 2004) é possível dividir os giroscópios MEMS em três tipos básicos de configuração: barras vibratórias simples; barras duplas ou garfos sintonizados e anéis ressonantes.

Giroscópios de barra vibratória empregam uma única haste central que vibra em um determinado plano quando não está sendo submetida a nenhuma rotação. Ao se aplicar rotação, fazendo com que o sensor adquira velocidade angular alinhada ao eixo da haste, os pontos desta estrutura são submetidos à aceleração de Coriolis e deixam de oscilar apenas no plano original. Esse desvio do plano é, então, registrado por algum tipo de pickoff .

Essa configuração apresenta desvantagens evidentes, quais sejam: a transmissão de esforços às articulações nas extremidades da barra e, de forma simétrica, a transmissão de vibrações, aplicadas sobre a carcaça, à haste vibratória. Visando contornar tais problemas, foi proposta a configuração empregando duas barras vibrando em contra-fase. A Figura 47 ilustra a configuração formada por duas barras, também chamada de configuração em garfo sintonizado (Tuning Fork Gyroscope).

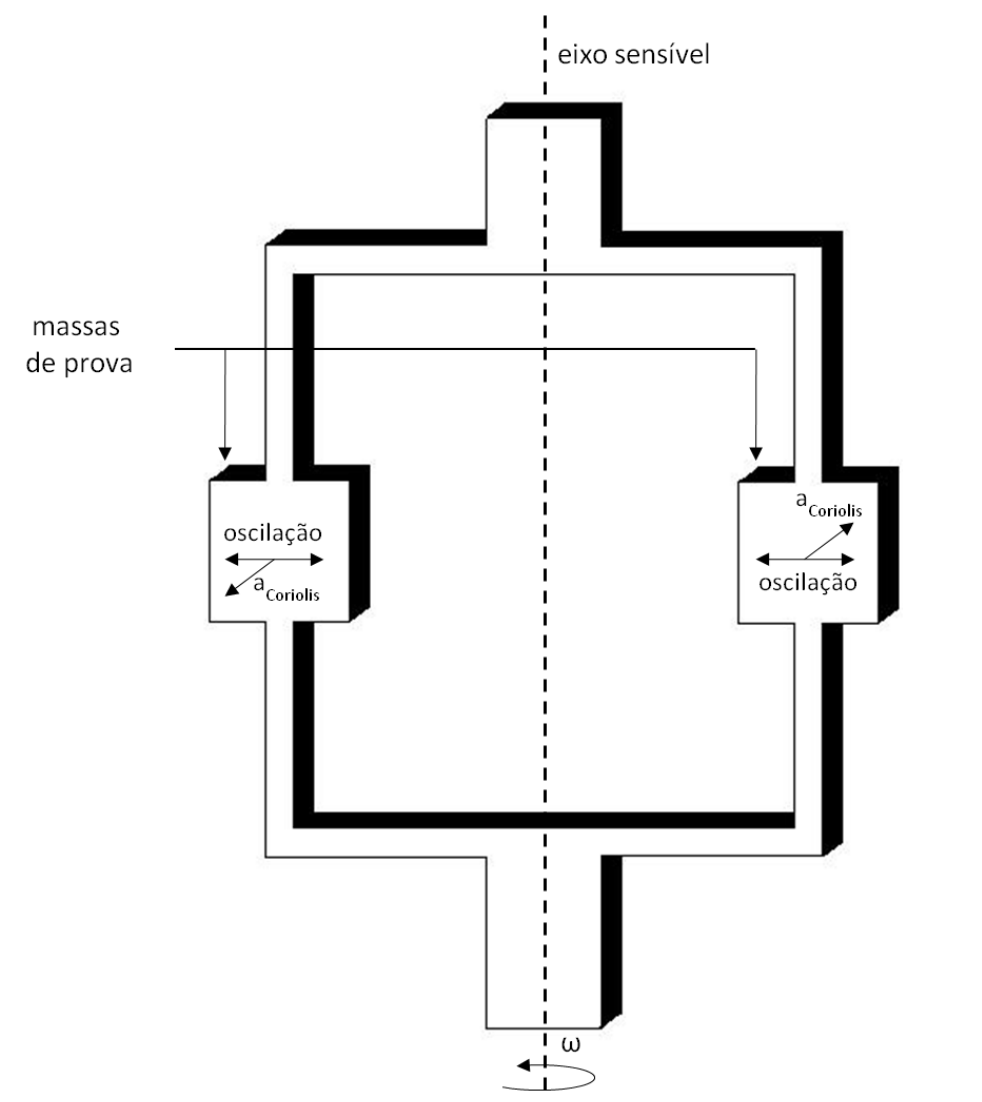

Figura 47 - Funcionamento de um girômetro MEMS do tipo TFG 
As duas barras, bem como as massas perfeitamente alinhadas oscilando em contrafase no plano do desenho, idealmente não transmitem esforços à carcaça do sensor, permitindo um sistema de suspensão capaz de isolar mecanicamente os elementos vibratórios do ambiente externo. Essa configuração, na realidade, foi a primeira a apresentar resultados satisfatórios dentre os giroscópios MEMS. Foi concluída com sucesso pela primeira vez no ano de 1992, no laboratório Charles Stark Draper, e como mostra a Figura 48, é constituída por duas massas de prova suspensas por uma sequência de vigas que são ancoradas a um substrato de vidro.

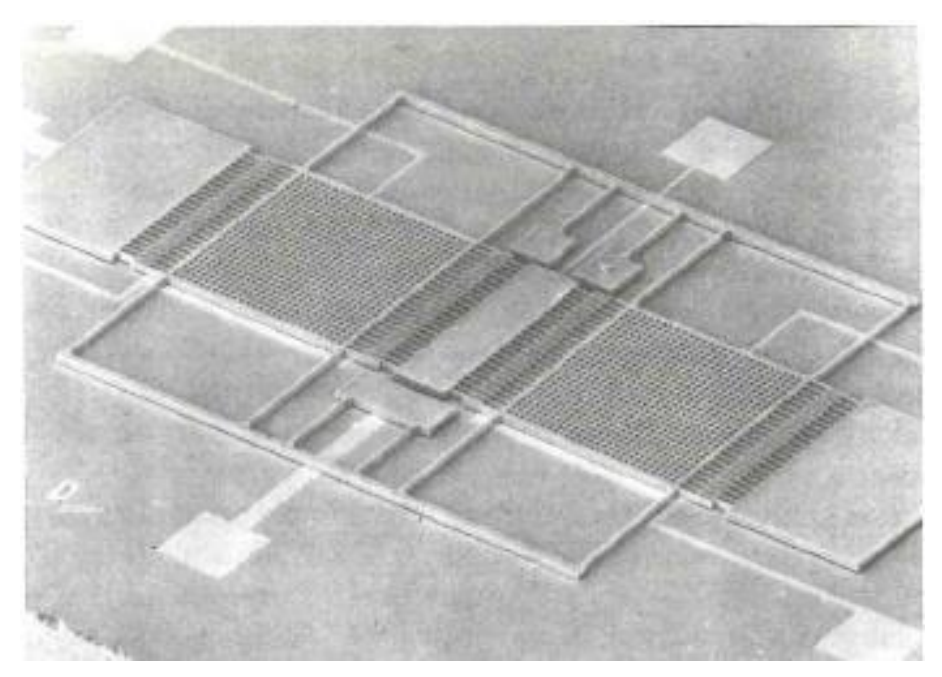

Figura 48 - Fotografia do primeiro girômetro TFG de desempenho satisfatório (LAWRENCE, 1998)

A Figura 49, extraída de (LAWRENCE, 1998), ilustra a direção em que as massas de prova vibram em fases opostas e como essas se deslocam conforme o sensor é rotacionado de acordo com o vetor $\Omega$ indicado na mesma figura. 


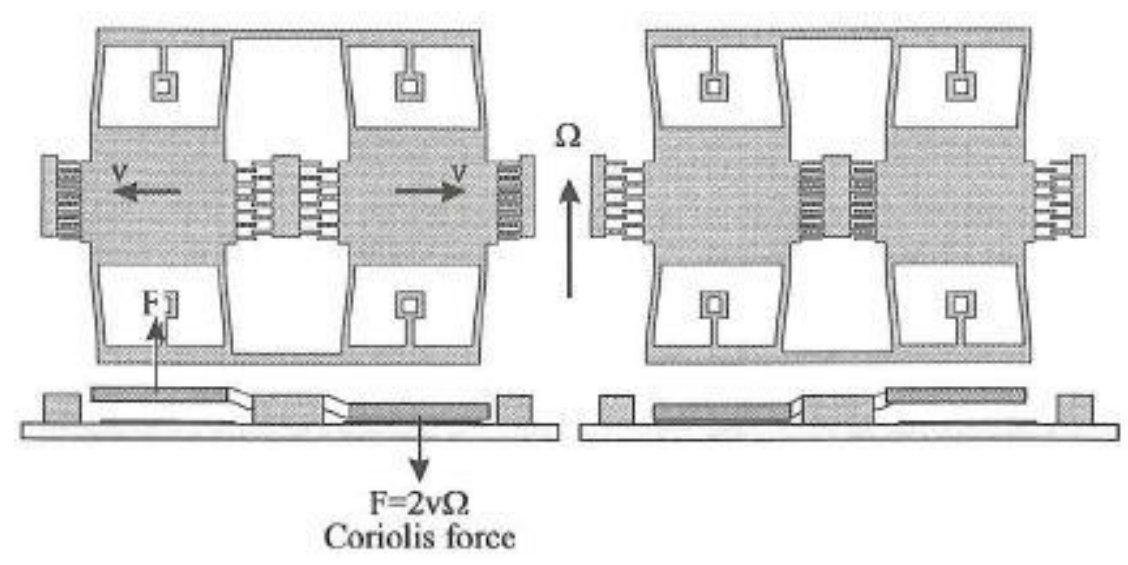

Figura 49 - Princípio de funcionamento do girômetro apresentado na Figura 48. (LAWRENCE, 1998)

Também é possível observar na Figura 39 os elementos que promovem a oscilação das massas, situados nas extremidades laterais. Estes elementos são chamados de pentes de atuadores e promovem o movimento por meio de forças eletrostáticas.

Entre o substrato de vidro e as massas de prova são colocados pickoffs capacitivos, ou seja, sensores capazes de medir a capacitância associada ao espaço entre as massas e o substrato. Assim como no caso dos acelerômetros vibratórios, o conjunto todo é selado a vácuo, buscando minimizar a dissipação viscosa.

Para apresentarem um bom funcionamento, os giroscópios de garfo sintonizado dependem da simetria e alinhamento perfeito entre as massas de prova.

A última configuração de giroscópio MEMS mencionada anteriormente visa, entre outras coisas, eliminar a necessidade de duas massas distintas. Trata-se dos chamados anéis ressonantes, que são estruturas simétricas em relação ao eixo de rotação.

Esta configuração consiste em um anel flexível de silício suportado por hastes ou pernas (tipicamente oito distribuídas simetricamente ao longo da circunferência do anel) que podem estar localizadas no interior ou exterior do anel. O dispositivo em funcionamento vibra o anel, fazendo com que este assuma a forma elíptica (Figura 50). Quando não submetido à rotação, a aceleração de Coriolis transfere energia do modo original de vibração para um segundo modo no qual a elipse encontra-se deslocada do eixo original (Figura 50). 

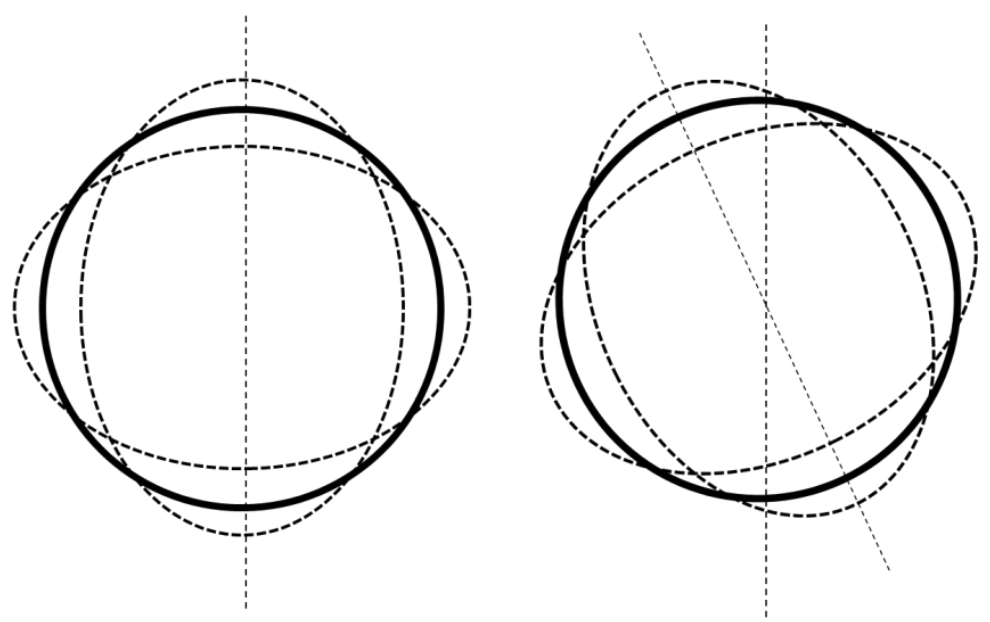

Figura 50 - princípio de funcionamento do girômetro MEMS de anél ressonante

A vibração é produzida pela interação entre correntes elétricas circulando em seções do anel e um campo magnético fixo, perpendicular ao plano do anel e produzido por um imã. Quando a direção de vibração é modificada, seções distintas do anel passam a sofrer influência do campo magnético e, nesses trechos, surgem correntes elétricas. Isso faz com que os sistemas de pickoff e de atuação sejam estruturas idênticas. A Figura 51, extraída de (TITTERTON e WESTON, 2004), apresenta um giroscópio de anel ressonante desenvolvido pela empresa BAE Systems.
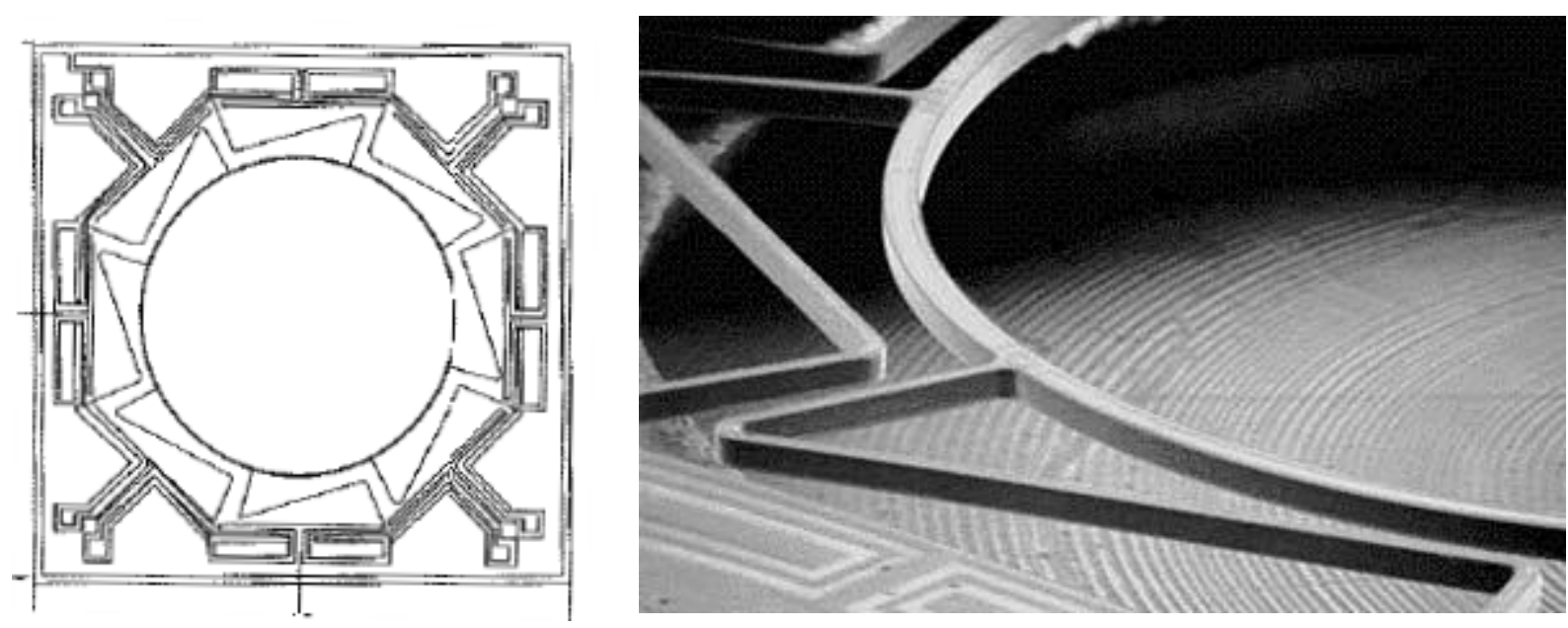

Figura 51 - Planta e fotografia do girômetro MEMS de anél ressonante (BERNSTEIN, 2003) 


\subsubsection{Erros associados a Acelerômetros e Giroscópios}

Erros na determinação da posição podem ser provenientes de imprecisões na determinação da condição inicial, de problemas no computador de navegação ou erros associados ao sinal dos sensores empregados. Nos próximos itens são discutidos detalhes acerca desta última fonte de erro, com vistas ao processo de navegação.

Erros associados à compensação incorreta do bias, à calibração do fator de escala ou ao próprio alinhamento do sistema com relação ao veículo possuem grandezas distintas, assim como, efeitos distintos entre os diferentes sistemas de navegação e tecnologias dos sensores empregados. Por esse motivo, ao final deste tópico é apresentada uma tabela que procura relacionar a importância dos tipos de erro a cada conjunto de sensores.

\subsubsection{Fator de Escala}

Trata-se da mudança no sinal de saída frente à mudança na grandeza medida pelo sensor. Como a maioria dos sensores fornece um sinal de saída proporcional ao sinal de entrada, o fator de escala é simplesmente o coeficiente angular da reta que melhor relaciona os dados de entrada e saída. Neste sentido, o fator de escala é dado por:

$$
K=S / I
$$

Onde $S$ é o sinal de entrada e $I$ o verdadeiro valor medido.

A determinação do fator de escala é feita da seguinte forma: inicialmente, são feitas aquisições enquanto o sinal de entrada é variado dentro do intervalo de funcionamento do sensor; em seguida, é ajustada uma reta que melhor representa a relação entre entradas e saídas; finalmente, o fator de escala, ou algumas vezes denominada sensibilidade, é dado pelo coeficiente angular da reta ajustada.

Habitualmente, os sensores são dispositivos analógicos que quando excitados produzem uma tensão de saída proporcional à grandeza medida. Como hoje em dia todo o processamento de sinais é feito por computadores, os sinais de saída passam por um conversor AnalógicoDigital - AD - antes de serem efetivamente interpretados. Neste caso, o fator de escala é o coeficiente linear que relaciona a informação de tensão de saída à medida percebida pelo sensor. 
O fator de escala, como se pode ver na equação (175), possui a unidade da escala utilizada sobre a unidade da grandeza medida. O fator de escala dos acelerômetros é habitualmente dado em Volts, ou fração deste, sobre múltiplos da aceleração gravitacional $(g)$.

\subsubsection{Deriva do Fator de Escala}

Define o montante pelo qual o fator de escala de um instrumento de medição varia conforme as condições ambientais mudam.

Muitos componentes dentro de um instrumento são afetados pelas flutuações do ambiente, principalmente com a mudança na temperatura.

Constantes de mola, propriedades piezelétricas e velocidade de propagação da luz em um determinado meio são exemplos de características de sensores influenciadas pela temperatura. Como será visto mais adiante, a temperatura também influencia outras características do sensor.

Caso o desvio causado por esse fenômeno seja significativo, o fator de escala deve ser encarado como função da temperatura e sua relação poderá ser determinada executando-se o procedimento descrito anteriormente - determinação do fator de escala -, para um intervalo de temperaturas.

\subsubsection{Não Linearidade}

Foi dito no item anterior que a saída da maioria dos sensores é proporcional ao sinal de entrada e essa relação é linear. Esse é um fato comum e desejável, porém nem sempre verdadeiro.

A não linearidade é definida como o maior desvio de qualquer uma das leituras (pontos) com relação à reta ajustada e é, habitualmente, expressa como uma fração ou porcentagem da escala completa do sensor. Essas diferenças entre a leitura e a reta ajustada podem se distribuir aleatoriamente em torno da mesma, eventualmente caracterizando outro tipo de curva.

Se as diferenças se dispersam randomicamente em torno da reta ajustada aos pontos, nenhuma modelagem posterior é possível, mas, se tais diferenças se dispersam formando eventuais curvas, é possível adicionar aproximações de segunda ou terceira ordem para melhorar o modelo do fator de escala. 


\subsubsection{Assimetria}

Em alguns casos a reta ajustada no intervalo de entrada de $-\infty$ a 0 possui inclinação diferente daquela ajustada no intervalo de 0 a $+\infty$. Desta forma, a assimetria é apresentada em (LAWRENCE, 1998) como a razão entre os fatores de escala positivos e negativos.

O mesmo autor afirma que assimetrias inferiores a 100ppm são aceitáveis nos casos em que as leituras não oscilem em torno do zero durante o ensaio.

Nos casos de assimetria apreciável para uma situação de estudo, basta considerar como fator de escala uma função não contínua no ponto zero.

\subsubsection{Bias ou Zero-Drift}

Em qualquer sensor, quando não há sinal de entrada, a saída não é perfeitamente nula.

Nestes casos, há certo desvio causado por imperfeições de fabricação, ou sensibilidade do sensor às condições ambientais, chamado de bias ou zero-drift.

A Figura 52 ilustra a influência do bias na medição. O bias é uma fonte determinística de erro e, em princípio, pode ser modelado da seguinte forma:

$$
\frac{S}{K}=B+I
$$

O bias sofre grande influência da temperatura. Tal correlação é fornecida pelo fabricante do sensor. No caso em que os sensores devem operar em ambientes cuja variação de temperatura é grande, como por exemplo: um lançamento submarino a grandes profundidades, o modelo de correção proposto na equação (176) deve, ainda, levar em consideração a variação do bias com a temperatura, resultando na equação (177).

$$
\frac{S}{K}=\left[B_{0}+\left(T-T_{0}\right) \gamma\right]+I
$$

Onde $B_{0}$ é um bias testado a uma determinada temperatura $T_{0}$ e $\gamma$ é a taxa de variação do bias com a temperatura.

A variação do bias com a temperatura para os sensores estudados neste trabalho é habitualmente linear, coerente com o modelo apresentado na equação (177). 


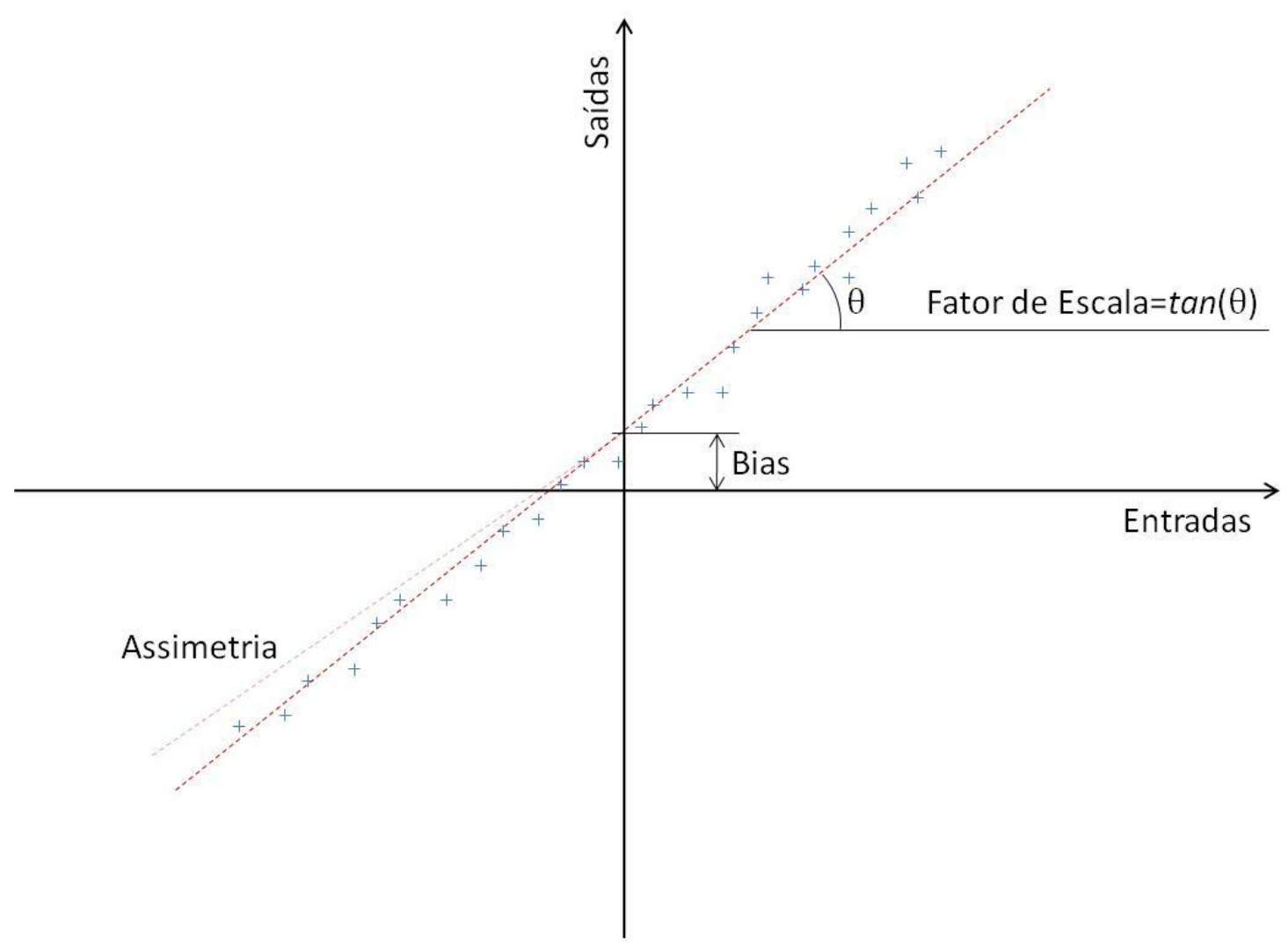

Figura 52 - Exemplo de curva de calibração (input x output) em que são destacados os principais parâmetros de calibração

\subsubsection{Desalinhamento}

É possível que, durante sua fabricação ou montagem na unidade de medição, o sensor possua algum desalinhamento entre seus eixos sensíveis e alguma referência visível, por exemplo, as faces de sua carcaça.

(LAWRENCE, 1998) apresenta separadamente o desalinhamento no plano perpendicular a gravidade (heading error) e o desalinhamento que envolve a direção da gravidade (tilt error). Faz desta forma, pois os efeitos de cada um destes tipos de erro são distintos.

Erros de direção no plano perpendicular à gravidade, quando não corrigidos, geram desvios perpendiculares a trajetória, chamados por Lawrence de cross-track distance error, tendo formulação dada por:

$$
e_{c}=\alpha v t
$$

Onde $\alpha$ é o desalinhamento angular em radianos que, por ser habitualmente pequeno, já é apresentado na forma linearizada. 
Sensores com mais de um grau de liberdade podem apresentar erro de perpendicularidade entre seus eixos sensíveis. Estes erros serão devidamente caracterizados, no capítulo seguinte, quando forem trabalhados os sensores foco do presente estudo.

O segundo tipo de erro de alinhamento destacado por (LAWRENCE, 1998) é aquele que possui componente paralela a gravidade. Segundo o autor, no caso dos acelerômetros, esse tipo de erro é indistinguível do próprio bias do sensor.

Assim, o bias causado pelo desalinhamento $\beta$ é mostrado na equação (179).

$$
B_{t}=\beta g
$$

\subsubsection{Erros não determinísticos}

Os erros não determinísticos associados ao sinal de sensores inerciais enquadram-se no que se conhece como processos aleatórios ou estocásticos. Antes de prosseguir na descrição dessa classe de processos cabe a discussão utilizada neste texto, sobre a divisão entre erros determinísticos e não determinísticos.

[...] it might be argued that no physical data in practice can be truly deterministic because there is always a possibility that some unforeseen event in the future might influence the phenomenon producing the data in a manner that was not originally considered. On the other hand, it might be argued that no physical data are truly random, because an exact mathematical description might be possible if a sufficient knowledge of the basic mechanisms of the phenomenon producing the data were available. In practical terms, the decision of whether physical data are deterministic or random is usually based on the ability to reproduce the data by controlled experiment. (BENDAT e PIERSOL, 2000)

Ainda Segundo Bendat, do ponto de vista experimental, se certo experimento visando obter dados específicos, produz os mesmo resultados ao ser repetido, é bastante provável que aqueles dados sejam determinísticos. Por outro lado, se não é possível projetar um experimento que produza sempre os mesmos resultados associados a certo parâmetro, o dado em questão deve ser considerado não determinístico.

Apoiado em tais definições este trabalho restringiu-se a considerar apenas certas fontes de erro como determinísticas, deixando as demais fora desta classificação. Esta escolha ficará evidente em capítulos posteriores. 
Retomando o tratamento matemático dos dados não determinísticos, (PAPOULIS, 1965) "Um processo aleatório ou estocástico é um modelo matemático para um fenômeno que evolui no tempo de forma imprevisível aos olhos do observador”. Os erros aleatórios serão chamados de ruídos.

É comum aos estudos do ruído, dividi-los em componentes e atribuir a cada uma delas uma origem distinta.

(LAWRENCE, 1998) agrupa os ruídos de alta frequência em um tipo básico chamado ruído de operação (in-run drift). Tais distorções provêm do interior do sensor, comumente geradas por imperfeição na construção do mesmo como, por exemplo, o ruído causado por pequenas defeitos nos rolamentos de um giroscópio mecânico.

No mesmo trabalho, os demais desvios não determinísticos são a instabilidade do bias e a variação do bias e do fator de escala de um dia para o outro (Day to Day uncertainty).

(EL-SHEIMY, HOU e NIU, 2008) apresentam uma divisão melhor definida com base na origem dos ruídos, a qual é brevemente apresentada a seguir.

\section{Ruído Quantizado (Quantization Noise)}

Trata-se de um ruído de alta frequência comum a sensores eletrônicos, produzido no processo de conversão do sinal analógico em digital. A diferença entre a tensão efetivamente produzida e a resolução do conversor analógico-digital produz tais desvios.

\section{Passeio Aleatório (Random Walk)}

É um ruído de período mais longo que aquele descrito acima e pode ser entendido como a escolha aleatória da direção em que o sinal pode seguir. Esse tipo de desvio é bastante comum em girômetros de fibra óptica. Segundo (EL-SHEIMY, HOU e NIU, 2008), isso se deve a emissão espontânea de fótons durante a operação do equipamento. Esse tipo de desvio interfere principalmente em medições de curta duração.

\section{Instabilidade do Bias (Bias Instability)}

Durante períodos mais longos de operação o bias pode flutuar graças a oscilações aleatórias do sistema eletrônico como um todo. 
Esse parâmetro não pode ser definido em sinais de curta duração, pois confunde-se com os ruídos de alta frequência.

Como será visto mais adiante no texto, o ponto mais baixo do gráfico log-log da variância de Allan do sinal corresponde ao valor da instabilidade do bias. Esse valor é habitualmente fornecido pelo fabricante e expressa, entre outras coisas, a qualidade do sensor.

A Figura 53, extraída de (TITTERTON e WESTON, 2004), divide os sensores - neste caso acelerômetros - de acordo com os valores de instabilidade do bias.

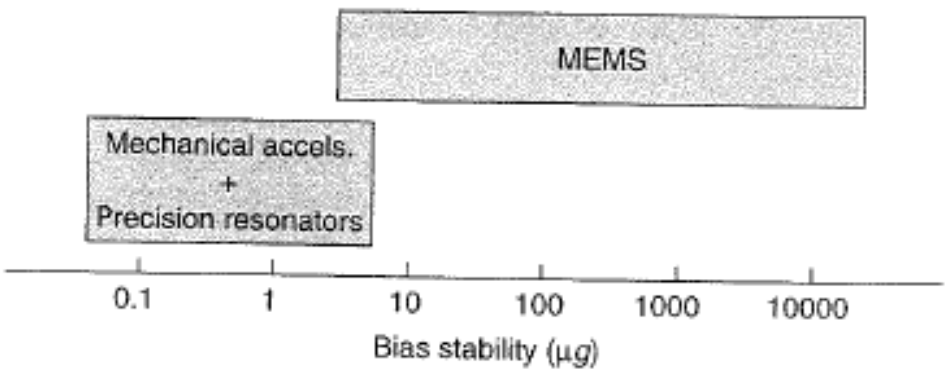

Figura 53 - Faixas de valor para a estabilidade do bias de acordo com a tecnologia do sensor empregado (TITTERTON e WESTON, 2004)

Sensores cujo bias possui menor flutuação permitem que este seja mais facilmente subtraído do sinal, melhorando a fidelidade do sinal medido. Essa estabilidade está atrelada a um aumento substancial na tecnologia empregada na fabricação do sensor e, consequentemente, em custos mais elevados como mostra a Tabela 4.

Tabela 4 - Relação de preços e técnologias de sensores inerciais

\begin{tabular}{|l|c|c|c|}
\hline \multicolumn{1}{|c}{ Sensor } & Marca & Tecnologia & Preço Aproximado [US\$] \\
\hline Acelerômetro & Analog Devices & MEMS & 8,13 \\
\hline Acelerômetro & Honeywell & Piezoelétrico & 310,00 \\
\hline Girômetro & Analog Devices & MEMS & 20,98 \\
\hline Girômetro & Vibtel & Fibra Óptica & 12000,00 \\
\hline
\end{tabular}

\section{Velocidade do passeio aleatório (Rate Random Walk)}

Esse processo aleatório possui origem incerta, possivelmente o caso limite de um ruído com correlação exponencial com tempos de correlação $^{16}$ muito longos. (IEEE Standard

${ }^{16}$ O tempo de correlação de um experimento é o tope ao longo do qual certo padrão apresenta correlação 
Specification Format Guide and Test Procedure for Single Axis Interferometric Fiber Optic Gyros, 1997 (R2008))

\section{Velocidade de Deriva (Drift Rate Ramp)}

Consiste em um desvio monotônico extremamente lento do sinal, que muitas vezes é tratado de forma determinística (EL-SHEIMY, HOU e NIU, 2008). O período desse fenômeno é tão longo que, na maioria dos casos, pode ser corrigido com a utilização de um filtro.

Nos tópicos seguintes será apresentado o método presente em (PAPOULIS, 1965) para modelagem das componentes do ruído, assim como sua identificação e quantificação por meio da Variância de Allan, discutida em (EL-SHEIMY, HOU e NIU, 2008).

\subsubsection{Definições matemáticas associadas ao processo estocástico}

Um processo estocástico pode ser visto como uma função de duas variáveis $t$ e $\zeta$.

O domínio de $\zeta$ é o conjunto de possíveis resultados de um experimento ou eventos, enquanto o domínio de $t$ é o conjunto dos números reais, correspondente a linha do tempo. O processo estocástico é, então, escrito como:

$$
\mathbf{x}(t, \zeta)
$$

A Figura 54 apresenta uma ilustração de um processo estocástico. Nesta, o significado da variável $\zeta$ fica claro por meio das linhas pontilhadas que cruzam transversalmente os gráficos. 


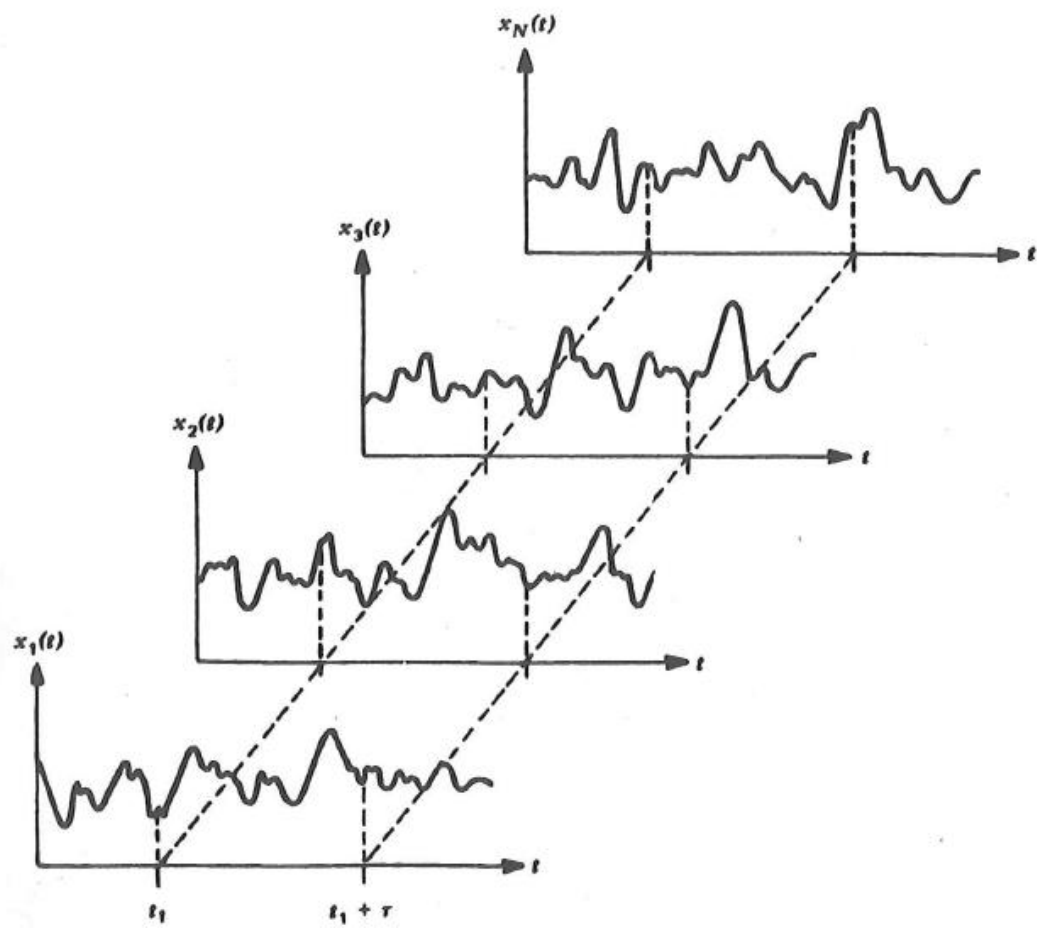

Figura 54 - Visualização das possíveis realizações de um processo estocástico (BENDAT e PIERSOL, 2000)

Para um possível resultado $\zeta_{i}, \mathbf{x}\left(t, \zeta_{i}\right)$ é uma única função com relação ao tempo. Fixado $t_{j}$, $\mathbf{x}\left(t_{j}, \zeta\right)$ percorre todos os possíveis valores $\zeta\left(t_{j}\right)$ correspondente as saídas do experimento. Para tornar mais sucinta a notação, o processo aleatório pode ser denotado apenas por $\mathbf{x}(t)$. A média de um processo $\mathbf{x}(t, \zeta)$ é uma função do tempo $\eta(t)$, ou também denominada $E\{\mathbf{x}(t)\}$, correspondente ao valor médio, em cada instante, de todos os possíveis resultados $\zeta$.

$$
E\{\mathbf{x}(t)\}=\int_{-\infty}^{\infty} x f(x, t) d x
$$

Onde $f(x, t)$ é a função densidade de probabilidade ou, ainda, a derivada da função frequência acumulada, ou função de distribuição de probabilidade.

$$
F(x ; t)=P\{\mathbf{x}(t) \leq x\}
$$

Repetindo um experimento $F n$ vezes e registrando no tempo $t$ o valor da grandeza medida, $F(x ; t)$ corresponde a razão entre o número de vezes em que o valor $\mathbf{x}(t)$ permanece igual ou inferior ao valor pré estabelecido $x$.

A função $f(x, t)$ mostrada na equação (183) é dada por: 


$$
f(x, t)=\frac{\partial F(x, t)}{\partial x}
$$

Introduzindo uma segunda restrição ao valor medido, é possível construir a distribuição de probabilidade de segunda ordem do processo $\mathbf{x}(t)$.

$$
\begin{gathered}
F\left(x_{1}, x_{2} ; t_{1}, t_{2}\right)=P\left\{\mathbf{x}\left(t_{1}\right) \leq x_{1}, \mathbf{x}\left(t_{2}\right) \leq x_{2}\right\} \\
f\left(x_{1}, x_{2} ; t_{1}, t_{2}\right)=\frac{\partial^{2} F\left(x_{1}, x_{2} ; t_{1}, t_{2}\right)}{\partial x_{1} \partial x_{2}}
\end{gathered}
$$

Por outro lado, a autocorrelação é um parâmetro estatístico importante do sinal e seu emprego na identificação e quantificação das fontes de ruído são discutidos nos tópicos subsequentes. Por enquanto, é importante descrever formalmente a autocorrelação $R\left(t_{1}, t_{2}\right)$ de um processo $\mathbf{x}(t)$ como sendo:

$$
R\left(t_{1}, t_{2}\right)=E\left\{\mathbf{x}\left(t_{1}\right) \mathbf{x}\left(t_{2}\right)\right\}=\int_{-\infty}^{\infty} x_{1} x_{2} f\left(x_{1}, x_{2} ; t_{1}, t_{2}\right) d x_{1} d x_{2}
$$

Antes de efetivamente apresentar os métodos de análise do ruído, cabe definir processo estocástico estacionário.

Designa-se por estacionário o processo cujos parâmetros estatísticos se mantêm constantes mesmo ao se realizar um deslocamento no tempo. Essa característica é demonstrada na equação (187).

$$
f(x, t)=f(x, t+\varepsilon)
$$

Com base na equação acima, é possível concluir que a função densidade de probabilidade de primeira ordem de um processo estocástico estacionário não depende do tempo.

No caso em que a função densidade é de ordem dois, é possível demonstrar que este parâmetro passa a depender apenas da diferença entre os tempos da amostra e, desta forma:

$$
f\left(x_{1}, x_{2} ; t_{1}, t_{2}\right)=f\left(x_{1}, x_{2} ; t_{1}+\varepsilon, t_{2}+\varepsilon\right)=f\left(x_{1}, x_{2} ; t_{1}-t_{2}\right)
$$

Aplicando o resultado da equação acima ao cálculo da autocorrelação, no caso de processos estacionários, passa a ser possível escrevê-la como: 


$$
R(\boldsymbol{\tau})=E\{\mathbf{x}(t+\boldsymbol{\tau}) \mathbf{x}(t)\}
$$

O chamado ruído branco é um exemplo de processo estocástico estacionário.

\subsubsection{Análise espectral das componentes do ruído}

A DEP (densidade espectral de potência) é a forma comumente utilizada na decomposição de uma série temporal.

É uma ferramenta poderosa na análise e caracterização de dados e modelagem estocástica (SCHWARTZ e FRIEDLAND, 1972).

Defini-se densidade espectral de potência de um processo $\mathbf{x}(t)$ como sendo a transformada de Fourier da sua autocorrelação (PAPOULIS, 1965).

$$
S(\omega)=\int_{-\infty}^{\infty} e^{-j \omega \boldsymbol{\tau}} R(\boldsymbol{\tau}) d \boldsymbol{\tau}
$$

É possível demonstrar que a relação descrita acima é válida mesmo para processos não estacionários (PAPOULIS, 1965). No entanto, há que se lembrar que as integrais empregadas na transformação de Fourier exigem o caráter estacionário do sinal, caso contrário não são obtidos valores finitos para os coeficiêntes da série.

A Tabela 5 condensa as expressões das densidades espectrais descritas anteriormente, provenientes de cada componente do ruído, conforme apresentado em (IEEE Standard Specification Format Guide and Test Procedure for Single Axis Interferometric Fiber Optic Gyros, 1997 (R2008)). 
Tabela 5 - Densidade espectral de potência de cada tipo de ruído

\begin{tabular}{|l|c|c|}
\hline Tipo de Ruído & Fórmula da DEP & Identificação do Coeficiente \\
\hline Quantization Noise & $S(f)=\frac{4 Q^{2}}{\tau} \sin ^{2} \pi f \tau$ & $Q:$ quantization - noise coefficient \\
\hline Random Walk & $S(f)=N^{2}$ & N: Random Walk coefficient \\
\hline Bias Instability & $S(f)=\frac{B^{2}}{2 \pi f}$ & B: Bias Instability coefficient \\
\hline Rate Random Walk & $S(f)=\frac{K^{2}}{(2 \pi f)^{2}}$ & K: Rate Random Walk coefficient \\
\hline
\end{tabular}

Os coeficientes na Tabela 5 são a quantificação de cada uma das componentes do ruído, sendo parâmetros importantes de projeto de um sistema inercial. O coeficiente de passeio aleatório, $N$, e o coeficiente de instabilidade do bias, $B$, são comumente encontrados nas especificações do sensor.

Tais coeficientes podem ser obtidos por meio da análise dos gráficos log-log da DEP versus a frequência de amostragem ou do gráfico log-log do desvio de Allan (raiz da variância) versus a grandeza $\tau$.

Ambos os métodos estão correlacionados e a opção entre qual empregar é associada à familiaridade do pesquisador com o tema. (HOU, 2004) apresenta a equação (191) como meio de calcular a variância de Allan em termos da Densidade Espectral de Potência.

$$
\operatorname{AVAR}(\tau)=4 \int_{0}^{\infty} S(f) \frac{\sin ^{4}(\pi f \tau)}{(\pi f \tau)^{2}} d f
$$

Neste texto o método apresentado será o do desvio de Allan.

Empregando-se a equação (191) é possível estabelecer relação entre a componente do ruído, modelada em termos da DEP, e a AVAR.

Segundo (EL-SHEIMY, HOU e NIU, 2008) a equação (191) leva à compreensão da AVAR como a potência total do erro passada por um filtro cuja função de transferência é dada por $\sin ^{4}(x) /(x)^{2}$, que é habitualmente utilizado para criar e operar sobre subconjuntos de um sinal.

Ao se efetuar a integração apresentada na equação (191) são obtidas as expressões listadas na Tabela 6. 
Tabela 6 - Quantificação dos ruídos a partir da AVAR

\begin{tabular}{|l|c|}
\hline Tipo de Ruído & Fórmula da AVAR \\
\hline $\begin{array}{l}\text { Quantization } \\
\text { Noise }\end{array}$ & $A V A R(\tau)=\frac{3 Q^{2}}{\tau^{2}}$ \\
\hline Random Walk & $A V A R(\tau)=\frac{N^{2}}{\tau}$ \\
\hline Bias Instability & $A V A R(\tau)=\frac{2 B^{2}}{\pi}\left[\ln 2-\frac{\sin ^{3} x}{2 x^{2}}(\sin x+4 x \cos x)+C_{i}(2 x)+C_{i}(4 x)\right] 17$ \\
Rate Random & $A V A R(\tau)=\frac{K^{2}}{(2 \pi f)^{3}}$ \\
\hline
\end{tabular}

Calculando a raiz quadrada das expressões da Tabela 6 é possível obter os respectivos desvios $\sigma(\tau)$

O emprego do gráfico log-log traz um benefício claro à representação das componentes do ruído: cada uma delas passa a ser representada por um segmento de reta.

Tomando como exemplo o ruído quantizado, cuja curva $A V A R(\tau)$ é dada por:

$$
\operatorname{AVAR}(\tau)=\frac{3 Q^{2}}{\tau^{2}} \rightarrow \sigma(\tau)=\frac{\sqrt{3} Q}{\tau}
$$

Aplicando-se o logaritmo à equação (192) obtêm-se:

$$
\log (\sigma)=-\log (\tau)+\log (Q)+\frac{\log (3)}{2}
$$

Sendo $Q$ uma constante, a equação (193) representa uma reta de coeficiente angular -1 no gráfico log-log. Da equação anterior é possível, ainda, se obter o valor do coeficiente $Q$ ao se igualar os demais termos a zero.

$$
\begin{gathered}
-\log (\tau)+\log \left(3^{1 / 2}\right)=0 \\
A V A R\left(3^{1 / 2}\right)=Q
\end{gathered}
$$

\footnotetext{
${ }^{17} x$ na expressão corresponde a $\pi f_{0} \tau$ e $f_{0}$, por sua vez, é a frequência de corte.
} 
Repetindo os procedimentos demonstrados nas equações (193) (194) e (195) é possível identificar os trechos referentes a cada componente do ruído e os respectivos valores quantitativos. A Figura 55 condensa tais informações.

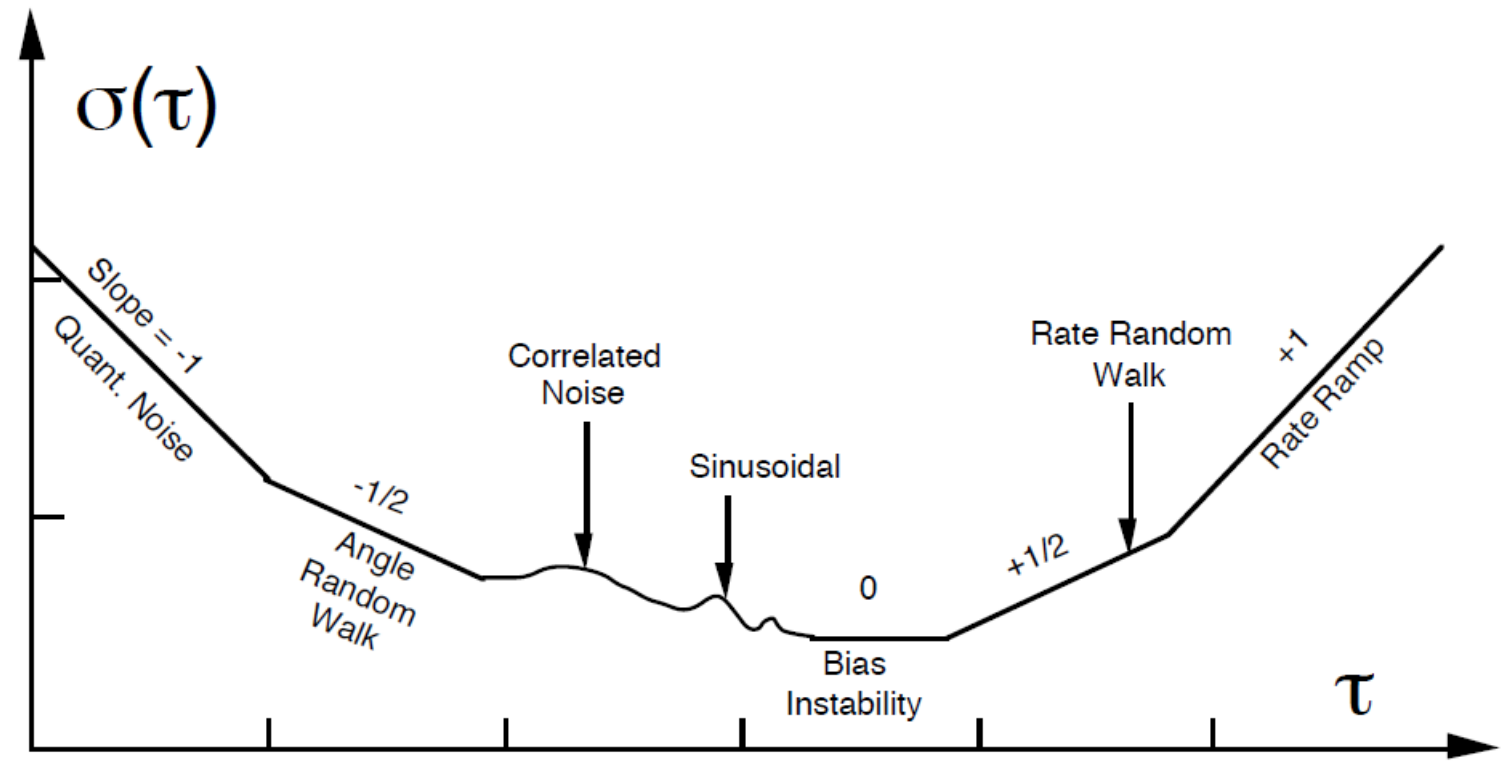

Figura 55 - Tipos de ruído identificados em uma curva exemplo do desvio de Allan (IEEE Standard Specification Format Guide and Test Procedure for Single Axis Interferometric Fiber Optic Gyros, 1997 (R2008))

Este tópico procurou mostrar de forma resumida a maneira como interpretar o gráfico AVAR. A seguir será apresentado o método de cálculo da variância a partir do sinal original. 


\subsubsection{Cálculo da Variância de Allan a partir do sinal original}

A variância de Allan é calculada segundo a equação (196). (STOCKWELL, 2006)

$$
\operatorname{AVAR}(\tau)=\frac{1}{2(n-1)} \sum_{i}\left(y(\tau)_{i+1}-y(\tau)_{i}\right)^{2}
$$

Onde $\tau$ é o tamanho de cada um dos $n$ compartimentos nos quais o sinal foi dividivo.

Pode-se concluir da equação (196) que a AVAR de certo $\tau$ é a média das variâncias móveis calculada para o sinal dividido em setores de tamanho $\tau$. Variando o tamanho destes setores é possível obter a curva $\operatorname{AVAR}(\tau)$ e, imediatamente, a curva $\sigma(\tau)$ que, representada em um gráfico do tipo log-log, é exemplificada na Figura 56.

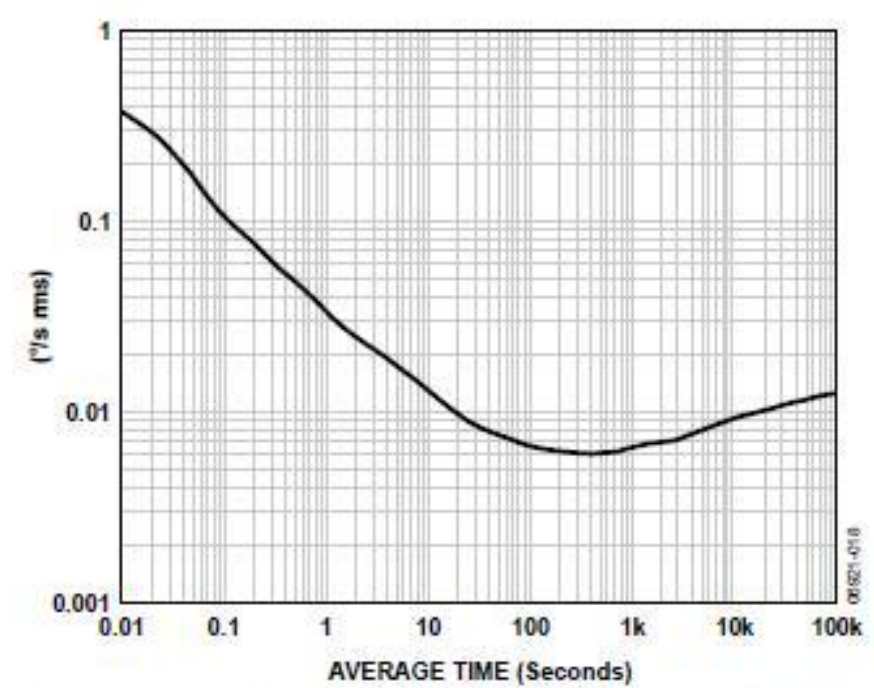

Figura 56 - Gráfico do desvio de Allan do sinal proveniente dos girômetros MEMS utilizados nesta pesquisa (ANALOG DEVICES, 2008)

Pode-se mostrar que o erro percentual para a estimação da variância de Allan é inversamente proporcional ao número de grupos nos quais o registro foi dividido. Esse fato cria um compromisso entre a extensão da curva passível de análise e o comprimento do registro. (EL-SHEIMY, HOU e NIU, 2008) apresentam a equação (197) como meio para obter o valor percentual do erro associado à estimativa do desvio de Allan. 


$$
\sigma(\delta)=\frac{1}{\sqrt{2\left(\frac{N}{k}-1\right)}}
$$

$\mathrm{Na}$ equação acima $N$ representa o número de intervalos em que o sinal foi dividido, $k$ o número de registros contidos no intervalo e $\delta$ corresponde à extensão (em tempo) do registro.

\subsubsection{Conclusões acerca dos Erros}

Esta seção explorou de forma bastante superficial os principais erros inerentes às medições inerciais. Recomenda-se a leitura de (LAWRENCE, 1998) e (TITTERTON e WESTON, 2004) para discussões mais aprofundadas, embora o tema ainda seja foco de inúmeros estudos e publicações científicas.

De maneira geral, erros determinísticos permitem modelos de correção, enquanto erros não determinísticos limitam a utilização do sensor para uma dada função, ou seja, no presente contexto são parâmetros de projeto da UMI.

Após breve apresentação das principais tecnologias de sensores e as fontes de erro comuns nas medições inerciais, a Tabela 7 associa e sintetiza ambas as informações.

Tabela 7 - Resumo das tecnologias de sensores e erros típicos

\begin{tabular}{|l|l|l|}
\multicolumn{1}{|l|}{ Tipo de sensor } & Erro dominante & \multicolumn{1}{l}{ Possível causa } \\
\hline $\begin{array}{l}\text { Acelerômetro } \\
\text { de Pêndulo } \\
\text { Forçado }\end{array}$ & $\begin{array}{l}\text { Bias e Sensibilidade } \\
\text { cruzada }\end{array}$ & $\begin{array}{l}\text { Pickoff com zero desviado. } \\
\text { Desalinhamento da massa de prova em relação à } \\
\text { articulação somada à vibração (aceleração) no eixo } \\
\text { do pêndulo gera leituras artificiais. }\end{array}$ \\
\hline $\begin{array}{l}\text { Acelerômetro } \\
\text { Mecânico de } \\
\text { Fibra Ótica }\end{array}$ & Precisão & $\begin{array}{l}\text { Resolução da matriz de sensores foto sensíveis } \\
\text { (CCD) }\end{array}$ \\
\hline $\begin{array}{l}\text { Acelerômetro } \\
\text { de Hastes } \\
\text { Vibratórias }\end{array}$ & $\begin{array}{l}\text { Desvio do bias } \\
\text { fator de escala }\end{array}$ & $\begin{array}{l}\text { As hastes metálicas tracionadas pela massa sofrem } \\
\text { escoamento ao longo do tempo modificando sua } \\
\text { frequência natural. } \\
\text { A rigidez do material das barras modifica-se com a } \\
\text { temperatura. }\end{array}$ \\
\hline
\end{tabular}




\begin{tabular}{|c|c|c|}
\hline Tipo de sensor & Erro dominante & Possível causa \\
\hline $\begin{array}{l}\text { Acelerômetro } \\
\text { de Fibra Ótica }\end{array}$ & $\begin{array}{l}\text { Linearidade do fator } \\
\text { de escala }\end{array}$ & $\begin{array}{l}\text { Fibras ópticas submetidas à tensão apresentam o } \\
\text { fenômeno de foto elasticidade (modificação na } \\
\text { refringência), que pode inserir distorções à } \\
\text { medida. }\end{array}$ \\
\hline $\begin{array}{l}\text { Giroscópio } \\
\text { Tradicional }\end{array}$ & $\begin{array}{l}\text { Ruídos durante a } \\
\text { operação; } \\
\text { dependência da } \\
\text { largura de banda } \\
\text { com a temperatura e } \\
\text { problemas de } \\
\text { realimentação no } \\
\text { sistema em malha } \\
\text { fechada. }\end{array}$ & $\begin{array}{l}\text { Causados por desalinhamento nos mancais ou } \\
\text { imperfeições das esferas dos rolamentos. } \\
\text { O sistema habitualmente é imerso em óleo que, } \\
\text { além de proteger as estruturas internas de choques, } \\
\text { garante o amortecimento das suspensões para } \\
\text { melhorar a resposta dinâmica do sistema. A } \\
\text { viscosidade do fluido no qual o conjunto é imerso } \\
\text { pode ser fortemente influenciada pela temperatura. }\end{array}$ \\
\hline $\begin{array}{l}\text { Giroscópio } \\
\text { Dinamicamente } \\
\text { Sintonizado }\end{array}$ & Bias & $\begin{array}{l}\text { Anisoelasticidade das hastes que conectam a } \\
\text { suspensão Cardan ao rotor. } \\
\text { Imperfeições na distribuição de inércia do rotor. } \\
\text { Interferências magnéticas entre o motor e os } \\
\text { atuadores que fecham a malha do sistema. }\end{array}$ \\
\hline $\begin{array}{l}\text { Giroscópio } \\
\text { Fibra ótica }\end{array}$ & $\begin{array}{l}\text { Bias e deriva do } \\
\text { fator de escala ; } \\
\text { Random Walk }\end{array}$ & $\begin{array}{l}\text { Bias e fator de escala causada principalmente por } \\
\text { gradientes de temperatura no interior do sensor } \\
\text { que modificam o comprimento de onda gerada nas } \\
\text { fontes de luz, assim como a propriedade refratária } \\
\text { da fibra óptica. } \\
\text { Em períodos curtos (ordem de segundos) o sensor } \\
\text { funciona como gerador de ruído branco graças à } \\
\text { quantização da luz em fótons e o efeito disso no } \\
\text { sensor. }\end{array}$ \\
\hline
\end{tabular}




\begin{tabular}{|c|c|c|}
\hline Tipo de sensor & Erro dominante & Possível causa \\
\hline $\begin{array}{l}\text { Sensores } \\
\text { MEMS }\end{array}$ & $\begin{array}{l}\text { Baixos fatores de } \\
\text { escala; elevados } \\
\text { níveis de ruído; forte } \\
\text { dependência com a } \\
\text { temperatura }\end{array}$ & $\begin{array}{l}\text { Segundo (TITTERTON e WESTON, 2004) a } \\
\text { redução no tamanho dos sensores tende a reduzir } \\
\text { também o fator de escala (diretamente relacionado } \\
\text { à precisão) e elevar o nível de ruído. } \\
\text { O módulo de elasticidade do silício é fortemente } \\
\text { influenciado pela temperatura, o que influencia o } \\
\text { bias e o fator de escala do sensor. }\end{array}$ \\
\hline
\end{tabular}

É possível perceber que os processos de fabricação de cada um dos tipos de sensores dão origem a problemas particulares, e são esses problemas que direcionam o aprimoramento da tecnologia do sensor, assim como o desenvolvimento de novas configurações. 


\section{Metodologia da Pesquisa}

No início do capítulo 2, foi feita uma breve caracterização do problema estudado neste trabalho. Tendo sido apresentada a revisão dos tópicos teóricos, é possível refazer tal caracterização com maior propriedade e dar início aos estudos e processos que levam à buscar por atender os objetivo estabelecidos.

Foram discutidos inúmeros conceitos associados à navegação inercial durante os capítulos anteriores embora o SMET (Sistema de Monitoração da Estaca Torpedo) não tenha sido concebido para realizar qualquer tipo de navegação. Esta unidade de medição inercial (UMI) e o algoritmo vigente de processamento dos dados foram desenvolvidos visando determinar parâmetros específicos da trajetória da estaca-torpedo. Tendo em vista estes objetivos específicos, o SMET foi equipado com sensores de baixo custo do tipo MEMS. Tais sensores, como discutido no item 4.4.4, são, em princípio, inadequados à navegação (inercial) propriamente.

Mesmo assim, o tema serviu como paralelo para o problema, uma vez que o SMET emprega sensores inerciais. Este assunto balizou as investigações com a instrumentação e os processos de correção do sinal, bem como motivou a criação de um algoritmo alternativo para determinação dos parâmetros de interesse.

\subsection{MATERIAIS}

\subsubsection{Descrição da Unidade de Medição Inercial}

Neste tópico será feita uma descrição detalhada da unidade de medição inercial utilizada durante a presente pesquisa. Tal descrição foi estruturada principalmente sobre os conceitos apresentados durante o item 4.4 .

Como já citado, o SMET é uma unidade de medição inercial equipada com três acelerômetros de dois graus de liberdade cada e três girômetros de um grau de liberdade, montados ortogonalmente entre si. Os sensores são do tipo MEMS e são montados sobre placas de circuito impresso semelhantes às mostradas na Figura 32. Além dos sensores inerciais, o SMET conta com um transdutor de pressão e um sensor de temperatura.

O sistema é do tipo strapdown e os eixos sensíveis dos sensores estão dispostos como indica a Figura 57. 


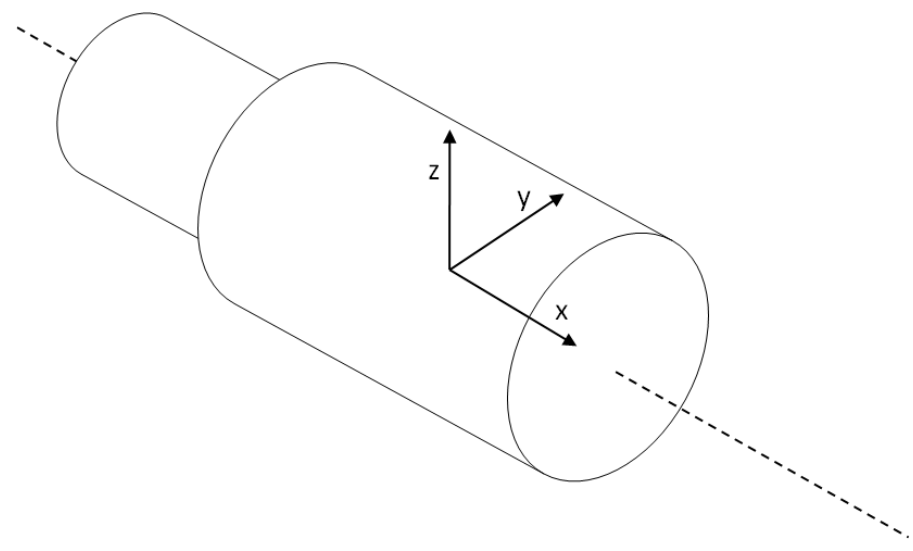

Figura 57 - Orientação dos eixos do SMET

Os sensores MEMS que equipam o SMET são fabricados em grande escala pela Analog Devices e, portanto, são sensores de baixo custo. A Tabela 4 apresenta um pequeno comparativo de custos entre diferentes tecnologias de sensores. Mais adiante esses sensores empregados serão detalhados.

O SMET fornece medidas pré-processadas, ou seja, embora seus sensores tenham como saída tensões elétricas, o usuário recebe a informação já nas unidades das grandezas medidas: $g$ para as medidas de aceleração e $\%$ para as medidas de velocidade angular. Este trabalho restringiu-se a lidar com as informações fornecidas pelo SMET não discutindo, por isso, aspectos da sua construção ou os métodos utilizados pelo fabricante (NavCon) para converter os sinais elétricos em medidas de aceleração e velocidade angular. Sendo assim, os valores de bias e fator de escala encontrados durante os experimentos em laboratório representam, apenas parâmetros de calibração.

\subsubsection{Acelerômetros no SMET}

Os acelerômetros empregados no SMET são pequenos sensores de perfil baixo similares a chips encontrados no interior de um aparelho eletrônico. Possuem fundo de escala nominal de \pm 18 g e são identificados no mercado como ADXL321. Seu princípio de funcionamento baseia-se no mecanismo de pêndulo descrito no item 4.4.2, exceto pelo fato de que as deflexões ocorrem no plano do substrato e são registradas em duas direções, já que se tratam de acelerômetros de dois graus de liberdade.

O sensor opera em malha aberta e o pickoff é a variação da capacitância associada ao deslocamento da massa de prova com relação a estruturas fixas ancoradas ao substrato. Todo 
esse conjunto é equipado com eletrodos. A Figura 58 apresenta uma fotografia dessa configuração para um sensor do mesmo fabricante e princípio de funcionamento semelhante.

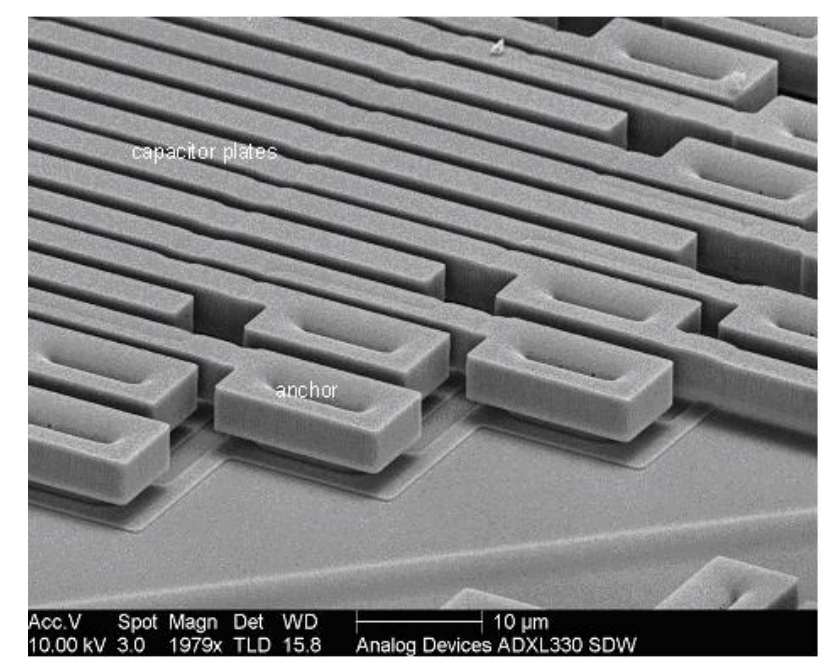

Figura 58 - Pontos de ancorágem e vigas que operam como pickoff do acelerômetro MEMS (DIXON)

Os sinais de saída do sensor são tensões proporcionais à aceleração em cada grau de liberdade.

A Tabela 8 condensa as principais especificações sobre o sensor.

Tabela 8 - Dados dos acelerômetros empregados no SMET (ANALOG DEVICES, 2008)

\begin{tabular}{|l|l|}
\hline Fundo de Escala & $\pm 18 \mathrm{~g}$ \\
\hline Bias & $1,5 \mathrm{~V} / 0,0855 \mathrm{~g}$ \\
\hline Fator de Escala & $57 \mathrm{mV} / \mathrm{g}$ \\
\hline Variação do Bias com a temperatura & $\pm 2 \mathrm{mg} /{ }^{\circ} \mathrm{C}$ \\
\hline Variação do Fator de Escala com a temperatura & $\pm 0,2 \%($ do fundo de escala) $/ \mathrm{g}$ \\
\hline Largura de Banda & $<50 \mathrm{~Hz}$ \\
\hline Erro de Alinhamento com relação a carcaça & $\pm 1^{\circ}$ \\
\hline Erro de Alinhamento entre eixos sensíveis & $\pm 0,1^{\circ}$ \\
\hline
\end{tabular}

Tais parâmetros são referentes aos valores típicos, medidos a $25^{\circ} \mathrm{C}$ e na condição em que o sensor não é submetido a nenhuma aceleração.

Os sensores MEMS são fabricados em grande quantidade e estão sujeitos a variação, embora haja um controle rígido nos processos produtivos. Desta forma, o fabricante disponibiliza 
histogramas provenientes de testes realizados em grandes amostras de sensores, como o exemplificado na Figura 59. Neste caso a figura provém de (ANALOG DEVICES, 2008).

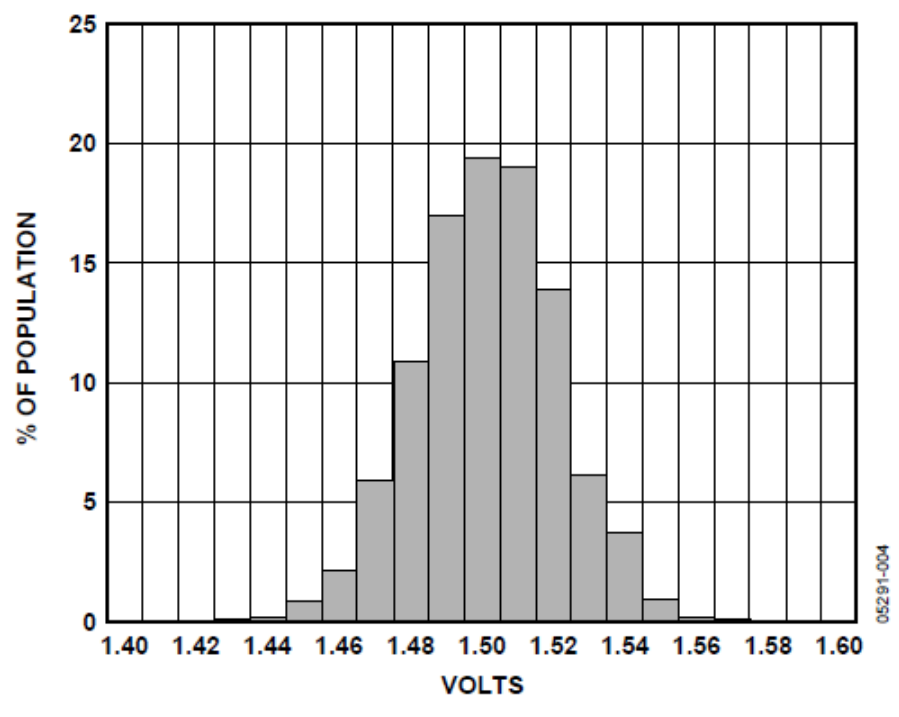

Figure 4. X-Axis Zero g Bias at $25^{\circ} \mathrm{C}$

Figura 59 - histograma do bias na população de sensores (ANALOG DEVICES, 2008)

Esta variabilidade nos parâmetros de calibração torna necessário submeter cada um dos sensores, presentes na unidade de medição inercial, a uma bateria de testes, caso se pretenda empregá-la na tarefa de navegação ou mesmo reconstrução da trajetória. Tais testes serão descritos adiante, capítulo 6.

\subsubsection{Girômetros no SMET}

O SMET emprega girômetros do mesmo fabricante (Analog Devices). A designação comercial dos girômetros empregado é ADXRS150, sendo o número 150 referente ao fundo de escala destes equipamentos: $\pm 150 \% \mathrm{~s}$.

Tratam-se de sensores MEMS, cujo princípio de funcionamento assemelha-se aos sensores de garfos ressonantes sintonizados (TFG) descritos no item 4.4.4. Como visto anteriormente, nesse tipo de sensor duas massas de prova são colocadas em movimento oscilatório por atuadores que, neste caso, baseiam-se em forças eletrostáticas. Massas em movimento, quando rotacionadas, ficam submetidas a aceleração de Coriolis que, por sua vez, é proporcional a velocidade angular do corpo. A aceleração é detectada por variação na capacitância entre pequenas estruturas condutoras em forma de pente, situadas nas 
extremidades das massas de prova. A Figura 60 ilustra o funcionamento do dispositivo. Devese observar, contudo, que se tratam de dois conjuntos de massas de prova e suspensões, dispostos em torno do centro do sensor.
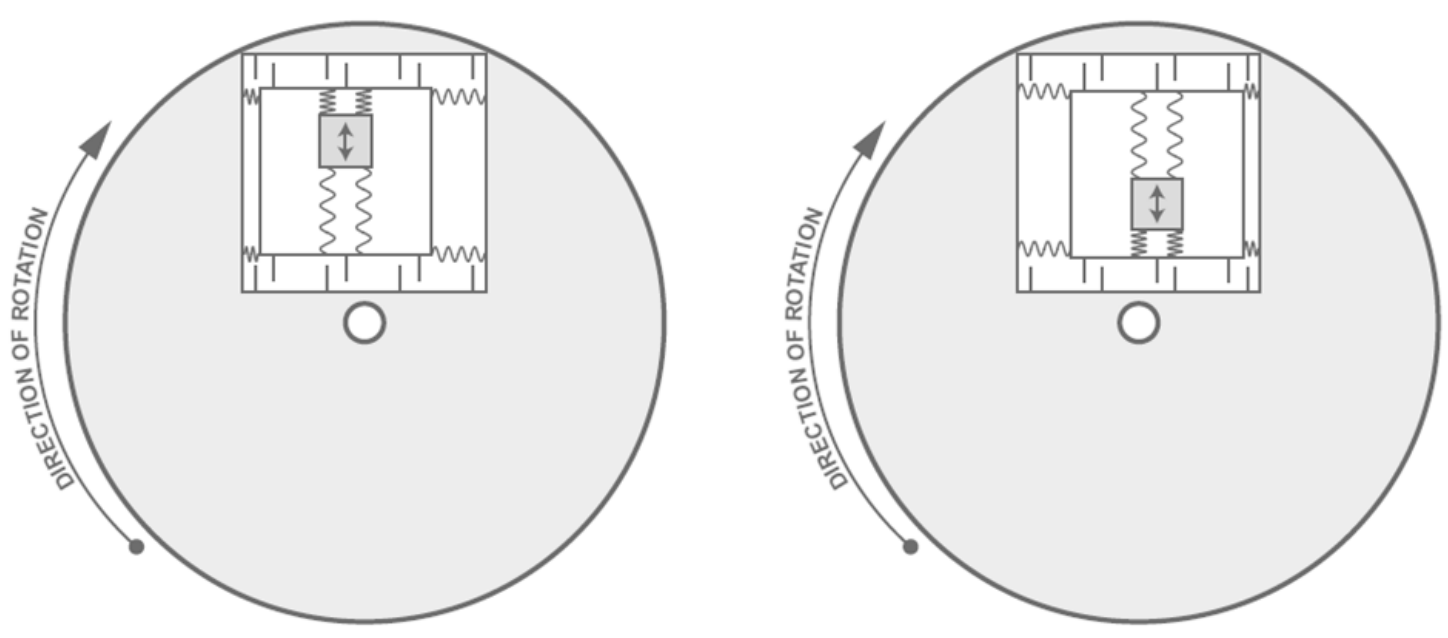

Figura 60 - Princípio de funcionamento dos giros empregados no SMET (GEEN e KRAKAUER, 2003)

Os pickoffs capacitivos são representados na Figura 60 por pequenos traços verticais dispostos entre a massa vibratória e a estrutura externa. A Figura 61 apresenta uma imagem ampliada do sensor real.

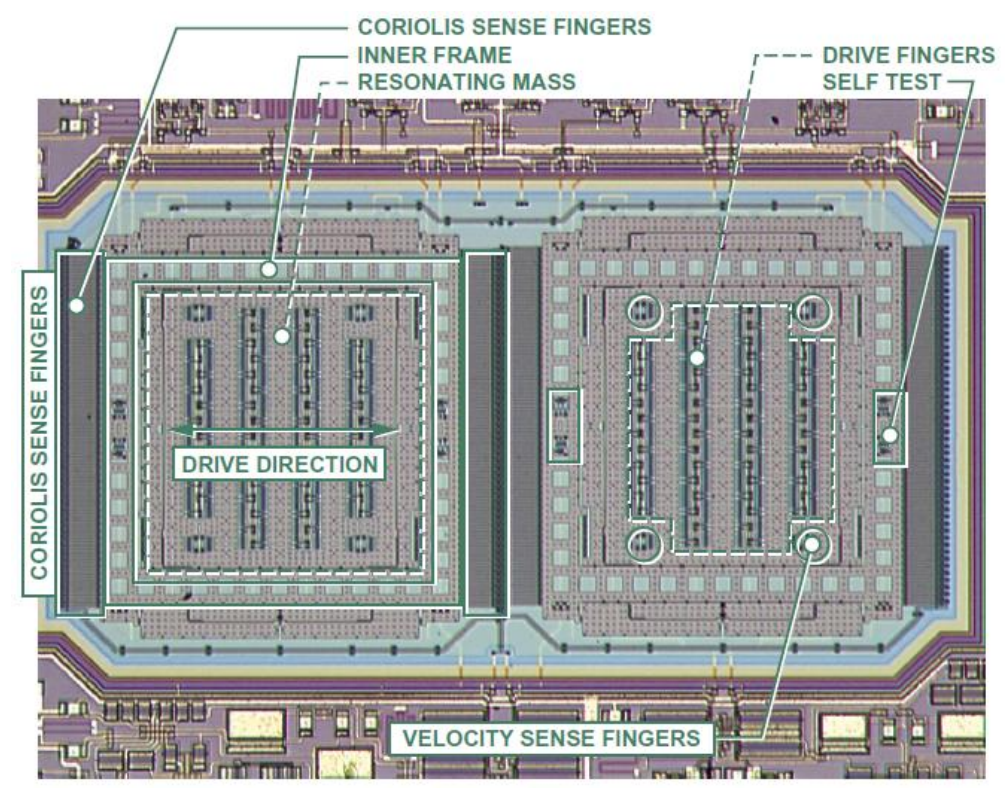

Figura 61 - Fotografia do interior dos giros empregados no SMET (GEEN e KRAKAUER, 2003) 
Nessa figura é possível observar as duas estruturas vibratórias posicionadas simetricamente em torno do centro do sensor, bem como as principais estruturas já descritas. As imagens aqui apresentadas, assim como o funcionamento detalhado da série de giroscópios ADXR, encontram-se na referência (GEEN e KRAKAUER, 2003).

A Tabela 9 contém os principais parâmetros do giroscópio.

Tabela 9 - Dados dos girômetros empregados no SMET (ANALOG DEVICES, 2008)

\begin{tabular}{|l|l|}
\hline Fundo de Escala & $\pm 150 \%$ \\
\hline Bias & $2,5 \mathrm{~V} / 0,0315 \%$ \\
\hline Fator de Escala & $12,5 \mathrm{mV} /{ }^{\circ} / \mathrm{s}$ \\
\hline Variação do Bias com a temperatura & $\pm 5 \mathrm{mV} /{ }^{\circ} \mathrm{C}$ ou $0,4^{\circ} / \mathrm{s} /{ }^{\circ} \mathrm{C}$ \\
\hline
\end{tabular}

Conhecendo a relação intrínseca entre a temperatura e os parâmetros de calibração dos girômetros MEMS, o fabricante equipa tais sensores com transdutores de temperatura. Estes dados de temperatura serão empregados no desenvolvimento deste trabalho, durante a tentativa de corrigir parâmetros como o bias.

\subsection{SinaIS OBTIDOS EM CAMPo}

Assim como o SMET, foi disponibilizado para a presente pesquisa um conjunto de registros obtidos em ensaios em campo. Estes ensaios corresponderam a lançamentos da estaca-torpedo “T-35” no campo Barracuda, na bacia de Campos, Rio de Janeiro, no ano de 2007.

Cada um dos registros tem duração de 100s e foram colhidos com taxa de aquisição de $100 \mathrm{~Hz}$.

Os registros contêm os seguintes dados:

- data na qual a aquisição foi realizada

- hora na qual a aquisição foi realizada na forma "horas : minutos : segundos"

- aceleração, mediada em relação a aceleração da gravidade , no eixo x do SMET

- aceleração, mediada em relação a aceleração da gravidade, no eixo y do SMET

- aceleração, mediada em relação a aceleração da gravidade, no eixo z do SMET

- aceleração, em $\%$, medida no eixo x do SMET

- aceleração, em $\%$, medida no eixo y do SMET 
- aceleração, em $\% / s$, medida no eixo z do SMET

- pressão já convertida em profundidade

- temperatura em ${ }^{\circ} \mathrm{C}$

Todos estes dados são dispostos em dez colunas adjacentes em um arquivo de texto.

Os registros referentes aos lançamentos da estaca-torpedo foram, ainda, identificados através do nome do arquivo, por meio do número do lançamento, da linha de amarração presa à estaca e o número de identificação do SMET que realizou o registro. Esta última informação é importante, pois os parâmetros obtidos em laboratório são particulares a cada conjunto de sensores.

A seguir, a Figura 62 exemplifica os sinais provenientes dos sensores inerciais referentes a um dado lançamento da estaca-torpedo.

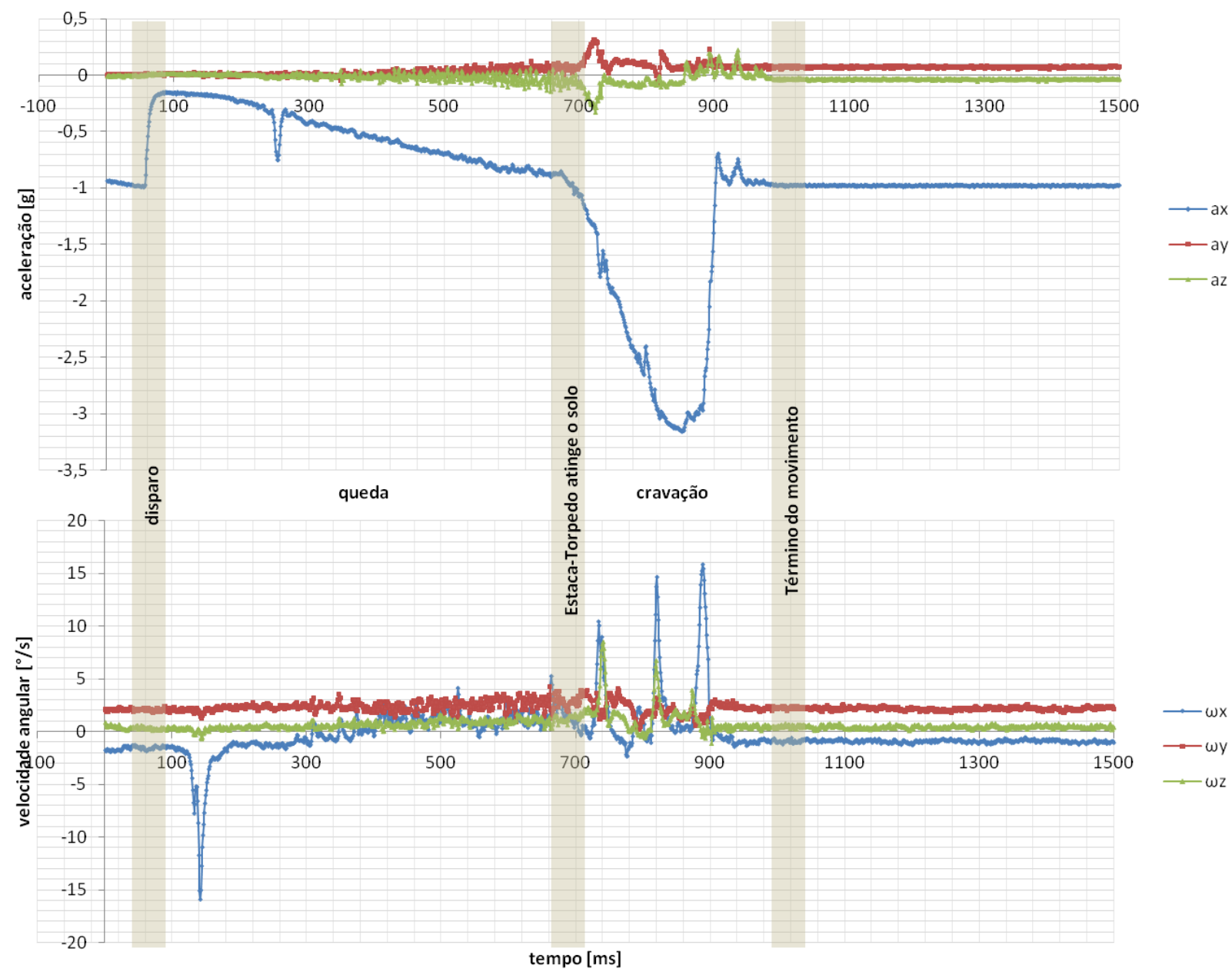

Figura 62 - Exemplo de sinal do lançamento da estaca-torpedo em que os marcos principais foram destacados 
Estão indicados no gráfico os principais eventos do lançamento tais como: a liberação da estaca; o momento em que a mesma atinge o solo e o momento em que o movimento cessa completamente.

São apresentados também, na Figura 63 e na Figura 64, os registros de profundidade e temperatura do mesmo lançamento. Como comentado anteriormente, o SMET fornece medidas pré-processadas nas unidades correspondentes às grandezas medidas. No caso das medidas de pressão, a unidade de medição também armazena a profundidade equivalente.

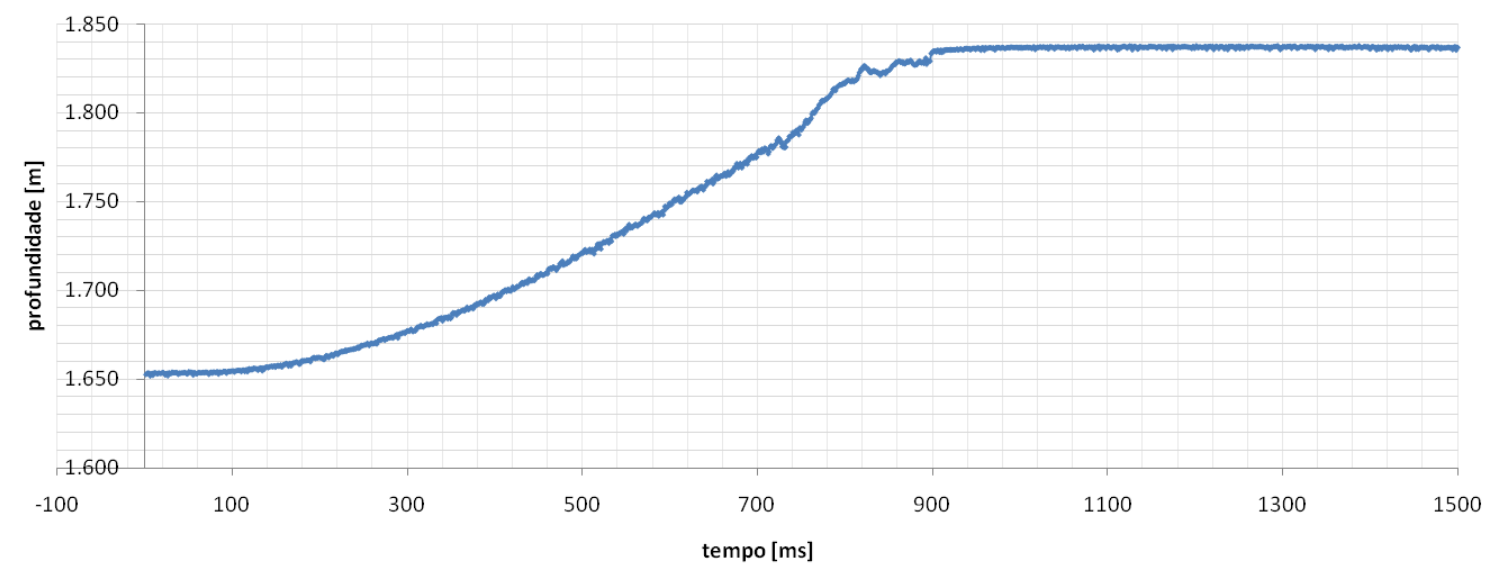

Figura 63 - Exemplo do registro de pressão(profundidade) de um lançamento da estaca-torpedo

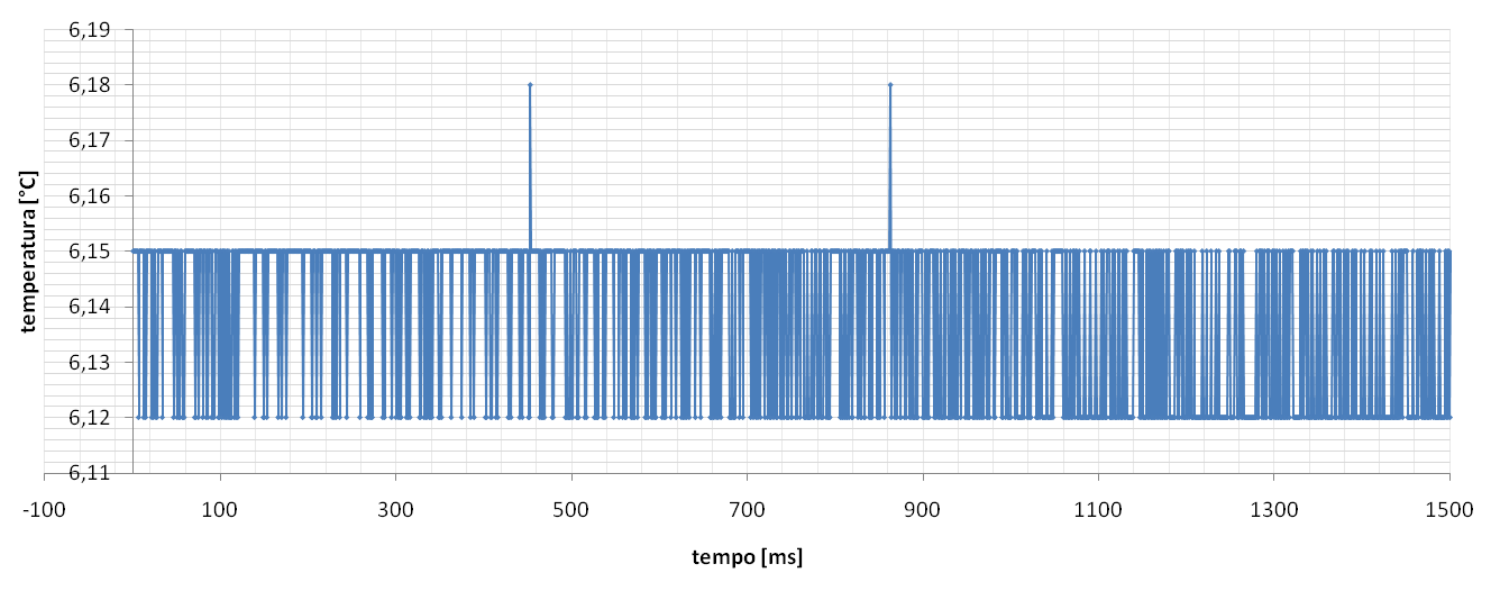

Figura 64 - Exemplo do registro de temperatura de um lançamento da estaca-torpedo 


\subsection{ALGORITMO Vigente}

Para o desenvolvimento da presente pesquisa, fez-se disponível, ainda, o procedimento de cálculo utilizado em campo para o processamento dos sinais e determinação dos parâmetros de interesse - velocidade vertical máxima, inclinação final e azimute. Esse procedimento foi consolidado na forma de uma planilha acompanhada de um breve relatório (PETROBRAS, 2007). Juntos, estes materiais descrevem brevemente as condições dos lançamentos - data, localização, embarcação empregada, estaca-torpedo empregada, equipamentos de medição - e os cálculos realizados para obtenção da velocidade vertical máxima da estaca, da inclinação final desta e do azimute do plano que contém a seção média da estaca quando a mesma encontra-se cravada. Este último parâmetro é denominado em (PETROBRAS, 2007) como azimute da inclinação. Mais detalhes sobre este e sobre os demais parâmetros, serão apresentados nos tópicos seguintes.

\subsection{MÉTODOS}

Neste item é feita uma breve descrição da evolução da pesquisa e do encadeamento entre eventos.

Tendo acesso a uma das UMIs empregadas nos lançamentos reais, o primeiro passo da pesquisa foi familiarizar-se com seu funcionamento. Essa etapa foi consolidada na forma de uma primeira bateria de experimentos, identificados como experimentos pendulares. Embora a trajetória descrita por um pêndulo seja muito diferente daquela percorrida pela estacatorpedo durante um lançamento típico, optou-se por essa configuração principalmente pela facilidade de montagem do experimento. Adicionalmente, o pêndulo esférico é um sistema dinâmico simples de ser modelado analiticamente, fato este que permitiu gerar sinais artificiais, análogos aos reais, para enriquecer as análises. Embora detalhes sobre a execução do experimento, assim como alguns resultados, sejam apresentados mais adiante, cabe comentar a principal conclusão deste conjunto de experimentos: os sinais provenientes do SMET possuem inúmeros erros associados que demandaram experimentos mais específicos. Com base nesta constatação, buscou-se estudar o tipo de sensor empregado no SMET, suas capacidades e limitações assim, como os erros associados à sua calibração. Este estudo, cujas bases encontram-se apresentadas no item 4.4, apontou para a necessidade de se verificar experimentalmente a condição de calibração de parâmetros como o bias e o fator de escala. 
Visando obter tais parâmetros, tanto para os acelerômetros da UMI, como para seus girômetros, foram elaborados e realizados ensaios estáticos sobre uma morsa reclinável e ensaios dinâmicos empregando-se uma rate table. Ambos os ensaios serão descritos em detalhes no capítulo seguinte.

Conhecendo os parâmetros de calibração para cada um dos sensores do SMET, a etapa seguinte envolveu aplicá-los na correção de sinais. Alguns modelos de correção, tradicionalmente empregados em sistemas de navegação inercial e discutidos no capítulo 3, foram aplicados. Os resultados mais promissores surgiram, no entanto, da composição dos métodos com a avaliação do analista do sinal. Essa união fez-se possível, e passou efetivamente a constituir um procedimento, quando assumiu a forma de uma rotina computacional provida de interface gráfica, justamente para permitir a inserção da intervenção humana no processo de correção.

As melhorias provenientes das correções realizadas nos sinais dos sensores só puderam ser verificadas após os cálculos dos parâmetros de interesse realizados. Porém, para que se pudesse definir o que representaria uma melhoria, foi necessário se conhecer tanto a velocidade, como a atitude final real da estaca. Tais dados não eram, e até o presente momento não são, disponíveis. As alternativas para se contornar este problema passaram a ser:

- Identificar claramente capacidades e limitações do algoritmo de processamento de dados vigente;

- Propor um algoritmo alternativo que empregasse outros métodos de cálculo que não envolvessem as mesmas hipóteses simplificadoras do método vigente.

No que se refere ao primeiro item apontado, a estratégia adotada foi traduzir a planilha vigente contendo a algoritmo de processamento de dados, para a linguagem MatLab®. Esse processo permitiu, entre outras coisas, que fosse adquirida grande familiaridade com os métodos de cálculo. Outra medida importante, tomada visando atingir o primeiro dos objetivos listados no parágrafo anterior, foi reinterpretar o algoritmo através do formalismo da cinemática do corpo rígido. Neste sentido, o item 4.2 deste texto apresentou as bases utilizadas para este estudo. Detalhes sobre o funcionamento deste algoritmo, resultados e constatações serão apresentados mais a frente neste documento.

Finalmente, objetivando-se criar uma fonte de comparação para os resultados atingidos, foi elaborado um algoritmo alternativo de processamento dos dados. Este foi baseado nos algoritmos empregados em navegação inercial strapdown e encontra-se em (TITTERTON e WESTON, 2004). 
Ao contrário do primeiro algoritmo, a nova proposta realiza a integração de todos os sinais e, com isso, reconstrói toda a cinemática da estaca torpedo.

Realizar todas as integrações, no entanto, passou por resolver o problema deste algoritmo alternativo ser muito sensível aos erros no sinal.

Os resultados deste algoritmo alternativo tornaram-se coerentes na medida em que os métodos de tratamento do sinal foram aprimorados.

Ao final, foi possível observar a melhora pretendida para os resultados dos dois algoritmos. Inclusive, comparando-os entre si, verificou-se a congruência entre eles. Estas comparações serão apresentadas em detalhes no capítulo 9.

O método descrito acima encontra-se condensado na forma de um diagrama de blocos na página seguinte, Figura 65. 


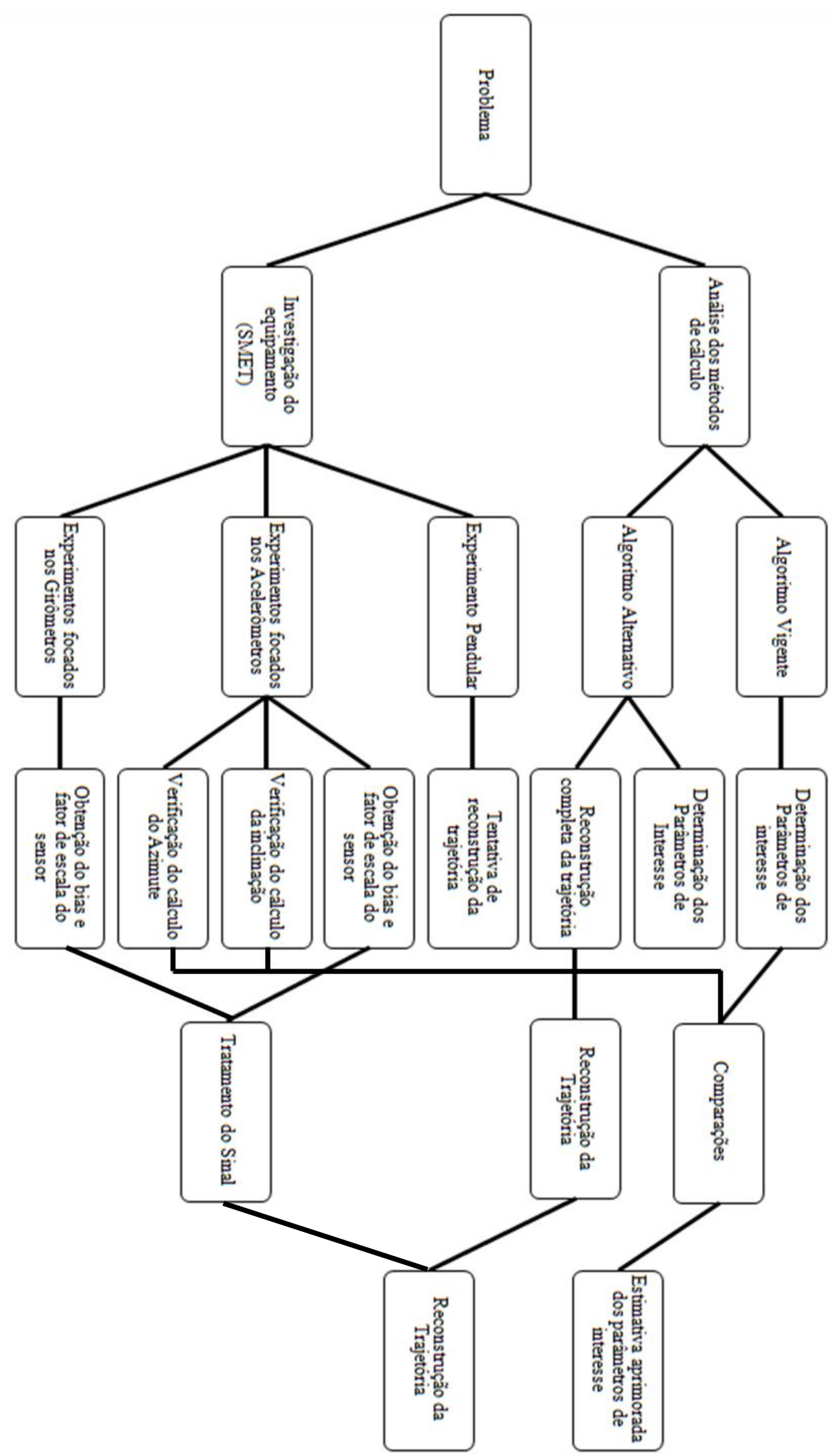

Figura 65 - Metodologia da pesquisa na forma de diagrama de blocos 


\section{INVESTIGAÇÃo DA UNIDADE DE MEDIÇÃo INERCIAL}

\subsection{EXPERIMENTo Pendular (AvaliaçÃo do SMET COMO UM TOdO)}

A forma mais direta de verificar o desempenho da unidade de medição inercial em descrever a cinemática do lançamento da estaca-torpedo, ou de um corpo similar, foi impor à UMI uma trajetória conhecida, obter os dados gravados e tentar reproduzir esta trajetória a partir destes. Inicialmente, foram concebidas idéias envolvendo trilhos sobre os quais um pequeno carro carregando o SMET percorreria certo trajeto. Imaginou-se, ainda, fixar a unidade de medição a um braço-robô que permitisse movê-la precisamente segundo certo caminho. Em ambos os casos, existiu a preocupação quanto ao conhecimento preciso da trajetória, o comprimento desta - consequentemente a duração do experimento - e sobre a rigidez e integridade da estrutura do experimento, uma vez que a UMI estudada possui massa aproximada de $7 \mathrm{~kg}$, incluindo suas baterias.

A alternativa encontrada foi construir um pêndulo e prender o SMET a sua extremidade. $O$ pêndulo é uma estrutura de construção rápida e de baixo custo, além de permitir movimentos em todas as direções. Outro aspecto importante do pêndulo é a possibilidade de se modelar analiticamente sua cinemática.

O pêndulo, ao contrário das alternativas apontadas no início deste item, por si só não garantiria uma trajetória conhecida, tornando imprescindível que esta fosse monitorada também de outra forma. Para tanto, foi empregado um sistema de monitoramento por imagem. Detalhes deste experimento assim como os demais equipamentos empregados são apresentados a seguir.

\subsubsection{Materiais Experimentais}

O pêndulo em questão foi montado nas dependências do CNAVAL/IPT (Centro de Engenharia Naval do Instituto de Pesquisas Tecnológicas do Estado de São Paulo). A montagem consistiu em fixar o SMET à extremidade de um cabo de aço preso ao teto do laboratório, de forma que os eixos sensíveis dos acelerômetros e girômetros que equipam a unidade de monitoração apresentassem a orientação mostrada na Figura 66. 


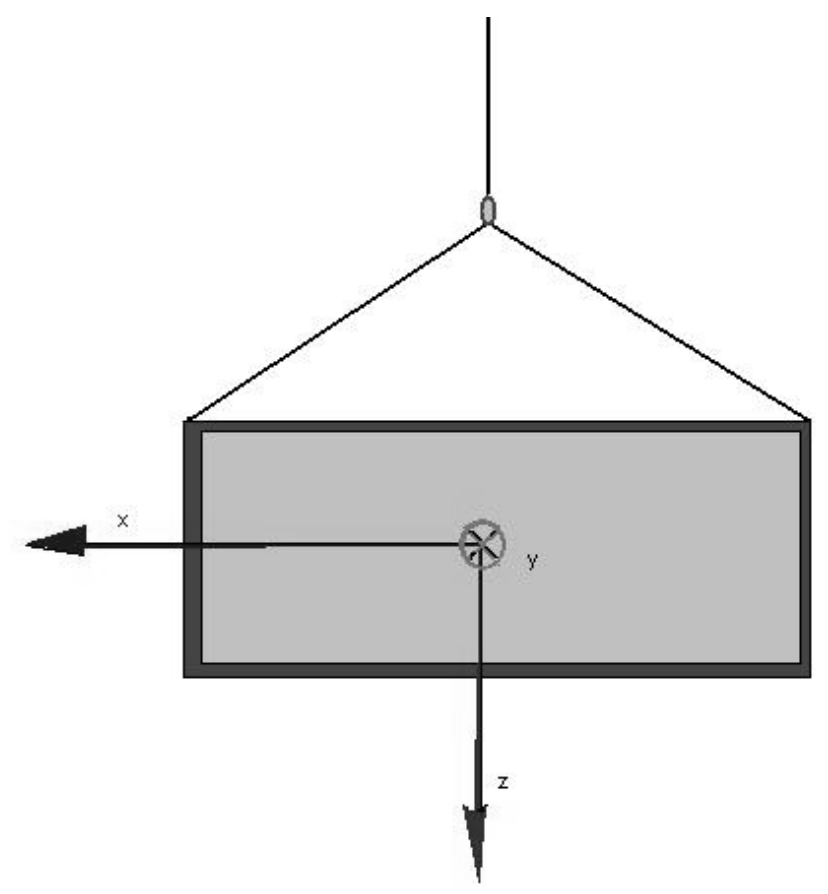

Figura 66 - Orientação dos eixos do SMET montado ao pêndulo

A opção pelo cabo de aço fundamentou-se na tentativa de reproduzir um pêndulo de haste rígida, porém de massa desprezível. Foi constatado, no entanto, que este cabo de aço devido à forma como é fabricado, opera como uma mola de torção, quando submetido à tração. Este efeito será posteriormente verificado por meio dos registros do movimento.

Visando maximizar o período natural do pêndulo, buscou-se construí-lo o mais alto possível. A altura do teto das instalações do CNAVAL, no IPT, permitiu construir um pêndulo de aproximadamente $7,4 \mathrm{~m}$.

Para acondicionar o SMET na extremidade do pêndulo, foi fabricado um cilindro de diâmetro ligeiramente maior que o da unidade de medição propriamente dita, com uma das extremidades fechadas. À lateral deste cilindro, foram aparafusados olhais que, além de prenderem-se ao cabo de aço (Figura 68), impediam que o SMET se movesse no interior do mesmo. 


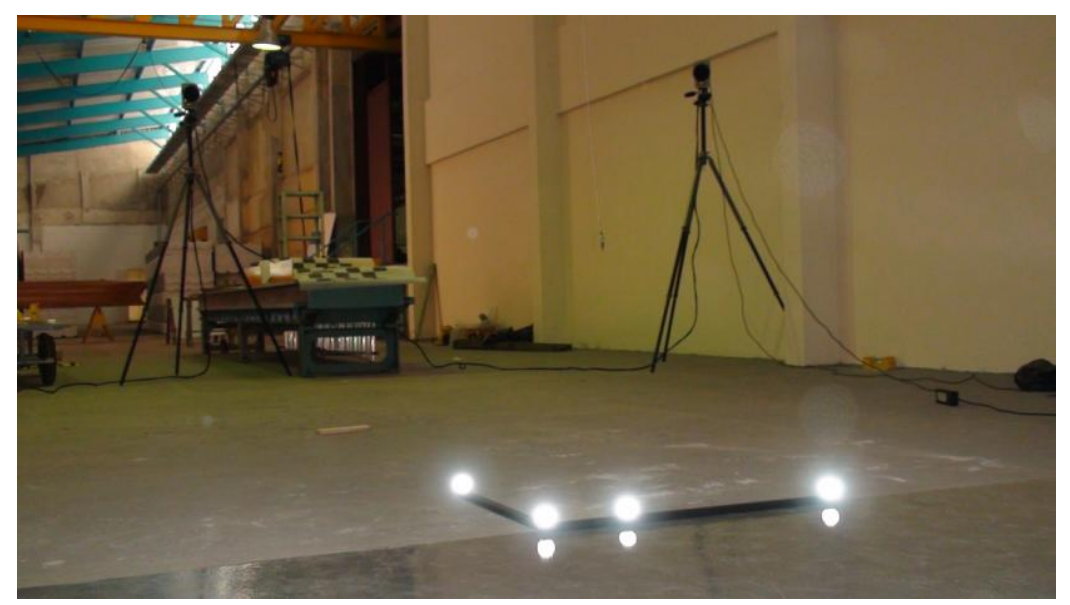

Figura 67 - Área de ensaio; frame de calibração ao centro e duas câmeras ao fundo

Para esta monitoração, em particular, foram instaladas três câmeras, com características especiais, tais como a sensibilidade a luz infravermelha, como visto na Figura 67.

Para que as câmeras pudessem registrar o movimento do corpo, a este foram fixados alvos reflexivos. No caso do experimento, foi preso ao "berço" do SMET uma placa rígida contendo o conjunto de alvos vistos na Figura 68.

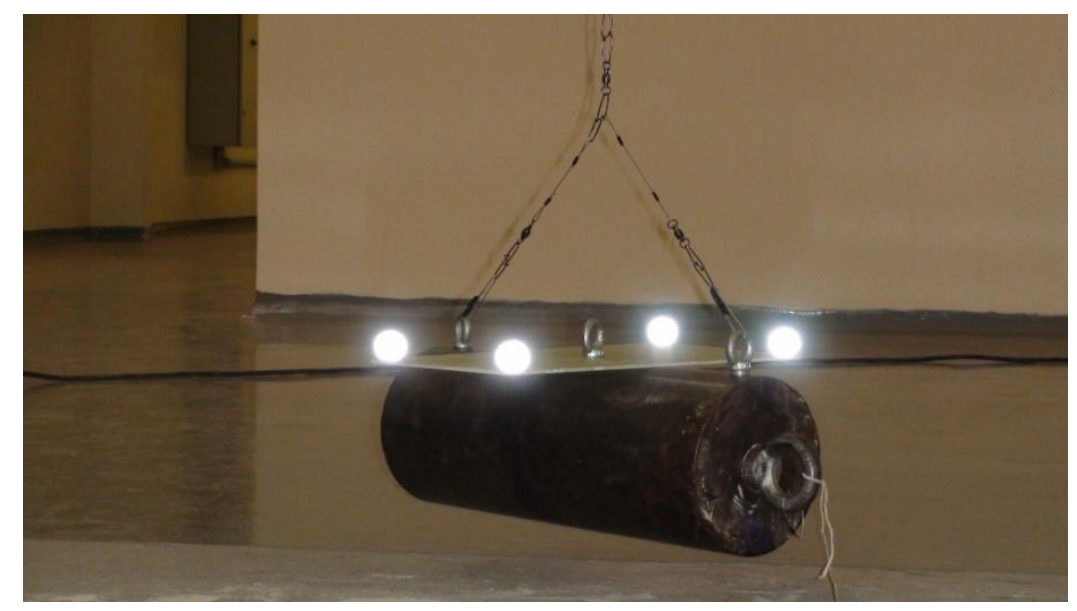

Figura 68 - "Berço" do SMET equipado com os alvos reflexivos

As câmeras equipadas com leds infravermelhos iluminam os alvos que se destacam do restante da imagem, permitindo que o corpo seja claramente identificado.

Embora o equipamento de monitoração por imagem permita aquisições até $500 \mathrm{~Hz}$, optou-se por fazê-lo a $100 \mathrm{~Hz}$, frequência essa compatível com a frequência de aquisição do SMET. Essa decisão visou permitir que, após o tratamento adequado, os dados pudessem ser comparados com maior facilidade. 


\subsubsection{Métodos Experimentais}

Foram realizados dezoito registros procurando-se variar a amplitude do movimento pendular e a presença ou ausência de rotação própria, rotação em torno do eixo alinhado ao cabo de aço. Cuidou-se ainda para que, em certos lançamentos, o movimento fosse contido em um plano e em outros, o movimento deixasse o plano, reproduzindo um pêndulo esférico.

Como medida facilitadora das análises posteriores, o início da aquisição de dados do SMET e do sistema de monitoração por imagem foi sincronizado.

O controle da condição inicial contou, basicamente, com um registro estático do sistema de monitoração por imagem, ou seja, após o início da aquisição aguardou-se cerca de três segundos antes da liberação do pêndulo. Tal medida foi adotada para que se fosse possível identificar claramente o início do experimento nos sinais registrados e, a partir daí, estabelecida a condição inicial.

A duração média das aquisições foi de trinta segundos.

A Tabela 10 condensa as principais informações dos testes realizados.

Tabela 10 - Relação dos ensaios pendulares

\begin{tabular}{|l|l|l|l|}
\hline \multicolumn{1}{|c|}{$\begin{array}{c}\text { Identificação do } \\
\text { Ensaio }\end{array}$} & \multicolumn{1}{c|}{$\begin{array}{c}\text { Amplitude } \\
\text { movimento }\end{array}$} & \multicolumn{2}{c|}{$\begin{array}{c}\text { Presença de Rotação } \\
\text { aproximada [m] }\end{array}$} \\
\hline 1 & Plano & 1,5 & Moderada \\
\hline 2 & Plano & 1,5 & Baixa \\
\hline 3 & Plano & 1 & Moderada \\
\hline 4 & Plano & 1 & Moderada \\
\hline 5 & Plano & 1 & Moderada \\
\hline 6 & Plano & 1 & Baixa \\
\hline 7 & Esférico & 1,5 & Baixa \\
\hline 8 & Esférico & 1,5 & Alta \\
\hline 9 & Esférico & 1,5 & Moderada \\
\hline 10 & Esférico & 1 & Moderada \\
\hline 11 & Esférico & 0,5 & Baixa \\
\hline 12 & Esférico & 0,3 & Baixa \\
\hline
\end{tabular}


O sistema de monitoração por imagem foi re-calibrado três vezes ao longo do ensaio. Isso ocorreu antes do início das aquisições; entre os ensaios dois e três e entre os ensaios quatro e cinco. Para tanto, foi empregada a estrutura de referência mostrada na Figura 68.

\subsubsection{Resultados}

Depois de concluídos os experimentos os dados provenientes das duas medições foram processados.

Na pagina a seguir são apresentadas a trajetória reconstruída pelo sistema de monitoração por imagem impressa em perspectiva, logo abaixo o módulo da velocidade tangencial a trajetória em $\mathrm{mm} / \mathrm{s}$ e por ultimo um gráfico contendo os três deslocamentos angulares, segundo os ângulos de Cardan apresentada no item 4.2.2, para um dos ensaios pendulares - ensaio 6. 


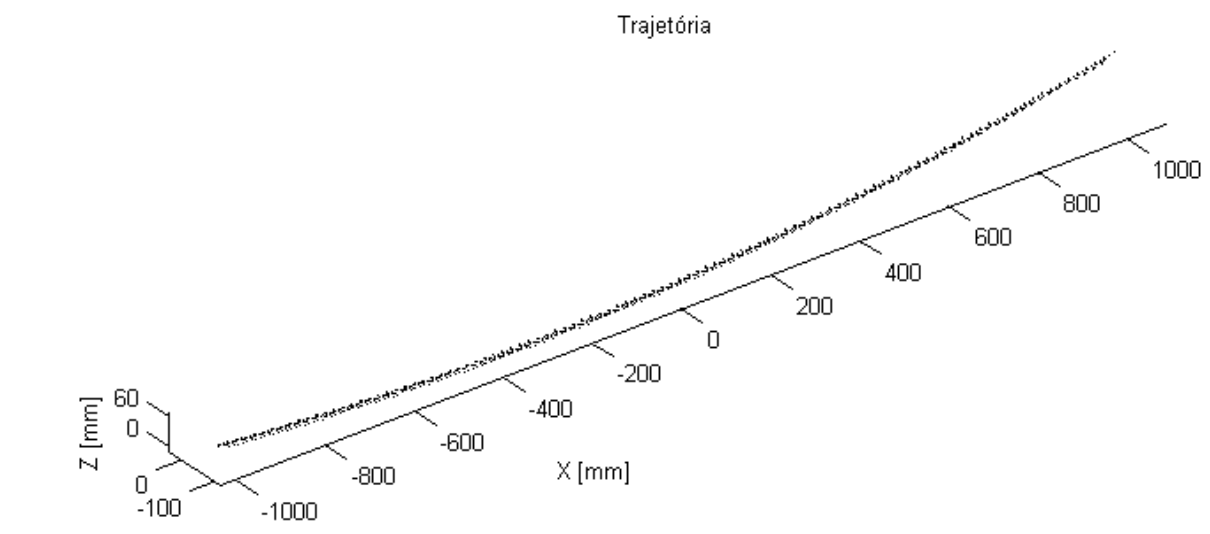

$Y[\mathrm{~mm}]$
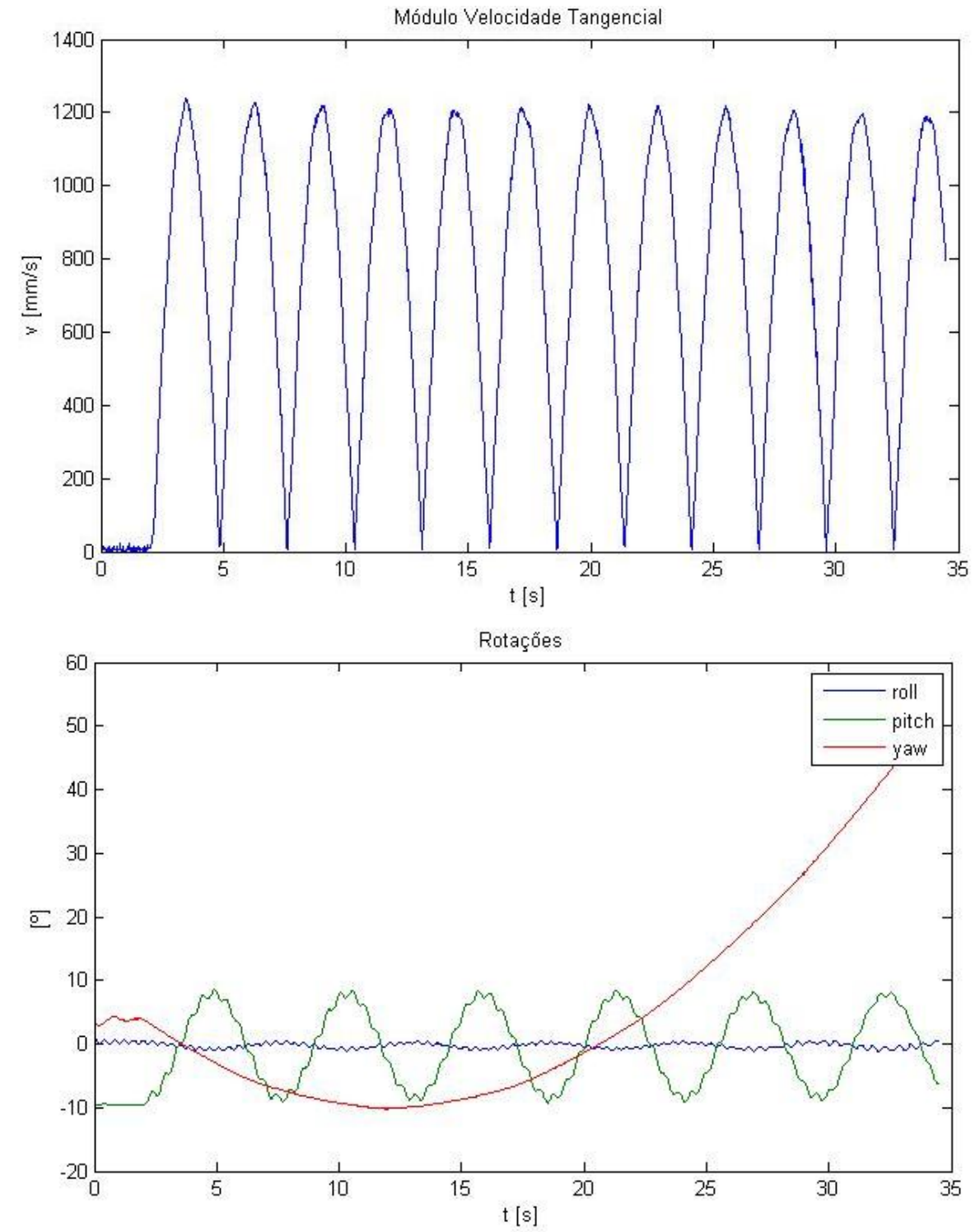

Figura 69 - Registros do sistema de aquisição por imagem; de cima para baixo: a trajetória, a velocidade tangencial e a atitude do SMET 
A Figura 70 apresenta uma fotografia que incorpora alguns instantes do movimento de oscilação do ensaio exemplificado.

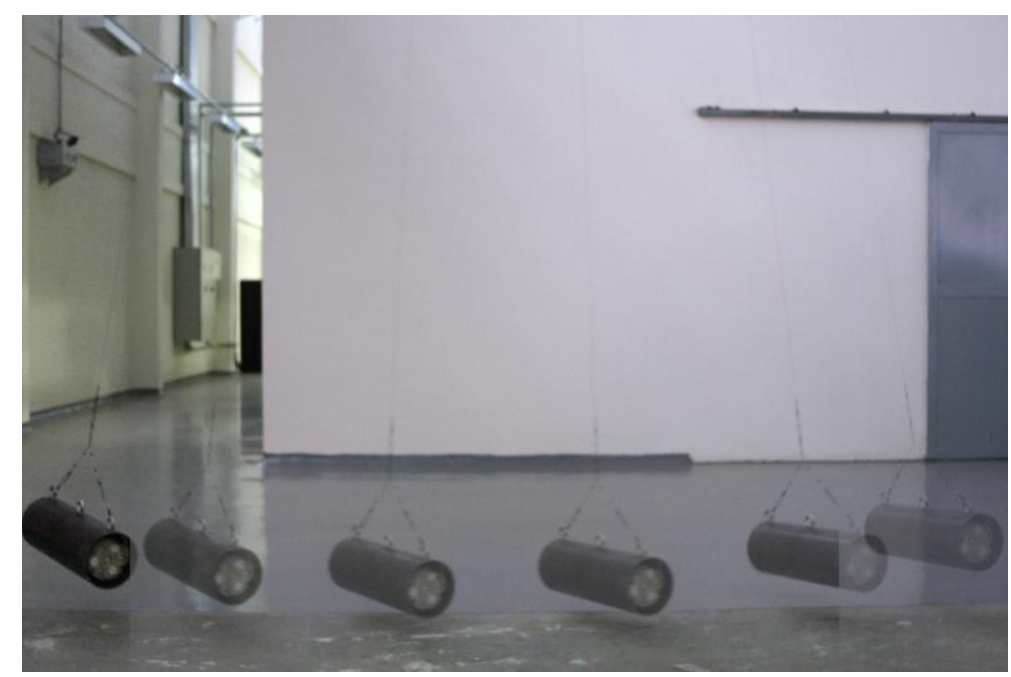

Figura 70 - Pêndulo contendo o SMET

Os dados experimentais provenientes do SMET foram inseridos no algoritmo de reconstrução de trajetória, porém os resultados obtidos foram muito distantes dos esperados. As aquisições que duravam em média 30 segundos produziam trajetórias completamente distorcidas e com derivas calculadas da ordem de milhares de metros em alguns casos.

As derivas excessivas se deveram ao fato de que o algoritmo não foi capaz de efetuar corretamente a correção da aceleração gravitacional gerando, com isso, resultantes de forças que não existiam no caso real. Fenômeno previsto através dos testes com sinais artificiais.

Os testes pendulares mostraram-se inconclusivos, pois muitas poderiam ser a fontes de erro. Optou-se por realizar testes padronizados e voltados apenas a avaliar a qualidade dos sinais provenientes dos sensores do SMET. 


\subsection{EXPERIMENTOS COM OS ACELERÔMETROS}

Elaborou-se uma bateria de ensaios estáticos visando obter a curva de calibração para os acelerômetros do SMET, ver Figura 52. Os ensaios consistiram basicamente em variar de forma controlada a inclinação do conjunto de sensores objetivando-se, com isso, modificar progressivamente a leitura das componentes da gravidade em cada um dos eixos sensíveis do SMET.

\subsubsection{Materiais Experimentais}

A montagem dos ensaios estáticos foi feita da seguinte forma:

Sobre uma superfície plana e nivelada - desempeno de granito - foi posicionada uma morsa reclinável de precisão que permitisse inclinações entre $0^{\circ}$ e $60^{\circ}$.

Foi fabricada, então, uma peça na forma de um bloco de aço para fixar firmemente o SMET à morsa (Figura 71 no canto superior direito e Figura 72). Esta peça foi fabricada respeitando-se tolerâncias dimensionais tais como paralelismo, perpendicularidade, acabamento superficial e a posição dos furos para fixação do SMET. Este, por sua vez, foi fixado à morsa de forma que seu eixo x estivesse alinhado com a vertical, ou seja, perpendicular ao plano do desempeno. À peça de fixação foram anexadas plataformas para receber um inclinômetro (Figura 71 no canto inferior direito). Tais plataformas garantiram que o inclinômetro permaneça precisamente paralelo ao plano que contém os eixos y e z do SMET (Figura 57), durante todo o experimento.

O inclinômetro utilizado - Mitutoyo Pro 360 - possui precisão de "0.1 " aferido pelo fabricante. 

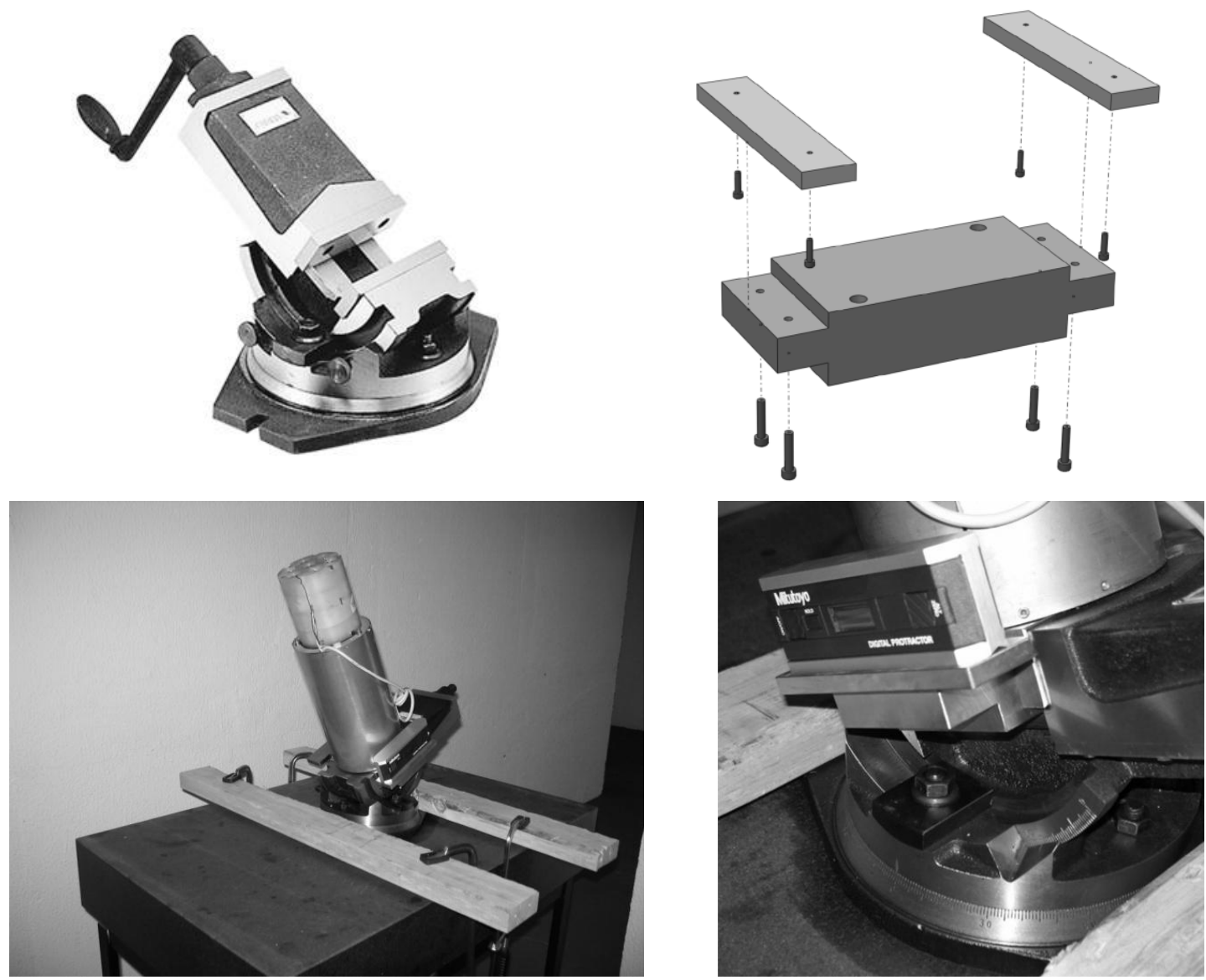

Figura 71 - Materias empregados no experimento estático dos acelerômetros; (superior esquerdo) morsa reclinável; (inferior esquerdo) montagem completa sobre o desempeno de granito; (superior direto) perspectiva explodida da peça de fixação SMET-morsa; (inferior direto) detalhe da fixação do inclinômetro

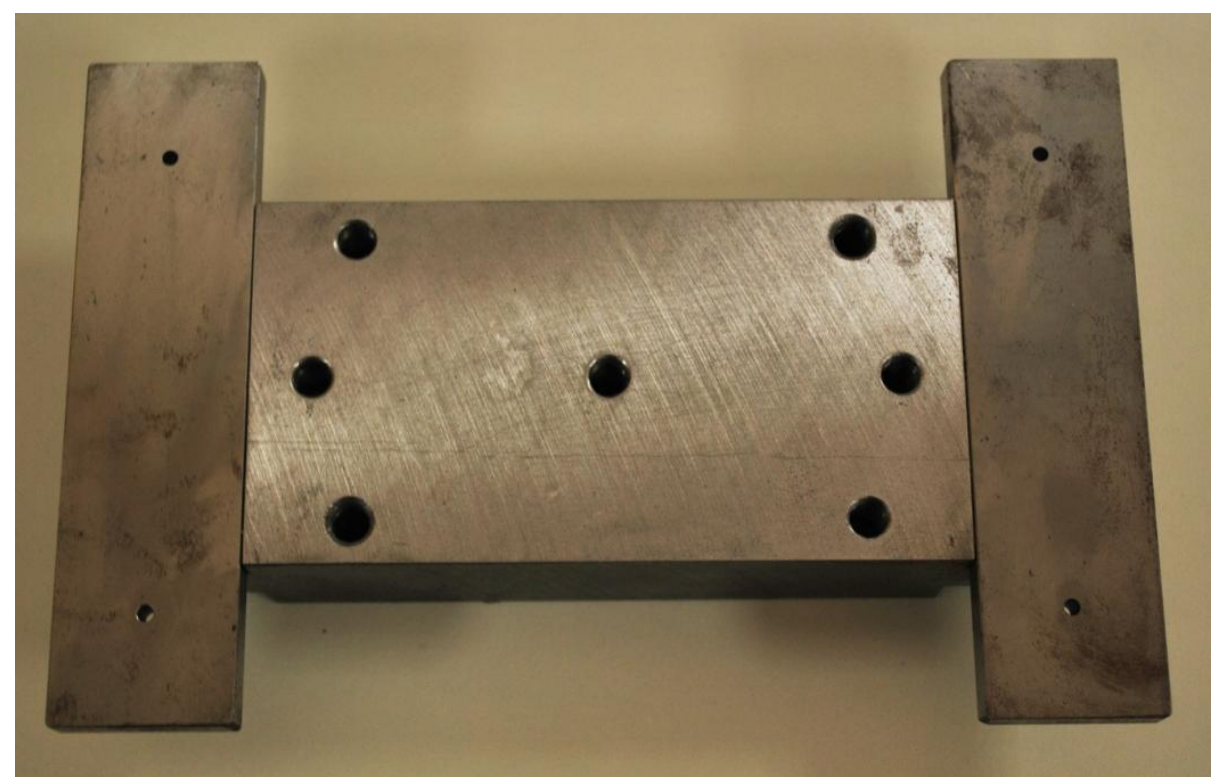

Figura 72 - Peça de fixação SMET-morsa e os furos para alinhamento do SMET 


\subsubsection{Métodos Experimentais}

Estes experimentos visaram obter curvas de calibração análogas à apresentada esquematicamente na Figura 52. A construção destas curvas demanda o conhecimento preciso das entradas as quais os sensores são submetidos, neste caso, as componentes da gravidade. Estas componentes, por sua vez, dependem basicamente da inclinação dos sensores.

Variando-se a inclinação, sabe-se que a leitura do acelerômetro alinhado com o eixo longitudinal do SMET deve corresponder ao cosseno do ângulo de inclinação.

A leitura nos eixos y e z, por sua vez, varia com o seno do ângulo de inclinação, porém, para que se conheça a magnitude da componente gravitacional lida por estes sensores, é preciso conhecer o plano no qual a inclinação é realizada.

A componente gravitacional percebida pelo sensor y corresponderá ao seno do ângulo de inclinação, caso esta seja realizada em um plano paralelo ao plano que contém as direções x e y do SMET. Analogamente, a leitura de aceleração no eixo z será conhecida de forma direta caso a inclinação seja realizada no plano xz. A Figura 73 ilustra tal situação.
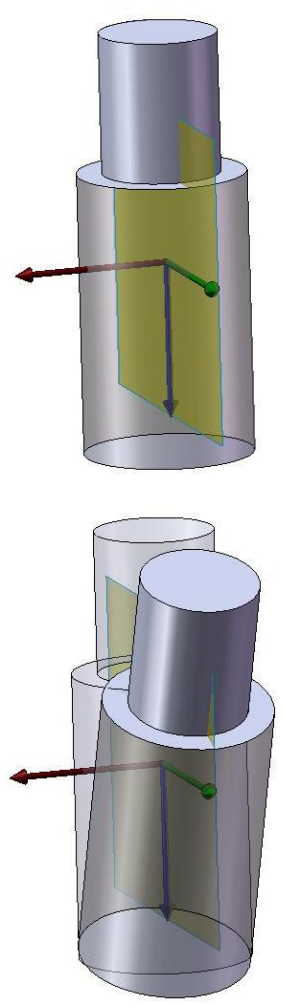
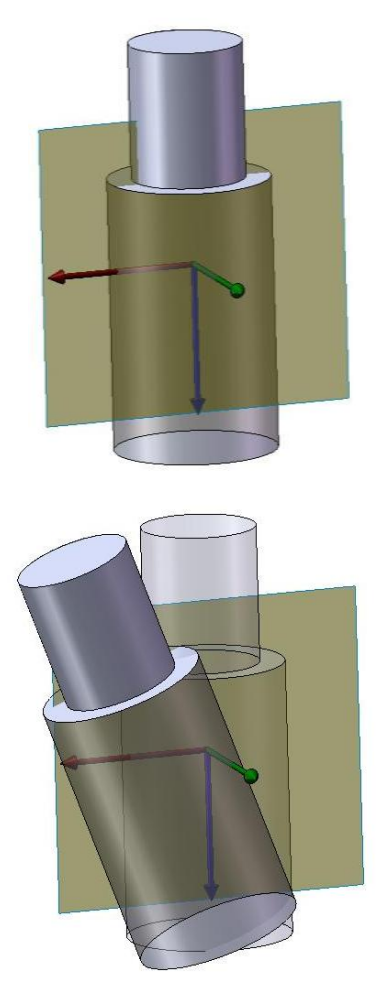

Figura 73 - Sequência de inclinações para isolar as leituras no eixo y e $z$; em azul o eixo x, em verdo o eixo y e em vermelho o eixo $z$; as ilustrações da direita representam o procedimento para obtenção da leitura em y; as ilustrações da direita representam o mesmo procedimento em z 
O inclinômetro empregado dispõe de um procedimento simples, recomendado pelo fabricante, para verificar sua calibração. Tal procedimento precedeu todos os conjuntos de experimentos realizados, sendo a calibração do aparelho avaliada como satisfatória em todos os casos.

Antes do início das medições, o desempeno foi verificado, assegurando sua horizontalidade. Essa verificação foi feita com o uso do inclinômetro disponível, posicionando o mesmo no centro de cada um dos lados do desempeno e garantindo que a leitura, em todos os casos, fosse $0 \pm 0.1^{\circ}$. O nível do desempeno pôde ser corrigido por meio de parafusos que suportam o tampo de granito sobre uma estrutura metálica.

O passo seguinte foi posicionar o SMET, já preso ao bloco de suporte sobre a morsa. Apenas para garantir a melhor distribuição de peso sobre a morsa, optou-se por posicionar o SMET centralizado com relação à mesma. A última etapa da montagem consistiu em fixar o inclinômetro à plataforma descrita anteriormente, com ajuda de dois parafusos.

Por ser um parâmetro importante para o experimento, foram realizadas medidas de inclinação baseadas tanto na escala da morsa, como no inclinômetro fixado ao conjunto.

As aquisições de dados com o SMET foram configuradas, iniciadas e encerradas por meio de um dispositivo portátil do tipo PocketPC que também armazena os dados após o término do registro.

Foram realizadas dez medições para cada ângulo de inclinação e esse conjunto de experimentos repetido para três ângulos de precessão distintos. Cada uma das aquisições durou dez segundos e os dados foram tomados a uma taxa de $100 \mathrm{~Hz}$.

Tabelas contendo a sequência de ensaios realizados, assim como as médias dos sinais obtidos encontram-se no APÊNDICE B.

Após o término dos experimentos os registros foram transferidos para um computador e devidamente identificados.

\subsubsection{Resultados}

Conhecendo a inclinação e a leitura de aceleração no eixo x, foi possível construir um gráfico apresentado na Figura 74. 


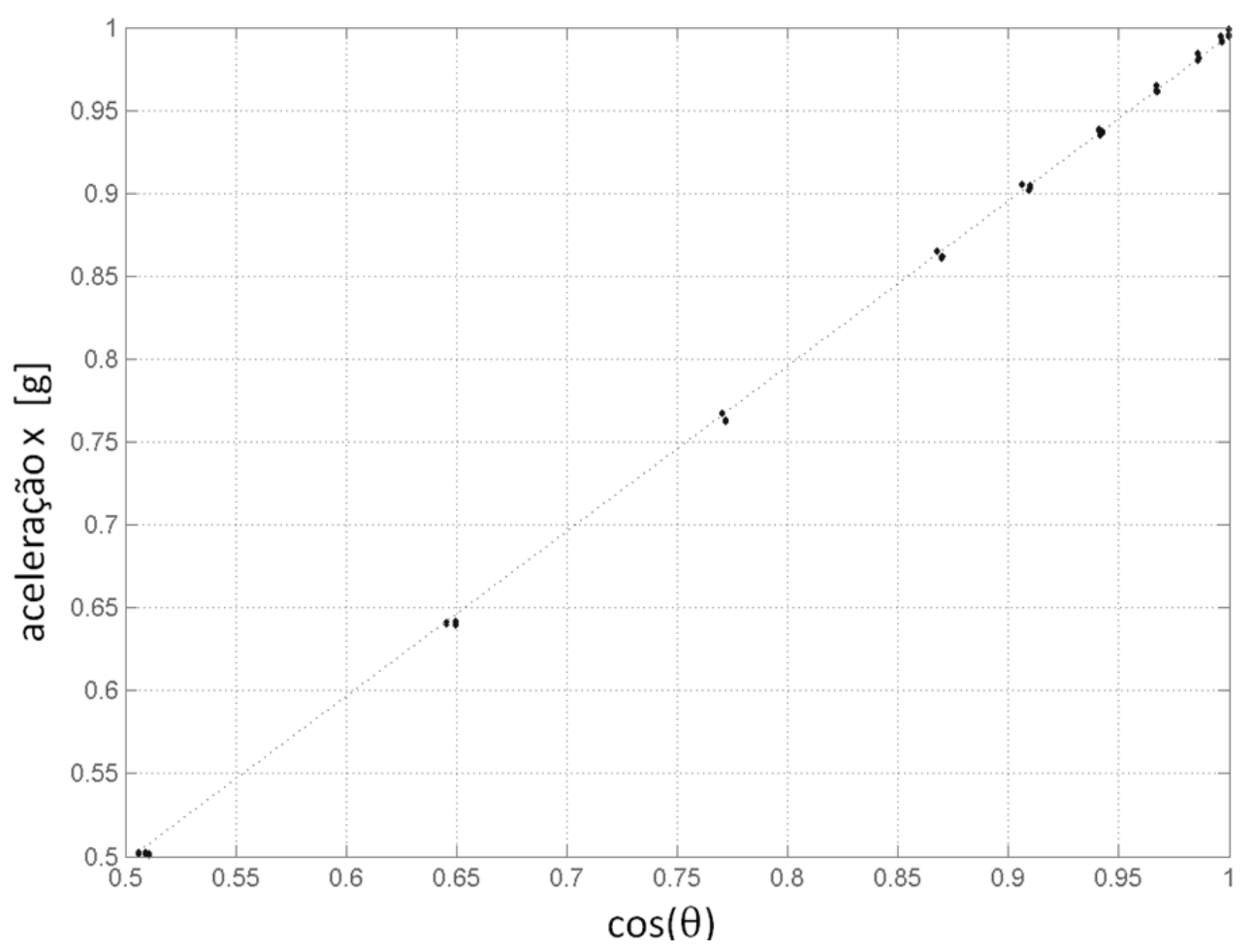

Figura 74 - Curva de calibração do acelerômetro x

Ao gráfico da Figura 74 ajustou-se uma reta através do método dos mínimos quadrados e, a partir da equação da reta, pode-se determinar o fator de escala e o bias do sinal.

Dos resultados obtidos, como o mostrado na Figura 75 e Figura 76, pode-se notar que o fator de escala encontra-se muito próximo de um, indicando que esse parâmetro está devidamente calibrado. 


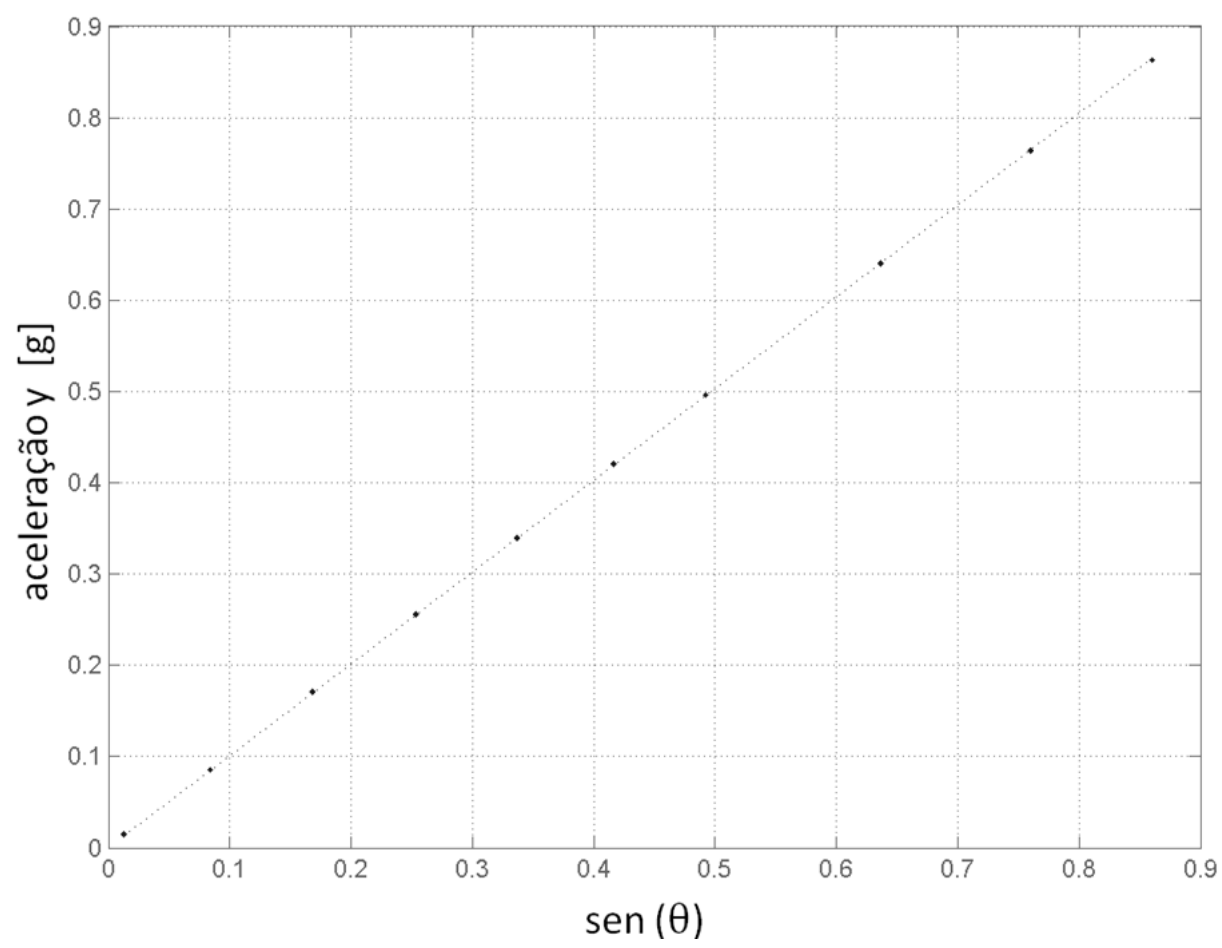

Figura 75 - Curva de calibração do acelerômetro y

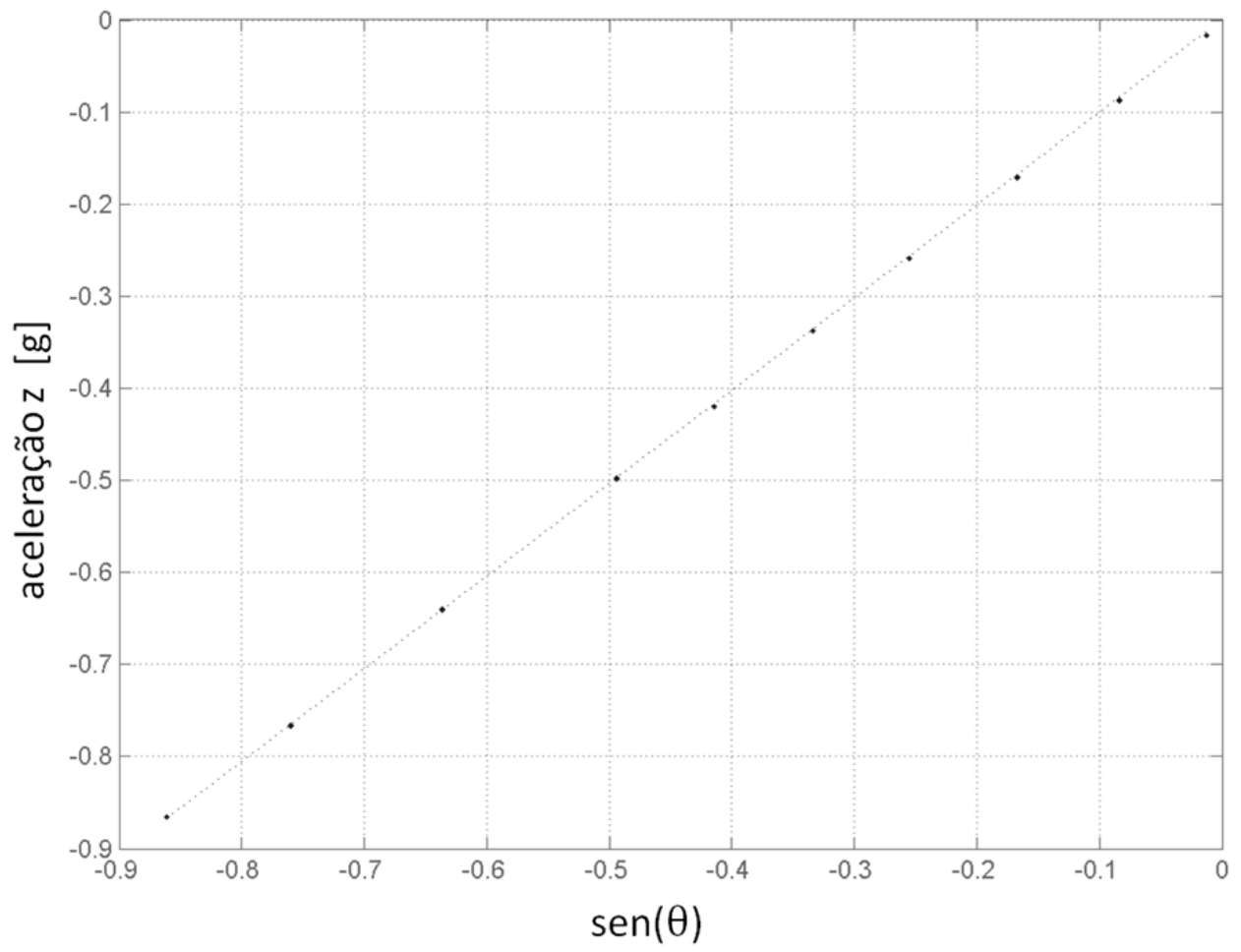

Figura 76 - Curva de calibração do acelerômetro z

O bias obtido possui valor próximo de zero, o que também indica que o sistema está corrigindo adequadamente o sinal. Deve-se lembrar, contudo, que o bias é uma grandeza 
integrada duas vezes no processo de reconstrução de trajetória e, por isso, mesmo valores muito pequenos podem provocar grandes desvios na posição calculada.

Tabela 11 - Parâmetros de calibração obtidos para os acelerômetros do SMET

\begin{tabular}{|l|l|l|}
\hline Sensor & Bias $\left(\mathrm{a} 25^{\circ} \mathrm{C}\right)$ & Fator de Escala \\
\hline Acelerômetro x & $0,0003 \mathrm{~g}$ & 0,9959 \\
\hline Acelerômetro y & $0,00048 \mathrm{~g}$ & 1,0082 \\
\hline Acelerômetro z & $0,00029 \mathrm{~g}$ & 1,0058 \\
\hline
\end{tabular}

Foi detalhada no item 4.4.10 a dependência do bias do sensor com a temperatura ambiente, principalmente no caso de sensores do tipo MEMS. Essa dependência torna os resultados apresentados na Tabela 11 vinculados à temperatura na qual os experimentos foram realizados, neste caso $23,5^{\circ} \mathrm{C}$. Infelizmente os experimentos não puderam ser repetidos em uma câmara climatizada para verificar se o SMET realiza adequadamente a correção do bias com a temperatura, ou determinar um modelo de correção adequado.

Estes experimentos produziram outros resultados que, por relacionarem-se diretamente ao desempenho do algoritmo de processamento dos dados, serão apresentados no capítulo seguinte.

\subsection{EXPERIMENTOS COM OS GIRÔMETROS (RATE TABLE)}

Tão importante quanto conhecer os parâmetros de calibração dos acelerômetros é caracterizálos para os girômetros. Esse procedimento, no entanto, possui dificuldades inerentes, pois envolvem movimento controlado. A gravidade, em última instância, foi a responsável por produzir as entradas necessárias para os experimentos descritos no item anterior. No caso da calibração dos girômetros, deve-se ser capaz de impor ao SMET velocidades angulares controladas. O equipamento indicado para realizar tal calibração recebe o nome de rate table. Seu funcionamento e os métodos experimentais empregados são detalhados nos tópicos subsequentes. 


\subsubsection{Materiais Experimentais}

A mesa rotativa ou rate table é um dispositivo composto por uma plataforma sobre a qual são fixados os sensores e que pode imprimir rotações com velocidade angular controlada. Mesas rotativas promovem rotações em torno de um eixo bem definido e são utilizadas para medir os fatores de escala dos girômetros. As mesas devem possuir anéis coletores para levar e trazer o sinal elétrico dos sensores e deve possuir medidores precisos de ângulo. A Figura 77 ilustra, simplificadamente, os sistemas presentes em uma rate table típica.

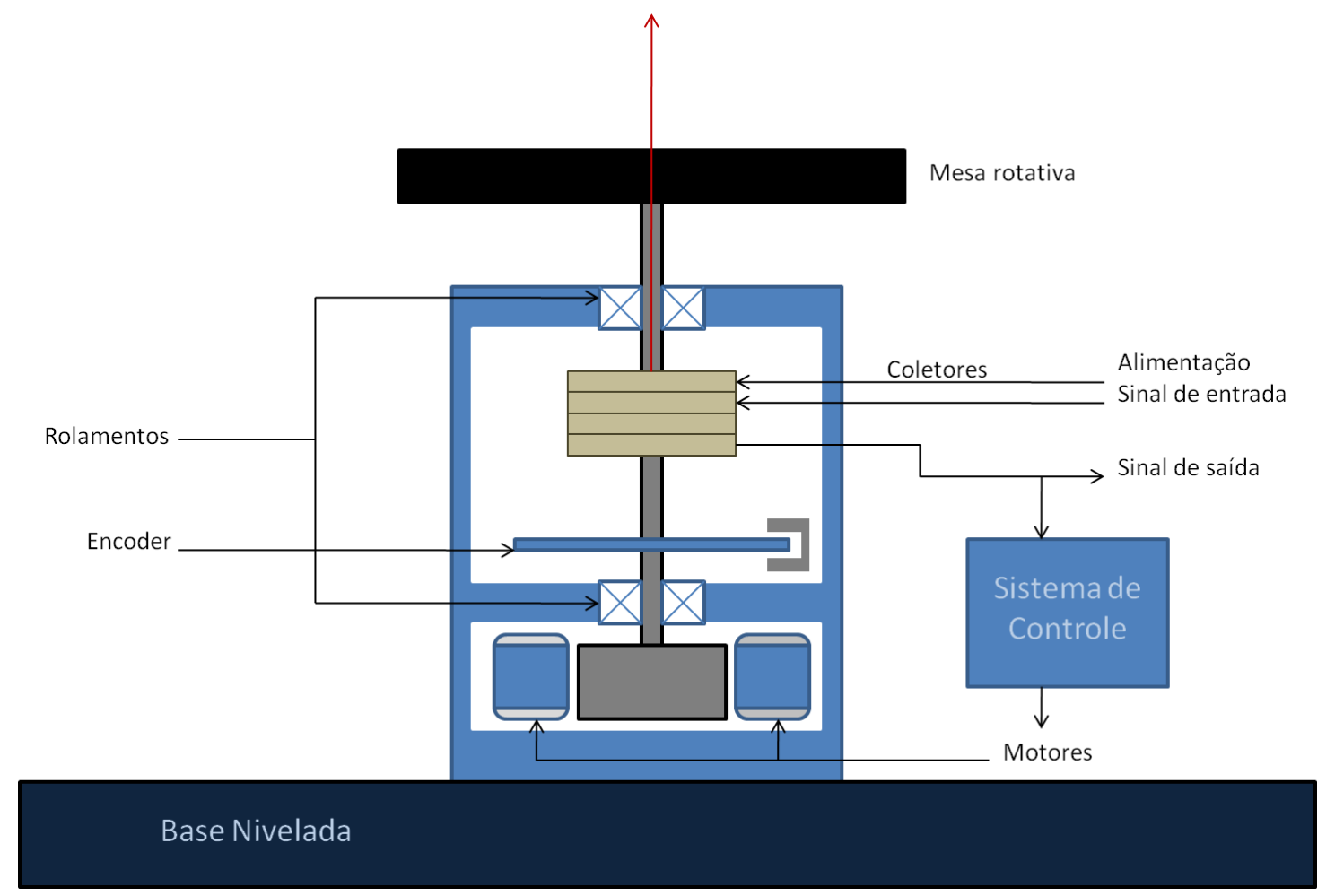

Figura 77 - Esquema dos componentes de uma rate table

A mesa de teste conta, ainda, com um console eletrônico que contém as fontes de energia, o sistema de controle dos circuitos de saída. Tais sistemas devem ser de qualidade superior aos empregados nos sensores que se deseja calibrar, para que se tenha certeza de se estar testando os sensores e não a mesa rotativa. Os dados são armazenados em um computador e processados de forma a ajustá-los aos modelos pré-determinados. Especificações detalhadas da rate table empregada no experimento encontram-se no ANEXO A. 


\subsubsection{Métodos Experimentais}

Em 24 de setembro de 2009 foram realizados ensaios com o SMET nas próprias dependências da NavCon.

Em linhas gerais, cada ensaio consistiu em fixar verticalmente o SMET na rate table, mostrada na Figura 78, de forma a alinhar seu eixo x com a direção do vetor da gravidade. Cabe lembrar que o eixo x do SMET é aquele paralelo à vertical durante o lançamento da estaca e responsável por registrar o spin próprio desta.

O conjunto foi colocado sobre um desempeno de granito devidamente nivelado.
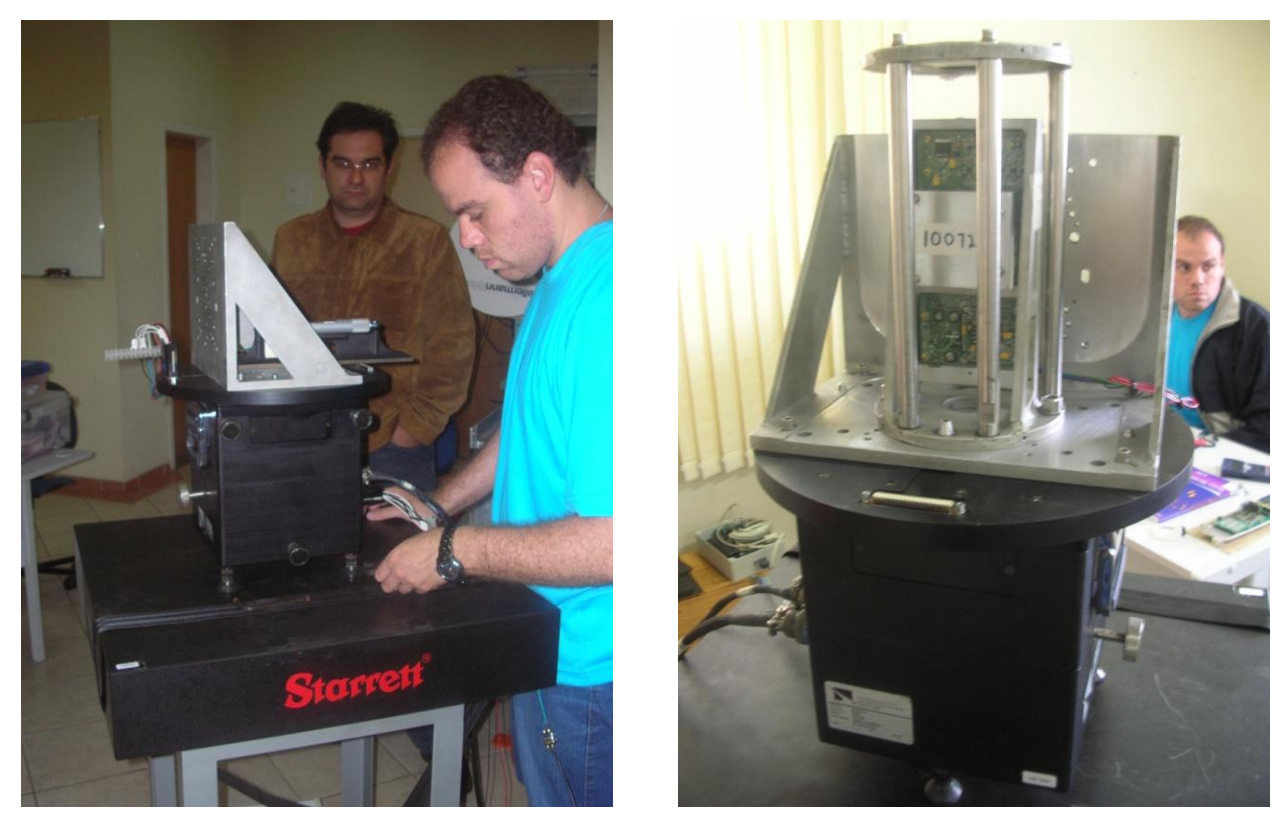

Figura 78 - (Equerda) Alinhamento da rate table; (Direita) SMET fixado à rate table

A faixa de velocidades testadas foi inicialmente determinada com base nos resultados de rotação provenientes da planilha de cálculo associadas ao documento (PETROBRAS, 2007) e empregando os dados obtidos em campanhas de campo. Foram testadas velocidades mais elevadas, a fim de verificar o fundo de escala da instrumentação. Em ambos os casos foram testadas velocidades angulares no sentido positivo e negativo, a fim de verificar a simetria da curva input versus output.

Foram feitos registros de 5, 10 e 15 segundos e taxa de aquisição de $100 \mathrm{~Hz}$, cada caso repetido 2 vezes para melhorar a confiabilidade do resultado.

Foram realizados, ainda, ensaios nos quais o SMET foi submetido a giros cíclicos de $+45^{\circ} \mathrm{e}$ $-45^{\circ}$. Os deslocamentos angulares ao longo do tempo seguiram distribuições senoidais, cujas freqüências em Hz estão listadas no APÊNDICE B. Os tempos das aquisições, nesse caso, 
foram maiores para garantir mais de um ciclo no período medido. Diferentemente dos primeiros ensaios, o SMET partiu da condição parada no ângulo $-45^{\circ}$.

\subsubsection{Resultados}

Os resultados em velocidade constante tiveram seu valor médio calculado conforme mostrado na Figura 79 e, em seguida, dispostos em um gráfico similar ao apresentado na Figura 80. Bias e fator de escala do giroscópio x foram determinados a partir dos coeficientes da reta que melhor ajustou os pontos obtidos experimentalmente.
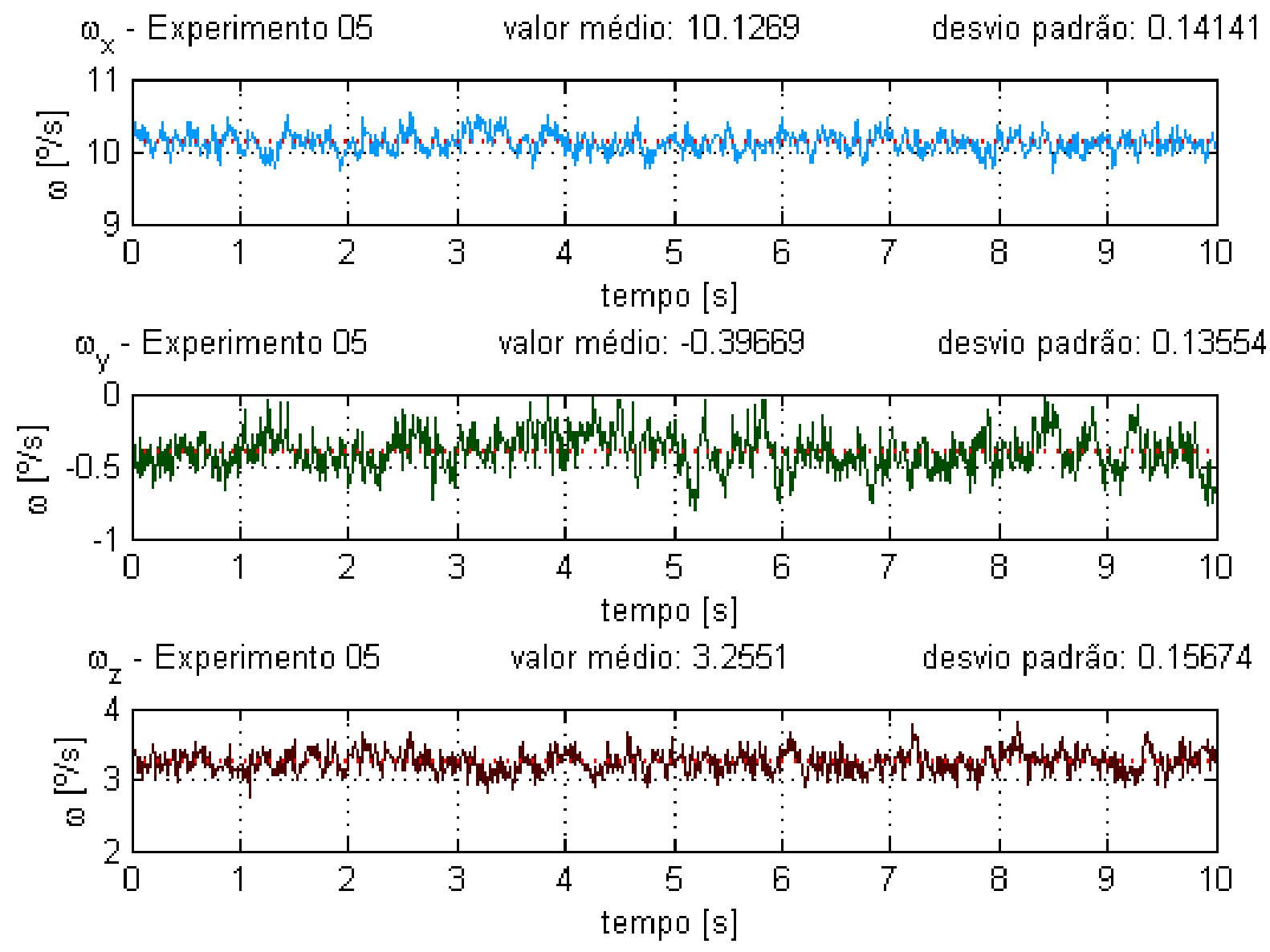

Figura 79 - Sinais de velocidade angular obtidos nos ensaios da rate table em que as respectivas médias estão indicadas 


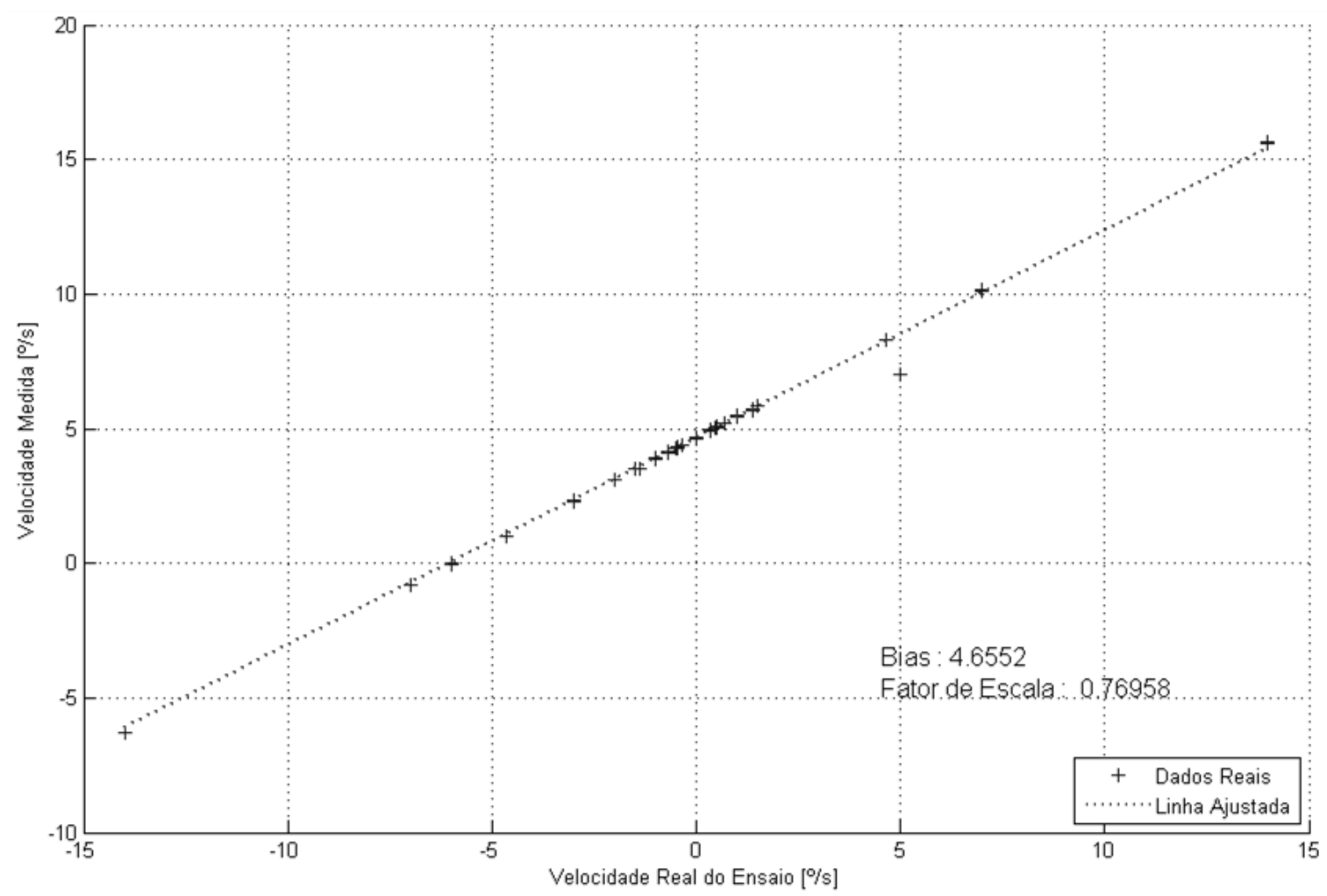

Figura 80 - Curva de calibração do girômetro x

É visível que os dados apresentaram uma distribuição linear e a reta ajustada deve reproduzir fielmente o comportamento do sensor. O bias corresponde ao ponto no qual a reta cruza o eixo ordenado e seu valor, nesse caso, é $4,6552 \%$ s. O fator de escala é dado pelo coeficiente angular da reta e vale 0,76958 .

Tabela 12 - Parâmetros de calibração obtidos para os girômetros do SMET

\begin{tabular}{|l|l|l|}
\hline Sensor & Bias $\left(\mathrm{a} 23,5^{\circ} \mathrm{C}\right)$ & Fator de Escala \\
\hline Girômetro $\mathrm{x}$ & $4,6552 \% \mathrm{~s}$ & 0,76958 \\
\hline Girômetro y & $-0,3990 \% \mathrm{~s}$ & $*$ \\
\hline Girômetro z & $3,2500 \% \mathrm{~s}$ & $*$ \\
\hline
\end{tabular}

* Calibrações não realizadas por escassez de tempo disponível da rate table 


\subsection{MÉtodo de Correção do Sinal}

Os ensaios descritos nos itens anteriores forneceram as seguintes informações: bias e fator de escala para cada um dos sensores. É importante frisar que tais informações estão atreladas as condições de ensaio, principalmente à temperatura em que foram realizados.

No próximo tópico serão discutidas as medidas de correção do sinal empregando os dados de calibração obtidos e seus efeitos na previsão dos parâmetros de interesse para ambos os algoritmos propostos - vigente e alternativo.

\subsubsection{Correção Simples}

Foi denominada aqui "Correção Simples do Bias" o processo de subtrair dos sinais do lançamento o valor do bias obtido experimentalmente (Tabela 11 e Tabela 12). Após tal subtração, o resultado ainda deve ser dividido pelo fator de escala como mostra a equação (176).

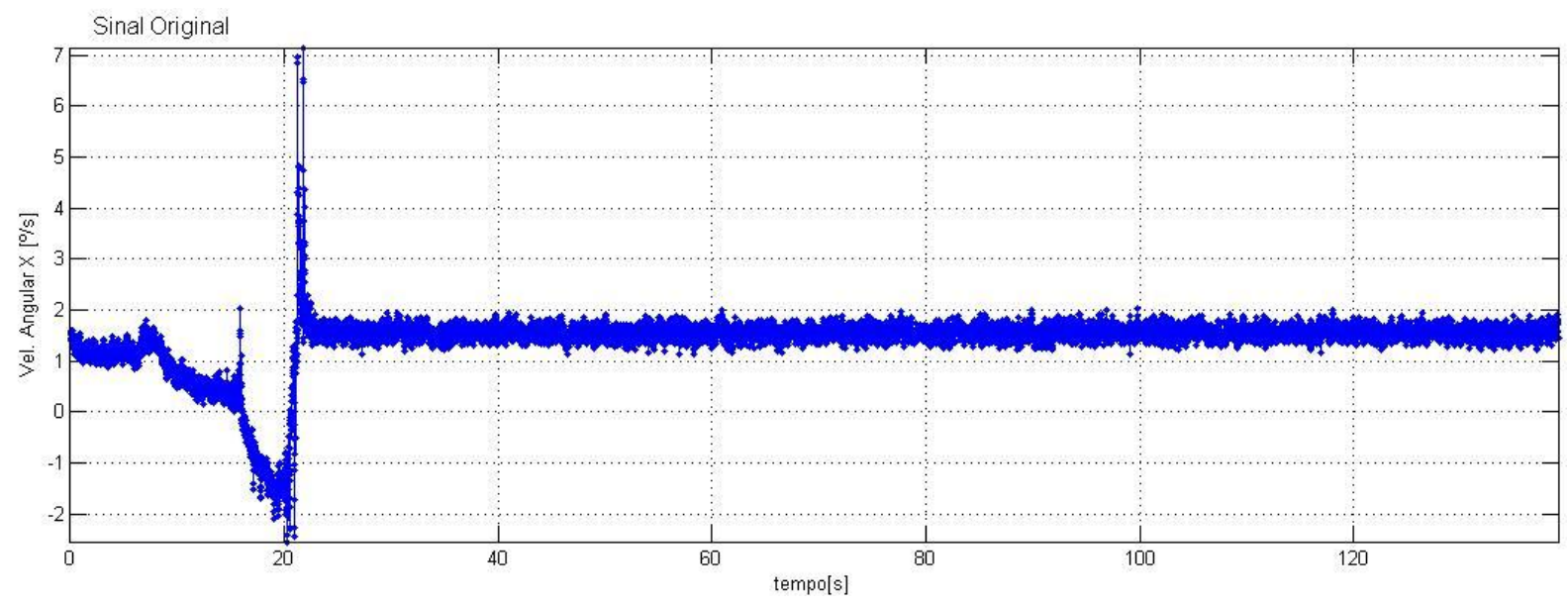

Figura 81 - Sinal de velocidade angular no eixo x de um lançamento da estaca-torpedo

A Figura 81 mostra o sinal de velocidade angular obtido em um dos lançamentos da estacatorpedo e, em seguida, a Figura 82 apresenta o mesmo sinal após a correção proposta neste item. Optou-se por usar como exemplo um sinal de velocidade angular, pois, como visto no item 6.2.3, os acelerômetros apresentaram boa calibração de acordo com testes realizados. 


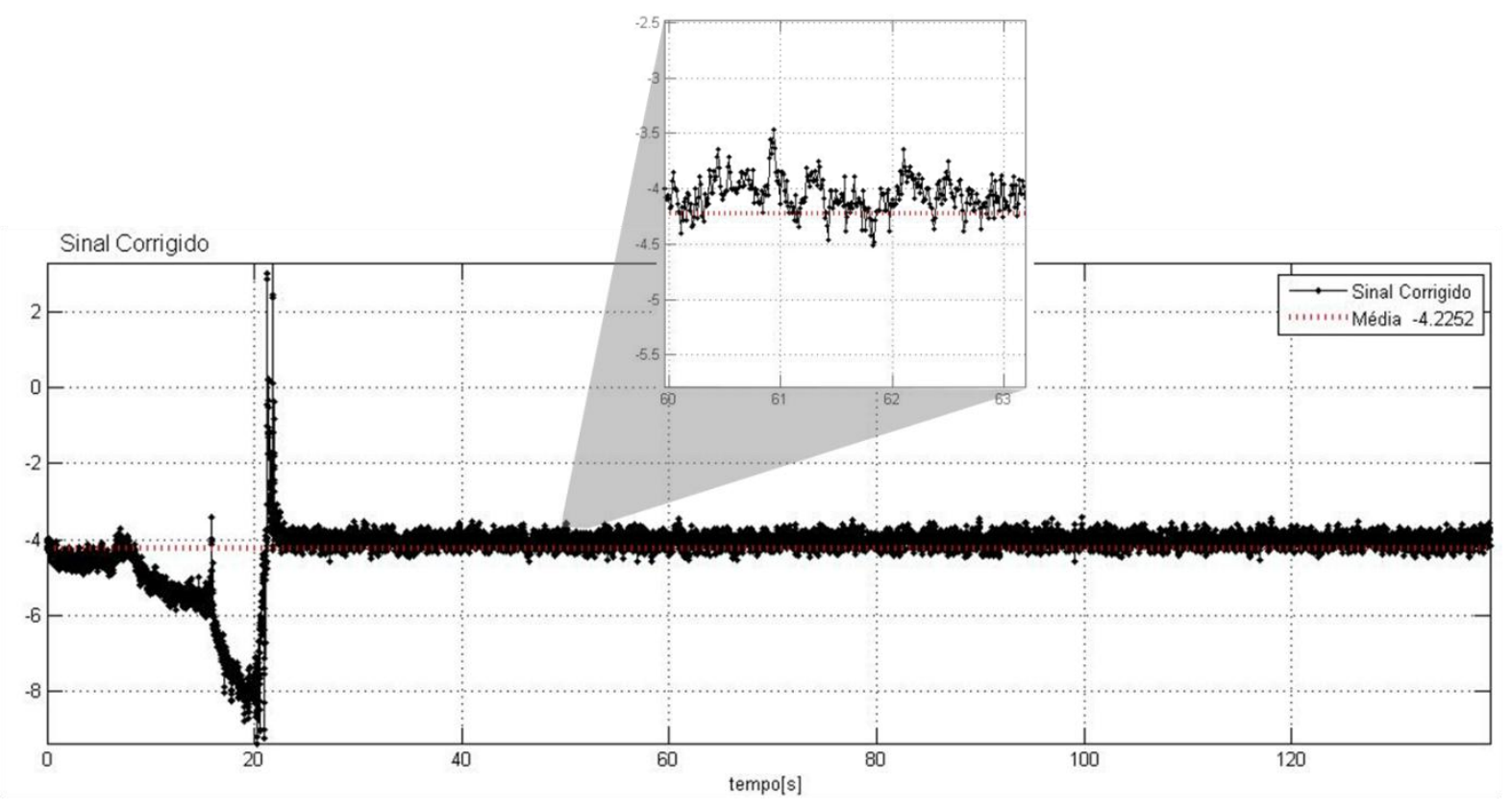

Figura 82 - Sinal apresentado na Figura 81 após a correção com o bias obtido em laboratório

Fica claro na Figura 82 que a correção simples do bias não produziu bons resultados uma vez que a velocidade angular, após a cravação da estaca-torpedo, permanece diferente de zero. A comparação feita acima foi repetida para os demais registros de lançamentos, resultando em valores distintos de zero, ou seja, comprovando a ineficiência do método para corrigir o sinal. De certa forma, este resultado era esperado, uma vez que o bias, mais do que o fator de escala, varia com a temperatura e, enquanto a temperatura em que os experimentos de bancada foram de aproximadamente $23^{\circ} \mathrm{C}$, a temperatura durante o lançamento, utilizado aqui como exemplo, de aproximadamente $6^{\circ} \mathrm{C}$.

\subsubsection{Correção com a Temperatura}

O passo seguinte foi corrigir o bias obtido experimentalmente por meio de uma relação linear com a temperatura. $\mathrm{O}$ fator de proporcionalidade entre bias e temperatura é fornecido indiretamente pelo fabricante do sensor. Novamente, apenas as velocidades angulares serão estudadas aqui, considerando os pelos motivos descritos no item anterior.

O modelo de correção do sinal empregado é descrito pela equação (177) e utiliza a dependência do bias com a temperatura. $\mathrm{O}$ fator de proporcionalidade $\gamma$ é apresentado na Tabela 12 embora seu sinal não esteja claro na descrição do fabricante do sensor.

Os experimentos descritos no item 6.2, embora realizados em temperatura ambiente, apresentaram ligeira variação desta grandeza. Isto porque os experimentos foram realizados 
ao longo de alguns dias e em diversos horários. Outra característica observada foi o aquecimento dos sensores após o início das aquisições.

Esta variação de temperatura permitiu construir gráficos como o apresentado na Figura 83.

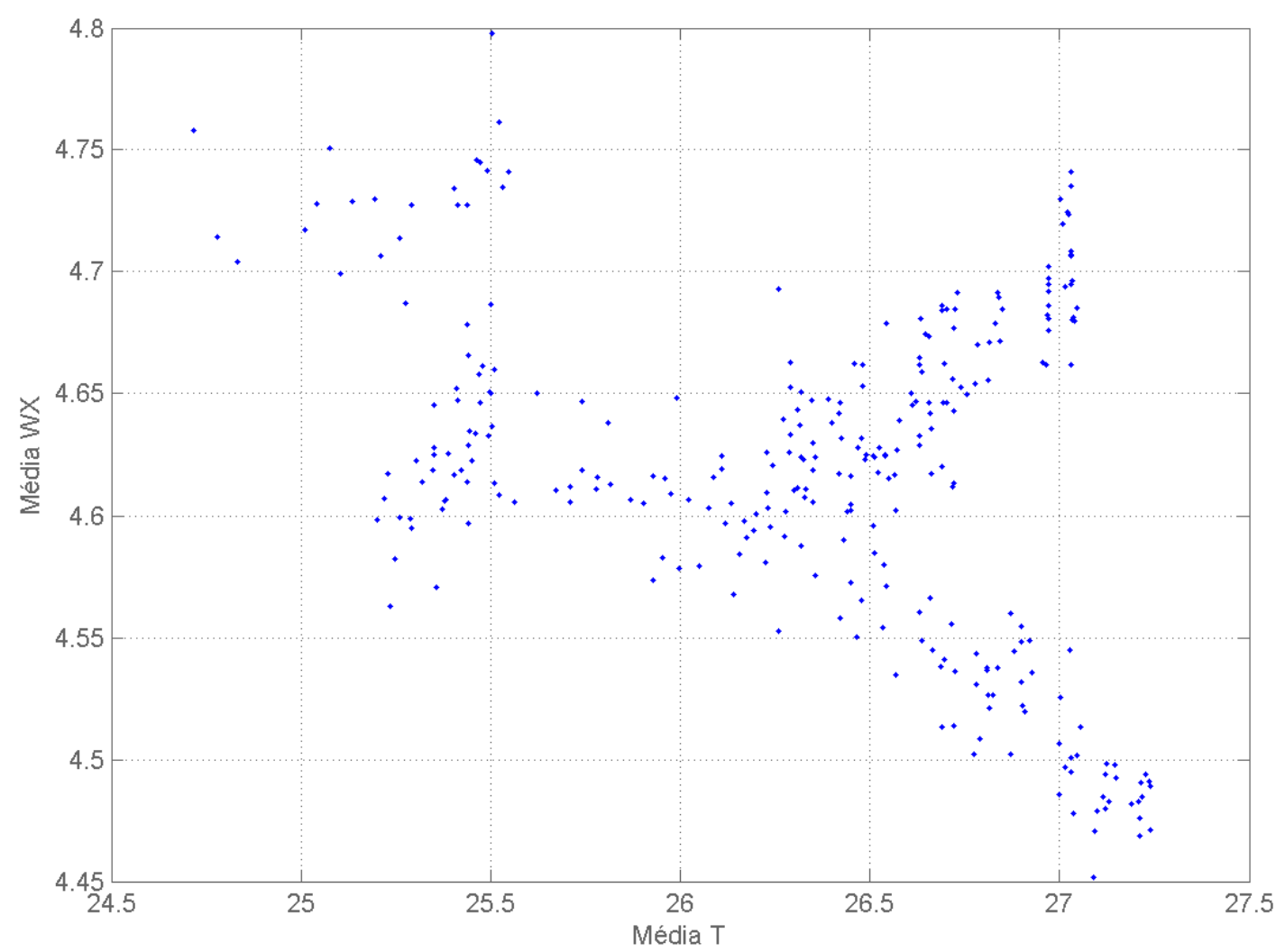

Figura 83 - Registros de velocidade angular (nos ensaios estáticos correspondem ao bias do sensor) para uma faixa de temperaturas

Embora o intervalo de temperatura não seja significativo, a dispersão dos dados, no caso o bias do girômetro $x$, não apresenta correlação clara com a temperatura. Essa ausência de correlação mantém a dúvida com relação ao sinal do fator de proporcionalidade $\gamma$ fornecido pelo fabricante. Sendo assim, foram testadas a correção positiva e negativa.

Aplicando-se a correção que incorpora a variação do bias com a temperatura ao sinal apresentado no item anterior, Figura 81, constatou-se que os resultados se mantiveram insatisfatórios. A Figura 84 é análoga a Figura 82 para o caso em que se fez a correção do bias com a temperatura do lançamento. 


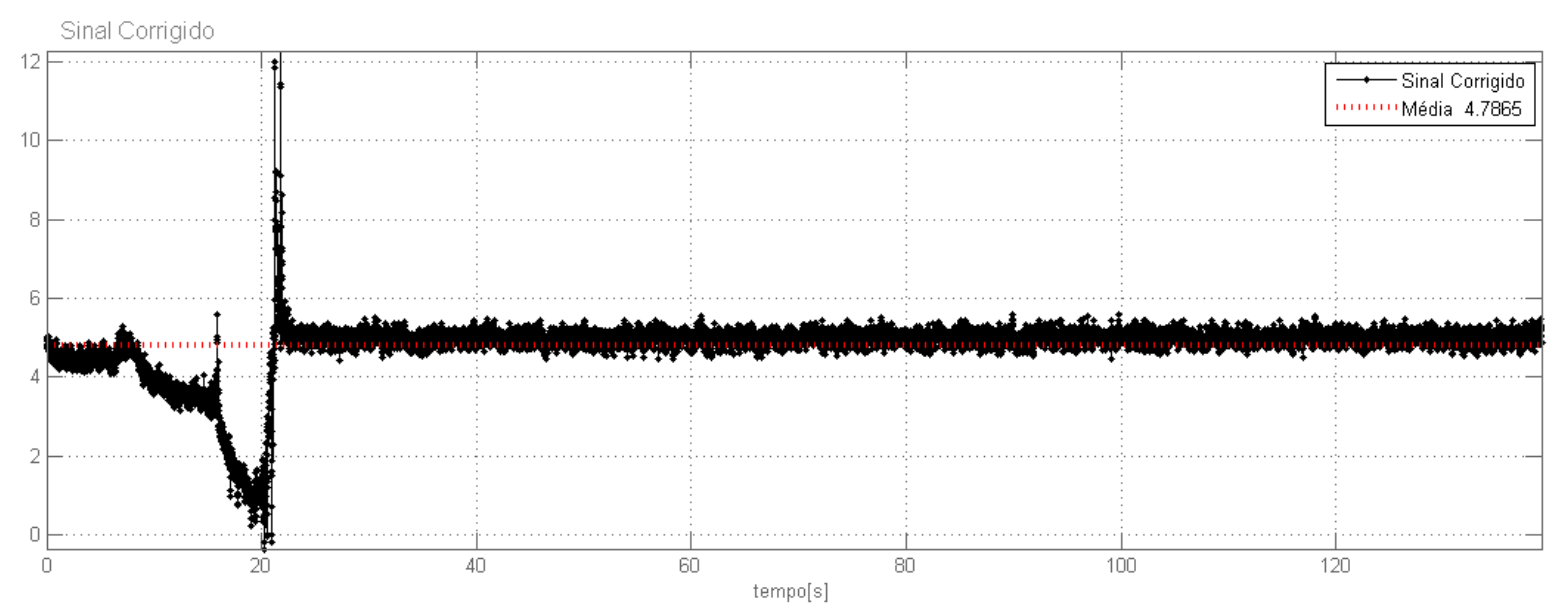

Figura 84 - Sinal apresentado na Figura 81 após a correção com o bias modificado pela temperatura

Neste caso, foi utilizada uma correção linear para o bias, embora existam trabalhos tais como (GULMAMMANDOV, 2009) que propõem outro modelo de correção envolvendo polinômios de ordem superior e efeitos de histerese. Tal trabalho foi desenvolvido empregando-se uma câmara climatizada e repetindo os experimentos descritos nos itens 6.2 e 6.3 para diversas faixas de temperatura.

Tais modelos de correção são especialmente importantes para o caso em que os dados necessitam ser corrigidos em tempo real. No estudo de caso apresentado aqui, os dados são processados após o término do lançamento e recuperação da unidade de medição. Sendo assim, não é imperativo que a correção ocorra em tempo real.

\subsubsection{Método Interativo}

A alternativa escolhida para determinação do bias foi avaliar o sinal após o lançamento e determinar qual a leitura do sensor quando é sabido que o movimento da estaca-torpedo cessou completamente.

Esse procedimento não dispensa completamente os ensaios em laboratório, pois, é só por meio destes que o fator de escala pode ser determinado.

Outra limitação importante deste método é o fato de que apenas os bias associados às velocidades angulares podem ser determinados, já que, após a parada completa da estaca esta assume certa atitude desconhecida com relação a vertical que produz, por sua vez, leitura nos acelerômetros.

Felizmente, como comprova a Tabela 11, os acelerômetros encontram-se devidamente calibrados, fato também comprovado na análise dos resultados. 
O procedimento consolidado para correção do sinal foi o seguinte:

- De posse dos sinais medidos durante o lançamento, analisar individualmente cada uma das leituras de velocidade angular;

- Para cada velocidade angular, determinar um ponto a partir do qual o movimento deve ser nulo;

- Calcular a média do sinal a partir desse ponto até o fim do registro;

- Subtrair do sinal original a média encontrada;

- Dividir o sinal obtido pelo fator de escala determinado experimentalmente;

- Repetir o procedimento para cada um dos registros de velocidade angular.

Após as correções realizadas, o sinal pode ser submetido aos algoritmos de análise.

Por se tratar de um procedimento que envolve decisão humana sobre onde o movimento da estaca-torpedo cessou, as etapas descritas acima foram programadas na forma de uma rotina de MatLab®, contendo interfaces gráficas. As interfaces permitem que o usuário insira os fatores de escala obtidos em laboratório e determine o trecho do sinal que será usado para o cálculo do bias.

A seguir, a sequência de telas geradas na rotina é mostrada, exemplificando o processo de correção para um dos lançamentos.

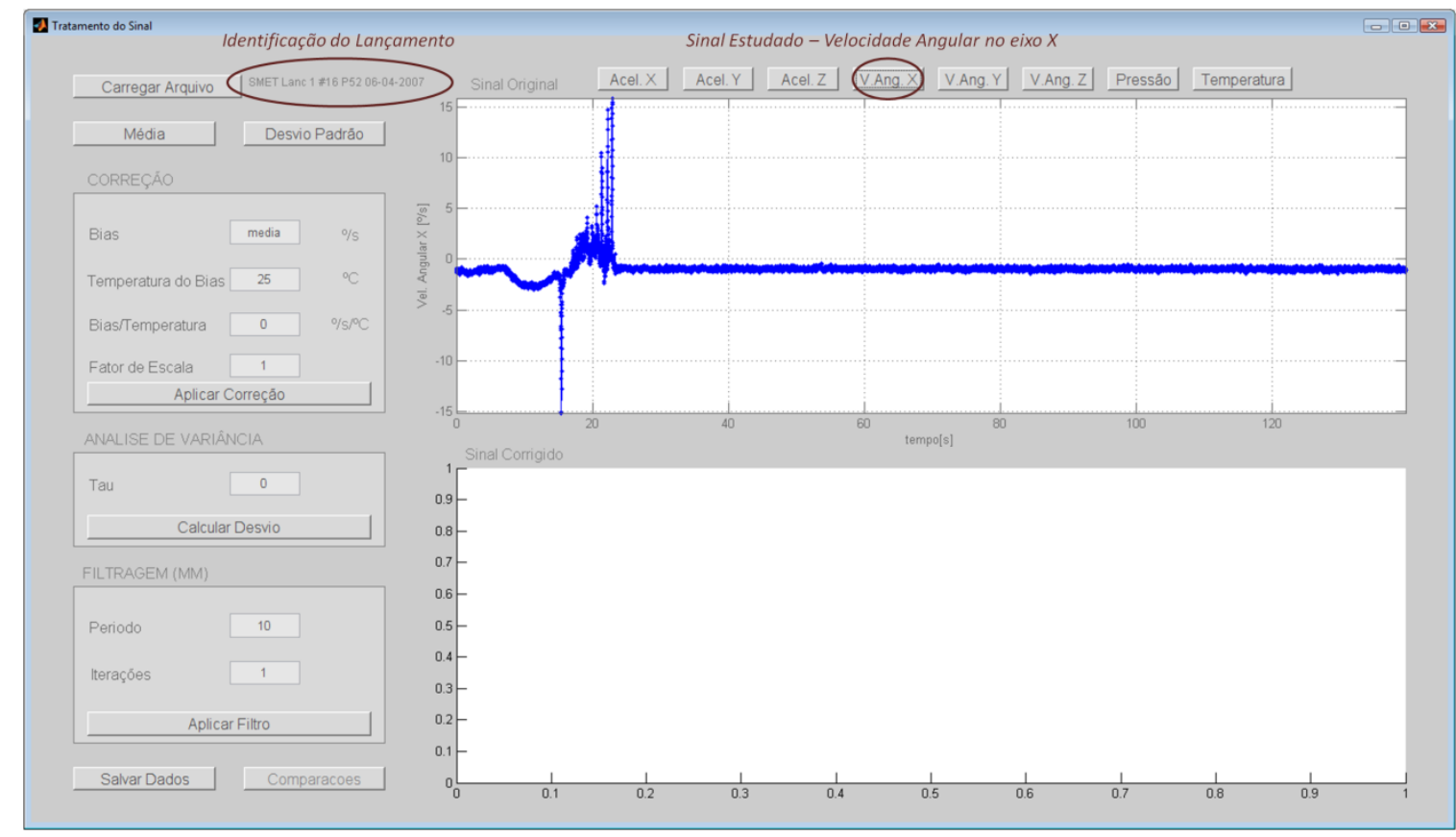

Figura 85 - Interface da rotina de correção do sinal; neste caso é exibido um registro de velocidade angular no eixo $x$ 
Inicialmente é selecionado o arquivo contendo os dados registrados pelo SMET durante um determinado lançamento da estaca-torpedo. Após a seleção do arquivo de origem, o usuário deve escolher o sensor ou a grandeza que deseja visualizar e/ou tratar, Figura 85.

No passo seguinte, o usuário deve selecionar o botão "média" que, por sua vez, habilitará a seleção do ponto correspondente ao início do cálculo da média, Figura 86.

O usuário julga o momento em que o movimento cessou completamente. Então a média é calculada, empregando os dados entre o ponto escolhido pelo usuário e o final da aquisição. Esta média é exibida no canto superior direito do gráfico do sinal, Figura 87.

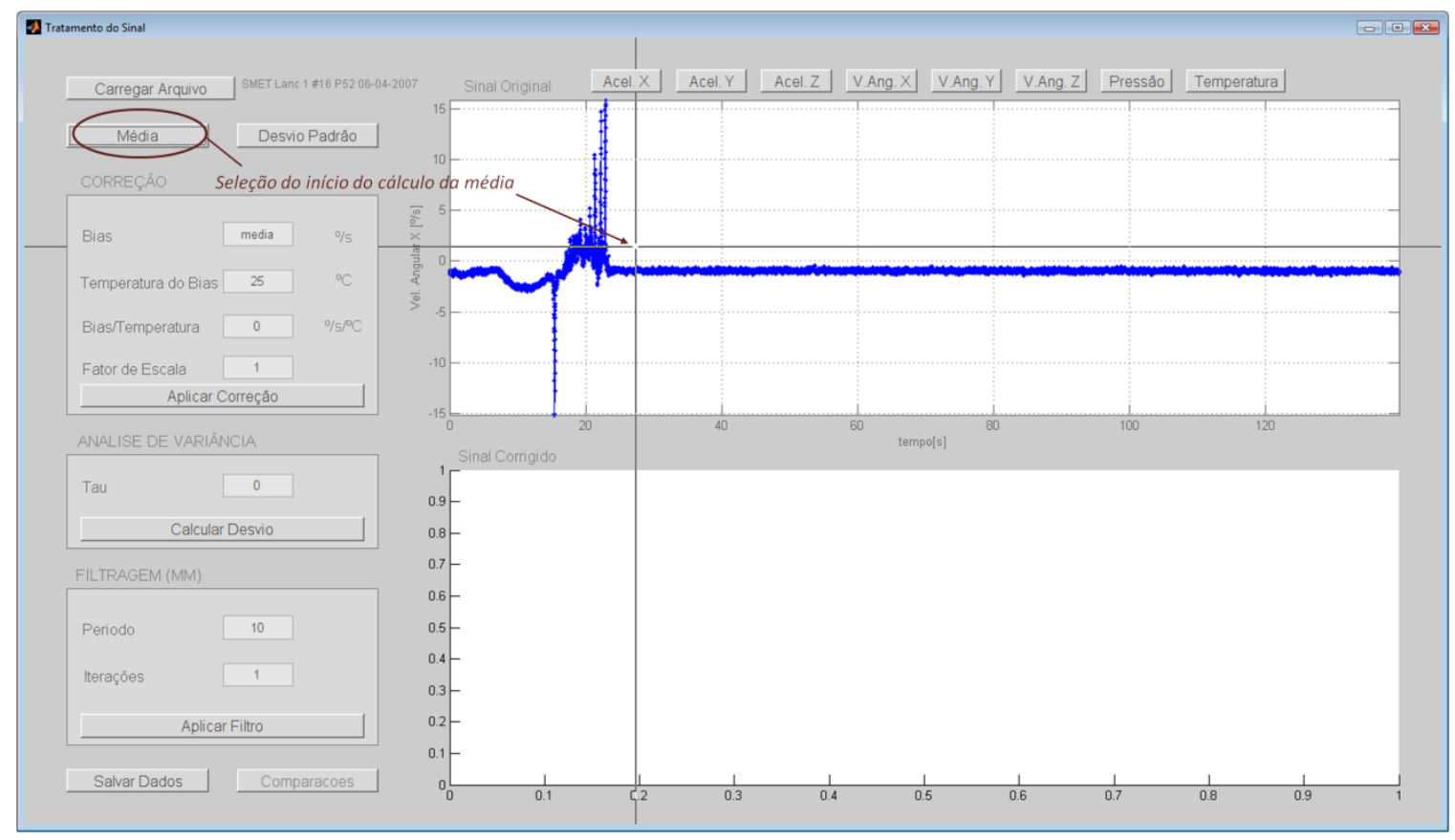

Figura 86 - Exemplo do mecanismo de seleção que permite ao usuário definir onde o movimento efetivamente cessou 


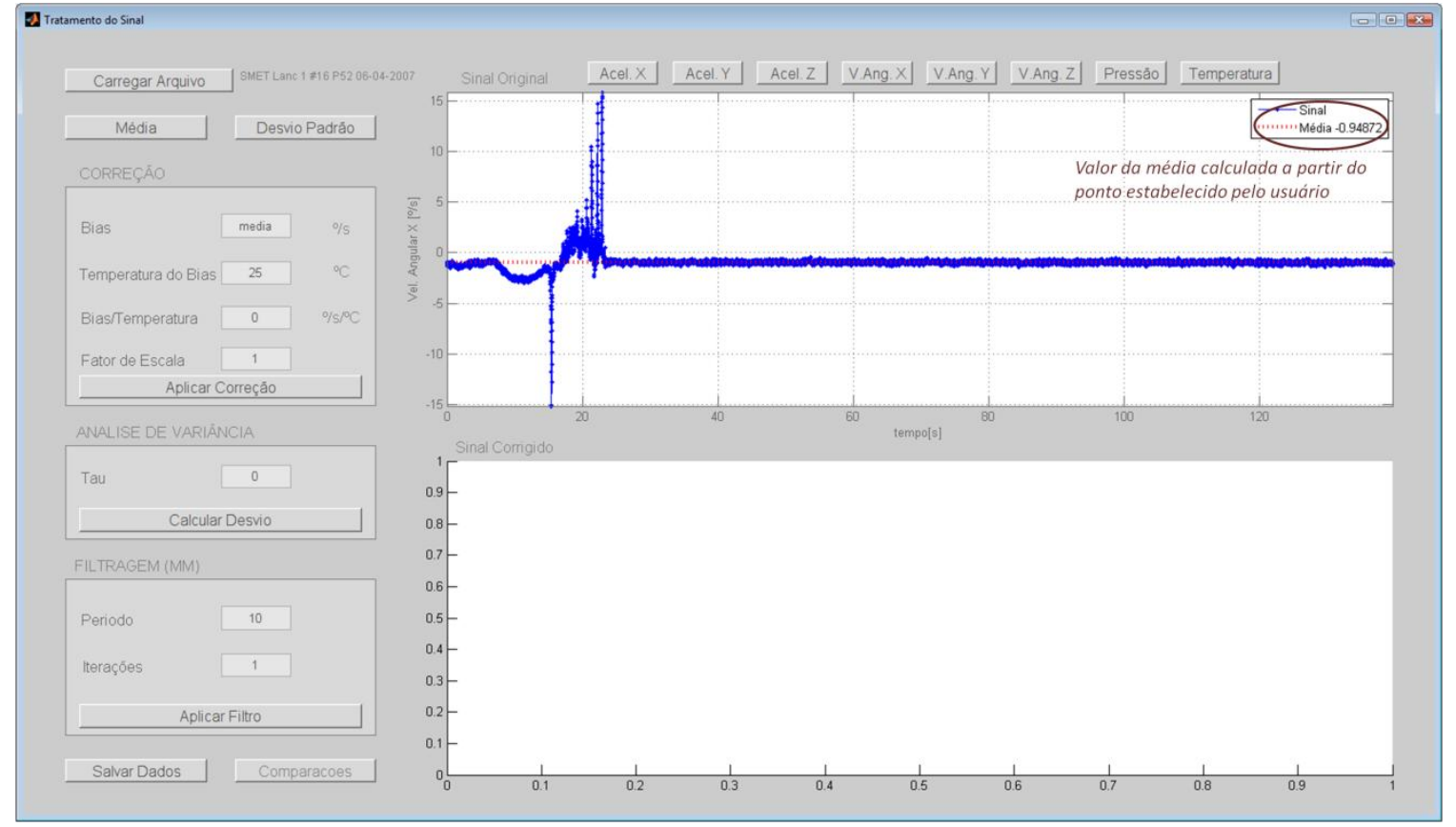

Figura 87 - Destaque da média calculada a partir do trecho estabelecido pelo usuário

O processo de seleção pode ser repetido até que o usuário avalie como satisfatório o valor calculado. Esse valor será o bias do sinal e deve ser colocado no respectivo campo , Figura 88.

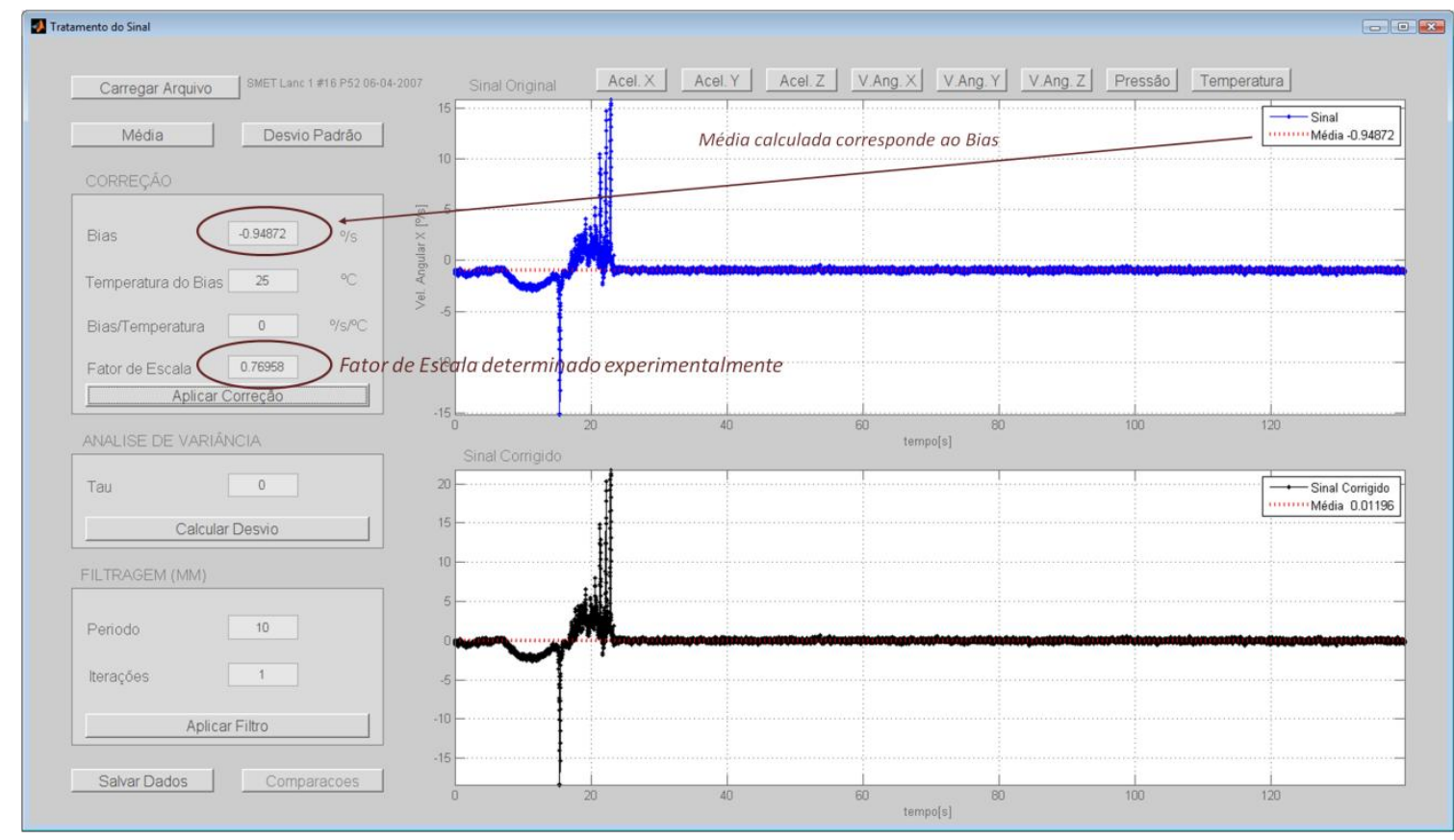

Figura 88 - Exemplo do preenchimento dos campos bias e fator de escala 
O campo referente ao fator de escala deve ser preenchido com o valor obtido em laboratório, neste caso, foi utilizado aquele presente na Tabela 12.

Selecionando a opção "Aplicar correção" o sinal é submetido ao modelo de correção descrito pela equação (177). No caso exemplificado não se empregou a correção de temperatura, pois o campo "Bias/Temperatura" foi mantido nulo, parâmetro $\gamma$.

Depois de realizada a correção das três velocidades angulares pode-se visualizar os resultados obtidos. O botão identificado como "Comparações" utiliza os dados originais e corrigidos como entrada dos dois algoritmos propostos anteriormente e exibe os resultados lado a lado.

Na Figura 89, o primeiro quadro da esquerda para direita traz o valor do azimute calculado utilizando-se o algoritmo vigente para o sinal sem a correção e com a correção, assim como a diferença entre os valores obtidos. Lembrando que o sinal não corrigido é aquele que provém diretamente do sensor, sem nenhum tipo de correção de bias ou fator de escala. Os cálculos empregados na rotina serão detalhados posteriormente neste texto.

O segundo quadro apresenta o valor da inclinação final, calculada por meio do algoritmo I (vigente) sobre os sinais originais e corrigidos. O último quadro apresenta os resultados anteriores calculados por meio do segundo algoritmo proposto - algoritmo de reconstrução de trajetória empregando quatérnios - partindo-se dos dados corrigidos.

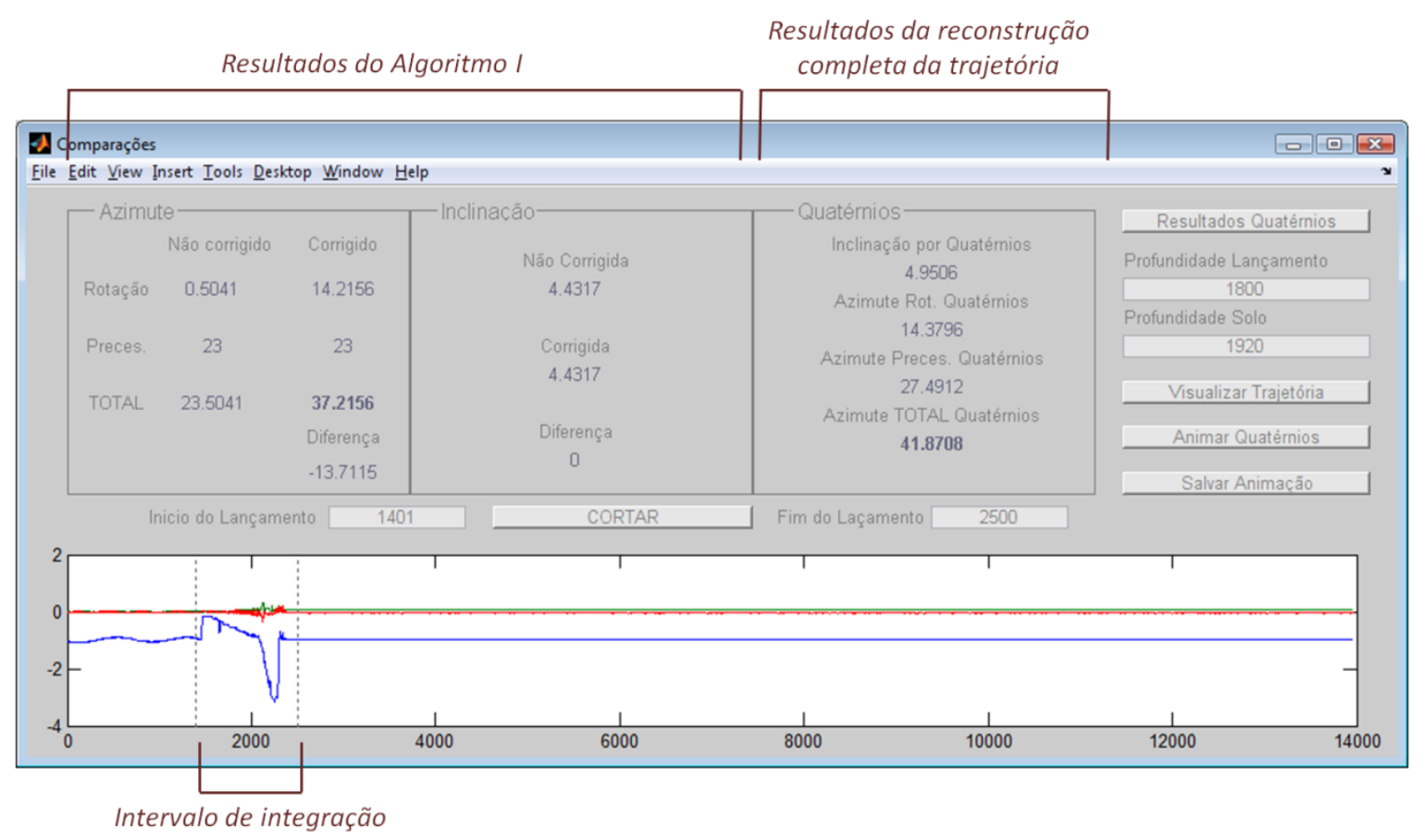

Figura 89 - Segunda inteface da rotina de correção do sinal; destaque para a definição manual do intervalo de integração 
Na parte inferior da janela há um gráfico exibindo as três acelerações medidas.

Assim, foi programada uma ferramenta que permite ao usuário definir precisamente o intervalo de tempo correspondente ao lançamento e, assim, evitar a integração de trechos desnecessários do sinal, o que adicionaria erros às estimativas dos parâmetros de interesse. Os efeitos da modificação do intervalo de integração são visualizados imediatamente, permitindo que o usuário avalie sua decisão.

Os botões no extremo direito da tela são utilizados para a visualização da cinemática do corpo reconstruída por meio do algoritmo dos quatérnios detalhado posteriormente.

\subsubsection{Análise dos Sinais por meio da Variância de Allan}

Durante a bateria de ensaios estáticos, foram realizados longos registros com a finalidade de analisar a natureza e os níveis de ruídos. Tal análise envolveu o cálculo da variância de Allan, descrita em detalhes no item 4.4.14 e 4.4.15.

A identificação da natureza do ruído foi feita por meio da comparação entre as curvas do desvio de Allan obtidas para os sinais medidos pelo SMET e a curva apresentada na Figura 55. Entretanto, não foi possível levantar a curva completa deste desvio, pois o tempo máximo de aquisição do equipamento é limitado. Sendo assim, para as análises foi empregado o maior sinal obtido, que correspondeu a aproximadamente uma hora e meia de medição.

Durante este registro, o SMET encontrou-se na posição vertical, ou seja, com seu eixo $\mathrm{x}$ alinhado à direção da gravidade.

A partir das análises do desvio de Allan é possível identificar e quantificar a origem do ruído presente nos sinais. Neste caso foi possível quantificar o Random Walk do sinal e a estabilidade do bias. As equações (198) e (199) foram empregadas na determinação do $N$, coeficiente de Random Walk.

$$
\begin{aligned}
& \operatorname{AVAR}(\tau)=\frac{N^{2}}{\tau} \rightarrow \sigma(\tau)=\frac{N}{\sqrt{\tau}} \\
& \log (\sigma)=-\log (N)-\frac{\log (\tau)}{2}
\end{aligned}
$$

O valor da chamada estabilidade do bias, segundo (STOCKWELL, W.;, 2004), corresponde ao ponto mais baixo da curva do desvio de Allan. 
As figuras seguintes apresentam as curvas obtidas para cada um dos sinais fornecidos pelo SMET. Nestas curvas foram identificados, ainda, o Random Walk e a estabilidade do Bias.

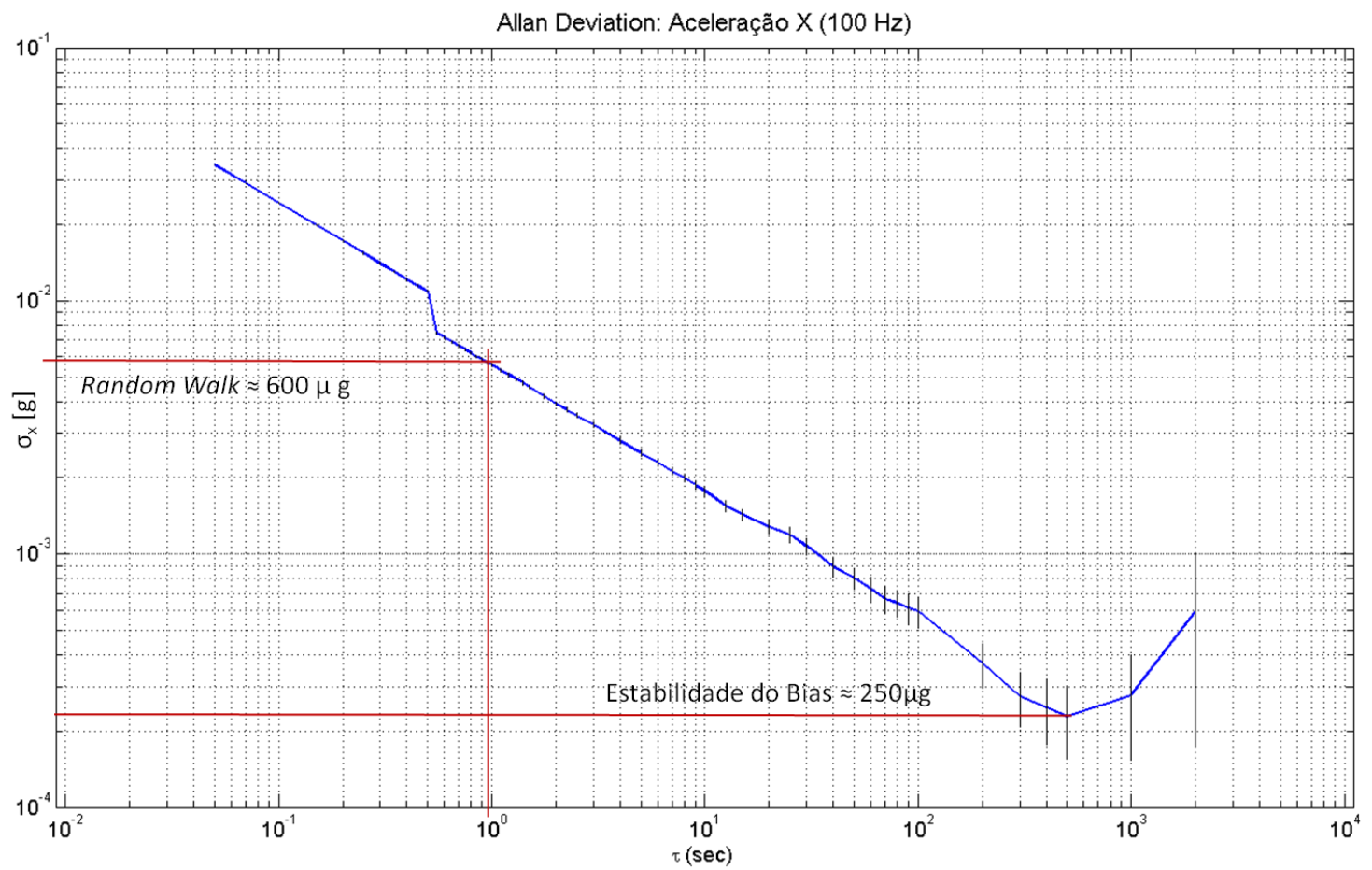

Figura 90 - Gráfico do desvio de Allan para um registro de aceleração X do SMET de cerca de 90 minutos.

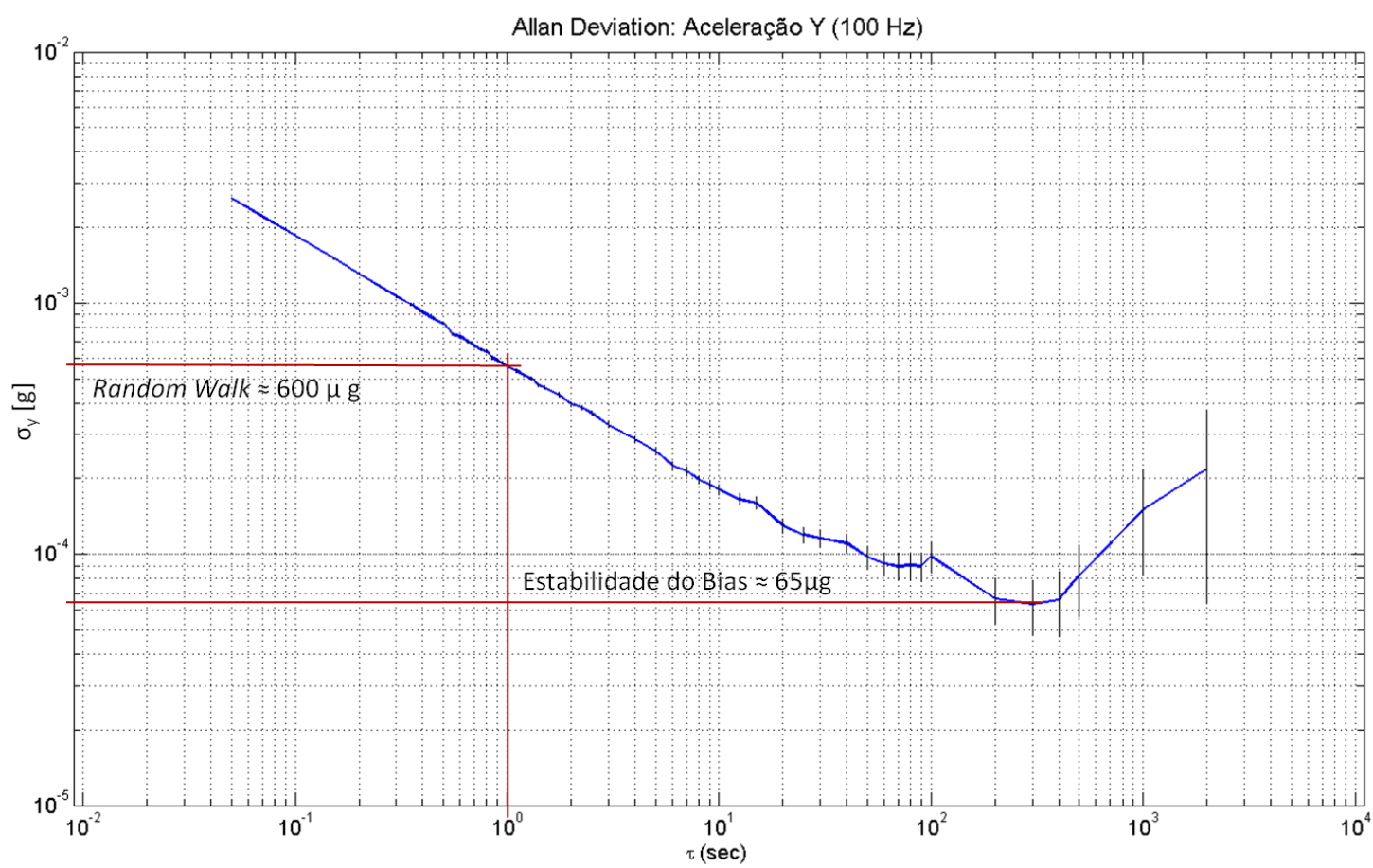


Figura 91 - Gráfico do desvio de Allan para um registro de aceleração Y do SMET de cerca de 90 minutos.

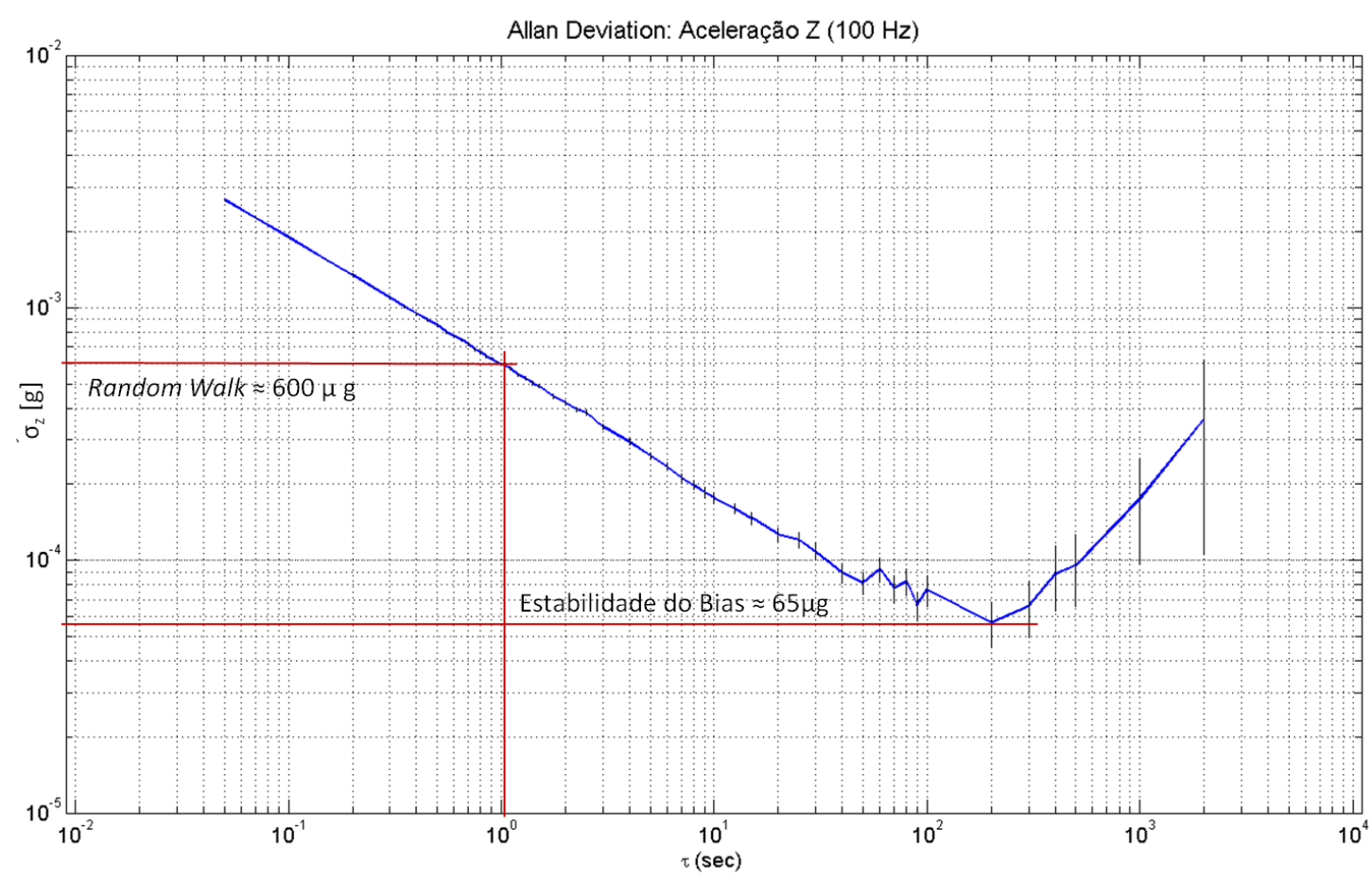

Figura 92 - Gráfico do desvio de Allan para um registro de aceleração Z do SMET de cerca de 90 minutos.

As análises de AVAR realizadas a partir dos registros de velocidade angular, em dois dos casos, apresentaram resultados distintos dos demais. É evidente nas Figura 94 e Figura 95 que as curvas atingem mínimos nas extremidades do intervalo - método apresentado no item 4.4.14. Este fato impossibilita afirmar que o desvio tenha assumido seu valor mínimo. Da mesma forma, é impossível afirmar que este resultado inesperado esteja associado a falhas do sensor já que apenas um registro foi analisado.

O registro de velocidade angular no eixo Z, por outro lado, produziu uma curva do desvio de Allan coerente com a expectativa inclusive do ponto de vista quantitativo. Essa afirmação baseia-se na comparação entre a curva apresentada na Figura 93 e a fornecida pelo fabricante do sensor, na Figura 56. 


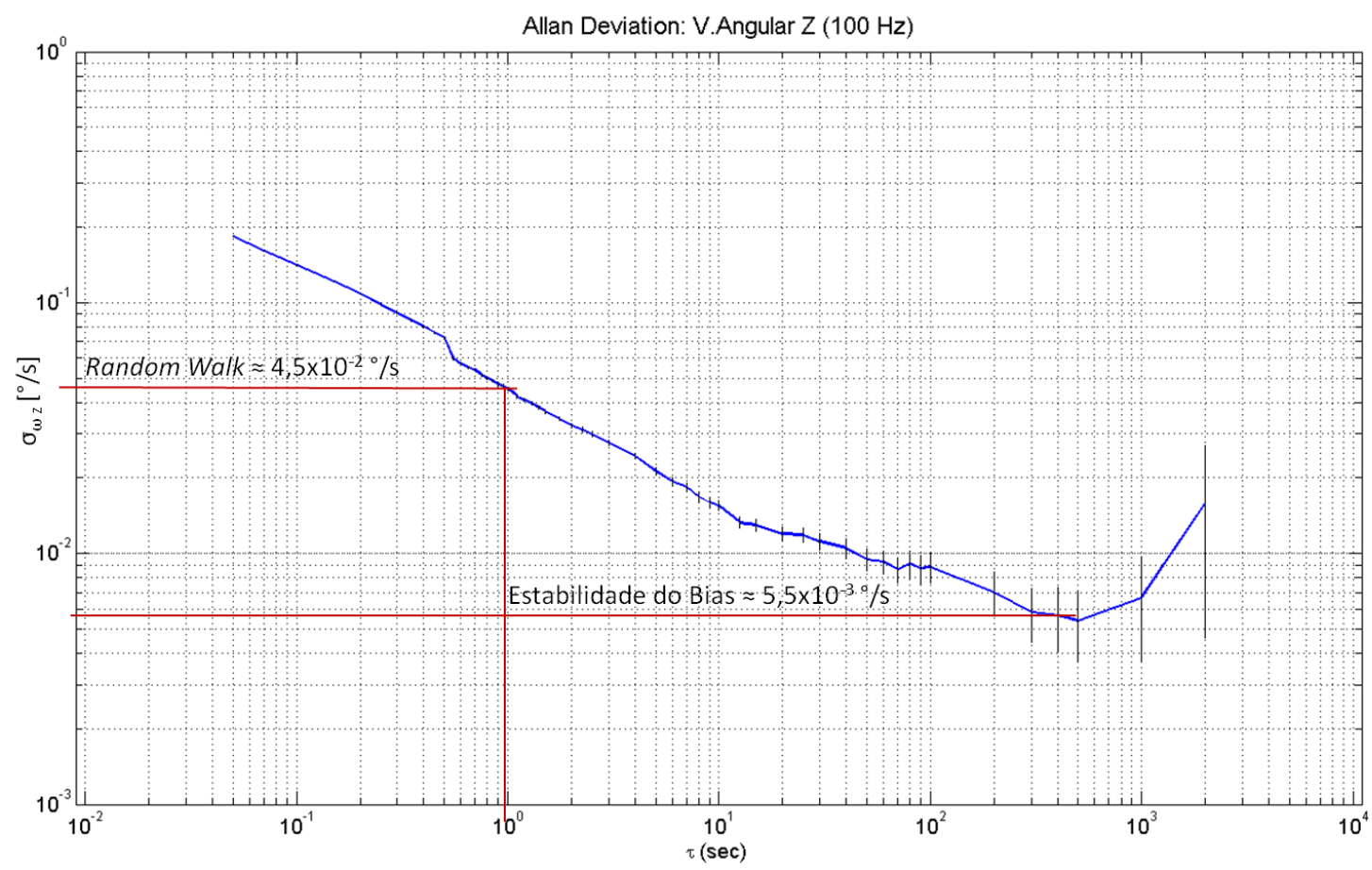

Figura 93 - Gráfico do desvio de Allan para um registro de velocidade angular no eixo Z do SMET de cerca de 90 minutos.

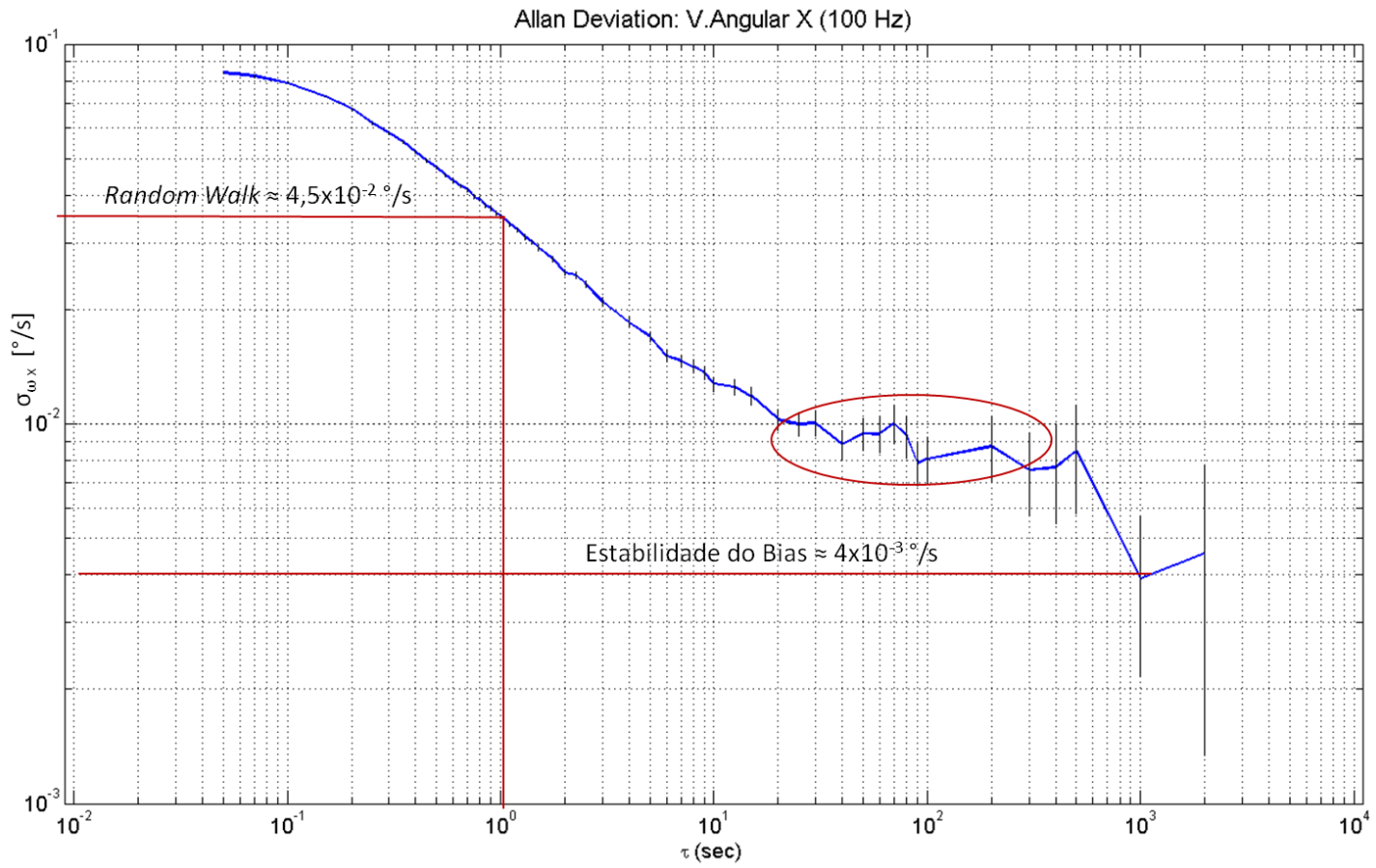

Figura 94 - Gráfico do desvio de Allan para um registro de velocidade angular no eixo X do SMET de cerca de 90 minutos. 


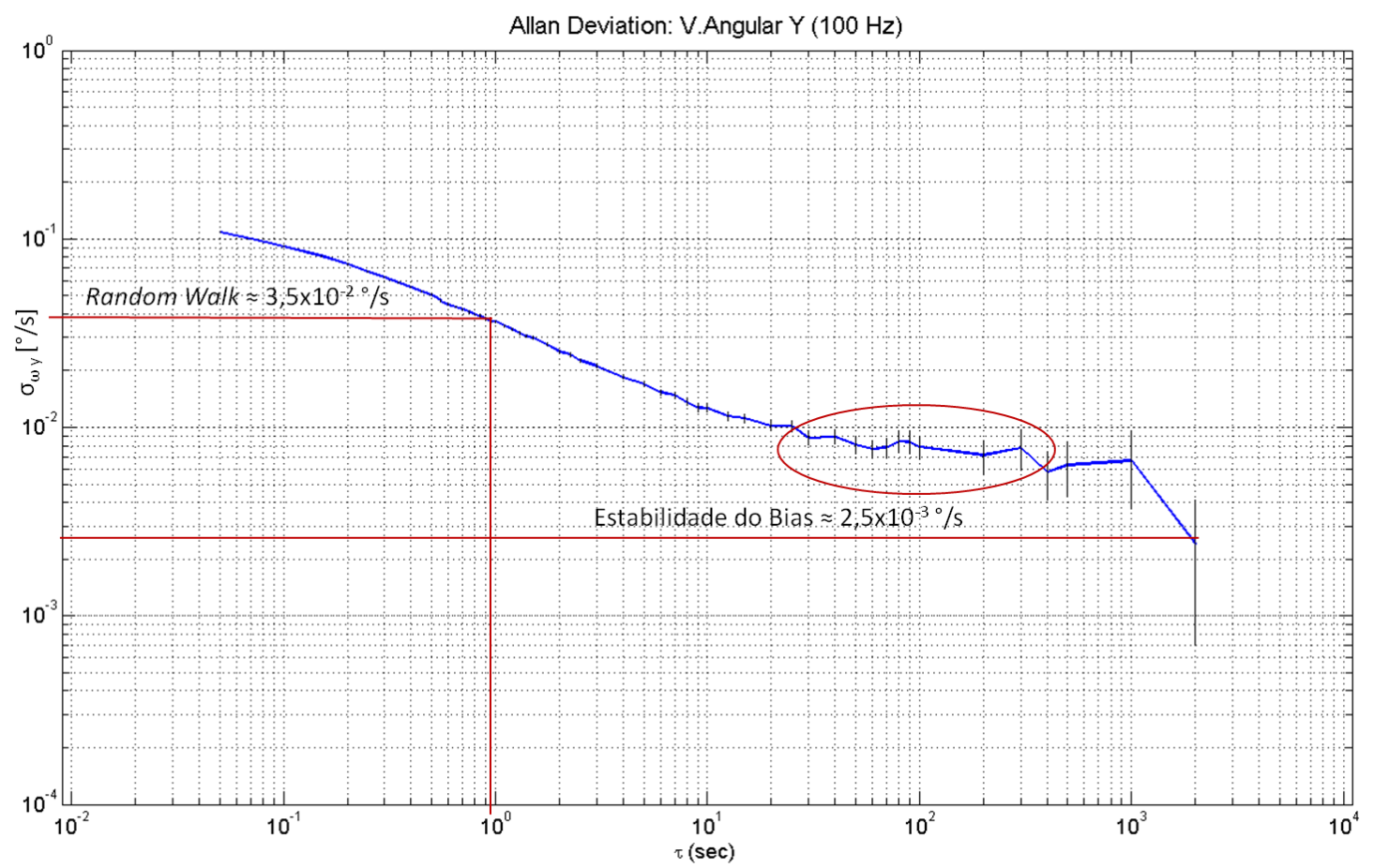

Figura 95 - Gráfico do desvio de Allan para um registro de velocidade angular no eixo Y do SMET de cerca de 90 minutos.

Embora esteja fora do escopo deste estudo propor métodos de filtragem que permitam eliminar ou minimizar os ruídos do sinal, identificar a origem destes ruídos tem importância como ponto de partida para estudos posteriores.

Estas análises indicaram que o principal ruído presente nos sinais fornecidos pelo SMET é o Random Walk que, como visto no item 4.4.12, pode ser modelado como um ruído branco. 


\section{Algoritmo Vigente}

O método descrito a seguir foi elaborado em (PETROBRAS, 2007) e apresentado como primeira alternativa ao cálculo dos parâmetros de interesse. Inicialmente consolidado na forma de uma planilha, o algoritmo foi reescrito em ambiente MatLab® para permitir posterior integração das demais rotinas, assim como melhorar a compreensão do autor sobre os cálculos realizados.

São detalhados neste tópico os cálculos associados à determinação dos parâmetros de interesse da trajetória: a velocidade terminal, a inclinação da estaca-torpedo ao final do lançamento e o azimute do plano vertical que contém toda a seção média da estaca, quando esta se encontra inclinada.

Este método restringe-se a calcular os parâmetros de interesse e, especificamente, em trajetórias similares à desempenhada pela estaca-torpedo durante seu lançamento.

\subsection{DESCRIÇÃo do ALGORITMO}

Um corpo em queda livre em um fluido apresentará uma velocidade máxima de queda chamada velocidade terminal. Essa velocidade é atingida quando as forças dissipativas geradas na interação entre o corpo e o fluido se igualam à força peso atuante no corpo. Neste instante, a resultante de forças é anulada e deixa de haver aceleração.

Em princípio, não será discutida a dinâmica do fenômeno, apenas sua cinemática e, neste caso, a velocidade terminal de interesse é apenas a componente vertical da velocidade do corpo.

A estratégia empregada para este cálculo consistiu em integrar o sinal de aceleração, este medido pelo acelerômetro x, que como mostram a Figura 96 e também a Figura 97, encontrase paralelo ao eixo longitudinal da estaca. No entanto, antes de executar a integração propriamente, foi subtraído do sinal o valor correspondente a aceleração da gravidade. Essa correção é necessária já que, para o cálculo da velocidade, deve-se apenas computar a parcela inercial de aceleração e os acelerômetros empregados no SMET registram, além desta parcela, a aceleração da gravidade local. 


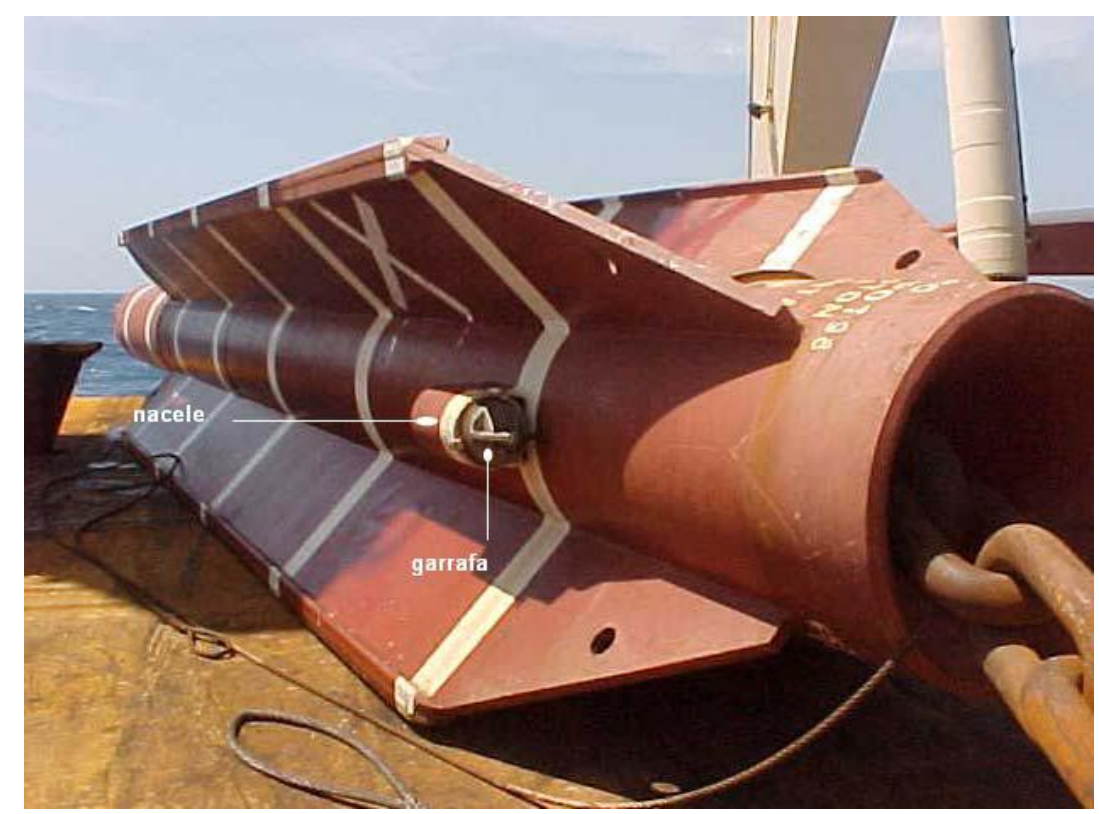

Figura 96 - Estaca-torpedo e nacela que contem o SMET durante o lançamento (PETROBRAS, 2007)

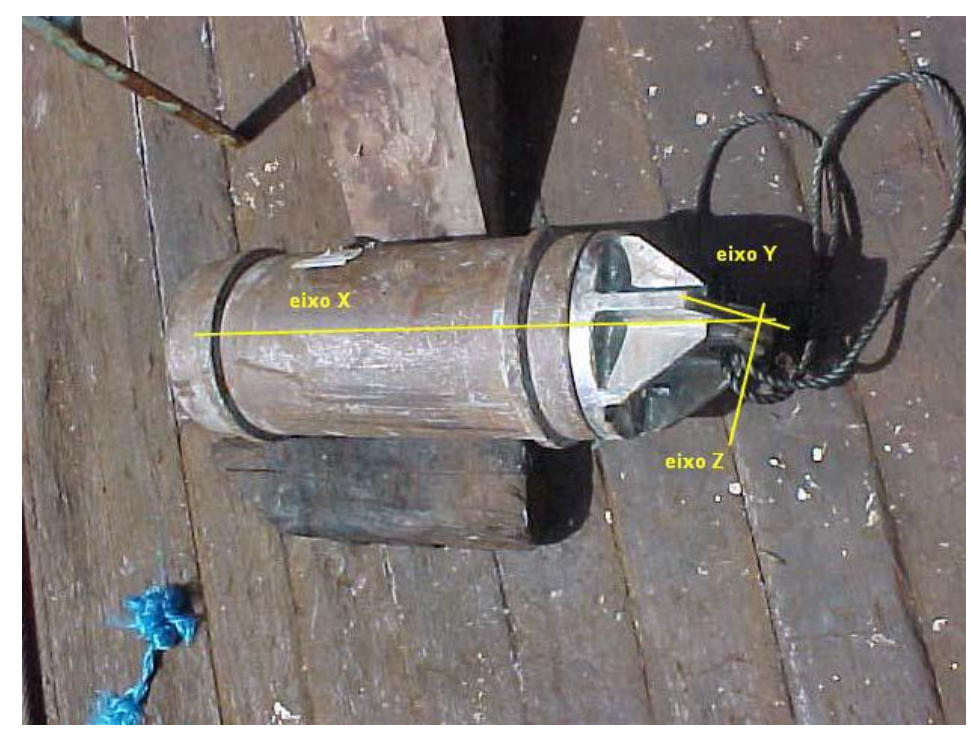

Figura 97 - Vaso de pressão que contem o SMET durante o lançamento (PETROBRAS, 2007)

O método proposto baseou-se na idéia de que a trajetória da estaca-torpedo é aproximadamente retilínea e vertical. Essa hipótese parece plausível tendo em vista a configuração inicial do lançamento e a ausência de perturbações externas durante a queda da estaca-torpedo.

O processo de integração foi restrito ao intervalo de tempo correspondente ao lançamento efetivo. A Figura 98 apresenta a região do sinal sobre a qual foi realizada a integração. 


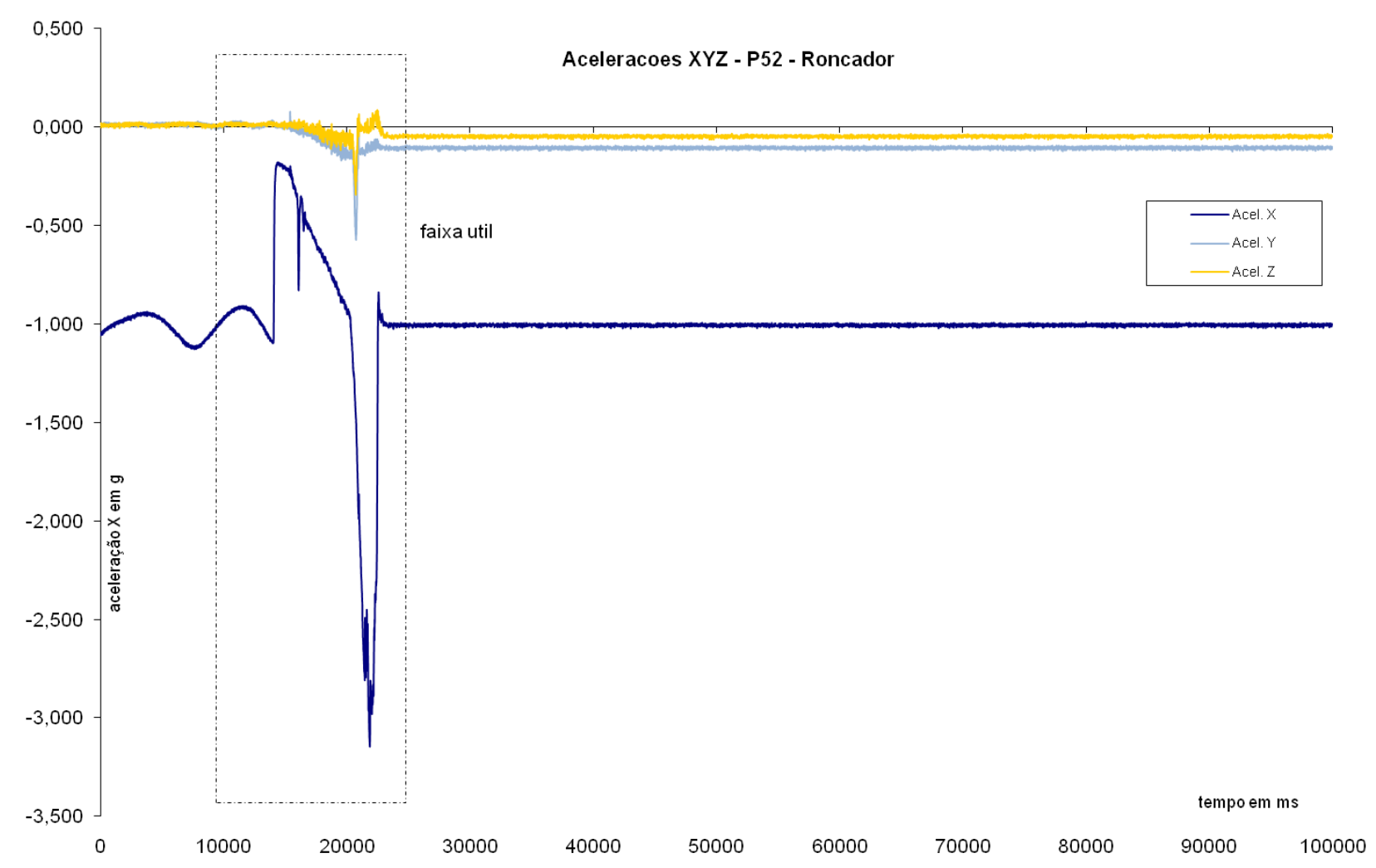

Figura 98 - Registro de acelerações de um lançamento da estaca-torpedo destacando a região de interesse e empregada no algoritmo

Fica a critério do analista, selecionar o ponto de início e término da integração, observando apenas que o limite inicial deve incorporar o momento em que a estaca é liberada e o segundo limite deve corresponder a um instante em que o movimento evidentemente tenha cessado. Embora seja perceptível movimento vertical no início da aquisição (Figura 98), nesta forma de cálculo assume-se que a estaca parte do repouso - velocidade vertical nula.

Foi escolhido o método dos trapézios para realizar a integração e o intervalo de tempo entre os diferentes passos foi o inverso da taxa de aquisição, neste caso $0,01 \mathrm{~s}$.

Imprimindo-se a evolução da velocidade ao longo do tempo obtém-se a Figura 99.

É possível observar no gráfico um período de aceleração correspondente à queda, onde a velocidade aumenta, até um valor máximo, a partir do qual ocorre a diminuição acentuada da velocidade, certamente causada pela penetração da estaca no leito marinho.

Após a desaceleração completa, a velocidade assume um valor constante e, neste momento, imagina-se que a estaca esteja completamente parada. Constata-se, no entanto, que a medida da velocidade vertical não atinge o valor zero ao final da desaceleração. 


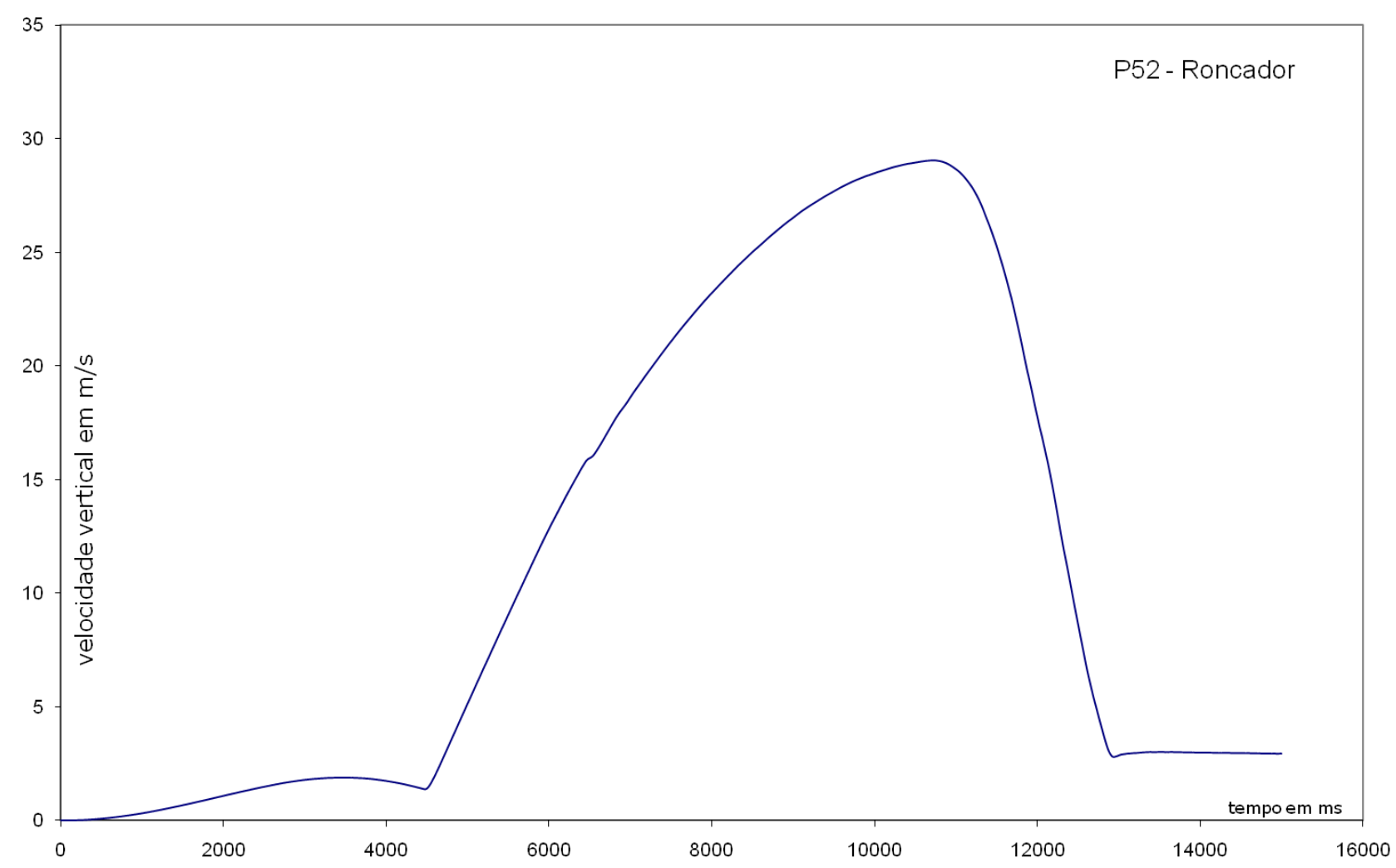

Figura 99 - Curva de velocidade vertical (integral da aceleração no eixo x do corpo) sem nenhuma correção

O idealizador deste método de cálculo avaliou que tal desvio fora causado por imprecisão do sensor, no caso um bias na leitura de aceleração. Porém, durante o desenvolvimento do algoritmo não foram realizados testes com o equipamento a fim de verificar a presença ou magnitude deste desvio. Sendo assim, o bias na aceleração x foi calculado iterativamente de forma a fazer com que o gráfico mostrado na Figura 99 assumisse a forma apresentada na Figura 100, onde, a velocidade vertical se anula, ao final da desaceleração.

Depois de realizadas as correções descritas acima, a velocidade vertical máxima foi obtida diretamente da inspeção do gráfico apresentado na Figura 100. 


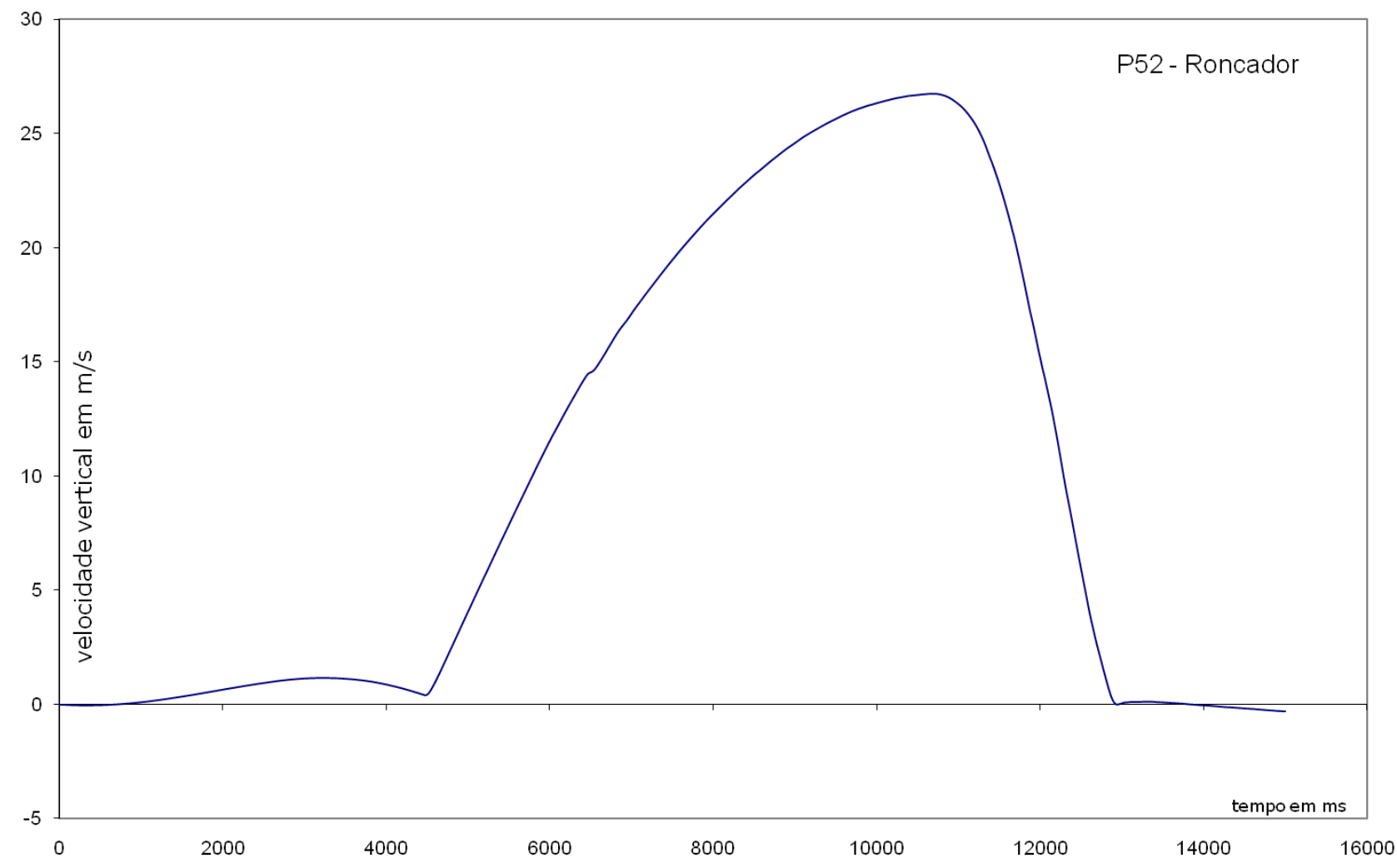

Figura 100 - Curva de velocidade vertical (integral da aceleração no eixo x do corpo) após o método iterativo de correção do bias

O cálculo da inclinação final foi feito com base em um segundo trecho do sinal, que se inicia no momento em que o analista avalia que o movimento cessou completamente. A partir desse ponto são calculadas as médias aritméticas das três componentes de aceleração registradas. Essa média deve corresponder às componentes da aceleração da gravidade medidas quando a estaca está em repouso no leito marinho. Chamando os valores médios calculados de $a_{x}$, $a_{y}, a_{z}$, pode-se determinar a inclinação do SMET e, consequentemente da estaca por meio da equação (200).

$$
\theta=\operatorname{atan}\left(\frac{\sqrt{a_{y}^{2}+a_{z}^{2}}}{a_{x}}\right)
$$

A rotina que realiza este cálculo ainda procura determinar um eventual desalinhamento entre a garrafa que contém o SMET e o eixo longitudinal da estaca-torpedo. Essa correção executa o mesmo procedimento utilizado para a determinação da inclinação final, empregando o primeiro trecho do sinal, ou seja, anterior à soltura da estaca. O valor estimado para o desalinhamento da estaca é subtraído do valor final da inclinação. 
Chamado aqui de azimute da inclinação, trata-se da grandeza descrita na introdução deste tópico como sendo o ângulo do plano vertical que corta todo o corpo da estaca quando a mesma encontra-se inclinada. O plano de referência para o cálculo do azimute é o plano paralelo à direção norte-sul. Na descrição euleriana, esse ângulo corresponde ao ângulo de precessão identificado no item 4.2.2 $\operatorname{como} \varphi$.

A determinação desse ângulo depende da determinação de três grandezas que serão chamadas neste documento de $A_{0}, A_{1}$ e $A_{2}$. Chamando a grandeza Azimute da Inclinação de $A$, pode-se escrever a frase anterior na forma da equação (201).

$$
A=A_{0}+A_{1}+A_{2}
$$

$A_{0}$ corresponde a condição inicial com relação ao norte geográfico. Essa grandeza, no lançamento real, é determinada visualmente por meio das câmeras de um ROV (Remotely operated underwater vehicle) que se alinha com relação a um par de aletas opostas do SMET e usa sensores internos para determinar a direção para a qual está apontado (Figura 101).

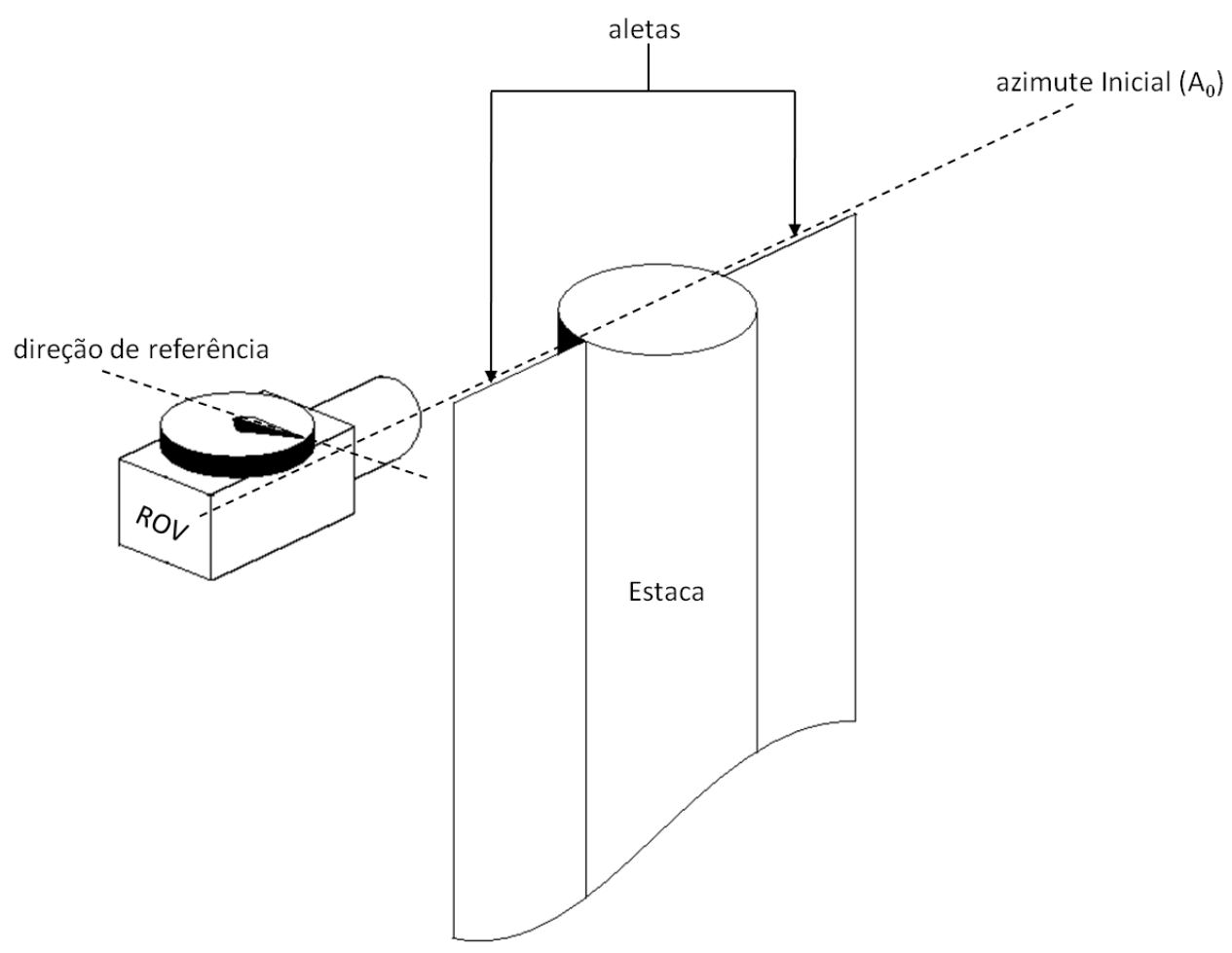

Figura 101 - Esquema de obtenção da orientação inicial da estaca empregando o ROV 
O segundo termo, $A_{1}$, representa a rotação da direção de referência até a posição final. Esse termo é calculado simplesmente integrando-se a componente x da velocidade angular do corpo, ou seja:

$$
A_{1}=\int \omega_{x} d t
$$

Reforçando que ao final deste tópico serão feitas definições mais precisas de cada um destes termos, assim como serão esclarecidas as hipóteses implícitas nestas equações.

O ultimo termo é obtido a partir da equação (203).

$$
A_{2}=\operatorname{atan}\left(\frac{\alpha_{z}}{\alpha_{y}}\right)
$$

Onde $\alpha_{y}$ e $\alpha_{z}$ são as mesmas grandezas utilizadas na equação (200).

Substituindo (202) e (203) em (201), obtém-se a equação (204).

$$
A=A_{0}+\int \omega_{x} d t+\operatorname{atan}\left(\frac{\alpha_{z}}{\alpha_{y}}\right)
$$




\subsection{ANÁLISES}

O método descrito anteriormente apóia-se na hipótese de que a trajetória do corpo desvia-se pouco da vertical e, por isso, o ângulo de inclinação $\theta$ é pequeno. A Figura 102 auxilia na visualização desta hipótese.
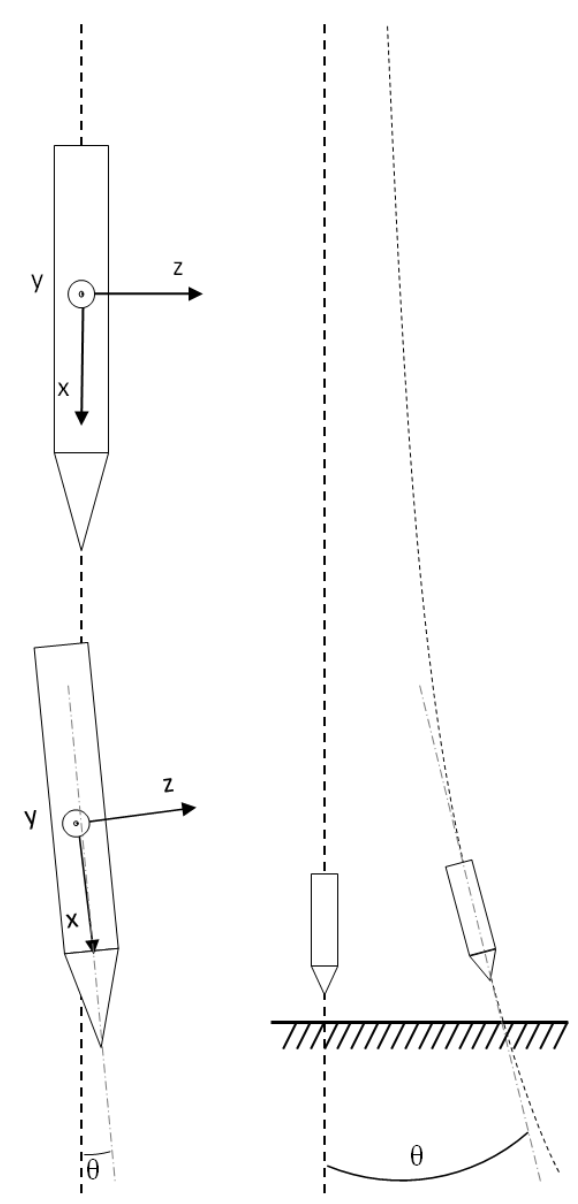

Figura 102 - Caracterização da inclinação da estaca-torpedo

Sob tal hipótese, assumir como velocidade vertical a velocidade proveniente da integração do sinal de um sensor alinhado ao eixo longitudinal da estaca incorrerá em erros pequenos. Para verificar a validade desta hipótese recorreu-se aos próprios resultados de inclinação.

O cálculo da inclinação final, supondo que o corpo encontre-se efetivamente em repouso, não está sujeito a nenhuma hipótese simplificadora. Desta forma é possível verificar se, de fato, valores de $\theta$ nos lançamentos reais são suficientemente pequenos. A Tabela 13 apresenta tais valores obtidos em todos os lançamentos cujos dados foram disponibilizados para este estudo. 
Tabela 13 - Inclinações finais calculadas

\begin{tabular}{|c|c|}
\hline $\begin{array}{c}\text { Número do } \\
\text { Lançamento }\end{array}$ & $\begin{array}{c}\text { Inclinação } \\
\text { Final [ }{ }^{\circ} \mathbf{]}\end{array}$ \\
\hline 1 & 4,4 \\
\hline 2 & 5,1 \\
\hline 3 & 6,1 \\
\hline 4 & 6,7 \\
\hline 5 & 4,6 \\
\hline 6 & 8,5 \\
\hline 7 & 5,8 \\
\hline 8 & 7,0 \\
\hline 9 & 8,3 \\
\hline 10 & 3,5 \\
\hline 11 & 7,1 \\
\hline 12 & 8,5 \\
\hline 13 & 7,9 \\
\hline 14 & 3,3 \\
\hline 15 & 5,7 \\
\hline 16 & 7,6 \\
\hline
\end{tabular}

Para os valores de inclinação apresentados na Tabela 13 o erro percentual na linearização do tipo $\cos (\theta) \cong 1$ não excede $1,1 \%$. Esse fato indica que a hipótese é válida.

O cálculo do parâmetro $A$ depende da hipótese de pequenas inclinações no cálculo de todos os seus termos.

A inspeção visual feita pelo ROV associa a orientação das aletas a um azimute inicial. Foi dito anteriormente que o parâmetro $A$ - azimute da inclinação - corresponde ao ângulo de precessão que, para inclinações - nutações - próximas de zero confunde-se com a rotação própria do corpo - spin. Essa correspondência permite associar $A_{0}$ a $\phi_{0}$.

Voltando-se agora para o segundo termo da equação (204), sabe-se que a componente vertical do vetor velocidade angular do corpo é dada pela expressão (205).

$$
\Omega_{z}=\dot{\psi}+\dot{\phi} \cos \theta
$$

Sendo esse o parâmetro que se deseja integrar ao longo da queda, o segundo termo da equação (201) pode ser escrito como mostra a equação (206).

$$
A_{1}=-\int(\dot{\psi}+\dot{\phi} \cos \theta) d t
$$


Assumindo $\theta \ll 1$ :

$$
A_{1} \cong-\int(\dot{\psi}+\dot{\phi}) d t=-\psi-\phi
$$

Foi discutido no item 4.2.5 que, nesta situação, acréscimos na precessão ou na rotação própria provocam o mesmo giro no corpo, ver equação (115).

O sensor cujo eixo sensível está aproximadamente alinhado à vertical é o giroscópio x, desta forma, a grandeza $A_{1}$ pode ser descrita segundo a equação (202).

O último termo da equação (201) é obtido por meio das componentes da aceleração da gravidade lidas pelo SMET. Supondo conhecida a atitude do corpo ao final da trajetória, o vetor aceleração da gravidade no referencial do corpo é dado por:

$$
\boldsymbol{g}=[M]\left[\begin{array}{l}
0 \\
0 \\
g
\end{array}\right]=\mathrm{g}\left[\begin{array}{c}
-\theta \cos (\psi) \\
\theta \sin (\psi) \\
1
\end{array}\right]
$$

Onde $[M]$ é a matriz de transformação de base, sob a hipótese de pequenos ângulos de inclinação apresentada na equação (100).

Computar a grandeza $A_{2}$, como mostra a equação (203), significa realizar a operação descrita a seguir:

$$
\operatorname{atan}\left(\frac{\alpha_{z}}{\alpha_{y}}\right)=\arctan \left(\frac{-\cos (\psi)}{\sin (\psi)}\right)=\psi-\frac{\pi}{2}
$$

Da equação (209) pode-se constatar que este último termo corresponde apenas à rotação própria do corpo.

Aplicando os resultados (207) e (209) em (201) chega-se a equação (210)

$$
A=A_{0}-\psi-\phi+\psi-\frac{\pi}{2}=\phi_{0}-\phi-\frac{\pi}{2}
$$




\subsection{COMPARAÇÕES EXPERIMENTAIS}

É possível fazer comparações diretas conhecendo-se em detalhes o algoritmo vigente e possuindo os resultados obtidos nos experimentos descritos nos item 6.2 e 6.3 .

A inclinação calculada conforme a equação (200), pode ser comparada com aquela medida pelo inclinômetro durante os experimentos na morsa reclinável.

Os dados experimentais e as medidas calculadas foram dispostos em um gráfico, mostrado na Figura 103. Este gráfico consolida cerca de 300 ensaios, cada um deles representado por um ponto.

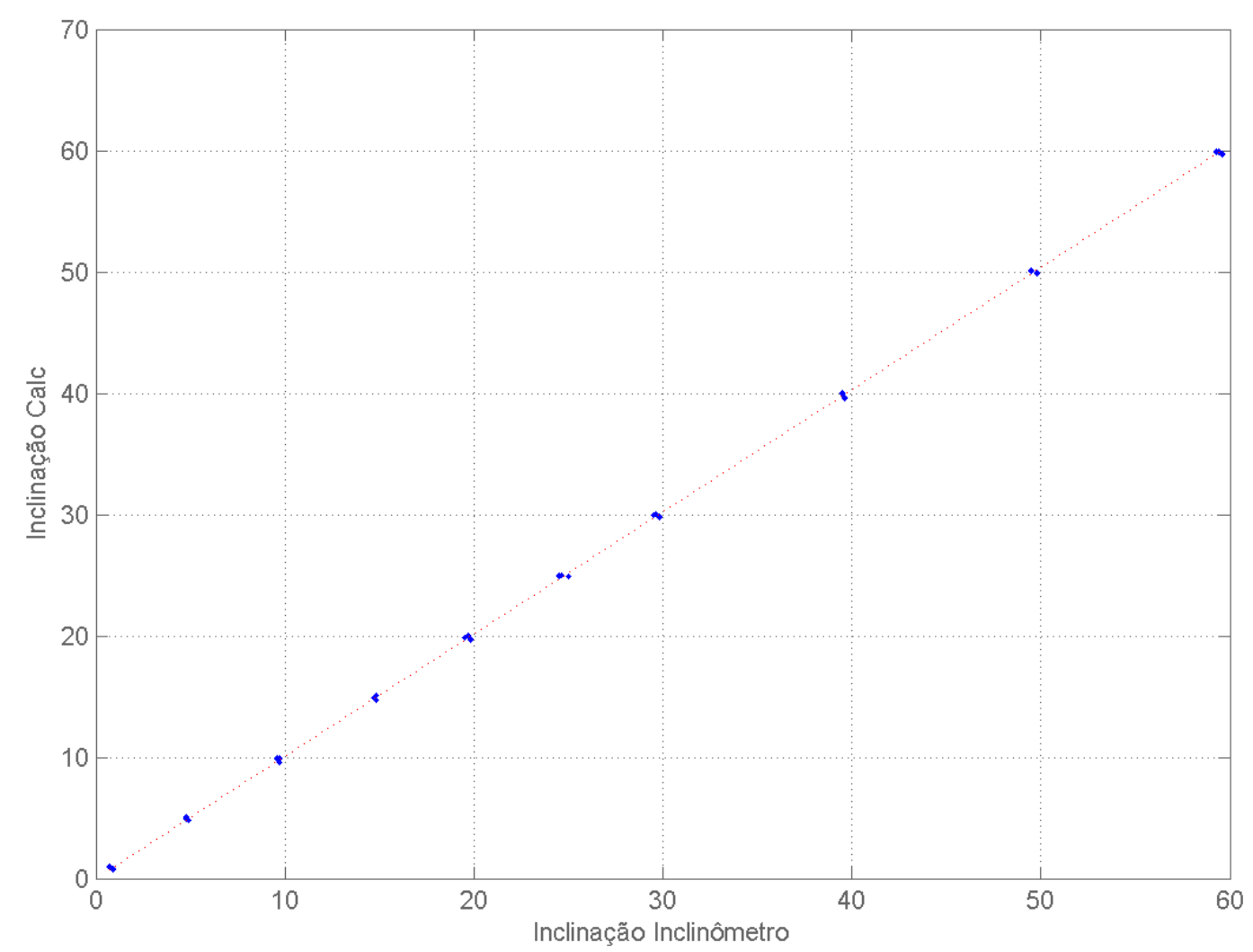

Figura 103 - Comparação entre inclinações medidas e calculadas, em graus.

Foi ajustada uma reta sobre os pontos para evidenciar a correspondência direta entre as medidas. O gráfico acima foi gerado a partir dos sinais experimentais isentos de qualquer correção e, com isso, comprova que o SMET, com sua condição padrão de calibração, e o algoritmo vigente são capazes de reproduzir adequadamente a inclinação da estaca-torpedo.

$\mathrm{O}$ termo $A_{2}$, por sua vez, pode ser calculado a partir dos sinais experimentais e comparado com o valor correspondente ao arranjo do ensaio. 
Conhecendo-se a relação apresentada na equação (209), o dispositivo de fixação do SMET na morsa reclinável foi fabricado permitindo que fosse possível fixar o SMET em diversos ângulos de rotação própria $\psi$, ver Figura 104.

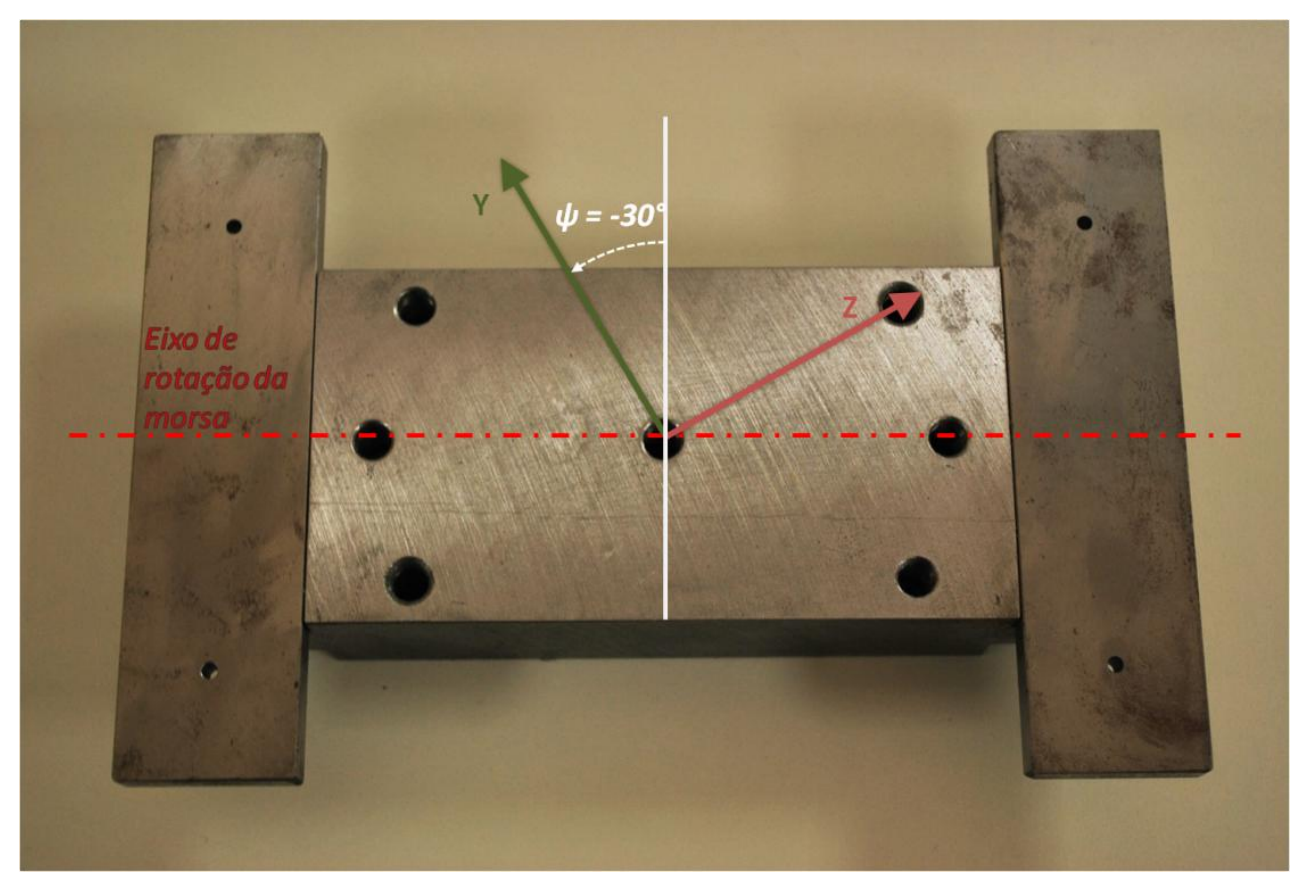

Figura 104 - Fixação do SMET rotacionado

Foram observadas diferenças significativas entre os valores de $\psi$ impostos experimentalmente e calculados segundo o algoritmo vigente. Estas diferenças, no entanto, possuem correlação com a inclinação do SMET, como mostra a Figura 105. 


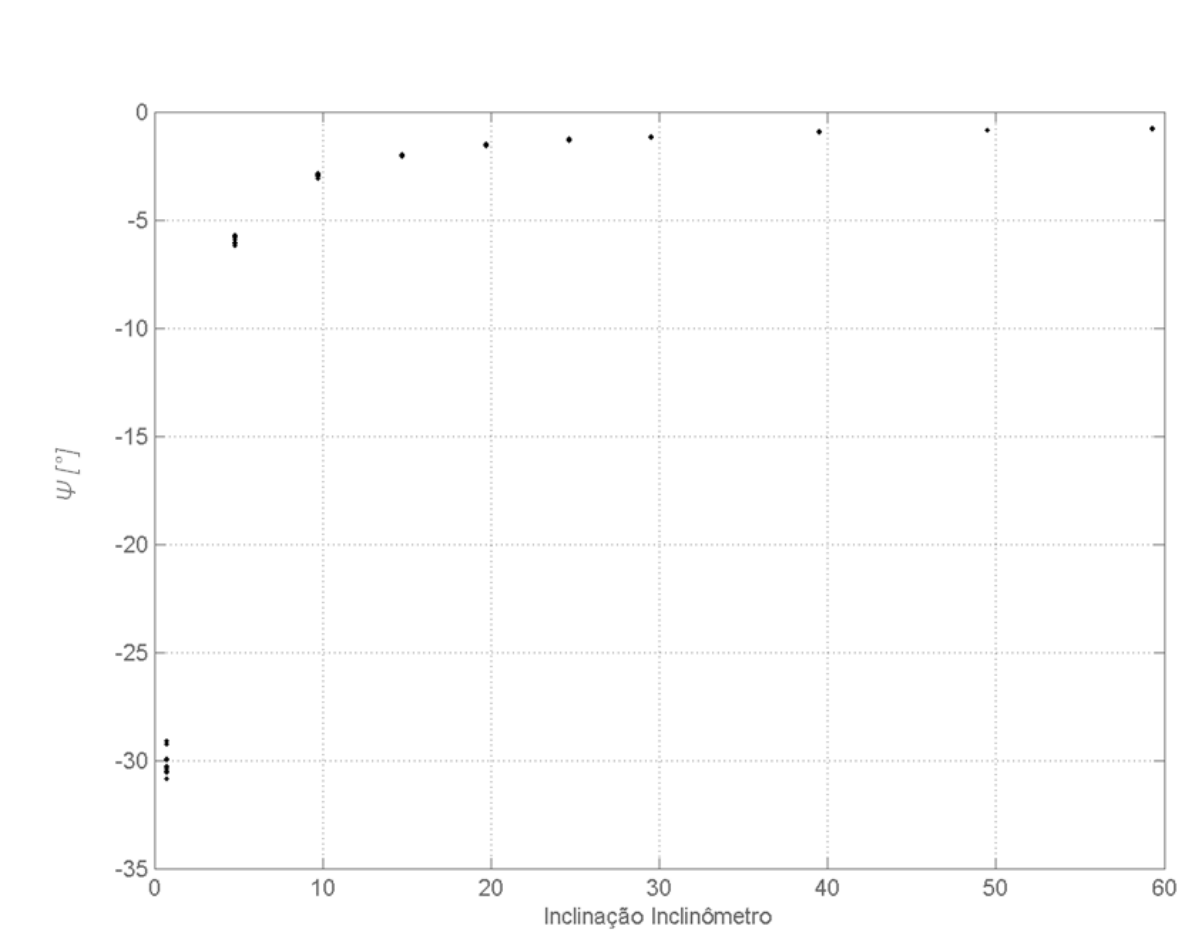

Figura 105 - Desvio na predição da rotação própria decorrente do ângulo de inclinaçaõ; neste caso a rotação própria imposta foi zero

Como esperado, para ângulos de inclinação próximos de zero, o erro na predição tende a infinito.

A última comparação experimental que pode ser realizada envolve o termo $A_{1}$, apresentado na equação (202), e os resultados obtidos durante os experimentos na rate table. Nestes ensaios foram impostas rotações conhecidas ao SMET.

Tabela 14 - Exemplos de dados esperados e obtidos a partir dos ensaios em rate table

\begin{tabular}{|ll|l|l|l|}
\hline Experimento & $\begin{array}{l}\text { Tempo } \\
\text { aquisição [s] }\end{array}$ & \multicolumn{2}{l|}{$\begin{array}{l}\text { Rotação } \\
\text { esperada }\left[{ }^{\circ}\right]\end{array}$} & \multicolumn{2}{l|}{$\begin{array}{l}\text { Rotação } \\
\text { calculada }\left[{ }^{\circ}\right]\end{array}$} \\
\hline 23 & 10 & 5 & 50,66 & 45,66 \\
\hline 24 & 15 & 5 & 73,78 & 68,78 \\
\hline 11 & 10 & 15 & 58,3 & 43,3 \\
\hline 12 & 15 & 15 & 82,07 & 67,07 \\
\hline 58 & 5 & -70 & $-31,52$ & 38,48 \\
\hline 2 & 10 & 70 & 101,62 & 31,62 \\
\hline
\end{tabular}


A Tabela 14 apresenta as rotações impostas e obtidas por meio dos cálculos. A diferença significativa entre os valores aponta para a necessidade de aplicar o procedimento de correção do sinal. No item seguinte serão apresentados os resultados provenientes desta correção. 


\section{Algoritmo Alternativo (Quatérnios)}

Embora as primeiras análises tenham indicado que o algoritmo vigente produz bons resultados por conta da coerência entre as hipóteses simplificadoras e a realidade do lançamento, optou-se por criar uma segunda rotina que fosse capaz de calcular os mesmos parâmetros de forma distinta. Neste caso, o algoritmo alternativo integra toda a trajetória e faz as transformações de base apropriadas, visto tratar-se de um sistema strapdown. Tais transformações são o principal elemento complicador para os computadores de navegação inercial e, sendo assim, são objeto de intenso estudo neste campo. A referência (TITTERTON e WESTON, 2004) traz os três principais métodos para se computar a atitude do corpo em cada instante de tempo com base nas leituras de velocidade angular, sendo eles: ângulos de Euler, matrizes de cossenos diretores e o método dos quatérnios.

Os três tipos de descrição foram discutidos no item 4.2 e foram apresentados os benefícios da descrição de atitudes empregando quatérnios. O menor número de equações diferenciais e a eliminação da situação de gimbal lock fazem do algoritmo alternativo baseado nos quatérnios o mais adequado para a descrição do movimento de um corpo no espaço.

De maneira geral, o algoritmo para reconstrução da trajetória aplicado em sistemas strapdown consiste em: calcular a atitude do corpo em um determinado instante, executando um pequeno giro na base considerada no passo anterior; em seguida, trazer a leitura de acelerações da base do corpo para o referencial terrestre, referencial de navegação; descontar a aceleração da gravidade e, finalmente, efetuar a integração.

\subsection{DESCRIÇÃo do AlGORITMO}

O principal desafio nos passos descritos acima reside em ser capaz de se prever a atitude do corpo com base apenas na leitura das velocidades angulares. O item 4.2.7 apresenta os subsídios teóricos para o desenvolvimento apresentado a seguir.

A taxa de variação de um quatérnio de rotação com o tempo relaciona-se diretamente com a velocidade angular do corpo em questão, por meio da equação (211). Os passos matemáticos apresentados a seguir são baseados em (TITTERTON e WESTON, 2004).

$$
\dot{\mathbf{q}}=\frac{1}{2} \mathbf{q} \cdot \mathbf{p}
$$

Em que $\mathbf{p}$ é um vetor no espaço $\mathbb{R}^{4}$ construído da seguinte forma: 


$$
\mathbf{p}=\left[0, \boldsymbol{\omega}^{\mathrm{T}}\right]
$$

(KUIPERS, 1999) apresenta em seu livro a dedução completa para a equação (211).

Reescrevendo o produto de quatérnios do termo à direita da equação na forma matricial apresentada no item 4.1.1, obtêm-se a equação abaixo:

$$
\dot{\mathbf{q}}=\frac{1}{2} \mathbf{W q}
$$

Em que $\mathbf{W}$ corresponde a:

$$
\mathbf{W}=\left[\begin{array}{cccc}
0 & -\omega_{x} & -\omega_{y} & -\omega_{z} \\
\omega_{x} & 0 & \omega & -\omega_{y} \\
\omega_{y} & -\omega_{z} & 0 & \omega_{x} \\
\omega_{z} & \omega_{y} & -\omega_{x} & 0
\end{array}\right]
$$

A equação diferencial (213) apresenta solução analítica do tipo:

$$
\mathbf{q}=\left[\exp \frac{1}{2} \mathbf{W} t\right] \mathbf{q}_{0}
$$

Sendo $\mathbf{q}_{0}$ o valor do quatérnio no instante inicial.

Do ponto de vista computacional, entre duas iterações com intervalo de tempo pequeno entre si, a equação (215) pode ser escrita como:

$$
\mathbf{q}_{k+1}=\left[\exp \frac{1}{2} \int_{t_{k}}^{t_{k+1}} \mathbf{W} d t\right] \mathbf{q}_{k}
$$

Assumindo que o vetor velocidade sofre modificações pequenas na sua direção durante um passo da integração, pode-se calcular a integral presente na equação (216) da forma indicada abaixo:

$$
\sigma_{\mathrm{i}}=\int_{t_{k}}^{t_{k+1}} \boldsymbol{\omega}_{\mathrm{i}} d t
$$

Aplicando (217) em (214) obtém-se: 


$$
\Sigma=\left[\begin{array}{cccc}
0 & -\sigma_{x} & -\sigma_{y} & -\sigma_{z} \\
\sigma_{x} & 0 & \sigma_{z} & -\sigma_{y} \\
\sigma_{y} & -\sigma_{z} & 0 & \sigma_{x} \\
\sigma_{z} & \sigma_{y} & -\sigma_{x} & 0
\end{array}\right]
$$

E, finalmente, substituindo (218) em (216) chega-se a equação (219):

$$
\mathbf{q}_{k+1}=\exp \left(\frac{\Sigma}{2}\right) \mathbf{q}_{k}
$$

Expandindo-se o termo exponencial:

$$
\exp \left(\frac{\Sigma}{2}\right)=\mathbf{I}+\left(\frac{\Sigma}{2}\right)+\frac{\left(\frac{\Sigma}{2}\right)^{2}}{2 !}+\frac{\left(\frac{\Sigma}{2}\right)^{3}}{3 !}+\frac{\left(\frac{\Sigma}{2}\right)^{4}}{4 !} \cdots
$$

Calculando o quadrado da matriz $\Sigma$ :

$$
\Sigma^{2}=\left(\sigma_{x}^{2}+{\sigma_{y}}^{2}+{\sigma_{z}}^{2}\right) \cdot \mathbf{I}
$$

E, ainda, definindo-se a grandeza $\sigma$ :

$$
\sigma^{2}=\sigma_{x}^{2}+{\sigma_{y}^{2}}^{2}+\sigma_{z}^{2}
$$

Pode-se reescrever a expansão (221) como sendo:

$$
\exp \left(\frac{\Sigma}{2}\right)=\mathbf{I}+\left(\frac{\Sigma}{2}\right)+\frac{\left(\frac{\sigma}{2}\right)^{2}}{2 !}+\frac{\left(\frac{\sigma}{2}\right)^{2}\left(\frac{\Sigma}{2}\right)}{3 !}+\frac{\left(\frac{\sigma}{2}\right)^{4}}{4 !} \cdots
$$

É possível identificar na expressão (223) a série correspondente as expansões de senos e cossenos. Esse procedimento dá origem à expressão (224), que corresponde a matriz (225).

$$
\exp \left(\frac{\Sigma}{2}\right)=\cos \left(\frac{\sigma}{2}\right) \mathbf{I}+\left(\frac{\Sigma}{2}\right) \frac{\sin \left(\frac{\sigma}{2}\right)}{\sigma}
$$




$$
\exp \left(\frac{\Sigma}{2}\right)=\left[\begin{array}{cccc}
\cos \left(\frac{\sigma}{2}\right) & -\sigma_{x} \frac{\sin \left(\frac{\sigma}{2}\right)}{\sigma} & -\sigma_{y} \frac{\sin \left(\frac{\sigma}{2}\right)}{\sigma} & -\sigma_{z} \frac{\sin \left(\frac{\sigma}{2}\right)}{\sigma} \\
\sigma_{x} \frac{\sin \left(\frac{\sigma}{2}\right)}{\sigma} & \cos \left(\frac{\sigma}{2}\right) & -\sigma_{z} \frac{\sin \left(\frac{\sigma}{2}\right)}{\sigma} & -\sigma_{y} \frac{\sin \left(\frac{\sigma}{2}\right)}{\sigma} \\
\sigma_{y} \frac{\sin \left(\frac{\sigma}{2}\right)}{\sigma} & -\sigma_{z} \frac{\sin \left(\frac{\sigma}{2}\right)}{\sigma} & \cos \left(\frac{\sigma}{2}\right) & \sigma_{x} \frac{\sin \left(\frac{\sigma}{2}\right)}{\sigma} \\
\sigma_{z} \frac{\sin \left(\frac{\sigma}{2}\right)}{\sigma} & \sigma_{y} \frac{\sin \left(\frac{\sigma}{2}\right)}{\sigma} & -\sigma_{x} \frac{\sin \left(\frac{\sigma}{2}\right)}{\sigma} & \cos \left(\frac{\sigma}{2}\right)
\end{array}\right]
$$

Empregando-se a correspondência apresentada na equação (35), o termo $\exp (\Sigma / 2)$ pode ser escrito na forma de quatérnio como mostram os passos a seguir:

$$
\begin{gathered}
a_{c}=\cos \left(\frac{\sigma}{2}\right) \\
a_{s}=\frac{\sin \left(\frac{\sigma}{2}\right)}{\sigma} \\
\exp \left(\frac{\Sigma}{2}\right)=\mathbf{r}_{k}=\left[\begin{array}{c}
a_{c} \\
a_{s} \sigma_{x} \\
a_{s} \sigma_{y} \\
a_{s} \sigma_{z}
\end{array}\right]
\end{gathered}
$$

Ao se substituir (228) em (219) obtém-se a equação (229) que permite calcular o a atitude do corpo em cada passo da integração.

$$
\mathbf{q}_{k+1}=\mathbf{q}_{k} \cdot \mathbf{r}_{\mathrm{k}}
$$

É importante ressaltar que o produto apresentado na equação (229) é um produto de quatérnios. Da observação da expressão acima nota-se, com base na definição de quatérnio apresentada em (142), que $\mathbf{r}_{\mathrm{k}}$ corresponde a rotação de magnitude $\sigma$ em torno do vetor $\left[\sigma_{x}, \sigma_{y}, \sigma_{z}\right]$.

Uma vez conhecido o quatérnio de rotação correspondente a cada instante de tempo do movimento, resta empregá-los para trazer os vetores de aceleração para o referencial de navegação. (TITTERTON e WESTON, 2004) apresenta a expressão (230) para efetuar esta transformação. 


$$
u_{k}^{n}=\mathbf{q}_{k} \cdot\left[0, v_{k+1}+\frac{1}{2} \alpha_{k+1} \times v_{k+1}+\frac{1}{2} \int_{t_{k}}^{t_{k+1}}\left(\alpha \times f^{b}-\omega^{b} \times v\right) d t\right] \cdot \mathbf{q}_{k}^{*}
$$

Sendo $u_{k}^{n}$ o acréscimo instantâneo de velocidade no passo $\mathrm{k}$ no referencial de navegação. Deve-se observar que a equação (230) é o produto triplo apresentado na expressão (128).

Tendo calculado o incremento de velocidade, a cada passo da integração, no referencial de navegação, resta realizar a soma cumulativa desta grandeza, ou seja:

$$
v_{k+1}^{n}=v_{k}^{n}+u_{k}^{n}+g d t
$$

Neste caso, a velocidade foi calculada no referencial fixo de modo que o termo de velocidade produzido artificialmente pela aceleração da gravidade durante a integração possa ser corrigido de forma direta, sem que se faça a transformação de base.

A posição pode ser obtida integrando-se $v^{n}$ ao longo do tempo.

A rotina computacional correspondente ao algoritmo recém descrito encontra-se no APÊNDICE D.

\subsection{TESTES DO ALGORITMO COM SINAL ARTIFICIAL}

Inicialmente, para verificar o funcionamento do algoritmo dos quatérnios foram gerados sinais artificialmente. Modelou-se um pêndulo esférico sem amortecimento com haste rígida e de massa desprezível. Na posição da massa foi colocada uma base de referência, como mostra a Figura 106. 


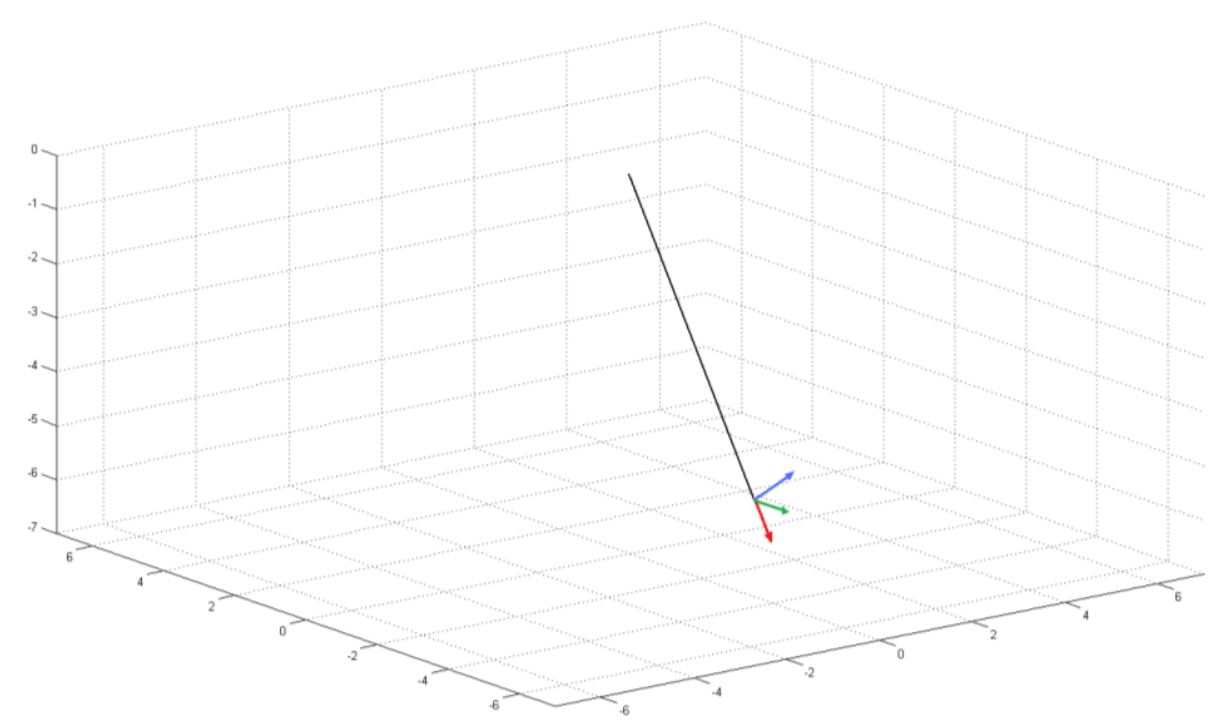

Figura 106 - Visualização computacional do modelo analítico de pêndulo esférico indicando a orientação da base correspondente ao SMET (azul - eixo x; verde - eixo y; vermelho - eixo z)

Optou-se pelo pêndulo esférico por se tratar de um sistema dinâmico tridimensional de modelagem simples e que, posteriormente, pôde ser recriado experimentalmente.

A base utilizada para a instrumentação foi fixada ao corpo de maneira ortonormal tendo sido seu eixo $\mathrm{z}$ alinhado com a haste do pêndulo.

Foram definidas duas coordenadas generalizadas, $\theta$ e $\phi$ que correspondem, respectivamente, ao ângulo que a haste faz com a vertical - análogo ao ângulo de nutação - e ao ângulo formado entre o plano que contém a reta vertical passando pela articulação do pêndulo e a haste do pêndulo e um plano vertical de referência - análogo ao ângulo de precessão. As equações dinâmicas encontradas foram (232) e (233):

$$
\begin{gathered}
\ddot{\theta}=\frac{\sin \theta\left(\dot{\phi}^{2} l \cos \theta-g\right)}{l} \\
\ddot{\phi}=0
\end{gathered}
$$

Estas equações foram resolvidas numericamente empregando a função ODE45 pertencente à biblioteca do MatLab® que, por sua vez, realiza a integração empregando o método de Runge-Kutta de quarta ordem.

Conhecendo a resposta do sistema em termos das coordenadas generalizadas, o passo seguinte foi convertê-las em acelerações e velocidades angulares no referencial do corpo, mostrado na Figura 106. 
O transporte das grandezas cinemáticas não empregou quatérnios para que os testes realmente avaliassem o desempenho deste último procedimento.

Foram gerados sinais correspondentes a diferentes condições iniciais e tempos de integração. A Figura 107 demonstra a trajetória de dois casos simulados, um para o movimento restrito ao plano (à esquerda) e outro para o movimento tridimensional (à direita). Nesta mesma figura, são apresentadas as leituras de aceleração e velocidades angulares no referencial do corpo. Os sinais gerados foram, então, aplicados ao algoritmo de reconstrução de trajetória para verificar se o mesmo reproduziria as trajetórias esperadas, ver Figura 108, onde as trajetórias reconstruídas são sobrepostas às geradas analiticamente.
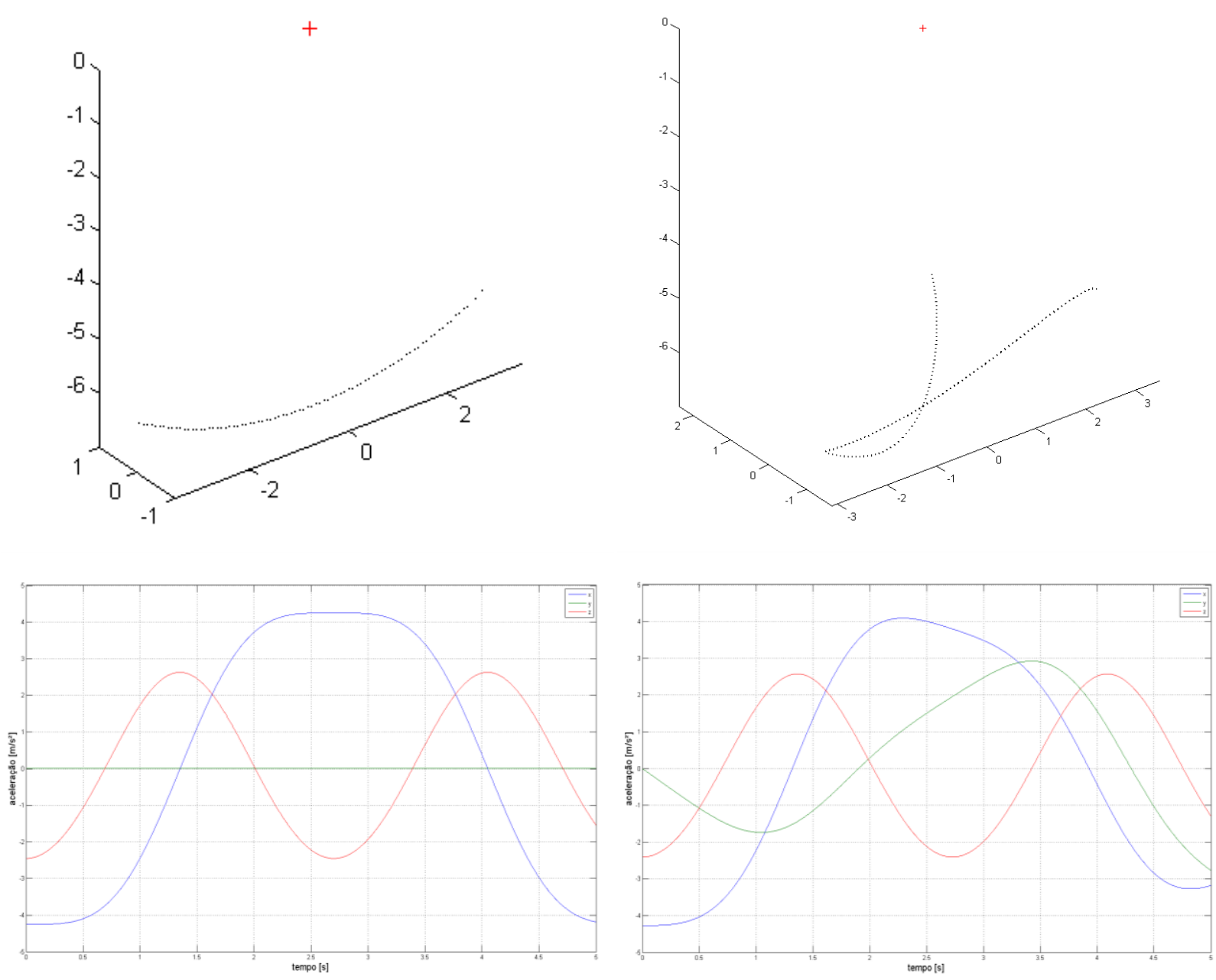

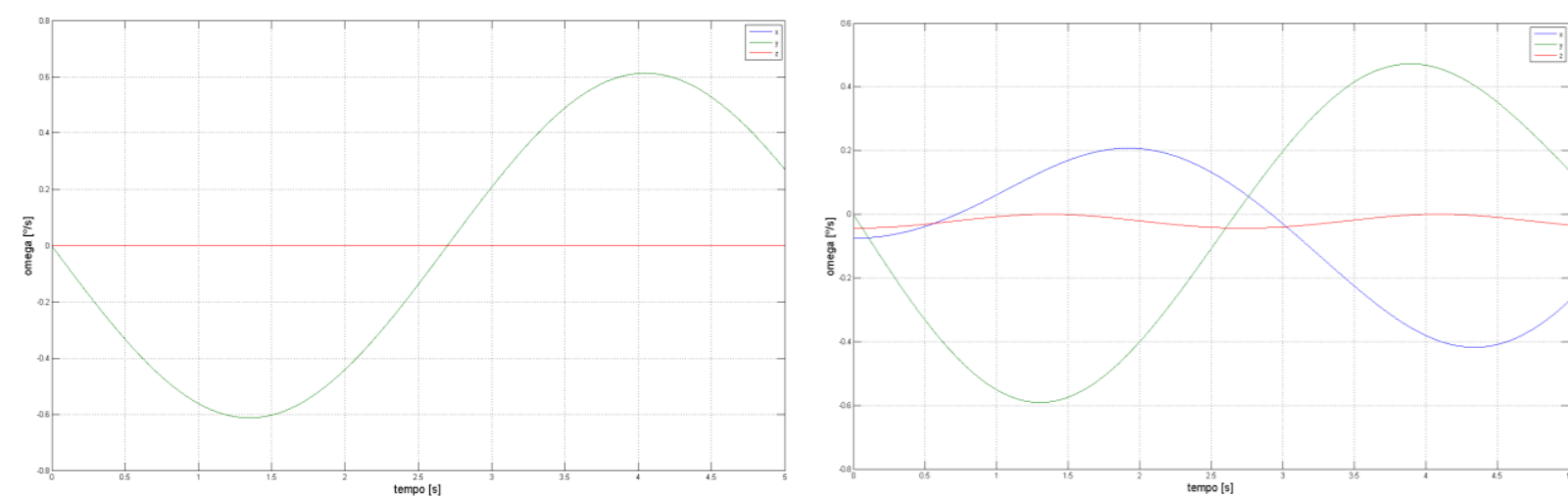

Figura 107 - Sinais artificiais produzidos; (de cima para baixo) trajetória, acelerações e velocidades angulares; (da esquerda para direita) o pendulo plano e o pêndulo esférico

O desempenho do algoritmo de reconstrução no caso do sinal analiticamente gerado (portanto, isento de ruídos) está associado à taxa de amostragem do sinal de entrada, aos métodos de integração e à precisão numérica com que os cálculos são realizados.

Desta forma, os testes procuraram ser coerentes com a taxa de aquisição do equipamento de sensoriamento empregado no caso real e as integrações foram feitas empregando-se o método de Simpson. Os resultados para os desvios da posição e inclinação final são apresentados na Tabela 15. Ao ângulo entre os vetores tangentes às trajetórias originais e reconstruídas deu-se o nome de erro na inclinação final.
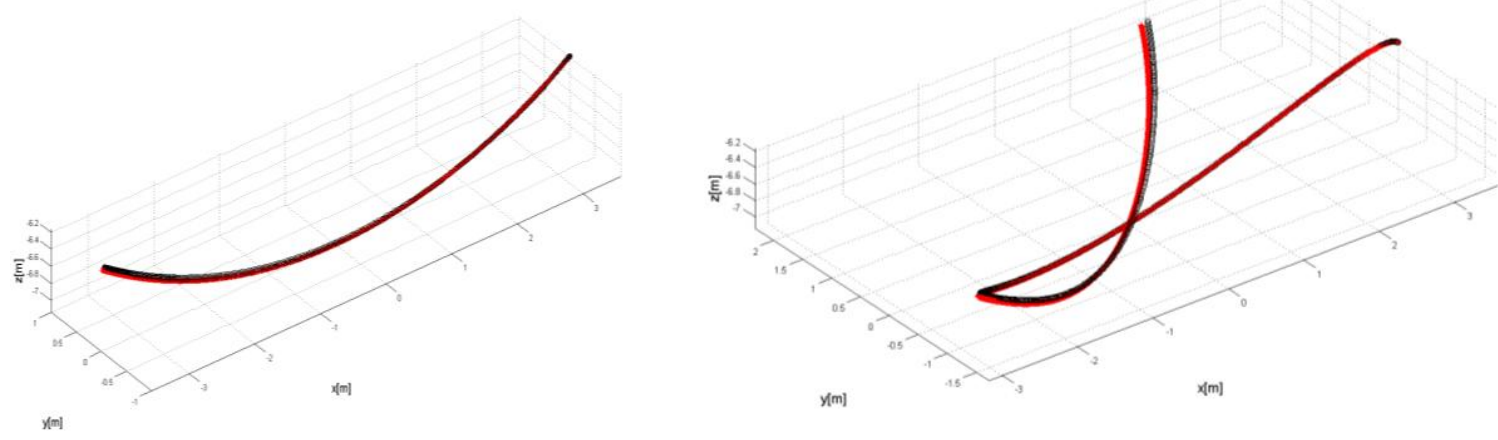

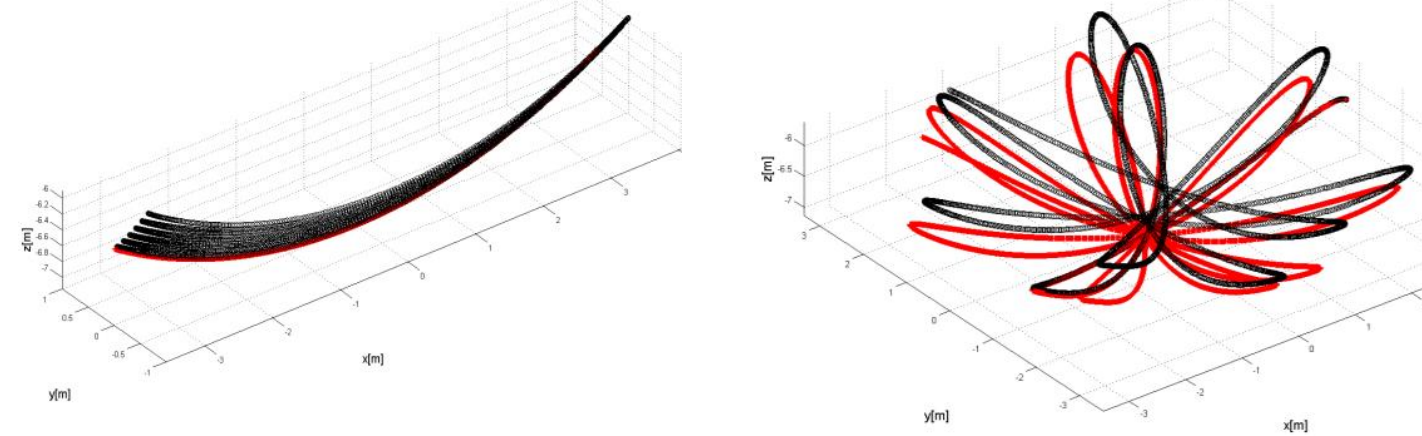

Figura 108 - Trajetórias pendulares geradas artificialmente (vermelha) reproduzidas empregando 0 algoritmo desenvolvido (preto); (esquerda) pendulo plano; (direita) pendulo esférico; (de cima para baixo) verifica-se o acúmulo do desvio proveniente do maior tempo de integração

Na Tabela 15 é possível perceber que o erro na posição se mantém aproximadamente constante em termos percentuais, próximo a $1 \%$, enquanto o desvio na inclinação não excede $3^{\circ}$.

Tabela 15 - Erros de posição e inclinação das reconstruções realizadas a partir de sinais artificiais

\begin{tabular}{|c|c|c|c|c|}
\hline $\begin{array}{c}\text { Tempo } \\
\text { do sinal [s] }\end{array}$ & $\begin{array}{c}\text { Erro na } \\
\text { posição [m] }\end{array}$ & $\begin{array}{c}\text { Peslocamento } \\
\text { Total [m] }\end{array}$ & $\begin{array}{c}\text { Erro } \\
\text { percentual }\end{array}$ & $\begin{array}{c}\text { Erro na } \\
\text { Inclinação final [ }{ }^{\circ} \text { ] }\end{array}$ \\
\hline 2 & 0,067 & 6,249 & $1,08 \%$ & 0,09 \\
\hline 3 & 0,045 & 7,658 & $0,59 \%$ & 0,64 \\
\hline 5 & 0,065 & 14,458 & $0,45 \%$ & 0,18 \\
\hline 6 & 0,136 & 15,663 & $0,87 \%$ & 0,20 \\
\hline 7 & 0,170 & 19,478 & $0,87 \%$ & 0,29 \\
\hline 10 & 0,138 & 28,051 & $0,49 \%$ & 0,31 \\
\hline 14 & 0,244 & 37,705 & $0,65 \%$ & 0,46 \\
\hline 20 & 0,340 & 54,210 & $0,63 \%$ & 0,13 \\
\hline 27 & 0,495 & 74,586 & $0,66 \%$ & 0,09 \\
\hline 31 & 0,560 & 84,474 & $0,66 \%$ & 0,157 \\
\hline & & PÊNDULO ESFÉRICO & (continua) \\
\hline Tempo & Erro na & Deslocamento & $\begin{array}{c}\text { Erro } \\
\text { Erro na }\end{array}$ \\
\hline do sinal [s] & posição [m] & Total [m] & percentual & Inclinação final [ ${ }^{\circ}$ ] \\
\hline 2 & 0,066 & 6,304 & $1,05 \%$ & 0,29 \\
\hline 3 & 0,042 & 7,924 & $0,54 \%$ & 1,49 \\
\hline 5 & 0,077 & 14,706 & $0,52 \%$ & 0,94 \\
\hline 6 & 0,132 & 16,077 & $0,82 \%$ & 0,13 \\
\hline 7 & 0,150 & 19,753 & $0,76 \%$ & 0,19 \\
\hline 10 & 0,199 & 28,470 & $0,70 \%$ & 0,59 \\
\hline 14 & 0,311 & 38,725 & $0,80 \%$ & 2,16 \\
\hline 20 & 0,527 & 55,232 & $0,95 \%$ & 0,39 \\
\hline & & & & \\
\hline
\end{tabular}


PÊNDULO ESFÉRICO

(conclusão)

\begin{tabular}{|c|c|c|c|c|}
\hline 27 & 0,685 & 76,267 & $0,90 \%$ & 0,08 \\
\hline 31 & 0,780 & 86,001 & $0,91 \%$ & 0,21 \\
\hline 60 & 1,460 & 168,510 & $0,87 \%$ & 0,24 \\
\hline 120 & 2,769 & 335,100 & $0,82 \%$ & 0,50 \\
\hline
\end{tabular}

Esclarecendo a divisão apresentada na Tabela 15, pêndulo plano corresponde a simulações em que a condição inicial $\dot{\phi}(0)=0$, enquanto aquilo que foi chamado de pêndulo esférico corresponde a condição inicial $\dot{\phi}(0) \neq 0$.

Os resultados apresentados acima são referentes à reconstrução da trajetória com base apenas nas acelerações inerciais, ou seja, não há gravidade somada às leituras artificiais. Cabe lembrar que os acelerômetros empregados no SMET mesmo em repouso apresentam a leitura da componente da aceleração da gravidade paralela ao seu eixo sensível. O passo seguinte foi avaliar o desempenho do algoritmo de reconstrução frente à inclusão da aceleração da gravidade nas componentes da aceleração no referencial do corpo.

A Tabela 16 é análoga a Tabela 15 para testes realizados com a presença da aceleração da gravidade.

Os desvios encontrados são maiores no segundo caso, pois erros na predição da atitude instantânea afetam a correção da aceleração da gravidade, fazendo com que surjam resultantes que aceleram a deriva da trajetória.

Tabela 16 - Erros de posição e inclinação das reconstruções realizadas a partir de sinais artificiais acrescidos da leitura (artificial) da gravidade

\begin{tabular}{|c|c|c|c|c|}
$\begin{array}{c}\text { Tempo } \\
\text { do sinal [s] }\end{array}$ & $\begin{array}{c}\text { Erro na } \\
\text { posição [m] }\end{array}$ & $\begin{array}{c}\text { Deslocamento } \\
\text { Total [m] }\end{array}$ & $\begin{array}{c}\text { Erro } \\
\text { percentual }\end{array}$ & $\begin{array}{c}\text { Erro na } \\
\text { Inclinação final [ }{ }^{\circ} \text { ] }\end{array}$ \\
\hline 2 & 0,1347 & 6,2486 & $2,16 \%$ & 0,4313 \\
\hline 3 & 0,204 & 7,6578 & $2,66 \%$ & 2,6571 \\
\hline 5 & 0,3392 & 14,4582 & $2,35 \%$ & 0,2495 \\
\hline 6 & 0,4079 & 15,6632 & $2,60 \%$ & 0,2675 \\
\hline 7 & 0,4778 & 19,4781 & $2,45 \%$ & 0,2063 \\
\hline 10 & 0,6224 & 28,0514 & $2,22 \%$ & 0,3929 \\
\hline 14 & 0,9447 & 37,7052 & $2,51 \%$ & 1,9202 \\
\hline 20 & 1,3397 & 54,2095 & $2,47 \%$ & 0,1925 \\
\hline 27 & 1,8001 & 74,5864 & $2,41 \%$ & 0,2161 \\
\hline 31 & 2,0578 & 84,4735 & $2,44 \%$ & 0,1035 \\
\hline 60 & 4,0265 & 170,7627 & $2,36 \%$ & 0,7326 \\
\hline
\end{tabular}




\begin{tabular}{|c|c|c|c|c|}
$\begin{array}{c}\text { Tempo } \\
\text { do sinal [s] }\end{array}$ & $\begin{array}{c}\text { Erro na } \\
\text { posição [m] }\end{array}$ & $\begin{array}{c}\text { Deslocamento } \\
\text { Total [m] }\end{array}$ & $\begin{array}{c}\text { Erro } \\
\text { percentual }\end{array}$ & $\begin{array}{c}\text { Erro na } \\
\text { Inclinação final [ }{ }^{\circ} \text { ] }\end{array}$ \\
\hline 2 & 0,1329 & 6,3037 & $2,11 \%$ & 0,4799 \\
\hline 3 & 0,1988 & 7,9243 & $2,51 \%$ & 2,8941 \\
\hline 5 & 0,3511 & 14,7056 & $2,39 \%$ & 1,1563 \\
\hline 6 & 0,4026 & 16,0765 & $2,50 \%$ & 0,1125 \\
\hline 7 & 0,4475 & 19,7527 & $2,27 \%$ & 0,5851 \\
\hline 10 & 0,7203 & 28,4698 & $2,53 \%$ & 1,0007 \\
\hline 15 & 1,0938 & 41,7474 & $2,62 \%$ & 0,7252 \\
\hline 20 & 1,4337 & 55,2316 & $2,60 \%$ & 0,2963 \\
\hline 27 & 1,8647 & 76,2665 & $2,44 \%$ & 0,1584 \\
\hline 31 & 2,1306 & 86,0007 & $2,48 \%$ & 1,1275 \\
\hline 60 & 3,9945 & 168,5995 & $2,37 \%$ & 0,3388 \\
\hline 2 & 0,1329 & 6,3037 & $2,11 \%$ & 0,4799 \\
\hline
\end{tabular}

A Figura 109 compara, lado a lado, trechos de trajetória de 6 segundos de duração, sem e com a correção da presença da gravidade.
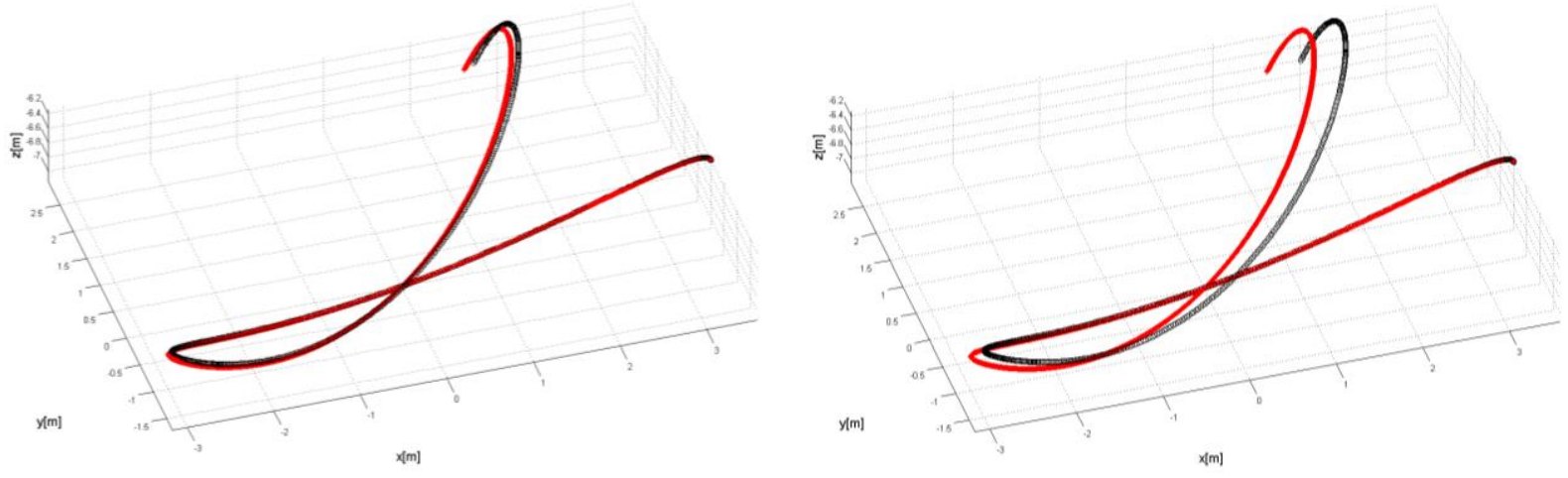

Figura 109 - Efeito da aceleração da gravidade na reconstrução da trajetória

Depois de verificado o desempenho do algoritmo para sinais ideais, foram acrescentados erros controlados para observar seus efeitos na reconstrução. Duas fontes de erro foram estudadas: o desvios nas condições iniciais e ruído no sinal.

Desvios nas condições iniciais para os sinais em que a gravidade não foi adicionada produziram erros previsíveis na reconstrução, como mostra a Figura 110. 

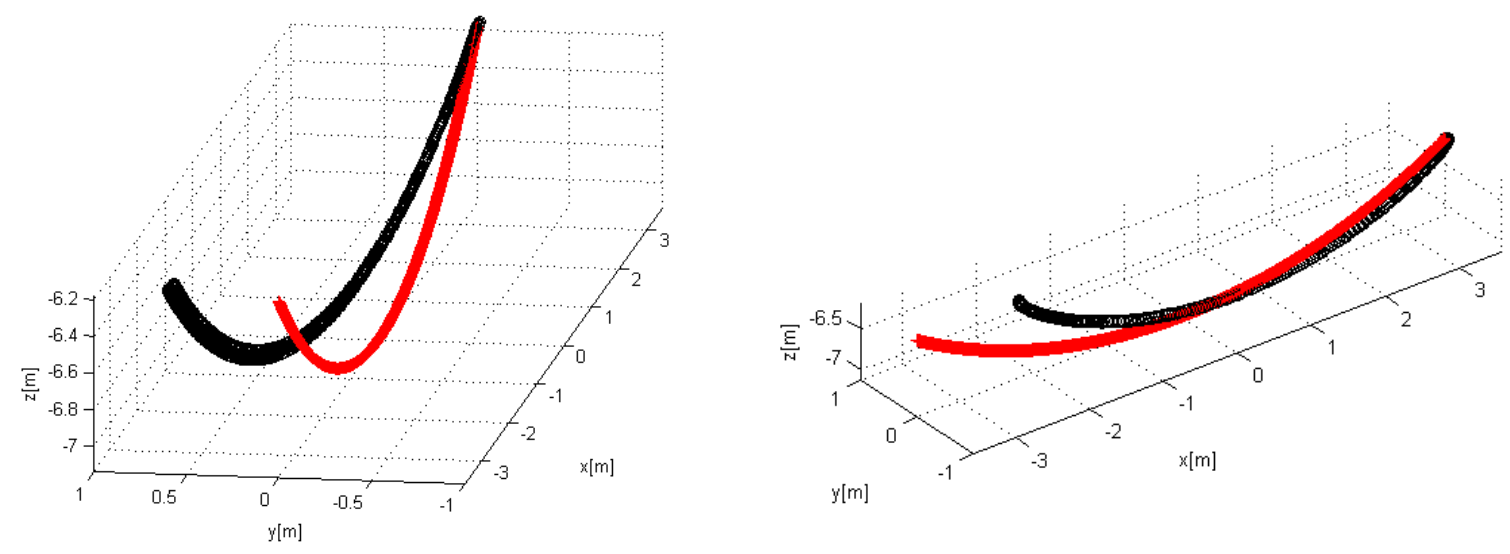

Figura 110 - Efeito de desvios da condição inicial na reconstrução da trajetória; (esquerda) desvio angular; (direita) desvio na velocidade inicial

Modificando-se o ângulo $\theta$, a trajetória é reproduzida simplesmente rotacionada com relação à trajetória original. Desvios na velocidade inicial provocam alongamento ou encurtamento da trajetória pendular.

A relevância dessa análise reside nos testes feitos com o sinal acrescido de gravidade. Nesse caso, como comentado anteriormente, desvios na atitude afetaram diretamente no processo de desconto da aceleração da gravidade.
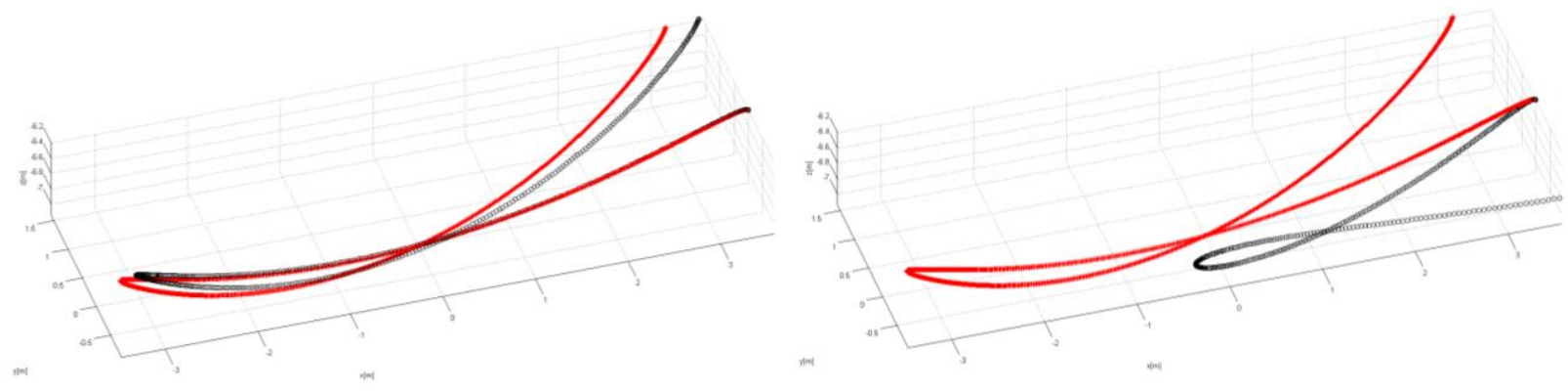

Figura 111 - Efeito do erro na condição inicial associado a presença da aceleração da gravidade no sinal

A Figura 111 ilustra como um pequeno desvio na inclinação inicial provoca grandes desvios na trajetória, graças à gravidade. Esse fato se mostrou o maior problema na utilização do algoritmo de reconstrução completa da trajetória, já que procedimento de determinação da atitude inicial, nas situações reais da estaca-torpedo, dá margem a desvios maiores que os mostrados acima.

Foi avaliado, ainda, o efeito de um ruído acrescido ao sinal artificial sobre o desempenho da reconstrução da trajetória. Novamente, foram testados sinais sem a presença da gravidade e com a presença desta. 
Foram adicionados ruídos regulares de frequiência e amplitude conhecidas e, posteriormente, ruídos brancos nos quais a amplitude foi variada.

No caso dos testes empregando ruídos regulares, a fase dessa oscilação foi modificada a fim de avaliar a pior situação em cada caso. Os dados foram dispostos em extensas tabelas das quais as principais informações extraídas foram parâmetros similares àqueles apresentados na Tabela 17 e na Tabela 18, ou seja, desvios com relação à trajetória real.

Tabela 17 - Resumo dos erros de posição dos testes com ruído

\begin{tabular}{|c|c|c|c|}
\hline \multicolumn{2}{|c|}{ Máximos $\Delta_{\text {posição }}[\mathrm{m}]$} & $\begin{array}{c}\text { sem } \\
\text { desconto } \\
\text { da } \\
\text { gravidade }\end{array}$ & \multirow[b]{2}{*}{$30,00 \%$} \\
\hline frequênciaslamplitudes & $10,00 \%$ & $20,00 \%$ & \\
\hline $60 \mathrm{~Hz}$ & 0,11033 & 0,15014 & 0,19491 \\
\hline $30 \mathrm{~Hz}$ & 0,12229 & 0,17853 & 0,23998 \\
\hline $10 \mathrm{~Hz}$ & 0,14507 & 0,21259 & 0,28026 \\
\hline $4 \mathrm{~Hz}$ & 0,23859 & 0,39821 & 0,5498 \\
\hline
\end{tabular}

Tabela 18 - Resumo dos erros de inclinação dos testes com ruído

\begin{tabular}{|c|c|c|c|}
\hline Máximos $\Delta_{\text {inclinạ }}$ & ão $\left[{ }^{\circ}\right]$ & $\begin{array}{c}\text { com } \\
\text { desconto } \\
\text { da } \\
\text { gravidade }\end{array}$ & \\
\hline frequênciaslamplitudes & $10,00 \%$ & $20,00 \%$ & $30,00 \%$ \\
\hline $60 \mathrm{~Hz}$ & 0,16656 & 0,29168 & 0,41782 \\
\hline $30 \mathrm{~Hz}$ & 0,22553 & 0,41102 & 0,59732 \\
\hline $10 \mathrm{~Hz}$ & 1,28894 & 2,54119 & 3,79346 \\
\hline $4 \mathrm{~Hz}$ & 2,979 & 5,9208 & 8,8607 \\
\hline
\end{tabular}

Ambas as tabelas foram geradas a partir da simulação de pêndulos planos durante um tempo correspondente a dois ciclos, ou seja, 5,36s.

Realizando-se os mesmos testes com a gravidade incorporada ao sinal, observou-se que o desempenho da reconstrução foi praticamente idêntico ao caso sem a gravidade, Tabela 17 e Tabela 18, para frequências mais baixas que a frequência de aquisição do sinal. Esse fato era esperado, pois o ruído regular associado ao sinal corresponde simplesmente a uma modificação na trajetória percebida e bem descrita pelos sinais dos sensores. Entretanto, se a frequência do ruído se aproximar da taxa de aquisição do sinal, ou a excede, o algoritmo dos quatérnios deixa de ser capaz de reproduzir adequadamente a trajetória. Esse efeito é análogo à incorporação de um ruído branco ao sinal, como será mostrado a seguir. 
Foram gerados ruídos brancos de diferentes amplitudes por meio de uma função pseudorandômica de distribuição uniforme, presente na biblioteca do Matlab®. Esses ruídos foram somados aos sinais artificiais, como foi feito para o caso dos ruídos regulares.

O efeito do ruído branco sobre o sinal é aleatório, resultando em desvios de magnitudes distintas de uma simulação para a outra. Foram feitas longas baterias de testes e extraídos os valores médios dos desvios, sendo possível observar uma independência entre a amplitude dos ruídos o desvio médio na trajetória, tanto para o caso sem gravidade como o para o caso contendo a gravidade. Essa independência se deve a forma homogênea como as flutuações se distribuem em torno do sinal original. No entanto, modificando-se os intervalos de integração, passou a ser perceptível o efeito da amplitude do ruído no sinal, como mostra a Figura 112.

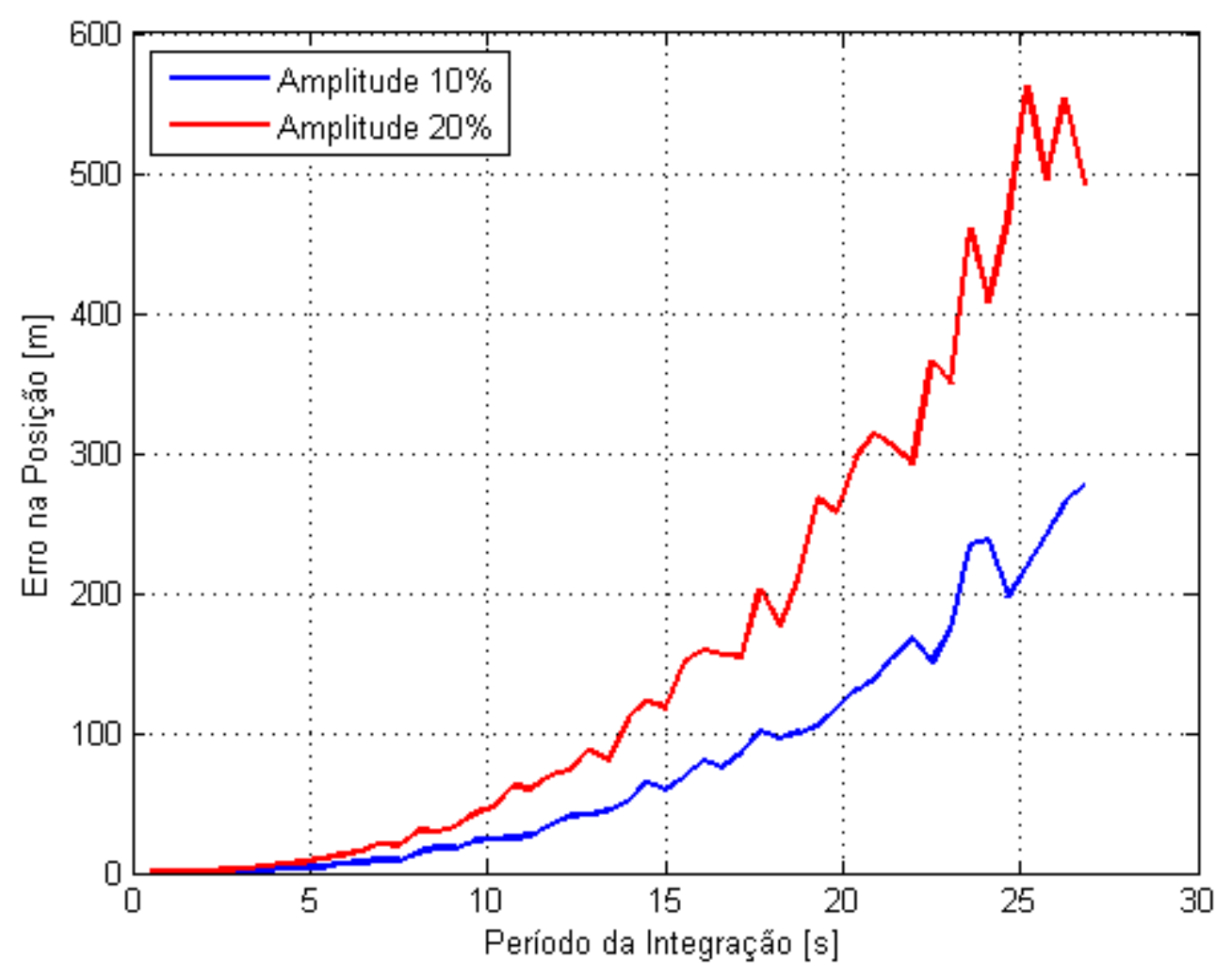

Figura 112 - Efeito do tempo de integração no erro dos sinais ruidosos

Os testes empregando sinais artificialmente gerados apontaram para as possíveis fontes de erro na reconstrução da trajetória empregando-se o algoritmo dos quatérnios. A principal constatação foi a importância da correção consistente da gravidade no desempenho da reconstrução já que, para movimentos como o pêndulo descrito, a aceleração gravitacional é muito superior às acelerações inerciais. 


\subsection{REsultados}

Depois de verificado o desempenho do algoritmo alternativo em reconstruir trajetórias artificiais, restou verificar sua eficiência em fazê-lo para os lançamentos reais.

Naquela oportunidade, esperou-se que os resultados provenientes da aplicação direta dos sinais dos lançamentos fossem insatisfatórios, como foram os primeiros testes análogos descritos nos itens 6.1.3. Porém, após o procedimento de correção, apresentado no item 6.4.3, estes resultados melhorem, a ponto de servirem como base de comparação entre os dois algoritmos propostos (vigente e alternativo via quatérnios).

Visando facilitar a visualização das diferenças promovidas pelo método de correção, foi elaborado o conjunto de gráficos apresentados a seguir. 


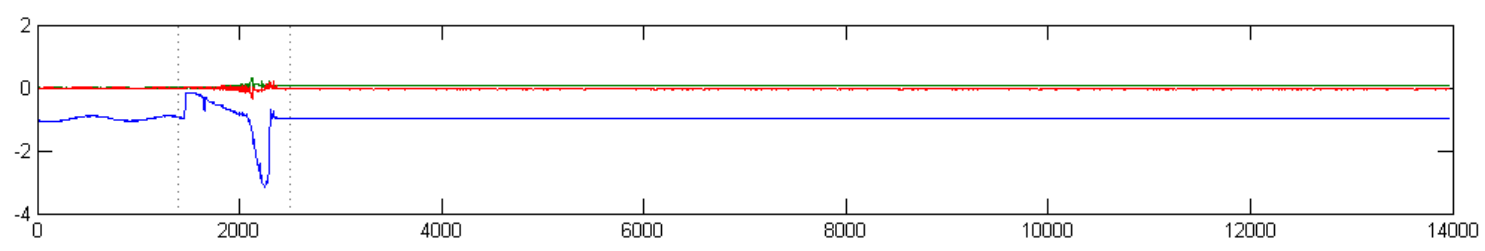

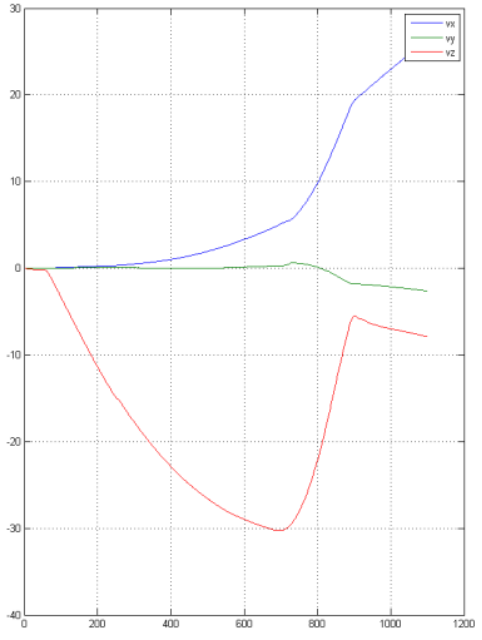

$10^{-2} \mathrm{~s}$

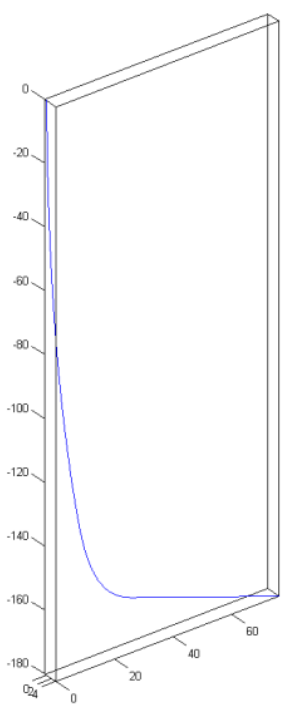

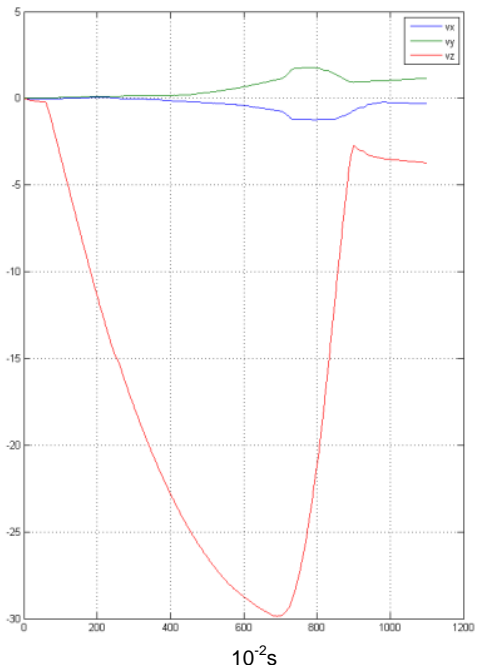

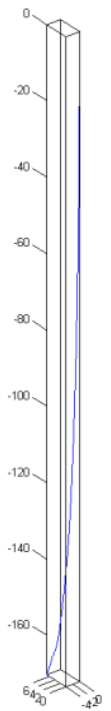

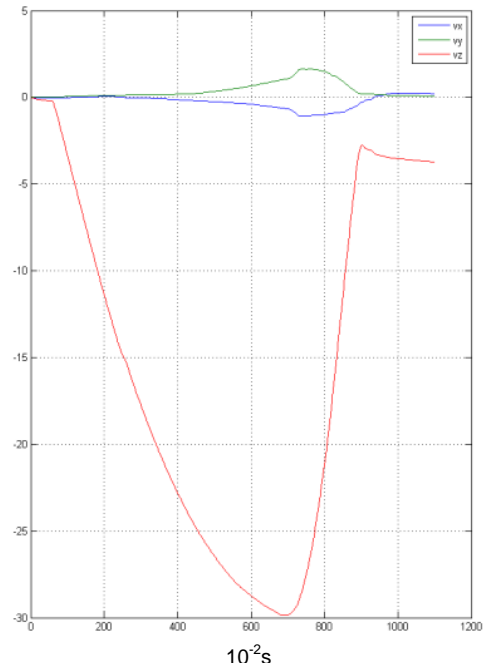

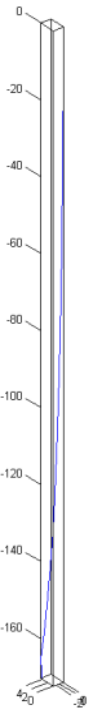

Figura 113 - Efeitos das correções do sinal sobre a reconstrução da trajetória. No primeiro gráfico a linha azul corresconde a aceleração registrada no eixo x, verde em y e vermelho em $z$.

O primeiro dos gráficos apresenta os sinais de aceleração e define o intervalo de integração, delimitado pelas linhas verticais tracejadas. Restringir este intervalo foi uma das medidas para minimizar os erros na integração. Na Figura 113, todos os gráficos correspondem a integrações realizadas no intervalo imediatamente acima. 
O conjunto de gráficos ao centro apresenta as componentes da velocidade da estaca no referencial inercial. O mais a esquerda deles apresenta este conjunto de velocidades calculado a partir do sinal bruto, sem nenhum tipo de correção; o gráfico ao centro apresenta o mesmo conjunto de resultados obtidos a partir do sinal cujo bias foi corrigido, segundo o método proposto no item 6.4.3; o gráfico mais à direita corresponde às velocidades calculadas a partir do sinal corrigido pelo bias e pelo fator de escala.

Abaixo dos gráficos de velocidade foram dispostos os respectivos gráficos de trajetória. Cada um deles corresponde à trajetória reconstruída pela simples integração no tempo das velocidades apresentadas.

Os resultados obtidos a partir do tratamento e reconstrução das demais trajetórias disponíveis à pesquisa encontram-se no APÊNDICE C.

Fica evidente que as maiores diferenças surgem quando são realizadas as correções do bias das velocidades angulares. Estes sensores não foram calibrados de forma alguma, como foi constatado e posteriormente confirmado pelo fabricante da unidade.

A Figura 114 apresenta as direções principais da estaca, sobrepostas às trajetórias reconstruídas. Estas imagens exibem o efeito do bias e fator de escala na predição de atitude e consequentemente na capacidade do algoritmo de corrigir a leitura da gravidade presente no sinal.
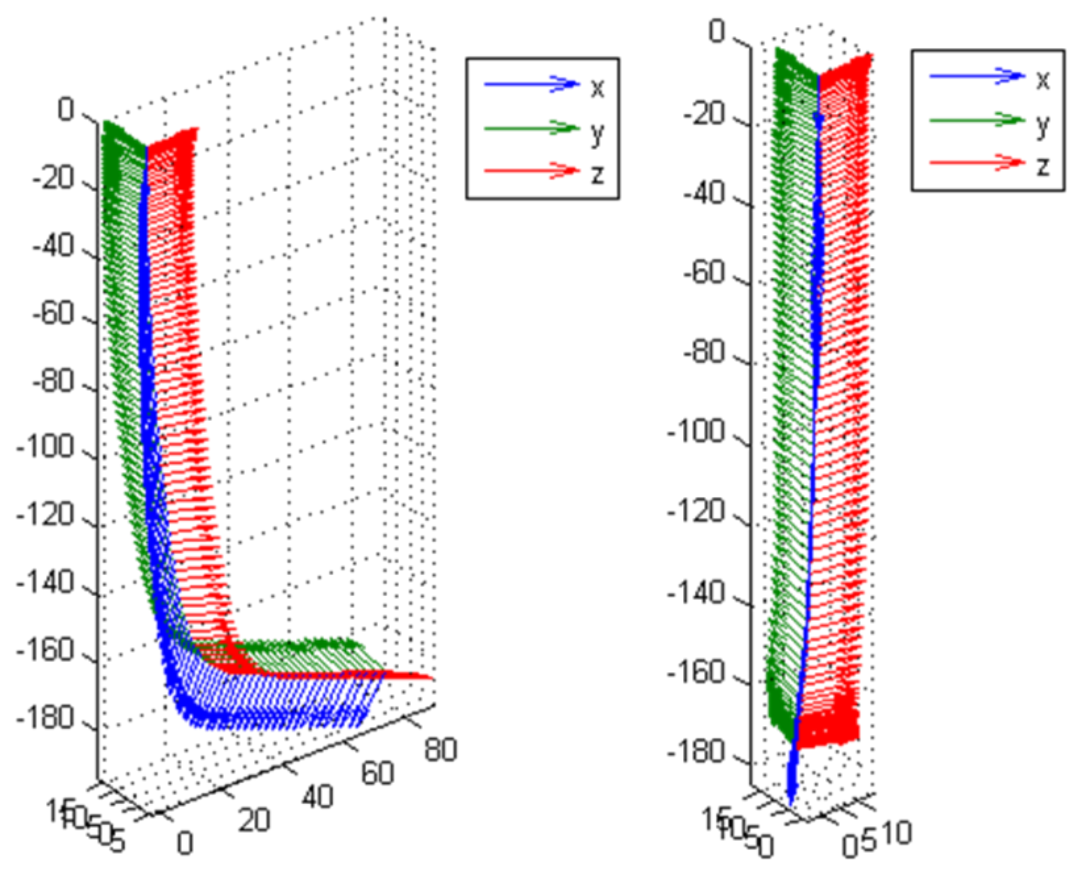
Figura 114 - (Esquerda) Atitude da estaca sobreposta a trajetória para o caso em não foi aplicada nenhuma correção ao sinal; (Direita) Mesma representação para o caso em que bias e fator de escala foram corrigidos

Finalmente, é possível adicionar o leito marinho na representação gráfica da trajetória.

Os dados referentes à profundidade de onde a estaca é lançada, assim como a profundidade do solo, são dados conhecidos, e no âmbito deste trabalho, assumidos como precisos.

A Figura 115 ilustra a trajetória da estaca situada na profundidade onde ocorreu o lançamento. É possível verificar o ponto onde a estaca atinge a velocidade máxima bom como uma estimativa da profundidade de penetração.

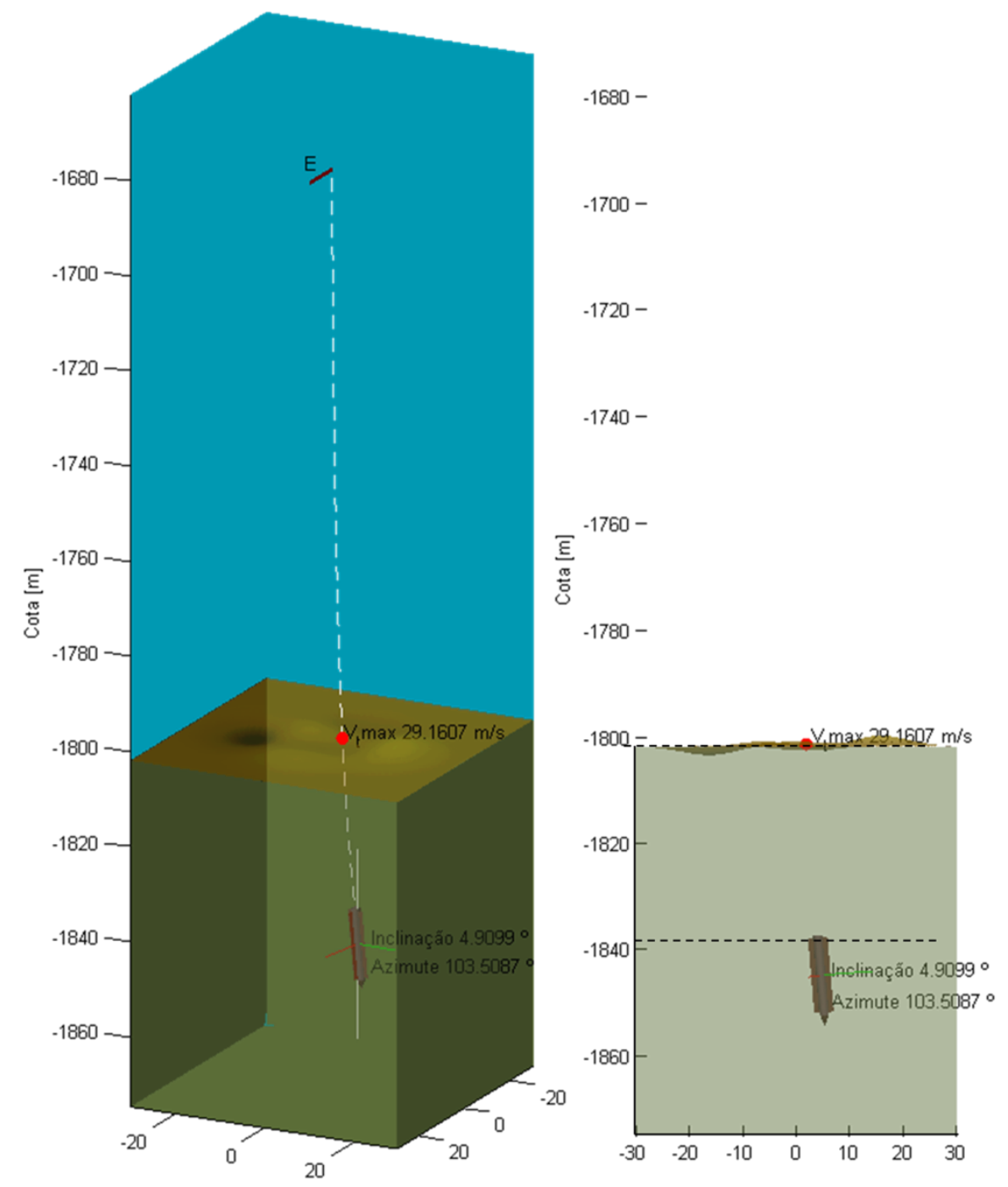

Figura 115 - (Esquerda)Trajetória da estaca sobreposta ao cenário do lançamento; (Direita)Ponto em que ocorre a velocidade máxima e estimativa da profundidade de penetração. 
Na Figura 115 o azimute final não corresponde à realidade, pois não foi utilizada a medida de condições inicial deste parâmetro obtidas pelo ROV. 


\section{Conclusões e Considerações finais À Luz das Comparações}

O presente texto tratou de diversas questões que cercam o problema central. Desta forma, são inúmeras as comparações possíveis de serem feitas e certamente este tópico não cobrirá todas elas. Entretanto, o diagrama apresentado na Figura 65 será utilizado como guia e, desta forma, a partir dele os principais resultados serão discutidos.

\subsection{PARÂMETROS de INTERESSE NA TRAJetória dA ESTACA-TORPEDO}

No início do capítulo 0 foi apresentado o problema central da utilização da estaca-torpedo, resumindo-se à em determinação da sua posição final. A descrição desta posição final é feita por meio dos parâmetros: profundidade de penetração, inclinação final e azimute. O primeiro parâmetro descrito - a profundidade de penetração - não foi devidamente explorado neste documento, porém depende diretamente da velocidade máxima atingida pela estaca.

\subsubsection{Velocidade Máxima e Profundidade de Penetração}

Os primeiros dados de velocidade máxima da estaca-torpedo foram apresentados no item 3.1 em que o trabalho de (BRANDÃO et al., 2006) foi discutido. O documento não especifica a velocidade mínima necessária para o cravamento adequado. Entretanto, após aprimorar o sistema de lançamento, a velocidade máxima registrada foi de $26,8 \mathrm{~m} / \mathrm{s}$. Embora não se tenha certeza quando a origem dos dados, acredita-se que estes dados de velocidade tenham sido obtidos por meio do próprio SMET.

Os demais trabalhos disponíveis na literatura utilizam o mesmo resultado, proveniente de campanhas reais de testes, para ajustar modelos dinâmicos. Desta forma, em última instância, a fonte de comparação é a mesma. Entretanto, verificando o valor dos coeficientes hidrodinâmicos, é possível reforçar a veracidade dos dados medidos. Sendo assim, a primeira informação de velocidade máxima apresentada aqui adveio dos trabalhos discutidos no capítulo de revisão bibliográfica, sendo identificada como tal na Tabela 19.

Ainda assim, estes dados servem apenas como referência, uma vez que cada lançamento é único e, certamente, haverá diferença nas velocidades atingidas.

A segunda estimativa de velocidade proveio dos registros do SMET que foram colocados À disposição do presente trabalho. Conforme afirmado anteriormente, a fonte dos dados é 
fundamentalmente a mesma, porém neste segundo caso, os dados provêm de outro conjunto de lançamentos. Enquanto (BRANDÃO et al., 2006) utilizam registros associados aos lançamentos das estacas empregadas na ancoragem da FPSO P-50, os dados fornecidos para a presente pesquisa referem-se à ancoragem da plataforma P-52. Este último conjunto de resultados será identificado como "vigente" já que provém do algoritmo intitulado desta forma no capítulo 7.

Em ambos os caso houve a necessidade de integrar os sinais uma vez que o SMET registra apenas aceleração.

As correções propostas não envolveram as acelerações e, desta forma, os resultados provenientes do algoritmo vigente não sofrem modificação quando este procedimento foi realizado.

Finalmente, a terceira estimativa da velocidade proveio do algoritmo de reconstrução da trajetória baseado em quatérnios. Este método foi amplamente discutido nos itens anteriores, porém cabe aqui destacar sua principal diferença com relação às demais fontes de estimativa da velocidade angular. Este algoritmo não emprega a hipótese de trajetória vertical, ou seja, realiza as devidas mudanças de base antes de realizar a integração. Esta estimativa é identificada na Tabela 19 por "Velocidade por Quatérnios".

Tabela 19 - Comparação das estimativas de velocidade vertical máxima $(\mathrm{m} / \mathrm{s})$

\begin{tabular}{|c|c|c|c|}
\hline $\begin{array}{l}\text { Máximo } \\
\text { Bibliografia }\end{array}$ & Vigente & $\begin{array}{l}\text { Por Quatérnios } \\
\text { (sem correções) }\end{array}$ & $\begin{array}{l}\text { (continua) } \\
\text { Por Quatérnios } \\
\text { (com correções) }\end{array}$ \\
\hline 26,8 & 29,78 & 30,6743 & 29,8886 \\
\hline 26,8 & 28,35 & 30,4525 & 28,3631 \\
\hline 26,8 & 29,72 & 30,13 & 29,6483 \\
\hline 26,8 & 28,94 & 30,3055 & 29,0304 \\
\hline 26,8 & 28,85 & 29,1168 & 28,9217 \\
\hline 26,8 & 27,75 & 28,1269 & 27,5404 \\
\hline 26,8 & 28,38 & 28,455 & 28,4531 \\
\hline 26,8 & 29,71 & 30,7033 & 29,7704 \\
\hline 26,8 & 27,43 & 53,1253 & 26,4217 \\
\hline 26,8 & 30,05 & 30,3802 & 29,4007 \\
\hline 26,8 & 27,92 & 45,9496 & 26,0771 \\
\hline
\end{tabular}




\begin{tabular}{|l|c|l|l|}
\hline \multicolumn{4}{|l|}{ (conclusão) } \\
\hline 26,8 & Dados corrompidos \\
\hline 26,8 & 25,35 & 53,3182 & 28,0095 \\
\hline 26,8 & 28,56 & 52,6804 & 26,5502 \\
\hline 26,8 & 28,18 & 52,8977 & 27,8513 \\
\hline 26,8 & 29,04 & 47,6957 & 27,5097 \\
\hline
\end{tabular}

Analogamente, a partir da Tabela 19 pode-se construir uma tabela destacando as profundidades de penetração. Este dado em particular está disponível, proveniente de medições executadas por ROV. Tais medidas referem-se à distância entre o olhal na parte de trás da estaca e a superfície do leito marinho.

Tabela 20 - Comparação das estimativas de profundidade de cravamento (m)

\begin{tabular}{|c|c|c|c|}
\hline ROV & Vigente & $\begin{array}{l}\text { Por Quatérnios } \\
\text { (sem correções) }\end{array}$ & $\begin{array}{l}\text { Por Quatérnios } \\
\text { (com correções) }\end{array}$ \\
\hline 24,6 & 43,1 & 60,09 & 50,28 \\
\hline 21,1 & 46,8 & 67,24 & 54,77 \\
\hline 22,3 & 43 & 53,05 & 50,09 \\
\hline 21,6 & 39,3 & 53,15 & 45,85 \\
\hline 22,7 & 28,2 & 35,56 & 31,15 \\
\hline 20,7 & 31,9 & 40,61 & 35,37 \\
\hline 20,2 & 34,2 & 51,45 & 47,1 \\
\hline 20 & 45,4 & 60,37 & 53,42 \\
\hline 24,3 & 47,3 & 50,29 & 36,22 \\
\hline 20 & 55 & 62,36 & 55,73 \\
\hline 20,4 & 50,1 & 63 & 31,65 \\
\hline 21 & \multicolumn{3}{|c|}{ Dados corrompidos } \\
\hline 21,9 & 47,8 & 71,9341 & 34,41 \\
\hline 24 & 44,9 & 59,45 & 22,68 \\
\hline 23 & 44 & 77,28 & 41,57 \\
\hline 23 & 47,3 & 67,2817 & 29,19 \\
\hline
\end{tabular}


Com base na Tabela 20, fica evidente que ambos os algoritmos superestimam a velocidade vertical máxima e, consequentemente, a profundidade de penetração da estaca. A correção, por outro lado, atua no sentido de reduzir as diferenças entre as predições matemáticas e as medidas reais.

Assumindo-se que os valores de profundidade de cravação medidos pelo ROV são os mais precisos, já que foram realizados in locus, é conveniente empregar a Tabela 20 como principal fonte de comparação. Observa-se que a estimativa por quatérnios sem correção apresenta a maior discrepância com relação às medidas do ROV. Por outro lado, após a correção das velocidades angulares - correção mostrada no item 6.4.3, os resultados se aproximam dos obtidos por meio do algoritmo vigente. Mesmo assim, ambos se mantêm superiores às medidas do ROV.

Acredita-se que este erro se deva à presença de bias nos sinais de aceleração. Esta constatação baseia-se na análise dos gráficos de velocidade obtidos após a integração dos sinais. Tais gráficos foram apresentados na Figura 99 e Figura 113 e estão construídos para todos os sinais no APÊNDICE C. Em todos os casos, após o período de desaceleração, a velocidade vertical não retornou ao valor nulo e, ao contrário do que se esperaria, passaram a divergir.

A Figura 116 demonstra o fato apontado acima, identificando o ponto em que supostamente ocorreu a parada completa da estaca. A mesma figura apresenta uma linha reta que aproximadamente reproduz a tendência de divergência da velocidade. 

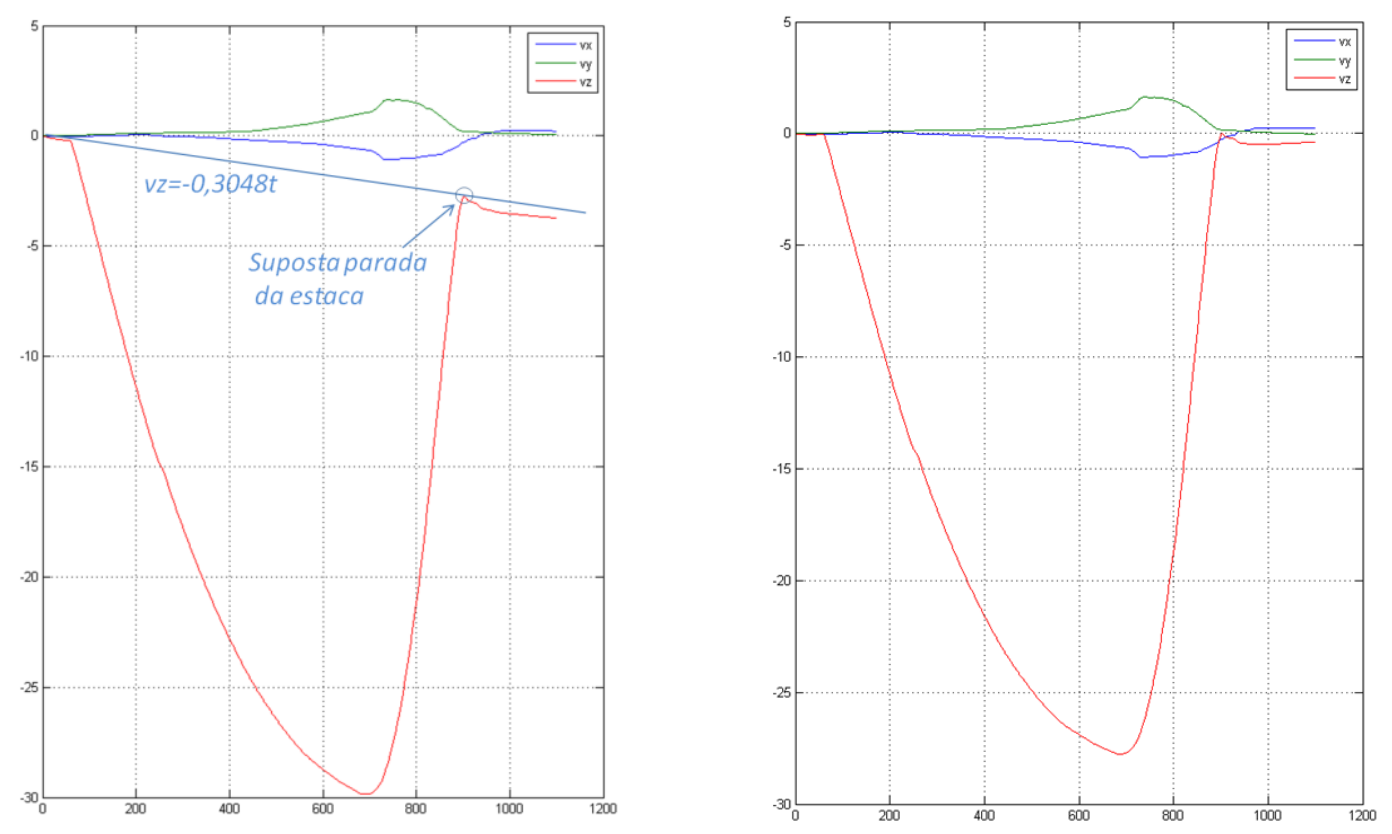

Figura 116 - (Esquerda) Identificação da deriva na estimativa da velocidade vertical; (Direita) Estimativa de velocidades após a correção do bias na aceleração $\mathrm{x}$

Em se tratando de uma divergência aproximadamente linear é possível associá-la a um sinal remanescente de aceleração.

Por meio da equação da reta que ajusta a deriva na velocidade vertical é possível quantificar o bias na aceleração que causa tal desvio. Assumindo-se que a trajetória da estaca é aproximadamente vertical, pode-se fazer a correspondência direta entre a direção $Z$ no referencial de navegação e a direção do eixo $x$ da estaca. Desta forma, pode-se subtrair a aceleração remanescente do sinal original de aceleração $x$ sem comprometimento das estimativas de velocidade e posição nas demais direções. O resultado deste procedimento é apresentado à direita na Figura 116.

Embora este procedimento melhore a coerência dos resultados, não foi apresentado no item 6.4, pois não foi possível identificar o bias na aceleração durante os experimentos em bancada. Na ocasião, os valores de bias encontrados nos sinais de aceleração foram inferiores ao menos uma ordem de grandeza que aqueles necessários para produzir o desvio mostrado na Figura 116.

É possível associar o desvio entre os resultados dos experimentos em bancada e os testes reais a efeitos de temperatura. Foi feita a correções do bias coma temperatura tomando como base os dados fornecidos pelo fabricante, forma ilustrada na Figura 117. 


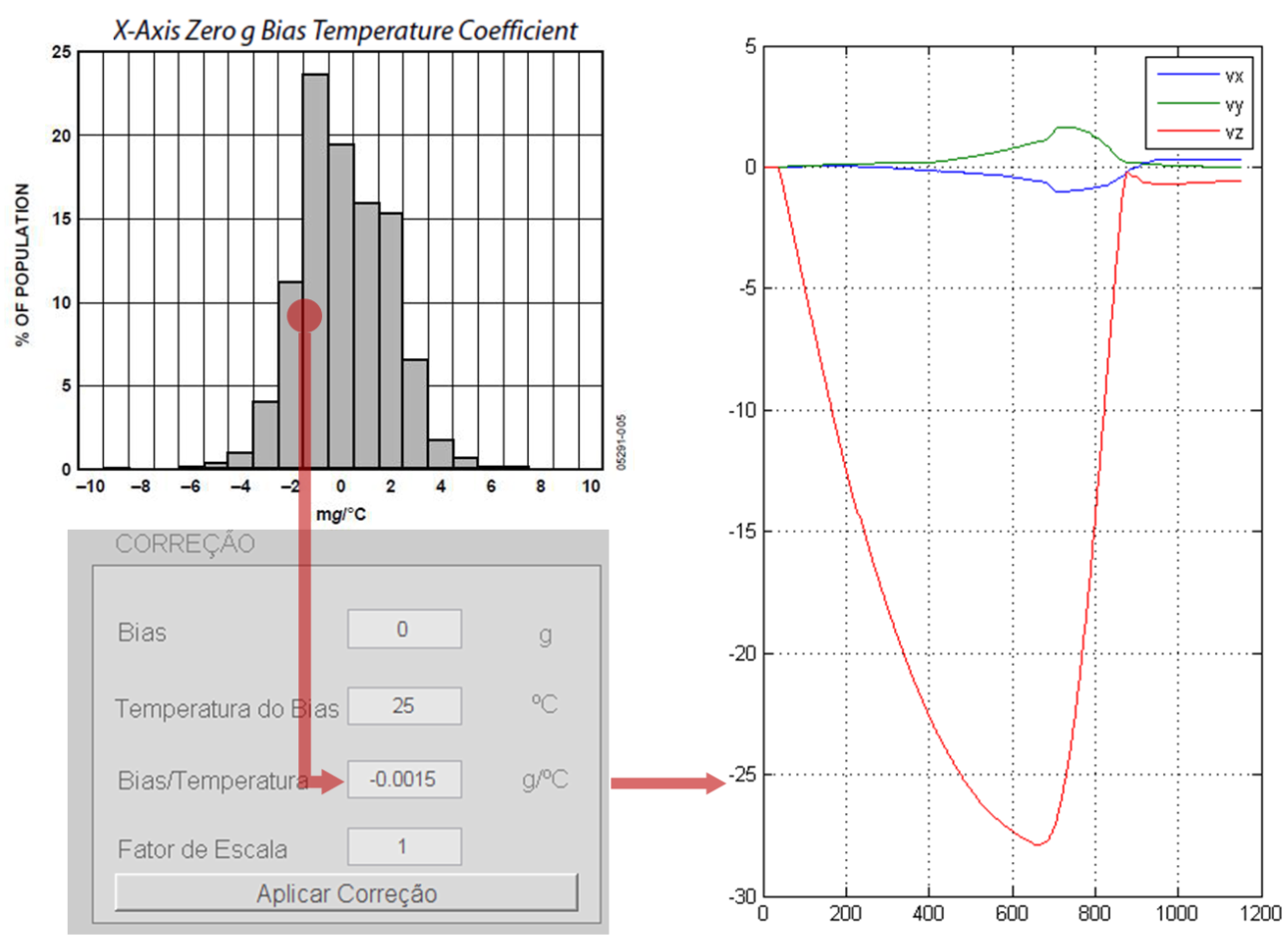

Figura 117 - Tentativa de correção do bias de aceleração por meio dos dados fornecidos pelo fabricante

O resultado apresentado na Figura 117 indicou melhora na estimativa de velocidades, porém somente após investigar algumas possibilidades de valores para o coeficiente angular da correção do bias com a temperatura - ver equação (177). Mesmo entre os eixos sensíveis da UMI, não houve homogeneidade entre os valores de $\gamma$. Desta maneira, não foi possível consolidar um procedimento que surtisse efeito positivo em todos os sinais analisados.

Certamente, tal problema seria contornado se fossem realizados testes em câmara climatizada para levantar as características detalhadas de todos os sensores do SMET como função da temperatura.

As principais conclusões da análise dos resultados para estimativas de velocidade foram, portanto:

- Os algoritmos tendem a superestimar a velocidade e, consequentemente, a profundidade de cravação.

- Embora não se tenha certeza da origem, os desvios da velocidade são fruto da incapacidade de previsão do bias dos acelerômetros.

- As correções de sinal propostas neste documento melhoram a qualidade dos resultados. 
- É fundamental o levantamento detalhado dos parâmetros de calibração de acelerômetros e girômetros do SMET como função da temperatura.

\subsubsection{Inclinação Final}

O segundo parâmetro de interesse na trajetória da estaca é sua inclinação final. Devidamente caracterizada em capítulos anteriores deste documento, a inclinação final, juntamente com os demais parâmetros de interesse descritos anteriormente, determina a carga necessária para o arrancamento da estaca.

Nas situações reais, este parâmetro é indesejado uma vez que, mediante o uso dos sensores e procedimentos em utilização, não é possível determinar o azimute desta inclinação ou, na nomenclatura euleriana, o ângulo de precessão. Tal incerteza obriga que se considere o pior caso possível. Para melhor visualizar estas situações recomenda-se consulta à Figura 8 e à Figura 102, assim como a leitura dos itens 7.1 e 7.2.

Tendo em vista tal limitação, a melhor situação é aquela em que não há inclinação ou que esta seja muito pequena.

No item 7.3 foram confrontadas as inclinações reais impostas ao SMET e os resultados dos algoritmos. Observou-se que a calibração dos acelerômetros é adequada, pois os desvios entre a inclinação real - medida por meio de um inclinômetro calibrado adequadamente - e a estimada via processamento dos sinais são bastante pequeno - ver Figura 103.

Resta aqui comparar as estimativas referentes aos lançamentos reais e assumir que, dado o desempenho obtido em bancada, a estimativa de inclinação a partir dos dados medidos pelo SMET e processados pelo algoritmo vigente são suficientemente precisos.

Assim como foi feito no item anterior, os dados previstos durante as etapas de projeto e testes da estaca também são confrontados. Entretanto, deve-se apenas ater à ordem de grandeza destes números uma vez que são referentes a lançamentos distintos e seus valores foram discutidos apenas superficialmente nos documentos estudados na revisão bibliográfica. 
Tabela 21 - Comparação entre estimativas da inclinação final (ํ)

\begin{tabular}{|c|c|c|c|}
\hline $\begin{array}{l}\text { Bibliografia }^{\mathbf{1 8}} \\
\left(<10^{\circ}\right)\end{array}$ & Vigente & $\begin{array}{l}\text { Por Quatérnios } \\
\text { (sem correções) }\end{array}$ & $\begin{array}{l}\text { Por Quatérnios } \\
\text { (com correções) }\end{array}$ \\
\hline 8,3 & 4,4 & 26,36 & 4,94 \\
\hline 8,3 & 5,1 & 20,51 & 5,21 \\
\hline 8,3 & 6,1 & 10,27 & 7,00 \\
\hline 8,3 & 6,7 & 11,50 & 6,06 \\
\hline 8,3 & 4,6 & 18,81 & 5,11 \\
\hline 8,3 & 8,5 & 19,77 & 8,91 \\
\hline 8,3 & 5.8 & 21,29 & 6,16 \\
\hline 8,3 & 7,0 & 11,42 & 7,75 \\
\hline 8,3 & 8,3 & 42,84 & 7,54 \\
\hline 8,3 & 3,5 & 14,83 & 3,65 \\
\hline 8,3 & 7,1 & 30,88 & 8,44 \\
\hline \multicolumn{4}{|c|}{ Dados corrompidos } \\
\hline 8,3 & 7,9 & 39,92 & 8,43 \\
\hline 8,3 & 3,3 & 42,79 & 3,51 \\
\hline 8,3 & 5,7 & 42,80 & 6,11 \\
\hline 8,3 & 7,6 & 46,47 & 7,45 \\
\hline
\end{tabular}

A Tabela 21 condensa os principais resultados obtidos para todos os lançamentos disponíveis. Fica evidente a melhora promovida pela correção do sinal no algoritmo empregando quatérnios. Os desvios entre os dados apresentados na segunda e quarta colunas são, na maioria das vezes, inferiores a $1^{\circ}$. Essa correspondência tem grande importância na verificação do desempenho do algoritmo de reconstrução completa da trajetória, pois nesta a inclinação final é obtida através das velocidades angulares. Trata-se, portanto, da comparação entre a leitura das componentes da gravidade ao final do lançamento - método cuja eficiência foi verificada - e o resultado da integração do sinal durante toda a trajetória.

Tendo em vista que os sinais de aceleração não foram corrigidos por motivos já citados, a estimativa proveniente do algoritmo vigente não sofreu modificação. Todavia, caso sejam

18 (BRANDÃO, HENRIQUES, et al., 2006) afirma que durante a instalação das estacas empregadas na $\mathrm{P}-50$ os ângulos finais de instalação foram, no geral, inferiores a $10^{\circ}$. 
consideradas as correções de bias apresentadas no final do item anterior, a modificação na estimativa da inclinação é extremamente pequena - cerca de duas ordens de grandeza inferiores aos desvios entre a segunda e quarta colunas da Tabela 21.

\subsubsection{Azimute}

Mediante o uso do SMET e algoritmo vigente, trata-se do parâmetro cuja determinação envolve os maiores desafios. Entretanto, o conhecimento do azimute permite aceitar certos níveis de inclinação final da estaca e, com isso, reduzir eventuais relançamentos desta.

O significado físico desta grandeza já foi discutido algumas vezes durante o presente trabalho e caso haja dúvida recomenda-se a leitura dos itens 7.1 e 7.2.

Não foram encontrados estudos específicos sobre a determinação deste parâmetro durante as pesquisas bibliográficas, embora no campo da navegação inercial a grandeza aqui chamada de azimute seja tratada como parte da determinação completa da atitude do corpo. Neste contexto, e dada à dificuldade de verificação de tal parâmetro no caso real, onde a estaca encontra-se enterrada sob o leito marinho, as comparações que podem ser feitas se concentram nas diferenças entre os dois algoritmos de processamento dos dados.

Novamente, para verificação das diferenças discutidas acima, sugere-se a leitura dos itens 7.1 e 8.1 .

Os resultados foram dispostos lado a lado na Tabela 22. Observa-se que, diferentemente das tabelas anteriores, nesta há distinção entre o sinal corrigido e não no caso dos resultados provenientes do algoritmo vigente. Isto se deve ao fato do algoritmo vigente empregar o sinal de velocidade angular apenas no cálculo do azimute e, como discutido anteriormente, a correção proposta atua somente sobre os sinais desta natureza - ver item 6.4.3.

Como intuito de facilitar a comparação, os dados apresentados na Tabela 22 foram obtidos partindo-se de uma mesma condição inicial, nula ou, ainda, na expressão $(210), \phi_{0}=0$. 
Tabela 22 - Comparação entre estimativas do Azimute $(\stackrel{\circ}{)})$

\begin{tabular}{|l|l|l|l|}
$\begin{array}{l}\text { Vigente } \\
\text { (sem correções) }\end{array}$ & $\begin{array}{l}\text { Vigente } \\
\text { (com correções) }\end{array}$ & $\begin{array}{l}\text { Por Quatérnios } \\
\text { (sem correções) }\end{array}$ & $\begin{array}{l}\text { Por Quatérnios } \\
\text { (com correções) }\end{array}$ \\
\hline 23,5 & 37,22 & 77,00 & 41,88 \\
\hline 268,07 & 268,07 & 46,37 & 279,76 \\
\hline 122,76 & 126,49 & 15,34 & 121,18 \\
\hline 288,11 & 306,80 & 65,64 & 307,48 \\
\hline 35,55 & 46,54 & 43,83 & 45,95 \\
\hline 111,01 & 118,56 & 48,55 & 118,43 \\
\hline 68,22 & 83,57 & 66,95 & 84,72 \\
\hline 233,04 & 248,40 & 76,40 & 246,54 \\
\hline 305,14 & 283,04 & 224,66 & 282,03 \\
\hline 280,23 & 292,68 & 38,96 & 294,84 \\
\hline 279,89 & 239,56 & 114,95 & 241,53 \\
\hline Dados corrompidos & 63,72 & 205,58 & \\
\hline 82,60 & 265,77 & 227,51 & 64,64 \\
\hline 284,02 & 59,14 & 182,77 & 255,83 \\
\hline 84,85 & 127,48 & 197,57 & 55,06 \\
\hline 149,48 & & \multicolumn{2}{|l}{128,68} \\
\hline
\end{tabular}

Constata-se que a correção modifica os resultados provenientes de ambos os algoritmos, porém faz com que os dois se aproximem. Esta aproximação é tão importante quanto aquela discutida no item anterior, no que se referia a inclinação final. Cada um dos algoritmos chega aos resultados de formas distintas.

$\mathrm{O}$ algoritmo vigente empregue a integral da velocidade angular medida no eixo x do SMET e as componentes da gravidade lidas ao final da queda no cálculo do azimute. Por outro lado, a rotina baseada em quatérnios integra a velocidade angular registra nos três eixos principais ao longo de toda a trajetória.

Acredita-se que a correção proposta atua no sentido de aproximar as estimativas dos valores reais, embora seja impossível mensurar a distância que ainda existe entre estes valores. 
O processo de correção em si pode ser melhorado se, por exemplo, forem determinados os fatores de escala dos girômetros alinhados aos eixos y e z do SMET - mais informação nos itens 6.3 e 6.4 .3 .

\subsection{ReCOnstruÇÃo da TRAJetória}

O processo de reconstrução da trajetória foi um desenvolvimento paralelo às investigações principais da presente pesquisa. Sua criação visou inicialmente gerar resultados que pudessem ser comparados aos resultados provenientes do algoritmo vigente. Tais comparações foram apresentadas nos itens anteriores. A reconstrução completa da trajetória, por outro lado, fornece muito mais informações sobre o lançamento do que simplesmente os parâmetros de interesse previamente discutidos. Estas informações certamente enriquecem a compreensão do lançamento da estaca e, sendo assim, são desejáveis.

A reconstrução da trajetória não foi o alvo inicial dos esforços de pesquisa acerca do lançamento da estaca, principalmente por se conhecer as limitações dos sensores empregados na monitoração. Tais sensores foram discutidos amplamente ao longo deste trabalho, mas, de forma bastante simplista, basta comparar a Figura 31 e Figura 32 para constatar a diferença de complexidade entre um equipamento usado para navegação inercial em aeronaves e sensores análogos aos empregados no SMET.

Viabilizar a navegação empregando sensores MEMS é uma pesquisa extremamente relevante na atualidade. Fazê-lo para veículos submarinos é igualmente importante e apresenta desafios particulares.

No presente trabalho, a reconstrução da trajetória foi possível após o estabelecimento de um procedimento de correção dos sinais. Trata-se de um método muito simples que corrige apenas os dois principais parâmetros de calibração dos sensores. Mesmo sendo extremamente simples a qualidade dos resultados melhorou significativamente depois de aplicada a correção. Os efeitos desta correção são apresentados na Figura 113 e discutidos em detalhes no mesmo tópico que a contém.

O desempenho da reconstrução está fortemente atrelado as características da trajetória, assim como ao reduzido tempo de integração. Tal afirmação baseia-se na análise das tentativas de reconstrução dos experimentos pendulares descritos no item 6.1.

$\mathrm{Na}$ ocasião em que o experimento foi realizado, não se tinha estabelecido o procedimento de correção do sinal. Mais precisamente, foi este experimento que levantou as dúvidas com relação à qualidade do sinal fornecido pelo SMET. 
Em uma etapa posterior da pesquisa foi possível corrigir o bias e o fator de escala dos sinais provenientes do experimento pendular, da mesma forma como foi feito para os registros de lançamento da estaca-torpedo.

Como descrito no item 6.1, o movimento pendular do SMET durante os experimentos foram monitorados precisamente. Isto permitiu, entre outras coisas, obter a condição inicial de atitude do SMET, como mostram a Figura 118 e também a Figura 66.

A Figura 118 e a Figura 119 mostram a tentativa de reconstrução da trajetória pendular - para o caso em que se buscou reproduzir um pêndulo plano - após a correção de bias e fator de escala das velocidades angulares. A deriva da trajetória é perceptível mesmo para um curto período de integração, cerca de $5 \mathrm{~s}$.

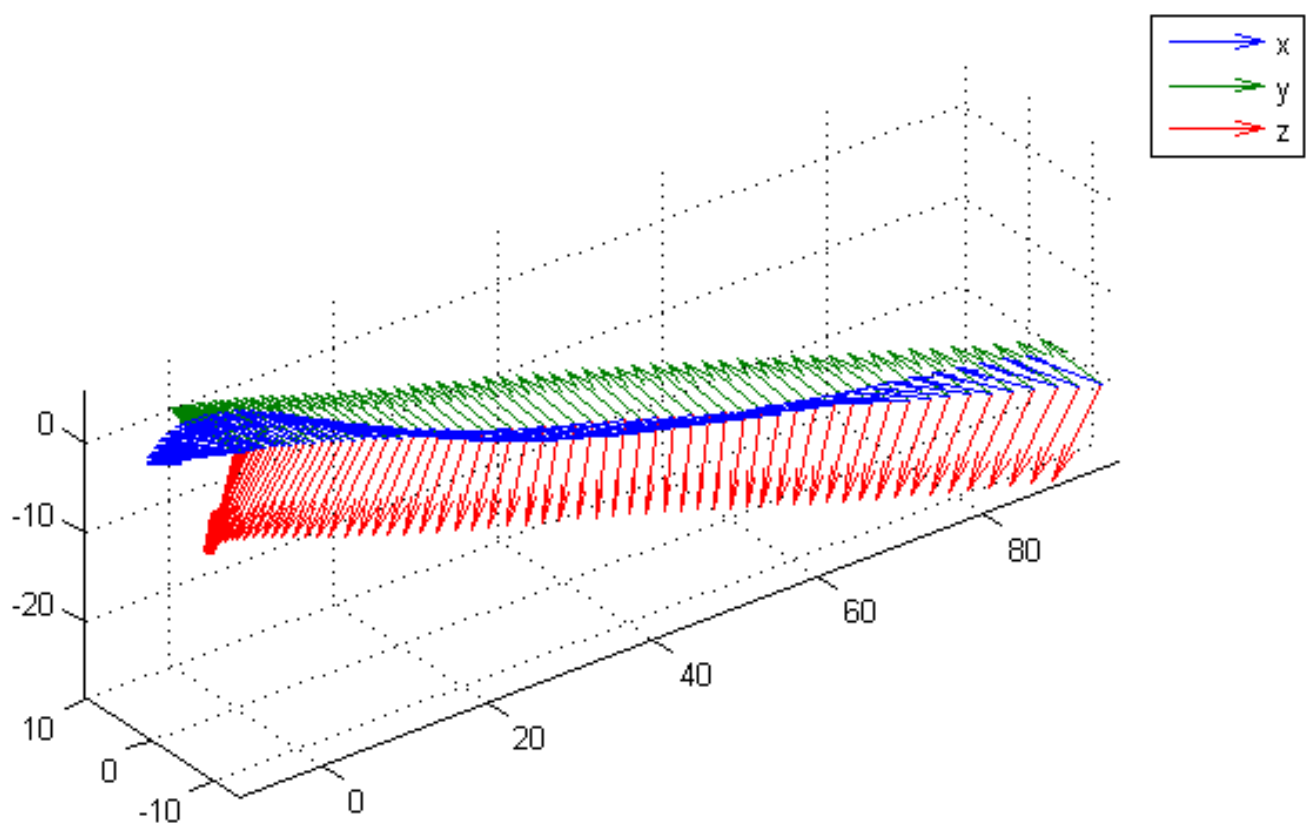

Figura 118 - Base solidária ao SMET após reconstrução empregando quatérnios (perspectiva)

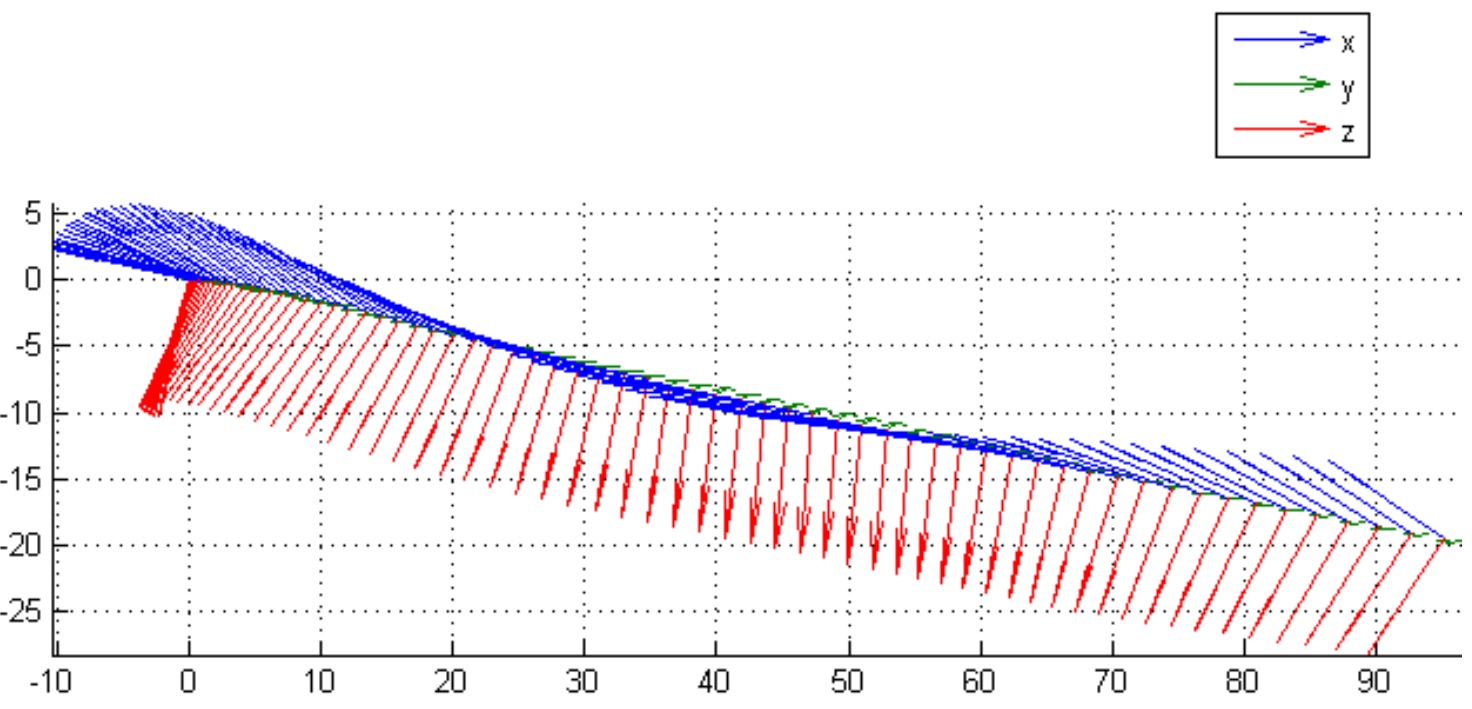


Figura 119 - Base solidária ao SMET após reconstrução empregando quatérnios (vista lateral)

Analisando-se a Figura 119, é possível identificar a mudança de atitude coerente com o movimento pendular, porém somente sobre uma trajetória irreal. Isto se deve certamente ao fato da estimativa de atitude provir de uma única integração no tempo, enquanto a trajetória demanda duas integrações sequenciais.

No movimento pendular ensaiado, as forças inerciais são muito inferiores à força de atração gravitacional, de modo que desvios mínimos na predição de atitude acarretam resíduos de acelerações irreais no sinal cujas magnitudes comprometem significativamente o processo de reconstrução da trajetória.

Não se descarta, ainda, a possibilidade de haver bias nos sinais de aceleração e destes serem significativos. No caso dos sinais provenientes do lançamento da estaca-torpedo, estes bias e possíveis correções foram discutidos no item 9.1.1. Naquela situação, observou-se uma deriva linear em certas componentes da velocidade reconstruída - ver Figura 116. Nos sinais obtidos nos experimentos pendulares é possível, da mesma maneira, identificar tais derivas, porém corrigi-las segundo a proposta do item 9.1.1 é inadequado, uma vez que a equivalência entre os referenciais é muito menos direta.

$\mathrm{O}$ eixo $\mathrm{x}$ do SMET se mantém aproximadamente alinhado ao eixo $\mathrm{x}$ do referencial de navegação ao longo da trajetória. Da mesma forma, os eixos y e z do SMET desviam-se muito pouco das posições iniciais. Esta semelhança permite o relativo funcionamento do algoritmo vigente - descrito no capítulo 7 - assim como permite que se aplique, ainda que de forma limitada, a correção descrita no item 9.1.1. No caso do pêndulo, a base solidária ao corpo assume orientações muito distintas da base de navegação, impossibilitando a relação direta entre desvios nas velocidades no referencial de navegação e o bias dos sensores. 


\section{Sugestão de Futuros Trabalhos}

Mesmo aprimorando-se os processos de correção dos sinais inerciais provenientes de sensores MEMS, nunca será possível reconstruir trajetórias por longos intervalos de tempo. As reconstruções dos sinais artificiais, mostradas nos item 8.2, confirmam esta afirmação. Mesmo empregando os sinais isentos de qualquer bias ou ruído, a reconstrução apresenta deriva com o passar do tempo.

A fim de contornar tal problema, atualmente os sistemas de navegação inerciais são "auxiliados" por sinais provenientes de outros sensores. A forma mais comum de combinação, ou fusão, de sensores para fins de navegação é feita entre sensores inerciais MEMS e GPSs.

Diferentemente dos sensores inerciais, os Sistemas de Posicionamento Globais (GPSs) fornecem dados de posição do corpo a uma taxa muito menor, próxima de $1 \mathrm{~Hz}$. Esta informação é empregada na atualização da posição estimada por meio da integração dos sensores inerciais. Sendo assim, a combinação destes dois sensores permite que a integração das acelerações restrinja-se a um curto período de tempo e, depois deste, seja atualizada com base nas informações do GPS.

Além do GPS, outros tipos de sensores podem ser combinados aos sistemas de navegação inercial, tais como: magnetômetros; barômetros ou tacômetros.

Este processo de combinação de sinais é chamado de Fusão Sensorial e do ponto de vista matemático é feita por meio do Filtro de Kalman.

\subsection{FILTRO de KALMAN}

O Filtro de Kalman é um estimador de estados de um sistema. Um estimador é uma função que aplicada sobre um conjunto de observações produz uma estimativa para os estados do sistema, segundo algum critério. Em particular, o critério utilizado pelo filtro de Kalman é a minimização da matriz de covariância dos erros.

O conjunto de observações descrito acima pode conter inúmeras medições, provenientes de diversos sensores, desde que todas possuam relação funcional com os estados do sistema.

O aumento no número de sensores e/ou emprego de sensores mais precisos tendem a produzir estimativas aprimoradas para os estados do sistema. 
É comum nas aplicações de navegação inercial considerar os erros do sistema os estados a serem estimados. Por exemplo, busca-se estimar grandezas como $\delta q_{0}, \delta q_{1}, \delta q_{2}, \delta q_{3}$ que representam o desvio na atitude do corpo descrito na forma de um quatérnio. Porém, não há regra definida para a escolha da descrição.

Para a construção da matriz de covariância dos erros é necessário conhecer os ruídos associados ao sistema dinâmico e ao conjunto de medições. Embora não esteja no escopo deste trabalho detalhar a construção e funcionamento do filtro é importante observar que o desenvolvimento apresentado no item 4.4.12, e principalmente 4.4.15, são de grande utilidade na quantificação dos ruídos descritos acima.

Acredita-se que a progressão natural deste trabalho seja a programação de uma versão do filtro de Kalman que aprimore a reconstrução da trajetória da estaca torpedo. O SMET já conta com um sensor de pressão que, em princípio, fornece a informação de profundidade instante a instante durante a queda. Outra fonte de medida poderia ser um magnetômetro de três eixos capaz de determinar a orientação do SMET com relação ao campo gravitacional da Terra. Estas e outras opções já vêm sendo estudadas, porém ainda em nível superficial e, portanto, desprovidas de resultados em nível para compor este texto.

De qualquer forma, a fusão sensorial é imprescindível ao uso de sensores de baixo custo visto que permite a incorporação engenhosa de diversas fontes de medida e, ainda assim, mantêm o custo e robustez do conjunto em patamares interessantes. 


\subsection{BibliografiA}

ANALOG DEVICES. ADXRS613 datasheet. Norwood. 2008.

AUSMAN, J. S. Inertial Guidance. New York: John Wiley \& Sons, 1962.

BARROS, E. A.; JUNQUEIRA, F. C. Modelagem Matemática de um Giroscópio Sintonizado Dinâmicamente. Controle \& Automação, São Paulo, v. Vol.16, n. no.2, p. 137-145, Abril, Maio e Junho 2005.

BENDAT, J. S.; PIERSOL, A. G. Random Data: Analysis and Measurement Procedures. 3․ ed. New York: John Wiley \& Sons, Inc, 2000.

BIASI, S. C.; GATTASS, M. Utilização de quatérnios para representação de rotações em 3D. PUC - Rio. [S.I.]. 2002.

BRANDÃO, F. E. N.; HENRIQUES, C. C. D.; ARAÚJO, J. B.; FERREIRA, O. C. G.; AMARAL, C. S.. Albacora Leste Field Development - FPSO P-50 Mooring System Concept and Instalations. Offshore Technology Conference. Houston: [s.n.]. 2006. p. 1-10.

CARVALHO E SILVA, D. F. CFD Hydrodynamic Analysis of a Torpedo Anchor Directional Stability. Proceedings of the 29th International Conference on Ocean, Offshore and Arctic Engineering. Shanghai: ASME. 2010. p. 9.

EL-SHEIMY, N.; HOU, H.; NIU, X. Analysis and Modeling of Inertial Sensors Using Allan Variance. IEEE TRANSACTIONS ON INSTRUMENTATION AND MEASUREMENT, v. VOL. 57, n. NO. 1, JANUARY 2008.

FERNANDES, A. C; ARAÚJO,J. B.; ALMEIDA, J. C. L.; MACHADO, R. D.; MATOS, $V$. Torpedo Anchor Installation Hydrodynamics. Journal of Offshore Mechanics and Arctic Engineering, v. 128, p. 286-293, November 2006. ISSN DOI: 10.1115/1.2355514.

FRANÇA, L. N. F.; MATSUMURA, A. Z. Mecânica Geral. 1a. ed. São Paulo: Edgard Blücher, 2001.

FUJARRA, A. L. C.;PESCE,C.P.;TANNURI, E. A.;MARTINS,C.A.;SIMOS, A. N.; LAVIERI, R. S. Validação do Procedimento de Monitoração da Instalação da Estaca-Torpedo. São Paulo. 2009.

GASVIK, K. J. Optical Metrology. 3a Edição. ed. Chichester, Inglaterra: Wiley, 2002. GEEN, J.; KRAKAUER, D. New iMEMS Angular Rate-Sensing Gyroscope. Analog Dialogue, v. 37, n. 3, 2003.

GEEN, J.; KRAKAUER, D. New iMEMS® Angular-Rate-Sensing Gyroscope. Analog Dialogue, p. 37-03, 2003.

GIACAGLIA, G. E. O. Mecânica Geral. 1a. ed. Rio de Janeiro: Campus, 1982.

GOLDSTEIN, H. Classical Mechanics. [S.I.]: Addison-Wesley, 1980. 
GULMAMMANDOV, F. Analysis, Modeling and Compensation of Bias Drift in MEMS Inertial Sennsors. 4th International Conference on Recent Advances in Space Technologies , 11-13 jun 2009.

HOU, H. Modeling Inertial Sensors Errors Using Allan Variance. UNIVERSITY OF CALGARY. CALGARY, ALBERTA, p. 128. 2004.

IEEE Standard Specification Format Guide and Test Procedure for Single Axis Interferometric Fiber Optic Gyros. IEEE Std 952. [S.I.]: [s.n.]. 1997 (R2008).

INTERMOOR. Torpedo pile anchors enter the GoM. E\&P, Houston, October 2009.

KUIPERS, J. B. Quaternions and Rotation Sequences. Princeton, New Jersey: Princeton University Press, 1999.

LAWRENCE, A. Modern Inertial Technology. New York: Springer, 1998.

LEFFLER, W. L.; PATTAROZZI, R.; STERLING, G. Deepwater Petroleum Exploration \& Production. Tulsa, Oklahoma: PennWell, 2003.

MERIAN, J. L. Statics and Dynamics. [S.I.]: John Wiley \& Sons, Inc., 1967.

NEWTON, S. I. The Mathematical Principles of Natural Philosophy. Tradução de Andrew Motte. London: [s.n.], v. I, 1729.

NIELSEN, J. N. Missile Aerodynamics. Palo Alto, California: McGraw-Hill, 1960.

PAPOULIS, A. Probability, Random Variables, and Stochastic Processes.

Internationa Edition. ed. Tokyo: McGraw-Hill Kogakusha, LTD., 1965.

PETROBRAS. Torpedo Pile "T-35" Field Testing Determination of Azimuth of Inclination - Calculation Report. [S.I.]. 2007.

SCHWARTZ, R. J.; FRIEDLAND, B. Sistemas Lineares. Tradução de P. B. Castrucci. São Paulo: EDUSP, v. II, 1972.

SOMMERFELD, A. Mechanics: Lectures on Theoretical Physics. New York: Academic Press, v. I, 1970.

STOCKWELL, W. Bias Stability Measurement: Allan Variance. Crossbow Technology, Inc. [S.I.], p. 5. 2006.

TITTERTON, D. H.; WESTON, J. L. Strapdow Inertial Navigation Technology. Reston: American Institute of Aeronautics and Astronautics, Inc, 2004.

TRIANTALYLLOU, M. S.; HOUVER, F. S. Maneuvering and Control of Marine Vehicles. Department of Ocean Engineering, MIT. Cambridge. 2004. 
VAN VERTH, J. M.; BISHOP, L. M. Essential Mathematics for Games and Interactive Applications. Second Edition. ed. Burlington,MA,USA: Elsevier, 2008.

YATAGAI, T. Óptica Aplicada: Introdução à Metrologia Óptica. Tradução de O. Horikawa. [S.I.]: Universidade de Tsukuba.

ZORMAN, C. A.; MEHREGANY, M. The MEMS Handbook. Boca Raton: CRC Press, 2002. 15-1 16-50 p.

BARTOLINI, D. Analog Devices. ITP SENSOR WORKSHOP, 2005. Disponivel em: $<$ http://itp.nyu.edu/physcomp/sensors/Reports/ADXRS150>. Acesso em: 20 Outubro 2010.

BERNSTEIN, J. Corning-IntelliSense Corp. Sensors Magazine, 2003. Disponivel em: <http://www.sensorsmag.com/sensors/acceleration-vibration/an-overview-memsinertial-sensing-technology-970>. Acesso em: 20 Outubro 2010.

BURKE, R. flickr. flickr. Disponivel em:

<http://www.flickr.com/photos/robertburke/92117605/>. Acesso em: 20 Outubro 2010.

CRRL. Disponivel em: <crrl.poly.edu/ tlng/IMU/IMU.html>. Acesso em: 05 nov. 2009. DIEBEL, J. Representing Attitude: Euler Angles, Unit Quaternions, and Rotation Vectors. Stanford,CA. 2006.

DIXON, S. Chipworks. Technology Insider. Disponivel em:

<http://www.chipworks.com/blogs. aspx?blogmonth=5\&blogyear=2008\&blogid=86>. DOMINGUES, H. H.; IEZZI, G. Álgebra Moderna. 2ª Edição. ed. São Paulo: Atual, 1982.

HOLSTING, E. Pictures from Maersk Assister. Pictures from Maersk Assister. Disponivel em: <www.menkent.dk/picassister.html>. Acesso em: 20 Julho 2010.

MOJOMARITIME. Mojomaritime. Mojomaritime. Disponivel em:

$<$ http://www.mojomaritime.com/case-studies/wave/swep-santona-pb40es-powerbuoy>. Acesso em: 20 Julho 2010.

PENNENERGY. PennEnergy. PennEnergy. Disponivel em:

<http://www.pennenergy.com/index/petroleum/display/315256/articles/offshore/volum e-67/issue-12/construction-installation/worldrsquos-largest-suction-anchors-installedoffshore-boston.html>. Acesso em: 20 Outubro 2010.

PETROBRAS. Plataformas - Águas Profundas. Petrobras. Disponivel em: $<$ http://www2.petrobras.com.br/Petrobras/portugues/plataforma/pla_aguas_profunda s.htm >. Acesso em: 20 Janeiro 2010.

SAFRAN Sagem. MARKET/PRODUCTS. Disponivel em: <http://www.sagemds.com/eng/site.php?spage=02010301 >. Acesso em: 30 ago. 2010. 
THE Institute of Navigation. Navigation Museum - Aviation Inertial. Disponivel em: <http://www.ion.org/museum/photos/photo1.JPG>. Acesso em: 30 ago. 2010. 


\section{APENDICE A - REVISÃo de ConCEITOS MATEMÁticos}

Uma parte importante deste trabalho é a descrição do movimento espacial, principalmente com relação às rotações.

Embora no item 4.2.2 sejam apresentadas figuras que buscam ilustrar geometricamente as rotações características do sistema em estudo, a melhor forma de tratá-las é por intermédio da sistematização algébrica.

Inicialmente, apresentam-se algumas propriedades dos conjuntos de números importantes para o posterior entendimento da relação entre os procedimentos algébricos e as transformações geométricas. Os conceitos apresentados a seguir são apresentados de maneira mais completa em (DOMINGUES e IEZZI, 1982) e (KUIPERS, 1999).

Um conjunto é dito "fechado" segundo uma determinada operação, caso o resultado dessa operação sempre forneça elementos pertencentes ao conjunto original. $\mathrm{O}$ termo fechado pode ser substituído por: “operação sobre o conjunto", bem definido no conjunto, ou ainda em composição interna.

O conjunto dos números naturais, por exemplo, é fechado sob a adição e a multiplicação e não é fechado sob a subtração e a divisão. Isso significa que, quaisquer dois naturais somados ou multiplicados geram outro natural, enquanto nem todo par de naturais ao ser subtraído ou dividido gera um número natural.

Um grupo é dito "definido" quando se tem um conjunto no qual algumas propriedades são válidas sobre uma lei de composição interna e, por isso, é habitualmente denominado por um par $(G, *)$ em que " $G$ ” é o conjunto, nesse caso o grupo, e “*” a composição interna. Para que se possa dizer que " $G$ ” é um grupo em relação a lei “*”, deve valer a propriedade associativa para a composição “*”, assim como existir um termo neutro para esta operação e, finalmente, todos os elementos de “G” devem ser "simetrizáveis" em relação à lei considerada. Antes de se detalhar tais propriedades cabe definir grupo comutativo e anel.

Quando a composição interna é a adição, o grupo é chamado aditivo e, por outro lado, quando a operação é a multiplicação é chamado multiplicativo. Ou seja:

$(G,+) \rightarrow$ grupo aditivo

$(G, \cdot) \rightarrow$ grupo multiplicativo

Grupo comutativo ou abeliano é aquele em que, além das propriedades descritas anteriormente, a composição interna possui propriedade comutativa.

"Anel" é um conjunto com duas operações bem definidas, adição e multiplicação, para as quais valem a seguintes características e propriedades: 
- O anel é um grupo comutativo para a propriedade de adição;

- Vale a propriedade associativa para a multiplicação;

- A multiplicação é distributiva com relação à adição;

O último conceito importante a ser introduzido nessa seção é o de "Corpo" ou "Campo".

"Corpos" são anéis em que valem a comutatividade da multiplicação; que possuem um elemento neutro para a multiplicação e que admitem simétricos para a multiplicação. Um “corpo" é um grupo comutativo com unidade (elemento neutro da multiplicação) aditivo e multiplicativo simultaneamente.

Há formas mais simples de caracterizar um corpo. Um conjunto que seja fechado sob as quatro operações básicas é um corpo. Os exemplos típicos de corpos são os números Racionais, Reais e Complexos.

Descrição mais detalhada das propriedades características dos corpos é dada a seguir.

Adição e Multiplicação são operações associativas, ou seja, se " $a$ ", “ $b$ " e " $c$ " pertencem ao corpo dos números reais, por exemplo:

$$
\begin{gathered}
(a+b)+c=a+b+c \\
(a \cdot b) \cdot c=a \cdot(b \cdot c)
\end{gathered}
$$

Adição e Multiplicação são comutativas, ou seja, se " $a$ " e " $b$ " pertencem ao corpo dos números reais:

$$
\begin{gathered}
a+b=b+a \\
a \cdot b=b \cdot a
\end{gathered}
$$

Existem elementos neutros para a adição e a multiplicação:

$$
\begin{aligned}
& a+0=a \\
& a \cdot 1=a
\end{aligned}
$$

Assim como existem elementos simétricos. O oposto é o elemento simétrico da adição e o inverso o simétrico da multiplicação:

$$
a+(-a)=0
$$




$$
a \cdot a^{-1}=1
$$

Lembrando apenas que não é possível definir o inverso do real 0.

Por último, a multiplicação é distributiva sobre a adição:

$$
a \cdot(b+c)=a \cdot b+a \cdot c
$$

Tais propriedades englobam as quatro operações descritas anteriormente, já que a subtração pode ser entendida como a adição do oposto e a divisão como a multiplicação do inverso.

Todas as propriedades descritas decorrem das definições de "grupo", "anel” e "corpo". As estruturas algébricas familiares a todos e que, por isso, balizam a maior parte do pensamento matemático, provêm das propriedades dos "corpos".

\section{Números Complexos}

São um "corpo" habitualmente designado por C, que possui a forma $a+i b$ sendo: " $a$ " e " $b$ " números reais e " $i$ " a unidade imaginária que corresponde à raiz quadrada de -1 . Os números complexos foram imaginados por Gerolamo Cardano, matemático italiano do século XVI, enquanto buscava solução para equações cúbicas. Porém, foi Rafael Bombelli, outro matemático italiano e contemporâneo a Cardano, que formalizou a álgebra dos complexos. $\mathrm{O}$ termo imaginário é herança desse período inicial em que a idéia da raiz do número negativo parecia "fictícia". Foi somente no final de século XVIII, início do século XIX, que o matemático alemão Johann Carl Fredrich Gauss efetivamente associou os números complexos à solução de equações polinomiais para " $a$ " e " $b$ " não nulos, como:

$$
\begin{gathered}
x^{2}+b^{2}=0 \\
x^{2}-2 a x+a^{2}+b^{2}=0
\end{gathered}
$$

Hoje em dia os números que satisfazem essas equações são bem conhecidos, respectivamente:

$$
\begin{gathered}
x= \pm \mathbf{i} b \\
x=a \pm \mathbf{i} b
\end{gathered}
$$

O corpo dos números complexos contém o corpo dos números reais já que: 


$$
z=a+\mathbf{i} b
$$

Para $b=0$ :

$$
z=a
$$

E a é um número real.

A notação usada até agora é chamada notação cartesiana, assim denominada pois, se considerados $(a, b)$ pontos de um plano, o complexo pode ser visualizado como o vetor que liga tal ponto à origem. Outra notação comum para os números complexos é a polar, que descreve o vetor citado anteriormente por meio de um módulo e um ângulo com relação ao eixo X, também chamado no plano dos complexos de eixo real.

A seguir será feita uma revisão das operações com números complexos e a simultânea verificação das propriedades de corpo do conjunto. Tais propriedades serão demonstradas partindo-se da definição de igualdade de números complexos. Assim:

$$
a+\mathbf{i} b=c+\mathbf{i} d
$$

Se e somente se: $a=c$ e $b=d$, bem como do fato de que $a, b, c$ e $d$ pertencem ao conjunto dos números reais e, por isso, compartilham das propriedades de corpo.

A adição e a multiplicação de dois complexos são definidas das seguintes formas,

$$
\begin{gathered}
(a+\mathbf{i} b)+(c+\mathbf{i} d)=(a+c)+\mathbf{i}(b+d) \\
(a+\mathbf{i} b) \times(c+\mathbf{i} d)=(a c-b d)+\mathbf{i}(b c+a d)
\end{gathered}
$$

É fácil demonstrar que ambas as operações mostradas acima são associativas.

Por se tratarem de operações características ao corpo dos complexos, cabe mostrar brevemente como estas respeitam as condições de simetria e identidade, como foi feito no caso dos números reais nas equações (240) e (241).

A identidade para a adição é representada por $0+i 0$ como:

$$
(a+\mathbf{i} b)+(0+\mathbf{i} 0)=(a+0)+\mathbf{i}(b+0)=(a+\mathbf{i} b)
$$

No caso da multiplicação, a identidade corresponde à unidade real $1+\mathbf{i} 0$ : 


$$
(a+\mathbf{i} b) \times(1+\mathbf{i} 0)=(a-0)+\mathbf{i}(b+0)=(a+\mathbf{i} b)
$$

Adição e multiplicação são comutativas, pois tal propriedade é válida para o conjunto dos reais e:

$$
\begin{aligned}
& (a+\mathbf{i} b)+(c+\mathbf{i} d)=(a+c)+\mathbf{i}(b+d) \\
& (c+\mathbf{i} d)+(a+\mathbf{i} b)=(c+a)+\mathbf{i}(d+b)
\end{aligned}
$$

E:

$$
\begin{aligned}
& (a+\mathbf{i} b) \times(c+\mathbf{i} d)=(a c-b d)+\mathbf{i}(b c+a d) \\
& (c+\mathbf{i} d) \times(a+\mathbf{i} b)=(c a-d b)+\mathbf{i}(c b+d a)
\end{aligned}
$$

Serão válidas se:

$$
\begin{aligned}
& (a+c)=(c+a) \\
& (b+d)=(d+b)
\end{aligned}
$$

$$
a c=c a, b d=d b, b c=c b, a d=d a
$$

A multiplicação de complexos é distributiva sobre a adição como se pode ver nas equações a seguir. Sendo $z_{1}, z_{2}, z_{3}$ três complexos:

$$
\begin{aligned}
& z_{1}=a_{1}+\mathbf{i} b_{1} \\
& z_{2}=a_{2}+\mathbf{i} b_{2} \\
& z_{3}=a_{3}+\mathbf{i} b_{3}
\end{aligned}
$$

A propriedade distributiva corresponde a:

$$
z_{1}\left(z_{2}+z_{3}\right)=z_{1} z_{2}+z_{1} z_{3}
$$

Reescrevendo o primeiro termo:

$$
\begin{gathered}
z_{1}\left(z_{2}+z_{3}\right)=\left(a_{1}+\mathbf{i} b_{1}\right)\left[\left(a_{2}+\mathbf{i} b_{2}\right)+\left(a_{3}+\mathbf{i} b_{3}\right)\right]= \\
=a_{1}\left[\left(a_{2}+\mathbf{i} b_{2}\right)+\left(a_{3}+\mathbf{i} b_{3}\right)\right]+\mathbf{i} b_{1}\left[\left(a_{2}+\mathbf{i} b_{2}\right)+\left(a_{3}+\mathbf{i} b_{3}\right)\right]=
\end{gathered}
$$




$$
=a_{1}\left(a_{2}+\mathbf{i} b_{2}\right)+\mathbf{i} b_{1}\left(a_{2}+\mathbf{i} b_{2}\right)+a_{1}\left(a_{3}+\mathbf{i} b_{3}\right)+\mathbf{i} b_{1}\left(a_{3}+\mathbf{i} b_{3}\right)
$$

Lembrado que $\mathbf{i}^{2}=-1$, o que implica em:

$$
z_{1}\left(z_{2}+z_{3}\right)=\left(a_{1}+\mathbf{i} b_{1}\right)\left(a_{2}+\mathbf{i} b_{2}\right)+\left(a_{1}+\mathbf{i} b_{1}\right)\left(a_{3}+\mathbf{i} b_{3}\right)
$$

Que, por sua vez, é o mesmo que: $z_{1} z_{2}+z_{1} z_{3}$.

Por fim, os complexos devem possuir inverso para adição e multiplicação. O primeiro caso é bastante simples:

$$
(a+\mathbf{i} b)+(-a-\mathbf{i} b)=(a-a)+\mathbf{i}(b-b)=0+\mathbf{i} 0 \text { (identidade da adição) }
$$

No caso da multiplicação, é preciso primeiramente observar que:

$$
(a+\mathbf{i} b) \times(a-\mathbf{i} b)=(a a+b b)+\mathbf{i}(-a b+b a)=\left(a^{2}+b^{2}\right)+\mathbf{i} 0=a^{2}+b^{2}
$$

E que $a^{2}+b^{2}$ é um número real.

Além disso, $a-\mathbf{i} b$ é chamado complexo conjugado de $a+i b$. Todo número complexo possui um complexo conjugado construído da forma descrita.

O inverso da multiplicação é construído da seguinte forma:

$$
\frac{1}{(a+\mathbf{i} b)}=\frac{1}{(a+\mathbf{i} b)} \frac{(a-\mathbf{i} b)}{(a-\mathbf{i} b)}=\frac{(a+\mathbf{i} b)}{a^{2}+b^{2}}=\frac{a}{a^{2}+b^{2}}+\mathbf{i} \frac{b}{a^{2}+b^{2}}
$$

E o resultado sempre pertencerá ao conjunto dos complexos, caso $a+i b$ seja não nulo.

Como foi dito anteriormente, a subtração e a divisão decorrem das operações e propriedades descritas. A subtração é a adição do inverso da adição e a divisão é a multiplicação do inverso da multiplicação, ou seja:

$$
\begin{gathered}
(a+\mathbf{i} b)-(c+\mathbf{i} d)=(a+\mathbf{i} b)+(-c-i d)=(a-c)+\mathbf{i}(b-d) \\
\frac{a+\mathbf{i} b}{c+\mathbf{i} d}=(a+\mathbf{i} b)(c+\mathbf{i} d)^{-1}= \\
(a+\mathbf{i} b)\left(\frac{c}{c^{2}+d^{2}}+\mathbf{i} \frac{d}{c^{2}+d^{2}}\right)=\frac{a c+b d}{c^{2}+d^{2}}+\mathbf{i} \frac{b c+a d}{c^{2}+d^{2}}
\end{gathered}
$$


Antes de prosseguir, é importante detalhar a representação polar, citada anteriormente.

A representação polar permite a visualização geométrica dos complexos e será especialmente útil na conexão com os quatérnios de Hamilton, discutidos mais adiante.

Assim, para cada complexo $z=a+i b$ pode se definir uma magnitude ou módulo da seguinte forma:

$$
|z|=\sqrt{a^{2}+b^{2}}
$$

E um ângulo ou argumento $\theta$ :

$$
\theta=\tan ^{-1}\left(\frac{b}{a}\right)
$$

As grandezas $|z|$ e $\theta$ possuem interpretação geométrica imediata, pois caracterizam um vetor no plano dos complexos. O plano dos complexos é construído considerando-se o eixo das abscissas contendo os números reais e o das ordenadas os números imaginários. A Figura 120 ilustra a interpretação geométrica de um número complexo.

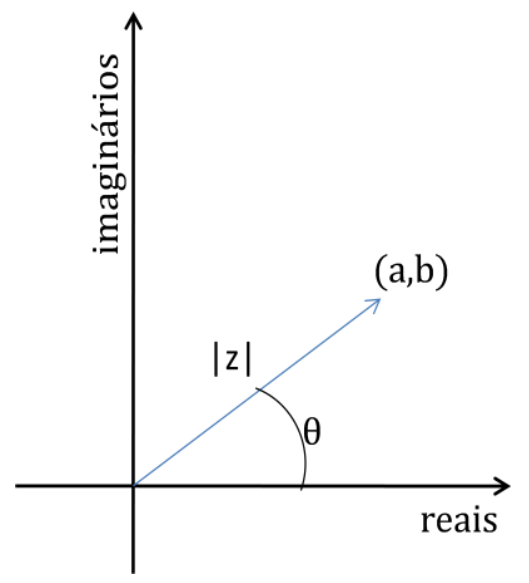

Figura 120 - Visualização da forma polar de um número complexo

Do ponto de vista geométrico, é fácil perceber que a soma de dois complexos corresponde à chamada regra do paralelogramo, empregada habitualmente na soma de vetores no plano (Figura 121). 


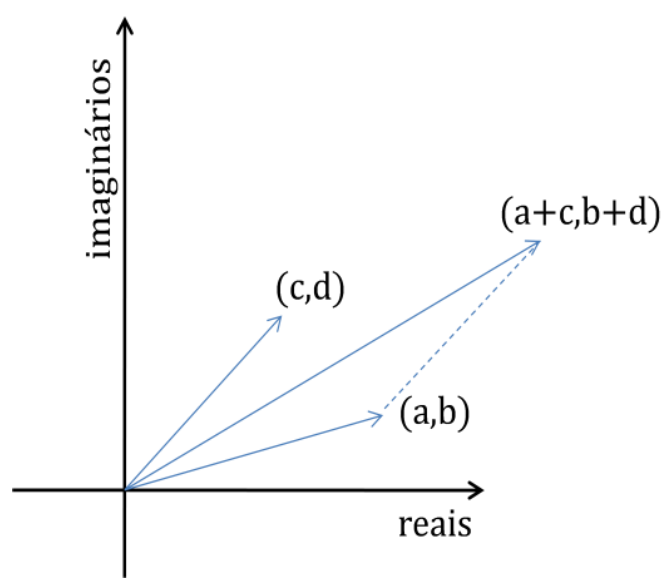

Figura 121 - Visualização da soma de números complexos

Na multiplicação de números complexos a magnitude do produto é igual ao produto das magnitudes, enquanto o ângulo do produto é a soma dos argumentos. Esse fato fica claro se representarmos os complexos na forma trigonométrica. Observando-se a Figura 120 é fácil perceber que:

$$
a=r \cos \theta \quad \text { e } \quad a=r \sin \theta
$$

Substituindo (276) em (247):

$$
\begin{gathered}
z=a+\mathbf{i} b=r \cos \theta+\mathbf{i} r \sin \theta \\
z=r(\cos \theta+\mathbf{i} \sin \theta)
\end{gathered}
$$

Conhecendo, ainda, a fórmula de Euler, que relaciona funções trigonométricas a exponenciais, $z$ pode ser escrito como:

$$
z=r(\cos \theta+\mathbf{i} \sin \theta)=r e^{\mathbf{i} \theta}
$$

Supondo agora dois complexos $z_{1}$ e $z_{2}$, cujos módulos são respectivamente $r_{1}$ e $r_{2}$ e os argumentos $\theta_{1}$ e $\theta_{2}$, e valendo-se da fórmula (279), pode-se escrever seu produto como,

$$
r_{1} e^{i \theta_{1}} r_{2} e^{i \theta_{2}}
$$


O qual pode ser re-arranjado da seguinte forma:

$$
r_{1} r_{2} e^{i\left(\theta_{1}+\theta_{2}\right)}
$$

Exibindo as características descritas inicialmente.

Conhecendo tais características constata-se que o imaginário puro, número complexo sem parte real, enquanto operador, promove apenas a rotação de um complexo qualquer no plano quando multiplicado por este.

Tal propriedade da álgebra dos complexos no plano provavelmente levou Hamilton, e outros estudiosos da época, a buscarem uma possível analogia no espaço tri-dimensional. Suas primeiras tentativas envolvendo trios de números reais não foram bem sucedidas e, como veio a ser provado posteriormente pelo matemático alemão Ferdinand Frobenius, seria impossível fazê-lo.

A solução posteriormente alcançada por Hamilton foi empregar quádruplas no lugar de triplas. Essa conclusão demandou um grande trabalho matemático, mas pode-se imaginar uma explicação simplificada para o emprego de quatro números reais.

Ao passar do plano para o espaço é acrescida apenas uma dimensão de translação, porém dois outros giros passam a ser possíveis e, com isso, de certa forma, dois outros parâmetros passam a ser necessários. 


\section{APÊNDICE B - Procedimentos EXPERIMENTAIS Detalhados}

\section{Ensaios da Morsa Reclinável}

Os passos seguintes devem ser seguidos sempre que uma nova bateria de ensaios for iniciada.

\section{Verificação da Calibração do Inclinômetro}

Posicionar o inclinômetro sobre o desempeno (em um local determinado), ligar o equipamento e esperar no mínimo 10s até registrar o valor obtido. Virar o inclinômetro com o display para o outro lado e fazer a medida novamente.

Virar o inclinômetro com a face inferior para cima e repetir a medição. Girar a face do instrumento para o observador e repetir a medida. Tomar o cuidado de manter o inclinômetro em um mesmo ponto da mesa. Os dados devem ser registrados na Tabela 23

Caso a variação das quatro medidas exceda $0,1^{\circ}$ contatar o fabricante.

A Figura 122 ilustra o procedimento.
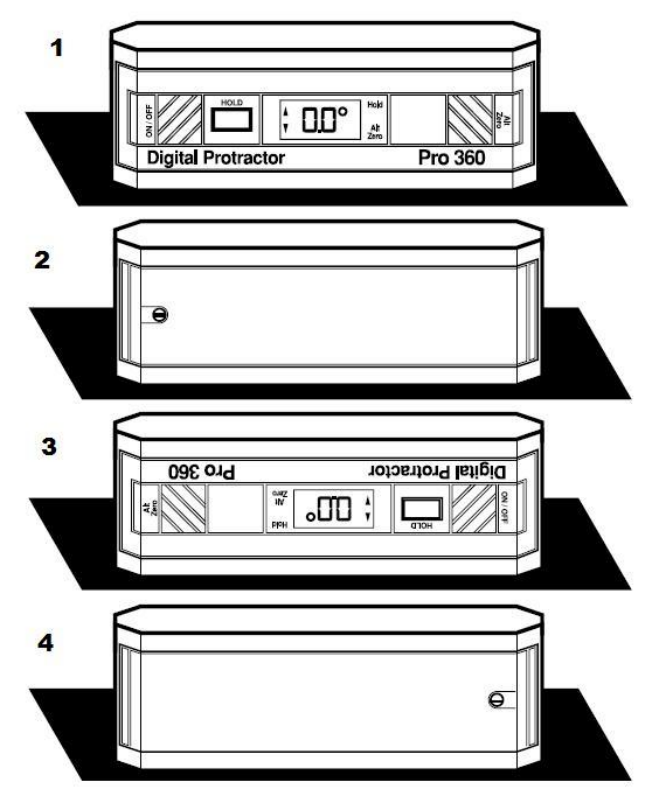

Figura 122 - llustração proveniente do manual do aparelho demonstrando o procedimento de verificação da calibração 


\section{Verificação do Nível do Desempeno}

Posicionar o desempeno no centro de cada um dos lados do desempeno e registrar os valores obtidos. Lembrando que, após posicionar o instrumento deve-se aguardar 10s para registrar o valor medido. Realizar o procedimento 2 vezes. Registrar os dados na Tabela 24. O desvio com relação ao 0 não deve exceder $0,1^{\circ}$.

\section{Posição do SMET na morsa}

Colocar o bloco de aço preso ao SMET cuidadosamente na morsa garantindo que este esteja tocando o fundo da mesma e toda a face dos mordentes quando apertados. Garantir que o SMET esteja alinhado com o centro da morsa medindo as distancias mostradas na Figura 123. Realizar as medições d1,d2,d3,d4 duas vezes e registrar os dados na Tabela 25.

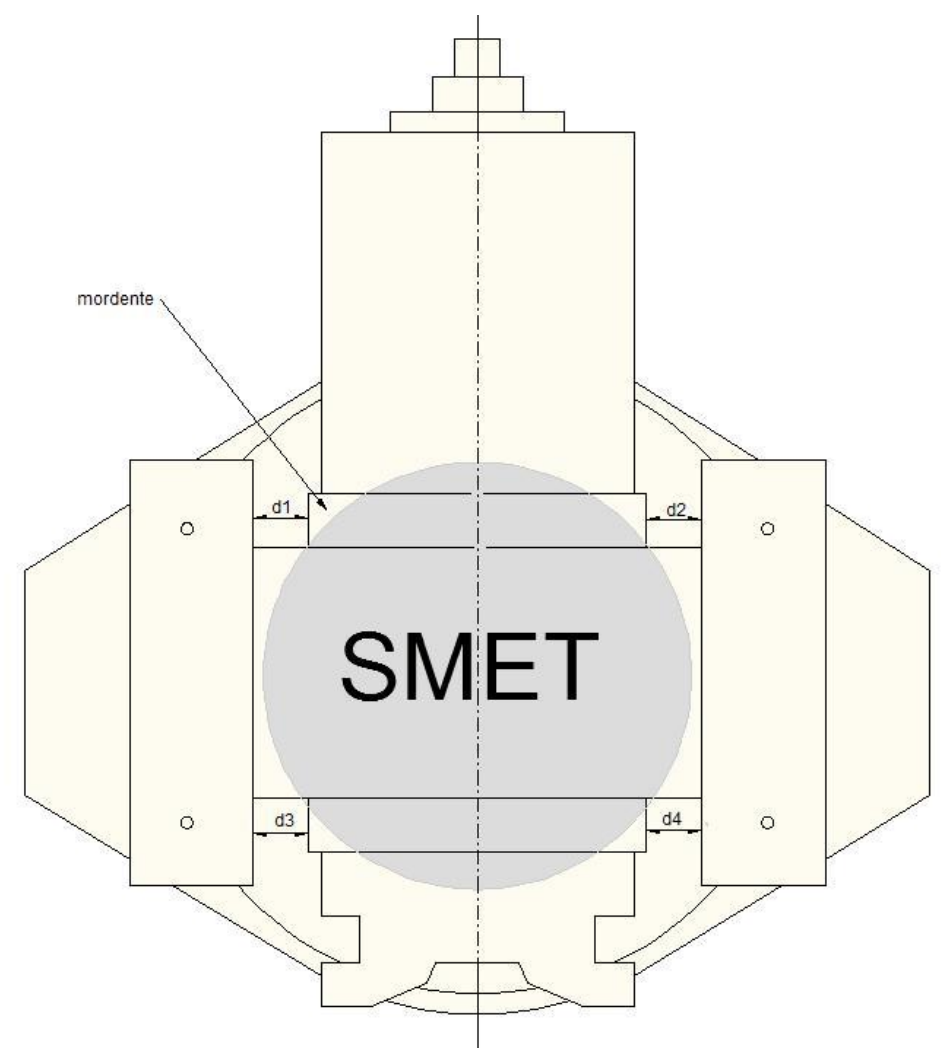

Figura 123 - Vista de topo do conjunto morsa, suporte e SMET identificando pontos para medição e verificação do alinhamento. 


\section{Fixação do Inclinômetro ao SMET}

Com a morsa na posição horizontal (verificar na escala) colocar o Inclinômetro em uma das plataformas da peça na base do SMET e fixá-lo manualmente com 2 parafusos \#6-32. Não é necessário apertar excessivamente os parafusos. Ligar o inclinômetro e verificar a coerência da leitura deste com a escala da morsa e o alinhamento da mesa.

\section{Experimento}

O experimento visa obter registros de 10 s de acelerações e velocidades angulares medidas pelo SMET em varias condições de inclinação e a grandeza chamada em (PETROBRAS, 2007) de azimute de precessão.

\section{Leitura do Ângulo}

Os experimentos são identificados por uma inclinação e um azimute, ambos nominais. O azimute depende da forma como o SMET foi posicionado na sua peça de fixação.

A morsa deve ser posicionada de forma que a indicação de sua escala coincida da melhor forma possível com o ângulo nominal da inclinação que identifica o experimento. Mesmo assim, 2 medidas visuais devem ser registradas na tabela de experimentos. Após posicionar a morsa aguardar no mínimo 10s e fazer a leitura do inclinômetro (registrar na tabela de experimentos).

Tabela 23 - Calibração do inclinômetro

\section{Teste}

do Inclinômetro

\begin{tabular}{|c|c|}
\hline Posição & Medida \\
\hline $\mathbf{1}$ & \\
\hline $\mathbf{2}$ & \\
\hline $\mathbf{3}$ & \\
\hline $\mathbf{4}$ & \\
\hline
\end{tabular}

Tabela 24 - Verificação do nível do desempeno

\begin{tabular}{|c|c|c|}
\hline \multicolumn{3}{|c|}{ Nível do Desempeno } \\
\hline Lado & $\begin{array}{c}\text { Medida } \\
1\end{array}$ & $\begin{array}{c}\text { Medida } \\
2\end{array}$ \\
\hline $\mathbf{1}$ & & \\
\hline $\mathbf{2}$ & & \\
\hline $\mathbf{3}$ & & \\
\hline $\mathbf{4}$ & & \\
\hline
\end{tabular}

Tabela 25 - Verificação do alinhamento do SMET

\begin{tabular}{|c|c|c|}
\hline \multicolumn{3}{|c|}{ Alinhamento SMET } \\
\hline Dimensão & $\begin{array}{c}\text { Medida } \\
1\end{array}$ & $\begin{array}{c}\text { Medida } \\
2\end{array}$ \\
\hline d1 & & \\
\hline d2 & & \\
\hline d3 & & \\
\hline d4 & & \\
\hline
\end{tabular}




\section{Tabela de Ensaios na Morsa Reclinável (Dados Obtidos)}

A Tabela 26, a Tabela 27 e também Tabela 28 apresentam os ensaios estáticos realizados na morsa reclinável. Cada linha das tabelas corresponde a 1 ensaio de duração 10 segundos. A primeira e segunda colunas correspondem à identificação do experimento e o instante em que cada um deles foi realizado. A terceira coluna contém as medidas de inclinação provenientes do próprio SMET - ao final de cada aquisição -, na tela do pocketPC responsável pela interface com o equipamento, é apresentado um valor de inclinação-. As quartas e quintas colunas correspondem à medida de inclinação obtida através do inclinômetro e da leitura da escala da morsa. Por fim, a última coluna identifica a grandeza $\zeta$ utilizada em cada experimento. A Figura 124, a Figura 125 e a Figura 126 esclarecem o significado dos valores apresentados na última coluna. Tendo em vista que as tabelas apresentadas são as preenchidas durante os experimentos, foram registradas todas as casas decimais fornecidas pelos aparelhos. 


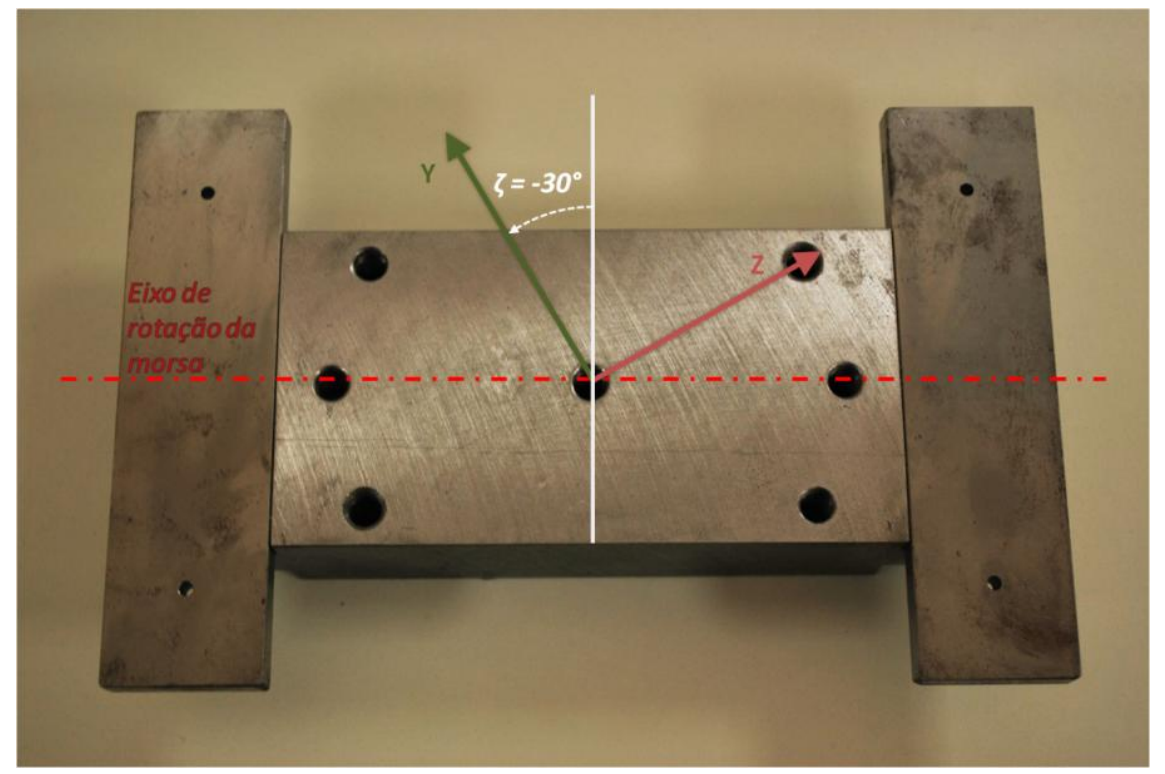

Figura 124 - Orientação do SMET montado sobre o suporte. Os eixos y e z na figura referem-se aos eixos sensíveis do SMET; A linha tracejada representa o eixo em torno do qual a inclinação da morsa foi variada

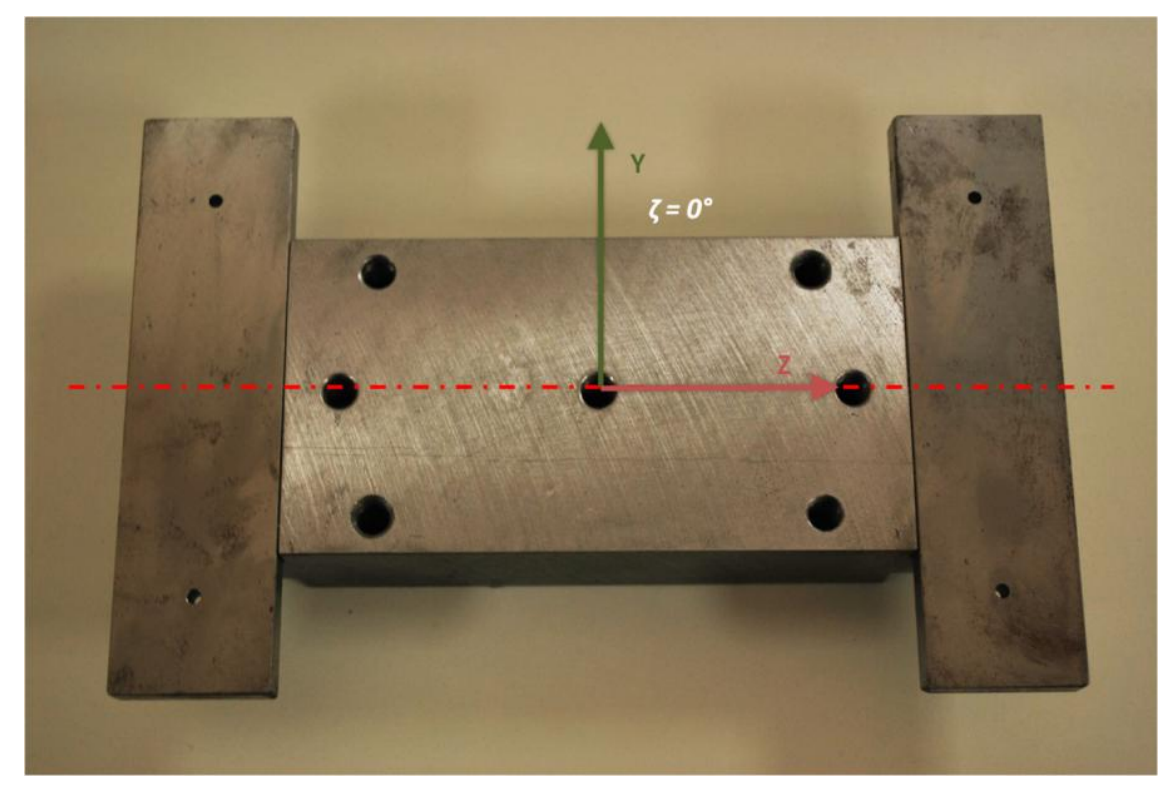

Figura 125 - Montagem reproduzindo $\zeta=0^{\circ}$ (experimentos 201 a 300) 


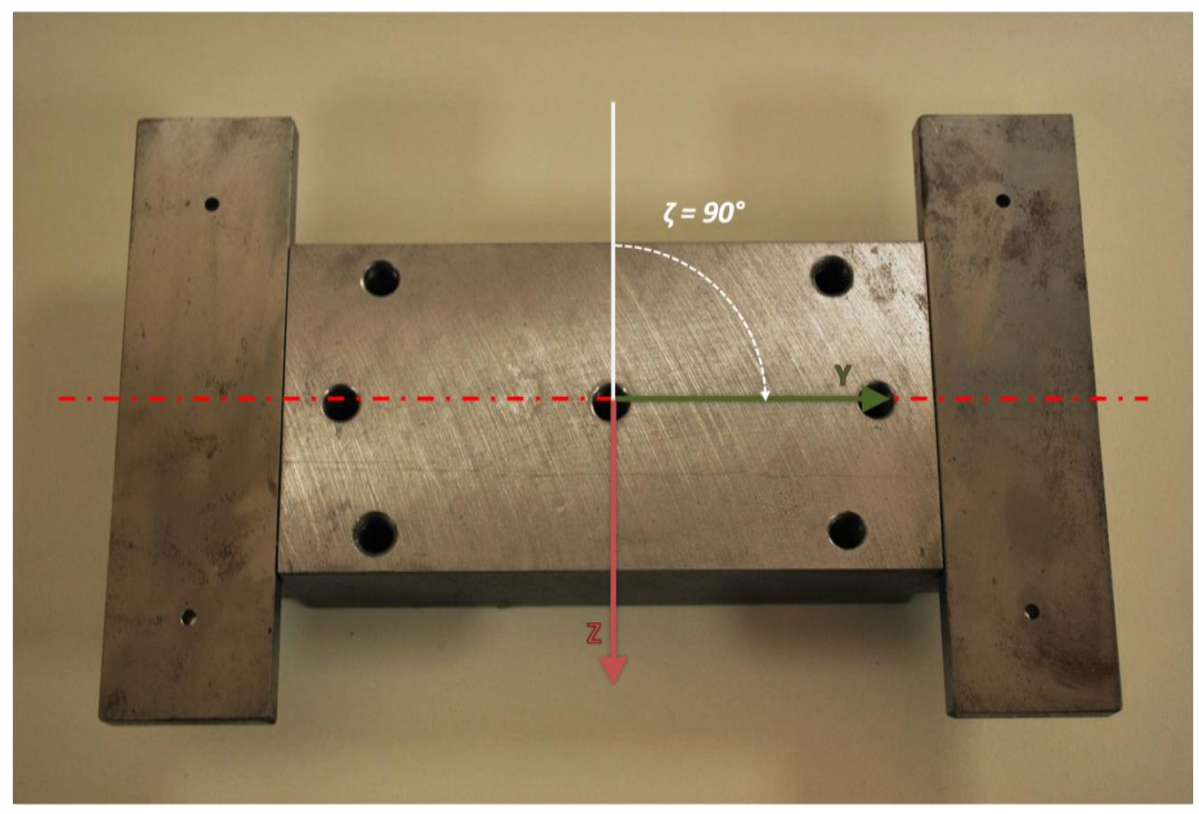

Figura 126 - Montagem reproduzindo $\zeta=90^{\circ}$ (experimentos 101 a 200)

Tabela 26 - Dados dos ensaios referentes a $\zeta=-30^{\circ}$

\begin{tabular}{|c|c|c|c|c|c|}
\hline \multicolumn{7}{|c}{ Resultados Experimentais $\left(\zeta=-30^{\circ}\right)$} \\
\hline $\begin{array}{c}\text { Identificação } \\
\text { de ensaio }\end{array}$ & Horário & $\begin{array}{c}\text { Inclinação } \\
\text { SMET }\end{array}$ & $\begin{array}{c}\text { Inclinação } \\
\text { Inclinômetro }\end{array}$ & $\begin{array}{c}\text { Inclinação } \\
\text { Morsa }\end{array}$ & $\zeta$ \\
\hline 1 & $10: 16: 28$ & 0,7845 & 0,9 & 1,0 & $-30,0$ \\
\hline 2 & $10: 17: 17$ & 0,7685 & 0,9 & 1,0 & $-30,0$ \\
\hline 3 & $10: 18: 10$ & 0,7650 & 0,9 & 1,0 & $-30,0$ \\
\hline 4 & $10: 18: 54$ & 0,7785 & 0,9 & 1,0 & $-30,0$ \\
\hline 5 & $10: 19: 40$ & 0,7675 & 0,9 & 1,0 & $-30,0$ \\
\hline 6 & $10: 20: 29$ & 0,7758 & 0,9 & 1,0 & $-30,0$ \\
\hline 7 & $10: 22: 43$ & 0,7747 & 0,9 & 1,0 & $-30,0$ \\
\hline 8 & $10: 23: 25$ & 0,7775 & 0,9 & 1,0 & $-30,0$ \\
\hline 9 & $10: 24: 15$ & 0,7876 & 0,9 & 1,0 & $-30,0$ \\
\hline 10 & $10: 24: 55$ & 0,7801 & 0,9 & 1,0 & $-30,0$ \\
\hline 11 & $10: 27: 27$ & 4,8140 & 4,9 & 5,0 & $-30,0$ \\
\hline 12 & $10: 28: 14$ & 4,8001 & 4,9 & 5,0 & $-30,0$ \\
\hline 13 & $10: 28: 59$ & 4,8121 & 4,9 & 5,0 & $-30,0$ \\
\hline 14 & $10: 29: 42$ & 4,8083 & 4,9 & 5,0 & $-30,0$ \\
\hline 15 & $10: 30: 33$ & 4,8104 & 4,9 & 5,0 & $-30,0$ \\
\hline 16 & $10: 31: 15$ & 4,8091 & 4,9 & 5,0 & $-30,0$ \\
\hline 17 & $10: 31: 59$ & 4,8018 & 4,9 & 5,0 & $-30,0$ \\
\hline 18 & $10: 32: 47$ & 4,8026 & 4,9 & 5,0 & $-30,0$ \\
\hline 19 & $10: 33: 28$ & 4,8109 & 4,9 & 5,0 & $-30,0$ \\
\hline 20 & $10: 34: 12$ & 4,8140 & 4,9 & 5,0 & $-30,0$ \\
\hline 21 & $10: 36: 22$ & 9,5410 & 9,7 & 9,9 & $-30,0$ \\
\hline 22 & $10: 37: 08$ & 9,5570 & 9,7 & 9,9 & $-30,0$ \\
\hline
\end{tabular}


Resultados Experimentais $\left(\zeta=-30^{\circ}\right)$

(continuação)

\begin{tabular}{|c|c|c|c|c|c|}
\hline 23 & $10: 37: 53$ & 9,5428 & 9,7 & 9,9 & $-30,0$ \\
\hline 24 & $10: 38: 37$ & 9,5636 & 9,7 & 9,9 & $-30,0$ \\
\hline 25 & $10: 39: 18$ & 9,5568 & 9,7 & 9,9 & $-30,0$ \\
\hline 26 & $10: 39: 57$ & 9,5588 & 9,7 & 9,9 & $-30,0$ \\
\hline 27 & $10: 40: 35$ & 9,5962 & 9,7 & 9,9 & $-30,0$ \\
\hline 28 & $10: 41: 16$ & 9,5631 & 9,7 & 9,9 & $-30,0$ \\
\hline 29 & $10: 41: 53$ & 9,5606 & 9,7 & 9,9 & $-30,0$ \\
\hline 30 & $10: 43: 13$ & 9,5494 & 9,7 & 9,9 & $-30,0$ \\
\hline 31 & $10: 45: 22$ & 14,6523 & 14,8 & 15,0 & $-30,0$ \\
\hline 32 & $10: 46: 20$ & 14,6774 & 14,8 & 15,0 & $-30,0$ \\
\hline 33 & $10: 47: 13$ & 14,6347 & 14,8 & 15,0 & $-30,0$ \\
\hline 34 & $10: 47: 58$ & 14,6683 & 14,8 & 15,0 & $-30,0$ \\
\hline 35 & $10: 48: 42$ & 14,6482 & 14,8 & 15,0 & $-30,0$ \\
\hline 36 & $10: 49: 22$ & 14,6605 & 14,8 & 15,0 & $-30,0$ \\
\hline 37 & $10: 50: 01$ & 14,6619 & 14,8 & 15,0 & $-30,0$ \\
\hline 38 & $10: 50: 42$ & 14,6441 & 14,8 & 15,0 & $-30,0$ \\
\hline 39 & $10: 51: 22$ & 14,6461 & 14,8 & 15,0 & $-30,0$ \\
\hline 40 & $10: 52: 03$ & 14,6553 & 14,8 & 15,0 & $-30,0$ \\
\hline 41 & $11: 42: 17$ & 19,6052 & 19,8 & 20,0 & $-30,0$ \\
\hline 42 & $11: 43: 02$ & 19,6169 & 19,8 & 20,0 & $-30,0$ \\
\hline 43 & $11: 43: 46$ & 19,6077 & 19,8 & 20,0 & $-30,0$ \\
\hline 44 & $11: 44: 31$ & 19,6348 & 19,8 & 20,0 & $-30,0$ \\
\hline 45 & $11: 45: 37$ & 19,6195 & 19,8 & 20,0 & $-30,0$ \\
\hline 46 & $11: 46: 27$ & 19,6278 & 19,8 & 20,0 & $-30,0$ \\
\hline 47 & $11: 47: 09$ & 19,6590 & 19,8 & 20,0 & $-30,0$ \\
\hline 48 & $11: 47: 54$ & 19,6226 & 19,8 & 20,0 & $-30,0$ \\
\hline 49 & $11: 48: 38$ & 19,6407 & 19,8 & 20,0 & $-30,0$ \\
\hline 50 & $11: 49: 25$ & 19,6772 & 19,8 & 20,0 & $-30,0$ \\
\hline 51 & $13: 58: 14$ & 24,8753 & 25 & 25,2 & $-30,0$ \\
\hline 52 & $13: 59: 07$ & 24,8699 & 25 & 25,2 & $-30,0$ \\
\hline 53 & $14: 00: 01$ & 24,8726 & 25 & 25,2 & $-30,0$ \\
\hline 54 & $14: 00: 51$ & 24,8620 & 25 & 25,2 & $-30,0$ \\
\hline 55 & $14: 02: 45$ & 24,8660 & 25 & 25,2 & $-30,0$ \\
\hline 56 & $14: 04: 12$ & 24,8455 & 25 & 25,2 & $-30,0$ \\
\hline 57 & $14: 05: 08$ & 24,8706 & 25 & 25,2 & $-30,0$ \\
\hline 58 & $14: 06: 19$ & 24,8662 & 25 & 25,2 & $-30,0$ \\
\hline 59 & $14: 07: 48$ & 24,8548 & 25 & 25,2 & $-30,0$ \\
\hline 60 & $14: 13: 27$ & 24,8683 & 25 & 25,2 & $-30,0$ \\
\hline 61 & $14: 19: 00$ & 29,6892 & 29,8 & 30 & $-30,0$ \\
\hline 62 & $14: 20: 12$ & 29,7220 & 29,8 & 30 & $-30,0$ \\
\hline 63 & $14: 21: 27$ & 29,6811 & 29,8 & 30 & $-30,0$ \\
\hline 64 & $14: 22: 16$ & 29,6966 & 29,8 & 30 & $-30,0$ \\
\hline 65 & $14: 23: 07$ & 29,6985 & 29,8 & 30 & $-30,0$ \\
\hline & & & & & \\
\hline
\end{tabular}


Resultados Experimentais $\left(\zeta=-30^{\circ}\right)$

(conclusão)

\begin{tabular}{|c|c|c|c|c|c|}
\hline 66 & $14: 23: 58$ & 29,6841 & 29,8 & 30 & $-30,0$ \\
\hline 67 & $14: 25: 04$ & 29,6882 & 29,8 & 30 & $-30,0$ \\
\hline 68 & $14: 25: 57$ & 29,6942 & 29,8 & 30 & $-30,0$ \\
\hline 69 & $14: 26: 45$ & 29,6955 & 29,8 & 30 & $-30,0$ \\
\hline 70 & $14: 27: 36$ & 29,6878 & 29,8 & 30 & $-30,0$ \\
\hline 71 & $14: 30: 11$ & 39,9113 & 39,6 & 40 & $-30,0$ \\
\hline 72 & $14: 31: 03$ & 39,4178 & 39,6 & 40 & $-30,0$ \\
\hline 73 & $14: 31: 55$ & 39,3987 & 39,6 & 40 & $-30,0$ \\
\hline 74 & $14: 34: 33$ & 39,4041 & 39,6 & 40 & $-30,0$ \\
\hline 75 & $14: 35: 23$ & 39,3936 & 39,6 & 40 & $-30,0$ \\
\hline 76 & $14: 36: 22$ & 39,3831 & 39,6 & 40 & $-30,0$ \\
\hline 77 & $14: 37: 09$ & 39,3908 & 39,6 & 40 & $-30,0$ \\
\hline 78 & $14: 37: 57$ & 39,3831 & 39,6 & 40 & $-30,0$ \\
\hline 79 & $14: 38: 47$ & 39,3906 & 39,6 & 40 & $-30,0$ \\
\hline 80 & $14: 39: 43$ & 39,3582 & 39,6 & 40 & $-30,0$ \\
\hline 81 & $14: 46: 17$ & 49,6258 & 49,8 & 50,2 & $-30,0$ \\
\hline 82 & $14: 47: 07$ & 49,6525 & 49,8 & 50,2 & $-30,0$ \\
\hline 83 & $14: 47: 54$ & 49,6260 & 49,8 & 50,2 & $-30,0$ \\
\hline 84 & $14: 49: 13$ & 49,5863 & 49,8 & 50,2 & $-30,0$ \\
\hline 85 & $14: 50: 15$ & 49,6195 & 49,8 & 50,2 & $-30,0$ \\
\hline 86 & $14: 52: 23$ & 49,6413 & 49,8 & 50,2 & $-30,0$ \\
\hline 87 & $14: 53: 15$ & 49,6476 & 49,8 & 50,2 & $-30,0$ \\
\hline 88 & $14: 54: 16$ & 49,5854 & 49,8 & 50,2 & $-30,0$ \\
\hline 89 & $14: 55: 07$ & 49,6160 & 49,8 & 50,2 & $-30,0$ \\
\hline 90 & $14: 55: 57$ & 49,6029 & 49,8 & 50,2 & $-30,0$ \\
\hline 91 & $14: 58: 16$ & 59,1752 & 59,6 & 60 & $-30,0$ \\
\hline 92 & $14: 59: 19$ & 59,1650 & 59,6 & 60 & $-30,0$ \\
\hline 93 & $15: 00: 05$ & 59,1683 & 59,6 & 60 & $-30,0$ \\
\hline 94 & $15: 02: 25$ & 59,1980 & 59,6 & 60 & $-30,0$ \\
\hline 95 & $15: 03: 15$ & 59,1582 & 59,6 & 60 & $-30,0$ \\
\hline 96 & $15: 04: 21$ & 59,5054 & 59,6 & 60 & $-30,0$ \\
\hline 97 & $15: 05: 06$ & 59,2067 & 59,6 & 60 & $-30,0$ \\
\hline 98 & $15: 05: 56$ & 59,1813 & 59,6 & 60 & $-30,0$ \\
\hline 100 & $15: 06: 50$ & 59,1895 & 59,6 & 60 & $-30,0$ \\
\hline 99 & $15: 07: 52$ & 59,2162 & 59,6 & 60 & $-30,0$ \\
\hline
\end{tabular}


Tabela 27 - Dados dos ensaios referentes a $\zeta=0^{\circ}$

\begin{tabular}{|c|c|c|c|c|c|}
\hline \multirow[b]{2}{*}{$\begin{array}{c}\text { Identificação } \\
\text { de ensaio }\end{array}$} & \multicolumn{3}{|c|}{ Resultados Experimentais $\left(\zeta=0^{\circ}\right)$} & \multicolumn{2}{|c|}{ (continua) } \\
\hline & Horário & $\begin{array}{c}\text { Inclinação } \\
\text { SMET }\end{array}$ & $\begin{array}{l}\text { Inclinação } \\
\text { Inclinômetro }\end{array}$ & $\begin{array}{c}\text { Inclinação } \\
\text { Morsa }\end{array}$ & $\zeta$ \\
\hline 101 & $11: 25: 54$ & 0,9870 & 0,7 & 1 & 0 \\
\hline 102 & $11: 54: 19$ & 0,9818 & 0,7 & 1 & 0 \\
\hline 103 & 11:55:55 & 0,9651 & 0,7 & 1 & 0 \\
\hline 104 & $11: 56: 51$ & 0,9535 & 0,7 & 1 & 0 \\
\hline 105 & $11: 57: 40$ & 0,9775 & 0,7 & 1 & 0 \\
\hline 106 & $11: 58: 38$ & 0,9810 & 0,7 & 1 & 0 \\
\hline 107 & 11:59:30 & 0,9576 & 0,7 & 1 & 0 \\
\hline 108 & $12: 00: 23$ & 0,9909 & 0,7 & 1 & 0 \\
\hline 109 & 12:01:50 & 0,9750 & 0,7 & 1 & 0 \\
\hline 110 & $12: 02: 22$ & 0,9803 & 0,7 & 1 & 0 \\
\hline 111 & $12: 06: 28$ & 5,0258 & 4,8 & 5 & 0 \\
\hline 112 & 12:07:19 & 5,0212 & 4,8 & 5 & 0 \\
\hline 113 & 12:08:03 & 5,0070 & 4,8 & 5 & 0 \\
\hline 114 & 12:08:49 & 5,0264 & 4,8 & 5 & 0 \\
\hline 115 & 12:09:39 & 5,0159 & 4,8 & 5 & 0 \\
\hline 116 & $12: 10: 27$ & 5,0284 & 4,8 & 5 & 0 \\
\hline 117 & $12: 11: 27$ & 4,9953 & 4,8 & 5 & 0 \\
\hline 118 & $12: 12: 22$ & 5,0239 & 4,8 & 5 & 0 \\
\hline 119 & $12: 13: 05$ & 5,0153 & 4,8 & 5 & 0 \\
\hline 120 & $12: 13: 52$ & 4,9816 & 4,8 & 5 & 0 \\
\hline 121 & $12: 17: 21$ & 9,8476 & 9,6 & 10 & 0 \\
\hline 122 & $12: 18: 23$ & 9,8366 & 9,6 & 10 & 0 \\
\hline 123 & 12:19:10 & 9,8480 & 9,6 & 10 & 0 \\
\hline 124 & 12:20:05 & 9,8670 & 9,6 & 10 & 0 \\
\hline 125 & $12: 20: 52$ & 9,8533 & 9,6 & 10 & 0 \\
\hline 126 & $12: 21: 50$ & 9,8491 & 9,6 & 10 & 0 \\
\hline 127 & $12: 23: 27$ & 9,8394 & 9,6 & 10 & 0 \\
\hline 128 & $12: 24: 11$ & 9,8526 & 9,6 & 10 & 0 \\
\hline 129 & $12: 25: 05$ & 9,8469 & 9,6 & 10 & 0 \\
\hline 130 & $12: 26: 45$ & 9,8523 & 9,6 & 10 & 0 \\
\hline 131 & $12: 30: 14$ & 14,9890 & 14,8 & 15 & 0 \\
\hline 132 & 12:31:02 & 15,0073 & 14,8 & 15 & 0 \\
\hline 133 & $12: 31: 46$ & 15,0211 & 14,8 & 15 & 0 \\
\hline 134 & $12: 32: 33$ & 15,0349 & 14,8 & 15 & 0 \\
\hline 135 & $12: 33: 20$ & 15,0387 & 14,8 & 15 & 0 \\
\hline 136 & $12: 34: 17$ & 15,0242 & 14,8 & 15 & 0 \\
\hline 137 & $12: 35: 15$ & 15,0192 & 14,8 & 15 & 0 \\
\hline
\end{tabular}


Resultados Experimentais $\left(\zeta=0^{\circ}\right)$

(continuação)

\begin{tabular}{|c|c|c|c|c|c|}
\hline 138 & $12: 36: 10$ & 15,0015 & 14,8 & 15 & 0 \\
\hline 139 & $12: 37: 15$ & 15,0136 & 14,8 & 15 & 0 \\
\hline 140 & $12: 38: 36$ & 14,9788 & 14,8 & 15 & 0 \\
\hline 141 & $12: 42: 21$ & 19,7675 & 19,5 & 20 & 0 \\
\hline 142 & $12: 43: 17$ & 19,7632 & 19,5 & 20 & 0 \\
\hline 143 & $12: 44: 06$ & 19,7471 & 19,5 & 20 & 0 \\
\hline 144 & $12: 45: 15$ & 19,7449 & 19,5 & 20 & 0 \\
\hline 145 & $12: 45: 54$ & 19,7611 & 19,5 & 20 & 0 \\
\hline 146 & $12: 46: 36$ & 19,7619 & 19,5 & 20 & 0 \\
\hline 147 & $12: 47: 19$ & 19,7548 & 19,5 & 20 & 0 \\
\hline 148 & $12: 48: 01$ & 19,7465 & 19,5 & 20 & 0 \\
\hline 149 & $12: 48: 54$ & 19,7416 & 19,5 & 20 & 0 \\
\hline 150 & $12: 49: 48$ & 19,7473 & 19,5 & 20 & 0 \\
\hline 151 & $12: 53: 33$ & 24,8597 & 24,5 & 25 & 0 \\
\hline 152 & $12: 54: 16$ & 24,8336 & 24,5 & 25 & 0 \\
\hline 153 & $12: 55: 03$ & 24,8508 & 24,5 & 25 & 0 \\
\hline 154 & $12: 55: 49$ & 24,8497 & 24,5 & 25 & 0 \\
\hline 155 & $12: 56: 56$ & 24,8498 & 24,5 & 25 & 0 \\
\hline 156 & $12: 57: 49$ & 24,8134 & 24,5 & 25 & 0 \\
\hline 157 & $12: 58: 31$ & 24,8348 & 24,5 & 25 & 0 \\
\hline 158 & $12: 59: 19$ & 24,8514 & 24,5 & 25 & 0 \\
\hline 159 & 13:00:18 & 24,8162 & 24,5 & 25 & 0 \\
\hline 160 & 13:01:04 & 24,8387 & 24,5 & 25 & 0 \\
\hline 161 & $14: 13: 18$ & 29,8773 & 29,6 & 30 & 0 \\
\hline 162 & $14: 14: 25$ & 29,8723 & 29,6 & 30 & 0 \\
\hline 163 & $14: 15: 13$ & 29,8846 & 29,6 & 30 & 0 \\
\hline 164 & $14: 16: 03$ & 29,8732 & 29,6 & 30 & 0 \\
\hline 165 & $14: 17: 12$ & 29,8819 & 29,6 & 30 & 0 \\
\hline 166 & 14:18:01 & 29,8937 & 29,6 & 30 & 0 \\
\hline 167 & $14: 18: 41$ & 29,8840 & 29,6 & 30 & 0 \\
\hline 168 & $14: 19: 20$ & 29,8763 & 29,6 & 30 & 0 \\
\hline 169 & $14: 20: 28$ & 29,8854 & 29,6 & 30 & 0 \\
\hline 170 & $14: 21: 26$ & 29,8754 & 29,6 & 30 & 0 \\
\hline 171 & $14: 24: 19$ & 39,7970 & 39,5 & 40 & 0 \\
\hline 172 & $14: 25: 19$ & 39,8161 & 39,5 & 40 & 0 \\
\hline 173 & $14: 26: 10$ & 39,8090 & 39,5 & 40 & 0 \\
\hline 174 & $14: 26: 50$ & 39,8452 & 39,5 & 40 & 0 \\
\hline 175 & $14: 27: 30$ & 39,8152 & 39,5 & 40 & 0 \\
\hline 176 & $14: 28: 18$ & 39,8182 & 39,5 & 40 & 0 \\
\hline 177 & $14: 29: 00$ & 39,8012 & 39,5 & 40 & 0 \\
\hline 178 & $08: 25: 10$ & 39,9124 & 39,5 & 40 & 0 \\
\hline 179 & 08:26:04 & 39,9020 & 39,5 & 40 & 0 \\
\hline 180 & 08:26:56 & 39,8934 & 39,5 & 40 & 0 \\
\hline
\end{tabular}




\begin{tabular}{|c|c|c|c|c|c|}
\hline \multicolumn{7}{|c}{ Resultados Experimentais $\left(\zeta=0^{\circ}\right)$} & 50 & 0 \\
\hline 181 & $08: 30: 07$ & 50,0431 & 49,5 & 50 & 0 \\
\hline 182 & $08: 30: 59$ & 50,0357 & 49,5 & 50 & 0 \\
\hline 183 & $08: 31: 50$ & 50,0204 & 49,5 & 50 & 0 \\
\hline 184 & $08: 32: 35$ & 50,0645 & 49,5 & 50 & 0 \\
\hline 185 & $08: 33: 31$ & 50,0532 & 49,5 & 50 & 0 \\
\hline 186 & $08: 34: 47$ & 50,0219 & 49,5 & 50 & 0 \\
\hline 187 & $08: 35: 32$ & 50,0172 & 49,5 & 50 & 0 \\
\hline 188 & $08: 36: 59$ & 50,0203 & 49,5 & 50 & 0 \\
\hline 189 & $08: 37: 53$ & 50,0457 & 49,5 & 50 & 0 \\
\hline 190 & $08: 38: 45$ & 50,0022 & 49,5 & 60 & 0 \\
\hline 191 & $08: 42: 32$ & 59,9399 & 59,4 & 60 & 0 \\
\hline 192 & $08: 43: 19$ & 59,9505 & 59,4 & 60 & 0 \\
\hline 193 & $08: 44: 10$ & 59,5957 & 59,4 & 60 & 0 \\
\hline 194 & $08: 45: 25$ & 59,9627 & 59,4 & 60 & 0 \\
\hline 195 & $08: 46: 08$ & 59,9538 & 59,4 & 60 & 0 \\
\hline 196 & $08: 46: 58$ & 59,9346 & 59,4 & 60 & 0 \\
\hline 197 & $08: 47: 59$ & 59,9440 & 59,4 & 60 & 0 \\
\hline 198 & $08: 48: 43$ & 59,9464 & 59,4 & 60 & 0 \\
\hline 199 & $08: 49: 26$ & 59,9327 & 59,4 & & 0 \\
\hline 200 & $08: 50: 15$ & 59,8833 & 59,4 & & 60 \\
\hline
\end{tabular}

Tabela 28 - Dados dos ensaios referentes a $\zeta=90^{\circ}$

\begin{tabular}{|c|c|c|c|c|c|}
\hline \multicolumn{5}{c}{} & \multicolumn{2}{c}{ Resultados Experimentais $\left(\zeta=90^{\circ}\right)$} & \multicolumn{3}{c|}{ (continua) } \\
$\begin{array}{c}\text { Identificação } \\
\text { de ensaio }\end{array}$ & Horário & $\begin{array}{c}\text { Inclinação } \\
\text { SMET }\end{array}$ & $\begin{array}{c}\text { Inclinação } \\
\text { Inclinômetro }\end{array}$ & $\begin{array}{c}\text { Inclinação } \\
\text { Morsa }\end{array}$ & $\zeta$ \\
\hline 201 & $12: 46: 53$ & 0,9980 & 0,7 & 1,0 & 90 \\
\hline 202 & $12: 47: 52$ & 0,9964 & 0,7 & 1,0 & 90 \\
\hline 203 & $12: 48: 43$ & 0,9708 & 0,7 & 1,0 & 90 \\
\hline 204 & $12: 49: 26$ & 0,9851 & 0,7 & 1,0 & 90 \\
\hline 205 & $12: 50: 19$ & 0,9936 & 0,7 & 1,0 & 90 \\
\hline 206 & $12: 51: 02$ & 0,9792 & 0,7 & 1,0 & 90 \\
\hline 207 & $12: 51: 44$ & 0,9955 & 0,7 & 1,0 & 90 \\
\hline 208 & $12: 52: 22$ & 0,9867 & 0,7 & 1,0 & 90 \\
\hline 209 & $12: 53: 00$ & 0,9870 & 0,7 & 1,0 & 90 \\
\hline 210 & $12: 53: 38$ & 0,9819 & 0,7 & 1,0 & 90 \\
\hline 211 & $12: 56: 01$ & 4,9177 & 4,8 & 5,0 & 90 \\
\hline 212 & $12: 56: 42$ & 4,9344 & 4,8 & 5,0 & 90 \\
\hline 213 & $12: 57: 21$ & 4,9128 & 4,8 & 5,0 & 90 \\
\hline 214 & $12: 58: 01$ & 4,4348 & 4,8 & 5,0 & 90 \\
\hline 215 & $12: 58: 41$ & 4,9298 & 4,8 & 5,0 & 90 \\
\hline 216 & $12: 59: 22$ & 4,9363 & 4,8 & 5,0 & 90 \\
\hline 217 & $13: 00: 01$ & 4,9271 & 4,8 & 5,0 & 90 \\
\hline
\end{tabular}




\begin{tabular}{|c|c|c|c|c|c|}
\hline & \multicolumn{3}{|c|}{ Resultados Experimentais $\left(\zeta=90^{\circ}\right)$} & \multicolumn{2}{|c|}{ (continuação) } \\
\hline 218 & $13: 00: 41$ & 4,9187 & 4,8 & 5,0 & 90 \\
\hline 219 & 13:01:20 & 4,9138 & 4,8 & 5,0 & 90 \\
\hline 220 & 13:01:59 & 4,9411 & 4,8 & 5,0 & 90 \\
\hline 221 & $13: 05: 23$ & 9,8604 & 9,7 & 10,0 & 90 \\
\hline 222 & 13:06:08 & 9,8488 & 9,7 & 10,0 & 90 \\
\hline 223 & 13:06:51 & 9,8507 & 9,7 & 10,0 & 90 \\
\hline 224 & $13: 07: 36$ & 9,8695 & 9,7 & 10,0 & 90 \\
\hline 225 & 13:08:14 & 9,8487 & 9,7 & 10,0 & 90 \\
\hline 226 & 13:09:11 & 9,8431 & 9,7 & 10,0 & 90 \\
\hline 227 & $13: 09: 50$ & 8,8648 & 9,7 & 10,0 & 90 \\
\hline 228 & $13: 10: 29$ & 9,8525 & 9,7 & 10,0 & 90 \\
\hline 229 & 13:11:08 & 9,8496 & 9,7 & 10,0 & 90 \\
\hline 230 & $13: 11: 51$ & 9,8519 & 9,7 & 10,0 & 90 \\
\hline 231 & $13: 14: 28$ & 14,8485 & 14,7 & 15,0 & 90 \\
\hline 232 & $13: 15: 21$ & 14,8297 & 14,7 & 15,0 & 90 \\
\hline 233 & $13: 16: 36$ & 14,8429 & 14,7 & 15,0 & 90 \\
\hline 234 & $13: 17: 16$ & 14,8484 & 14,7 & 15,0 & 90 \\
\hline 235 & $13: 17: 57$ & 14,8563 & 14,7 & 15,0 & 90 \\
\hline 236 & $13: 19: 50$ & 14,8419 & 14,7 & 15,0 & 90 \\
\hline 237 & $13: 20: 48$ & 14,8495 & 14,7 & 15,0 & 90 \\
\hline 238 & $13: 21: 33$ & 14,8429 & 14,7 & 15,0 & 90 \\
\hline 239 & $13: 22: 48$ & 14,8137 & 14,7 & 15,0 & 90 \\
\hline 240 & $13: 24: 05$ & 14,8402 & 14,7 & 15,0 & 90 \\
\hline 241 & $13: 28: 02$ & 19,8655 & 19,7 & 20,0 & 90 \\
\hline 242 & $13: 29: 11$ & 19,8929 & 19,7 & 20,0 & 90 \\
\hline 243 & $13: 30: 16$ & 19,8607 & 19,7 & 20,0 & 90 \\
\hline 244 & $13: 31: 20$ & 19,8718 & 19,7 & 20,0 & 90 \\
\hline 245 & $13: 32: 19$ & 19,8624 & 19,7 & 20,0 & 90 \\
\hline 246 & $13: 32: 57$ & 19,8765 & 19,7 & 20,0 & 90 \\
\hline 247 & $13: 33: 37$ & 19,8461 & 19,7 & 20,0 & 90 \\
\hline 248 & $13: 34: 25$ & 19,8660 & 19,7 & 20,0 & 90 \\
\hline 249 & $13: 35: 09$ & 19,8838 & 19,7 & 20,0 & 90 \\
\hline 250 & $13: 36: 04$ & 19,8752 & 19,7 & 20,0 & 90 \\
\hline 251 & $13: 39: 26$ & 24,8816 & 24,6 & 25,0 & 90 \\
\hline 252 & $13: 40: 10$ & 24,8702 & 24,6 & 25,0 & 90 \\
\hline 253 & 13:41:01 & 24,8647 & 24,6 & 25,0 & 90 \\
\hline 254 & $13: 41: 50$ & 24,8772 & 24,6 & 25,0 & 90 \\
\hline 255 & $13: 42: 42$ & 24,8635 & 24,6 & 25,0 & 90 \\
\hline 256 & $13: 43: 28$ & 24,8657 & 24,6 & 25,0 & 90 \\
\hline 257 & $13: 44: 10$ & 24,8574 & 24,6 & 25,0 & 90 \\
\hline 258 & $13: 44: 54$ & 24,8547 & 24,6 & 25,0 & 90 \\
\hline 259 & $13: 45: 35$ & 24,8582 & 24,6 & 25,0 & 90 \\
\hline 260 & $13: 46: 28$ & 24,8555 & 24,6 & 25,0 & 90 \\
\hline
\end{tabular}




\section{Resultados Experimentais $\left(\zeta=90^{\circ}\right)$}

(conclusão)

\begin{tabular}{|c|c|c|c|c|c|}
\hline 261 & $13: 49: 42$ & 29,7603 & 29,5 & 30,0 & 90 \\
\hline 262 & $13: 50: 23$ & 29,7447 & 29,5 & 30,0 & 90 \\
\hline 263 & $13: 51: 13$ & 29,7554 & 29,5 & 30,0 & 90 \\
\hline 264 & $13: 52: 08$ & 29,7464 & 29,5 & 30,0 & 90 \\
\hline 265 & $13: 52: 50$ & 29,7631 & 29,5 & 30,0 & 90 \\
\hline 266 & $13: 53: 32$ & 29,7325 & 29,5 & 30,0 & 90 \\
\hline 267 & $13: 54: 16$ & 29,7471 & 29,5 & 30,0 & 90 \\
\hline 268 & $13: 55: 01$ & 29,7424 & 29,5 & 30,0 & 90 \\
\hline 269 & $13: 55: 51$ & 29,7809 & 29,5 & 30,0 & 90 \\
\hline 270 & $13: 56: 31$ & 29,7440 & 29,5 & 30,0 & 90 \\
\hline 271 & $14: 03: 49$ & 39,8013 & 39,5 & 40,0 & 90 \\
\hline 272 & $14: 04: 35$ & 39,7938 & 39,5 & 40,0 & 90 \\
\hline 273 & $14: 05: 28$ & 39,8100 & 39,5 & 40,0 & 90 \\
\hline 274 & $14: 06: 30$ & 39,7921 & 39,5 & 40,0 & 90 \\
\hline 275 & $14: 07: 27$ & 39,8079 & 39,5 & 40,0 & 90 \\
\hline 276 & $14: 08: 13$ & 39,8267 & 39,5 & 40,0 & 90 \\
\hline 277 & 14:09:01 & 39,7968 & 39,5 & 40,0 & 90 \\
\hline 278 & 14:09:48 & 39,7974 & 39,5 & 40,0 & 90 \\
\hline 279 & $14: 10: 33$ & 39,8773 & 39,5 & 40,0 & 90 \\
\hline 280 & $14: 11: 17$ & 39,8025 & 39,5 & 40,0 & 90 \\
\hline 281 & $14: 14: 12$ & 49,8354 & 49,5 & 50,0 & 90 \\
\hline 282 & $14: 14: 55$ & 49,7961 & 49,5 & 50,0 & 90 \\
\hline 283 & $14: 15: 36$ & 49,8025 & 49,5 & 50,0 & 90 \\
\hline 284 & $14: 16: 24$ & 49,8150 & 49,5 & 50,0 & 90 \\
\hline 285 & $14: 17: 11$ & 49,8236 & 49,5 & 50,0 & 90 \\
\hline 286 & $14: 17: 56$ & 49,8256 & 49,5 & 50,0 & 90 \\
\hline 287 & $14: 18: 44$ & 49,8271 & 49,5 & 50,0 & 90 \\
\hline 288 & $14: 19: 49$ & 49,8159 & 49,5 & 50,0 & 90 \\
\hline 289 & $14: 20: 35$ & 49,8127 & 49,5 & 50,0 & 90 \\
\hline 290 & $14: 21: 28$ & 49,8300 & 49,5 & 50,0 & 90 \\
\hline 291 & $14: 24: 48$ & 59,7064 & 59,3 & 60,0 & 90 \\
\hline 292 & $14: 25: 34$ & 59,7006 & 59,3 & 60,0 & 90 \\
\hline 293 & $14: 26: 22$ & 59,6547 & 59,3 & 60,0 & 90 \\
\hline 294 & $14: 27: 07$ & 59,6897 & 59,3 & 60,0 & 90 \\
\hline 295 & $14: 27: 51$ & 59,6496 & 59,3 & 60,0 & 90 \\
\hline 296 & $14: 28: 31$ & 59,6940 & 59,3 & 60,0 & 90 \\
\hline 297 & 14:29:08 & 59,6964 & 59,3 & 60,0 & 90 \\
\hline 298 & $14: 29: 48$ & 59,6535 & 59,3 & 60,0 & 90 \\
\hline 299 & $14: 30: 27$ & 59,6951 & 59,3 & 60,0 & 90 \\
\hline 300 & $14: 31: 15$ & 59,6784 & 59,3 & 60,0 & 90 \\
\hline
\end{tabular}


Ensaios na Rate Table

Tabela 29 - Baixas velocidades angulares

\section{Ensaios Rate Table (continua)}

Ensaio Velocidade angular [\% $\quad \mathrm{t}$ aquisição [s]

\begin{tabular}{|c|c|c|}
\hline 1 & 14,0000 & 5 \\
\hline 2 & 7,0000 & 10 \\
\hline 3 & 4,6667 & 15 \\
\hline 4 & 14,0000 & 5 \\
\hline 5 & 7,0000 & 10 \\
\hline 6 & 4,6667 & 15 \\
\hline 7 & 5,0000 & 5 \\
\hline 8 & 1,5000 & 10 \\
\hline 9 & 1,0000 & 15 \\
\hline 10 & 5,0000 & 5 \\
\hline 11 & 1,5000 & 10 \\
\hline 12 & 1,0000 & 15 \\
\hline 13 & 1,4000 & 5 \\
\hline 14 & 0,7000 & 10 \\
\hline 15 & 0,4667 & 15 \\
\hline \begin{tabular}{|l|}
16 \\
\end{tabular} & 1,4000 & 5 \\
\hline \begin{tabular}{|l|}
17 \\
\end{tabular} & 0,7000 & 10 \\
\hline \begin{tabular}{|l|}
18 \\
\end{tabular} & 0,4667 & 15 \\
\hline \begin{tabular}{|l|}
19 \\
\end{tabular} & 1,0000 & 5 \\
\hline 20 & 0,5000 & 10 \\
\hline 21 & 0,3333 & 15 \\
\hline 22 & 1,0000 & 5 \\
\hline 23 & 0,5000 & 10 \\
\hline 24 & 0,3333 & 15 \\
\hline 25 & 0,0000 & 5 \\
\hline 26 & 0,0000 & 10 \\
\hline 27 & 0,0000 & 15 \\
\hline 28 & 0,0000 & 5 \\
\hline
\end{tabular}




\begin{tabular}{|c|c|c|}
\hline \multicolumn{3}{|c|}{ Ensaios Rate Table $\quad$ (conclusão) } \\
\hline 29 & 0,0000 & 10 \\
\hline 30 & 0,0000 & 15 \\
\hline 31 & $-1,0000$ & 5 \\
\hline 32 & $-0,5000$ & 10 \\
\hline 33 & $-0,3333$ & 15 \\
\hline 34 & $-1,0000$ & 5 \\
\hline 35 & $-0,5000$ & 10 \\
\hline 36 & $-0,3333$ & 15 \\
\hline 37 & $-1,4000$ & 5 \\
\hline 38 & $-0,7000$ & 10 \\
\hline 39 & $-0,4667$ & 15 \\
\hline 40 & $-1,4000$ & 5 \\
\hline 41 & $-0,7000$ & 10 \\
\hline 42 & $-0,4667$ & 15 \\
\hline 43 & $-3,0000$ & 5 \\
\hline 44 & $-1,5000$ & 10 \\
\hline 45 & $-1,0000$ & 15 \\
\hline 46 & $-3,0000$ & 5 \\
\hline 47 & $-1,5000$ & 10 \\
\hline 48 & $-1,0000$ & 15 \\
\hline 49 & $-6,0000$ & 5 \\
\hline 50 & $-3,0000$ & 10 \\
\hline 51 & $-2,0000$ & 15 \\
\hline 52 & $-6,0000$ & 5 \\
\hline 53 & $-3,0000$ & 10 \\
\hline 54 & $-2,0000$ & 15 \\
\hline 55 & $-14,0000$ & 5 \\
\hline 56 & $-7,0000$ & 10 \\
\hline 57 & $-4,6667$ & 15 \\
\hline 58 & $-14,0000$ & 5 \\
\hline 59 & $-7,0000$ & 10 \\
\hline 60 & $-4,6667$ & 15 \\
\hline
\end{tabular}


Tabela 30 - Altas velocidades angulares

\begin{tabular}{|l|l|l|}
\hline Ensaio & Velocidade angular [\%/s] & $\mathrm{t}$ aquisição [s] \\
\hline 61 & -360 & 10 \\
\hline 62 & -360 & 10 \\
\hline 63 & -180 & 10 \\
\hline 64 & -180 & 10 \\
\hline 65 & -64 & 10 \\
\hline 66 & -64 & 10 \\
\hline 67 & -36 & 10 \\
\hline 68 & -36 & 10 \\
\hline 69 & 36 & 10 \\
\hline 70 & 36 & 10 \\
\hline 71 & 64 & 10 \\
\hline 72 & 64 & 10 \\
\hline 73 & 180 & 10 \\
\hline 74 & 180 & 10 \\
\hline 75 & 360 & 10 \\
\hline 76 & 360 & 10 \\
\hline & & \\
\hline
\end{tabular}

Tabela 31 - Velocidade variando segundo uma senoide

\begin{tabular}{|l|l|l|l|}
\hline Ensaio & Frequência [Hz] & Amplitude [ $\left.{ }^{\circ}\right]$ & $\mathrm{t}$ aquisição [s] \\
\hline 77 & 0,01592 & 45 & 240 \\
\hline 78 & 0,07958 & 45 & 240 \\
\hline 79 & 0,15915 & 45 & 60 \\
\hline 80 & 0,79577 & 45 & 60 \\
\hline 81 & 0,01592 & 45 & 60 \\
\hline 82 & 0,07958 & 45 & 60 \\
\hline 83 & 0,15915 & 45 & 60 \\
\hline 84 & 0,79577 & 45 & 60 \\
\hline 85 & 1,00000 & 45 & 60 \\
\hline 86 & 1,00000 & 45 & 60 \\
\hline
\end{tabular}


Tabela 32 - Repetições da mesma velocidade angular

\begin{tabular}{|l|l|l|}
\hline Ensaio & Velocidade angular [\%/s] & t aquisição [s] \\
\hline 87 & 1,5 & 10 \\
\hline 88 & 1,5 & 10 \\
\hline 89 & 1,5 & 10 \\
\hline 90 & 1,5 & 10 \\
\hline 91 & 1,5 & 10 \\
\hline 92 & 1,5 & 10 \\
\hline 93 & 1,5 & 10 \\
\hline 94 & 1,5 & 10 \\
\hline 95 & 1,5 & 10 \\
\hline 96 & 1,5 & 10 \\
\hline
\end{tabular}




\section{APÊNDice C - Resultados de Todos os Sinals de lançamento DisPoníveIS}

A seguir são apresentadas as tentativas de reconstrução de trajetória de todos os sinais disponíveis. Os gráficos seguem a lógica da Figura 113, ou seja, a primeira figura de cima para baixo exibe o sinal original de acelerações e as retas verticais tracejada mostram o inicio e término da integração; os três gráficos imediatamente abaixo são as estimativas de velocidade no referencial de navegação, submetidos, respectivamente: a nenhuma correção, a correção apenas do bias e a correção do bias e fator de escala. Observar que as correções seguem o procedimento descrito no item 6.4.3; a terceira linha de gráficos apresenta as trajetórias reconstruídas referentes aos três casos de correção dispostos imediatamente acima. Finalmente a tabela apresenta os resultados quantitativos para os parâmetros de interesse obtidos por meio do algoritmo baseado em quatérnios. As identificações I, II e III referem-se as situações de correção descritas anteriormente - nenhuma correção, apenas bias e bias mais fator de escala, respectivamente. 

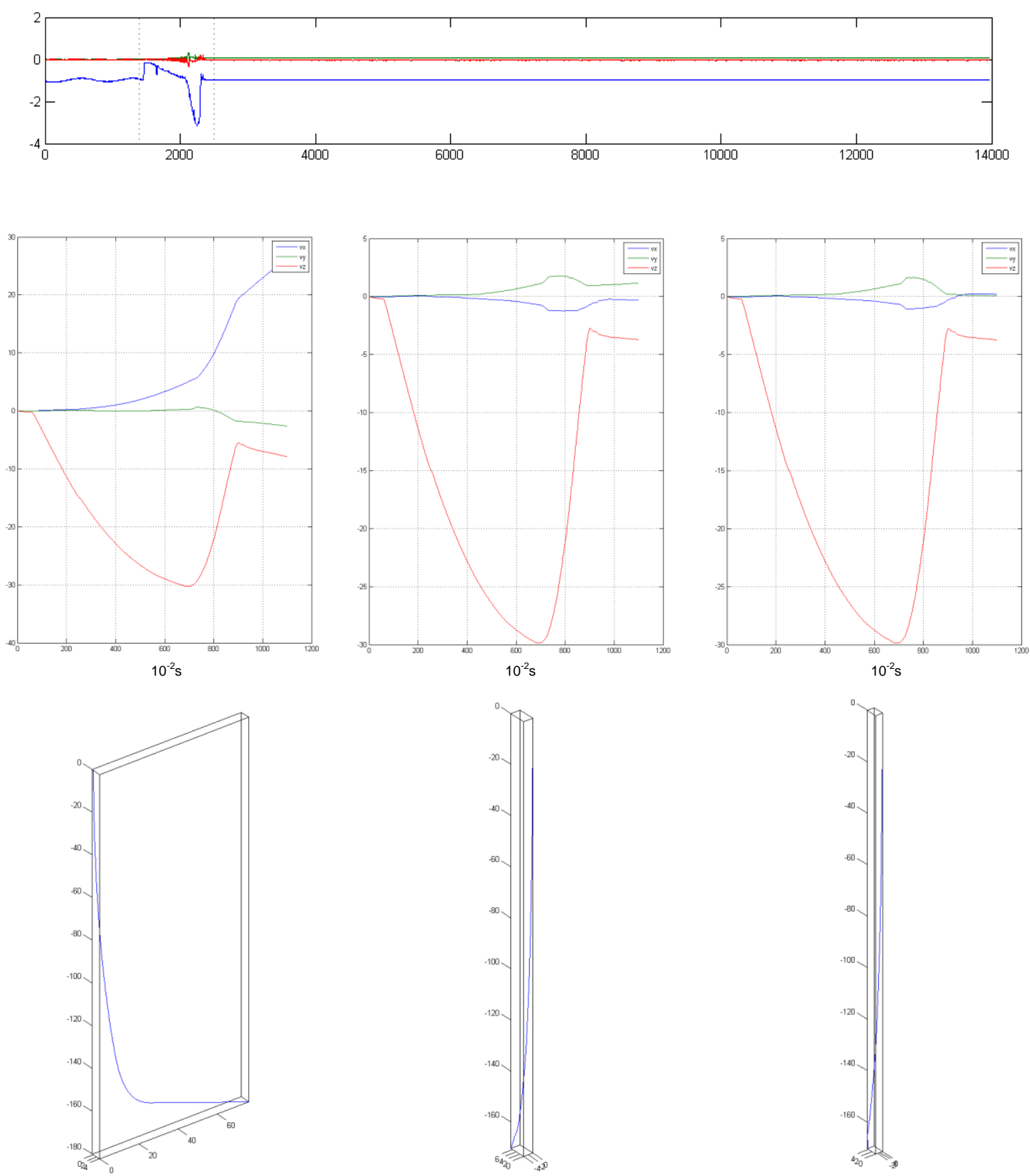

Lançamento 1

SMET ?

data 06/04/2007

\begin{tabular}{|c|c|c|c|c|c|c|c|c|}
\hline \multicolumn{3}{|c|}{ Inclinação $\left[^{\circ}\right]$} & \multicolumn{3}{c|}{ Velocidade Terminal [m/s] } & \multicolumn{3}{c|}{ Azimute $\left.{ }^{\circ}\right]$} \\
I & II & III & I & II & III & I & II & III \\
\hline 26,36 & 3,84 & 4,95 & 30,67 & 29,90 & 29,89 & 77,00 & 36,46 & 41,88 \\
\hline
\end{tabular}



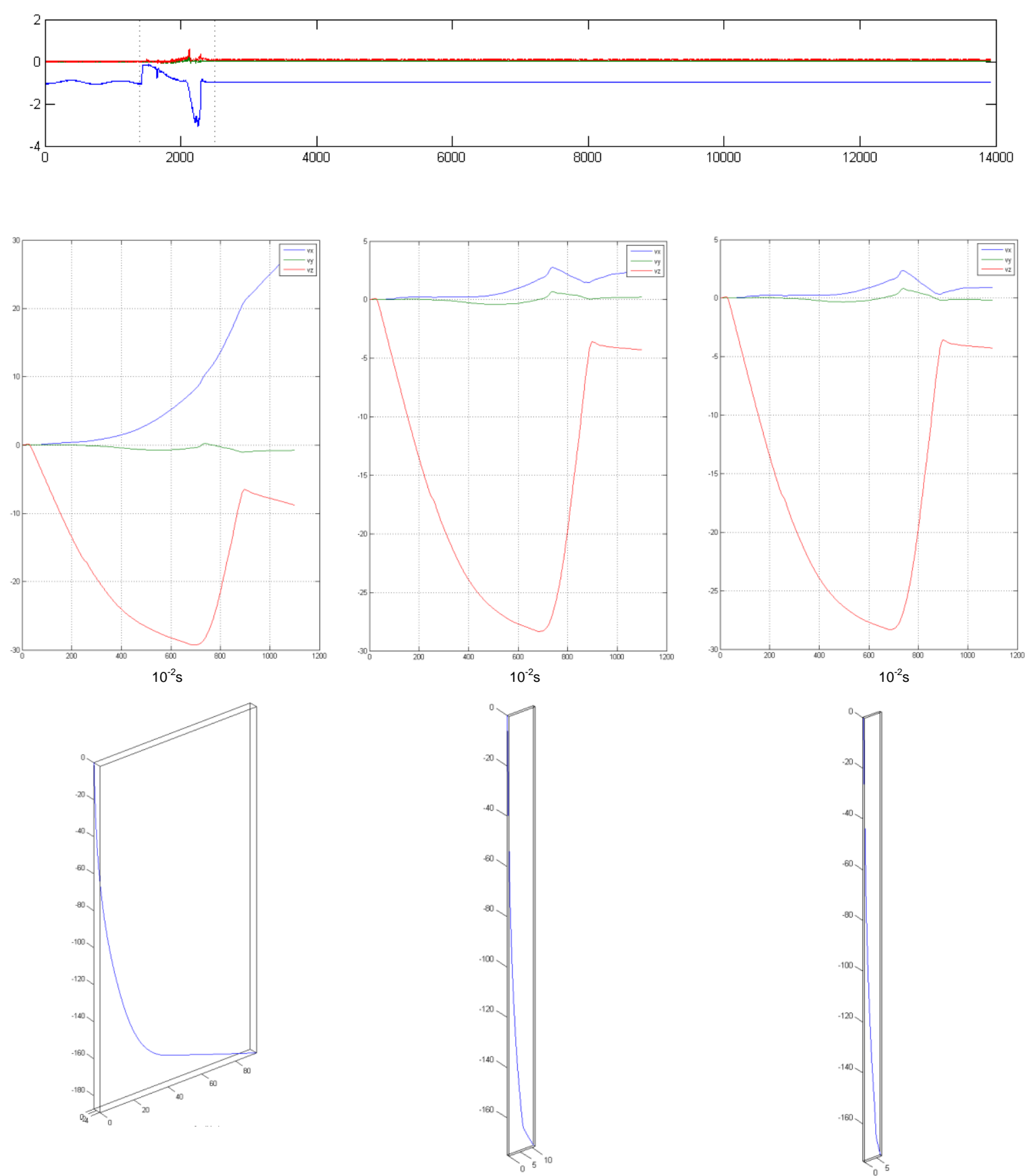

$\begin{array}{ll}\text { Lançamento } & 2 \\ \text { SMET } & ?\end{array}$

data 07/04/2007

\begin{tabular}{|c|c|c|c|c|c|c|c|c|}
\hline \multicolumn{2}{|c}{ Inclinação $\left[{ }^{\circ}\right]$} & \multicolumn{4}{c}{ Velocidade Terminal [m/s] } & \multicolumn{3}{c|}{ Azimute [ $\left.{ }^{\circ}\right]$} \\
I & II & III & I & II & III & I & II & III \\
\hline 20,51 & 4,06 & 5,21 & 30,45 & 28,39 & 28,36 & 46,37 & 283,17 & 279,98 \\
\hline
\end{tabular}



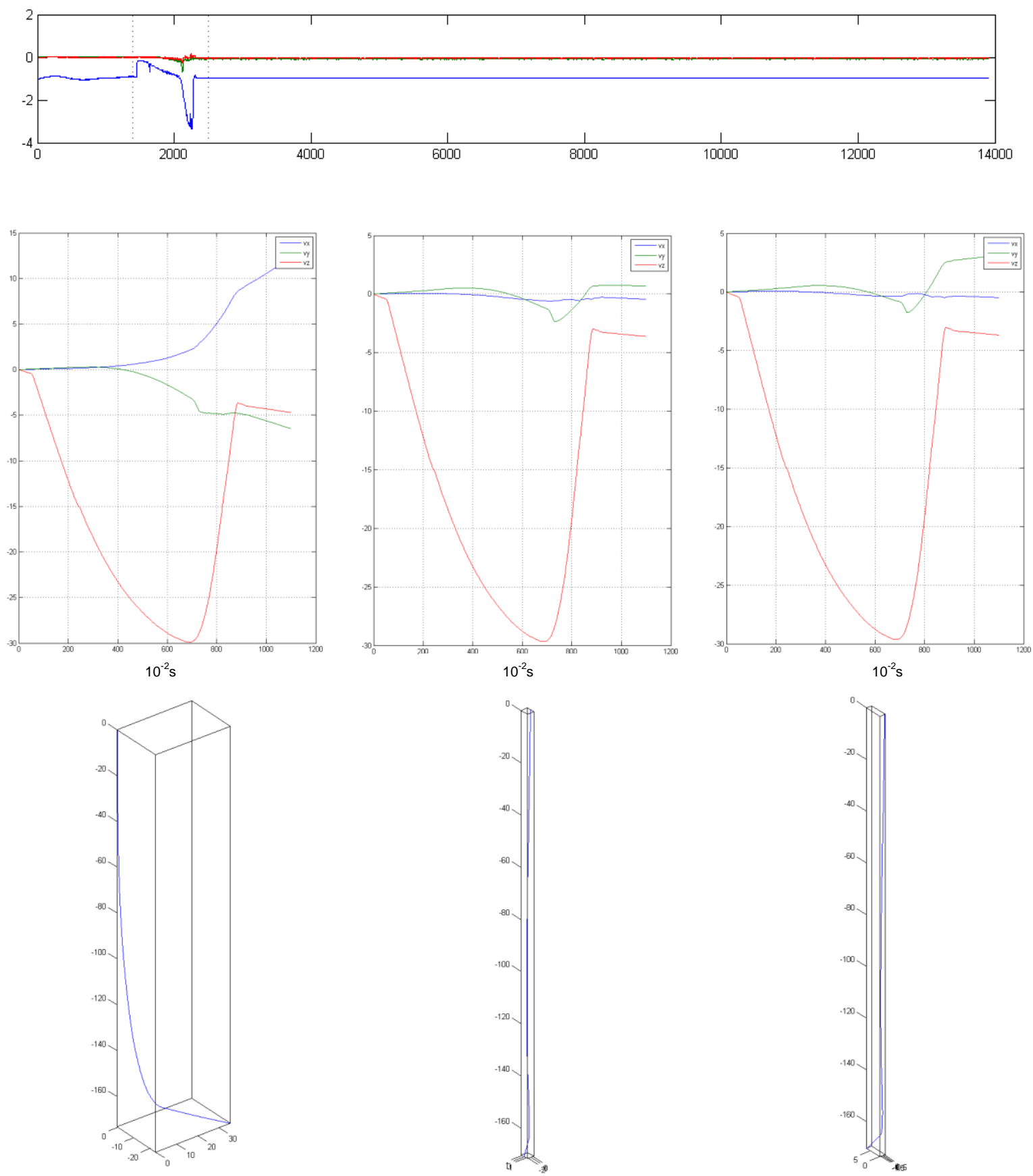

Lançamento 3

SMET 4

data

09/04/2007

\begin{tabular}{|c|c|c|c|c|c|c|c|c|}
\hline \multicolumn{3}{|c|}{ Inclinação [ $\left.{ }^{\circ}\right]$} & \multicolumn{3}{c|}{ Velocidade Terminal [m/s] } & \multicolumn{3}{c|}{ Azimute $\left.{ }^{\circ}\right]$} \\
I & II & III & I & II & III & I & II & III \\
\hline 26,36 & 3,84 & 4,95 & 30,13 & 29,69 & 29,65 & 15,33 & 133,43 & 121,43 \\
\hline
\end{tabular}




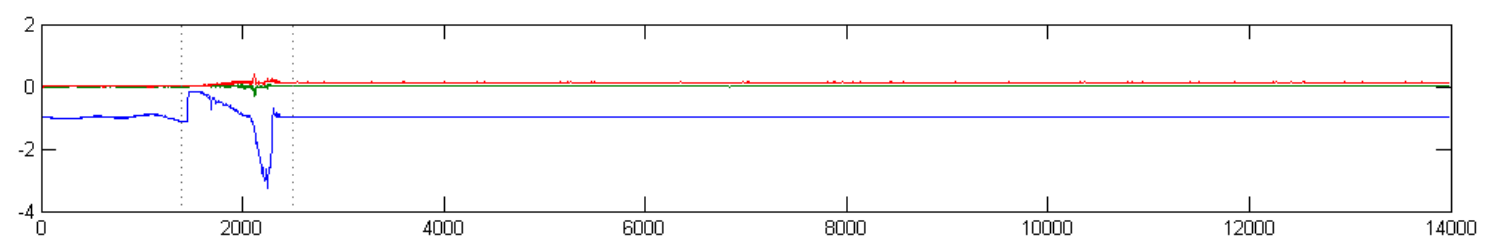

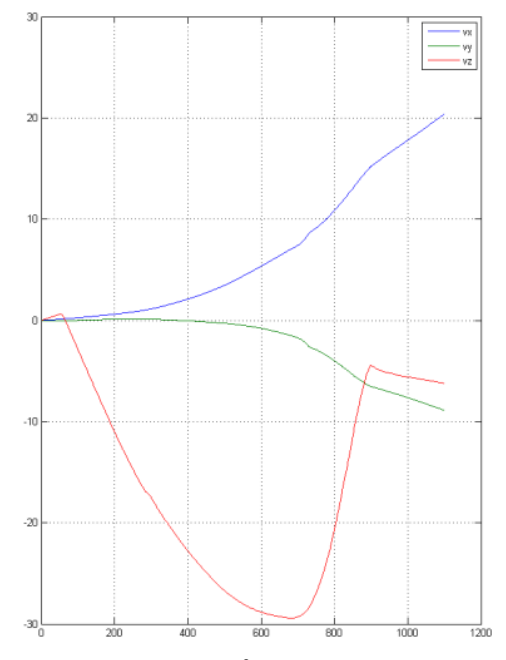

$10^{-2} \mathrm{~s}$

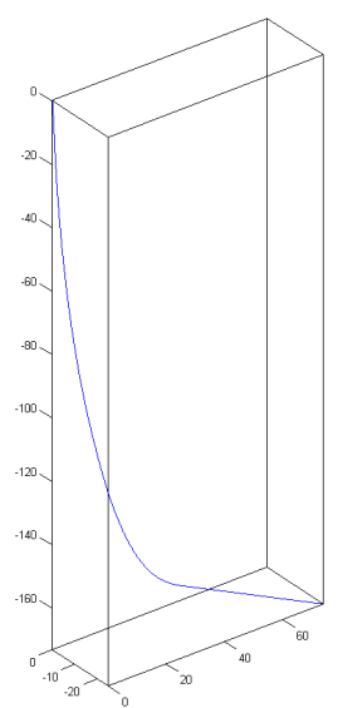

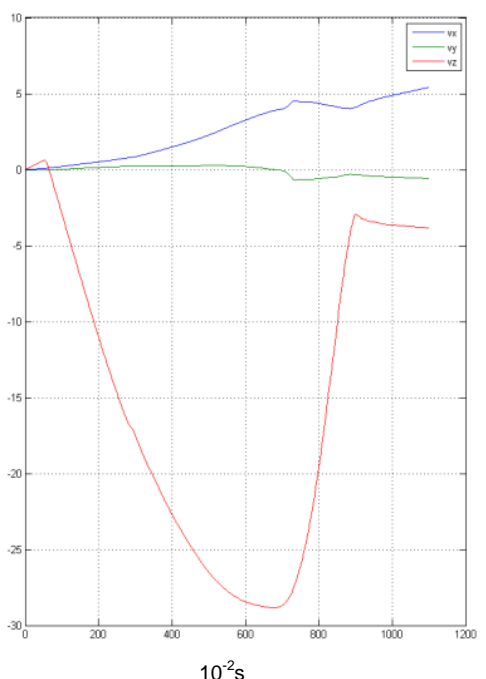

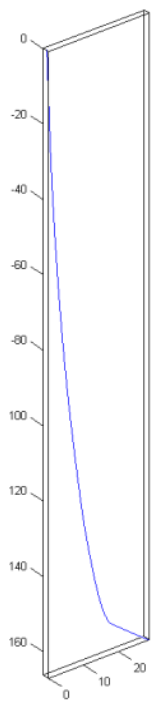

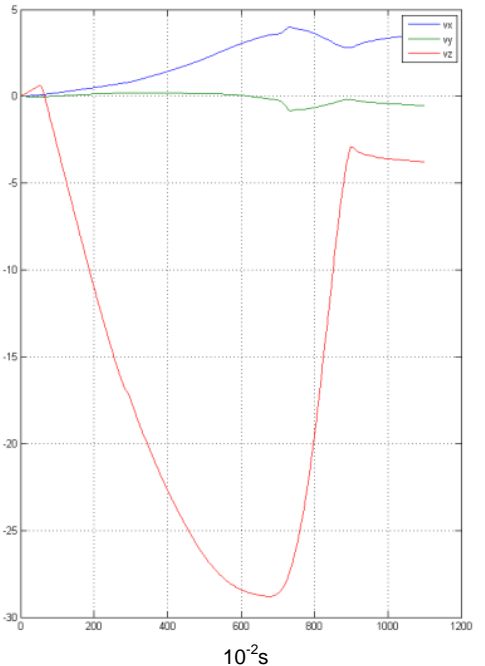

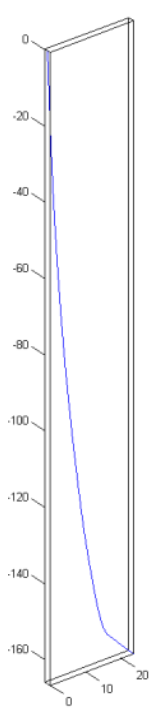

$\begin{array}{lc}\text { Lançamento } & 4 \\ \text { SMET } & 4 \\ \text { data } & \text { 13/04/2007 }\end{array}$ Inclinação [ [ $]$ I II

11,51
Velocidade Terminal [m/s] I II III 30,31 29,11 III 29,03 Azimute $\left[{ }^{\circ}\right]$ \begin{tabular}{l|l}
4,66 & 6,06
\end{tabular} II 

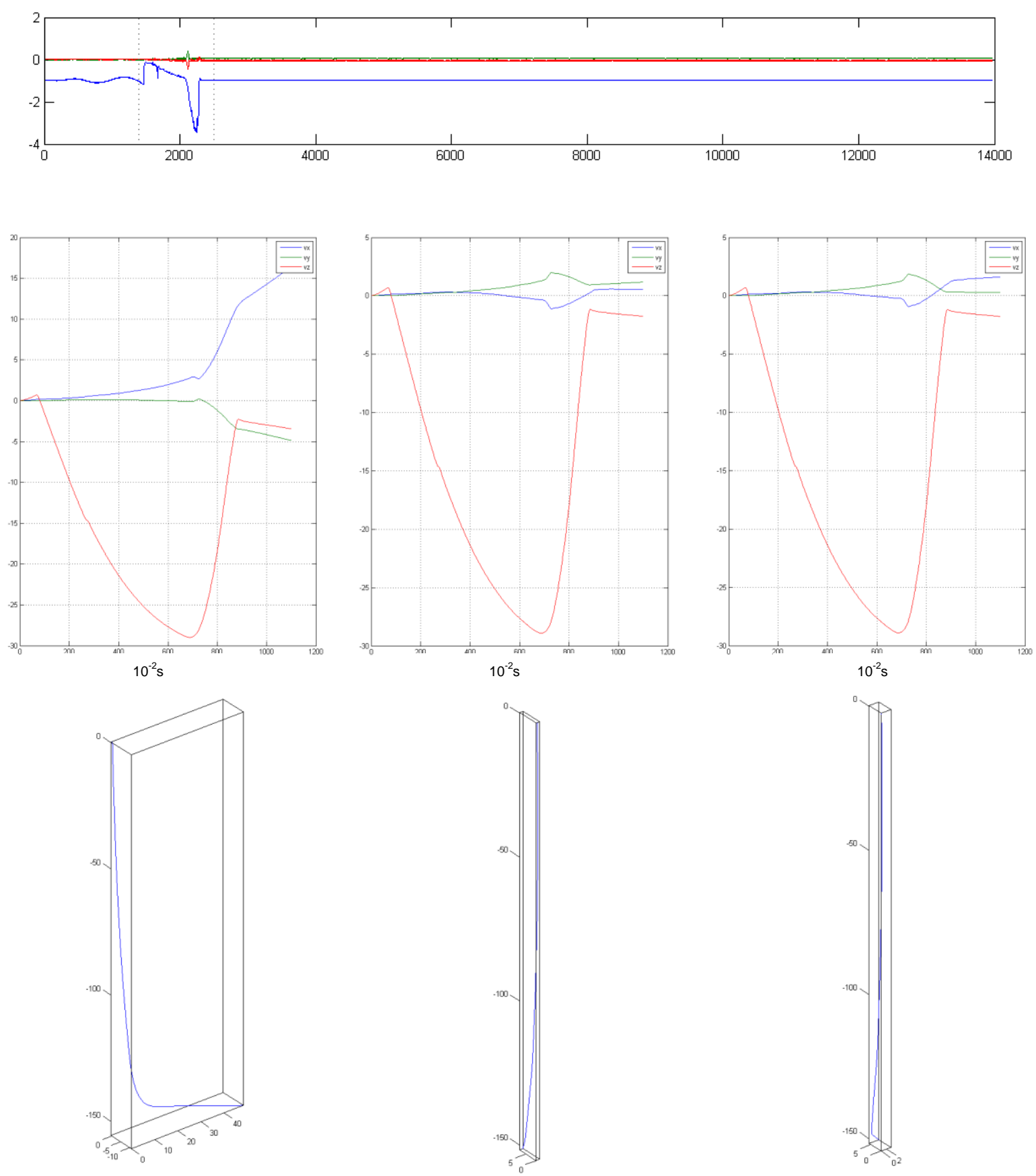

Lançamento 5

SMET

data 14/04/2007

\begin{tabular}{|c|c|c|c|c|c|c|c|c|}
\hline \multicolumn{3}{|c|}{ Inclinação ${ }^{\circ}{ }^{\circ}$} & \multicolumn{3}{c|}{ Velocidade Terminal [m/s] } & \multicolumn{3}{c|}{ Azimute $\left.{ }^{\circ}\right]$} \\
I & II & III & I & II & III & I & II & III \\
\hline 18,81 & 3,94 & 5,11 & 29,12 & 28,93 & 28,92 & 43,83 & 45,34 & 45,53 \\
\hline
\end{tabular}



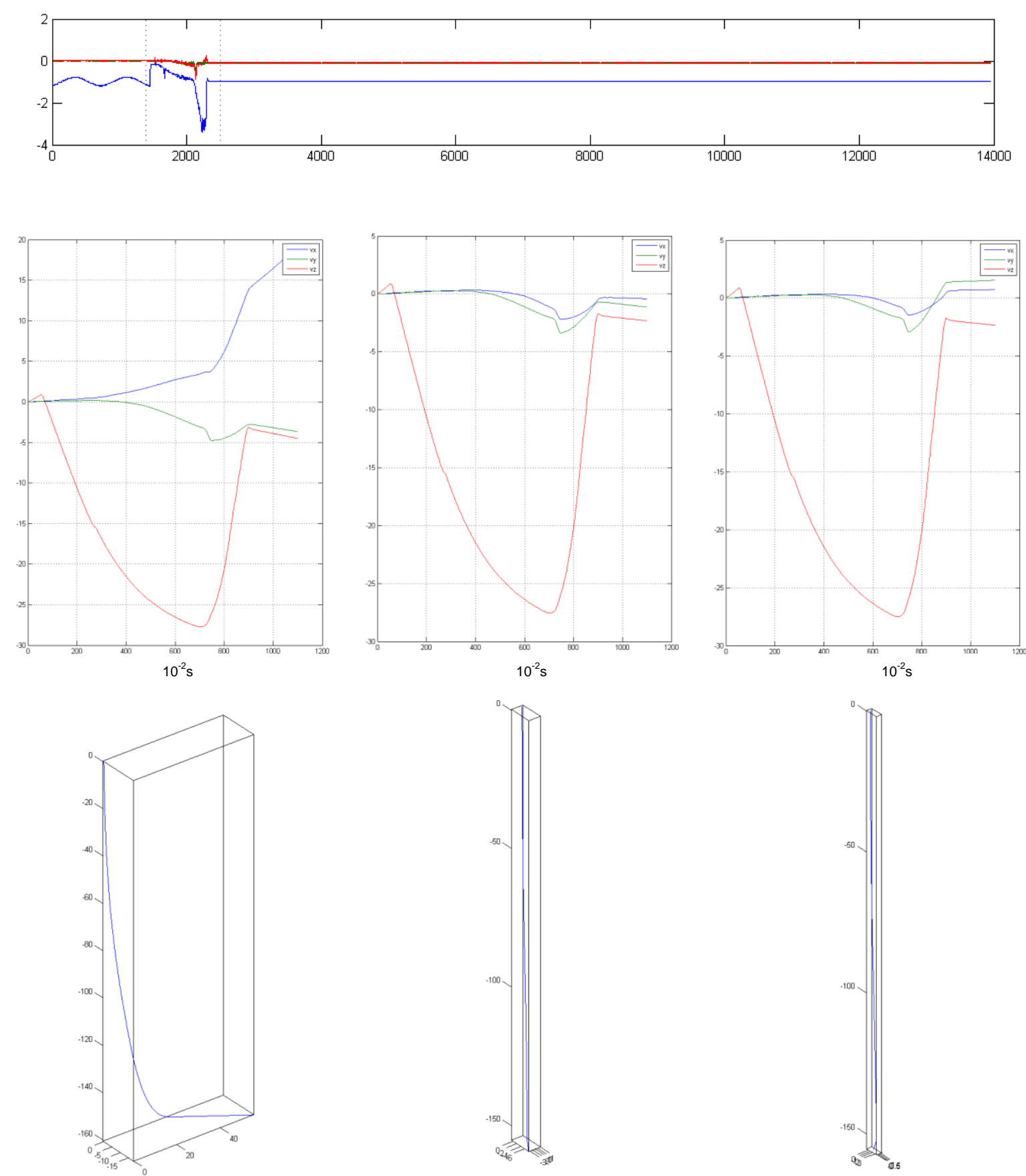

\begin{tabular}{|c|c|c|c|c|c|c|c|c|}
\hline $\begin{array}{l}\text { Lançamento } \\
\text { SMET } \\
\text { data }\end{array}$ & $\begin{array}{c}6 \\
4 \\
5 / 04 / 200 \\
\end{array}$ & & & & & & & \\
\hline \multicolumn{3}{|c|}{ Inclinação $\left[{ }^{\circ}\right]$} & \multicolumn{3}{|c|}{ Velocidade Terminal [m/s] } & \multicolumn{3}{|c|}{ Azimute $\left[{ }^{\circ}\right]$} \\
\hline $\mathbf{I}$ & II & III & I & II & III & I & II & III \\
\hline 19,78 & 6,89 & 8,91 & 28,13 & 27,63 & 27,54 & 48,55 & 122,50 & 118,42 \\
\hline
\end{tabular}



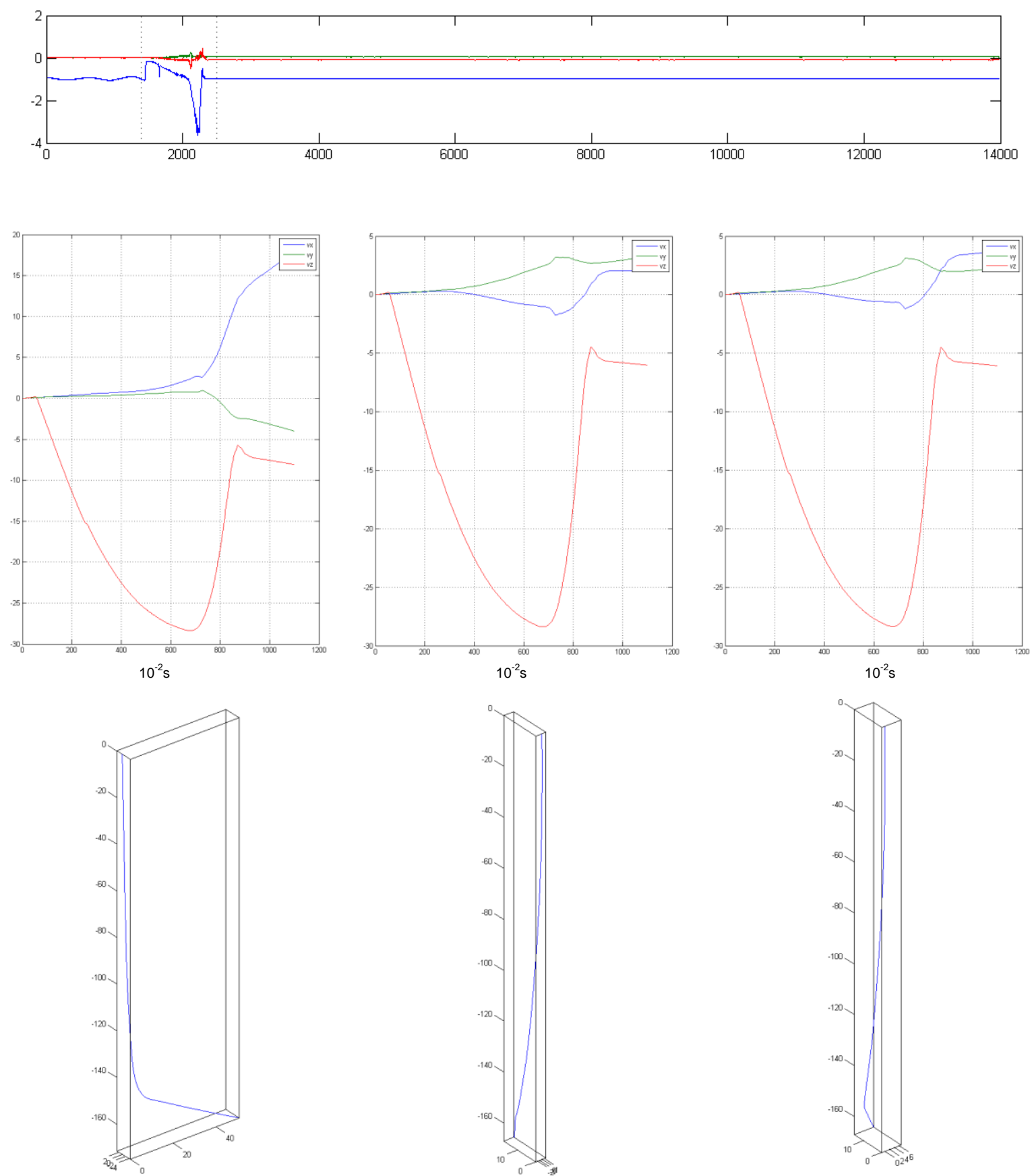

\section{Lançamento 7}

SMET

4

data 16/04/2007

\begin{tabular}{|c|c|c|c|c|c|c|c|c|}
\hline \multicolumn{3}{|c}{ Inclinação [ $\left.{ }^{\circ}\right]$} & \multicolumn{4}{c|}{ Velocidade Terminal [m/s] } & \multicolumn{3}{c|}{ Azimute $\left.{ }^{\circ}\right]$} \\
I & II & III & I & II & III & I & II & III \\
\hline 21,30 & 4,77 & 6,16 & 28,46 & 28,49 & 28,45 & 66,95 & 79,78 & 84,95 \\
\hline
\end{tabular}


260

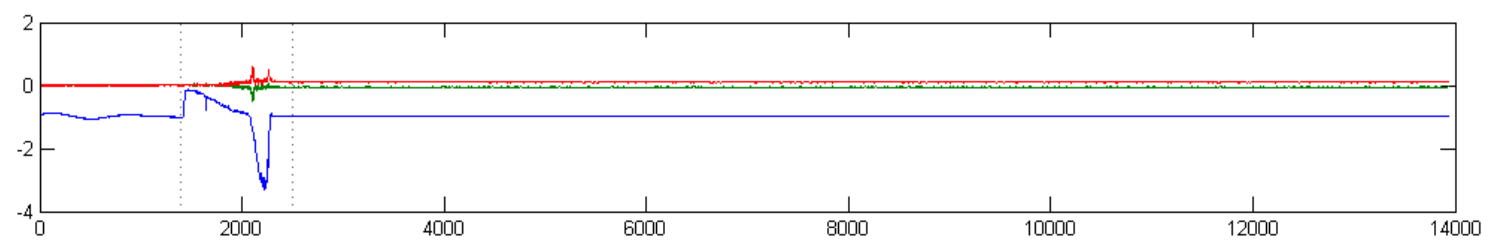

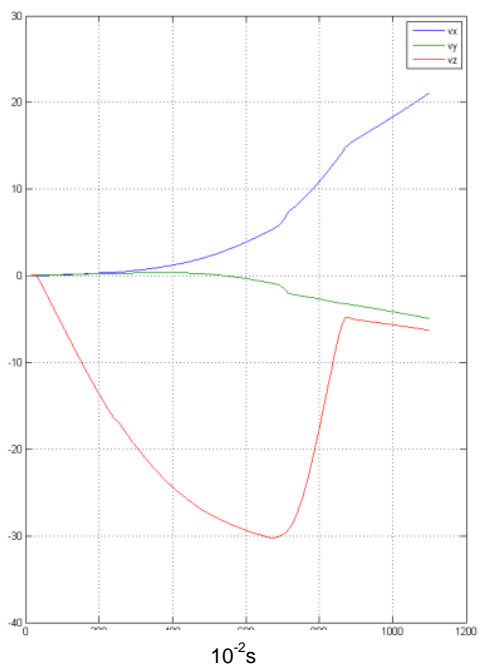

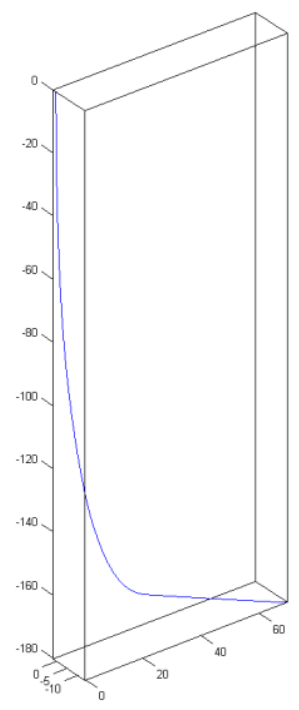

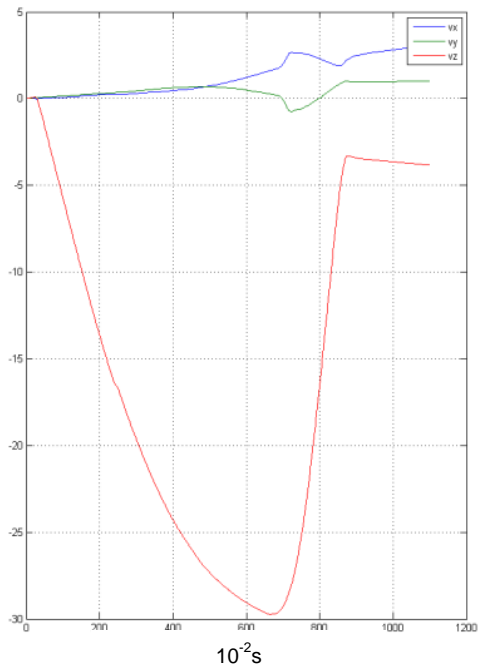

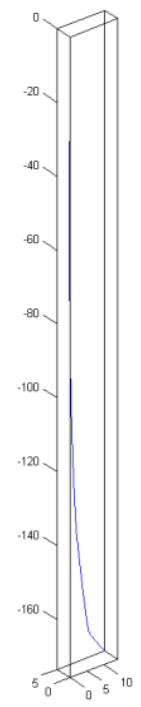

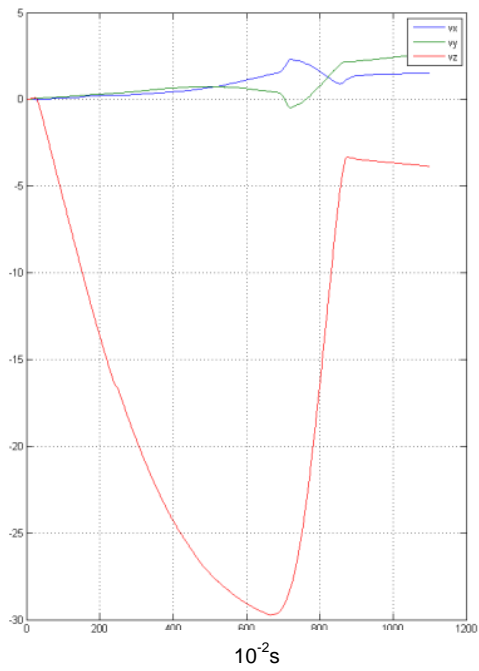

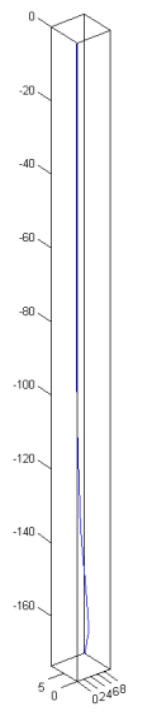

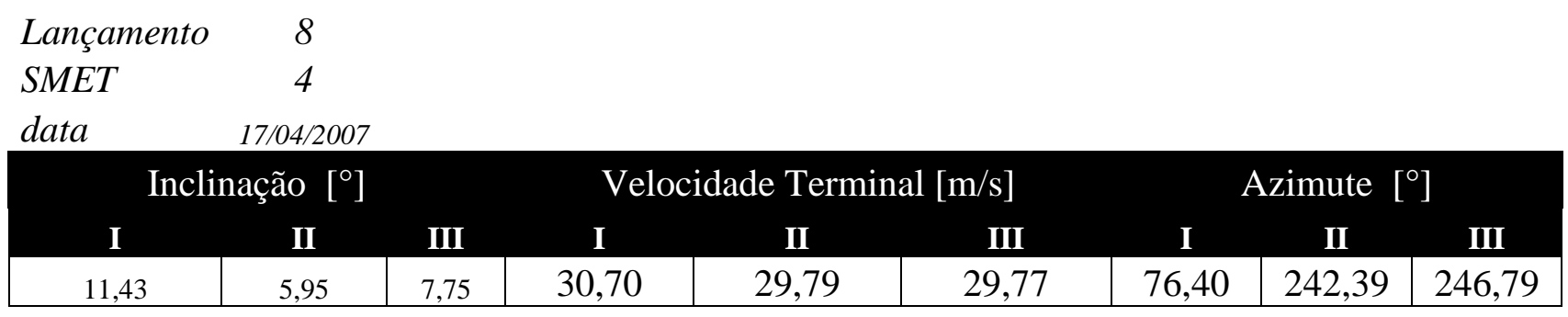



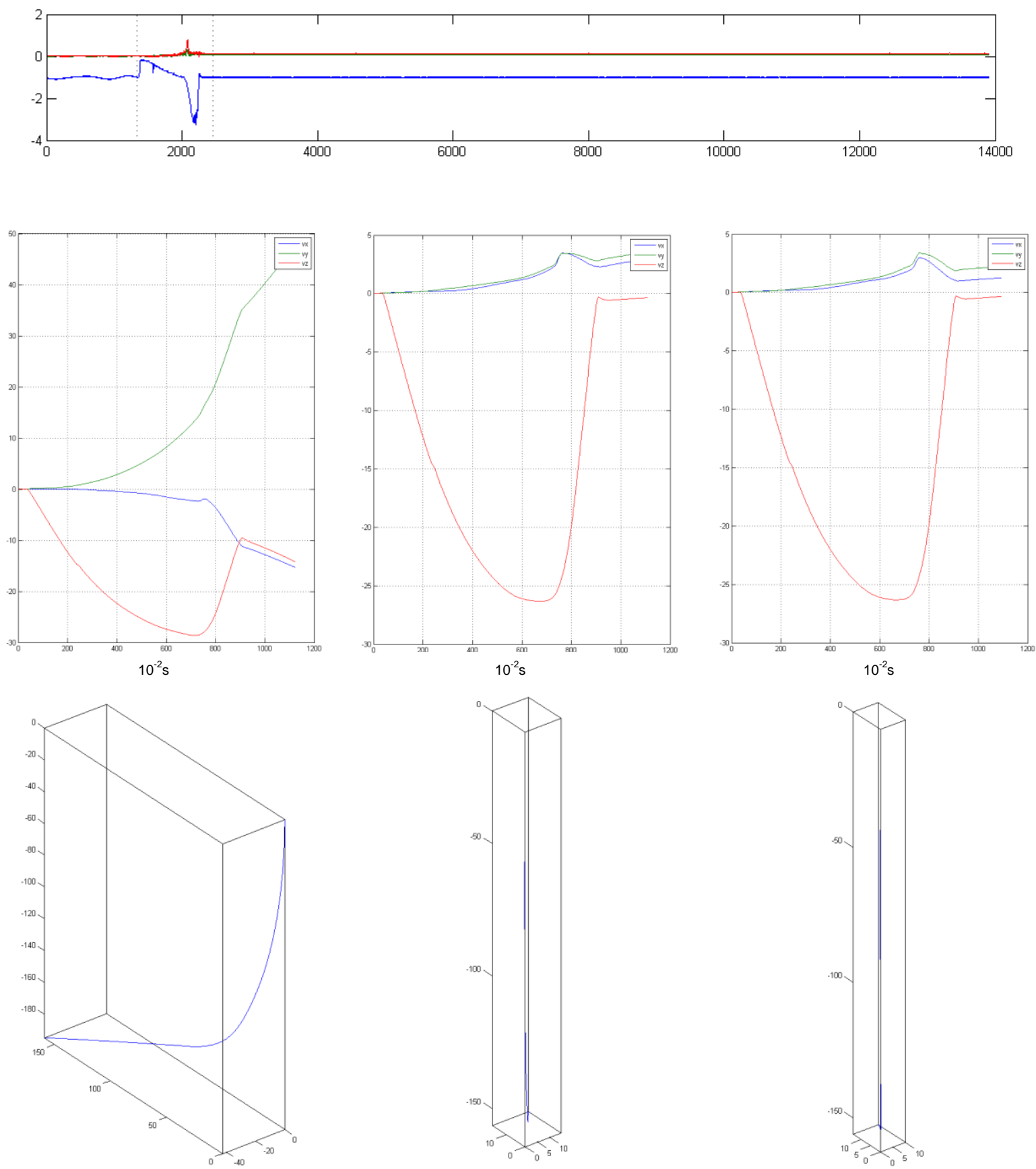

Lançamento 9

SMET 5

data 24/04/2007

\begin{tabular}{|c|c|c|c|c|c|c|c|c|}
\hline \multicolumn{3}{|c}{ Inclinação $\left[{ }^{\circ}\right]$} & \multicolumn{4}{c|}{ Velocidade Terminal [m/s] } & \multicolumn{3}{c|}{ Azimute [ $\left.{ }^{\circ}\right]$} \\
\hline I & II & III & I & II & III & I & II & III \\
\hline 42,28 & 5,80 & 7,54 & 53,13 & 24,47 & 26,42 & 224,66 & 287,04 & 282,16 \\
\hline
\end{tabular}



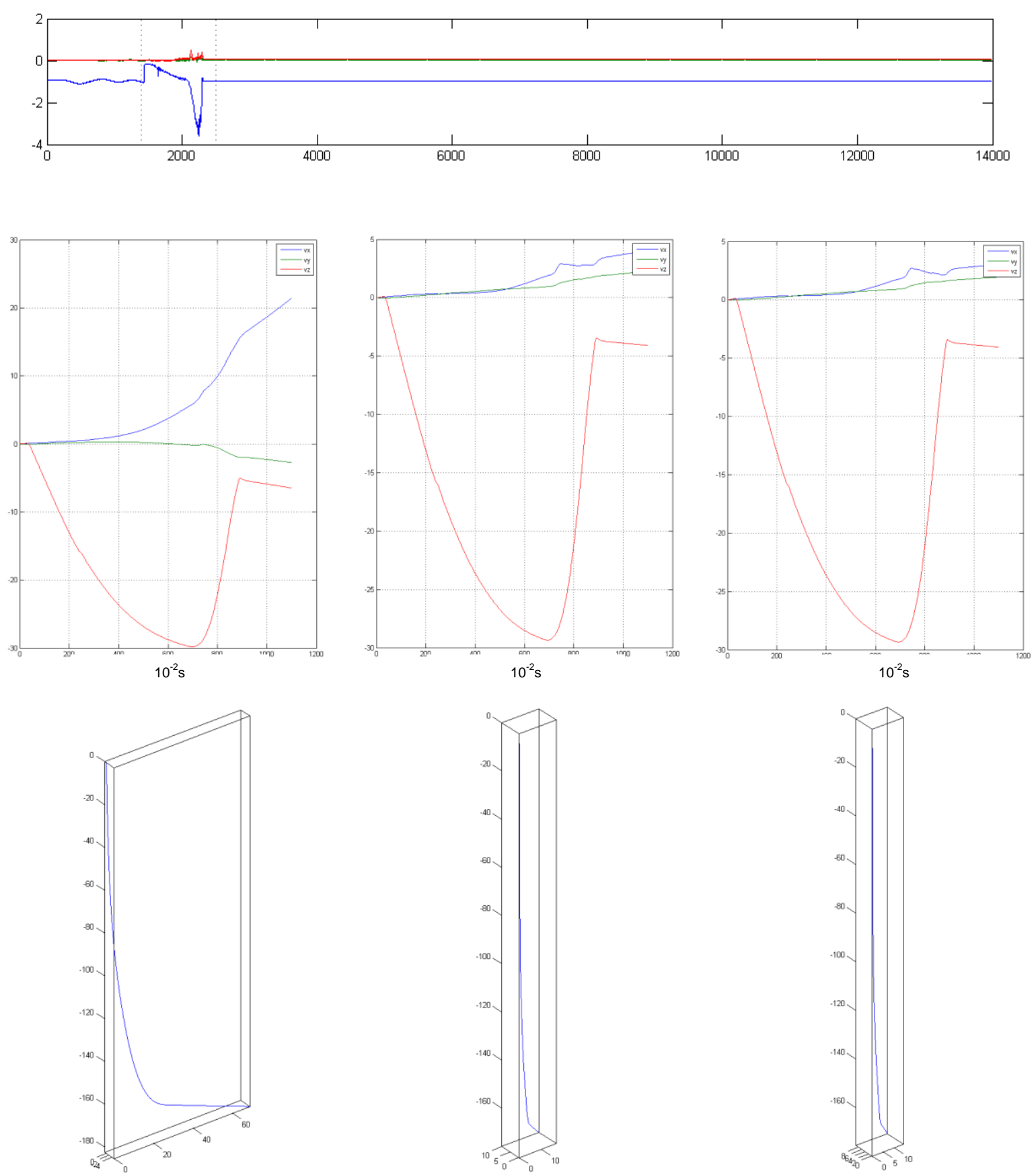

\begin{tabular}{|c|c|c|c|c|c|c|c|c|}
\hline $\begin{array}{l}\text { Lançamento } \\
\text { SMET } \\
\text { data }\end{array}$ & $\begin{array}{c}10 \\
4 \\
25 / 04 / 2007\end{array}$ & & & & & & & \\
\hline \multicolumn{3}{|c|}{ Inclinação $\left[{ }^{\circ}\right]$} & \multicolumn{3}{|c|}{ Velocidade Terminal $[\mathrm{m} / \mathrm{s}]$} & \multicolumn{3}{|c|}{ Azimute $\left[{ }^{\circ}\right]$} \\
\hline I & II & III & I & II & III & I & II & III \\
\hline 14,84 & 2,81 & 3,65 & 30,38 & 29,41 & 29,40 & 38,96 & 296,92 & 295,16 \\
\hline
\end{tabular}



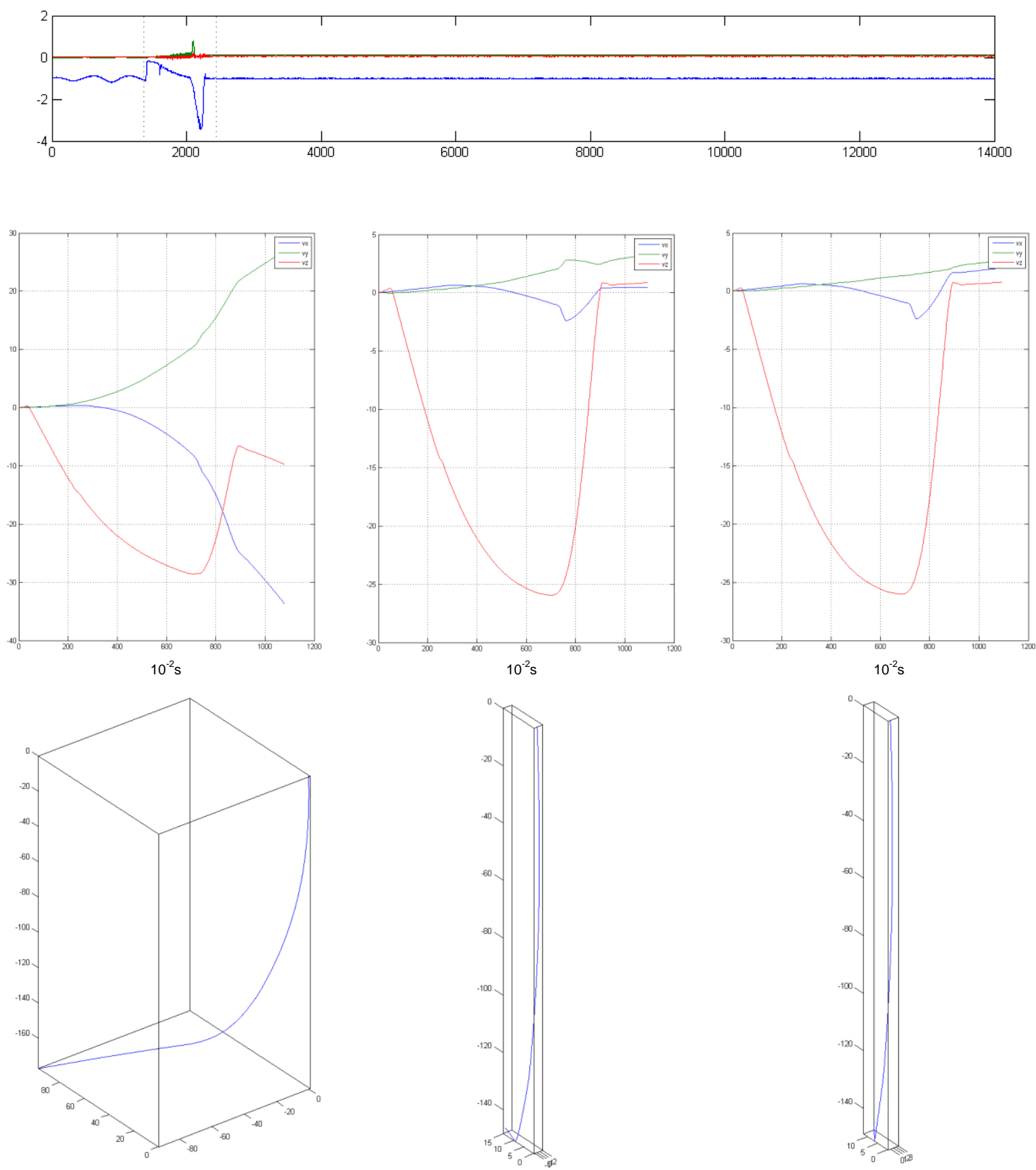

Lançamento 11

SMET 5

data 27/04/2007

\begin{tabular}{|c|c|c|c|c|c|c|c|c|}
\hline \multicolumn{2}{|c}{ Inclinação ${ }^{\circ}{ }^{\circ}$} & \multicolumn{4}{c|}{ Velocidade Terminal [m/s] } & \multicolumn{3}{c|}{ Azimute $\left.{ }^{\circ}\right]$} \\
I & II & III & I & II & III & I & II & III \\
\hline 30,88 & 6,41 & 8,44 & 45,95 & 26,15 & 26,08 & 114,95 & 270,18 & 601,59 \\
\hline
\end{tabular}



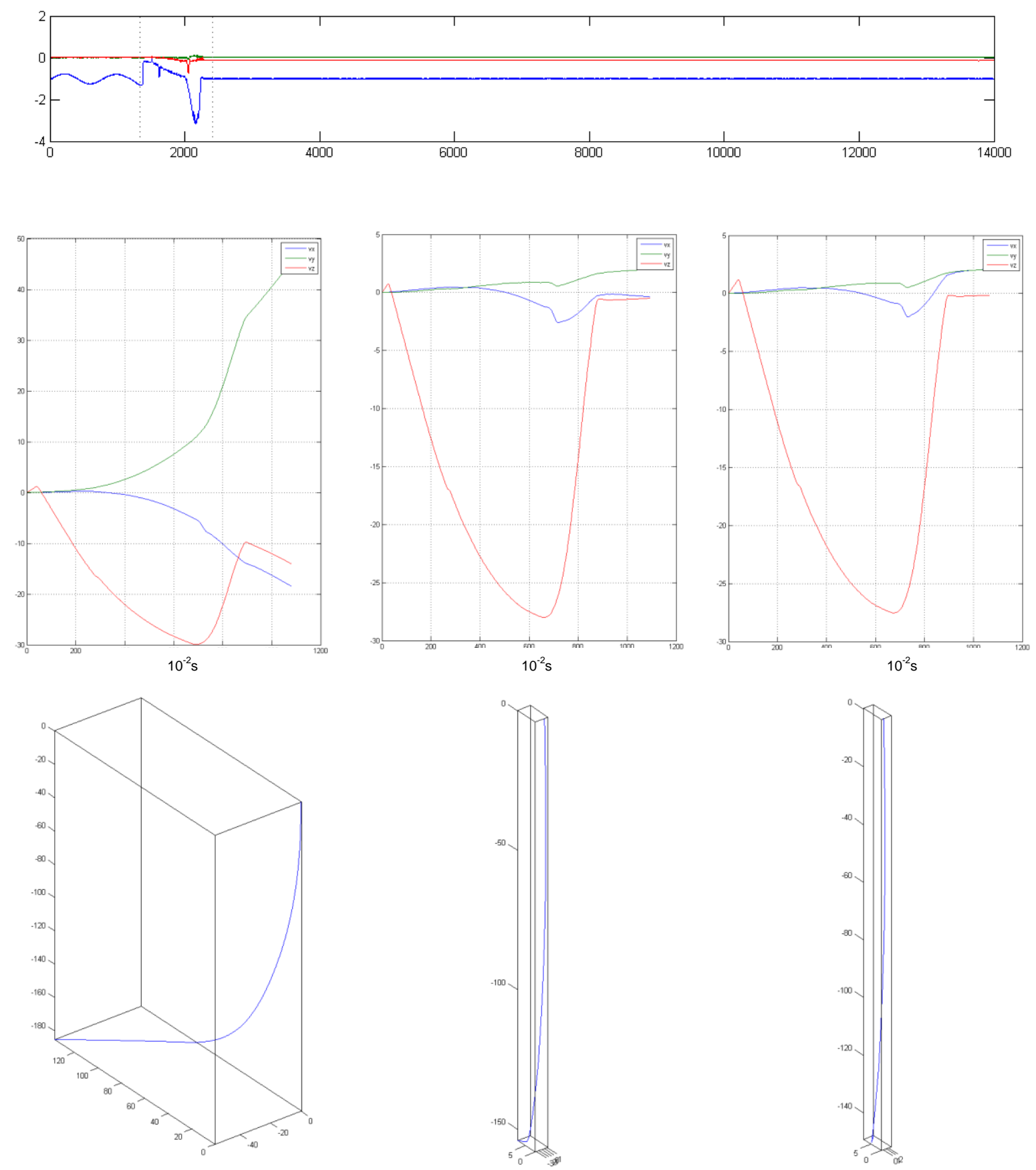

$\begin{array}{lc}\text { Lançamento } & 13 \\ \text { SMET } & 5\end{array}$

data 03/05/2007

\begin{tabular}{|c|c|cccc|c|c|c|c|}
\hline \multicolumn{3}{|c}{ Inclinação $\left[{ }^{\circ}\right]$} & \multicolumn{4}{c}{ Velocidade Terminal [m/s] } & \multicolumn{3}{c|}{ Azimute [ $\left.{ }^{\circ}\right]$} \\
\hline I & II & III & I & II & III & I & II & III \\
\hline 39,92 & 6,45 & 8,43 & 53,32 & 28,05 & 28,01 & 205,58 & 68,94 & 63,70 \\
\hline
\end{tabular}



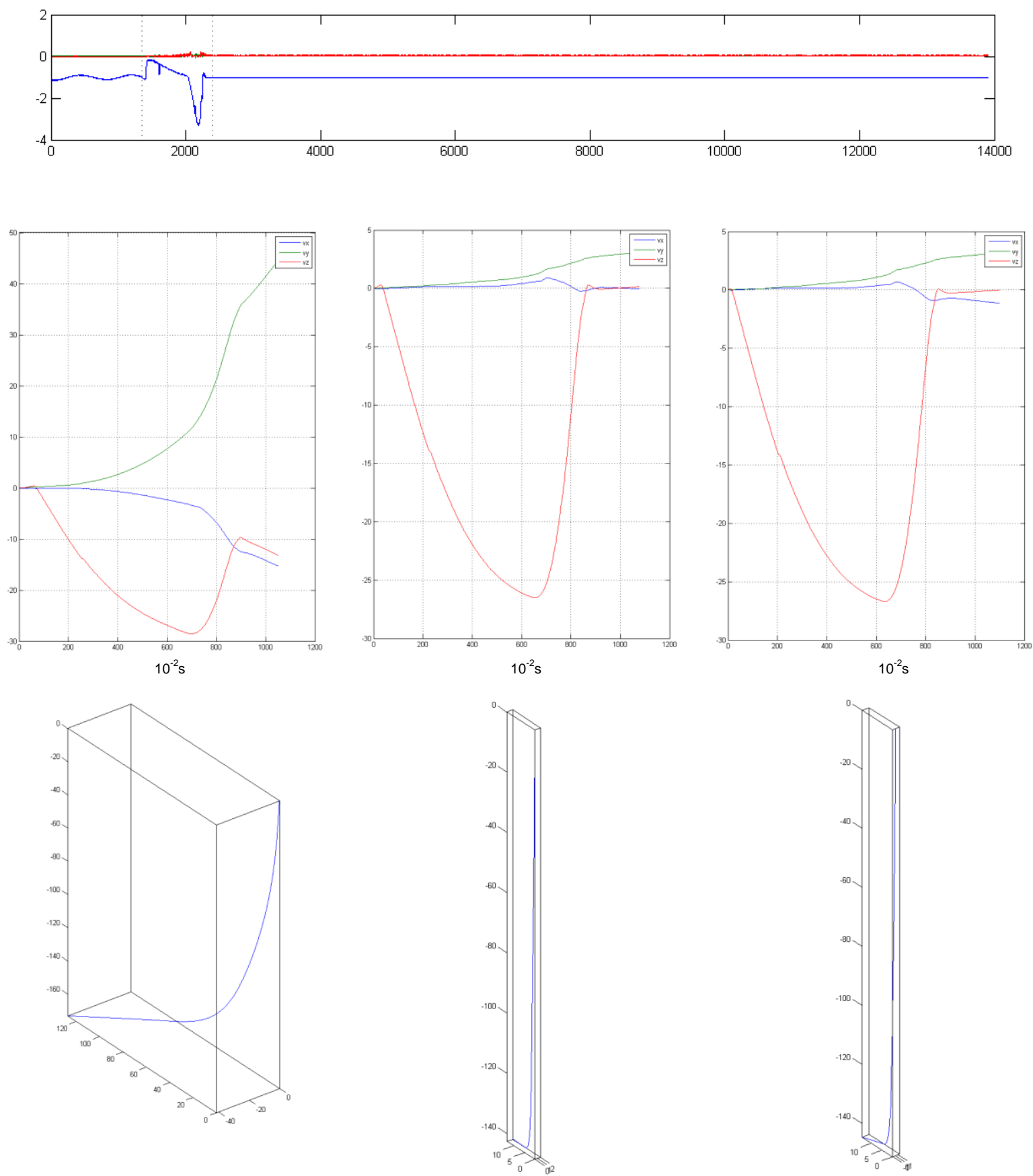

\section{Lançamento $\quad 14$ \\ SMET 5 \\ data 06/05/2007}

\begin{tabular}{|c|c|c|c|c|c|c|c|c|}
\hline \multicolumn{3}{|c}{ Inclinação $\left[{ }^{\circ}\right]$} & \multicolumn{4}{c|}{ Velocidade Terminal [m/s] } & \multicolumn{3}{c|}{ Azimute $\left.{ }^{\circ}\right]$} \\
I & II & III & I & II & III & I & II & III \\
\hline 42,79 & 2,69 & 3,51 & 52,68 & 26,55 & 26,55 & 227,51 & 258,42 & 255,29 \\
\hline
\end{tabular}



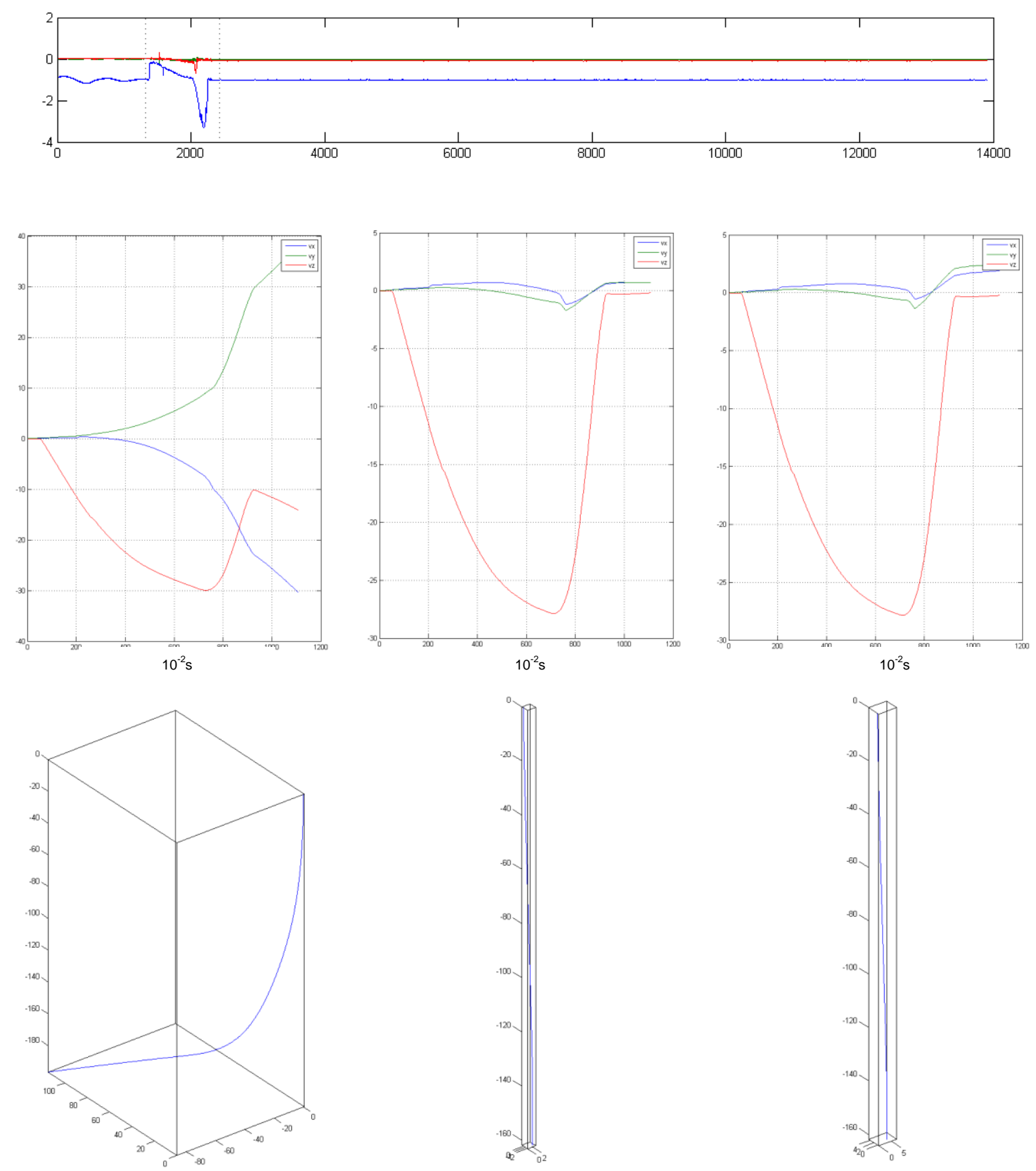

Lançamento 15

SMET 5

data 08/08/2007

\begin{tabular}{|c|c|ccc|c|c|c|c|}
\hline \multicolumn{3}{|c}{ Inclinação $\left[{ }^{\circ}\right]$} & \multicolumn{4}{c}{ Velocidade Terminal [m/s] } & \multicolumn{3}{c|}{ Azimute $\left[{ }^{\circ}\right]$} \\
\hline I & II & III & I & II & III & I & II & III \\
\hline 42,81 & 4,66 & 6,11 & 52,90 & 27,88 & 27,85 & 182,77 & 67,66 & 55,24 \\
\hline
\end{tabular}



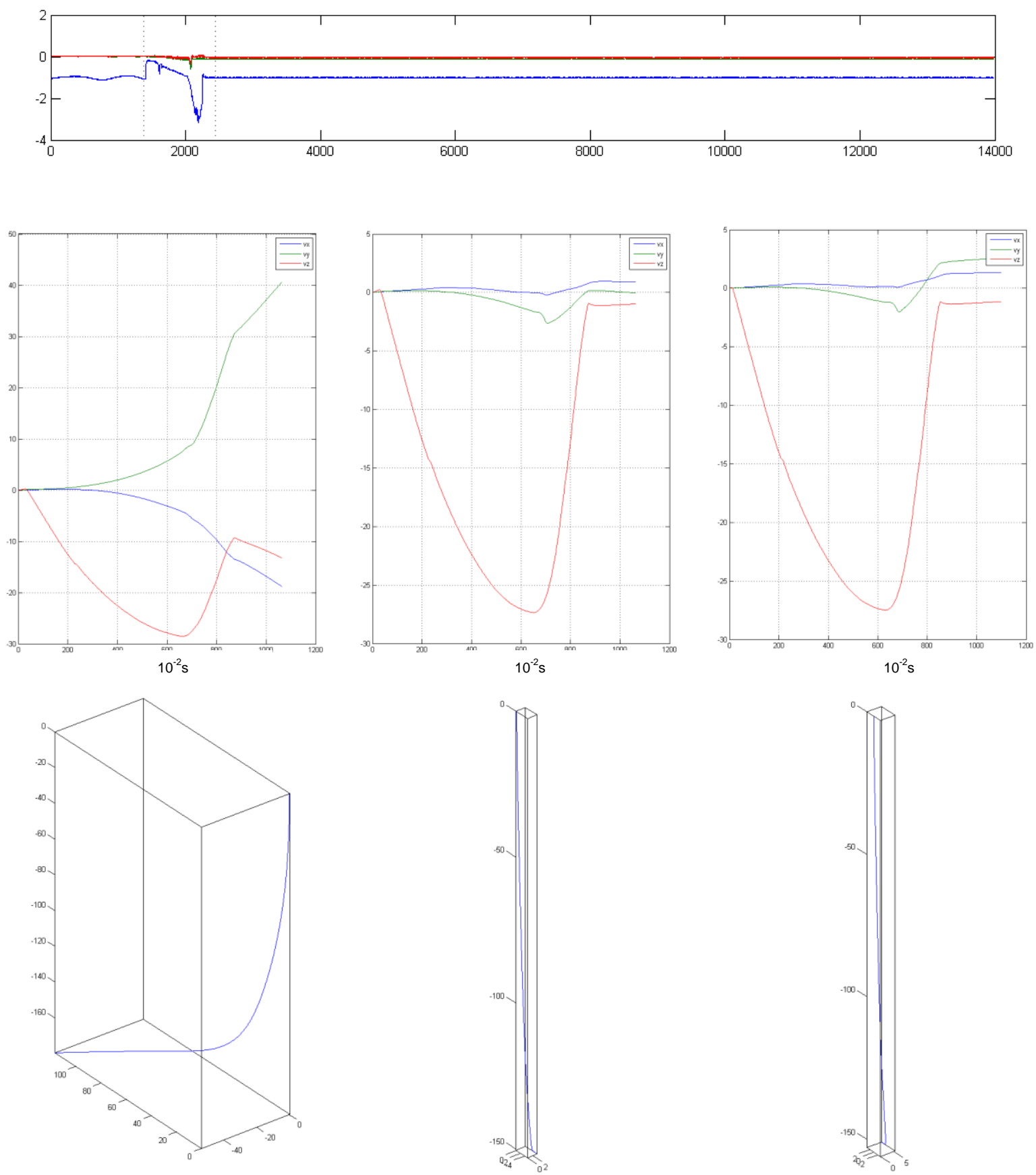

Lançamento $\quad 16$

SMET 5

data 09/05/2007

\begin{tabular}{|c|c|c|c|c|c|c|c|c|}
\hline \multicolumn{2}{|c}{ Inclinação $\left.{ }^{\circ}\right]$} & \multicolumn{4}{c|}{ Velocidade Terminal [m/s] } & \multicolumn{3}{c|}{ Azimute $\left.{ }^{\circ}\right]$} \\
I & II & III & I & II & III & I & II & III \\
\hline 46,48 & 5,77 & 7,45 & 47,70 & 27,39 & 27,51 & 197,57 & 138,62 & 129,20 \\
\hline
\end{tabular}




\section{APÊNDICE D - ROTINAS COMPUTACIONAIS DESENVOLVIDAS}

As rotinas computacionais empregadas na presente pesquisa foram desenvolvidas em ambiente MatLab®.

Não serão apresentadas sub-rotinas que desempenham funções como o cálculo do produto ou da norma entre quatérnios, pois, além de serem algoritmos de simples programação, estão disponíveis nas bibliotecas de MatLab®.

Da mesma forma, não serão incluídos os trechos de programa referentes à geração das interfaces gráficas.

Sendo assim, a seguir estão mostrados respectivamente o algoritmo vigente e o algoritmo de reconstrução empregando.

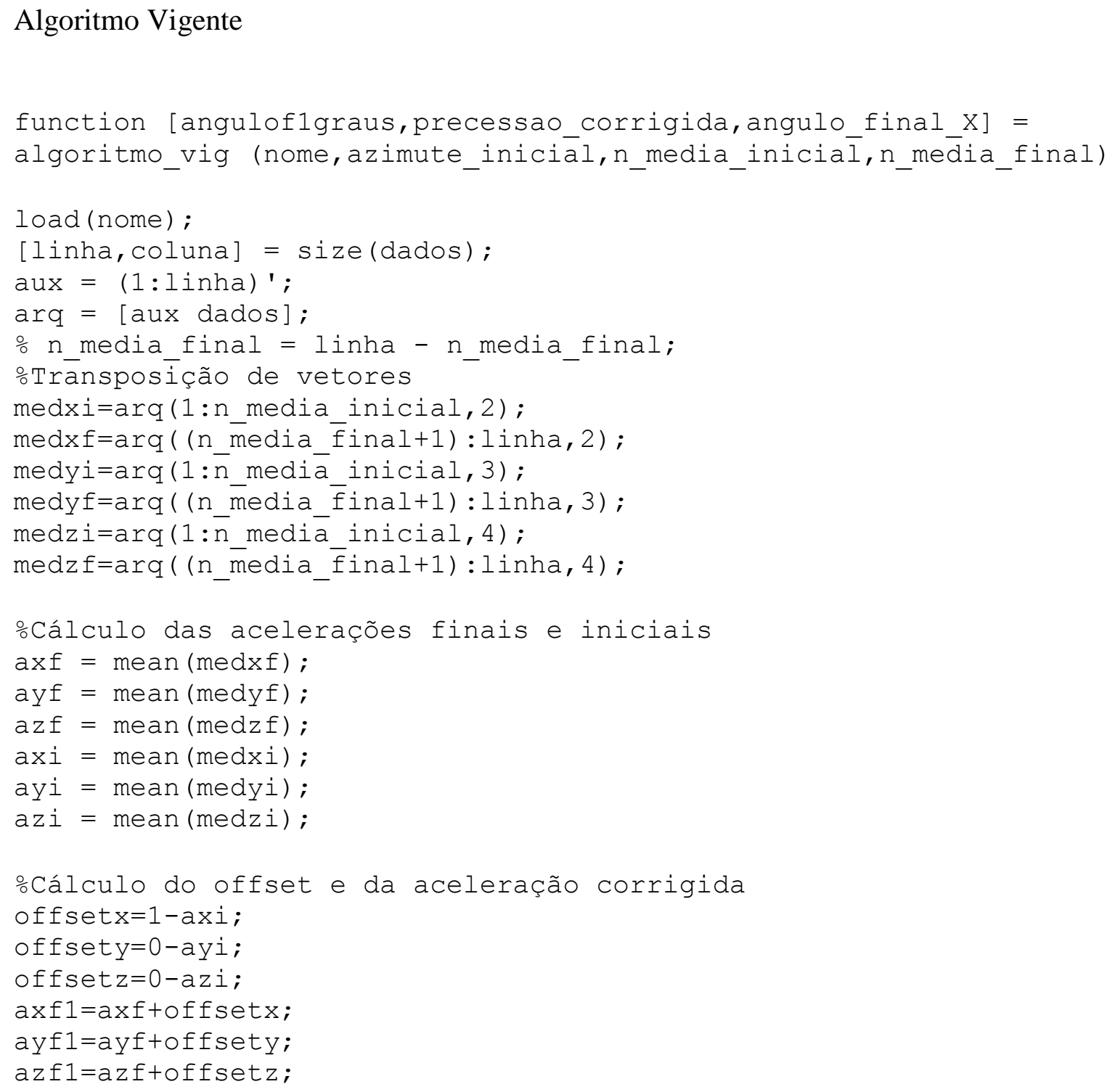


oCálculo do àngulos de inclinação para cada uma das acelerações angulof=atan ( $\left.\operatorname{sqrt}\left(\operatorname{ayf} f^{\wedge} 2+\operatorname{azf} f^{\wedge} 2\right) / \operatorname{abs}(\operatorname{axf})\right)$; anguloi=atan (sqrt (ayi^2+azi^2)/abs (axi)); angulofl=atan (sqrt (ayfl^2+azf1^2)/abs (axf1));

oTransformação do ângulo em radianos para graus angulofgraus=angulof $* 180 / \mathrm{pi}$;

anguloflgraus=angulof $1 * 180 / \mathrm{pi}$;

anguloigraus=anguloi*180/pi;

oDesvio do offset

offset=anguloigraus/angulofgraus*100;

Precessão

\% azimute_inicial $=252$;

precessao $=$ floor $((\operatorname{atan}(\operatorname{azf} 1 / \operatorname{ayf} 1)) * 180 / p i) ;$

if ayfl $>=0$

precessao_corrigida $=$ rem $(360$-precessao, 360);

else

end

precessao_corrigida $=180$-precessao;

angulo_X $(1)=0$;

for $t=\bar{n}$ media_inicial:n media_final

angülo $x(\bar{t})=\operatorname{arq}(t, \overline{5}) / 100 ;$

end

angulo_final_X $=$ sum (angulo_X);

oAzimute Final

azimute = azimute_inicial+precessao_corrigidatangulo_final_X; end 


\section{Algoritmo de Reconstrução de Trajetória por Quatérnios}

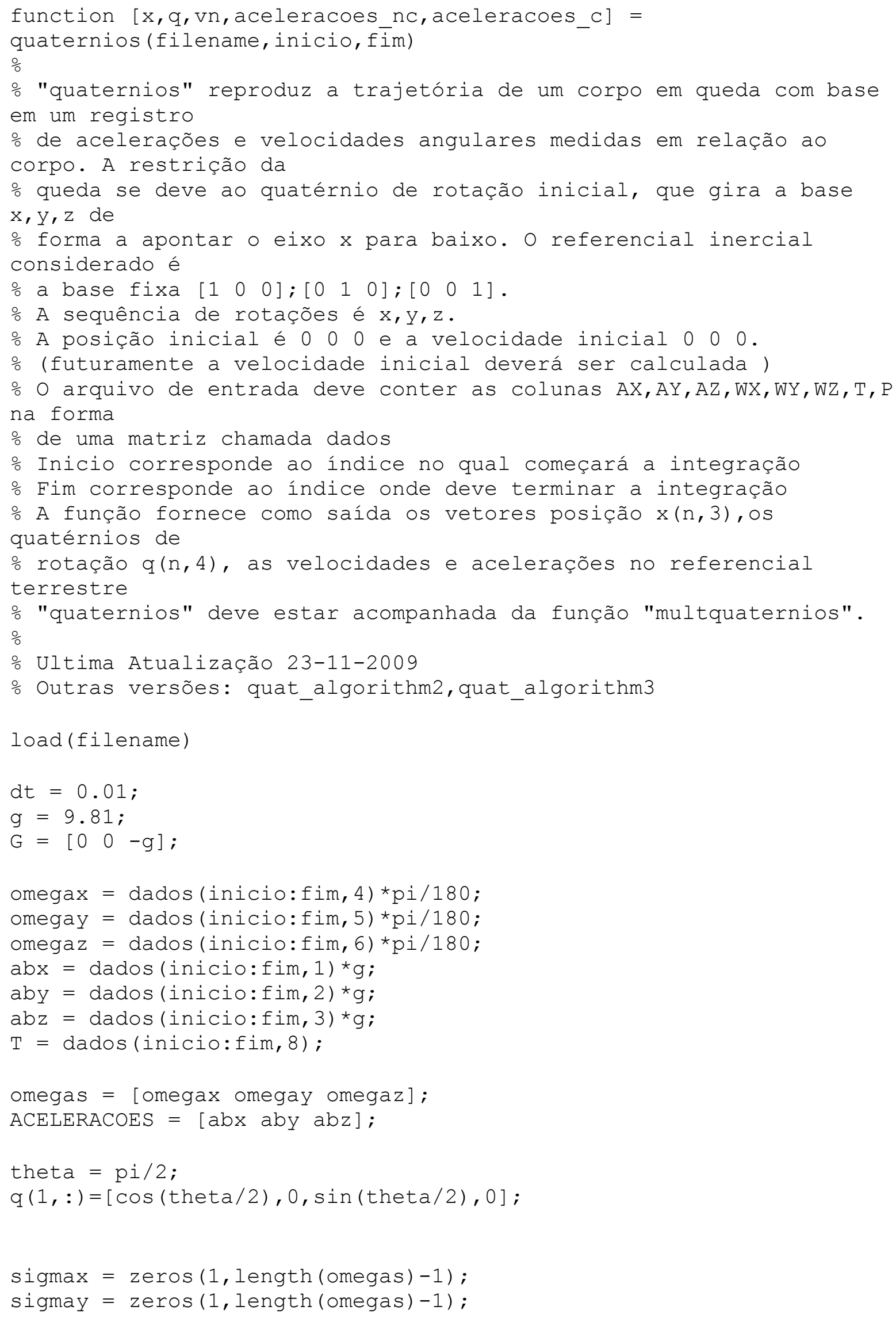




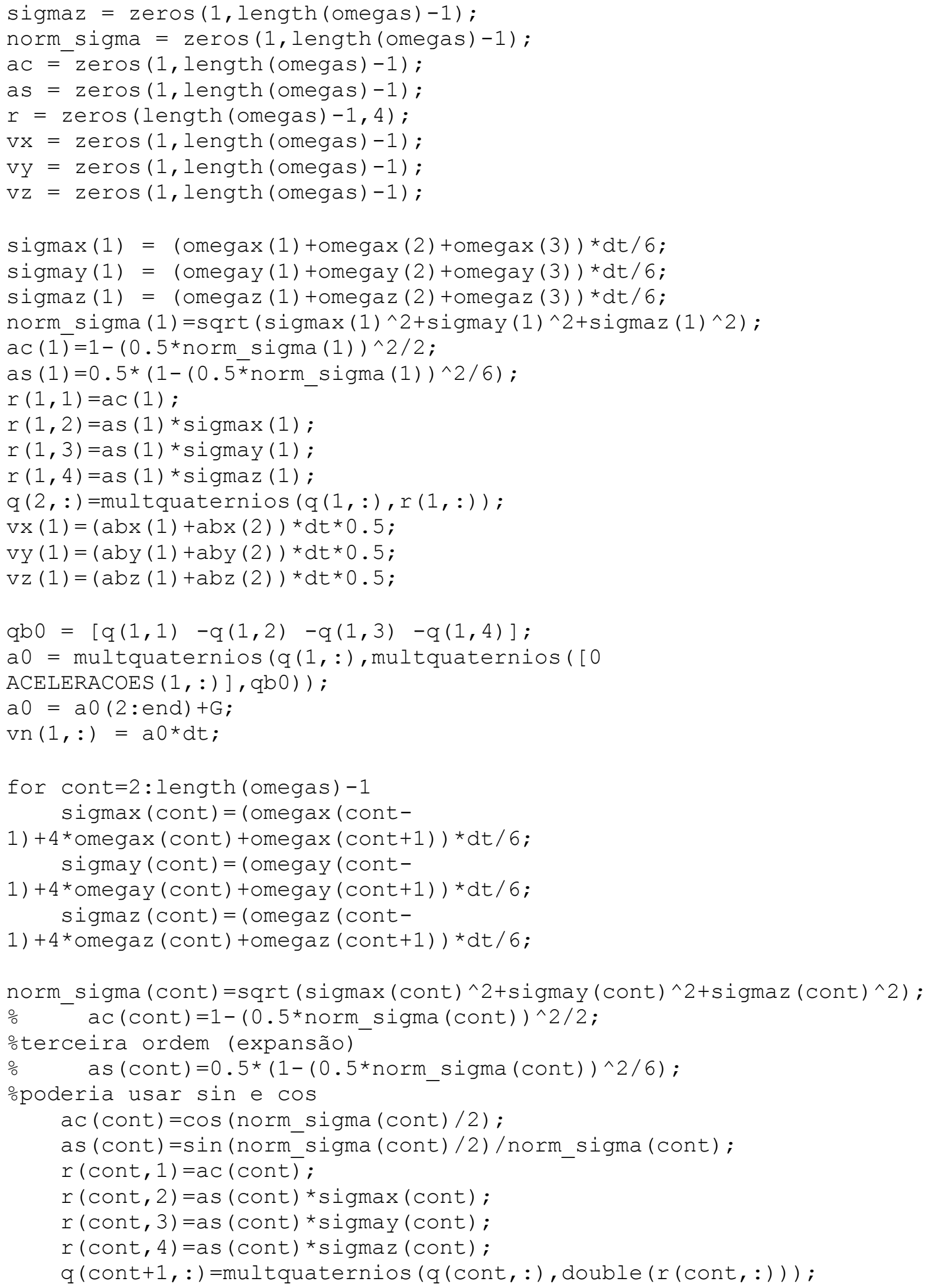




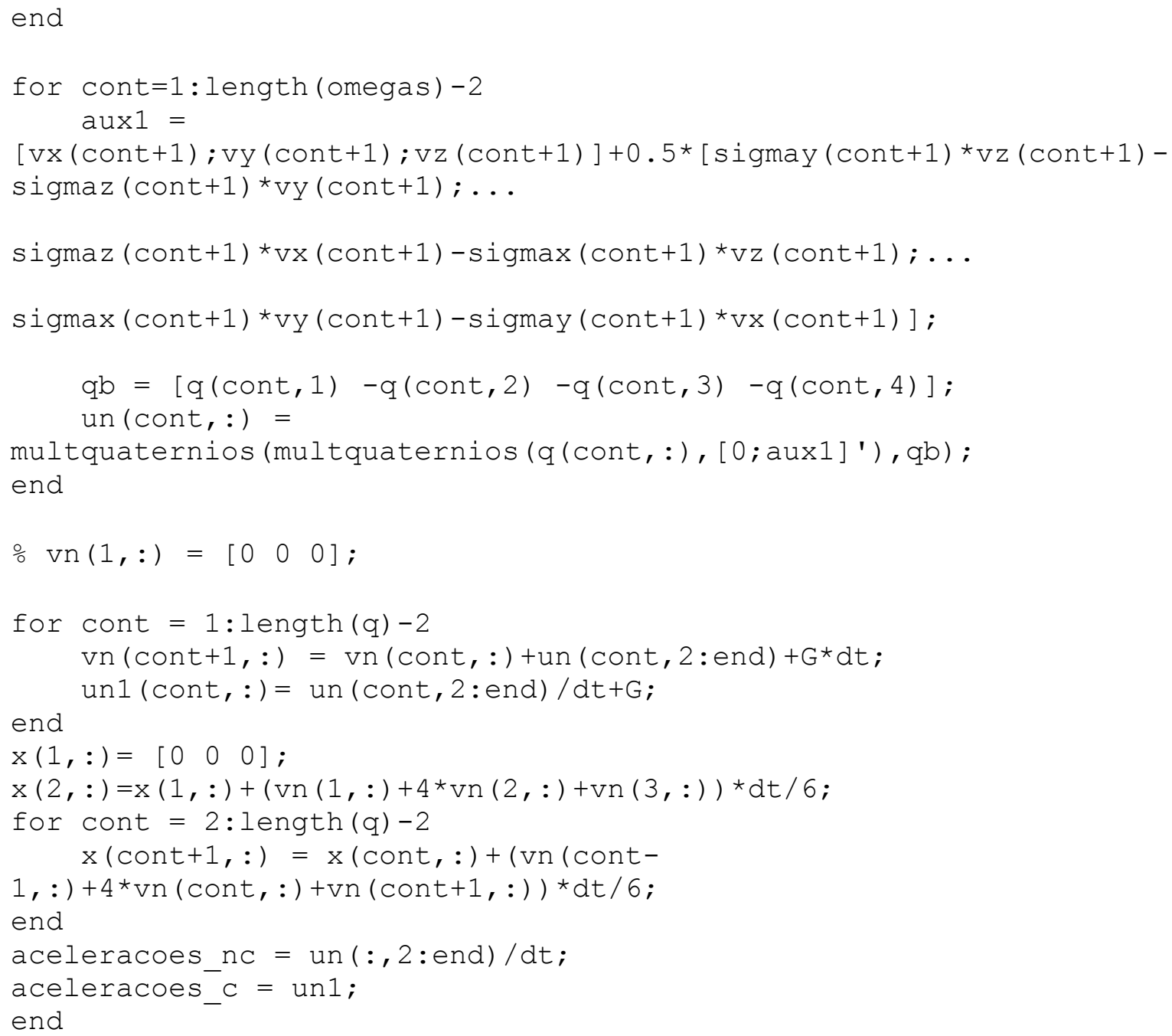




\section{ANEXO A - ESPECIFICAÇÕES TÉCNICAS DA RATE TABLE}

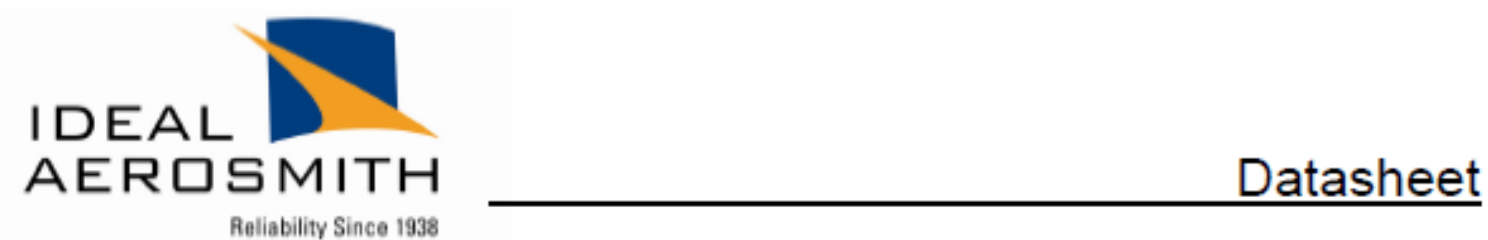

\section{BR Series Technical Specification Single-Axis Rate and Positioning Table System}

\section{DESCRIPTION}

The Model 1291BR Single Axis Positioning and Rate Table System is designed to provide precise position, rate anc acceleration motion for development or production testing of commercial or military inertial sensors. The 1291BR was specifically designed for testing today's considerably smaller inertial sensors and systems.

Accurate and reliable motion control of the 1291BR test table is achieved with a servo controlled system consisting of a direct drive DC torque motor, a precision optical encoder, and an internal microprocessor based motion control card. Position, rate, and acceleration as well as motion profiles are commanded remotely from a host PC (not provided) via the standard RS-232 communication interface. The user can utilize an Ideal-provided LabVIEW Application Program, or their own communication software package with Ideal's software command set to precisely control the 1291BR. The table system includes a 19 inch rack-mountable servo controller that interfaces to the host $\mathrm{PC}$.

\section{STANDARD FEATURES}

- Rate Accuracy: $0.01 \%$ (Over 1 revolution)

- Rate Range:

Setting 1: 0.000125 to $500 \mathrm{deg} / \mathrm{sec}$ Setting 2: 0.0005 to $2000 \mathrm{deg} / \mathrm{sec}$

- Position Accuracy: \pm 15 Arc Sec

- Position Repeatability: \pm 3 Arc Sec

- Tabletop Diameter: 8 inches (203 mm)

- Payload Capacity: $50 \mathrm{lbs}(23 \mathrm{Kg})$

- $5 \mathrm{lbf}$-ft direct drive DC torque motor

- 34 user lines to tabletop (2A per line)

- Digital closed loop servo control

- RS-232 Remote Interface

- LabVIEW Interface

- User-friendly Ideal Aerosmith Table Language (ATL)

- Tests in a Vertical or Horizontal Axis Configuration

- Precision-ground anodized aluminum tabletop

- Trapezoidal motion profiles with programmable velocity and acceleration

- Sinusoidal Motion with programmable frequency and amplitude

- Configurable and scaleable Analog Input

- Configurable and scalable Analog Output (1 KHz update frequency)

\section{OPTIONS}

- $20 \mathrm{lbf}$-ft motor, provides better acceleration/bandwidth performance for larger payloads

- 64 line slipring package

- IEEE-488 (GPIB) Communication Interface, via extemal converter harness

- 14,18 or 24 inch $(356,457$ or $610 \mathrm{~mm})$ diameter tabletops

- Pedestal for floor mounting

- Custom mounting hole patterns

- Tilt stand

- Temperature Chamber (see separate section on Page 5)

- Analog Output at $8 \mathrm{KHz}$ update frequency (see separate section on page 6)

- CE Mark available with table and chamber

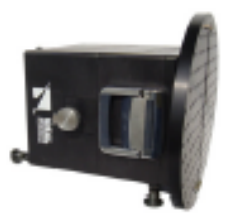

1291BR in horizontal axis configuration

$1291 \mathrm{BR}$ in vertical axis configuration

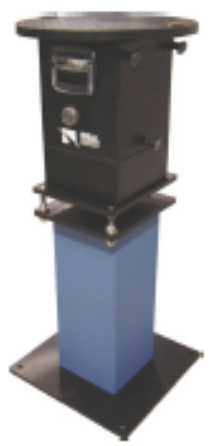

1291BR with Pedestal

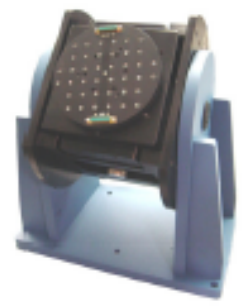

1291BR with Tilt Stand 


\begin{tabular}{|c|c|}
\hline \multicolumn{2}{|c|}{ Physical Configuration and Specifications } \\
\hline Tabletop Surface Characteristics: & \\
\hline - Diameter & Std: 8 inches $(203 \mathrm{~mm})$ Optional: 14,18 or 24 inch $(356,457$ or $610 \mathrm{~mm})$ \\
\hline $\begin{array}{l}\text { - Hole Pattern: } \\
\text { Standard for } 8 \text { inch diameter } \\
\text { Standard for } 14,18 \text { or } 24 \text { inch diameter }\end{array}$ & $\begin{array}{l}1 / 4-20 \text { threaded holes on a one-inch }(25 \mathrm{~mm}) \text { grid pattern. } \\
1 / 4-20 \text { threaded holes on a two-inch }(51 \mathrm{~mm}) \text { grid pattern. } \\
\text { (Other interface patterns available upon request.) }\end{array}$ \\
\hline - Face Flatness & 0.002 inches $(0.051 \mathrm{~mm}) \mathrm{TIR}$ \\
\hline - Face Runout & 0.002 inches $(0.051 \mathrm{~mm}) @ 3$ inch $(76.2 \mathrm{~mm})$ Radius \\
\hline - Material & Aluminum, black anodized \\
\hline - $\quad$ Surface Finish & 63 RMS \\
\hline - Usable tabletop surface: & $\begin{array}{l}\text { Due to the location of the connectors, not all of the tabletop's surface is } \\
\text { usable. For details, request tabletop drawings from Ideal Aerosmith }\end{array}$ \\
\hline - Axis Wobble, arc sec & 10 \\
\hline \multicolumn{2}{|l|}{ Test Load Capacity: } \\
\hline - Height & 11 inches $(279 \mathrm{~mm})$ \\
\hline - Weight: (vertical or horizontal axis) & $50 \mathrm{lbs} .(23 \mathrm{Kg})$ centered \\
\hline \multicolumn{2}{|l|}{ Electrical Access to the UUT: } \\
\hline - Slip ring lines & $\begin{array}{l}\text { Standard: } 34 \text { lines at } 2 \mathrm{~A} \text { each ( } 16 \text { twisted shielded pair, } 2 \text { shielded } \\
\text { singles) } \\
\text { Optional: } 64 \text { lines ( } 26 \text { twisted shielded pair at } 2 \mathrm{~A} \text { per line, } 2 \text { singles at } 2 \mathrm{~A} \\
\text { per line, } 10 \text { singles at } 5 \mathrm{~A} \text { per line) }\end{array}$ \\
\hline $\begin{array}{l}\text { - Slip ring resistance variation per line, with } \\
\text { table rotating at } 30 \mathrm{deg} / \mathrm{sec} \text {. }\end{array}$ & $\begin{array}{l}60 \text { milliohms for } 34 \text { line slip ring } \\
10 \text { milliohms for } 64 \text { line slip ring }\end{array}$ \\
\hline - Connectors & $\begin{array}{l}\text { Tabletop: (2) } 37 \text { pin Female D-sub connectors } \\
\text { Base: (2) } 37 \text { pin Male D-sub connectors }\end{array}$ \\
\hline \multicolumn{2}{|l|}{ Test Table (34 line slip ring, $8^{n}$ tabletop) } \\
\hline - Dimensions & $10.2 \times 10.8 \times 12.3$ inches Height $(259 \times 274 \times 312 \mathrm{~mm}$ Height $)$ \\
\hline - Weight, approximate, without Tilt Stand & 65 lbs. $(29.5 \mathrm{Kg})$ \\
\hline - Weight, approximate, with Tilt Stand & $230 \mathrm{lbs} .(104 \mathrm{Kg})$ including counterweights \\
\hline - Leveling Range & $+/-1$ degree \\
\hline \multicolumn{2}{|l|}{ Control Chassis: } \\
\hline - Dimensions & $19.0 \times 18.6 \times 7.0$ inches Height $(483 \times 472 \times 178 \mathrm{~mm}$ Height $)$ \\
\hline - Weight & 50 lbs. $(23 \mathrm{Kg})$ \\
\hline Controller: & NOTE: A user supplied PC (with RS-232 or IEEE-488 port) is required \\
\hline - Type & Internal \\
\hline - Communication Interface & RS-232 standard (Max 19200 Baud) \\
\hline - Analog Input & Rate or Position. Two $\pm 10 \mathrm{~V} 12$ Bit Inputs, scaleable \\
\hline - Analog Output & $\begin{array}{l}\text { Rate. } \pm 10 \mathrm{~V}=\text { full scale, scaleable. Update Rate is } 1 \mathrm{KHz} \text { (standard), } 8 \\
\mathrm{KHz} \text { (optional). } 16 \text { bits resolution. }\end{array}$ \\
\hline - Software Control & Uses simple software command set (ATL) via host PC \\
\hline \multicolumn{2}{|l|}{ Operating Environment: } \\
\hline - Temperature & 50 to $95^{\circ} \mathrm{F}\left(10\right.$ to $\left.35^{\circ} \mathrm{C}\right)$ \\
\hline - Relative Humidity & $20 \%$ to $85 \%$ non-condensing \\
\hline \multicolumn{2}{|l|}{ Non-Operating Environment: } \\
\hline - Temperature & -20 to $120^{\circ} \mathrm{F}\left(-29\right.$ to $\left.49^{\circ} \mathrm{C}\right)$ \\
\hline Power Requirements: & $\begin{array}{l}\text { Standard: } 115 \text { VAC, } 50 / 60 \mathrm{~Hz}, 6.25 \mathrm{~A} \text { IEC } 60320 \text { Power Entry Module } \\
\text { Optional: } 230 \text { VAC. } 50 / 60 \mathrm{~Hz} .3 .25 \mathrm{~A}\end{array}$ \\
\hline
\end{tabular}

\section{NOTE:}

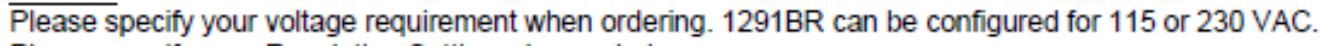

Please specify your Resolution Setting when ordering.

Resolution Setting 1: Max Rate of $500 \mathrm{deg} / \mathrm{sec}$; Rate resolution of $0.000125 \mathrm{deg} / \mathrm{sec}$

Resolution Setting 2: Max Rate of $2000 \mathrm{deg} / \mathrm{sec}$; Rate resolution of $0.0005 \mathrm{deg} / \mathrm{sec}$ 
Performance Specifications Common for all 1291BR Systems

\begin{tabular}{|c|c|c|}
\hline Rotational Freedom & \multicolumn{2}{|c|}{ Unlimited } \\
\hline Positioning & Resolution Setting $1^{\star}$ & Resolution Setting $2^{*}$ \\
\hline - $\quad$ Range, deg & 0.0000000 to 359.9999375 & 0.00000 to 359.99975 \\
\hline - Accuracy, arc sec (deg) & $\pm 15(0.00417)$ & $\pm 15(0.00417)$ \\
\hline - Display Resolution, deg & 0.0000625 & 0.00025 \\
\hline - Repeatability, arc sec (deg) & $\pm 3(0.00083)$ & $\pm 3(0.00083)$ \\
\hline - Homing & Index Mark & Index Mark \\
\hline \multicolumn{3}{|l|}{ Rate } \\
\hline - Maximum, deg/sec & 500 & 2000 \\
\hline - Minimum, deg/sec & 0.000125 & 0.0005 \\
\hline - Display Resolution, deg/sec & 0.000125 & 0.0005 \\
\hline $\begin{array}{l}\text { - Accuracy (measured over } 360 \text { deg), } \% \pm \\
\text { Resolution }\end{array}$ & $0.01 \%$ & $0.01 \%$ \\
\hline Acceleration, Min. for Trapezoidal move & $0.064 \mathrm{deg} / \mathrm{sec} / \mathrm{sec}$ & $0.256 \mathrm{deg} / \mathrm{sec} / \mathrm{sec}$ \\
\hline $\begin{array}{l}\text { Acceleration, Max. for Trapezoidal move } \\
\text { (no load) }\end{array}$ & $\begin{array}{l}\text { Lesser of } 4,194 \mathrm{deg} / \mathrm{sec} / \mathrm{sec} \text { or } \\
\text { sinusoidal value below }\end{array}$ & $\begin{array}{l}\text { Lesser of } 16,776 \mathrm{deg} / \mathrm{sec} / \mathrm{sec} \text { or } \\
\text { sinusoidal value below }\end{array}$ \\
\hline
\end{tabular}

'The 1291BR Series Tables can be operated in either of two resolution settings. The system is initially configured at Ideal per customer's preference, but can be changed in the field as required.

\begin{tabular}{|c|c|c|}
\hline \multicolumn{3}{|c|}{ Acceleration Performance Specs. for 1291BR and 1291BR-T20 Systems } \\
\hline Model & 1291BR & 1291BR-T20 \\
\hline Motor Torque & $5 \mathrm{lbf}-\mathrm{ft}(6.8 \mathrm{Nm})$ & $20 \mathrm{lbf}-\mathrm{ft}(27.1 \mathrm{Nm})$ \\
\hline \multicolumn{3}{|l|}{$\begin{array}{l}\text { Acceleration, Maximum for Sinusoidal } \\
\text { move, deg/sec/sec (no load) }\end{array}$} \\
\hline - 8 inch tabletop & 20,000 & $>20,000$ \\
\hline - 14 inch tabletop & 4,500 & 18,000 \\
\hline - 18 inch tabletop & 1,800 & 7,200 \\
\hline - 24 inch tabletop & 625 & 2,500 \\
\hline \multicolumn{3}{|l|}{ Tare Inertia, $\mathrm{Ibm} \mathrm{in}^{2}\left(\mathrm{~kg} \mathrm{~m}^{2}\right)$} \\
\hline - 8 inch tabletop & $63(0.0184)$ & $81(0.0237)$ \\
\hline - 14 inch tabletop & $254(0.0743)$ & $272(0.0796)$ \\
\hline - 18 inch tabletop & $589(0.1724)$ & $607(0.1776)$ \\
\hline - 24 inch tabletop & $1,692(0.4951)$ & $1,710(0.5004)$ \\
\hline Frequency, Maximum, -3dB (no load): & $(8 \text { or } 14 \text { inch tabletop })^{*+\pi}$ & $(8 \text { or } 14 \text { inch tabletop) })^{\star \star \star \star *}$ \\
\hline - $\quad$ Resolution Setting 1 & $100 \mathrm{~Hz}$ & $100 \mathrm{~Hz}$ \\
\hline - $\quad$ Resolution Setting 2 & $75 \mathrm{~Hz}$ & $75 \mathrm{~Hz}$ \\
\hline
\end{tabular}

"Other factors may affect bandwidth performance including use of the Tit Stand, Pedestal and/or Thermal Chamber options.

"'As the payload size increases, the -T20 will exhibit higher acceleration and bandwidth characteristics than the Model $1291 \mathrm{BR}$ (-T5 motor). 
